May 27, 2009

Dr. Prem C. Srivastava

Program Manager

Medical Sciences, SC-73

U.S. Department of Energy

19901 Germantown Road

Germantown, MD 20874

Dear Dr. Srivastava:

Subject: EERC Center for Biomass Utilization ${ }^{\circledR} 2006$ Final Technical Report

U.S. Department of Energy (DOE) Agreement No. DE-FG02-06ER64269

EERC Fund 9426

Please find enclosed the subject final report for the work performed by the Energy \& Environmental Research Center (EERC) under DOE Agreement No. DE-FG02-06ER64269. An electronic copy was uploaded to the Project Management site.

If you have any questions or comments, please contact me by phone at (701) 777-5123, by fax at (701) 777-5181, or by e-mail at czygarlicke@undeerc.org.

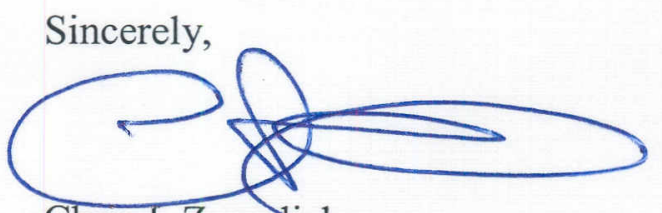

Chris J. Zygarticke

Deputy Associate Director for Research

CJZ/jre

Enclosure

c: Tobe Larson, EERC 


\section{EERC CENTER FOR BIOMASS UTILIZATION ${ }^{\circledR}$ 2006}

Final Technical Report

(for the period of July 1, 2006, through December 31, 2008)

Prepared for:

Prem C. Srivastava

Medical Sciences, SC-73

U.S. Department of Energy

19901 Germantown Road

Germantown, MD 20874

U.S. Department of Energy Agreement No. DE-FG02-06ER64269

Prepared by:

Christopher J. Zygarlicke John P. Hurley Ted R. Aulich Bruce C. Folkedahl Joshua R. Strege Nikhil Patel Richard E. Shockey

Energy \& Environmental Research Center University of North Dakota 15 North 23rd Street, Stop 9018

Grand Forks, ND 58202-9018 


\section{EERC DISCLAIMER}

LEGAL NOTICE This research report was prepared by the Energy \& Environmental Research Center (EERC), an agency of the University of North Dakota, as an account of work sponsored by the Biological and Environmental Research Program for the U.S. Department of Energy (DOE) Office of Science. Because of the research nature of the work performed, neither the EERC nor any of its employees makes any warranty, express or implied, or assumes any legal liability or responsibility for the accuracy, completeness, or usefulness of any information, apparatus, product, or process disclosed, or represents that its use would not infringe privately owned rights. Reference herein to any specific commercial product, process, or service by trade name, trademark, manufacturer, or otherwise does not necessarily constitute or imply its endorsement or recommendation by the EERC.

\section{DOE DISCLAIMER}

This report was prepared as an account of work sponsored by an agency of the United States Government. Neither the United States Government, nor any agency thereof, nor any of their employees makes any warranty, express or implied, or assumes any legal liability or responsibility for the accuracy, completeness, or usefulness of any information, apparatus, product, or process disclosed or represents that its use would not infringe privately owned rights. Reference herein to any specific commercial product, process, or service by trade name, trademark, manufacturer, or otherwise does not necessarily constitute or imply its endorsement, recommendation, or favoring by the United States Government or any agency thereof. The views and opinions of authors expressed herein do not necessarily state or reflect those of the United States Government or any agency thereof.

This report is available to the public from the National Technical Information Service, U.S. Department of Commerce, 5285 Port Royal Road, Springfield, VA 22161; phone orders accepted at (703) 487-4650.

\section{ACKNOWLEDGMENT}

This report was prepared with the support of the Biological and Environmental Research Program for the DOE Office of Science Cooperative Agreement No. DE-FG02-06ER64269, Catacel Corporation, and Johnson Matthey, Inc. However, any opinions, findings, conclusions, or recommendations expressed herein are those of the author(s) and do not necessarily reflect the views of DOE. 


\section{TABLE OF CONTENTS}

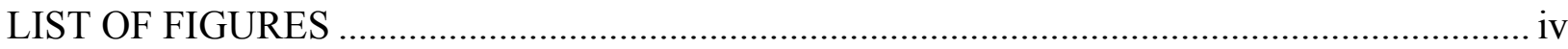

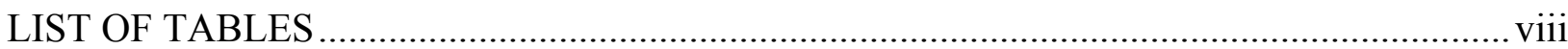

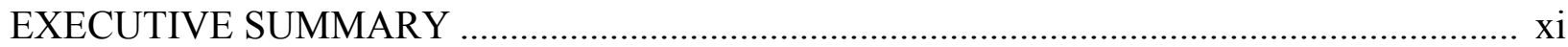

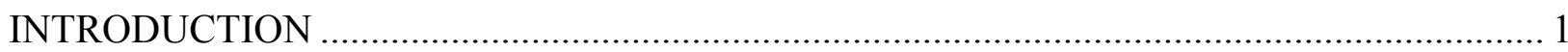

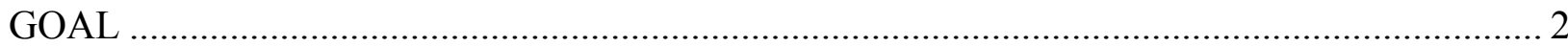

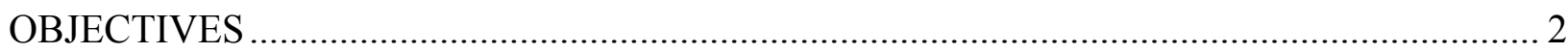

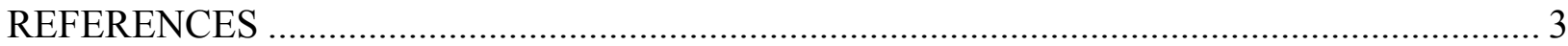

TASK 1 - THERMOCHEMICAL CONVERSION OF BIOMASS TO SYNGAS AND

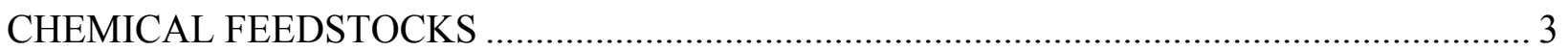

Activity 1.1 - Integrated Thermochemical and Liquid Fuel Synthesis............................... 3

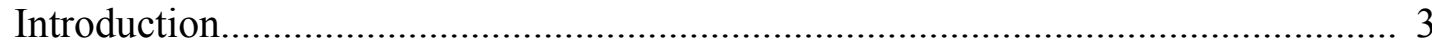

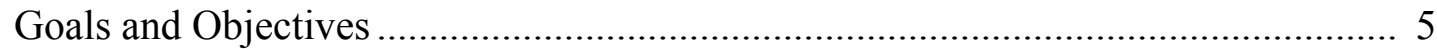

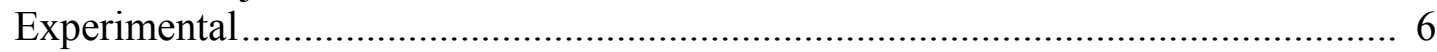

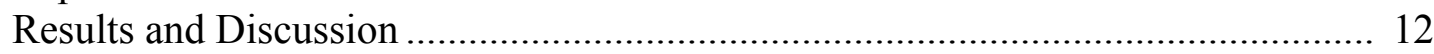

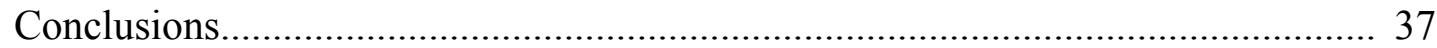

Catacel Corporation's Low-Pressure Reactor ....................................................... 40

FT Liquid Synthesis Experiments: Part 2 ..................................................... 40

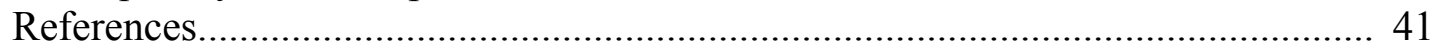

Activity 1.2 - Engineering Analysis of an Indirect Liquefaction Process ........................ 41

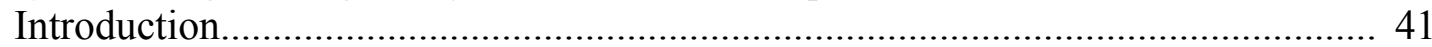

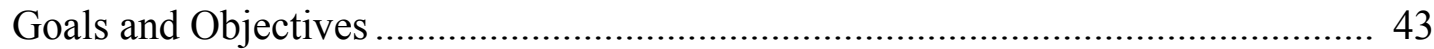

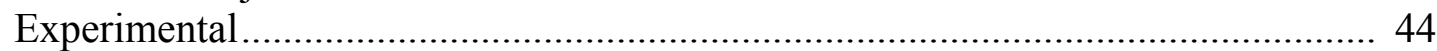

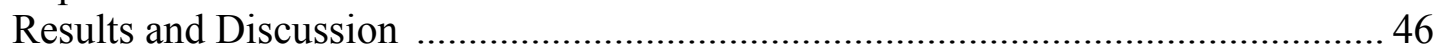

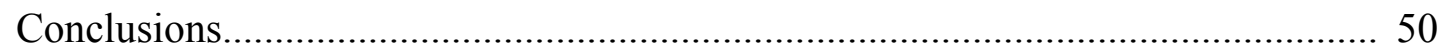

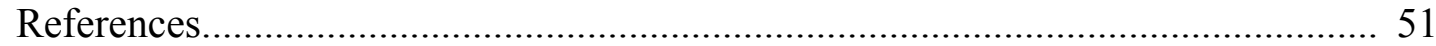

Activity 1.3 -Thermochemical Conversion of Biomass to Dimethyl Ether ..................... 51

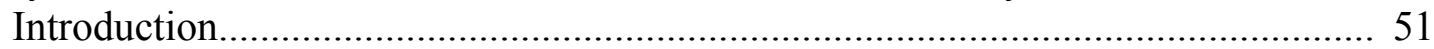

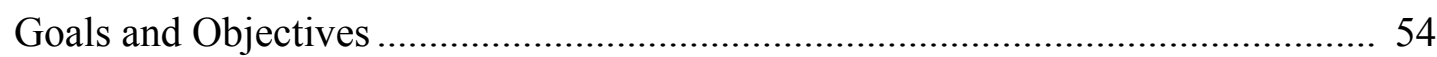

Commercial Gasifier Review ……………………….................................... 54

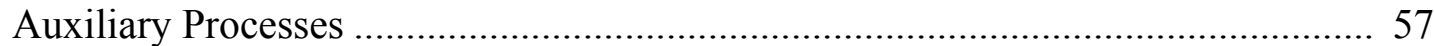

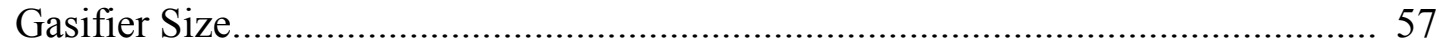

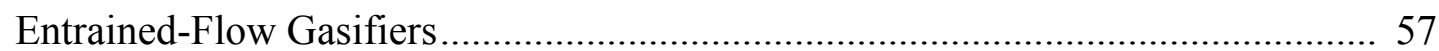

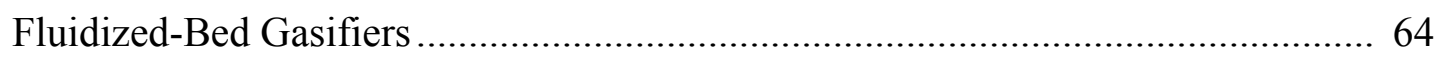

Moving Packed-Bed Gasifiers ............................................................................. 71

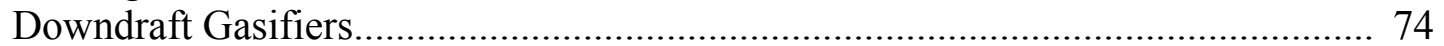

Continued ... 


\section{TABLE OF CONTENTS (continued)}

Gas-to-Liquids Catalyst Review ......................................................................... 77

Review of Ethanol Demonstration Projects............................................................ 81

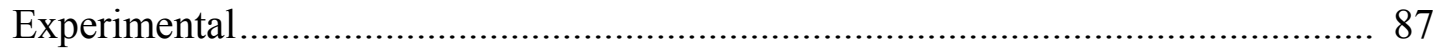

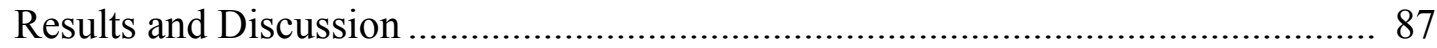

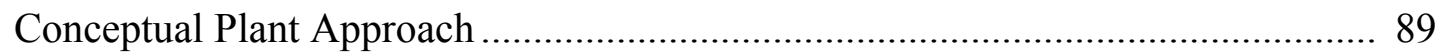

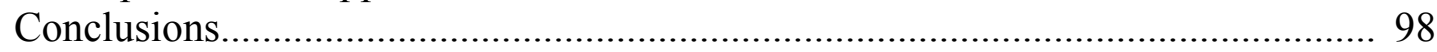

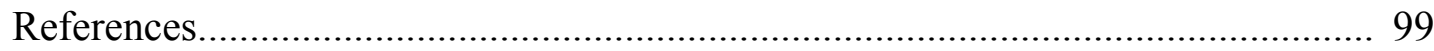

TASK 2 - CROP OIL BIOREFINERY PROCESS DEVELOPMENT.................................. 104

Activity 2.1 - Candidate Fuel Generation and Fuels Testing ........................................ 104

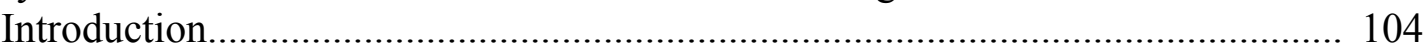

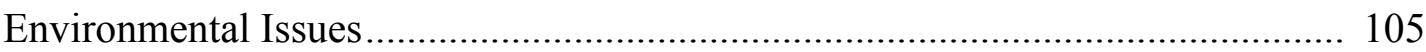

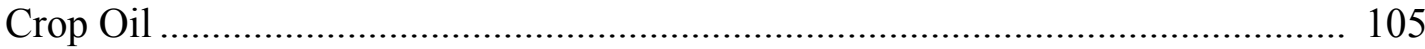

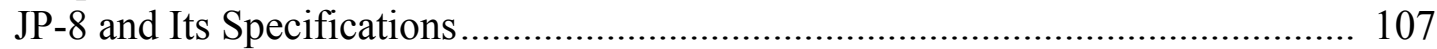

Cold-Flow Impacts/Cold-Flow Properties........................................................... 107

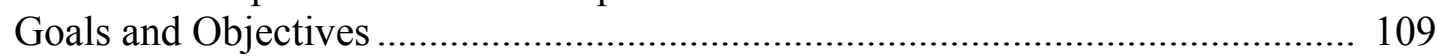

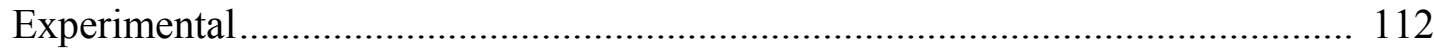

Results and Discussion ................................................................................. 117

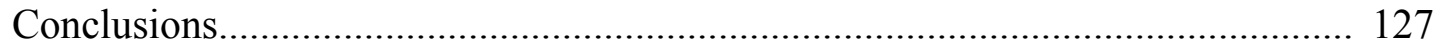

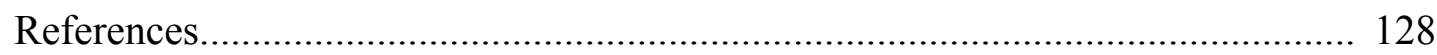

Activity 2.2 - Commercial Feasibility Study .......................................................... 129

Introduction......................................................................................... 129

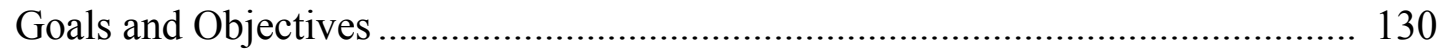

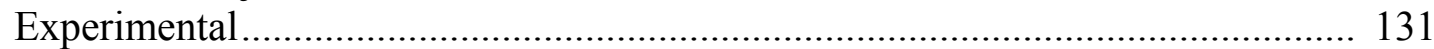

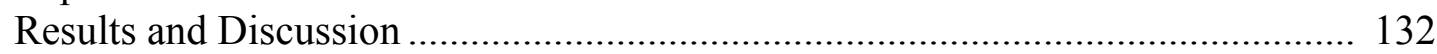

Economic Sensitivity Analysis .................................................................... 136

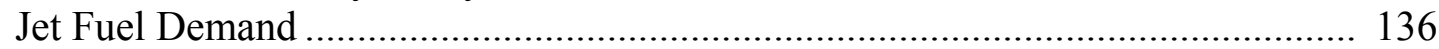

Business Model Development ……………………….................................. 140

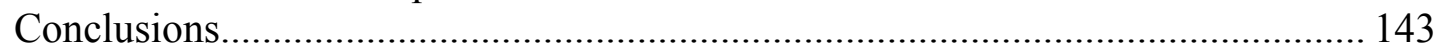

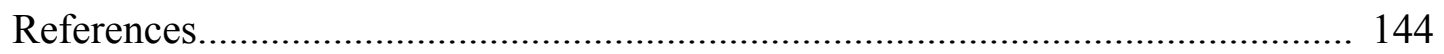

Activity 2.4 - Low-Temperature Diesel Additives from Extracted Oil.......................... 145

Introduction............................................................................................ 145

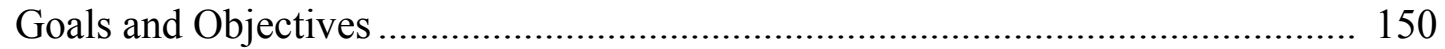

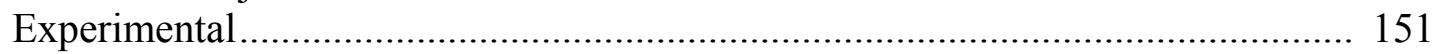

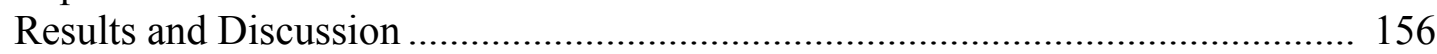

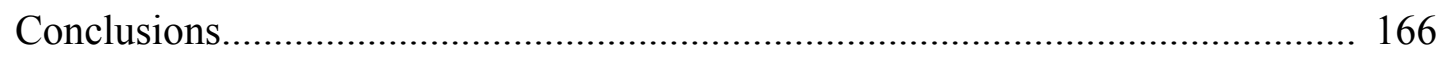

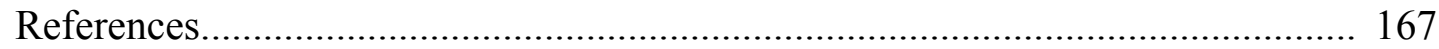

Activity 2.5 - Guerbet Alcohol Condensation Process Development ............................. 170

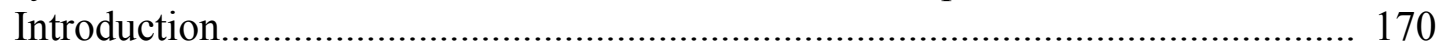

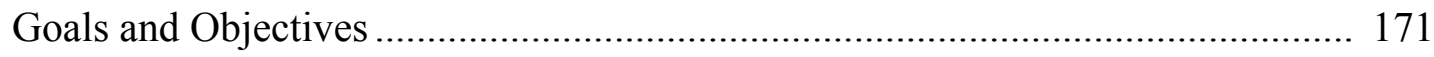

Experimental......................................................................................... 171

Continued ... 


\section{TABLE OF CONTENTS (continued)}

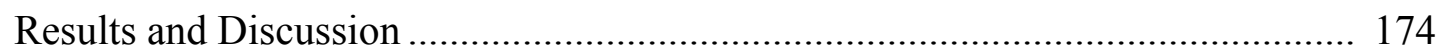

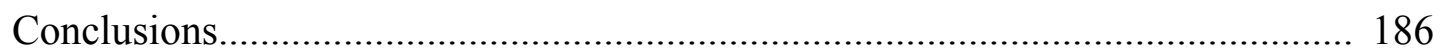

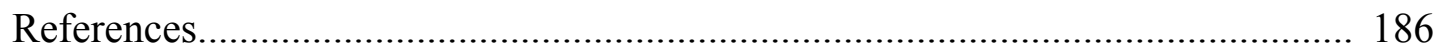

TASK 3 - MANAGEMENT, EDUCATION, AND OUTREACH …………...................... 189

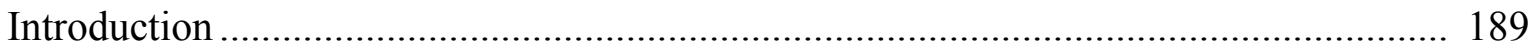

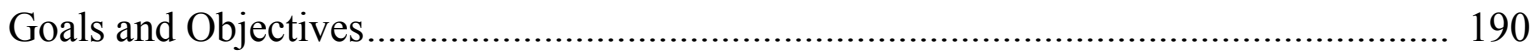

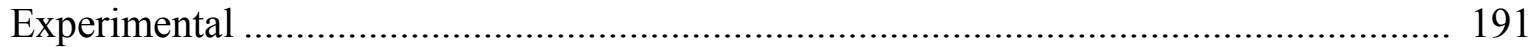

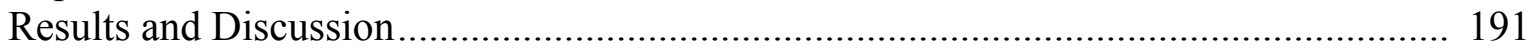

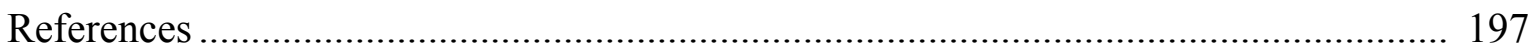

GASIFICATION OF CORN STOVERS: COMPARISON OF ETHANOL

VERSUS FISCHER-TROPSCH (FT) DIESEL.................................................PPENDIX A

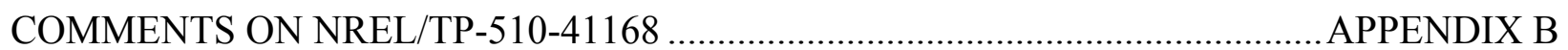

PROCESS FLOW DIAGRAM (PFD) OF THE LIGNIN GASIFICATION DIESEL FACILTY 


\section{LIST OF FIGURES}

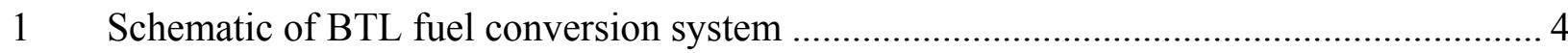

2 Catacel Corporation's novel fixed-bed FT reactor capable of operating at pressures

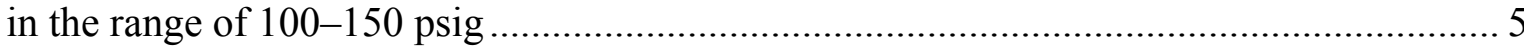

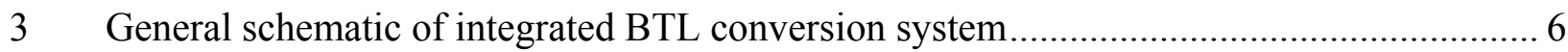

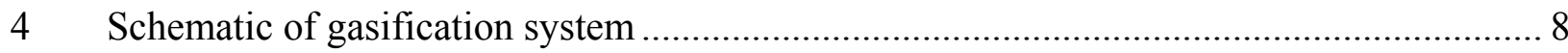

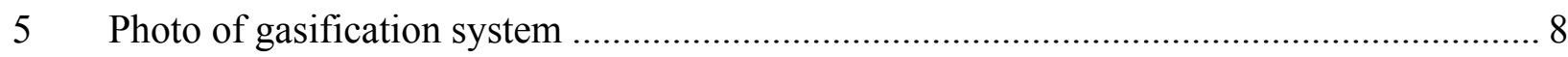

6 Schematic of the gas-to-FT liquid experimental setup.................................................... 10

7 Bench-scale gas-to-liquid test setup showing syngas supply system, FT reactor, liquid

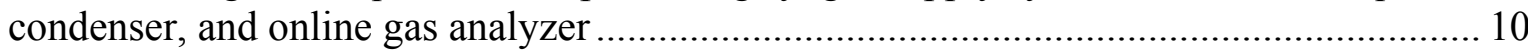

8 Computer display showing temperature and pressure measurement location on the schematic of two FT reactors used in the experiments

9 The effect of gasification airflow rate on syngas composition obtained at a $900^{\circ} \mathrm{C}$ bed temperature gasification of a) $70 \mathrm{wt} \%$ biomass and $30 \%$ moisture and b) mixture of biomass $41 \%$, plastics $32 \%$, and moisture $27 \%$.............................................................. 13

10 Nondimensionalized concentrations of $\mathrm{H}_{2}, \mathrm{CO}$, and $\mathrm{CO}_{2}$ as a function of air injection rate

11 The variation of syngas composition obtained as a function of air injection rate on the gasification of sunflower hulls conducted at $900^{\circ} \mathrm{C}$

12 Variation of $\mathrm{O} / \mathrm{F}$ ratio with air injection rate for pine wood and sunflower hulls................ 18

13 Wet turkey litter gasification: a) gas concentration time history and b) bed temperature

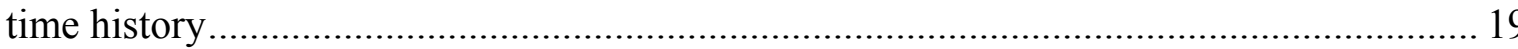

14 Dry turkey litter gasification: a) gas concentration time history and b) bed temperature time history

15 Syngas composition and bed temperature time history of the ASR gasification test ......... 21

16 Syngas composition and bed temperature time history of the 50\% ASR-50\% sunflower hull gasification experiment

Continued ... 


\section{LIST OF FIGURES (continued)}

17 Comparison of the syngas concentration time history of self-sustained gasification of

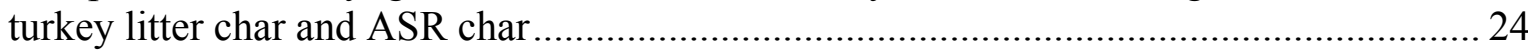

18 a) Time variation of syngas composition at the reactor outlet, b) temperature time history of the FT reactor, and c) FT reactor inlet and outlet pressure ................................ 26

19 Gas chromatogram of the FT liquid collected during the synthesis experiment and composition of noncondensable hydrocarbons in the gas phase

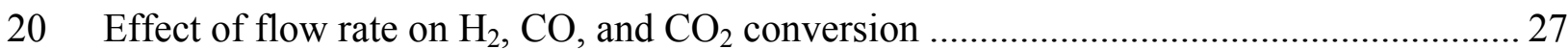

21 FTS experiments conducted at 250 psig and $200^{\circ} \mathrm{C}$ : a) conversion time history,

b) temperature time history, and c) GC-MS analysis of the product liquid 31

22 FTS experiments conducted at 200 psig and $230^{\circ} \mathrm{C}$ : a) conversion time history, b) temperature time history, and c) GC-MS analysis of the product liquid

23 Effect of forced bed temperature variations on $\mathrm{CO}$ and $\mathrm{H}_{2}$ conversion at $220^{\circ} \mathrm{C}$ and $200 \mathrm{psig}$

24 FTS experiments conducted at 300 psig and $230^{\circ} \mathrm{C}$ with forced catalyst bed cooling: a) conversion time history, b) temperature time history, and c) GC-MS analysis of the product liquid

25 FTS experiments conducted at 300 psig and $220^{\circ} \mathrm{C}$ without forced bed cooling:

a) conversion time history, b) temperature time history, and(c) GC-MS analysis of the

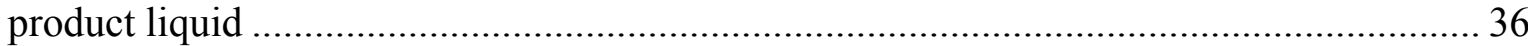

26 FTS results of syngas conversion at $220^{\circ} \mathrm{C}$ and $300 \mathrm{psig}$ without forced cooling ...............38

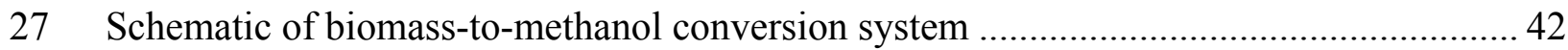

28 The IdaTech fuel cell-based electric power generator ........................................................ 44

29 Schematic of the syngas-to-methanol synthesis experimental setup.................................... 45

30 a) Syngas-to-methanol test setup showing syngas supply system, synthesis reactor, liquid condenser, and online gas analyzer. b) Computer display showing temperature and pressure measurement location on the schematic of the syngas-to-methanol test setup 


\section{LIST OF FIGURES (continued)}

31 Effect of reactor pressure on the concentrations of various alcohols and liquid oxygenates formed during the synthesis experiments conducted at a constant reactor temperature of $220^{\circ} \mathrm{C}$ and syngas with $\mathrm{H}_{2} / \mathrm{CO}$ and $\mathrm{H}_{2} /\left(\mathrm{CO}+\mathrm{CO}_{2}\right)$ ratios of less than 0.89 and average space velocity of $1580 \mathrm{~h}^{-1}$

32 Effect of pressure methanol yield and $\mathrm{CO}$ and $\mathrm{H}_{2}$ conversion.....................................49

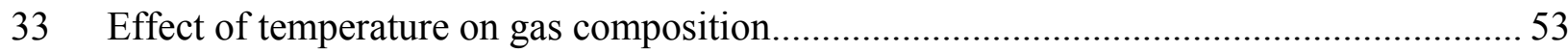

34 Effect of temperature and pressure on gas composition..................................................... 53

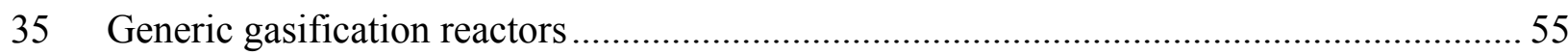

36 Texaco gasifier at Tampa Electric Integrated Gasification Combined Cycle Project......... 59

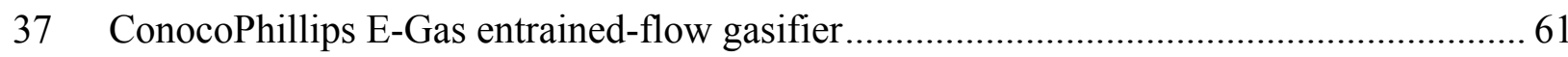

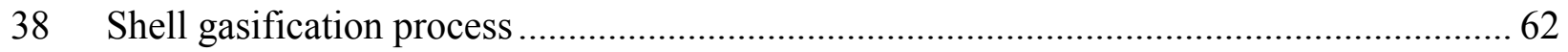

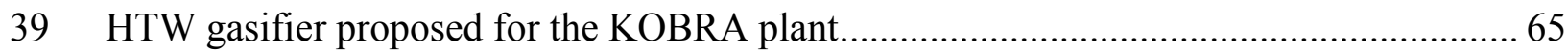

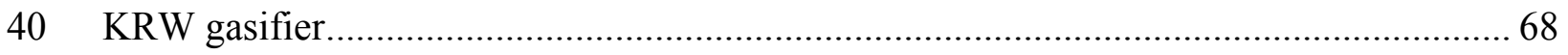

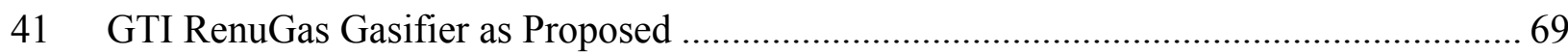

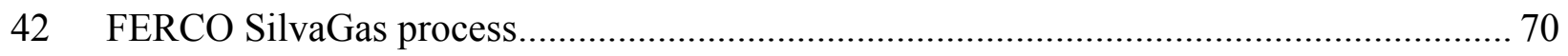

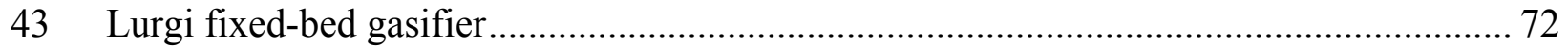

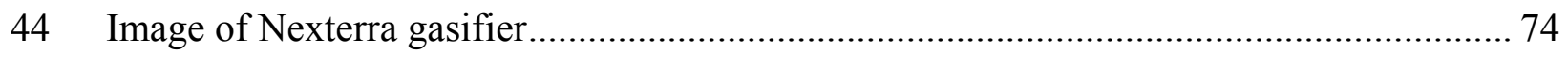

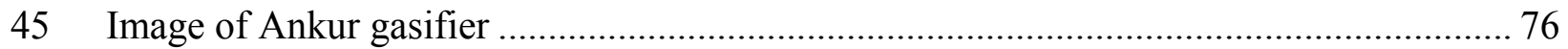

46 EERC mobile gasification unit utilizing the Ankur gasifier ............................................ 76

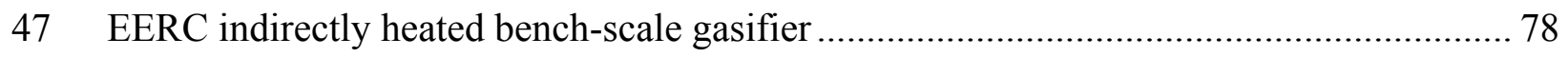

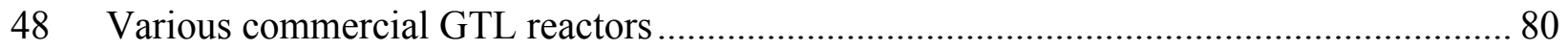

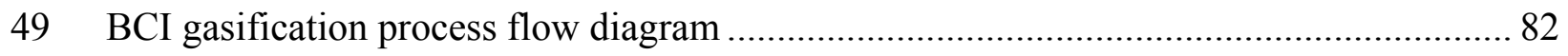

Continued ... 


\section{LIST OF FIGURES (continued)}

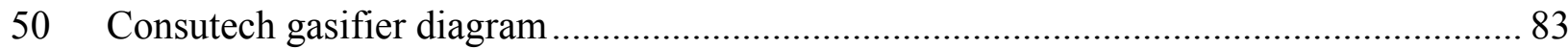

51 Dependence of IRR in base case economics to CO conversion........................................... 96

52 Dependence of IRR in base case economics to diesel contract price.................................. 97

53 Dependence of IRR in base case economics to diesel escalation rate ............................... 97

54 Dependence of IRR in base case economics to plant size................................................. 98

55 Structure of a typical triglyceride molecule .................................................................... 106

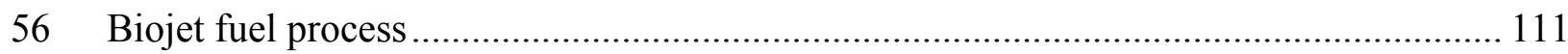

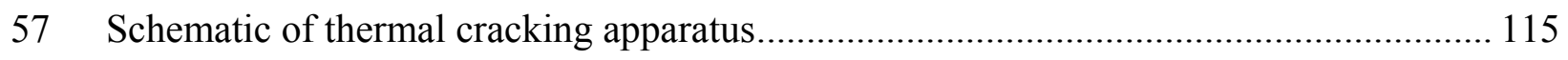

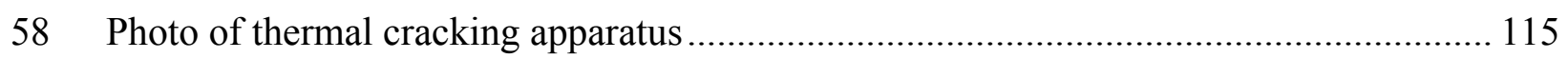

59 Generation of biojet fuel from soybean oil and SME ……………............................... 122

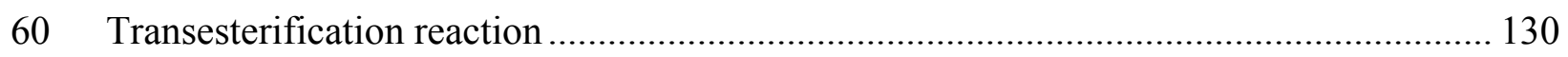

61 Operating cost basis for a 3-million-gallon-per-year biojet fuel facility............................ 135

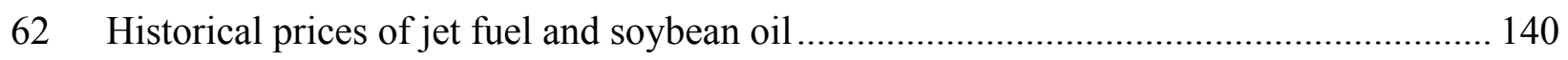

63 North Dakota jet fuel (JP-8) usage by regional airports.................................................. 141

64 Compounds produced by glycerol ozonolysis .......................................................... 148

65 Process flow diagram of a slipstream glycerol ozonolysis reactor system installed at a preexisting biodiesel facility.............................................................................. 150

66 Laboratory reactor system used to optimize ozonolysis process ………………............. 153

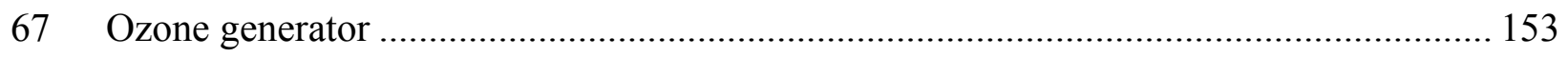

68 Ion chromatograph of an early glycerol ozonolysis product.......................................... 156

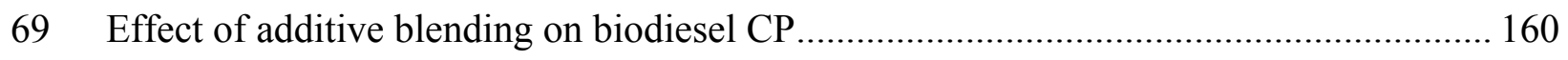

Continued... 


\section{LIST OF FIGURES (continued)}

70 Bulk chemical costs as reported by $C M R$ during the period September 25, 2004, to

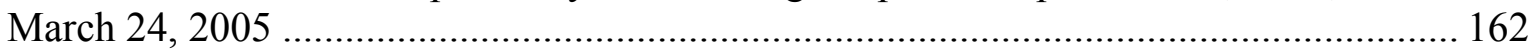

71 Biodiesel ozonolysis plant with fractionation to recover separate products ................... 164

72 Results of 100-case Monte Carlo sensitivity analysis using parameters in Table 58 ....... 166

73 Schematic diagram of reactor system.............................................................. 173

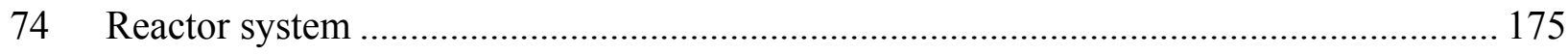

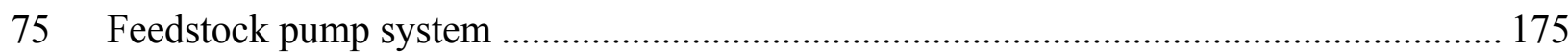

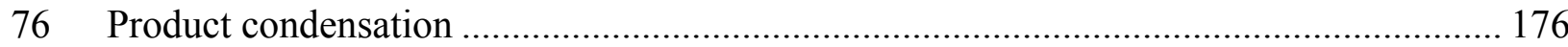

77 Percent selectivity of condensation reactions FM catalyst........................................ 185

78 Ethanol conversion product selectivity with regenerated FM catalyst.......................... 185

79 Isobutanol selectivity with both fresh and regenerated FM catalyst .......................... 187

$80 \quad$ Ethanol selectivity with both fresh and regenerated FM catalyst .............................. 187 


\section{LIST OF TABLES}

1 Gas Concentrations and $\mathrm{H}_{2} / \mathrm{CO}$ and $\mathrm{CO} / \mathrm{CO}_{2}$ Ratios During Steady-State Gasification

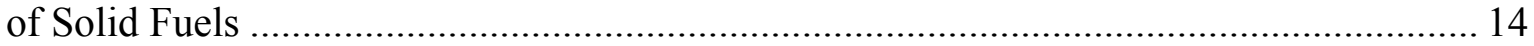

2 Syngas Species Concentrations from Sunflower Hull Gasification................................ 17

3 Average Syngas Concentrations from Peach Stone Gasification................................... 17

4 Inlet and Outlet Gas Composition Conversion from Low-Pressure FT Reactor ............... 25

5 Range of Species Concentration of Synthetic Syngas Within the EERC FTS Reactor..... 29

6 Range of Species Concentration in the Syngas Used in the FTS Experiments.................29

7 Effect of $\mathrm{CO}_{2}$ Ratio on Conversion and Methanol Yield at 500-psi Synthesis Reactor

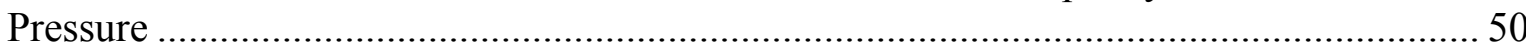

8 Comparison of Moist Lignin and Low-Rank Lignite Based on Ultimate Analysis........... 54

9 Important Characteristics of Generic Gasifiers ........................................................ 56

10 Typical Fuel Gas Composition of Selected Gasifier Technologies ............................... 60

11 Published Fuel Gas Compositions for Selected Gasifier Technology on Lignites ............ 71

12 Typical Cold-Gas Composition of Selected Gasifier Technologies .............................. 78

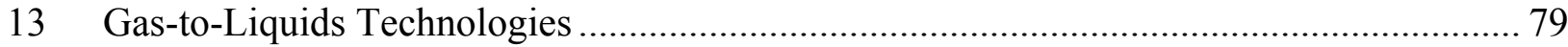

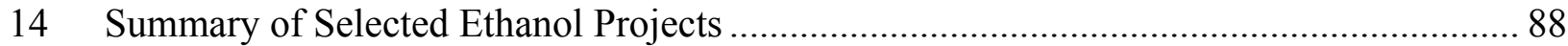

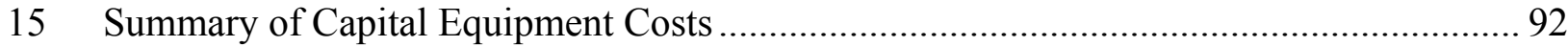

16 Summary of Operating Costs for Base Case Pro Forma .............................................. 93

17 Detailed Maintenance Cost Estimate ........................................................................ 93

18 Summary of Revenue for Base Case Pro Forma .................................................... 93

19 Average Annual Escalation for Diesel Wholesale Price ............................................ 94

20 U.S. Historical Industrial Prices for Electricity and Natural Gas.................................. 95

Continued ... 


\section{LIST OF TABLES (continued)}

21 Chemical Structure of Common Fatty Acids ............................................................... 106

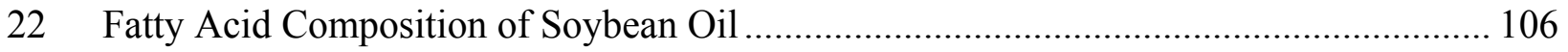

23 Typical Properties of JP-8 Aviation Fuel .................................................................. 108

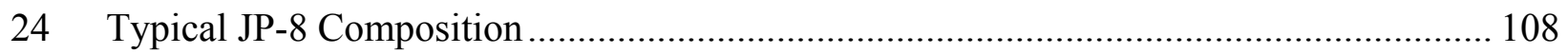

25 ASTM D5972 Freezing Point of JP-8 Biodiesel (SME) Blends ...................................... 110

26 Key Components of CME/SME and Canola/Soybean Oil.............................................. 113

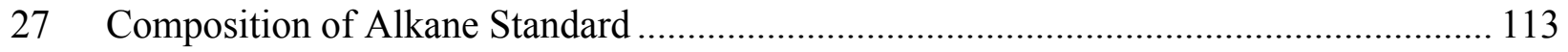

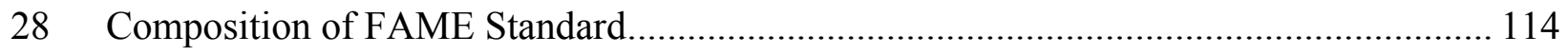

29 Design of Experimental Matrix for Thermal Cracking Optimization................................ 118

30 Parameters in Experimental Matrix for the Cracking of CME …………........................ 118

31 Parameters in Experimental Matrix for the Cracking of Canola Oil................................. 119

32 Results from Experimental Matrix Tests for the Cracking of CME ................................ 119

33 Results from Experimental Matrix Tests for the Cracking of Canola Oil ....................... 119

34 Cold-Flow Properties of Biojet Fuel Produced from CME.............................................. 121

35 Cold-Flow Properties of Biojet Fuel Produced from CME.............................................. 122

36 The Composition of Crackates and Final Biojet Fuel Samples Generated from SME ..... 123

37 The Composition of Crackates and Final Biojet Fuel Samples Generated from

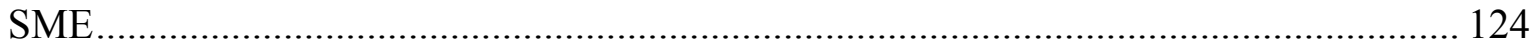

38 Results and GC Analysis of CME Crackates Using Column 1....................................... 124

39 Results and GC Analysis of CME Crackates Using Column 2...................................... 125

40 Results and GC Analysis of CME Biojet Fuel Using Column 2 ..................................... 126

41 Results and GC Analysis of Canola Oil Using Crackates Using Column 2 .................... 127 


\section{LIST OF TABLES (continued)}

42 Results and GC Analysis of Canola Oil Biojet Fuel Using Column 2 ............................. 127

43 Annual Operating (manufacturing) Expenses for a 3-M-gal/yr Biojet Fuel Facility and a 3-million-gallon-per-year Biodiesel Facility ......................................................... 133

44 Capital Cost Summary for a 3-million-gallon-per-year Biojet Fuel Facility .................... 134

45 Annual Revenues for a 3-million-gallon-per-year Biojet Fuel Facility and a 3-MM-gal/yr Biodiesel Facility .............................................................................. 136

46 Cash Flow Sheet for a 3-million-gallon-per-year Biojet Fuel Facility with a \$1/gallon Subsidy

47 Cash Flow Sheet for a 3-million-gallon-per-year Biojet Fuel Facility with No

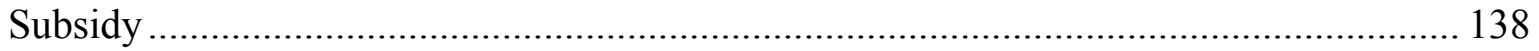

48 Comparison of Economic Worth for 3-million-gallon-per-year Facilities ....................... 139

49 Comparison of First-Year Balance Sheets for a 3-million-gallon-per-year Facility

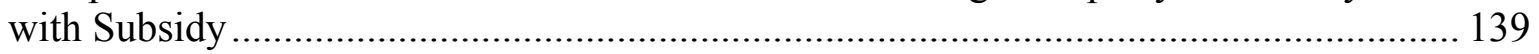

50 Comparison of Production Costs per Gallon of Product................................................. 139

51 Implicit Valuation Analysis for a 3-million-gallon Biojet Fuel Start-Up Venture Based in North Dakota ............................................................................................... 144

52 Marketability Data for Various Glycerol Ozonolysis Products ........................................ 149

53 Theoretical List of Compounds Produced by Ozonolysis of Soybean Oil in Methanol... 149

54 Planned Box-Behnken Test Design...................................................................... 152

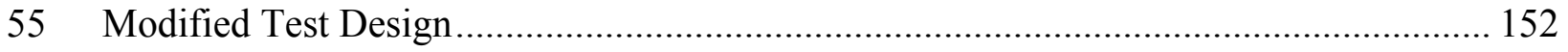

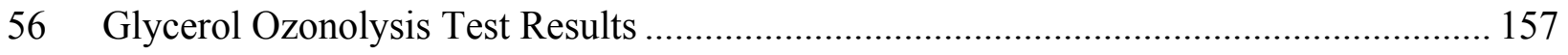

57 Results of Economic Analysis and Assumptions Used to Construct Economic

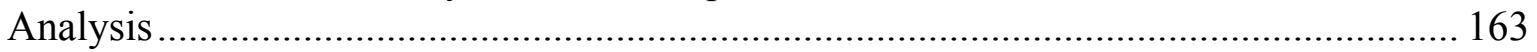

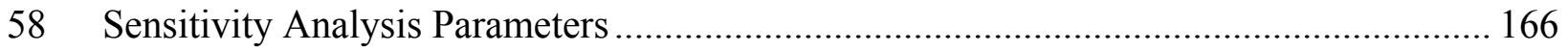

Continued ... 


\section{LIST OF TABLES (continued)}

59 Effect of Preparative Technique on the Structure of the HAP Catalyst............................. 173

60 Yield of Ethanol Condensation Reactions with FM Catalyst .......................................... 174

61 Percent Selectivity of Ethanol Condensation Reactions With FM Catalyst ...................... 176

62 Product Distribution of Ethanol Condensation with FM Catalyst .................................... 176

63 Product Distribution of Methanol/Ethanol Condensation .............................................. 177

64 Product Distribution of Methanol/Ethanol Condensation Reactions .............................. 177

65 Percent Selectivity of Condensation of Methanol-Ethanol Mixture................................. 177

66 Product Distribution of Methanol-Ethanol Condensation Reactions ……...................... 178

67 Effect of Reaction Conditions on the Condensation of Alcohols ..................................... 178

68 Condensation Reaction Product Composition Utilizing Fresh FM Catalyst...................... 181

69 Condensation Reaction Product Composition Utilizing Regenerated FM Catalyst ......... 183

70 Ethanol Conversion Product Selectivity Utilizing Fresh FM Catalyst ............................ 184

71 Ethanol Conversion Product Selectivity Utilizing Thermally Regenerated FM

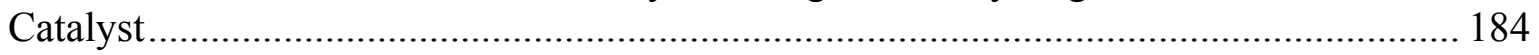

72 Selectivity for Isobutanol and Ethanal Using Fresh FM Catalyst.................................... 186

73 Selectivity of Isobutanol and Ethanal Utilizing Thermally Regenerated FM Catalyst..... 186 


\section{EERC CENTER FOR BIOMASS UTILIZATION ${ }^{\circledR} 2006$}

\section{EXECUTIVE SUMMARY}

The Center for Biomass Utilization $\left(\mathrm{CBU}^{\circledR}\right) 2006$ project at the Energy \& Environmental Research Center (EERC) consisted of three tasks related to applied fundamental research focused on converting biomass feedstocks to energy, liquid transportation fuels, and chemicals. Task 1, entitled Thermochemical Conversion of Biomass to Syngas and Chemical Feedstocks, involved three activities. Task 2, entitled Crop Oil Biorefinery Process Development, involved four activities. Task 3, entitled Management, Education, and Outreach, focused on overall project management and providing educational outreach related to biomass technologies through workshops and conferences.

\section{Task 1 - Thermochemical Conversion of Biomass to Syngas and Chemical Feedstocks}

Task 1 involved developing a distributed thermochemical conversion process for converting biomass to liquid (BTL) fuels. The effort included first devising a small-scale biomass gasification system and, second, developing a Fischer-Tropsch synthesis (FTS) system for converting the syngas to liquids. Both systems performed fundamental experiments to develop an understanding of the effect of gasifier operating conditions in the production of syngas and the conversion of syngas as a function of reactor pressure and temperature. With respect to the gasification study, syngas quality and conversion rates were determined for sunflower hulls, turkey litter, pine wood, peach stones, and mixtures of woody biomass and plastic. The highest $\mathrm{H}_{2} / \mathrm{CO}$ ratios in the case of air gasification of pine wood and a mixture of biomass and plastic waste were 1.4 and 1.7, respectively. $\mathrm{H}_{2}$ and $\mathrm{CO}$ concentration in the syngas decreased with an increase in air injection rate as observed in the case of woody biomass and a mixture of woody biomass and plastics, primarily due to the increase in concentrations of $\mathrm{N}_{2}$ and $\mathrm{CO}_{2}$. Wet turkey litter can produce a $\mathrm{H}_{2} / \mathrm{CO}$ ratio favorable for the liquid synthesis process; however, the $\mathrm{CO}_{2}$ concentration is unacceptably high (ranged between $15 \%$ and $20 \%$ ). The $\mathrm{H}_{2} / \mathrm{CO}$ ratio in the case of dry turkey litter gasification is 0.95 . The $\mathrm{CO}_{2}$ level averages between $13 \%$ and $14 \%$, which is expected to increase to a higher level, rendering the dry litter an unfavorable feedstock for conventional air gasification based the liquid production process. Air gasification is found to produce syngas with a composition unfavorable for the liquid synthesis process; however, synergistic blending with biomass can favorably produce hydrogenrich syngas. With respect to syngas-to-FT liquid conversion, the EERC worked with Catacel Corporation's reactor for catalytic FT liquid production. The FTS reactor operating temperature had a significant effect on $\mathrm{H}_{2}$ and $\mathrm{CO}$ conversion. At $180^{\circ} \mathrm{C}$, the $\mathrm{H}_{2}$ and $\mathrm{CO}$ conversions were $1.5 \%$, while at $200^{\circ} \mathrm{C}$, they were $8 \%$. At $230^{\circ} \mathrm{C}$, the highest $\mathrm{H}_{2}$ and $\mathrm{CO}$ conversions attained were $80 \%$ and $28 \%$, respectively. The FTS produced a spectrum of alkanes and alkenes with carbon numbers ranging from $\mathrm{C} 5$ to $\mathrm{C} 15$, characteristic of gasoline at a reactor pressure of 200 psig. At higher pressure, the carbon number ranged from C5 to C23, characteristic of diesel fuel. The Catacel reactor could achieve better conversion at 115 psig, producing hydrocarbons with carbon numbers ranging from $\mathrm{C} 5$ to $\mathrm{C} 24$. Reactor operation at a temperature of $230^{\circ} \mathrm{C}$ caused the catalyst bed temperature at the reactor inlet to increase by about $50^{\circ} \mathrm{C}$, achieving the highest $\mathrm{CO}$ and $\mathrm{H}_{2}$ conversions; but forced cooling of the bed significantly reduced $\mathrm{CO}$ 
conversion. Without forced bed cooling, the temperature and conversion in the reactor follow a cyclic trend without causing any temperature runaway condition.

Another activity within Task 1 focused on experiments to create methanol from biomass. Experiments were carried out using a synthetic mixture of bottled gas to simulate biomass gasification syngas to understand the effect of pressure on the conversion of syngas for production of methanol. An experimental reactor or reformer capable of yielding less than $0.5 \mathrm{~L}$ of methanol per hour was assembled. It was found that the reactor design and heat management system performed well and within the operating regime and syngas composition; coking was not observed nor did the conversion degrade during individual experiments. The concentration of methanol in the product liquid was in the range of $70 \%-82.5 \%$ and either remained constant or slightly increased with an increase in synthesis pressure range of 100-500 psig while maintaining a $\mathrm{H}_{2} / \mathrm{CO}$ ratio in the vicinity of 1 . Compounds other than alcohols were mostly organic oxygenates and water and constituted about $19 \%-28 \%$ of the total yield of liquid. These mixtures showed a decreasing trend with an increase in pressure. $\mathrm{CO}$ and $\mathrm{H}_{2}$ conversion increased with an increase in synthesis pressure, and the increase in $\mathrm{H}_{2}$ conversion was higher than that of $\mathrm{CO}$. Methanol yield increased in a way that indicated distinct synthesis pressure regimes. The methanol yield significantly increases beyond an operating pressure of 300 psig. An increase in $\mathrm{H}_{2} / \mathrm{CO}$ ratio to greater than 1 significantly improved $\mathrm{CO}$ conversion and methanol yield, but conversion of hydrogen was not significantly affected, most likely because, at a lower ratio, more of the hydrogen went to the oxygenates and water, and at the higher ratio, more went to the methanol. Based on the experimental determination of methanol yield at half the pressure of a typical fixed-bed synthesis reactor (which is 1000 psig), methanol production costs were estimated.

In Activity 1.3 Several gasification systems specific to biomass were examined for utilization at existing corn-based ethanol facilities for converting both virgin agricultural residues such as corn stover and by-products of the corn ethanol process such as lignin and corn fiber. The Kellogg, Brown and Root (KBR) transport reactor gasification system was evaluated for such an application and, in design, appeared to be one of the better selections for gasification of lignin, corn fiber, and other biomass residues. The context of utilizing the transport reactor gasification system was an approximately 25-tpd system to operate at an existing midwestern ethanol plant. However, conversations with KBR led the EERC to the conclusion that the transport reactor gasification system would be unavailable commercially for many years at this scale or for biomass use, with the company focus on upcoming coal installations. It was, therefore, suggested that the commercial partner for the project, ICM, and the EERC team develop a proprietary gasification system for the purpose of lignin utilization. As a first look at potential economics and performance, the EERC chose an entrained-flow-style gasification system for modeling purposes. The gasifier was operated using oxygen at an $\mathrm{O} / \mathrm{C}$ molar ratio of 0.93, suggested by the Electric Power Research Institute for the gasification of Texas lignite. This provides an equivalence ratio of 0.40 and gasifier energy efficiency of $77 \%$ (higher heating value basis), which are typical of most gasifier technologies. Syngas composition was modeled using FactSage 5.5 and gas-phase equilibrium at an operating temperature of $2800^{\circ} \mathrm{F}$ and pressure of $350 \mathrm{psia}$. The high operating temperatures of entrained-flow gasifiers minimize tars in the syngas and melt the inorganic ash in the lignin to slag for easy discharge under pressure. Heat recovery can thus be obtained by heating the air for lignin drying and cooling the syngas to 
about $600^{\circ} \mathrm{F}$ via a heat exchanger without tar deposition. This system was also modeled as integrated to a FT liquid fuel production facility utilizing an iron catalyst. An iron catalyst was modeled because of the greater variety of operating conditions it can handle versus a cobaltbased catalyst; it is a much less expensive catalyst and it is more tolerant to sulfur levels.

Process economics were measured by analyzing and providing a pro forma analysis over a 20-year term, an internal rate of return, and a sensitivity analysis to determine the economic factors that have the most impact on the plant's financial performance. The base case pro forma assumes a net zero cost for the lignin. The pro forma is based on a feed rate of 50-tons/day-dryash-free-lignin basis. This is equivalent to approximately 150-tons/day-wet-lignin basis, assuming $64 \%$ moisture for wet lignin and $10 \%$ moisture for dry lignin. Product generation was estimated to be 0.68 million gallons of diesel annually. The pro forma includes escalation rates on all economic factors based on historical data. Capital and operating costs came from vendor quotes, engineering texts such as Peters and Timmerhaus ${ }^{1}$, and review of public reports from the U.S. Department of Energy. Revenue was from the expected sale of diesel, with historical escalation values included in assumed sale prices.

Process economics are sensitive to a number of economic factors and assumptions. Sensitivity analyses were performed for CO conversion (yield), diesel contract price, diesel escalation rate, and facility size. The internal rate of return (IRR) is used as the sensitivity metric. Typically, an IRR of $12 \%$ provides a rate of return comparable to the stock market. For comparison, the base case IRR is $19 \%$.

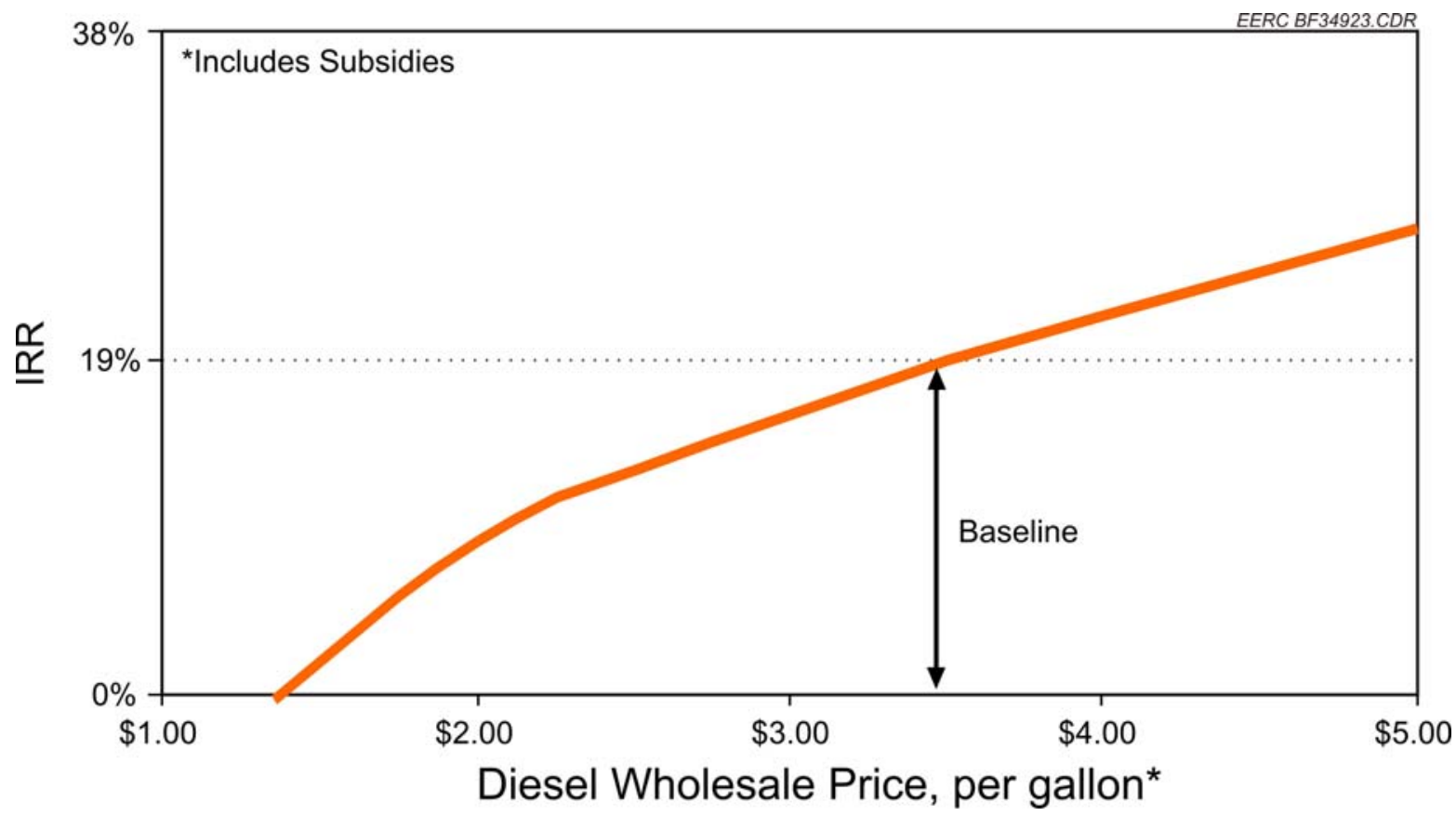

Figure ES-1. Dependence of IRR in base case economics to diesel contract price.

\footnotetext{
${ }^{1}$ Peters, M.S.; Timmerhaus, K.D. Plant Design and Economics for Chemical Engineers, 3rd Edition; McGraw-Hill Book Company: New York, 1980.
} 
The variation in IRR with the contract price of diesel is shown in Figure ES-1, assuming all other economic factors of the base case remain the same. The base case contract price is $\$ 3.50$ per gallon, with an escalation rate of $13.8 \%$ per year. At $\$ 2.50$ per gallon, the IRR is $12 \%$, approximately the same as the stock market. As the contract price increases to $\$ 5.00$ per gallon, the IRR increases to $26 \%$.

Increasing the facility size would benefit from economies of scale. Figure ES-2 shows the variation in IRR with the facility size. A 25-ton/day-dry-lignin basis plant decreases the IRR to approximately $13 \%$. The IRR increases to $25 \%$ when the facility size is doubled to 100 tons/day. At 200 tons/day, the IRR increases to $31 \%$.

\section{Task 2 - Crop Oil Biorefinery Process Development}

Task 2 centered mostly around developing biorefining processes for liquid biofuels such as green diesel, biodiesel, or other renewable jet fuel and associated hydrocarbon fuel by-products. A 1-L bench-scale cracking reactor was fabricated and the system optimized for cracking a soybean oil methyl ester compound, soybean oil, canola oil methyl ester, and canola oil at reaction temperatures between $430^{\circ}$ and $440^{\circ} \mathrm{C}$. A high yield of kerosene-type jet fuel crackate was produced that met required military specifications for JP-8, such as aromatics, olefins, specific gravity, flash point, freeze point, and heat of combustion. For a single-pass reaction/single-pass separation and residence time of 20-30 minutes, about 50\% of the feedstock oil or methyl ester biodiesel was converted to what has been labeled a biojet fuel. When using a recycle loop, the amount increased to around $86 \%$ of feedstock conversion to biofuel. The biojet fuel consisted of approximately 15\% alkanes, 2\% alkenes, 2\% BTEX (benzene, toluene,

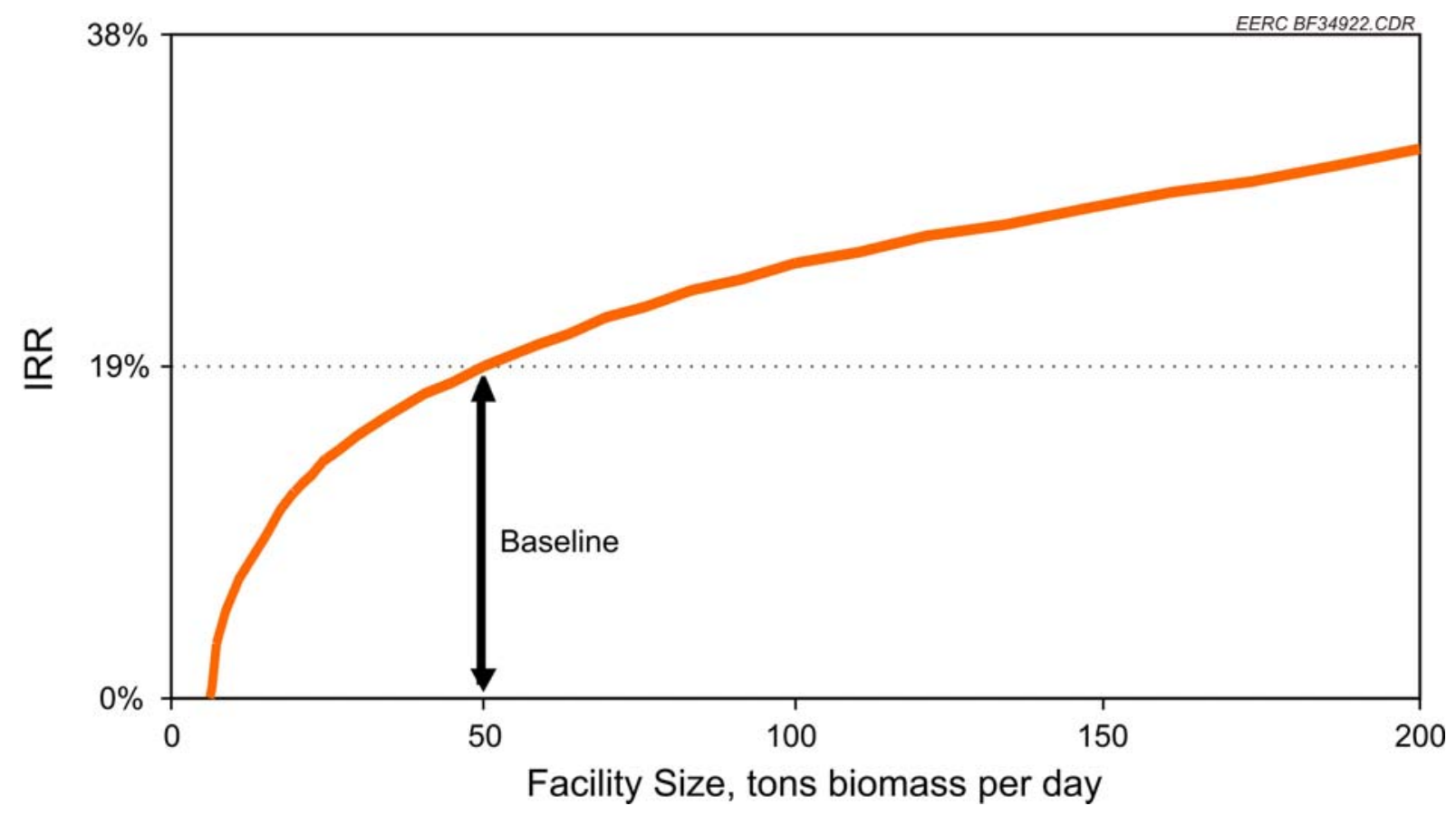

Figure ES-2. Dependence of IRR in base case economics to plant size. 
ethylbenzene, and xylenes), and 34\% C4-C15 saturated fatty compounds. It was determined that hydrogen does not play an important role in the cracking process and formation of products but helps minimize polymerization, especially for oil as a feedstock. A higher yield of crackate was obtained from methyl ester biodiesel than its feedstock oil, but the quality (defined as percentage of C4-C15 content) is less from biodiesel than its feedstock oil. Canola oil and canola methyl ester cackates had a higher concentration of alkane compounds present in them compared to soybean oil and methyl ester fuels produced at the same cracking conditions. Reaction temperature was determined as the most important variable for the yield and quality of biojet fuel generation. A higher reaction temperature of cracking near the feedstock's boiling point results in a higher yield and better cold-flow properties of crackates. As a follow-on to the biojet technical process work a preliminary business model was developed.

A new technical approach toward producing cold-weather additives for a methyl ester biodiesel was investigated using vegetable oil ozonolysis in methanol. Some alkene linkages were cleaved via ozonolysis, but it was unclear if significant glycerol, thought to be susceptible to cleavage via partial oxidation by periodic acid, was affected. In the end, diesel fuel components or additives with reduced freezing points were not achieved in sufficient quantities using ozonolysis, and the method did not prove to be technically feasible.

\section{Task 3 - Management, Education, and Outreach}

Project management and quality control were provided for all of the project's technical activities. This included administering all obligations to the Biological and Environmental Research Program of the DOE Office of Science. All project postaward contract negotiations related to reporting, project extensions, and billing were handled by this task; the preparation of all reports and project review presentations; the management of quality assurance/quality control activities; the facilitation of kickoff, midproject review, and bimonthly renewables/biomass informational meetings with individual task leaders; and a host of miscellaneous project management activities. Part of the education and outreach objectives of Task 3 was to support, host, and conduct a biomass workshop. A workshop was assembled and facilitated called Biomass '07: Power, Fuels, and Chemicals Workshop, held at the Alerus Center in Grand Forks, North Dakota, on May 15 and 16. The workshop exceeded expectations, with 400 participants and 40 exhibitors from over 230 different organizations, three foreign countries, and 28 states.

In addition to the workshop- and conference-type educational activities, materials were developed to provide an overview of the opportunities and activities related to biomass as an alternative fuel in the United States, with special emphasis on the northern Great Plains region. These materials were incorporated into a booth display that was used for public outreach at the North Dakota State Fair in Minot, North Dakota, in the summer of 2006. As a result of interaction and discussion in formal peer review meetings and other more informal meetings with DOE personnel and biomass industry experts, specific areas related to biofuels and bioenergy were identified and targeted as great needs to the United States and as relevant areas needing federal assistance to perform higher-risk applied research or demonstration. Some of these areas include indirect liquefaction of wood wastes integrated with small-scale syngas reactors for methanol/ethanol or distributed hydrogen production; low-temperature catalytic reforming of glycerol to hydrogen using improved catalysts; high-pressure electrolysis of bio- 
based glycerol and bio-based alcohols for on-demand hydrogen production; well-integrated gas turbine biomass gasifier power plants for distributed power production; gasification of wet biomass utilizing supercritical hydroconversion; mitigation of hydrogen sulfide concomitant enhancement of methane production; thermal conversion of torrefied-biomass pellets; integrating fermentation ethanol and crop oil in processing that creates ethyl biodiesel and glycerol-based products; production of formic-acid-based chemicals and hydrogen via gasification of cellulosic biomass; and developing robust microgasification technology for municipal solid waste.

Also, through the strategic studies portion of Task 3, the debate was carried forth at several meetings and educational venues on the topic of starch-based ethanol versus lignocellulosic ethanol and biodiesel-based fuels. Opinions from politicians, scientists, investors, and developers range from the ability of the United States to replace nearly all its transportation fuel use with biofuels to less than a fourth. Replacing a significant portion of petroleum-derived transportation fuels with domestic renewable alternatives from biomass will require new, innovative pathways that 1) compete economically with petroleum and 2) maximize the fuel production capacity of U.S. agricultural lands, which means achieving a maximum "vehicle miles traveled" per acre. This involves a paradigm shift in thinking and conducting research on both the development of biofuels and how the fuels are consumed. Possible options to accomodate such a paradigm shift may include 1) enzyme hydrolysis of biomass followed by conventional fermentation of the sugars made available from the cellulose to ethanol; 2) thermal gasification of the biomass to convert it to mostly volatile carbon monoxide, hydrogen, carbon dioxide, and methane, followed by fermentation of this mixture to ethanol; 3) thermal gasification of the biomass followed by nonfermentative alcohol synthesis and mixed alcohol production; 4) thermal gasification of the biomass followed by FT conversion to distillates or "green diesel"; 5) thermal gasification of the biomass followed by methanol synthesis, dehydration, and catalytic conversion to dimethyl ether, a higher-reaction-temperature, higher cetane compound that is an excellent diesel fuel substitute; and 6) pyrolysis conversion of biomass to bio-oil followed by hydrogenation and conversion to distillates or "green diesel." The six pathways described are by no means the only pathways from biomass to transportation fuel being considered today, but the EERC considers these pathways the most likely to find success on a large scale. 


\section{EERC CENTER FOR BIOMASS UTILIZATION ${ }^{\circledR} 2006$}

\section{INTRODUCTION}

Traditionally, renewable energy and products are derived from hydroelectric, solar, biomass, wind, wave, and geothermal energy forms. These energy forms are renewable in the sense that they are sustained in the earth's environment year after year without depletion, unlike fossil fuels which were formed only once, thousands of years ago, and are being depleted each year.

The Energy \& Environmental Research Center (EERC) deems biomass resources as a viable and necessary component of renewable energy to become a significant component of the total energy mix in the United States in the future. Presently, the U.S. Energy Information Administration estimates that biomass is only about $2.5 \%$ of the total U.S. energy generation (1). This percentage is bound to grow for a variety of reasons.

One reason for the necessity of growth in biomass utilization is that domestic fossil fuels are bound to dwindle in the next several decades, especially petroleum and natural gas, and steps need to be taken now to find alternative energy forms. U.S. coal reserves have the potential to sustain the U.S. electrical generation need for many, many decades, but petroleum for transportation fuels and chemicals has a more near-term timetable for depletion. It also makes sense, for national security and domestic economic reasons, to promote the development of bioenergy and biofuels now. A final reason that necessitates the growth of biomass utilization is the positive impact on the environment.

Environmental impacts that are related to energy production take two major pathways: terrestrial and atmospheric. The consumption of fossil fuels results in a variety of terrestrial or land-based environmental challenges, some of which include coal mine reclamation, preventing contamination of hydrologic aquifers from oil rig activity or coal mine drainage water, land surface disruption from oil and gas rigs, oil spills on land and sea, and negative impacts on pristine plant and wildlife. Atmospheric emission challenges are actually more direct and include controlling the atmospheric release of acids (nitrogen- or sulfur-based), particulate, mercury and other metals, and greenhouse gases. Shifting to biomass resources can, in some cases, eliminate and, in most cases, at least slow down detrimental impacts on the earth's terrestrial and atmospheric environments. Biomass can be grown in fields and does not have to be excavated out of the ground; biomass contains no sulfur and very little, if any, mercury; biomass is $\mathrm{CO}_{2-}$ neutral; and spills of ethanol and biodiesel, at least in pure form, are harmless to the environment. With respect to greenhouse gas emissions, biomass utilization in the replacement of fossil fuels can help slow down this deleterious effect. Fossil fuels release $\mathrm{CO}_{2}$ that has been locked in the Earth for millions of years. Biomass conversion also releases $\mathrm{CO}_{2}$, but that $\mathrm{CO}_{2}$ comes directly from the current atmosphere with a fairly balanced ecosystem. Biomass cycles $\mathrm{CO}_{2}$ and does not add additional fossil $\mathrm{CO}_{2}$ to the atmosphere. Another type of by-product environmental impact of biomass utilization is that biomass normally taken to a landfill to decay into methane or be burned in the field can be reduced using conversion systems to capture energy and reduce the production of methane, which is much more of a greenhouse gas agent than $\mathrm{CO}_{2}$. 
In summary, biomass utilization is one solution to our nation's dependence on oil and fossil fuels. Applied fundamental research and economical technology development will lead to the utilization of the diverse biomass resources in the United States. This project contributes to the development of economical biomass utilization for energy, transportation fuels, and marketable chemicals using biorefinery methods that include thermochemical and fermentation processes.

The fundamental and basic applied research supports the broad scientific objectives of the Biological and Environmental Research Program of the U.S. Department of Energy (DOE) Office of Science, especially in the area of life sciences, climate change, and environmental remediation. Deliverables include 1) identifying and understanding environmental consequences of energy production from biomass, including the impacts on greenhouse gas production, carbon emission abatement, and utilization of waste biomass residues, and 2) developing biology-based solutions that address DOE and national needs related to waste cleanup, hydrogen production from renewable biomass, biological and chemical processes for energy and fuel production, and environmental stewardship.

This project serves the public purpose of encouraging good environmental stewardship by developing biomass-refining technologies that can dramatically increase domestic energy production to counter current trends of rising dependence on petroleum imports. Decreasing the nation's reliance on foreign oil and energy will enhance national security, the economy of rural communities, and future competitiveness. Although renewable energy has many forms, including wind and solar, biomass is the only renewable energy source that can be governed through agricultural methods and that has an energy density that can realistically compete with, and even replace, petroleum and other fossil fuels in the near future. It is a primary domestic, sustainable, renewable energy resource that can supply liquid transportation fuels, chemicals, and energy currently produced from fossil sources, and it is a sustainable resource for a hydrogen-based economy in the future.

\section{GOAL}

The goal of the EERC Center for Biomass Utilization $\left(\mathrm{CBU}^{\circledR}\right)$ Program 2006 was to develop economically and environmentally sound technologies to promote efficient biopower or bioenergy, transportation biofuels, and bioproducts such as marketable chemicals and hydrogen. Biomass is a critical domestic resource in the United States for meeting future electrical demand, reducing dependence on foreign oil, and achieving the numerous "greening" initiatives launched by federal and state government. An overarching goal of the EERC CBU is to develop technologies that will expand the use of biomass in practical and economical ways within the framework of sustainable development and environmental protection.

\section{OBJECTIVES}

Specific objectives of the EERC CBU Program 2006 are addressed in individual tasks and activities. 


\title{
REFERENCES
}

1. Energy Information Administration. Annual Energy Review 2005; Report No. DOE/EIA0384(2005); July 27, 2006.

\section{TASK 1 - THERMOCHEMICAL CONVERSION OF BIOMASS TO SYNGAS AND CHEMICAL FEEDSTOCKS}

\author{
Activity 1.1 - Integrated Thermochemical and Liquid Fuel Synthesis
}

\section{Introduction}

Under this activity, the EERC partnered with Catacel Corporation, an Ohio-based manufacturer of advanced catalytic combustors, reformers, and heat exchangers, and Johnson Matthey Inc. (JMI), a major Fischer-Tropsch (FT) catalyst manufacturer, in developing a distributed-scale biomass-to-liquid (BTL) fuel conversion system. Woody biomass, animal waste, and a range of carbonaceous wastes such as automotive shredder residue (ASR) (tires) and wastes containing plastics are critical domestic resources in the United States that can be utilized as a feedstock for conversion into energy or energy carrier liquid fuels. The development of technologies capable of utilizing such vast distributed resources can help achieve the goal of reducing the dependency on foreign oil. The primary approach to reach this goal is to provide energy independence by developing conversion technology for small-scale industries producing biomass waste as their process by-products or industries located close to such resources. Typical examples include sunflower seed processors, turkey farms, saw mills, and the forest product industry. These small-scale operations, in addition to utilizing by-products and reducing the environmental impact caused by the by-products, can improve process economics and energy reliability critical for their sustained growth. Another example of an end user of such technology is military units deployed in the battlefield, producing waste (a mixture of biomass waste such as food waste, cardboard, and plastics) and requiring fuel. Figure 1 shows a schematic of an integrated BTL production system, with electricity and heat as the by-product.

The important components of the technology are the gasifier and FT synthesis (FTS) reactor. The gasifier converts biomass into syngas, a mixture of combustible gases $\mathrm{H}_{2}, \mathrm{CO}, \mathrm{CO}_{2}$ $\mathrm{CH}_{2}$, and $\mathrm{N}_{2}$. The cleaned and compressed syngas is fed to the FTS reactor for the production of liquid fuels. The unconverted syngas can be utilized for the production of heat and electricity. Depending on the gasifier operating conditions and the feedstock used, residue can be recovered as value-added by-products such as char or activated carbon or inorganics. An example is the residue of turkey waste gasification, which can be used as turkey feed or fertilizer.

Based on a DOE-sponsored study on the engineering and economic analysis of converting biomass to methanol (1), it was concluded that air gasification of woody biomass in a thermally integrated downdraft gasifier can produce syngas that can be directly fed to a liquid synthesis reactor for producing methanol at a price comparable to or lower than the market price. It was also found that lowering syngas-compressing costs by lowering the synthesis pressure requirement can significantly reduce the cost of methanol production. 


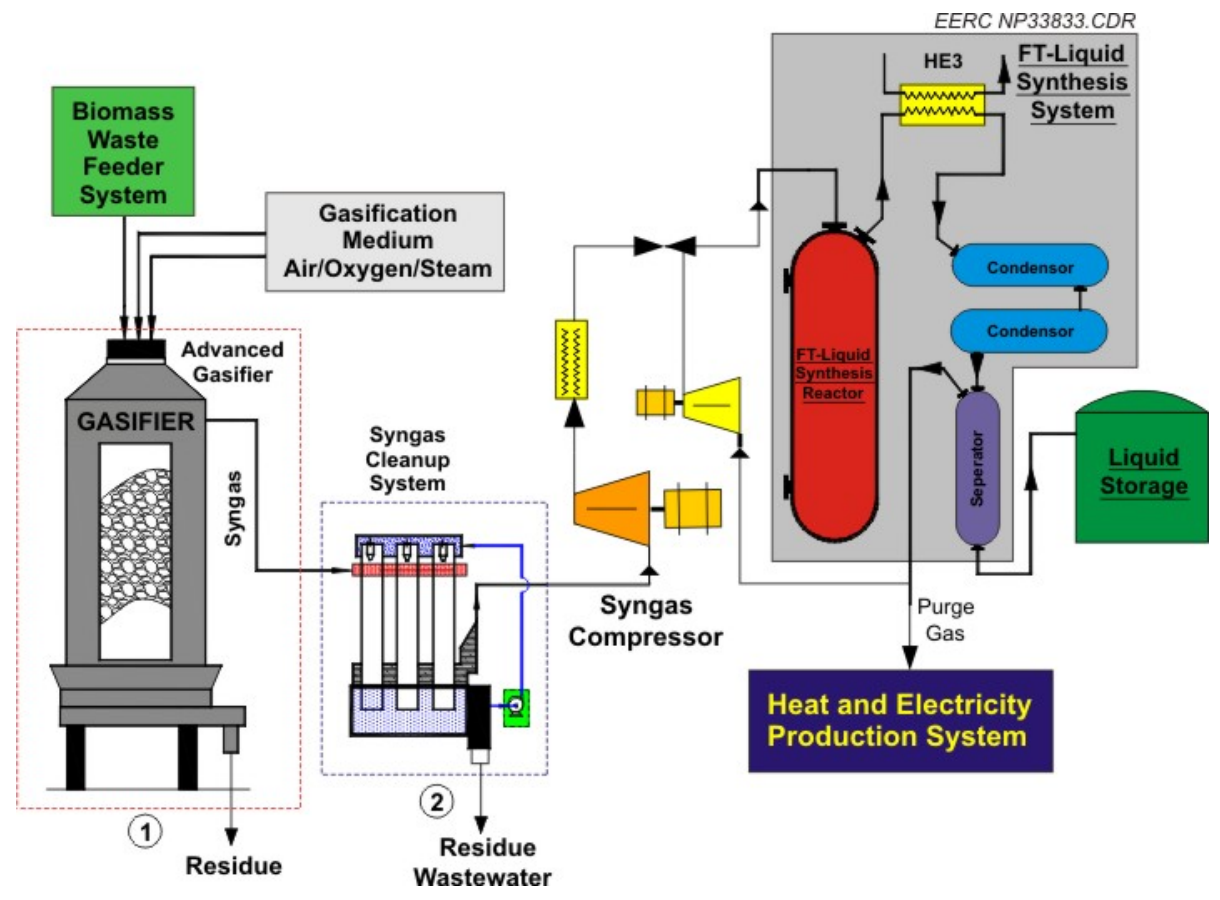

Figure 1. Schematic of BTL fuel conversion system.

While most large-scale liquid production processes either utilize high-pressure steam reforming of natural gas or oxygen gasification of coal for the production of syngas, none of these processes are economical at a small scale. These processes utilize $\mathrm{CO}_{2}$ scrubbers followed by a shift reactor used for adjusting syngas composition to meet the stoichiometric requirements of the synthesis process. For the distributed conversion process, the additional syngas balance systems are not only cost-ineffective but also complicate the production process. It is, therefore,important to advance both gasification and FTS technologies such that the capital and operating costs of the integrated BTL system are low, a critical factor for the success of the technology.

Catacel Corporation has designed its first low-pressure FTS reactor based on its proprietary Stackable Structural Reactor (SSR ${ }^{\mathrm{TM}}$ ) technology for the project. The FTS reactor, shown in Figure 2, has highly improvised heat-transfer and flow characteristics within the structured catalyst bed. This feature is critical in maintaining the exothermic heat profile in the reactor. Proprietary FTS catalyst was used in this reactor. The EERC conducted a series of tests to understand low-pressure syngas conversion. Preliminary tests on the FT catalyst provided by JMI were conducted in the EERC's specially designed fixed-bed reactor. These tests provided a basis for the comparison of FTS processes in two different reactor systems. The EERC conducted gasification tests on pine wood, a mixture of pine wood and plastic, turkey litter, ASR, sunflower hulls, and peach stones in order to understand the effect of gasifier operating conditions in the production of syngas. 


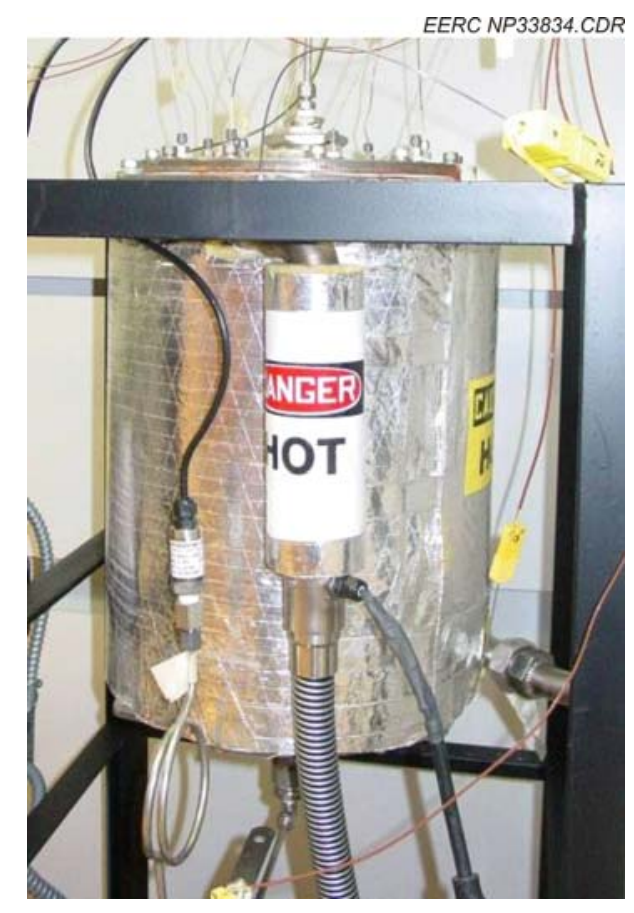

Figure 2. Catacel Corporation's novel fixed-bed FT reactor capable of operating at pressures in the range of $100-150$ psig.

\section{Goals and Objectives}

The goal of the EERC CBU Program 2006 is to develop economically and environmentally sound technologies to promote efficient biopower or bioenergy, transportation biofuels, and bioproducts such as marketable chemicals and hydrogen. Biomass is a critical domestic resource in the United States for meeting future electrical demand, reducing dependence on foreign oil, and achieving the numerous greening initiatives launched by federal and state government. An overarching goal of the EERC CBU is to develop technologies that will expand the use of biomass in practical and economical ways within the framework of sustainable development and environmental protection.

The goal of the work performed under Activity 1.1 was to identify a range of biomass fuels that represents woody biomass, agricultural and animal waste, and humanmade waste that can be used as feedstock for the production of syngas and by-products. Early in the program, it was determined to focus on the conversion of syngas to FT liquids instead of the original goal of converting biomass to just hydrogen-rich syngas, with carbon residue as a by-product. To achieve this goal, the task was organized to conduct gasification tests on biomass fuels to understand the performance of these fuels as gasifier feedstock, determine syngas composition as a function of gasifier operating conditions, and then conduct bench-scale FTS process tests and experimentally determine reactor operating pressure and temperature for converting syngas to FT liquid. 


\section{Experimental}

The primary focus of the effort is the utilization of distributed resources for the production of FT liquids and value-added by-products such as gasification residue that can improve overall process economy. Figure 3 depicts a schematic of the BTL conversion system. The conversion process is divided into three main steps. The first and most important step is the conversion of biomass or complex carbonaceous fuel into a mixture of gaseous species such as $\mathrm{CO}, \mathrm{CO}_{2}, \mathrm{H}_{2}$, $\mathrm{CH}_{4}$, and $\mathrm{N}_{2}$, commonly known as syngas, which can be used as a feedstock for FT liquid production. The residue from this step can be recovered as useful by-product, depending on the gasifier operating conditions. The second step consists of components that prepare the syngas for the synthesis process. This step primarily prepares syngas for the synthesis reaction. The system components in this step are gas scrubbers and a set of compressors. The gas scrubbers aretypically of the fixed-bed configuration used for effective removal of sulfur and halogen compounds known to act as catalyst poison, which can cause premature deactivation and the failure of the catalyst. The syngas is then compressed to the required operating pressures of the syngas-to-liquid synthesis reactor system. The output of the third step is the synthesized liquid and unconverted syngas and/or purge syngas. The liquid is further processed in an additional step integrated with the third step in order to obtain the desired composition of the liquid or chemicals. The unconverted syngas is recycled by recompressing in the compressor stage of the step process. It is likely that, at this stage, the syngas composition is balanced either by removal of product $\mathrm{CO}_{2}$ or injection of hydrogen-rich gas or by both the steps integrated with Step 2 .

Step 1 and Step 3 are conducted separately in the current project in order to understand the output streams from the individual steps, syngas and residue from Step 1, and FT liquid from

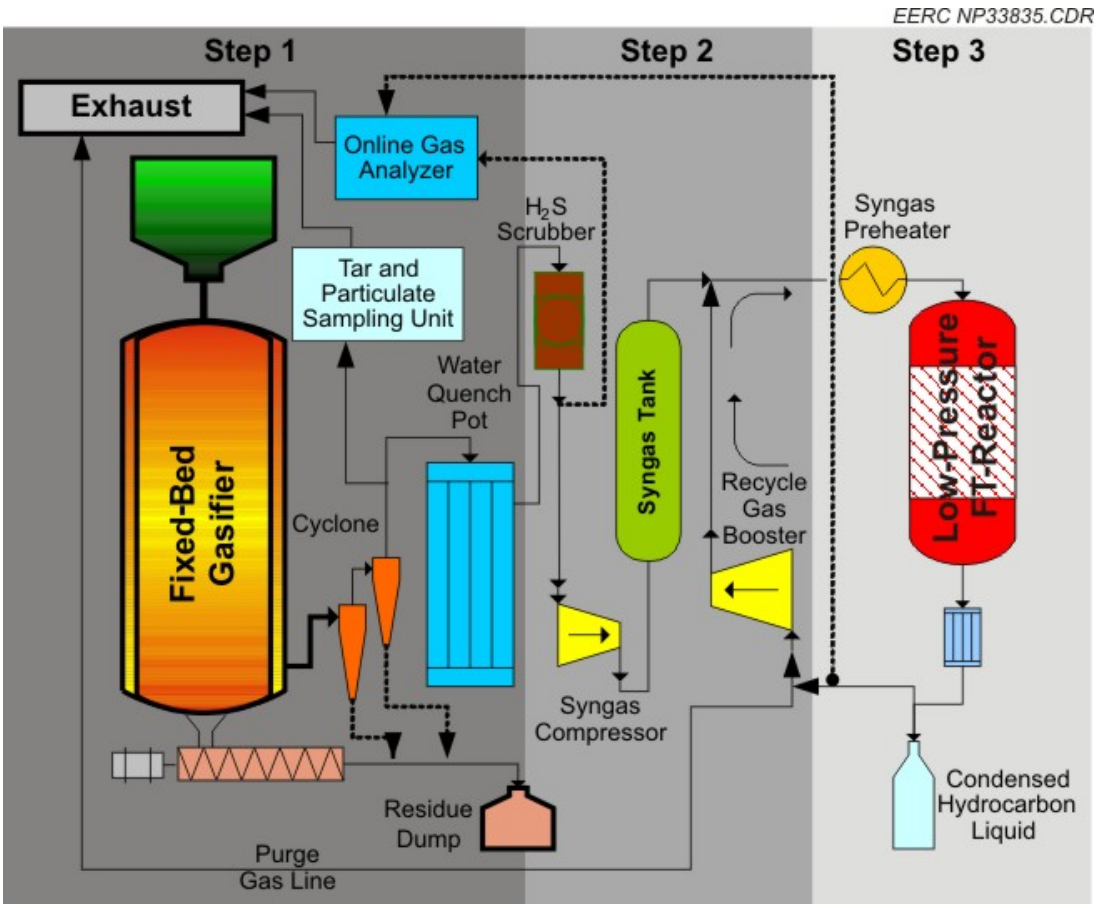

Figure 3. General schematic of integrated BTL conversion system. 
Step 2. The step utilizes a fixed-bed downdraft gasifier capable of simulating a range of operating conditions from self-sustained gasification to fully heat-assisted gasification in order to achieve different $\mathrm{H}_{2} / \mathrm{CO}$ ratios. The Step 3 experiments were conducted using simulated syngas fed into a specially designed fixed-bed gas-to-liquid reactor. The test systems used in Step 1 and Step 3 are described as follows.

\section{Gasifier System: Step 1}

The schematic and photo of the bench-scale gasifier are shown in Figures 4 and 5, respectively. Gasification experiments on various biomass and mixed-biomass wastes containing synthetic materials such as plastics and ASR were conducted using this gasifier in order to obtain a preliminary understanding of the performance of these materials as gasification feedstocks. The thermal output of the system is $10 \mathrm{~kW}$, with a turndown ratio of 6 . The fuel is auger-fed from a closed hopper from the top of the gasifier at feed rates up to $6 \mathrm{lb} / \mathrm{h}$. The residue (ash and char) is extracted through an auger at the bottom of the reactor. The gasification medium used in the experiments was air, injected from the closed top of the reactor.

In order to achieve quick thermal steady-state operation of the reactor, the reactor's ceramic insulation is initially heated to temperatures in the range of $500^{\circ}-600^{\circ} \mathrm{C}$, which prevents excessive heat loss during reactor start-up. The heating is achieved by switching on the natural gas burner (not shown in the schematic) for 20 minutes and then permanently switching it off throughout the rest of the experiment. During the initial heating period, hot product gas leaving the combustor convectively heats the reactor and insulation. The product gas is then exhausted into the atmosphere. The self-sustained steady-state operation of the gasifier is verified by determining the higher bed temperature as compared to the insulation temperature. This is an indication that the reactor oxidation zone provides an exothermic heat profile necessary to sustain endothermic gasification reactions. This procedure helps in understanding the ability of the fuel to sustain the gasification reaction by excluding or minimizing the effect of heat loss, even in the case of a bench-scale gasifier. Thus the performance study of various fuels can be effectively understood by comparing the bed temperature profile of different fuels. Experiments conducted by maintaining reactor wall temperature within a narrow range were primarily aimed at simulating a large reactor with high thermal inertia. The auxiliary fuel burner will be kept operational at a very low power level, just to maintain the reactor heat loss profile.

The syngas leaving the reactor passes through particulate cyclone filters. At this point, the producer gas passes through a heat exchanger, water quench pots, and a moisture condenser, as shown in the schematic. The gasifier can be operated by injecting pressurized air in the fuel bed while simulating a closed-top gasifier operation mode or it can be injected by inducing lowerthan-atmospheric-pressure air in the bed created with the help of a vacuum pump in order to simulate an open-top gasifier. The vacuum pump is located downstream of the scrubber system, which creates the negative pressure in the gasifier and causes air injection in the reaction zones. The producer gas flow rate is measured with the help of a rotameter or a gas flowmeter. A slipstream of syngas is sampled downstream of the rotameter for determining gas composition. The sampled gas is analyzed using a precalibrated gas analyzer capable of measuring five gas components: $\mathrm{CO}, \mathrm{CO}_{2}, \mathrm{H}_{2}, \mathrm{CH}_{4}$, and $\mathrm{O}_{2}$. The mainstream syngas is vented into the exhaust duct or is flared in a diffusion burner when not used for FT liquid synthesis experiments. Purge gas 


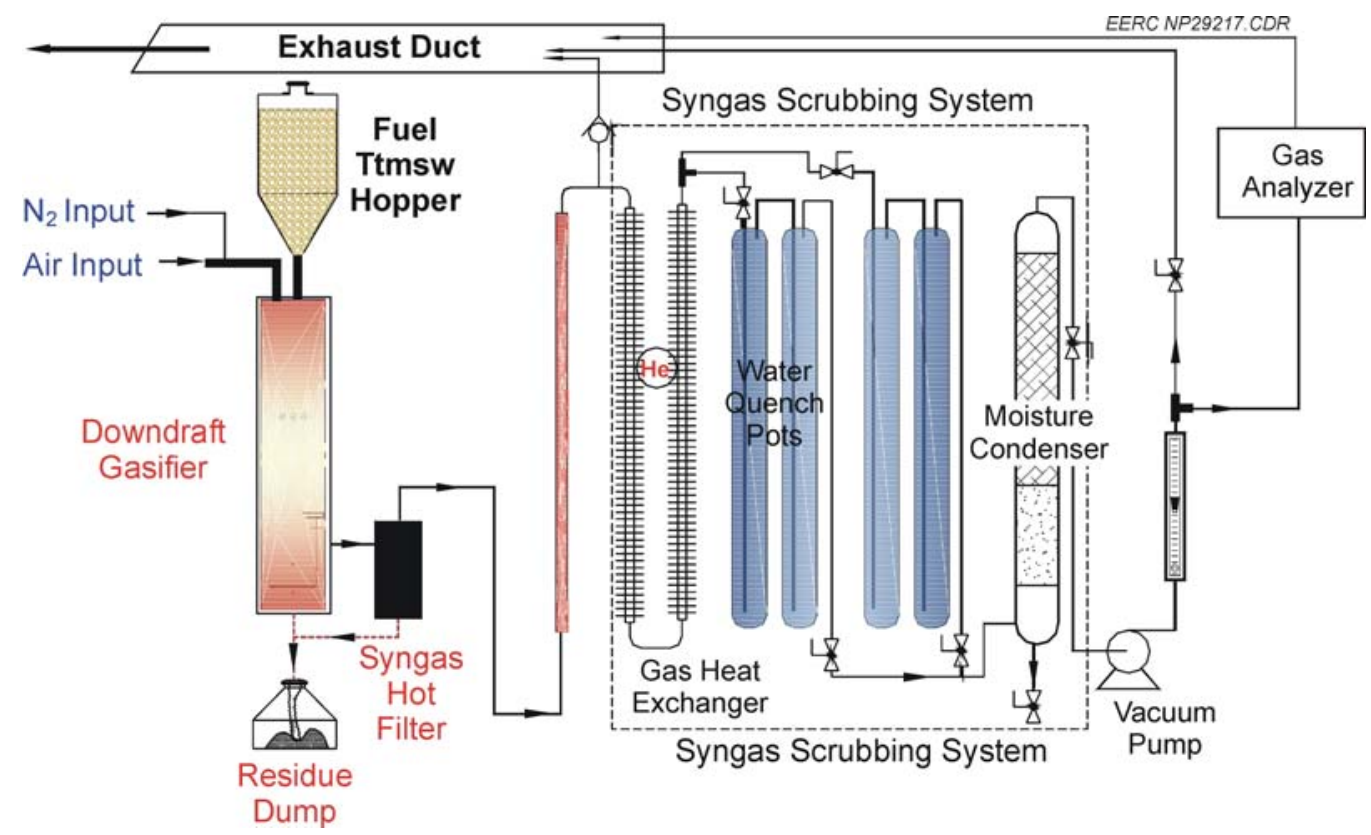

Figure 4. Schematic of gasification system.

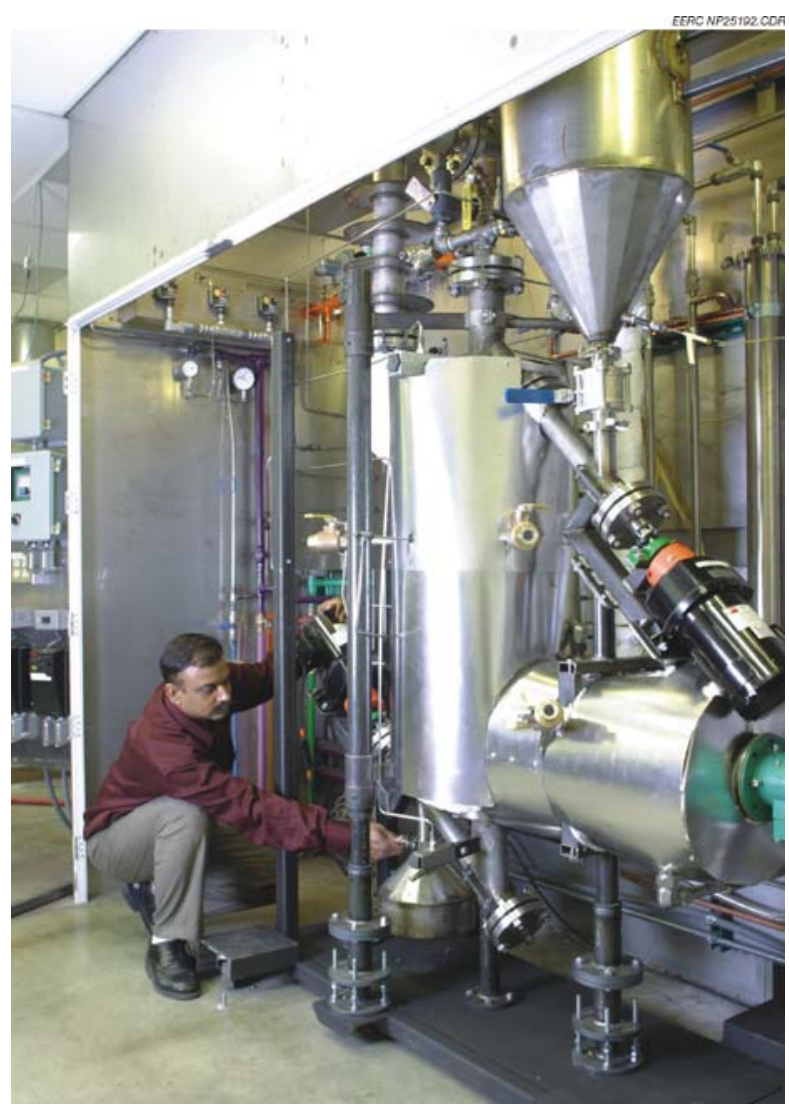

Figure 5. Photo of gasification system. 
nitrogen is introduced from the top of the gasifier to achieve quick shutdown, which is desirable in order to freeze reactions and stop carbon conversion prior to cooling the bed.

The trace gas contaminants such as $\mathrm{H}_{2} \mathrm{~S}, \mathrm{NH}_{3}$, and hydrocarbon contaminants are measured using calorimetric tubes through which a known volume of syngas is sampled at the gasifier downstream. For determining contaminants in the producer gas, a slipstream of syngas is isokinetically sampled from the main stream from a sample port located between the cyclone train and the cold-water condenser train. The sampled gas is filtered by passing it through a hot quartz filter maintained at $450^{\circ} \mathrm{C}$ to quantify the particulate levels. The producer gas sample is then cooled by a cold-water condenser and passed through a series of solvent impingers for capturing hydrocarbon contaminants or tar for its quantification.

The experimental setup has the option of scrubbing $\mathrm{H}_{2} \mathrm{~S}$ from the syngas with the help of a catalyzed iron oxide bed prior to compression and feeding to the low-pressure FT reactor located downstream.

\section{Syngas-to-FT Liquid Conversion System: Step 3}

The general schematic of the experimental setup designed to understand the FT liquid synthesis process is shown in Figure 6. This system consists of three main subsystems: 1) syngas supply system, 2) syngas synthesis reactor, and 3) gas analysis system. The operating pressure of the system ranges between 50 and 1000 psig, depending on the design pressure of the liquid synthesis reactor. The system is designed to maintain a constant reactor temperature ranging from $40^{\circ}$ to $300^{\circ} \mathrm{C}$ achieved by direct as well as indirect heat-transfer modes using air, nitrogen, and syngas as heat-transfer mediums. The synthesis reaction is mildly exothermic, and the heat management system ensures constant catalyst bed temperature under steady-state operation. The maximum design syngas flow rate of the experimental setup is $70 \mathrm{~L} / \mathrm{min}$.

The syngas supply system consists of mass flow controllers for injecting $\mathrm{H}_{2}, \mathrm{CO}, \mathrm{CO}_{2}, \mathrm{~N}_{2}$, and $\mathrm{CH}_{4}$ gases from a pure gas cylinder depending on the required syngas composition. Syngas composition and flow rate adjustments were controlled by a computer. A set of in-line and backpressure regulators as well as flow control valves were used to maintain syngas pressure and flow rate through the reactor. The syngas was preheated to temperatures ranging from $100^{\circ}$ to $300^{\circ} \mathrm{C}$, as required. A set of pressure relief valves were provided to maintain safe operation of the reactor in the event of excessive pressure buildup in the reactor.

The pressure and temperature data were monitored and recorded using a computerized data-logging system. The computer display screen used for monitoring operating parameters of the experiments is depicted in Figure 7. Alarm signals for overpressure and temperature were used to automatically maintain safe operation of the system.

The first sets of tests were conducted to determine the possibility of FT liquid production using syngas from the biomass gasifier at low-pressure operating regimes where the synthesis pressures were limited to 140 psig. Catacel Corporation specially designed a FT reactor based on its propriety SSR technology capable of achieving better reactor heat management due to improved syngas flow distribution and heat-transfer properties. A proprietary iron-based FT catalyst was used in the experiment. Figure 8 shows a computer screen of the reactor mounted on the test stand. 


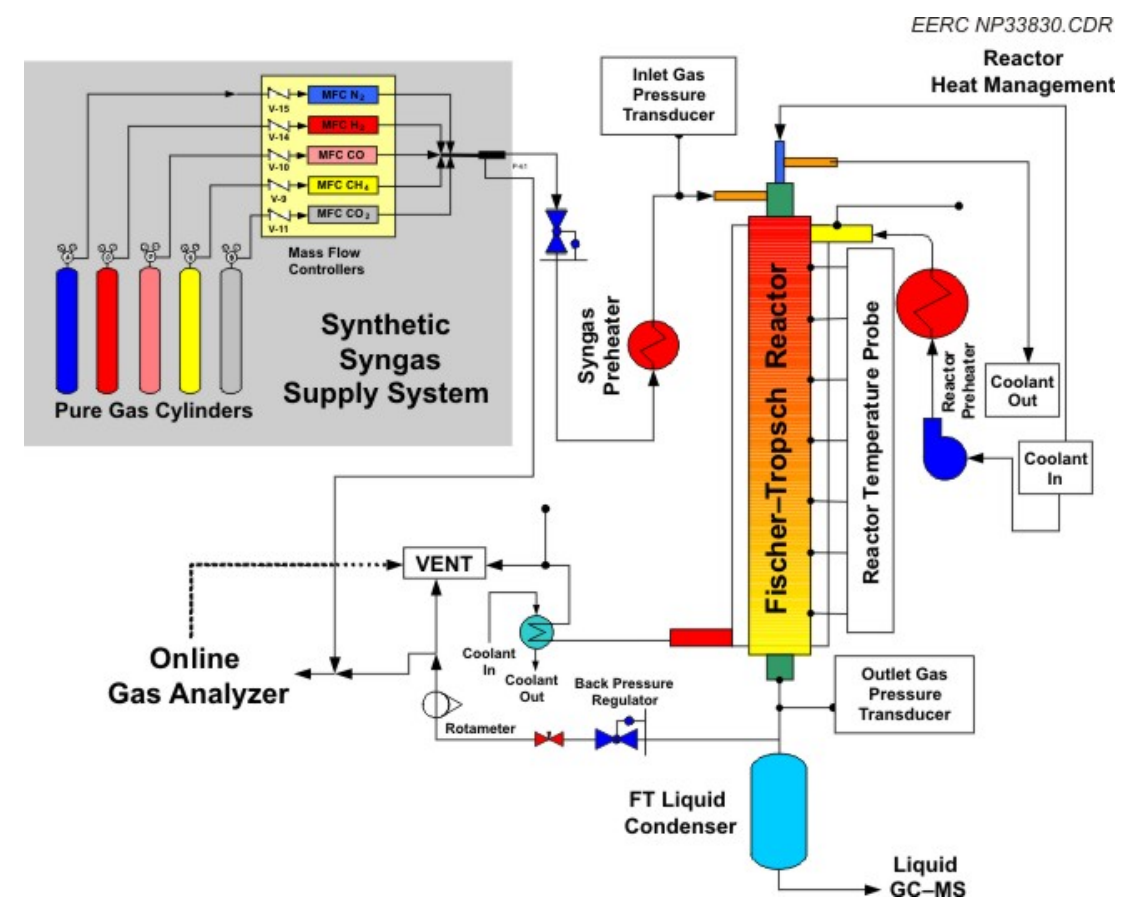

Figure 6. Schematic of the gas-to-FT liquid experimental setup.

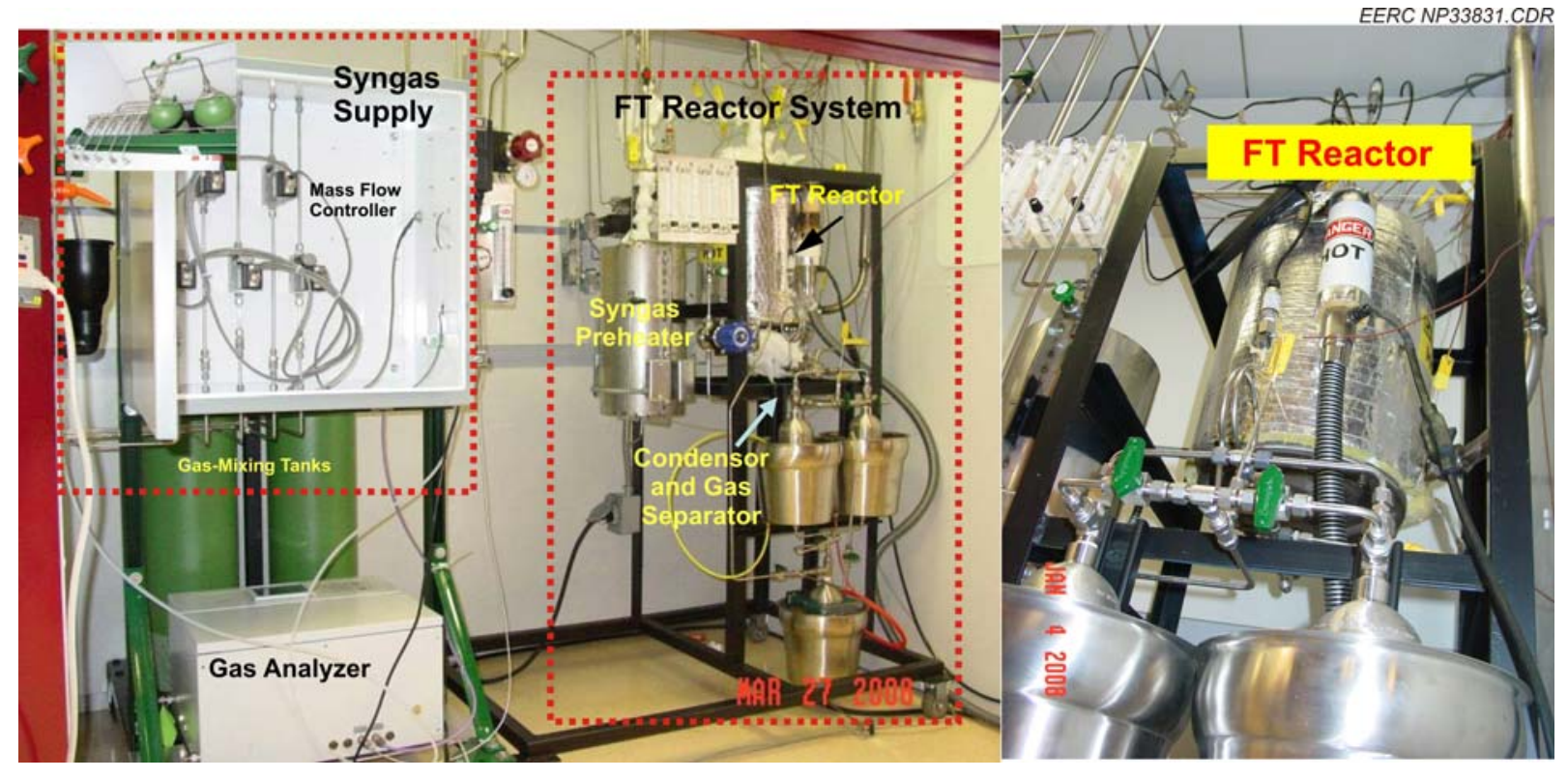

Figure 7. Bench-scale gas-to-liquid test setup showing syngas supply system, FT reactor, liquid condenser, and online gas analyzer. 
The second set of experiments was conducted using a commercial iron-based FT catalyst obtained from JMI in the EERC's fixed-bed FT reactor. Both the experimental reactors were used to develop a preliminary understanding of the effect of reactor operating conditions on syngas conversion. These reactors were designed to operate at a space velocity in the range of $200-15,000 \mathrm{~h}^{-1}$ in order to understand syngas conversion. The reactor bed temperatures were measured in order to understand the effectiveness of the heat management system in maintaining constant reactor bed temperature. The locations of the thermocouples are shown in Figure 8.

The pressure drop across the bed was measured with the help of pressure transducers located upstream and downstream of the reactor. The tube dimensions at the reactor exit ensured free flow of the gas-phase products until the stream was injected in the liquid condenser.

The high-pressure liquid condensers ensured collection of liquid product and effective separation of unconverted gaseous products without causing loss of liquid due to entrainment. An ice-salt mixture was used to maintain the subzero (about $-10^{\circ} \mathrm{C}$ ) temperature of the condenser wall. The liquid was collected in a cold solvent trap to prevent the loss of lighter fractions such as ethers during liquid extraction process. The back-pressure regulator and flow control valve at the downstream of the condenser ensured constant pressure and gas flow. The gas flow rate is measured with the help of precalibrated rotameters. Except for the specific gravity of the gas, pressure and temperature downstream of the rotameters were maintained at the calibration conditions specified by the manufacturer. The actual gas flow rates were determined by applying the required specific gravity corrections. The purge gas is exhausted in the hood vent system. A slipstream of gas is sampled at the downstream of the rotameter for determining product gas composition. The other gaseous hydrocarbons leaving the reactor were analyzed using gas chromatography (GC), while condensed liquid products were analyzed using a GC- mass spectroscopy (MS).

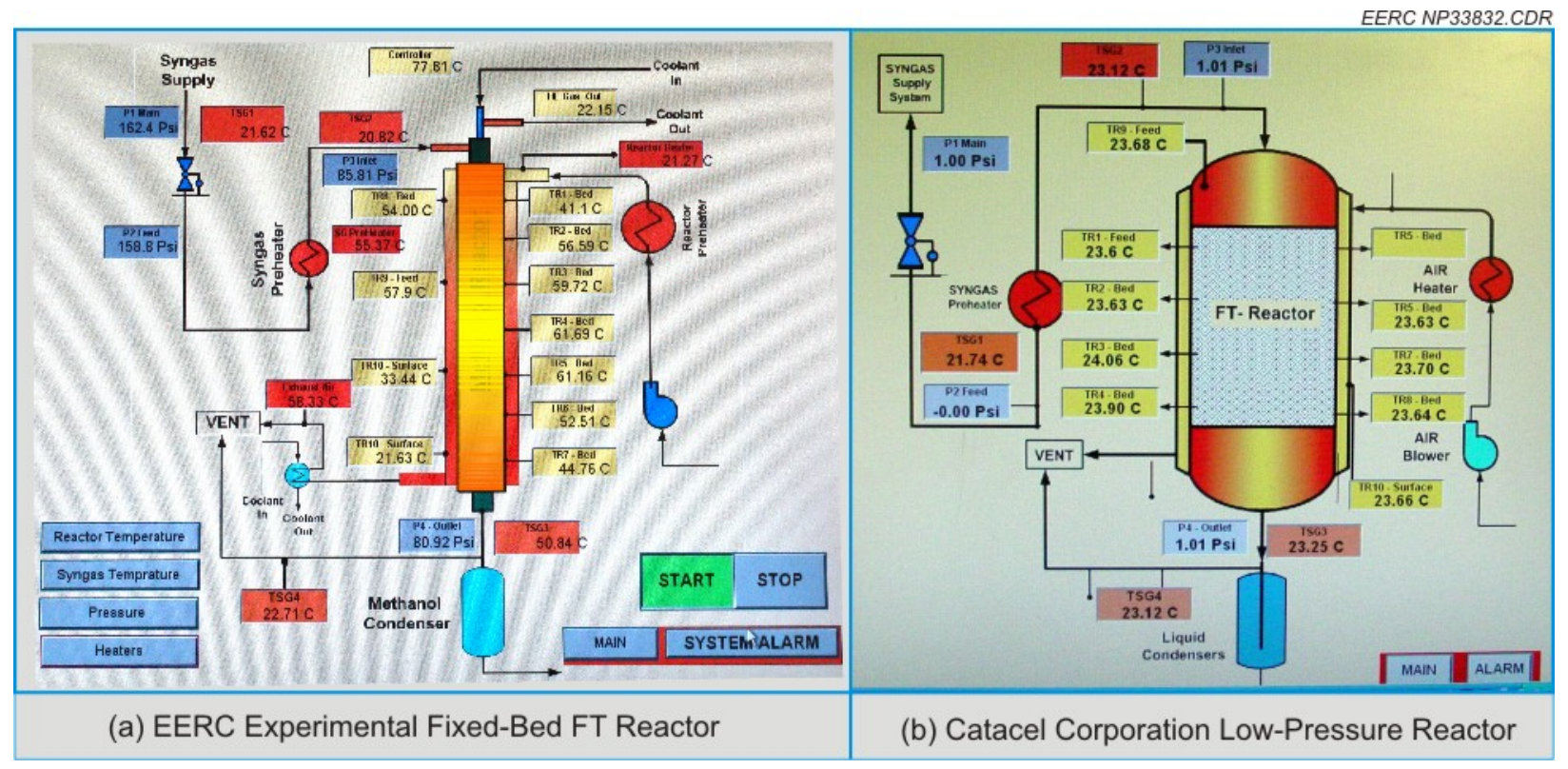

Figure 8. Computer display showing temperature and pressure measurement location on the schematic of two FT reactors used in the experiments. 


\section{Results and Discussion}

\section{Gasification Experiments}

The gasification experiments were conducted with the aim of understanding the performance of various forms of biomass in the fixed-bed gasifier selected for the liquid synthesis process. Based on the economic analysis of distributed-scale indirect liquefaction processes for converting biomass to liquid fuels (1), gasification of biomass using air as a partial oxidation or gasification medium is imperative to achieve an economically viable system. However, the major drawback of the air gasification process is the composition of syngas having lower than the stoichiometric requirement of $\mathrm{H}_{2} / \mathrm{CO}$ ratio, a higher $\mathrm{CO}_{2}$ concentration, and an undesirable $\mathrm{N}_{2}$ dilution. This can seriously lower the carbon-to-liquid conversion efficiency. The air gasification experiments were conducted to understand the effect of gasifier operating conditions and fuel characteristics on syngas composition.

\section{Effect of Air Injection Rate on Syngas Composition}

Figure 9 shows the experimental results of the gasification of biomass (pine wood) and a mixture of biomass and plastic feedstocks. It shows the effect of air injection rate on syngas composition when the feedstocks are gasified at an average bed temperature of $900^{\circ} \mathrm{C}$. The addition of plastics (32\%) is to mimic the actual waste-containing plastic. The primary effect of increasing air injection rate was found to be an increased fuel conversion rate, a feature of heterogeneous gasification of solids in fixed beds. Gasifier operation at a higher conversion rate is critical to achieving a compact conversion system; however, the concentration of diluents $\mathrm{N}_{2}$ and $\mathrm{CO}_{2}$ limits air injection rate. Table 1 shows the range of individual gas concentrations in the syngas and $\mathrm{H}_{2} / \mathrm{CO}$ and $\mathrm{CO} / \mathrm{CO}_{2}$ ratio measured during steady-state gasification of solid fuels. These data are important in selecting an optimum gasifier operating range. It also helps in selecting a range of syngas composition for the design of experiments to conduct a parametric study to understand the performance of the syngas-to-liquid synthesis reactor.

\section{Air Gasification of Woody Biomass}

The analysis of the results of green pine wood gasification, as shown in Figure 9, is as follows:

- The highest $\mathrm{H}_{2} / \mathrm{CO}$ and $\mathrm{CO} / \mathrm{CO}_{2}$ ratios obtained were 1.4 and 5.9, respectively.

- Higher $\mathrm{H}_{2}$ concentration in the syngas is due to inherent biomass moisture acting as a gasification medium; however, the average bed temperature ranging from $850^{\circ}-900^{\circ} \mathrm{C}$ is required to be maintained.

- The highest $\mathrm{CO}_{2}$ concentration of $16.5 \%$ was obtained at an air injection rate of $0.4 \mathrm{~g} / \mathrm{s}$. For syngas-to-liquid production, this is a high starting concentration of $\mathrm{CO}_{2}$, which is expected to build up, eventually causing synthesis catalyst deactivation. $\mathrm{CO}_{2}$ removal from the syngas becomes imperative at such an air injection rate. 

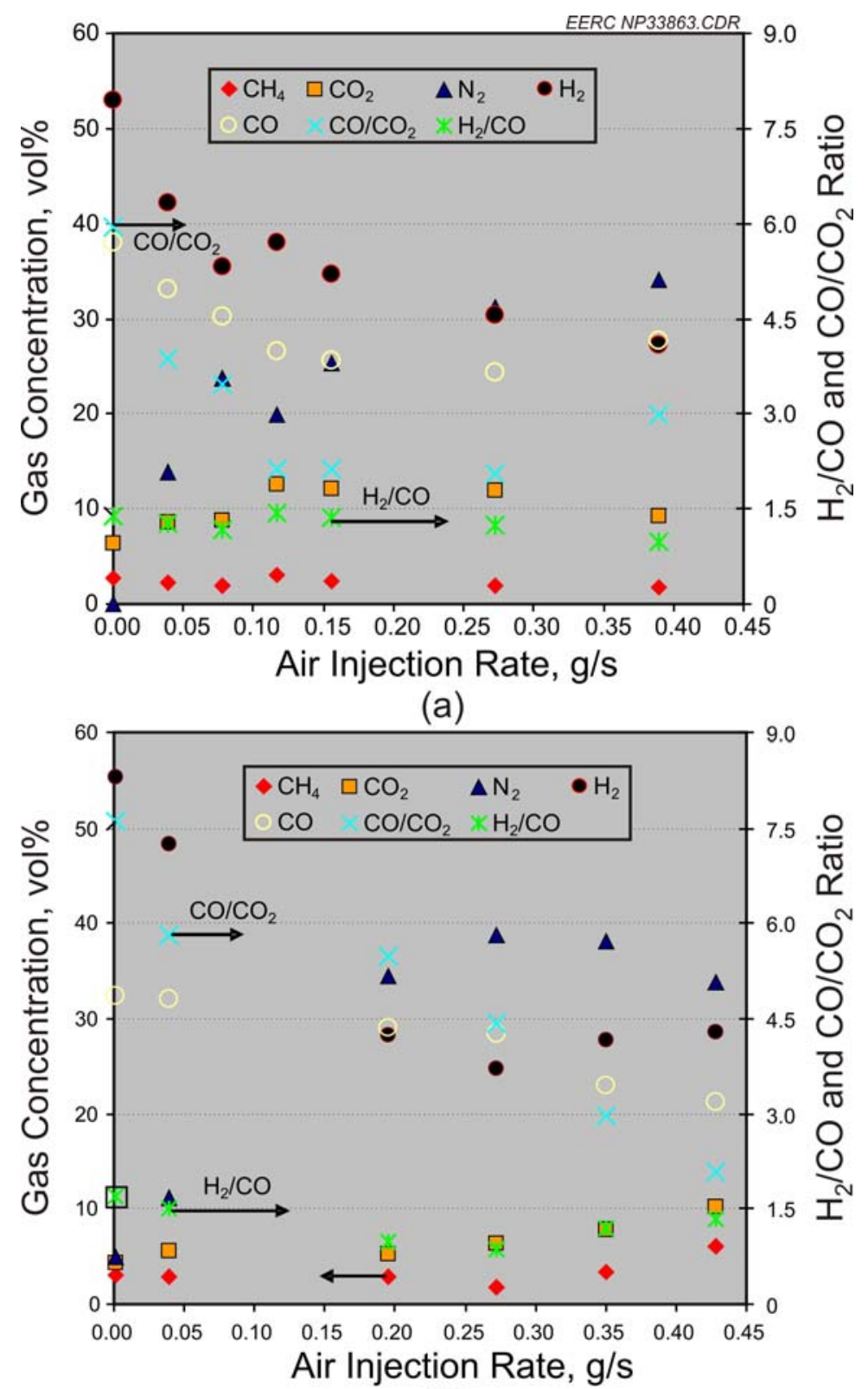

(b)

Figure 9. The effect of gasification airflow rate on syngas composition obtained at a $900^{\circ} \mathrm{C}$ bed temperature gasification of a) $70 \mathrm{wt} \%$ biomass and $30 \%$ moisture and b) mixture of biomass $41 \%$, plastics $32 \%$, and moisture $27 \%$. 


\begin{tabular}{lcc}
\multicolumn{3}{l}{$\begin{array}{l}\text { Table 1. Gas Concentrations and } \mathrm{H}_{2} / \mathbf{C O} \text { and } \mathbf{C O} / \mathrm{CO}_{2} \\
\text { Ratios During Steady-State Gasification of Solid Fuels }\end{array}$} \\
\hline & Biomass (41\%) \\
& Moisture (30\%) & $\begin{array}{c}\text { Plastic }(32 \%) \\
\text { Moisture }(27 \%)\end{array}$ \\
\hline Air Injection Rate, g/s & $0.0-0.4$ & $0.0-0.4$ \\
$\mathrm{CH}_{4}$ & $1.7-3.1$ & $1.8-6.1$ \\
$\mathrm{CO}_{2}$ & $6.4-16.5$ & $4.3-10.2$ \\
$\mathrm{~N}_{2}$ & $0.0-34.1$ & $4.9-38.7$ \\
$\mathrm{H}_{2}$ & $27.2-53$ & $24.7-55.4$ \\
$\mathrm{CO}$ & $24.4-38$ & $21.3-32.5$ \\
$\mathrm{CO} / \mathrm{CO}$ & $2-5.9$ & $2.1-7.6$ \\
$\mathrm{H}_{2} / \mathrm{CO}$ & $1.0-1.4$ & $0.9-1.7$ \\
\hline
\end{tabular}

- The expected catalyst deactivation limits the gasifier operation at a high air injection rate.

- The decrease in $\mathrm{H}_{2} / \mathrm{CO}$ ratio with an increase in air injection rate is attributed primarily to the increase in $\mathrm{N}_{2}$ concentration in the syngas. The increases in $\mathrm{CO}_{2}$ concentration also slightly contribute to the drop in this ratio.

- The decrease in $\mathrm{CO} / \mathrm{CO}_{2}$ ratio with an increase in air injection rate is due to the combined effect of an increase in $\mathrm{N}_{2}$ and $\mathrm{CO}_{2}$ concentration in the syngas.

\section{Air Gasification of Woody Biomass-Plastic Waste}

The composition of the mixed biomass and plastic waste on a weight basis is $40 \%$ pine wood, $32 \%$ plastic, and $28 \%$ moisture. The plastics were an equal mixture of high- and lowdensity polypropylene, polystyrene, and polyethylene. The addition of plastics is to mimic a range of waste-containing plastic. The analysis of the results of the mixture of wood and plastic gasification as shown in Figure 9(b) and summarized as follows:

- The highest $\mathrm{H}_{2} / \mathrm{CO}$ and $\mathrm{CO} / \mathrm{CO}_{2}$ ratios obtained were 1.7 and 7.6, respectively.

- Unlike biomass, the higher $\mathrm{H}_{2}$ concentration in the biomass-plastic mixture syngas is due to the higher fraction of hydrogen in the plastics in addition to the inherent biomass moisture acting as a gasification medium at gasifier operating temperatures of $850^{\circ}-900^{\circ} \mathrm{C}$.

- The $\mathrm{CH}_{4}$ concentration is higher compared to that obtained from biomass gasification at the same air injection rate. A low air injection rate can reduce this concentration.

- The highest $\mathrm{CO}_{2}$ concentration of $10.2 \%$ was obtained at an air injection rate of $0.42 \mathrm{~g} / \mathrm{s}$. For syngas-to-liquid production, this is acceptable; however, a lower concentration is preferred. 
- The decrease in $\mathrm{H}_{2} / \mathrm{CO}$ ratio with an increase in air injection rate is attributed primarily to the increase in $\mathrm{N}_{2}$ concentration in the syngas. The increase in $\mathrm{CO}_{2}$ concentration also slightly contributes to the drop in this ratio.

- The decrease in $\mathrm{CO} / \mathrm{CO}_{2}$ ratio with an increase in air injection rate is due to the combined effect of increase in $\mathrm{N}_{2}$ and $\mathrm{CO}_{2}$ concentration in the syngas.

It is apparent that the increase in air injection rate increases the $\mathrm{N}_{2}$ dilution in the syngas, causing a decrease in $\mathrm{H}_{2}$ and $\mathrm{CO}$ concentrations. The $\mathrm{N}_{2}$ dilution reduces syngas calorific value significantly and also reduces adiabatic flame temperature, affecting the performance of the combustion systems. However, the $\mathrm{N}_{2}$ dilution is not expected to affect the liquid synthesis process except that it assists heat removal from the reaction site within the synthesis catalyst bed. It is, therefore, important to understand the effect of air injection rate on the concentration of those reactants that actively participate in the synthesis reaction independent of a $\mathrm{N}_{2}$-free basis. In order to understand this, nondimensionalized $\mathrm{H}_{2}{ }^{*}, \mathrm{CO}^{*}$, and $\mathrm{CO}_{2}{ }^{*}$ concentrations are plotted with respect to air injection rate. The nondimensionalized ratio is obtained by dividing the concentration of the individual species at a given air injection rate and that obtained at a zero air injection rate on a $\mathrm{N}_{2}$-free basis. Figure 10 shows the plot of variation of nondimensionalized concentration with air injection rate. It is clearly seen that the air injection rate has a relatively insignificant effect on the concentrations of $\mathrm{H}_{2}{ }^{*}$ and $\mathrm{CO}^{*}$ compared to $\mathrm{CO}_{2}{ }^{*}$ concentration, which significantly increases with an increase in air injection rate. The higher $\mathrm{CO}_{2}$ concentration in the syngas can be detrimental to the catalyst and, therefore, the air injection rate is required to have an upper limit. Both fuels, however, have distinct concentration profiles, primarily due to their physicochemical compositions.

\section{Gasification of Biomass Waste - Sunflower Hulls and Peach Stones}

The analysis of the results of air gasification of sunflower hulls containing $20 \%$ moisture, as shown in Figure 11, is summarized as follows:

- Varying of the air injection rate does not have any significant effect on the gas composition variation, as shown in Table 2 . This is in contrast to that observed in the case of woody biomass. The fuel morphology and low packing density $\left(126 \mathrm{~kg} / \mathrm{m}^{3}\right.$, which is about half of the woody biomass) appear to be contributing factors for greatly minimizing the effect of air injection rate.

- The highest average values of the $\mathrm{H}_{2} / \mathrm{CO}$ and $\mathrm{CO} / \mathrm{CO}_{2}$ ratios obtained were 1.1 and 2.7 , respectively.

- The $\mathrm{CH}_{4}$ concentration ranged between $1.9 \%$ and $2.4 \%$.

- The highest $\mathrm{CO}_{2}$ concentration of $11.4 \%$ was obtained at an air injection rate of $0.29 \mathrm{~g} / \mathrm{s}$. Based on the increasing trend of the $\mathrm{CO}_{2}$ concentration with air injection rate, a higher injection rate can produce an unacceptable level of $\mathrm{CO}_{2}$ in the syngas for the liquid synthesis process. 

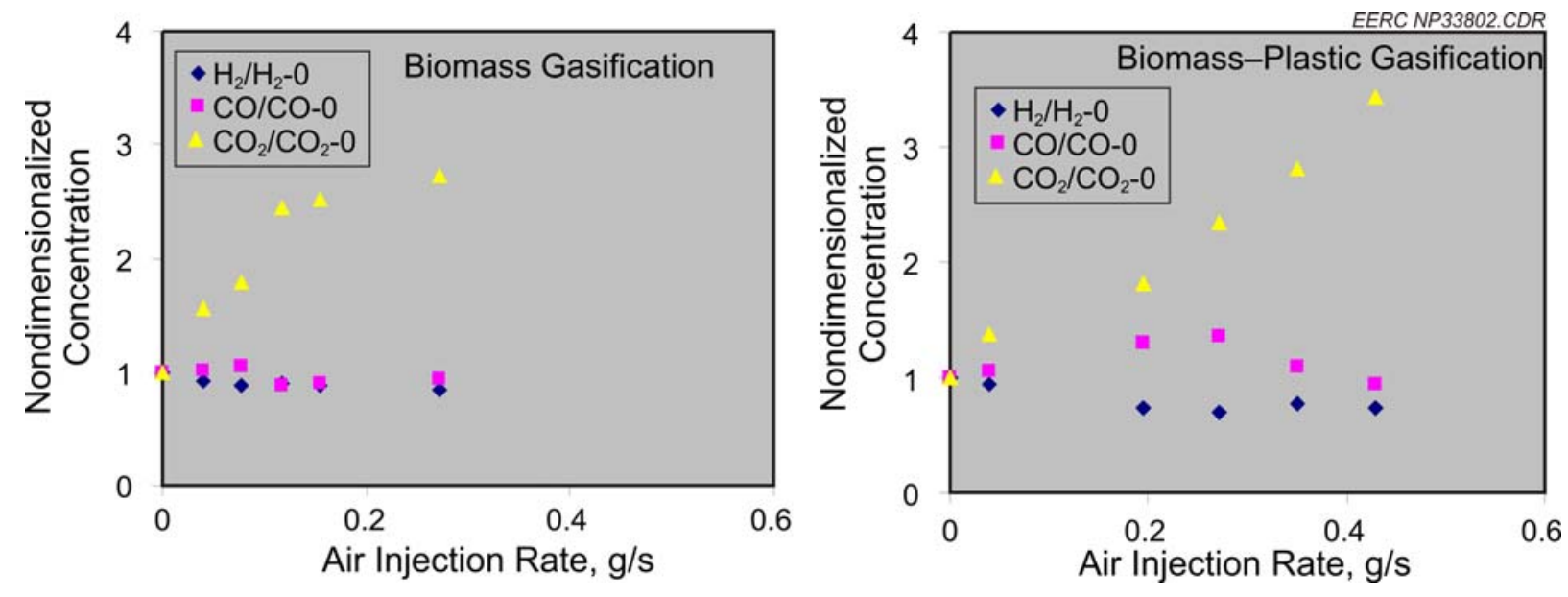

Figure 10. Nondimensionalized concentrations of $\mathrm{H}_{2}, \mathrm{CO}$, and $\mathrm{CO}_{2}$ as a function of air injection rate.

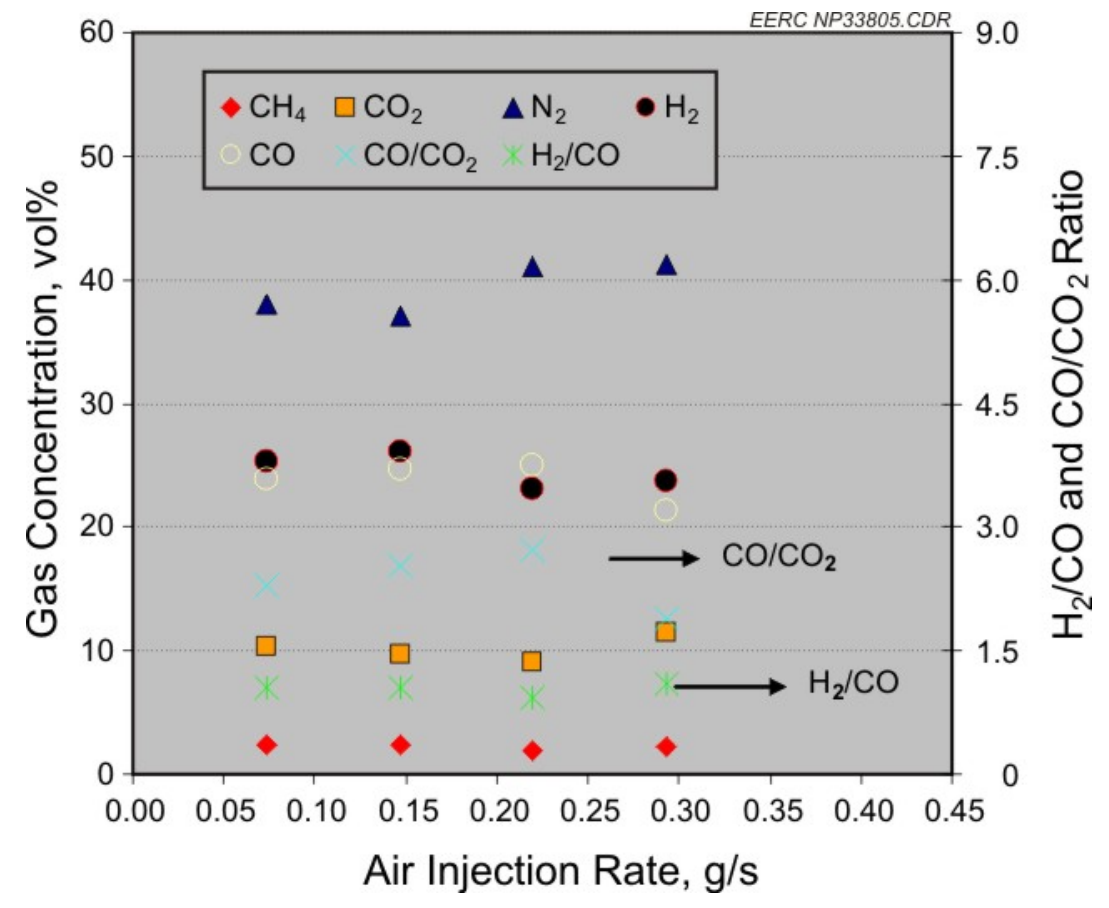

Figure 11. The variation of syngas composition obtained as a function of air injection rate on the gasification of sunflower hulls conducted at $900^{\circ} \mathrm{C}$. 
Table 2. Syngas Species Concentrations from Sunflower (20\% moisture) Hull Gasification

\begin{tabular}{lc}
\hline Air Injection Rate, g/s & $0.07-0.29$ \\
$\mathrm{CH}_{4}, \mathrm{vol} \%$ & $1.9-2.4$ \\
$\mathrm{CO}_{2}, \mathrm{vol} \%$ & $9.1-11.4$ \\
$\mathrm{~N}_{2}, \mathrm{vol} \%$ & $37.1-41.3$ \\
$\mathrm{H}_{2}, \mathrm{vol} \%$ & $23.0-26.1$ \\
$\mathrm{CO}, \mathrm{vol} \%$ & $21.4-24.9$ \\
$\mathrm{CO} / \mathrm{CO}_{2}$, vol$\%$ & $1.9-2.7$ \\
$\mathrm{H}_{2} / \mathrm{CO}, \mathrm{vol} \%$ & $0.9-1.1$ \\
\hline
\end{tabular}

Table 3 shows the average syngas composition of peach stones containing $10 \%$ moisture. The first test was conducted using peach stones as-received, and the second test was conducted to understand the effect of inorganic leaching on gasification performance by comparing the fuel conversion rates and syngas compositions of both fuels. The preliminary leaching test showed no change in conversion rate and a change in gas composition. The leaching tests conducted on biomass feedstock are beyond the scope of this work.

Figure 12 shows a variation of oxidizer to fuel $(\mathrm{O} / \mathrm{F})$ ratio with the air injection rate for pine wood and sunflower hulls. The figure also shows O/F for peach stones at a single air injection rate in order to achieve a comparison. The curve shown on the plot joining the data points does not represent any theoretical data. Since the pine wood, sunflower hulls, and peach stones have different moisture-retaining capacities because of differences in their morphologies, the data shown on the plot are on a dry basis. The $\mathrm{O} / \mathrm{F}$ ratio was obtained based on experimentally determined biomass conversion rates. This shows that for a given air injection rate, higher $\mathrm{O} / \mathrm{F}$ indicates lower conversion rate. As can be seen in Figure 13, the $\mathrm{O} / \mathrm{F}$ ratios of three biomass fuels are different. This shows that their conversion rates are quite different and are a strong function of air injection rate. The conversion rate of sunflower hulls is lower than pine wood at low air injection rates; however, this trend changes at higher air injection rates. The conversion rate of peach stones is comparable to pine wood and higher than sunflower hulls.

It is generally observed that $\mathrm{CO}_{2}$ concentration in the syngas increases with increases in $\mathrm{O} / \mathrm{F}$ (primarily due to oxidation). The data are, therefore, plotted with respect to $\mathrm{O} / \mathrm{F}$ to show comparative trends of $\mathrm{CO}_{2}$ concentration in both the fuels as a function of air injection rate. At

Table 3. Average Syngas Concentrations from Peach Stone Gasification

\begin{tabular}{clccccc}
\hline & & $\mathrm{CO}$ & $\mathrm{CO}_{2}$ & $\mathrm{CH}_{4}$ & $\mathrm{H}_{2}$ & $\mathrm{~N}_{2}$ \\
\hline Peach Stone, & vol\% & 25.2 & 10.6 & 3.1 & 23.6 & 37.6 \\
as received & Standard deviation & 1.4 & 1.7 & 1.1 & 1.1 & 2.6 \\
& & & & & & \\
$\begin{array}{c}\text { Peach Stone, } \\
\text { leached }\end{array}$ & vol\% & 24.9 & 11.7 & 4.0 & 23.4 & 35.9 \\
\hline
\end{tabular}




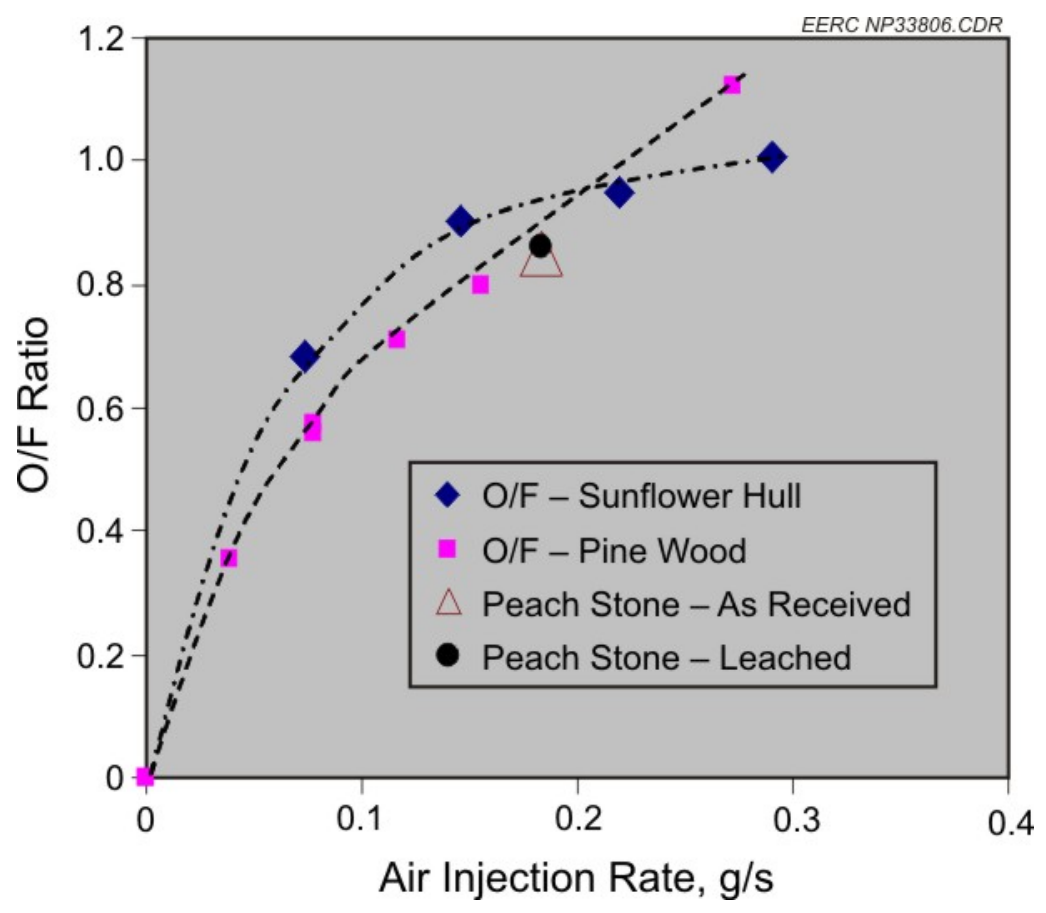

Figure 12. Variation of $\mathrm{O} / \mathrm{F}$ ratio with air injection rate for pine wood and sunflower hulls.

lower air injection rates, sunflower hull syngas has a higher $\mathrm{CO}_{2}$ concentration compared to pine wood; however, the trend changes at higher air injection rates. The contribution of $\mathrm{CO}_{2}$ in the the syngas due to the reactions with steam (biomass moisture plus $\mathrm{H}_{2} \mathrm{O}$-fuel oxidation product) further increases its concentration. Since the $\mathrm{CO}_{2}$ concentration in syngas is critical in the liquid synthesis process, the gasifier operating conditions with respect to a specific fuel are significant considerations. The above discussion is aimed at clearly bringing out this point.

\section{Gasification of Turkey Litter and ASR}

Gasification tests were conducted to understand the performance of turkey litter as a feedstock for liquid fuel production. Both wet and dry litter has an acrid, pungent odor. The typical ash and moisture contents of the litter are $38.5 \%$ and $35 \%$, respectively. These values, however, vary from farm to farm because of variations in bird feed, bedding material, and litter collection methods. Weight loss experiments were conducted to understand the release ofinorganics during the combustion of the predried litter in quiescent hot air in a furnace maintained at temperatures ranging from $450^{\circ}$ to $1000^{\circ} \mathrm{C}$. The weight loss varied from $14 \%$ to $39 \%$ of the total ash content, indicating the need for capturing the aerosol during gas scrubbing.

Figure 13 shows the test results of the gasification of wet turkey litter. Because of high ash and moisture content in the litter, the initial gasification test was conducted by maintaining the reactor bed temperature in the range of $700^{\circ}$ to $800^{\circ} \mathrm{C}$, as shown in Figure $13(\mathrm{~b})$. The syngas concentration time history shown in Figure 13(a) indicates favorable $\mathrm{H}_{2} / \mathrm{CO}$ ratio; however, the $\mathrm{CO}_{2}$ concentration was unacceptably high (ranged between 15\% and 20\%) for the liquid synthesis process. The calorific value of the gas was found in the narrow range of $150 \mathrm{Btu} / \mathrm{cubic}$ feet, making it a desirable gaseous fuel for heat and power production. Owing to the higher 


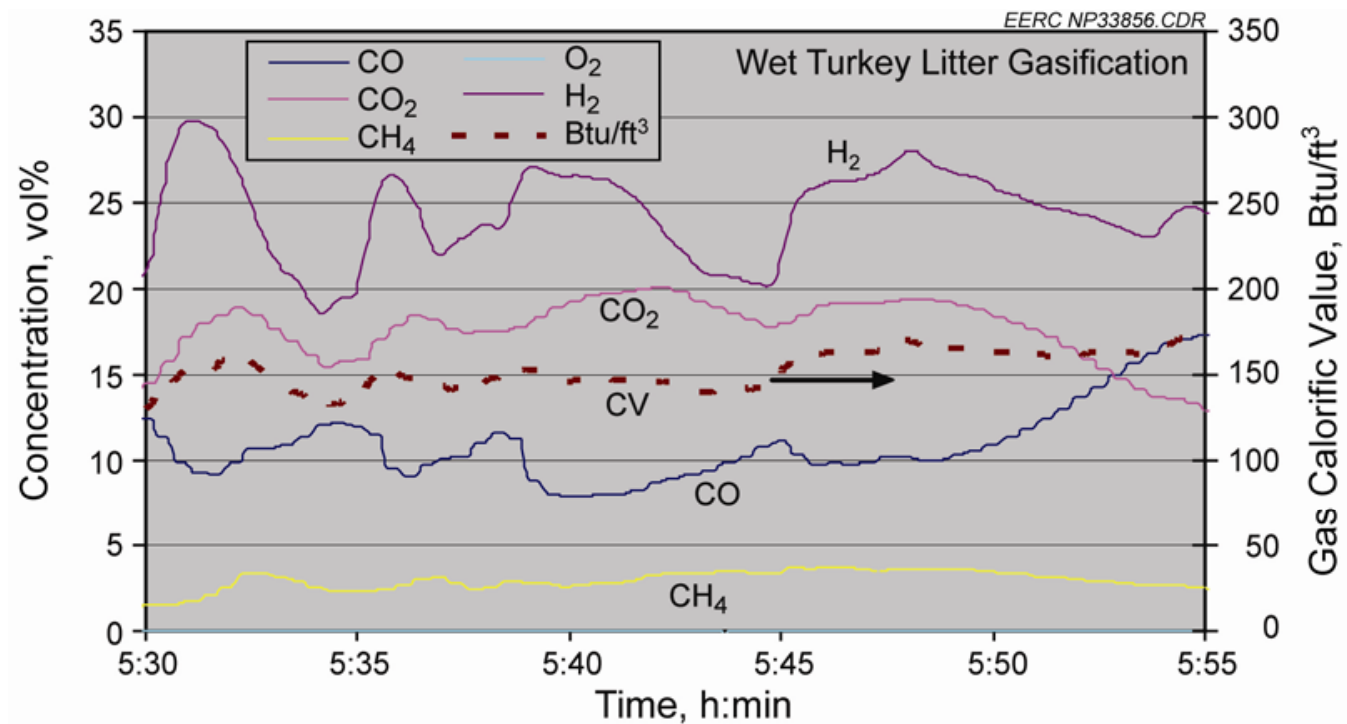

(a)

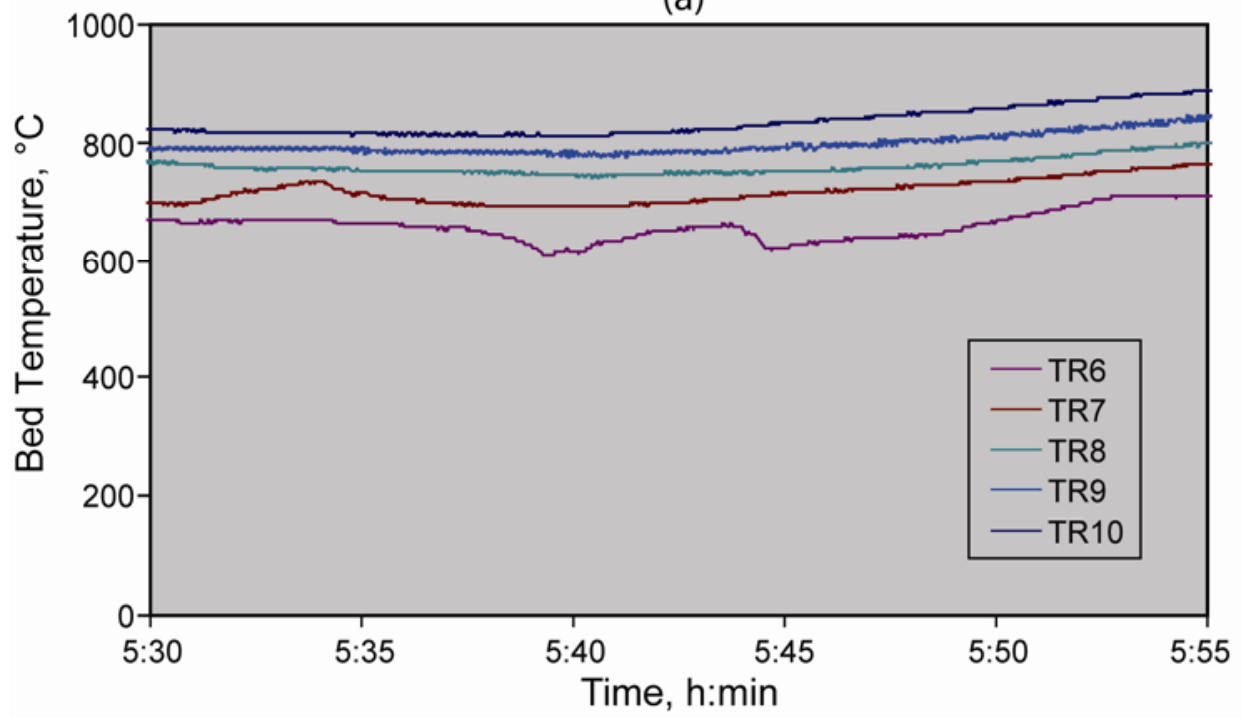

(b)

Figure 13. Wet turkey litter gasification: a) gas concentration time history and b) bed temperature time history.

concentration of fuel nitrogen, the ammonia concentration was found to be in excess of $1000 \mathrm{ppm}$. The wet syngas scrubbing is imperative for stripping the ammonia from syngas.

Since the $\mathrm{CO}_{2}$ concentration in the wet turkey litter gasification is unacceptable for application in the synthesis process, additional gasification tests were conducted using lowmoisture turkey litter (5\%). Figure 14 shows the test results of the gasification of low-moisture (air-dried) turkey litter. In order to determine whether the gasification reaction self-sustains even with $38.5 \%$ inorganic, the auxiliary heat supply used for maintaining constant reactor bed temperature was stopped. The bed temperature time history shown in Figure 14(b) indicates the ability of turkey litter to attain steady-state gasification. The average bed temperature attained during self-sustained gasification was $700^{\circ} \mathrm{C}$. 


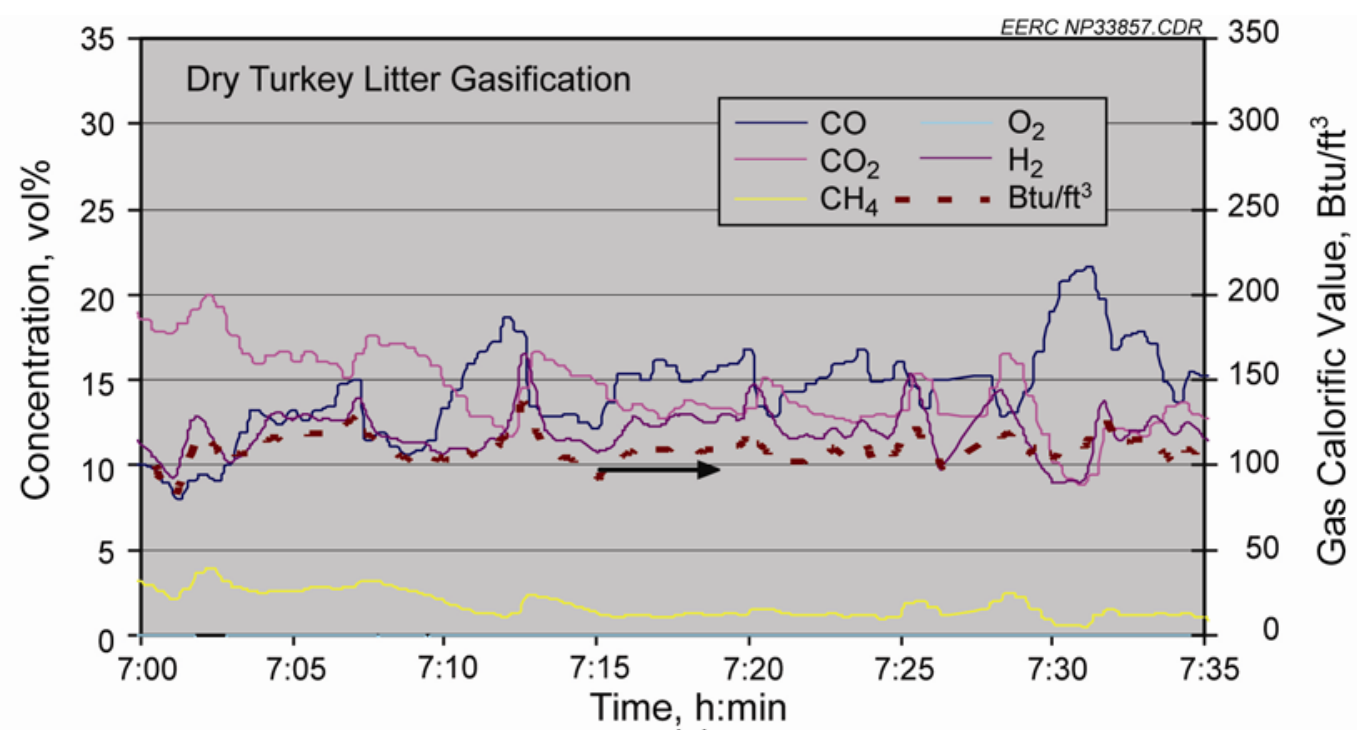

(a)

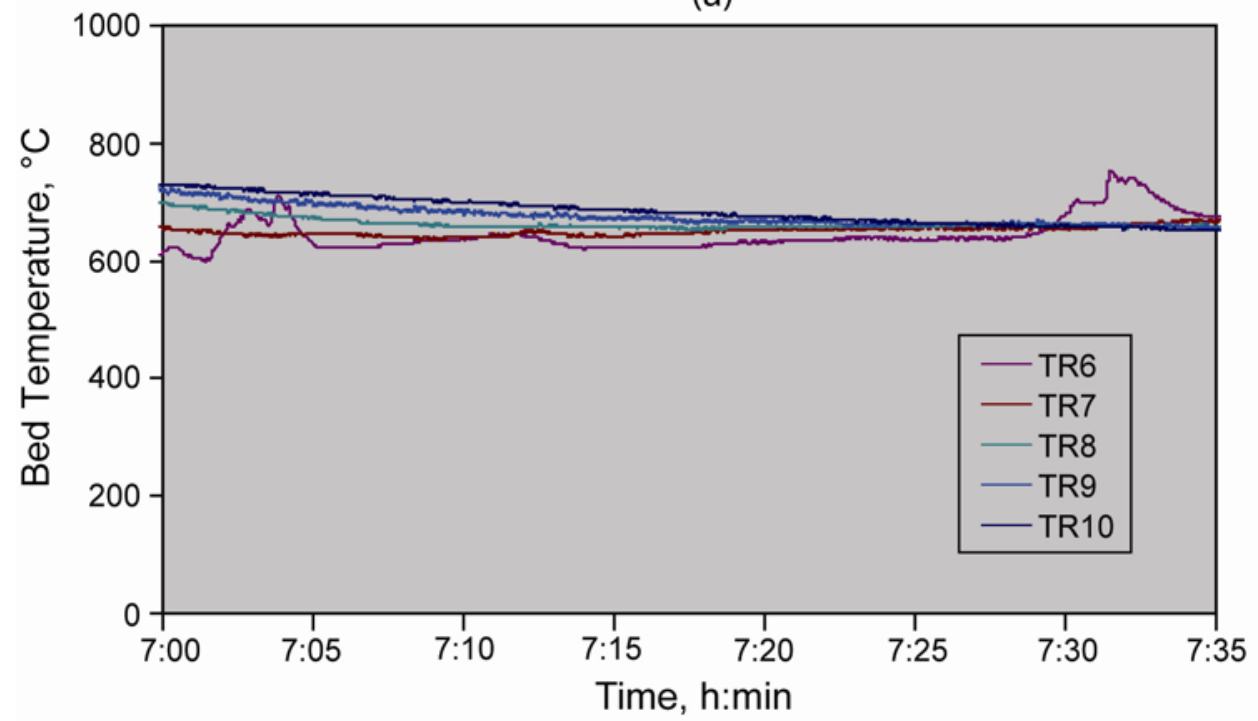

(b)

Figure 14. Dry turkey litter gasification: a) Gas concentration time history and b) bed temperature time history.

Figure 14(a) shows that the $\mathrm{CO}_{2}$ concentration is reduced to below $15 \%$. This value is lower than the previous case of wet litter gasification; however, for the liquid synthesis process, a value lower than $10 \%$ is preferred. The $\mathrm{H}_{2} / \mathrm{CO}$ ratio was found in the range of 0.95 , which is yet another concern since the shift reaction in the synthesis reactor will increase the concentration of $\mathrm{CO}_{2}$ to an intolerable level that can deactivate the synthesis catalyst. Further gasification tests on the fuel are required to be conducted to see the possibility of producing syngas compatible to the liquid synthesis process. 


\section{Gasification of ASR}

The tests were conducted to understand the gasification of ASR, which is a complex mixture of natural and humanmade rubber, carbon black, and inorganics. Since the calorific value of tire is about twice that of biomass $(30-33 \mathrm{MJ} / \mathrm{kg})$, the first impression of the fuel is that it can easily achieve the exothermic heat profile required to self-sustain endothermic gasification reactions, producing higher-quality syngas. Also, because it is a high-energy, dense fuel, it is conceivable that it can complement the gasification of biomass or low-energy, dense fuels and improve the flexibility of utilizing them as gasification feedstock. Such blending can achieve the higher bed temperature necessary for cracking tar and produce syngas with the high $\mathrm{H}_{2} / \mathrm{CO}$ ratio and low $\mathrm{CO}_{2}$ concentration required for liquid synthesis processes. The gasification tests, therefore, were conducted using 100\% ASR and a 50\%-50\% blend of ASR and sunflower hulls.

Figures 15 and 16 show the result of ASR gasification. The $100 \%$ tire gasification tests were conducted by maintaining an air injection rate about twice $(0.73 \mathrm{~g} / \mathrm{s})$ that of the injection rates used for biomass gasification. The high-air-injection-rate tests were planned in order to ensure cracking of devolatilized products from the tire and, thus, reduce tar in a large oxidation zone in the gasifier bed.

(a)

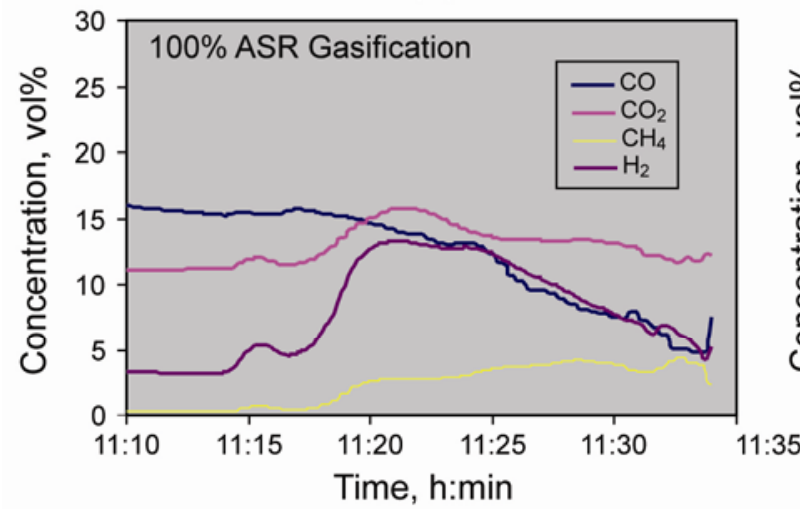

(b)

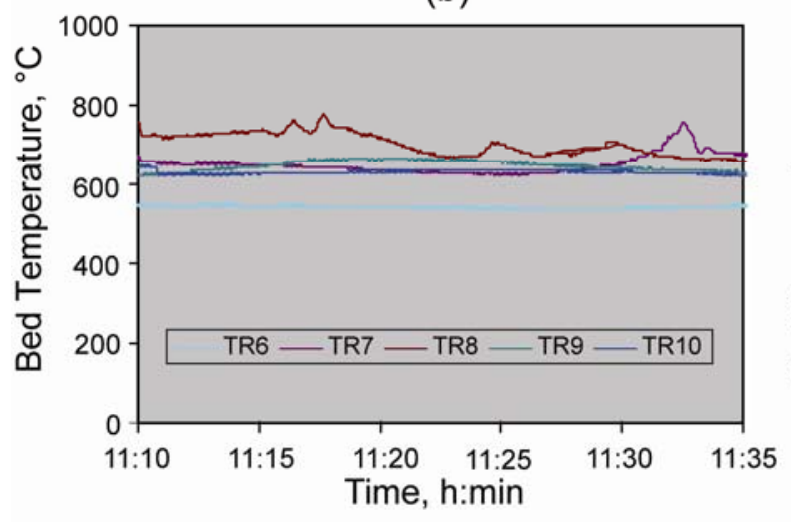

(c)

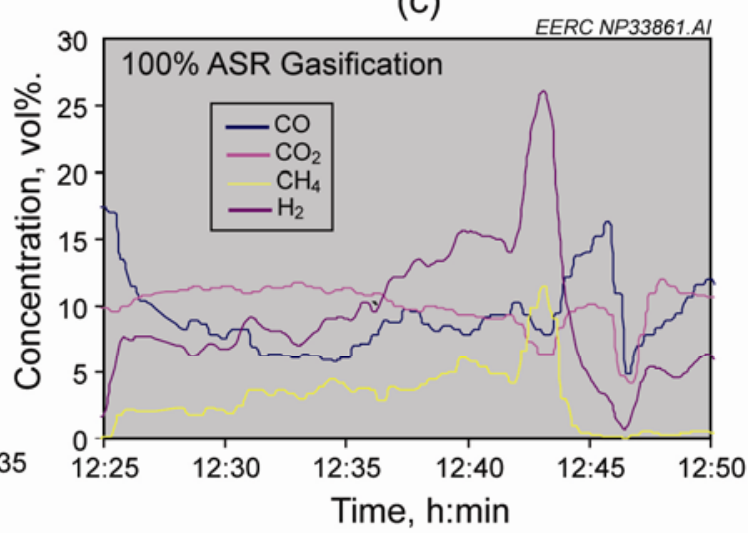

(d)

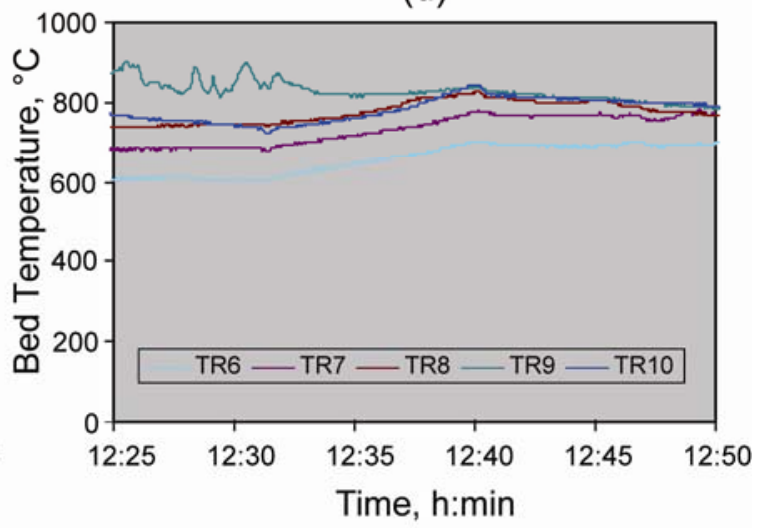

Figure 15. Syngas composition and bed temperature time history of the ASR gasification test. 


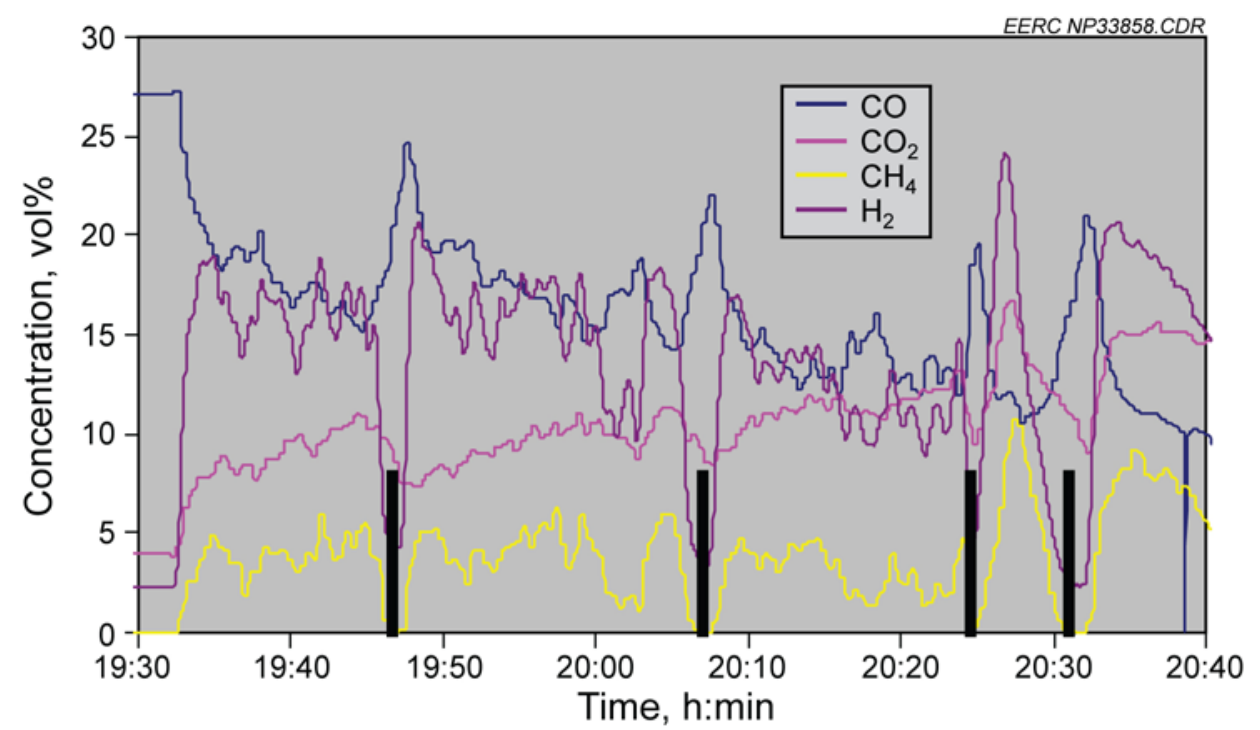

(a)

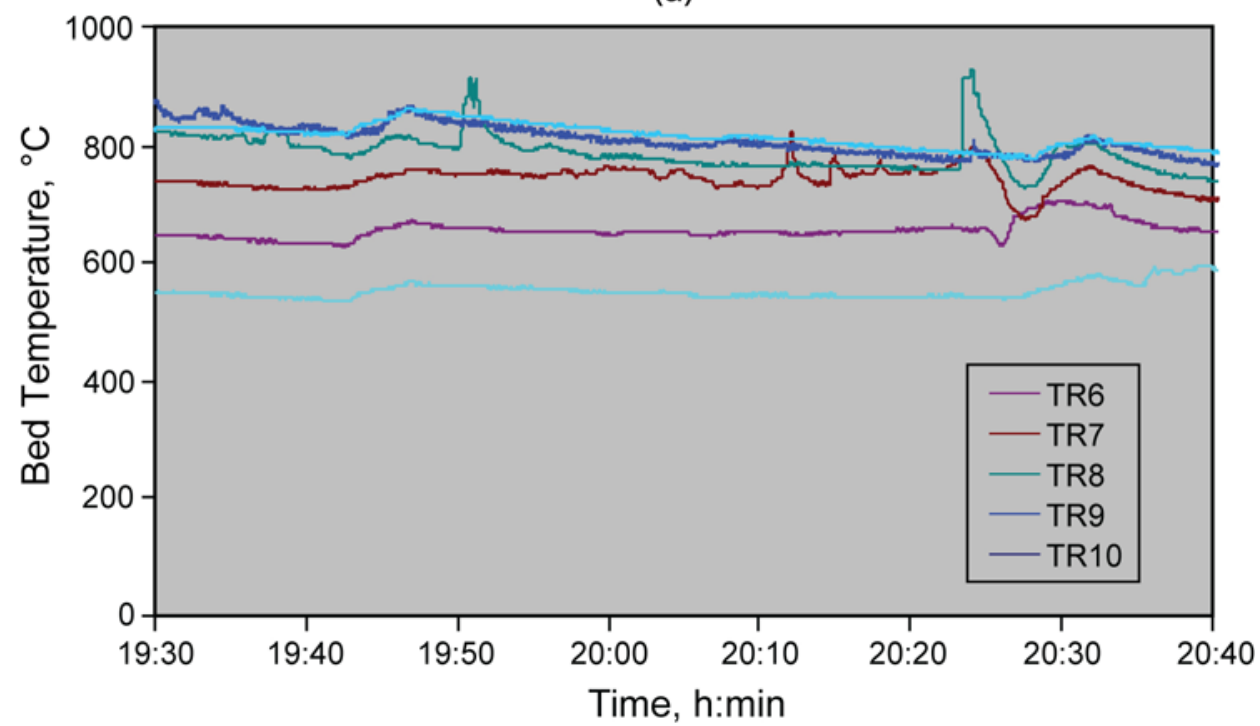

(b)

Figure 16. Syngas composition and bed temperature time history of the $50 \%$ ASR-50\% sunflower hull gasification experiment.

Since softening of the tire at gasification temperature can cause solid flow issues during $100 \%$ tire gasification, the tire gasification was initiated by injecting it on the hot bed of charcoal. Steady-state charcoal gasification was attained first. Figures 15(a) and 15(b) show the syngas composition and bed temperature profile. As can be seen in Figure 15(a), the steady-state syngas concentration profile of the charcoal gasification changes as soon as the ASR is injected into the gasification bed. The $\mathrm{H}_{2}$ and $\mathrm{CO}$ concentration significantly dropped, while the $\mathrm{CH}_{4}$ concentration increased to up to $4.5 \%$, which is significantly higher than the typical equilibrium value as well as those observed during biomass gasification. In spite of a well-maintained bed temperature, the new $\mathrm{H}_{2}$ and $\mathrm{CO}$ levels attained were in the range of $6 \%-8 \%$. The $\mathrm{CO}_{2}$ concentration slightly increased compared to that found initially during charcoal gasification. 
Considering the lowering of the $\mathrm{H}_{2}$ and $\mathrm{CO}$ concentration an effect of low bed temperature, additional experiments were conducted by increasing bed temperature by about $50^{\circ} \mathrm{C}$ with the help of an auxiliary fuel burner. The following experiments were conducted without any heat support. Figures 15(c) and (d) show the syngas concentration and bed temperature profiles, respectively. It appears from the syngas concentration profile that the increase in bed temperature improved the $\mathrm{H}_{2}$ and $\mathrm{CO}$ concentration very little. A spike in $\mathrm{H}_{2}$ and $\mathrm{CH}_{4}$ followed by an increase in bed temperature was an indication of a spike in the ASR devolatilization rate. The significant increase in bed pressure drop followed by the spike in devolatilization rate forced stopping the experiment. Based on these experiments, it was concluded that $100 \%$ ASR gasification cannot be achieved in the current fixed-bed gasifier configuration.

The results of the $50 \%$ sunflower hull- $50 \%$ ASR blend tests are shown in Figure 16 . The concentration profile shown in Figure 16(a) shows a distinct difference in the gasification of pure fuels. Unlike $100 \%$ ASR gasification, the average $\mathrm{H}_{2}$ and $\mathrm{CO}$ concentration values were about twice of those found in the blended fuel. The sunflower char mixed with the ASR char (carbon black and inorganic filler material) formed a carbon bed, which was necessary for the reduction reactions to occur to achieve characteristic syngas composition. As can be seen in Figure 16(a), the variation in $\mathrm{CH}_{4}$ concentration and its high value are characteristics of ASR devolatilization. The black bars on the concentration profile show the point of time when the fuel feed was momentarily stopped. This was an intentional procedure followed to observe the variations in syngas concentration as an effect of fuel. The $\mathrm{H}_{2}$ and $\mathrm{CH}_{4}$ concentration profile showed steep drops, while the $\mathrm{CO}$ concentration showed a steep rise when the feed was stopped. The original concentration was restored with the initiation of fuel feed.

It is concluded that the ASR can be utilized in conventional fixed-bed gasifiers when blended with biomass or charring material that can form a carbon bed. Although the $\mathrm{H}_{2} / \mathrm{CO}$ ratio and $\mathrm{CO}_{2}$ values are not favorable for utilizing ASR as a feed gas for the liquid synthesis process, adjustment in the gasifier design can make it possible to achieve the desired syngas composition. The synergy of the reactive biomass (or any other solid carbonaceous fuel) char and the energydense devolatilized products from ASR can achieve the hydrogen-rich syngas required for liquid synthesis.

Figure 17 shows a comparison of the syngas concentration time history of self-sustained gasification of turkey litter char and ASR char (mostly carbon black). The bed temperatures achieved in both gasification cases were identical. As can be seen, the $\mathrm{CO} / \mathrm{CO}_{2}$ ratio of highly reactive turkey litter char is about 4.5, while it ranges between 0.95 and 1 in the case of ASR char gasification. This shows the possibility of improving syngas quality by combining tire with biomass wastes like turkey litter. Further experiments will be conducted in order to understand the synergy of different carbonaceous fuels for the production of syngas for liquid fuel production.

\section{Syngas-to-FT Liquid Conversion}

The results and analysis of the FTS experiments performed in Catacel Corporation's lowpressure reactor (LPR) and the EERC's modular trickling fixed-bed reactor (MTFBR) are presented in the following two sections. Both the reactors were highly experimental and, therefore, the screening experiments were conducted in order to understand the possibility of FT 

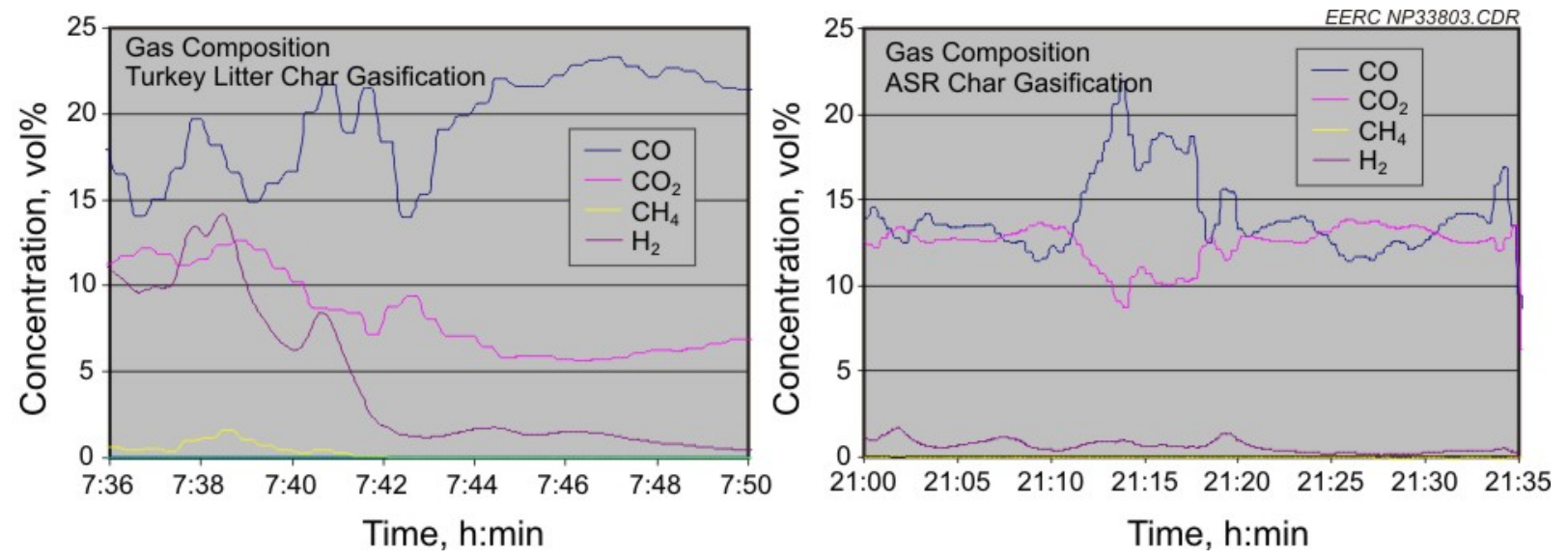

Figure 17. Comparison of the syngas concentration time history of self-sustained gasification of turkey litter char and ASR char.

liquid production from biomass syngas. Both reactors used two different $\mathrm{Fe}$ catalysts with different loading techniques. The catalyst and its loading in the LPR was proprietary to Catacel Corporation and had unique heat-transfer and flow characteristics, while the catalyst loading in the EERC reactor was based on conventional fixed-bed methodology. Unlike LPR, the MTFBR had the ability to achieve forced heat transfer. The gas hourly space velocity (GHSV) of the LPR, as specified by the manufacturer, was $3500 \mathrm{~h}^{-1}$; however, it was operated at a lower value ranging from 400 to $1000 \mathrm{~h}^{-1}$ after determining the optimum reactant conversion regime. The EERC reactor was operated at a GHSV of about $400 \mathrm{~h}^{-1}$.

\section{Part 1. Low-Pressure Reactor}

In order to facilitate the understanding of the performance of the LPR, experiments were first conducted using synthetic syngas prepared based on gas composition obtained by the gasification of high-moisture pine wood. The low-air-injection-rate gasification utilized moisture in the biomass as gasification medium and, therefore, the $\mathrm{N}_{2}$ concentration was in the range of $2 \%-3 \%$. The initial FTS experiments were conducted without any $\mathrm{N}_{2}$ in the syngas, and the effect of $\mathrm{N}_{2}$ on the conversion was separately studied. Table 4 shows the typical inlet gas composition and average outlet gas compositions and reactant conversions.

The experiments were conducted at a flow rate ranging between 1 and $15 \mathrm{~L} / \mathrm{min}$. Based on the initial screening experiments, it was found that the best $\mathrm{CO}$ conversion could be obtained with the inlet flow rate ranging between 1 and $2.5 \mathrm{~L} / \mathrm{min}$. Since the purpose of the effort was to develop a low-pressure FT reactor, the design pressure of the reactor was $175 \mathrm{psig}$, and the experiments were conducted between 50 and $145 \mathrm{psig}$. One of the main limitations of the reactor was that the maximum working temperature of the gasket material used was $300^{\circ} \mathrm{C}$. The reactor operating temperature during synthesis reaction was maintained below $275^{\circ} \mathrm{C}$, while the catalyst regeneration or reactivation was conducted at a temperature lower than $300^{\circ} \mathrm{C}$ in order to prevent gasket failure. 


\begin{tabular}{|c|c|c|c|c|c|}
\hline Reactor Operating Condition: & $\begin{array}{c}\text { Pressure: } \\
\text { Temperature: }\end{array}$ & $\begin{array}{l}115.00 \\
275.00\end{array}$ & $\begin{array}{l}\text { psig } \\
{ }^{\circ} \mathrm{C}\end{array}$ & & \\
\hline Syngas Species & & $\mathrm{CO}$ & $\mathrm{CO}_{2}$ & $\mathrm{H}_{2}$ & $\mathrm{CH}_{4}$ \\
\hline \multirow{2}{*}{ Gas Composition, vol\% } & Inlet & 34.20 & 5.72 & 57.77 & 2.31 \\
\hline & Outlet & 27.96 & 10.86 & 55.62 & 5.56 \\
\hline \multirow[t]{2}{*}{ Reactant Flow, mol/h } & Inlet & 1.01 & 0.17 & 1.71 & 0.07 \\
\hline & Outlet & 0.71 & 0.27 & 1.41 & 0.14 \\
\hline \multirow[t]{2}{*}{ Conversion, $\%$} & & 0.30 & -0.11 & 0.30 & -0.07 \\
\hline & & 30.07 & -62.21 & 17.67 & -106.35 \\
\hline
\end{tabular}

It was discovered during the initial experiment that the $\mathrm{CO}$ and $\mathrm{H}_{2}$ molar conversion were $3.2 \%$ and $2.3 \%$ at the operating temperature and pressure $250^{\circ} \mathrm{C}$ and $145 \mathrm{psig}$, respectively. The catalyst activity was improved followed by its reduction with pure hydrogen, and in the following experiments, the $\mathrm{CO}$ and $\mathrm{H}_{2}$ conversion was found to be $30.1 \%$ and $17.7 \%$, respectively, at a reactor operating pressure of 115 psig. Table 4 and Figure 18 show the results of the FTS experiments conducted in the LPR. The gas composition at the inlet and outlet of the FTS reactor is shown in Figure 18(a). Figure 18(b) shows the temperature time history of the FT reactor, and Figure 18(c) depicts reactor inlet and outlet pressure. Interestingly, the temperature profile shows no variation in the reactor temperature. This is one of the most important features of the FTS reactor. Also, the pressure drop across the reactor was about 1 psig, which is another important feature of the reactor. Since the operating pressure of the reactor was about six times lower than the conventional FTS reactor operating condition, an insignificantly small conversion of $\mathrm{CO}$ and $\mathrm{H}_{2}$ and no long-chain hydrocarbons were expected to have synthesized. However, the GC-MS analysis of the liquid collected from the condenser showed a spectrum of alkane and alkenes with carbon numbers ranging from $\mathrm{C}_{6}$ to $\mathrm{C}_{24}$ (see Figure 19).

\section{Effect of Syngas Flow Rate on Conversion}

Experiments were conducted to understand the effect of syngas flow rate on $\mathrm{CO}$ and $\mathrm{H}_{2}$ conversion. As shown in Figure 20, the $\mathrm{CO}$ and $\mathrm{H}_{2}$ conversion significantly reduces with an increase in flow rate greater than $1.17 \mathrm{~L} / \mathrm{min}$. The flow rate increase by about $80 \%$ causes $\mathrm{CO}$ and $\mathrm{H}_{2}$ conversion drop by about $68 \%$ and $61 \%$, respectively. On the same plot, the variation of $\mathrm{CO}_{2}$ conversion as a direct effect of variation in $\mathrm{CO}$ and $\mathrm{H}_{2}$ conversion can be seen. The negative value signifies the increase in $\mathrm{CO}_{2}$ concentration in the output stream primarily due to an internal shift reaction. The increase in flow rate also significantly reduces $\mathrm{CO}_{2}$ concentration in the outlet stream. It is likely that the increased syngas flow rate may have augmented bed heat loss, causing a reduction in catalyst activity. The reactor bed temperature profile showed negligibly small variation as an effect of increase in flow rate. It is likely due to the characteristic flow and heat transfer of Catacel Corporation's SSR technology, the temperature variation is not apparent. However, it is also observed that catalyst activity also significantly dropped. This unique feature of the reactor needs further investigation in order to enhance its performance in terms of improving FT liquid yield. 


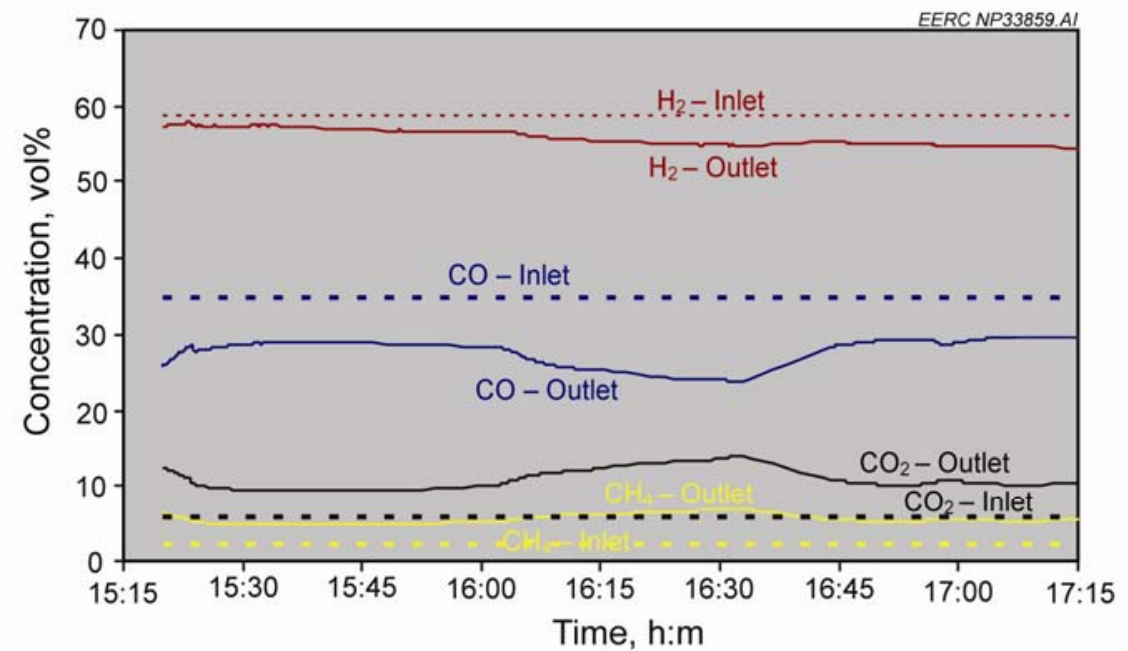

(a)

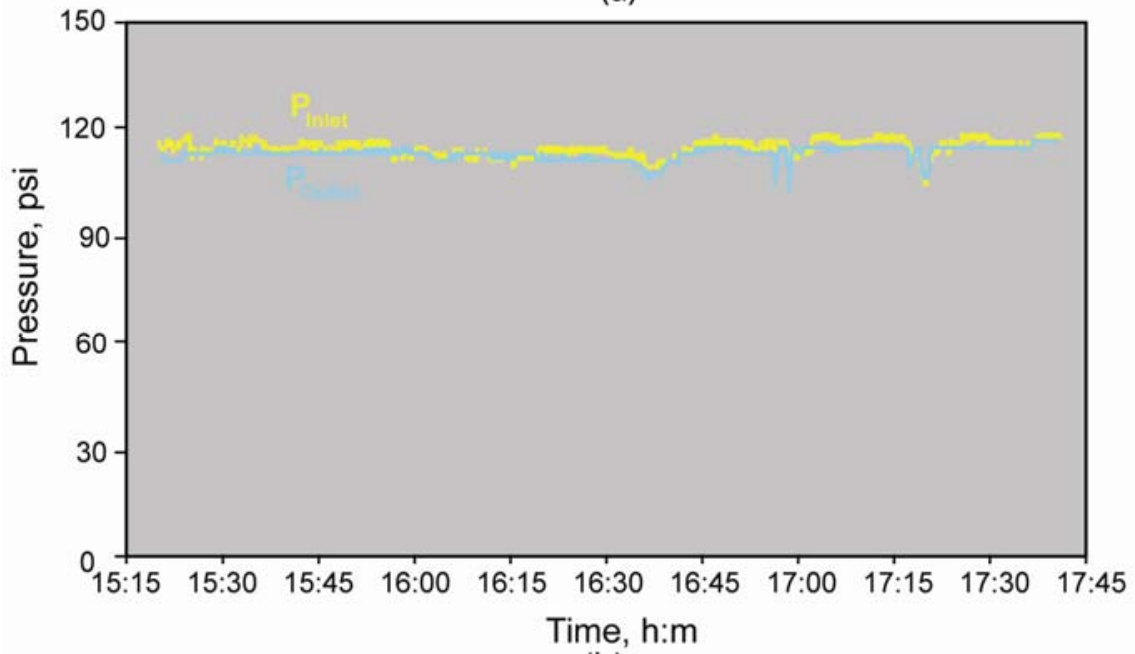

(b)

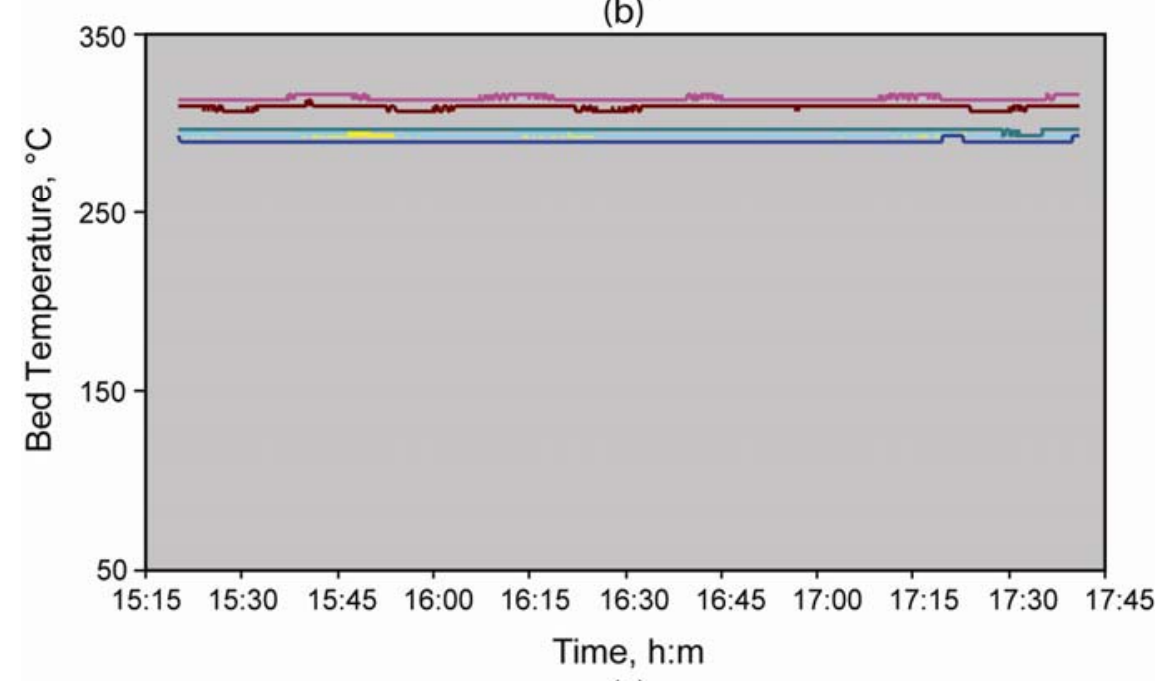

(c)

Figure 18. a) Time variation of syngas composition at the reactor outlet, b) temperature time history of the FT reactor, and c) FT reactor inlet and outlet pressure (pressure drop less than $1 \mathrm{psi}$ ). 


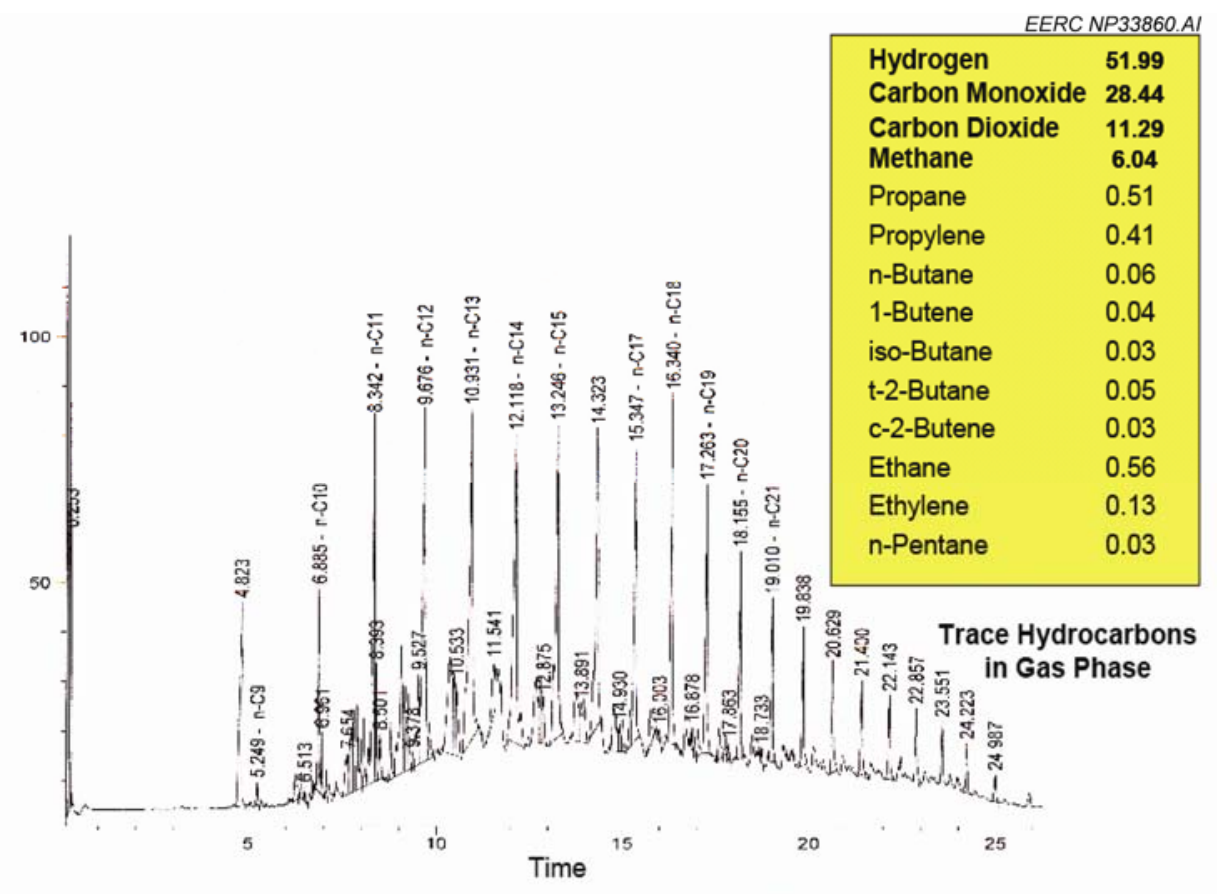

Gas Chromatogram of Liquid Collected During Steady-State Test

Figure 19. Gas chromatogram of the FT liquid collected during the synthesis experiment and composition of noncondensable hydrocarbons in the gas phase.

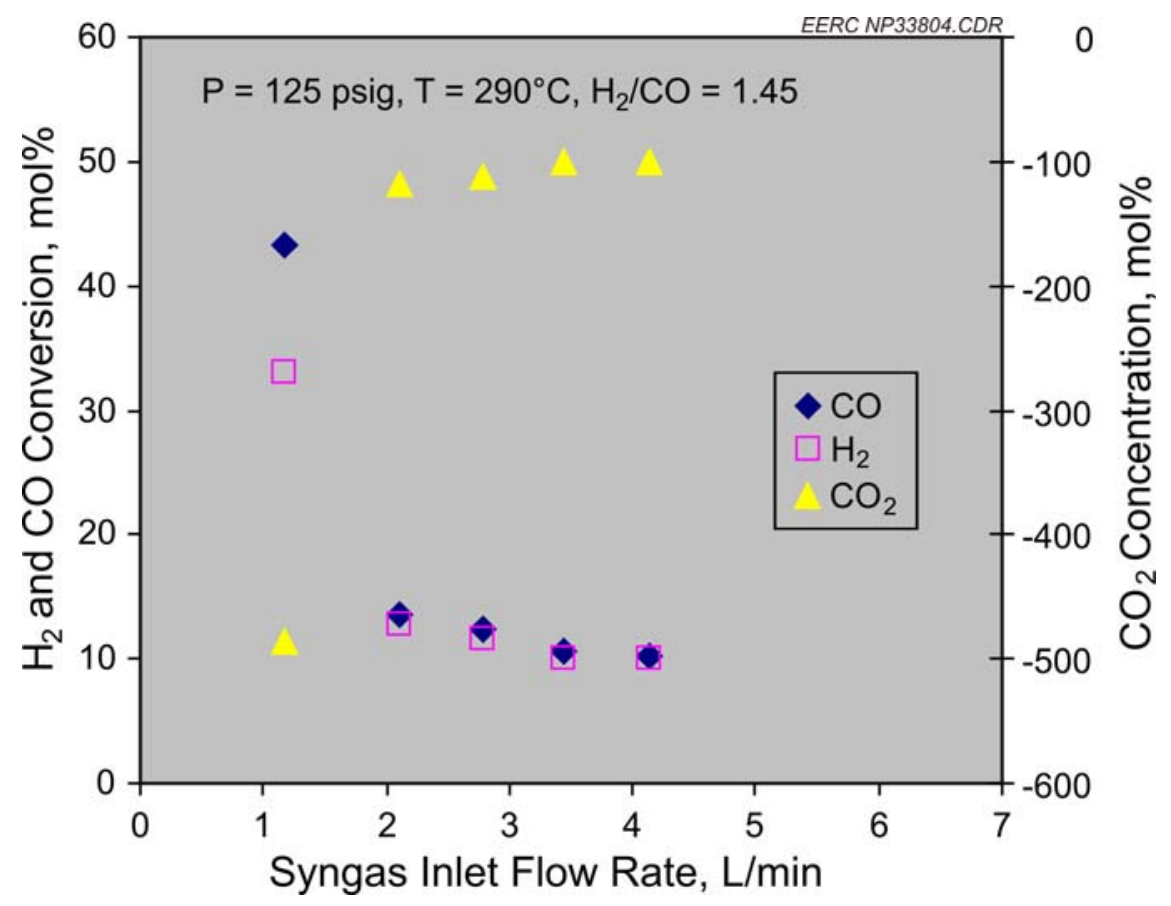

Figure 20. Effect of flow rate on $\mathrm{H}_{2}, \mathrm{CO}$, and $\mathrm{CO}_{2}$ conversion. 


\section{Effect of Nitrogen on Conversion}

Nitrogen is one of the major constituents of syngas produced in an air gasification process. It is believed that $\mathrm{N}_{2}$ plays the role of an inert and may affect the temperature profile in the FT reactor, depending on the reactor configuration. Experiments were conducted to determine the effect of $\mathrm{N}_{2}$ on $\mathrm{CO}$ and $\mathrm{H}_{2}$ molar conversion. The syngas was diluted by adding $\mathrm{N}_{2}$ at up to $12 \%$, and the $\mathrm{CO}$ and $\mathrm{H}_{2}$ conversion data were compared with syngas with a zero concentrationof $\mathrm{N}_{2}$. The reactor temperature and pressure were maintained constant at $275^{\circ} \mathrm{C}$ and 80 psig. It was found that the $\mathrm{CO}$ and $\mathrm{H}_{2}$ conversion dropped by about $19 \%$ and $15 \%$, respectively, and it regained its original values (17\% and 9\%) once $\mathrm{N}_{2}$ injection was stopped. These initial experiments were indicative of the sensitivity of partial pressures of the reactant and need further investigation.

\section{Parametric Study}

A set of experiments were planned in order to understand the effect of reactor operating parameters pressure, temperature, and $\mathrm{H}_{2} / \mathrm{CO}$ ratio on the conversion of $\mathrm{CO}$ and $\mathrm{H}_{2}$. These were the screening experiments to determine the range of operating parameters suitable for future experimental planning for statistical evaluations. The selected temperature range was $150^{\circ}$ to $300^{\circ} \mathrm{C}$, pressure ranged between 50 and $110 \mathrm{psig}$, and $\mathrm{H}_{2} / \mathrm{CO}$ ratio ranged between 1 and 2 . The experiments were conducted at constant flow rate of $2.14 \mathrm{~L} / \mathrm{min}$. The following are the general conclusions drawn from the experiments:

- For a constant pressure and $\mathrm{H}_{2} / \mathrm{CO}$ ratio, an increase in temperature significantly increases $\mathrm{CO}$ and $\mathrm{H}_{2}$ conversion beyond $200^{\circ} \mathrm{C}$. Table 5 shows the $\mathrm{H}_{2}$ and $\mathrm{CO}$ conversion at a reactor operating pressure of $80 \mathrm{psig}, \mathrm{H}_{2} / \mathrm{CO}=1.8$, and flow rate of $2.14 \mathrm{~L} / \mathrm{min}$.

- Data in the table show that reactant conversion was insignificantly low at a temperature lower than $250^{\circ} \mathrm{C}$. The $\mathrm{H}_{2}$ and $\mathrm{CO}$ conversion of 9.4 and 3.7, respectively, occurred at pressure and temperature of $50 \mathrm{psig}$ and $300^{\circ} \mathrm{C}$, respectively, at a $\mathrm{H}_{2} / \mathrm{CO}$ ratio of 1.5 . The future experiments, therefore, should be conducted at a temperature in the range of $200^{\circ}-300^{\circ} \mathrm{C}$.

\section{Part 2. FT Liquid Synthesis Experiments}

The Catacel FT reactor achieved $\mathrm{CO}$ and $\mathrm{H}_{2}$ conversion at reactor pressures ranging between 50 psig ( 3.4 bar) and 125 psig ( 8.5 bar). The highest molar conversions of $\mathrm{CO}$ and $\mathrm{H}_{2}$ found were $30 \%$ and $17 \%$, as shown in Table 6 . The liquid composition determined by GC-MS indicated formation of $\mathrm{C}^{+}$to $\mathrm{C}_{2} 4^{+}$components (shown in Figure 19). The catalyst bed temperature remained fairly constant during the experiments, which indicates that the reactor heat transfer was excellent. It was, however, not clear whether at such gas flow rates and conversions there would be any significant heat produced at which the bed temperature may show an observable change. Also, it was not clear if conversions could be obtained at such low pressures. In order to understand the unique features of the Catacel reactor, additional benchscale experiments were conducted using the tubular fixed-bed reactor (TFBR) with an internal, indirect heat-transfer system. The aim of the experiments was to develop a preliminary 
Table 5. Range of Species Concentration of Synthetic Syngas Within the EERC

FTS Reactor

\begin{tabular}{lc}
\hline Syngas Species & Concentration, vol\% \\
\hline $\mathrm{CO}$ & $26-32$ \\
$\mathrm{~N}_{2}$ & $28-44$ \\
$\mathrm{H}_{2}$ & $25-38$ \\
$\mathrm{CO}_{2}$ & $4-6$ \\
\hline
\end{tabular}

understanding of the performance of a commercial catalyst obtained from JMI in the TFBR using a simulated syngas containing about $35 \% \mathrm{~N}_{2}$, which is a typical concentration of syngas from the air gasifier. Table 6 shows the range of species concentration in the syngas used in the FTS experiments.

The results of preliminary experiments conducted in the TFBR are represented on CO and $\mathrm{H}_{2}$ conversion time histories and temperature time histories. The GC-MS results of the condensed liquid hydrocarbon are also shown in order to understand the effect of operating conditions based on the comparison of the $C_{n}$ composition as an effect of reactor operating parameters. The experiments were also conducted to determine range of operating parameters imperative for experimental design for future efforts.

\section{FTS at Reactor Temperatures of Less than $200^{\circ} \mathrm{C}$}

The first two experiments were conducted at a 150-psig reactor pressure and temperatures of $180^{\circ}$ and $200^{\circ} \mathrm{C}$. The syngas flow rate was maintained in the range of $1 \mathrm{~L} / \mathrm{min}$ and a $\mathrm{H}_{2} / \mathrm{CO}$ ratio of 0.96 . The low $\mathrm{H}_{2} / \mathrm{CO}$ ratio was intended to decrease methane production and also examine performance of the Fe catalyst as a promoter of water-gas shift reaction at the reactor operating conditions. It is also important to note that the syngas from air gasification can comfortably achieve a $\mathrm{H}_{2} / \mathrm{CO}$ ratio in the vicinity of 1 (as discussed earlier). The $\mathrm{CO}$ and $\mathrm{H}_{2}$ conversion at $150 \mathrm{psig}$ and $180^{\circ} \mathrm{C}$ were less than $1.5 \%$, indicating that these operating conditions are the lower limits. The increase in reactor temperature to $200^{\circ} \mathrm{C}$ slightly increased conversions, however, remained lower than $5 \%$. The effects of $\mathrm{H}_{2} / \mathrm{CO}$ ratio at these operating conditions need to be further evaluated.

Table 6. Range of Species
Concentration in the Syngas
Used in the FTS Experiments
\begin{tabular}{lll} 
Temperature ${ }^{\circ} \mathrm{C}$ & $\mathrm{CO}, \%$ & $\mathrm{H}_{2}, \%$ \\
\hline 150 & 1.47 & 0 \\
200 & 1.33 & 1.03 \\
250 & 5.34 & 1.33 \\
\hline
\end{tabular}




\section{FTS at a Reactor Temperature of $200^{\circ} \mathrm{C}$}

Figure 21 shows the results of the next screening experiments. The plots show conversion time history, temperature history, and GC-MS analysis of the product liquid synthesized during the experiment conducted at a pressure of $250 \mathrm{psig}$, a temperature of $200^{\circ} \mathrm{C}$, and $\mathrm{H}_{2} / \mathrm{CO}$ ratio of 0.95. The $\mathrm{CO}$ and $\mathrm{H}_{2}$ conversions increased compared to previous experiments as a combined effect of increase in temperature and pressure. The conversion plot also depicts the increase in $\mathrm{CO}_{2}$ in the outlet gas stream represented as negative conversion. The steady-state conversion could be obtained after about 5 hours. The uniform wavy temperature profile is characteristic of reactor heater operation captured as a result of the surface mounting of thermocouple junctions achieved by direct welding on the reactor wall. This minor variation in temperature is not expected to cause any upset condition for steady-state operation of the TFBR; however, the variations were closely monitored to determine whether it could become a possible trigger for any runaway temperature conduction during the experiment. FTS produced a spectrum of alkanes and alkenes with carbon numbers ranging from $\mathrm{C}_{1}$ to $\mathrm{C}_{15}$. The liquid product had a characteristic of gasoline.

It can be concluded from these TFBR experiments that the Catacel reactor can achieve better conversion at low-pressure operation and produce hydrocarbons with carbon numbers ranging from $\mathrm{C}_{5}$ to $\mathrm{C}_{24}$.

Further experiments were conducted at temperatures and pressures greater than $200^{\circ} \mathrm{C}$ and 200 psig, respectively.

\section{FTS at Reactor Temperatures Greater than $200^{\circ} \mathrm{C}$}

Figure 22 shows the results of the screening experiments conducted at a reactor pressure of 200 psig and a temperature of $230^{\circ} \mathrm{C}$, which is higher than the previous experiment. The $\mathrm{H}_{2} / \mathrm{CO}$ ratio was 1.5. The steady-state $\mathrm{CO}$ and $\mathrm{H}_{2}$ conversion was achieved within 2 hours, relatively quicker than previous experiments at $200^{\circ} \mathrm{C}$.

As shown in Figure 22(a), the average $\mathrm{CO}$ and $\mathrm{H}_{2}$ conversions were $80 \%$ and $28 \%$, respectively. The FTS produced a spectrum of alkanes and alkenes similar to the products in the previous experiment, with carbon numbers ranging from $\mathrm{C}_{1}$ to $\mathrm{C}_{15}$. The liquid product had a characteristic of gasoline. The $\mathrm{CH}_{4}$ and higher gaseous hydrocarbon produced was about $19 \%$ and $12 \%$ of the FTS products, respectively.

It was found that the bed temperature close to the inlet increased by about $50^{\circ} \mathrm{C}$ above the set point $\mathrm{C}$ during the first 2 hours and then gradually achieved the steady-state temperature about $10^{\circ} \mathrm{C}$ higher than the set temperature. The temperature drop occurred without the forced heat exchange this reactor is capable of achieving. Interestingly the highest $\mathrm{CO}$ conversion was achieved during this experiment. In order to understand whether this conversion is primarily achieved because of the self-sustained bed temperature higher than $230^{\circ} \mathrm{C}$, the next screening experiment was conducted to determine the effect of reducing temperature by coolant flow through the bed. The results of this experiment are shown in Figure 23. The experiment was conducted at $200 \mathrm{psig}$ and $220^{\circ} \mathrm{C}$. 


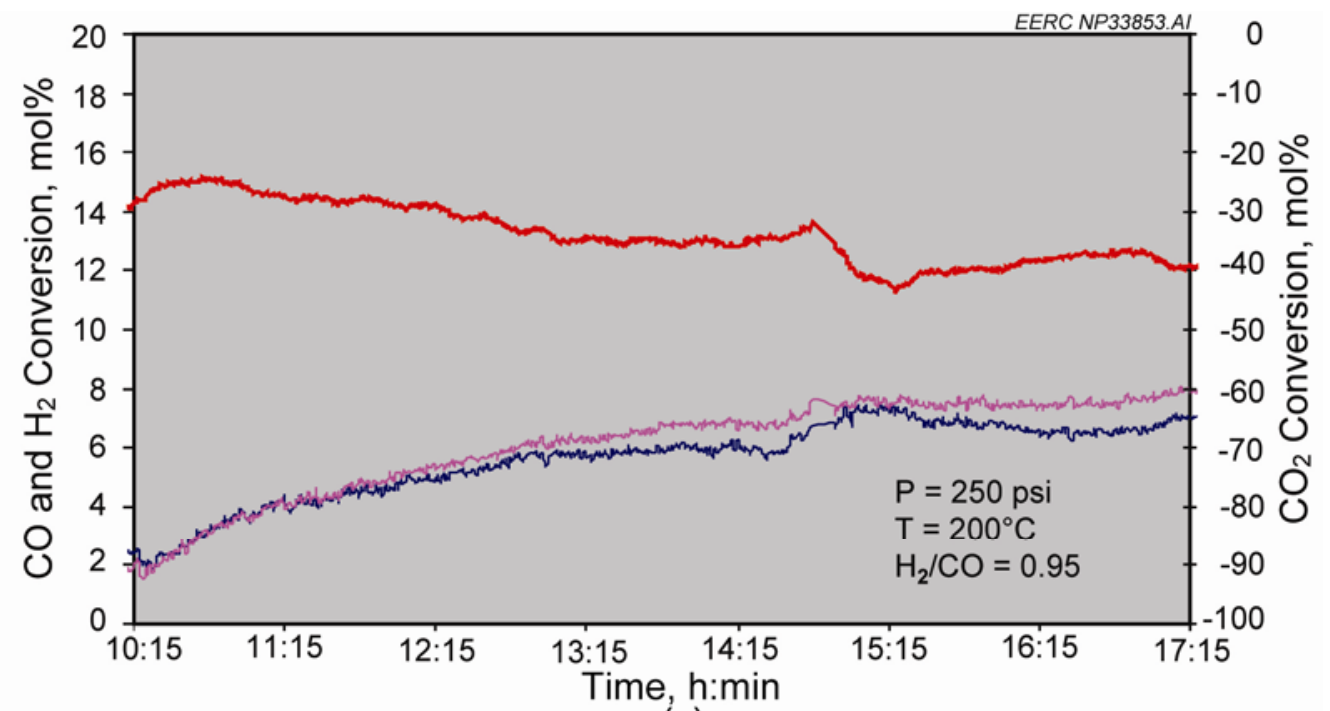

(a)

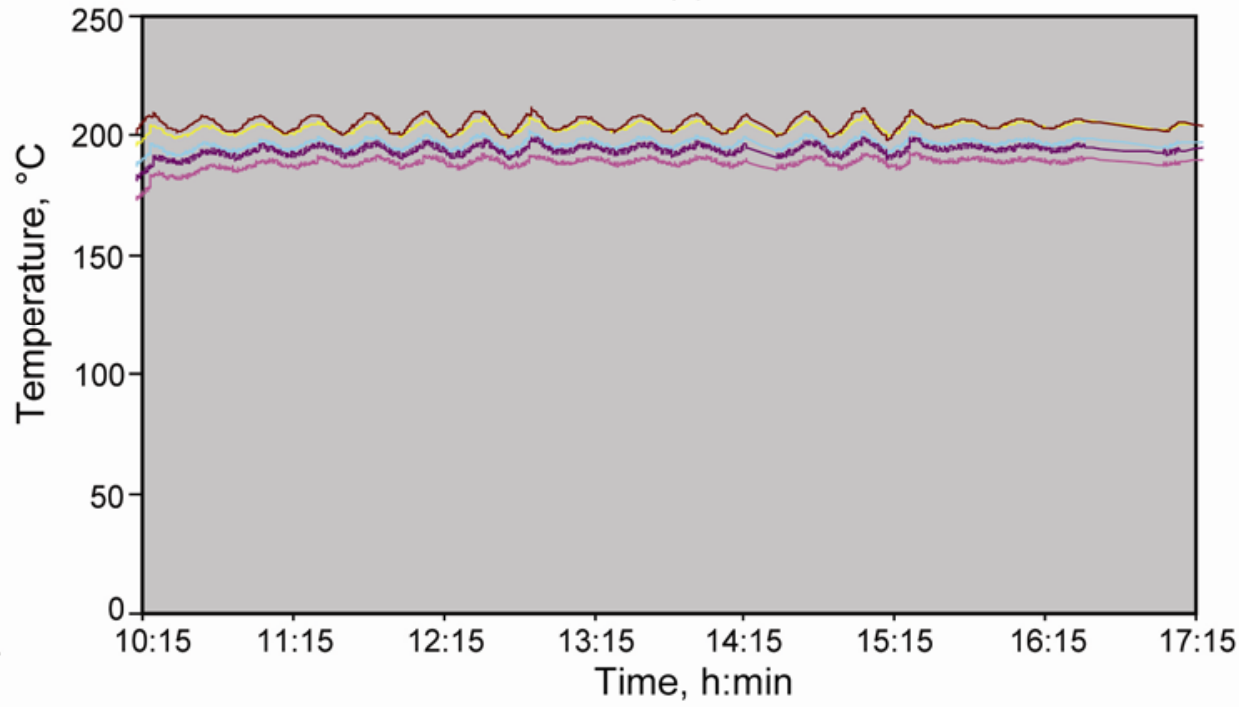

(b)

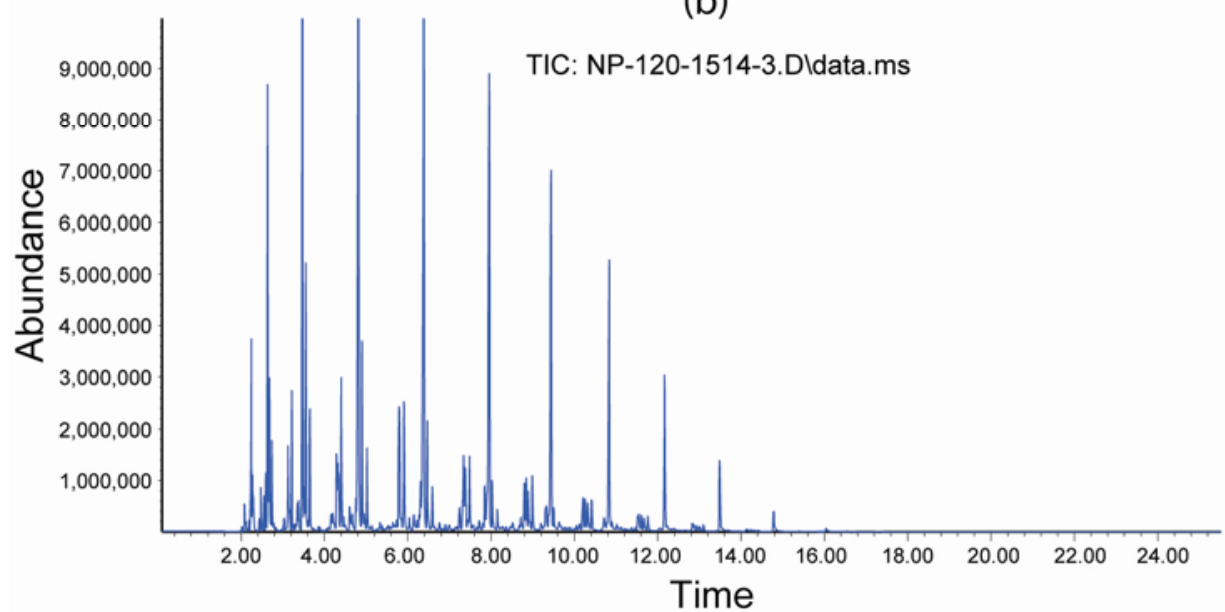

(c)

Figure 21. FTS experiments conducted at 250 psig and $200^{\circ} \mathrm{C}$ : a) conversion time history,

b) temperature time history, and c) GC-MS analysis of the product liquid. 


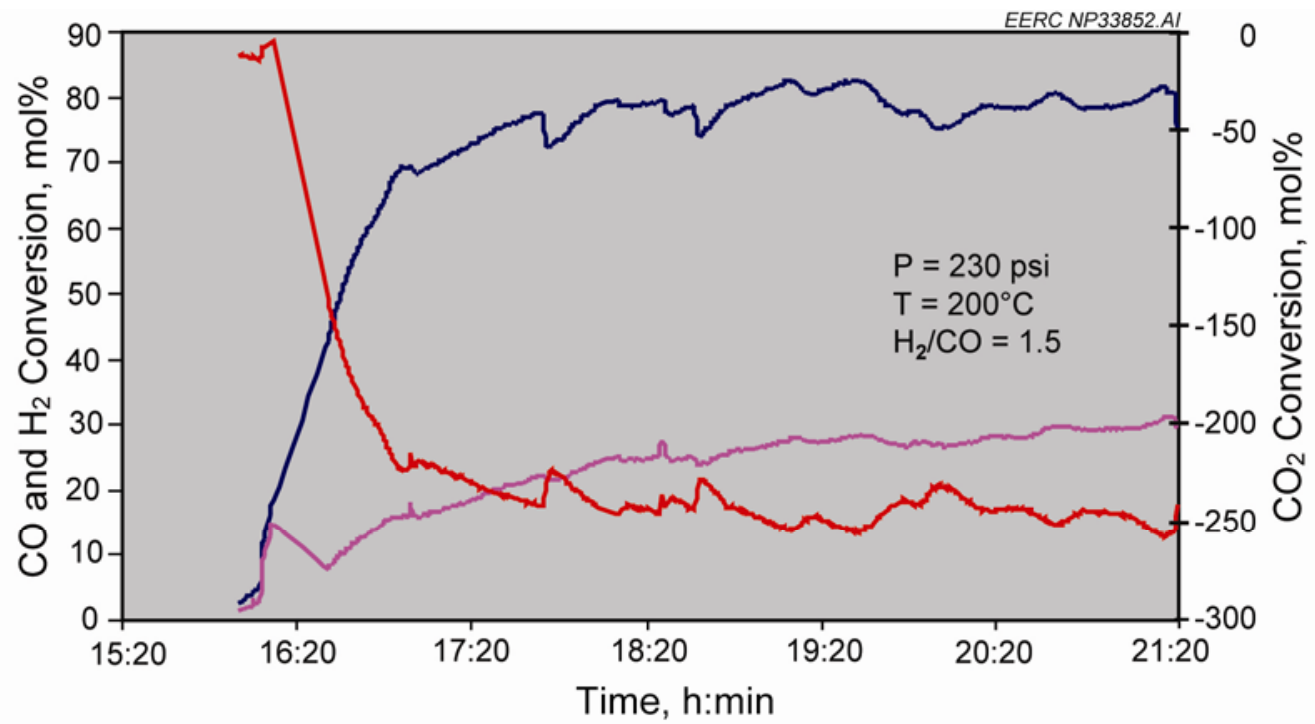

(a)

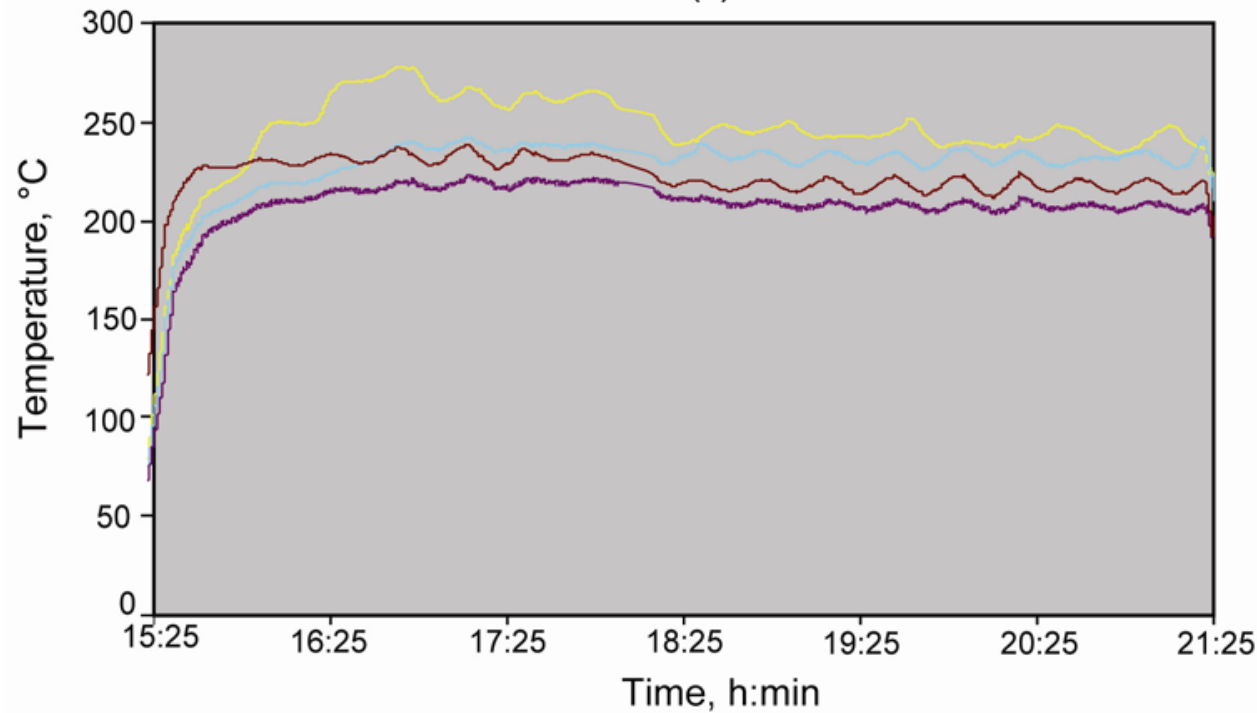

(b)

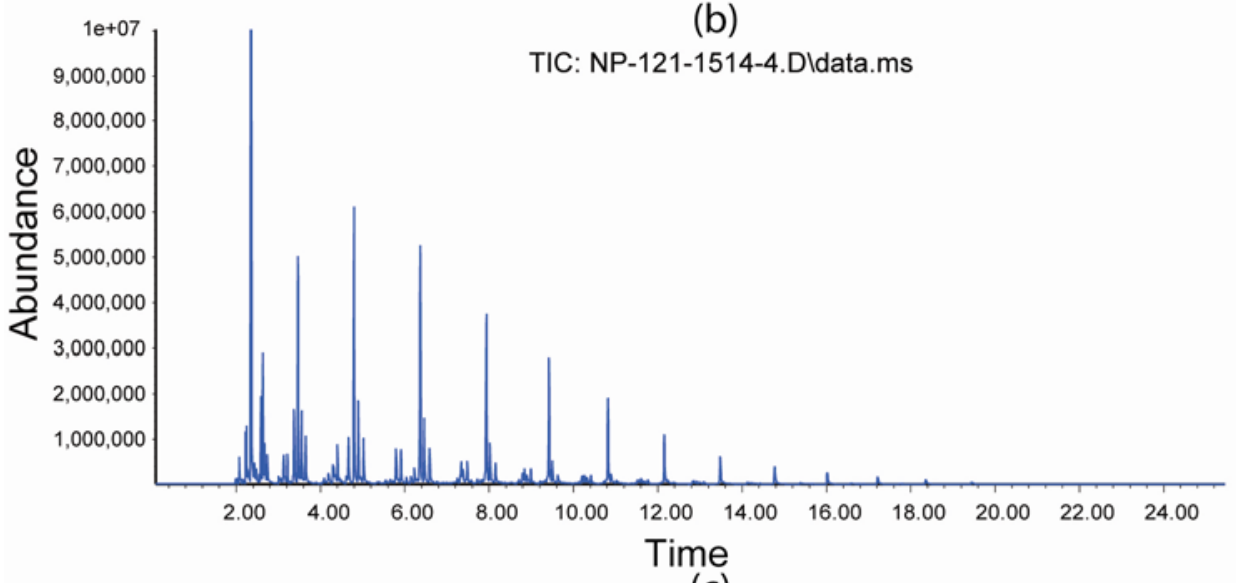

(c)

Figure 22. FTS experiments conducted at 200 psig and $230^{\circ} \mathrm{C}$ : a) conversion time history, b) temperature time history, and c) GC-MS analysis of the product liquid. 


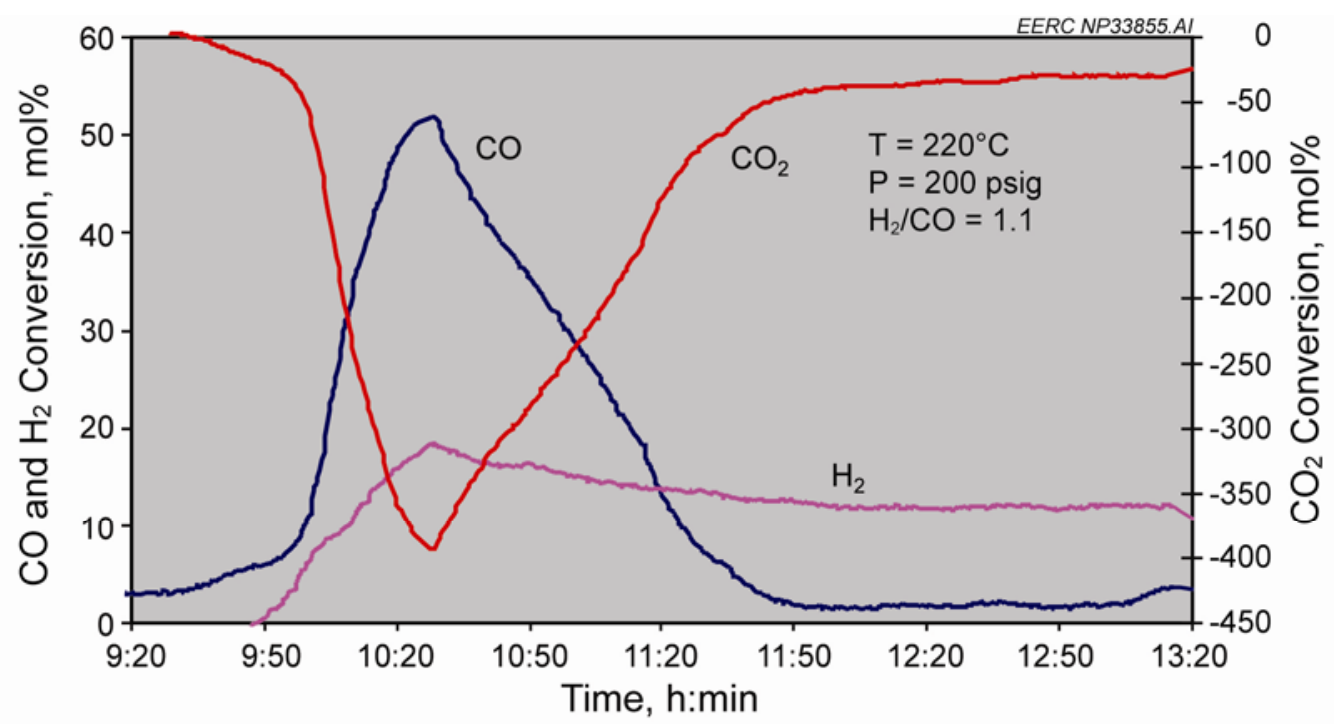

(a)

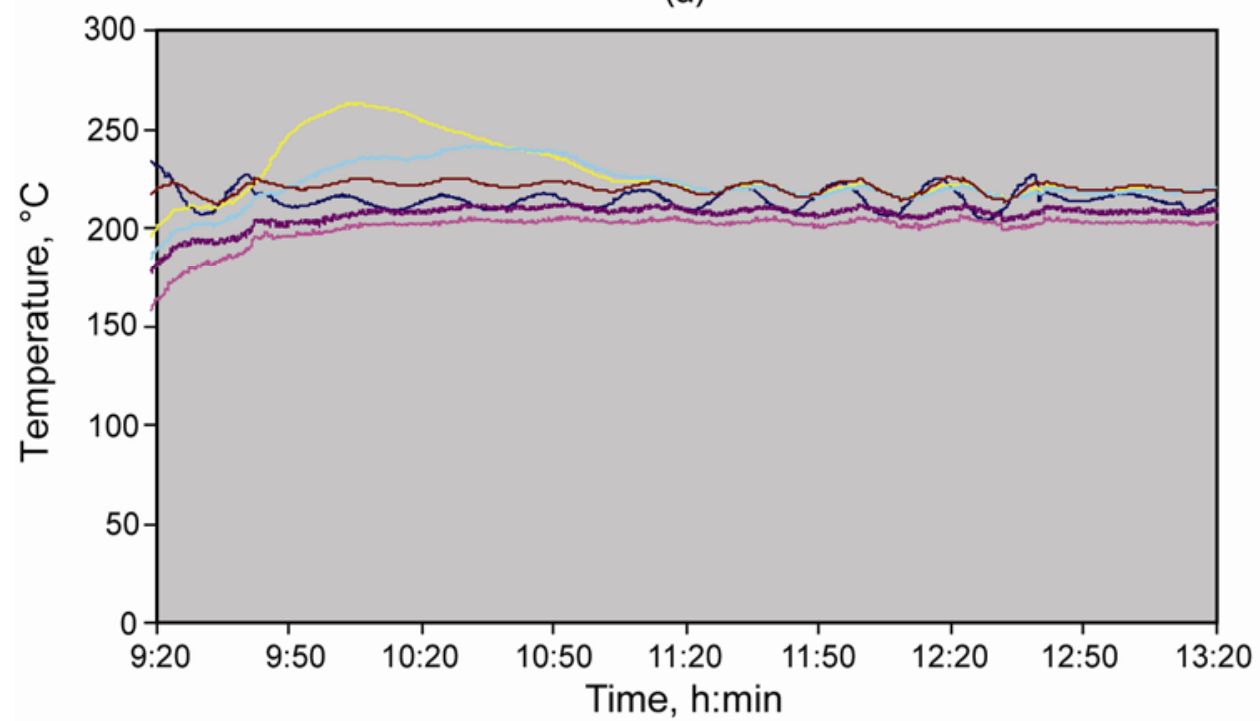

(b)

Figure 23. Effect of forced bed temperature variations on $\mathrm{CO}$ and $\mathrm{H}_{2}$ conversion at $220^{\circ} \mathrm{C}$ and 200 psig.

\section{Effect of Forced Bed Cooling}

As can be seen in Figure 23(a), the reactor bed temperature time profile showed an increase in temperature at the reactor inlet (yellow curve). The $\mathrm{CO}$ and $\mathrm{H}_{2}$ conversion increased with the increase in temperature. At this point, the bed temperature was forced to reduce and attain set temperature. The syngas flow rate was not changed during the entire experiment; therefore, the same hourly gas space velocity was maintained. The effect of reduced temperature was seen as a steep reduction in $\mathrm{CO}$ conversion. This caused a reduction in $\mathrm{CO}_{2}$ formation, indicating a significant effect of lowering temperature on the water-gas shift reaction. Interestingly, $\mathrm{H}_{2}$ conversion did not significantly decrease. This experiment confirmed the need 
for maintaining a bed temperature higher than $220^{\circ} \mathrm{C}$ for FTS and temperature limits for forced cooling.

The earlier experiment was repeated at a higher reactor pressure in order to understand its effect on conversion behavior. The syngas flow rate was maintained at the same reactor pressure of 300 psig. Also in this experiment, the forced bed cooling was stopped to observe the ability of the FTS process to restore bed temperature and reactant conversions. As can be seen in Figure 24, the bed temperature increased, as was observed in the previous experiment, within the same time span. The forced cooling of the bed reduced reactant conversions. The $\mathrm{CO}$ conversion dropped from $40 \%$ to $9 \%$. After ensuring that new steady-state conversions and bed temperatures were achieved, the forced bed cooling was stopped. This instantaneously affected the steady state, and, as can be observed in Figure 24, conversion and temperature profiles showed an increasing trend of these parameters. This demonstrated that the FTS process is strongly temperature-dependent.

It was also observed that the low-temperature (achieved because of bed cooling) steadystate conversion of CO reduced to slightly lower than $10 \%$, which was relatively higher than that observed at $200 \mathrm{psig}$, which was close to $2 \%$ achieved at same bed temperature condition. This could be seen as an effect of reactor operating pressure on the FTS process. The effect of pressure is also clearly observed by comparing the GC-MS analysis of the FTS liquid from 200- and 300-psig experiments, as shown in Figures 22 and 24, respectively. The major distinction between the two product streams consisting of a spectrum of alkane and alkenes is the range of carbon numbers. In the case of the 200-psig experiment, the liquid had a characteristic of gasoline with a carbon number range of $\mathrm{C}_{5}-\mathrm{C}_{15}$, while in the case of the 300-psig experiment, it ranged from $\mathrm{C}_{5}$ to $\mathrm{C}_{23}$, a characteristic of diesel.

These preliminary observations are important in understanding and determining the operating parameters of the FTS reactor. The current experiments were conducted by maintaining constant reactor wall temperature; however, it was observed that the internal bed temperature increases with conversion and that such a rise can be controlled only if the heattransfer surface is extended close to the reaction sites located in the single catalyst particle. The desired conversion in such a highly temperature-controlled system can be easily obtained.

It was further observed that even without any forced cooling, the bed temperature and reactor conversions significantly dropped after about 3 hours of continuous operation (Figure 24). It was not clear whether catalyst deactivation caused such a significant decrease in conversion. The experiment was discontinued at this point. Additional experiments were conducted to understand this phenomenon without regenerating catalyst.

\section{Conversion Without Forced-Bed Cooling at $220^{\circ} \mathrm{C}$}

Figure 25 shows the result of the 12-hour-long experiment conducted to understand if the bed temperature profile shows any thermal runaway situation or signs of catalyst deactivation indicated by a decrease in $\mathrm{CO}$ and $\mathrm{H}_{2}$ conversions. The FTS reactor ambient temperature was maintained at $220^{\circ} \mathrm{C}$, the same as in the previous experiment; however, forced cooling of the bed was not conducted in order to observe the variations in exothermic heat profile with time as an indicator of catalytic activity. As can be observed, the bed temperature measured close to the 


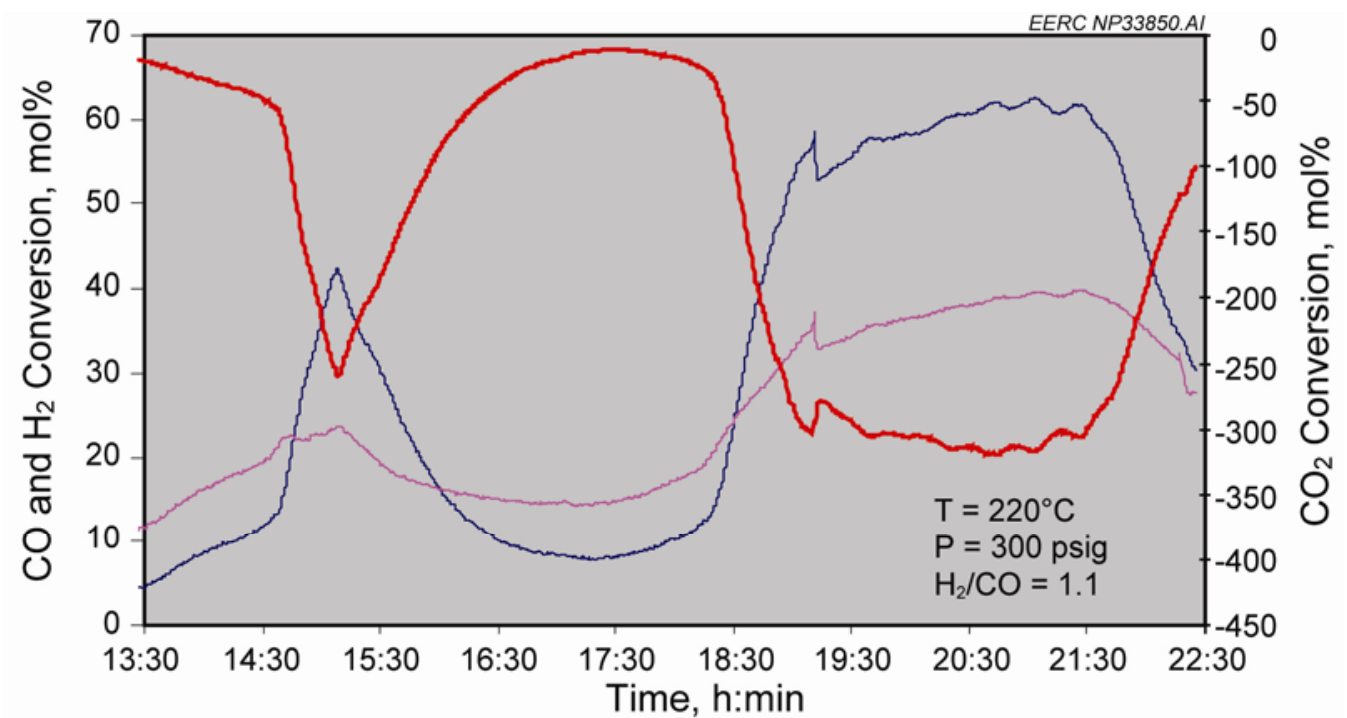

(a)

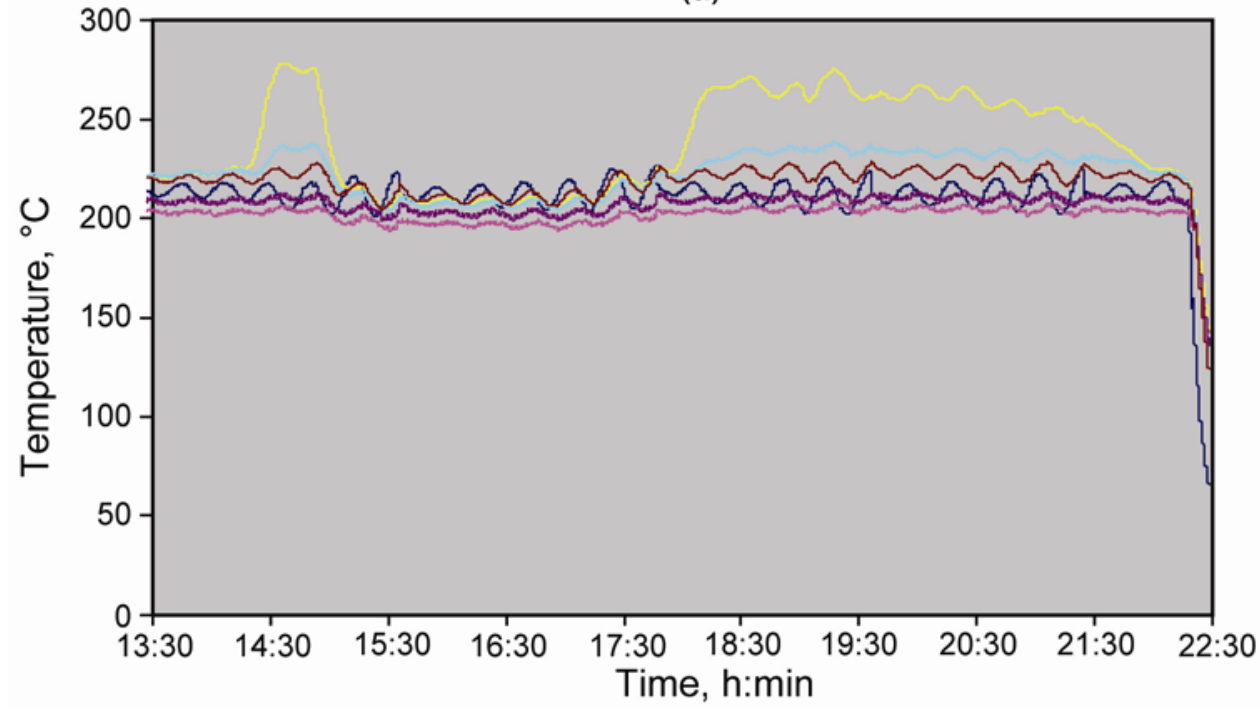

(b)

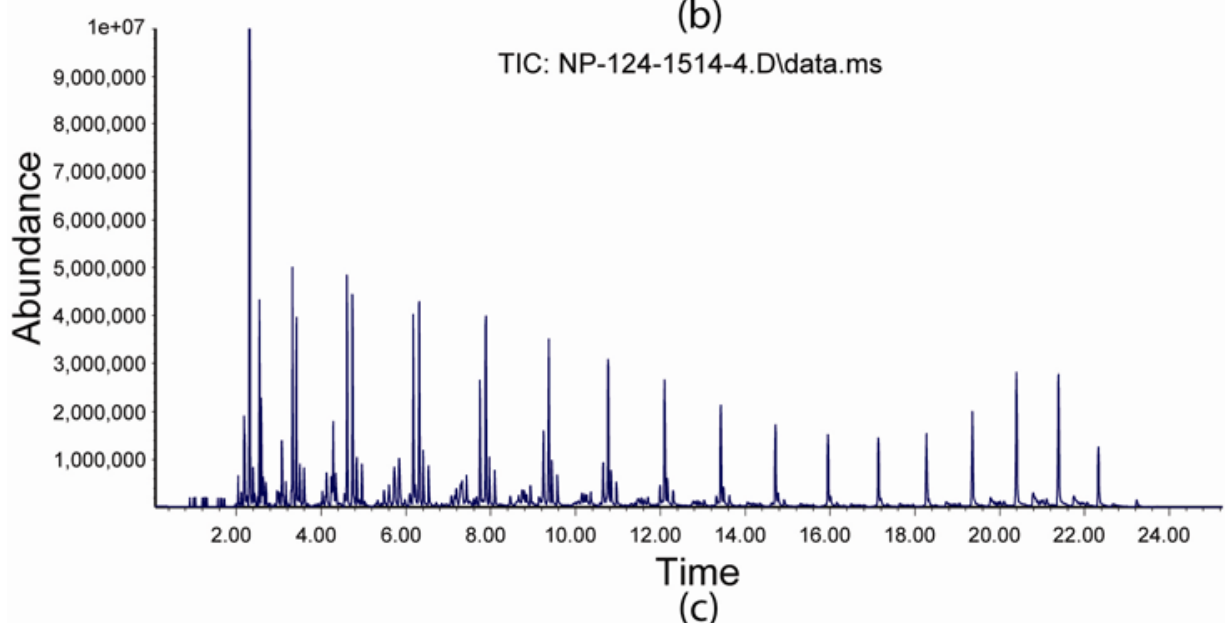

Figure 24. FTS experiments conducted at 300 psig and $230^{\circ} \mathrm{C}$ with forced catalyst bed cooling: a) conversion time history, b) temperature time history, and c) GC-MS analysis of the product liquid. 


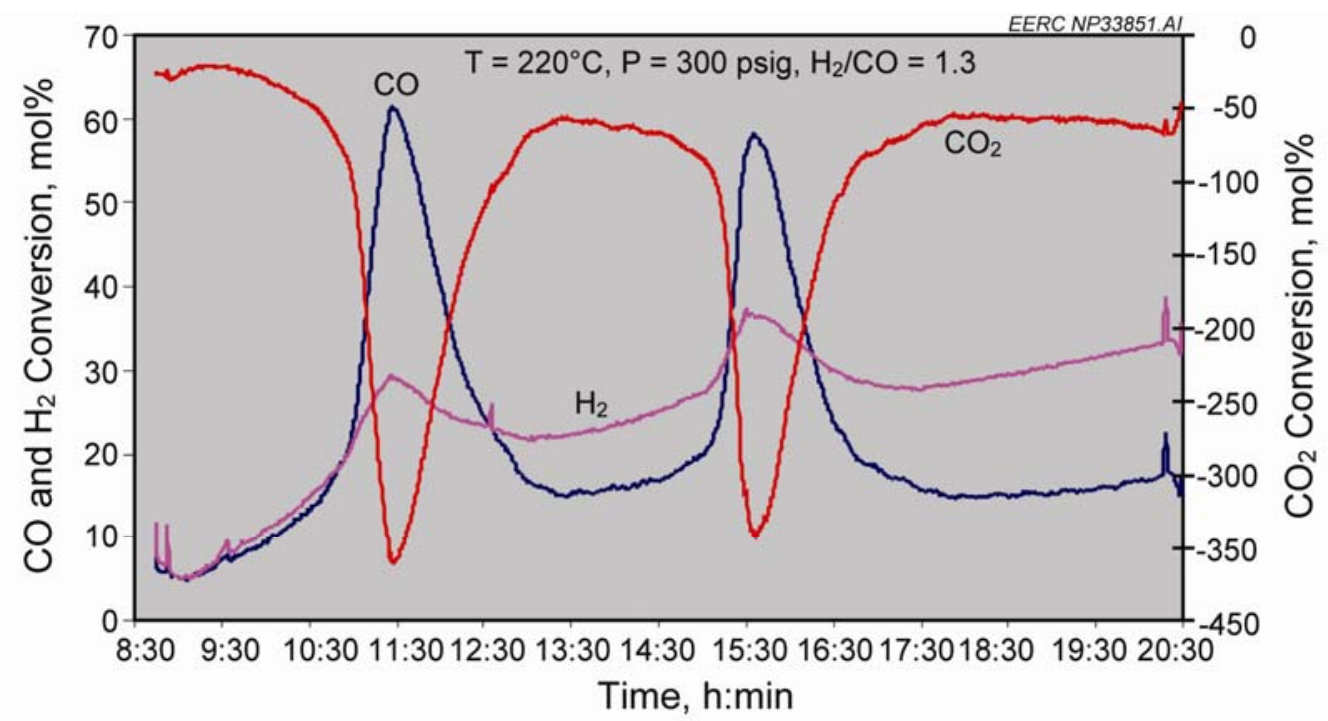

(a)

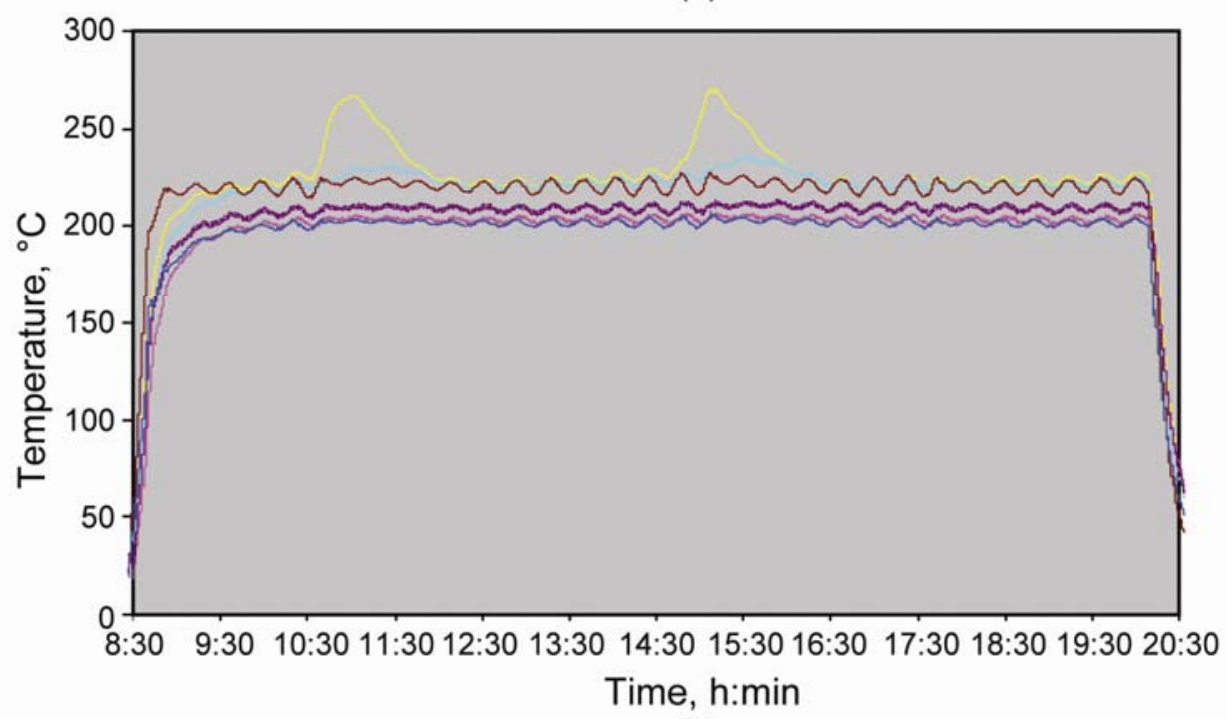

(b)

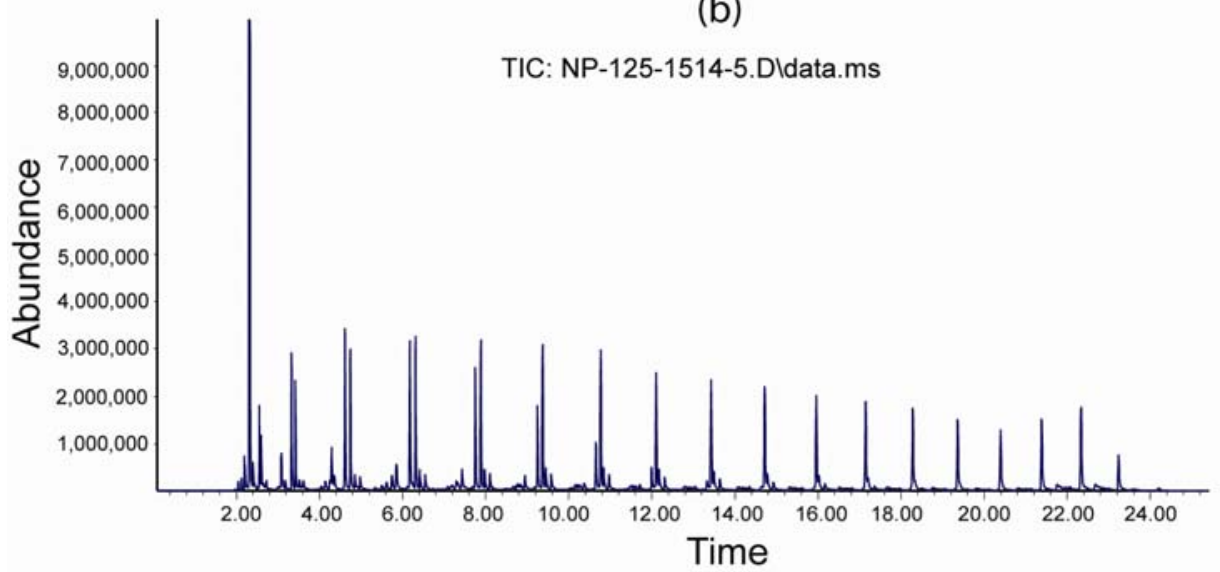

(c)

Figure 25. FTS experiments conducted at 300 psig and $220^{\circ} \mathrm{C}$ without forced bed cooling: a) conversion time history, b) temperature time history, and(c) GC-MS analysis of the product liquid. 
syngas injection point showed an increase similar to that observed in the previous experiment and attained a peak temperature of about $265^{\circ} \mathrm{C}$. The temperature then gradually dropped, attaining the reactor ambient temperature, indicating a drop in heat generation rate. The same temperature pattern repeated after about 3 hours. The $\mathrm{CO}$ and $\mathrm{H}_{2}$ conversion profiles were also found to follow the same cyclic rise and fall pattern of the bed temperature. The $\mathrm{CO}$ conversion first increased, attaining a peak conversion of $60 \%$ and then dropped to about $15 \%$. $\mathrm{The}^{\mathrm{H}} \mathrm{H}_{2}$ conversion profile showed a peak coinciding with the $\mathrm{CO}$ conversion profile. The $\mathrm{CO}_{2}$ conversion, as is found in all the experiments, closely followed the $\mathrm{CO}$ and $\mathrm{H}_{2}$ conversion.

It can be inferred from the results of these experiments that the reduction in conversion is not necessarily a sign of catalyst deactivation. The cyclic nature of the FTS conversion is likely a feature of steady-state operation and is expected to be a complex function of reacting flow hydrodynamics. This feature is required to be further understood, particularly in order to design a small-scale FTS reactor that lacks the thermal inertia that large-scale reactors can typically offer.

The GC-MS analysis of the liquid product stream is shown in Figure 25(c). The spectrum depicts the presence of alkane and alkenes with carbon numbers ranging from $\mathrm{C}_{5}$ to $\mathrm{C}_{23}$, a characteristic of diesel fuel observed in the previous experiment at a 300-psig FTS reactor operating pressure.

\section{Conversion Without Forced Bed Cooling at $230^{\circ} \mathrm{C}$}

Based on the observed strong temperature dependency of FTS reactions in earlier experiments (Figure 25[b]), screening experiments were conducted to understand the effect of increasing reactor ambient temperature on the cyclic nature of the FTS reactions.

The results of the experiments are shown in Figure 26. The FTS reactor operating temperature was maintained at $220^{\circ} \mathrm{C}$ as in the previous experiment until the first cycle of rise and fall in temperature and conversion, as was observed earlier. The reactor temperature was increased to $230^{\circ} \mathrm{C}$ after maintaining a constant low conversion value for at least an hour. The increase in reactor temperature resulted in achieving higher peak bed temperatures for longer durations in contrast to what was observed earlier. This also resulted in a sharp increase in CO and $\mathrm{H}_{2}$ conversions, which achieved peak values of $65 \%$ and $41 \%$, respectively. The difference observed in the case of the $220^{\circ} \mathrm{C}$ (Figure 25) and $230^{\circ} \mathrm{C}$ (Figure 26) studies is that the width of the peak conversions observed in a cycle is broader for the higher-temperature case, indicating a higher average conversion. It is, however, important to note that with an increase in reactor temperature, the peak bed temperature (typically close to the inlet) significantly increases, which may lead to accelerated catalyst sintering and deactivation. Long-duration experiments are planned to understand the reactor temperature limits and their effect on conversion profiles.

\section{Conclusions}

Biomass and a range of carbonaceous wastes like ASR and wastes containing plastics are critical domestic resources in the United States that can be utilized for reducing dependency on foreign oil. The study was performed as a major technology development effort undertaken by the EERC CBU to effectively and economically utilize vast available resources which otherwise would become a liability to the environment. The effort was primarily aimed at developing a 


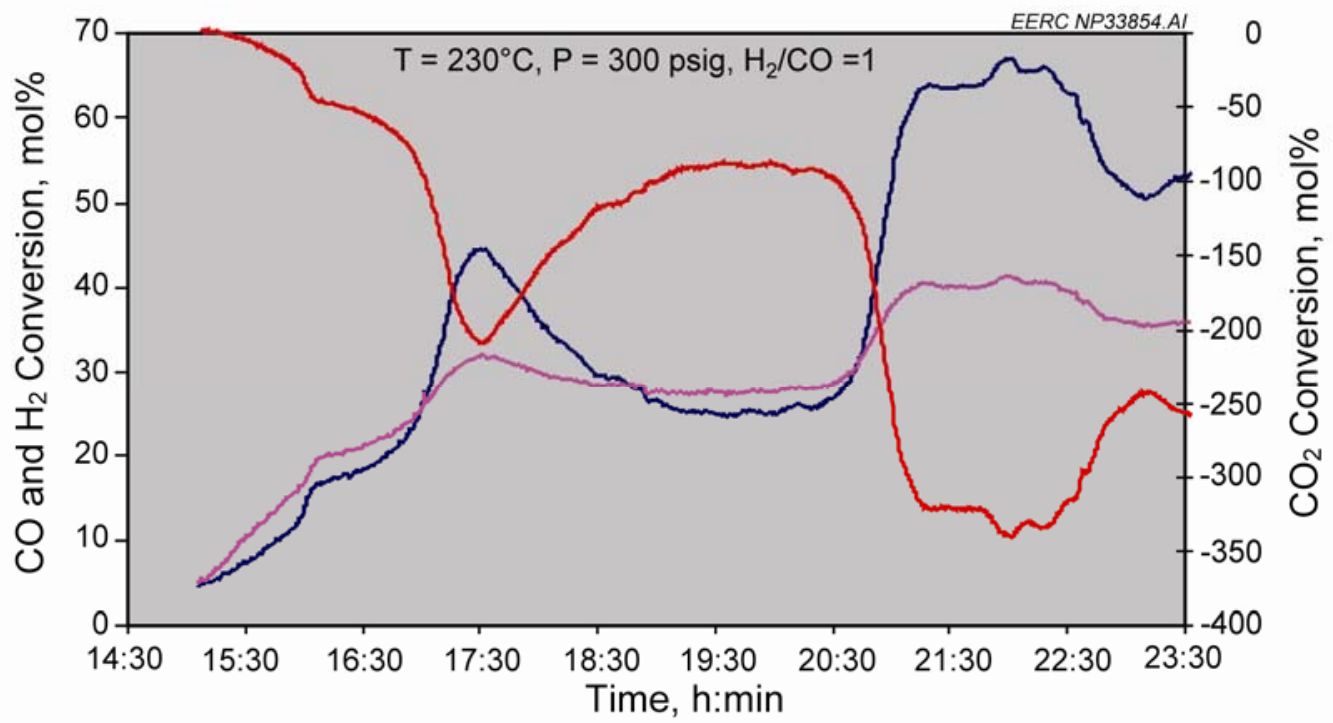

(a)

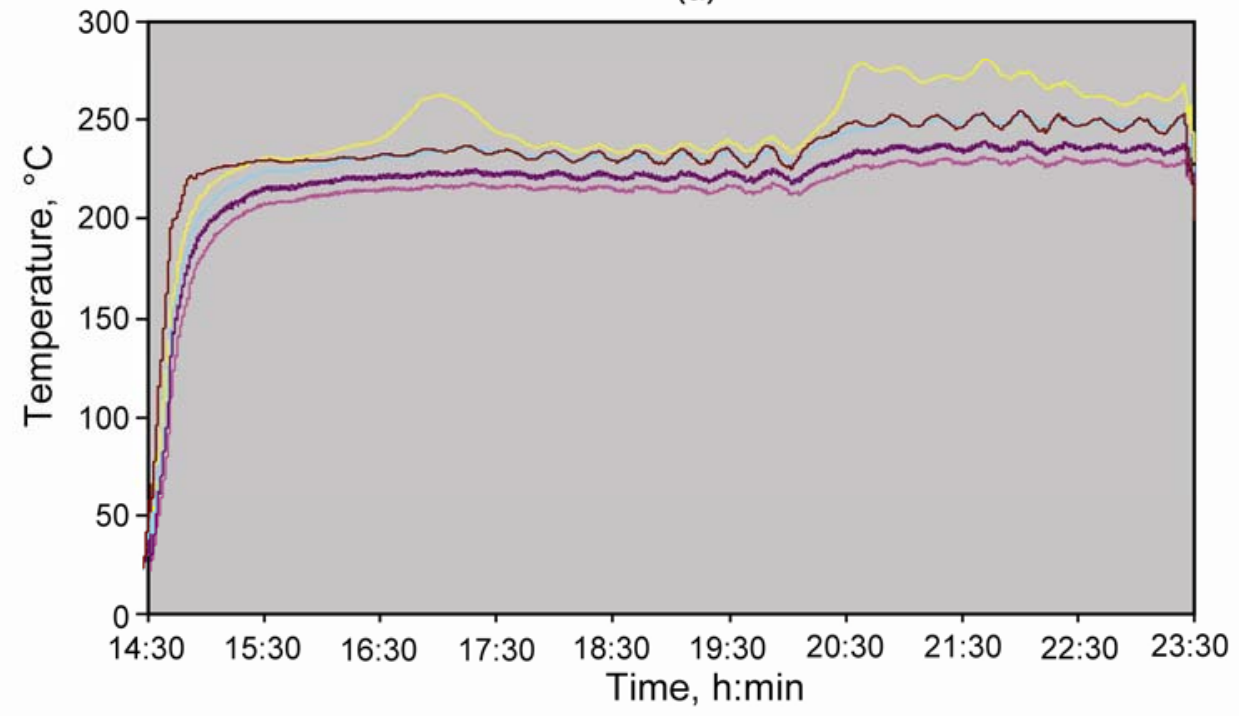

(b)

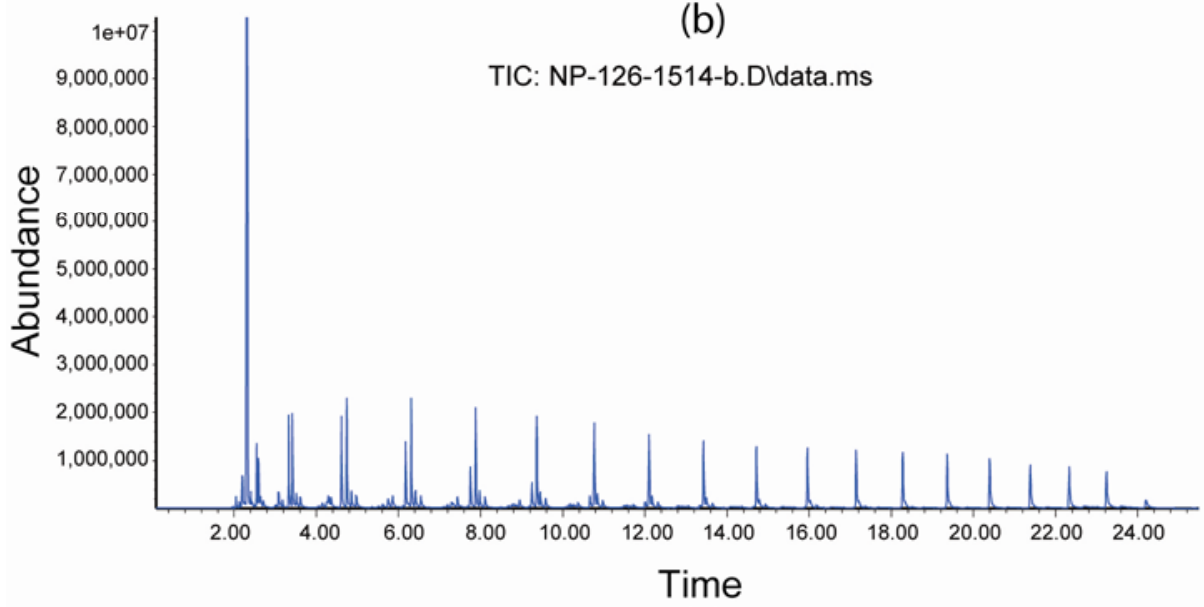

(c)

Figure 26. FTS results of syngas conversion at $220^{\circ} \mathrm{C}$ and 300 psig without forced cooling. 
distributed thermochemical conversion process for converting BTL fuels. The effort was divided in two phases to fulfill this goal. The first phase of study was aimed at understanding air gasification of biomass fuel and the effect of gasifier operating conditions in the production of syngas. The second phase of study was aimed at understanding the conversion of syngas as a function of reactor pressure and temperature on the conversion of syngas to FT liquid and, thus, evaluates the performance of specially designed low-pressure FT reactors. The following are the general conclusions drawn from the results in both the phases.

\section{Phase 1 Gasification Study}

1. The highest $\mathrm{H}_{2} / \mathrm{CO}$ ratios in the case of air gasification of pine wood and a mixture of biomass and plastic waste were 1.4 and 1.7 , respectively.

2. The $\mathrm{H}_{2}$ and $\mathrm{CO}$ concentration in the syngas decreases with an increase in air injection rate as observed in the case of woody biomass and a mixture of woody biomass and plastics. This is primarily due to the increase in concentrations of $\mathrm{N}_{2}$ and $\mathrm{CO}_{2}$.

3. The effect of air injection rate on the gasification of agricultural waste such as sunflower hulls is not significant. This is attributed to the fuel properties such as morphology and low packing density.

4. Independent of change in $\mathrm{N}_{2}$ concentration, the increase in air injection rate increases the $\mathrm{CO}_{2}$ concentration in the syngas; however, it does not significantly change $\mathrm{H}_{2}$ and $\mathrm{CO}$ concentration.

5. The biomass conversion rate increases with increasing air injection rate; however, considering the fact that the higher $\mathrm{CO}_{2}$ level promotes deactivation of synthesis catalyst, there exists a limit on air injection rate specific to the biomass fuel.

6. The conversion rate of sunflower hulls is lower than pine wood at low air injection rates; however, this trend changes at higher air injection rates. The conversion rate of peach stones is comparable to pine wood and higher than sunflower hulls.

7. The wet turkey litter can produce a $\mathrm{H}_{2} / \mathrm{CO}$ ratio favorable for the liquid synthesis process; however, the $\mathrm{CO}_{2}$ concentration is unacceptably high (ranged between 15\% and 20\%).

8. The $\mathrm{H}_{2} / \mathrm{CO}$ ratio in the case of dry turkey litter gasification is 0.95 . The $\mathrm{CO}_{2}$ level averages between $13 \%$ and $14 \%$, which is expected to increase to a higher level, rendering the dry litter as not a favorable feedstock for conventional air gasification based the liquid production process.

9. Air gasification of $100 \%$ ASR is found to produce syngas with a composition unfavorable for the liquid synthesis process; however, synergistic blending with biomass can favorably produce hydrogen-rich syngas. 


\section{Syngas-to-FT Liquid Conversion}

\section{Catacel Corporation's Low-Pressure Reactor}

1. The highest $\mathrm{CO}$ and $\mathrm{H}_{2}$ were found to be $30.1 \%$ and $17.7 \%$, respectively, for the syngas having a $\mathrm{H}_{2} / \mathrm{CO}$ ratio of 1.67 and a reactor operating pressure and temperature of $115 \mathrm{psig}$ and $270^{\circ} \mathrm{C}$, respectively.

2. $\mathrm{CO}$ and $\mathrm{H}_{2}$ conversion significantly reduces with an increase in flow rate greater than $1.17 \mathrm{~L} / \mathrm{min}$. The increase in flow rate by $80 \%$ causes $\mathrm{CO}$ and $\mathrm{H}_{2}$ conversion drop by about $68 \%$ and $61 \%$, respectively.

3. The reactor bed temperature profile showed a negligibly small variation as an effect of increase in flow rate. This is likely due to the characteristic SSR technology that enhances heat-transfer performance of the reactor.

4. The $\mathrm{N}_{2}$ dilution by $12 \%$ caused a $19 \%$ and $15 \%$ drop in $\mathrm{CO}$ and $\mathrm{H}_{2}$ conversions at constant reactor temperature and pressure of $275^{\circ} \mathrm{C}$ and $80 \mathrm{psig}$, respectively. Stopping the dilution helped regain the conversion. These initial experiments were indicative of the sensitivity of partial pressures of the reactant and needs further investigation.

5. For a constant pressure and $\mathrm{H}_{2} / \mathrm{CO}$ ratio, an increase in temperature significantly increases $\mathrm{CO}$ and $\mathrm{H}_{2}$ conversion beyond $200^{\circ} \mathrm{C}$.

6. GC-MS analysis of the liquid collected from the condenser showed a spectrum of alkanes and alkenes with carbon numbers ranging from $\mathrm{C}_{6}$ to $\mathrm{C}_{24}$.

\section{FT Liquid Synthesis Experiments: Part 2}

1. The FTS reactor operating temperature has a significant effect on $\mathrm{H}_{2}$ and $\mathrm{CO}$ conversion. At $180^{\circ} \mathrm{C}$, the $\mathrm{H}_{2}$ and $\mathrm{CO}$ conversions were $1.5 \%$, while at $200^{\circ} \mathrm{C}$, they were $8 \%$. At $230^{\circ} \mathrm{C}$, the highest $\mathrm{H}_{2}$ and $\mathrm{CO}$ conversions attained were $80 \%$ and $28 \%$, respectively.

2. The FTS produced a spectrum of alkanes and alkenes with carbon numbers ranging from $\mathrm{C}_{5}$ to $\mathrm{C}_{15}$, characteristic of gasoline at a reactor pressure of $200 \mathrm{psig}$. At higher pressure, the carbon number ranged from $\mathrm{C}_{5}$ to $\mathrm{C}_{23}$, characteristic of diesel fuel.

3. The Catacel reactor could achieve better conversion at 115 psig, producing hydrocarbons with carbon numbers ranging from $\mathrm{C}_{5}$ to $\mathrm{C}_{24}$.

4. Reactor operation at a temperature of $230^{\circ} \mathrm{C}$ causes the catalyst bed temperature at the reactor inlet to increase by about $50^{\circ} \mathrm{C}$, achieving the highest $\mathrm{CO}$ and $\mathrm{H}_{2}$ conversions. Forced cooling of the bed to restore set temperature can significantly reduce $\mathrm{CO}$ conversion (about $94 \%$ ); however, the $\mathrm{H}_{2}$ conversion reduces by about $10 \%-12 \%$.

5. Without forced bed cooling, the temperature and conversion in the reactor follow a cyclic trend without causing any temperature runaway condition. 
6. Variations in exothermic heat profile within the catalyst bed actuated by forced heat transfer can significantly affect the syngas conversion. Therefore, the heat-transfer surface within the bed requires careful design and operational considerations, particularly in the small-scale reactor used in distributed-scale BTL conversion systems.

\section{References}

1. Patel, N.; Schmidt, D.D.; Botnen, L.S.; Hurley, J.P. Engineering Analysis of Indirect Biomass Liquefaction: Year 1 - Activity 2.2 Under the Development of a National Center for Hydrogen Technology Program; Topical Report for U.S. Department of Energy National Energy Technology Laboratory Cooperative Agreement No. DE-FC26-05NT42465; Energy \& Environmental Research Center: Grand Forks, ND, May 2007.

\section{Activity 1.2 - Engineering Analysis of an Indirect Liquefaction Process}

\section{Introduction}

The EERC recently teamed with IdaTech LLC, an Oregon-based company that markets 0.25- to $5-\mathrm{kW}$ fuel cell-based electric power generators fueled by wet methanol, to perform a DOE-funded engineering and economic review of portable technologies that could be used to convert wood waste into wet methanol (1). This study was undertaken primarily to support the remote power and forest product industries by identifying technologies to convert wet wood waste that would otherwise be incinerated into a green fuel for IdaTech fuel cell-based remote power generation systems. The analysis focused on indirect liquefaction, which involves gasifying the waste to create a synthesis gas which is then converted into methanol.

For the gasification technology, the study focused on downdraft gasifiers because of their inherently simple design, low operating maintenance, and low emissions. Four main gasifier scenarios were investigated: air-blown, oxygen-blown, injected steam-enhanced, and thermally integrated gasification.

The primary aim of the study was to determine the design of an economically feasible trailer-mounted system. It was assumed that the syngas balance systems such as a water-gas shift reactor or $\mathrm{CO}_{2}$ scrubber will not only complicate the system but also render it economically less feasible. Therefore, the study focused on identifying a gasification system that produces syngas that, after cleaning, can be directly fed to the methanol synthesis reactor.

Figure 27 is a schematic of the conceptual biomass-to-methanol synthesis plant, showing the components and their location with respect to the biomass gasifier in a tight integration mode. The mass and energy balance is also represented in Figure 27.

The biomass-to-methanol synthesis plant with the lowest capital cost and that produces wet methanol at the lowest cost was determined to be the thermally integrated downdraft gasifier, which can gasify wet wood waste. The EERC has demonstrated this gasification technology on a bench scale. Under Activity 1.2, the EERC built and operated a bench-scale syngas-to-methanol reactor in order to better identify appropriate system design and operating conditions and likely conversion efficiencies as functions of system pressure and $\mathrm{H}_{2}$-to- $\mathrm{CO}$ ratio. 


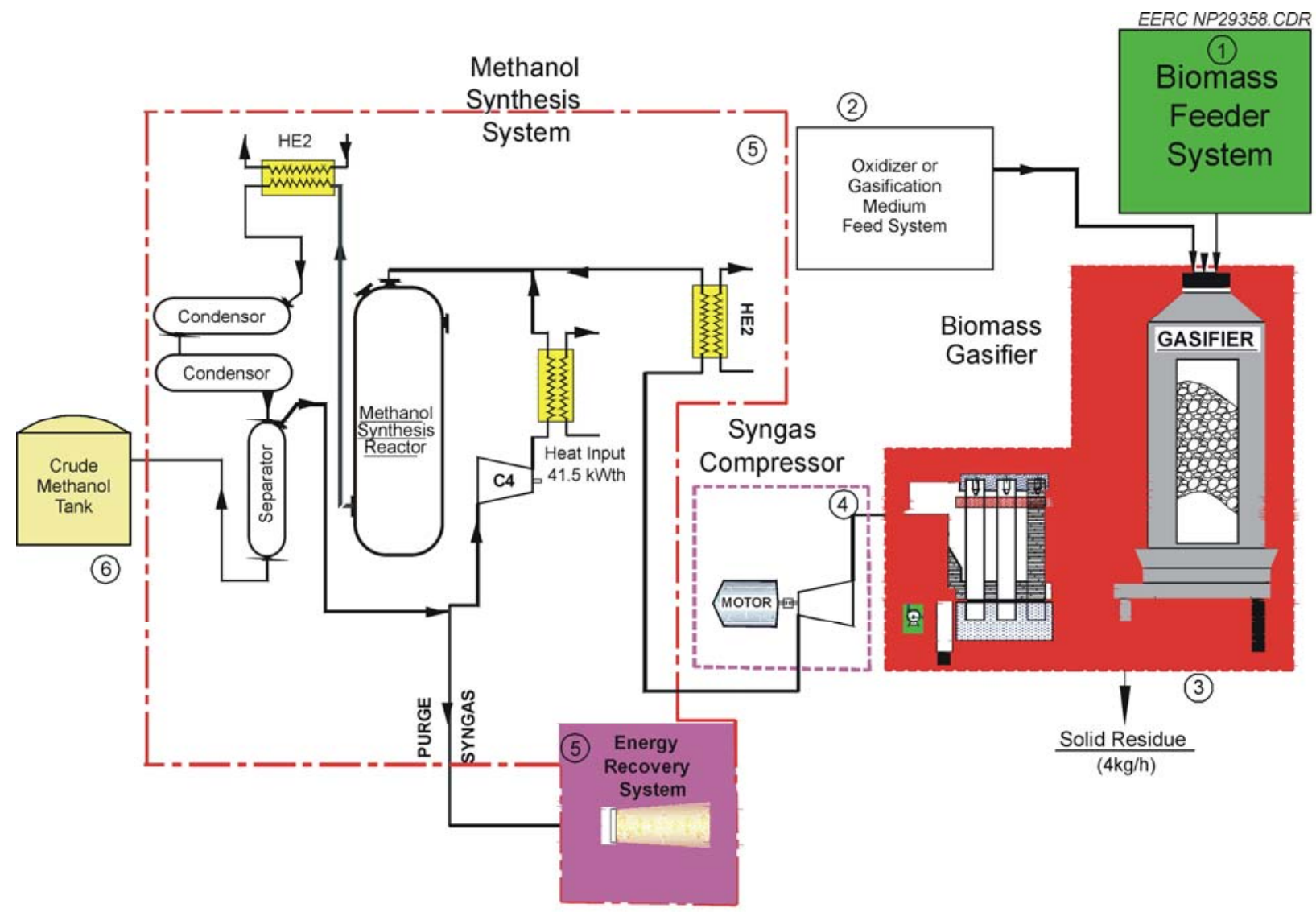

\begin{tabular}{|c|c|c|c|c|c|c|c|}
\hline \multirow[b]{2}{*}{$\begin{array}{c}\text { Type of Gasification } \\
\text { Process }\end{array}$} & \multirow[b]{2}{*}{$\begin{array}{l}\text { Operating } \\
\text { Parameter }\end{array}$} & \multicolumn{3}{|c|}{ Gasifier } & \multicolumn{3}{|c|}{ Methanol Synthesis } \\
\hline & & $\begin{array}{c}\text { Biomass } \\
\text { Input }\end{array}$ & $\begin{array}{l}\text { Clean } \\
\text { Syngas } \\
\text { Output }\end{array}$ & $\begin{array}{c}\text { Solid } \\
\text { Residue }\end{array}$ & $\begin{array}{l}\text { Syngas } \\
\text { Input }\end{array}$ & $\begin{array}{l}\text { Methanol } \\
\text { Synthesis }\end{array}$ & $\begin{array}{c}\text { Purge } \\
\text { Gas }\end{array}$ \\
\hline \multirow[b]{2}{*}{ Air Gasification } & Flow Rate, $\mathrm{kg} / \mathrm{h}$ & 200 & 508 & 9 & 508 & \begin{tabular}{|l|}
46 \\
\end{tabular} & 461 \\
\hline & Thermal Energy, $\mathrm{kW}_{\text {th }}$ & 865 & 675 & ---- & 675 & 291 & 384 \\
\hline \multirow[b]{2}{*}{ Oxygen Gasification } & Flow Rate, kg/h & 200 & 220 & 4 & 220 & 67 & 125 \\
\hline & Thermal Energy, $\mathrm{kW}_{\text {th }}$ & 875 & 748 & $+\cdots$ & $\cdot$ & 423 & 325 \\
\hline \multirow[b]{2}{*}{ Steam Gasification } & Flow Rate, kg/h & 200 & 226 & 20 & 141 & 125 & 9 \\
\hline & Thermal Energy, $\mathrm{kW}_{\text {th }}$ & 875 & 1013 & -.-- & 1013 & 792 & 64 \\
\hline \multirow{4}{*}{$\begin{array}{c}\text { Thermally Integrated } \\
\text { Gasification } \\
\end{array}$} & Flow Rate, kg/h & 200 & 304 & 4 & 294 & 71.3 & 216 \\
\hline & Thermal Energy, $\mathrm{kW}_{\mathrm{th}}$ & 717 & 864 & ---- & 864 & 452 & 372 \\
\hline & Temperature, ${ }^{\circ} \mathrm{C}$ & 20 & 20 & 50 & 200 & 20 & 150 \\
\hline & Pressure, bar & 1 & 1 & ב--- & 68 & 1 & 65 \\
\hline
\end{tabular}

Figure 27. Schematic of biomass-to-methanol conversion system. 
There are several advantages to using fuel cell-based systems for remote power generation over internal combustion (IC)-based generators. Fuel cells have inherently higher efficiencies than IC generators, reaching $40 \%$ for just electricity and over $80 \%$ for combined heat and power (CHP) applications. The higher efficiencies translate to less fuel transportation and lower emissions, lower weight, and smaller size. Also, in the scenario presented here, the fuel is made from a renewable, nonfossil source so there are no net $\mathrm{CO}_{2}$ emissions. Wet methanol is also inherently less combustible than gasoline so explosions and fire hazards are reduced. Methanol is also completely biodegradable. Reformer/fuel cell systems have very few moving parts, so maintenance is much reduced compared to IC systems. Fuel cell systems are also much quieter than even fully muffled generators, producing $<60 \mathrm{~dB}$ of noise compared to $70 \mathrm{~dB}$ or more for IC generators.

The IdaTech FCS $1200^{\mathrm{TM}}$ is a self-contained fuel cell system, shown in Figure 28. Hydrogen is generated by IdaTech's onboard FPM $20^{\mathrm{TM}}$ fuel processor. The processor uses fuel from an onboard tank and ambient air to convert liquid fuel into high-purity hydrogen using metal membrane purification technology. High-purity hydrogen is then delivered to the anode side of the proton exchange membrane (PEM) fuel cell stack. Inside the fuel cell stack, electrons are separated from the hydrogen, creating a hydrogen ion. The ion passes through the PEM, where electrons are stripped, collected, and delivered to connected loads as electricity. The hydrogen ion, the stripped electrons, and ambient oxygen combine at the cathode side to produce the only system emission, warm water vapor. Electricity is generated at the fuel cell stack as direct current (DC). An optional pure sine wave inverter converts the DC electricity into highquality alternating current (AC) electricity if desired.

A major issue for fuel cell-based systems is their relatively high cost, which relegates them to small niche markets at present. Because the promise of fuel cell-based power systems is so great, major automobile manufacturers and the federal government are investing billions of dollars in research funds to bring down their cost so that, in 10 to 15 years, it is expected that fuel cell-based vehicles will become competitive with IC engine-based vehicles. However, the cost per kilowatt hour to be competitive in the auto market is much lower than for power generation so it is expected by IdaTech that fuel cell-based power generation, and especially CHP, should become cost-competitive with IC engine-based power generation in as little as 5 to 10 years while still maintaining the many advantages discussed above.

\section{Goals and Objectives}

The goal of the EERC CBU Program 2006 was to develop economically and environmentally sound technologies to promote efficient biopower or bioenergy, transportation biofuels, and bioproducts such as marketable chemicals and hydrogen. Biomass is a critical domestic resource in the United States for meeting future electrical demand, reducing dependence on foreign oil, and achieving the numerous greening initiatives launched by federal and state government. An overarching goal of the EERC CBU is to develop technologies that

will expand the use of biomass in practical and economical ways within the framework of sustainable development and environmental protection. 


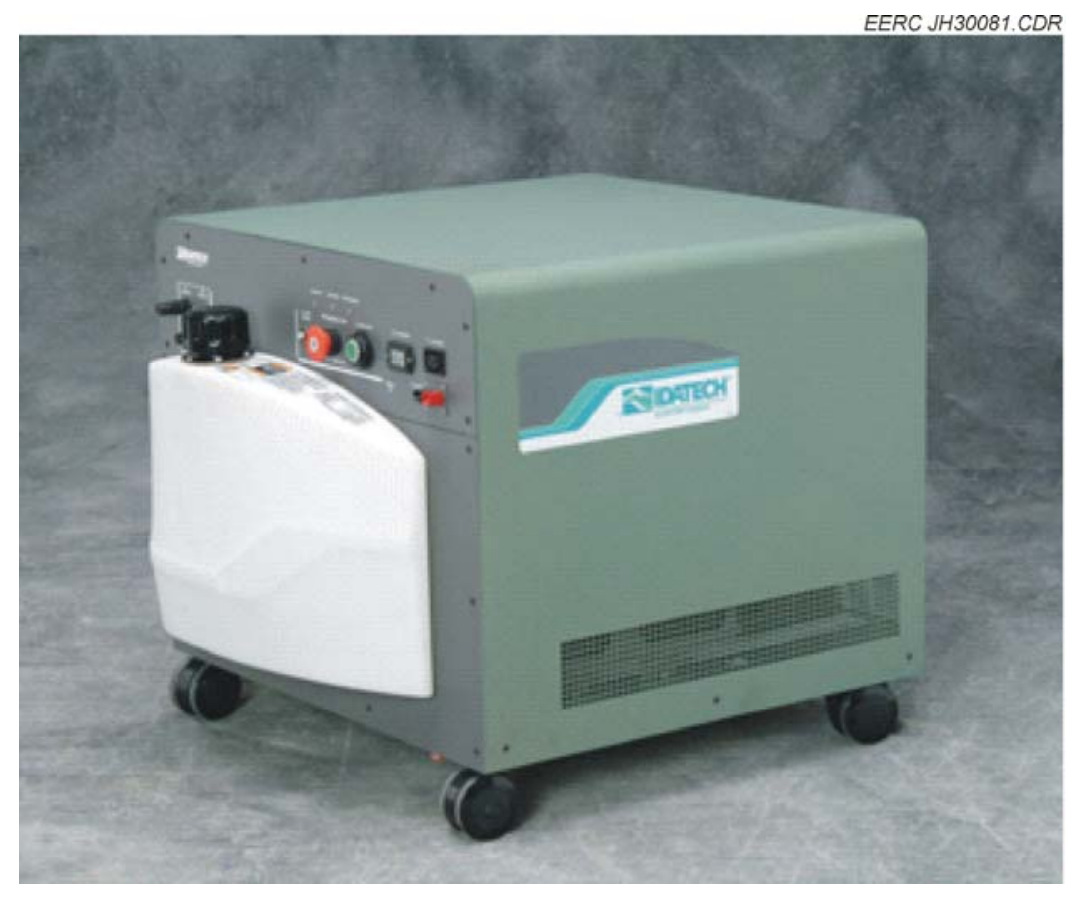

Figure 28. The IdaTech fuel cell-based electric power generator.

The original goal of the work performed under Activity 1.2 was to identify the process equipment, technical feasibility, and performance of small-scale conversion of syngas produced from wood waste gasification into methanol or ethanol. Early in the program, it was decided to focus only on methanol. To reach this goal, the task was organized to design and build a smallscale reactor and use it to determine appropriate catalysts and operating conditions for converting syngas to methanol and to determine likely conversion efficiencies as functions of system pressure and gas composition, important parameters on which the overall process economics of the biomass-to-methanol conversion depend.

\section{Experimental}

The schematic of the experimental setup specially designed to understand the methanol synthesis process is shown in Figure 29. A picture of the setup is shown in Figure 30(a). This system consists of three main subsystems: 1) a syngas supply system, 2) a syngas synthesis reactor and heat management system, and 3) a gas analysis system. The operating pressure of the system ranges between 100 and $1000 \mathrm{psig}$. The system is designed to maintain a constant reactor temperature of $40^{\circ}-300^{\circ} \mathrm{C}$, achieved by direct as well as indirect heat-transfer modes using air, nitrogen, and syngas as heat-transfer media. The synthesis reaction is mildly exothermic, and the heat management system ensures constant catalyst bed temperature under steady-state operation. The maximum design syngas flow rate of the experimental setup is $70 \mathrm{~L} / \mathrm{min}$.

The syngas supply system consists of mass flow controllers for injecting $\mathrm{H}_{2}, \mathrm{CO}, \mathrm{CO}_{2}, \mathrm{~N}_{2}$, and $\mathrm{CH}_{4}$ gases into a pair of storage cylinders, depending on the required syngas composition. The syngas composition and flow rate adjustment is controlled by a computer. A set of in-line and back-pressure regulators as well as flow control valves are used to maintain syngas 


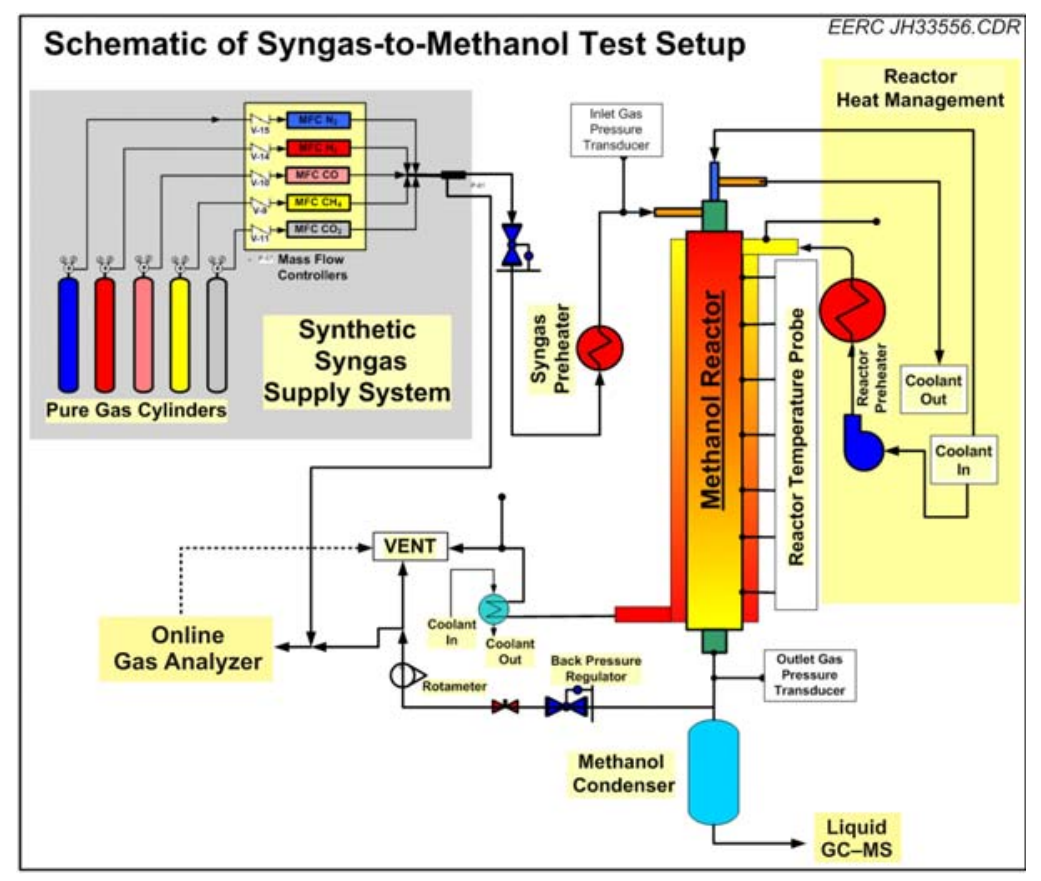

Figure 29. Schematic of the syngas-to-methanol synthesis experimental setup.

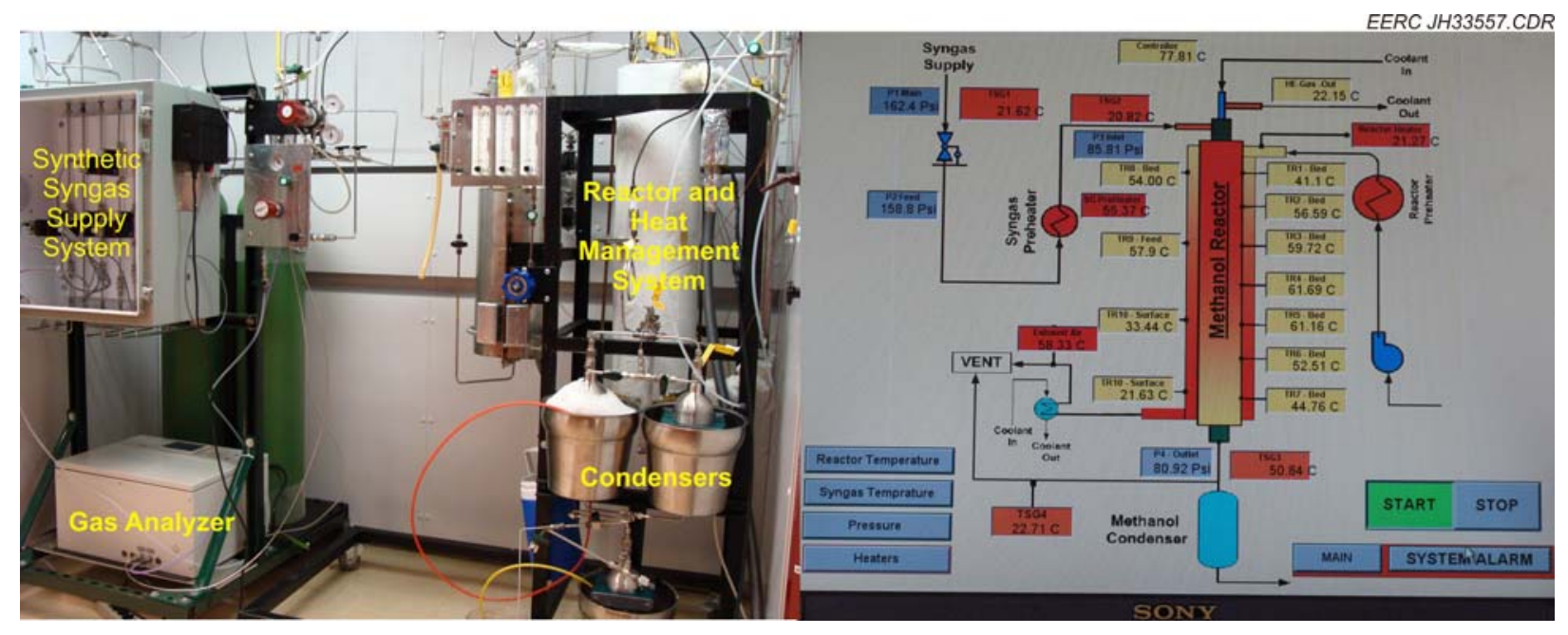

Figure 30(a). Syngas-to-methanol test setup showing syngas supply system, synthesis reactor, liquid condenser, and online gas analyzer.
Figure 30(b). Computer display showing temperature and pressure measurement location on the schematic of the syngas-tomethanol test setup. 
pressure and flow rate from the storage cylinders to the reactor. The syngas was preheated to temperature ranging from $100^{\circ}$ to $300^{\circ} \mathrm{C}$ as required. A set of pressure relief valves were included to maintain safe operation of the reactor in the event of excessive pressure buildup in the reactor.

The pressure and temperature data were monitored and recorded using a computerized data-logging system. A computer display screen used for monitoring operating parameters of the experiments is depicted in Figure 30(b). Alarm signals for overpressure and temperature were used to automatically maintain safe operation of the system.

The methanol synthesis reactor is a proprietary fixed-bed configuration with the capability of removing heat from the packed bed. The catalyst used is $\mathrm{ZnO}-\mathrm{Cu}-\mathrm{Al}_{2} \mathrm{O}_{3}$. The reactor is designed to operate at a space velocity in the range of 1000-15,000 $\mathrm{h}^{-1}$. The reactor bed temperature is determined at seven equidistant axial locations as depicted in the schematic in Figure 30(b). The pressure drop across the bed was measured with the help of pressure transducers located upstream and downstream of the reactor. The tube dimensions at the reactor exit ensured free flow of the gas-phase products until the stream was injected into the liquid condenser.

The high-pressure liquid condensers ensured collection of liquid product and effective separation of unconverted gaseous products without causing loss of liquid due to entrainment. An ice-salt mixture was used to maintain a subzero (about $-10^{\circ} \mathrm{C}$ ) temperature of the condenser wall. The liquid was collected in a cold solvent trap so that loss of lighter fractions such as ethers would not occur during the liquid extraction process. The back-pressure regulator and flow control valve at the downstream of the condenser ensured constant pressure and gas flow. The gas flow rate is measured with the help of precalibrated rotameters. Except for the specific gravity of the gas, pressure and temperature at the downstream of the rotameters were maintained the same as that of the calibration conditions specified by the manufacturer. The actual gas flow rates were determined by applying required specific gravity corrections. The purge gas was exhausted in the hood vent system. A slipstream of gas was sampled downstream of the rotameter to determine product gas composition.

\section{Results and Discussion}

The experimental study was performed to understand the effect of pressure and syngas composition on the conversion of syngas expected to be produced in an air gasification process specifically designed for utilizing distributed biomass resources. Synthesis experiments were conducted at a constant reactor temperature of $220^{\circ} \mathrm{C}$ and varying pressure ranging from 100 to 500 psig. The typical operating pressure range of a commercial methanol production process is 1000 psig. However, the current synthesis experiments were conducted at pressures not exceeding $500 \mathrm{psig}$. The low-pressure operating regime is of particular interest in order to arrive at an economical technology for converting highly distributed and low-energy-density biomass to methanol. The success of mobile or small biomass throughput systems very much depends on their ability to produce methanol synthesis at low operating pressures. It is also necessary that the methanol synthesis occurs even if the $\mathrm{H}_{2}$ and $\mathrm{CO}$ concentrations, normally expressed as ratios $\mathrm{H}_{2} / \mathrm{CO}$ and $\mathrm{H}_{2} /\left(\mathrm{CO}+\mathrm{CO}_{2}\right)$, are less than or equal to 1.0 , unlike the typical value of 2 , which is a designed value for most commercial methanol production systems. This operational feature of 
the synthesis reactor is important for avoiding the need for additional process equipment required to balance syngas composition to achieve a $\mathrm{H}_{2} / \mathrm{CO}$ ratio value of 2 , which is typically not possible in a simplified air-blown biomass gasification process. The experiments for understanding low-pressure methanol synthesis were also planned for utilizing syngas with a $\mathrm{H}_{2} / \mathrm{CO}$ ratio less than 1 .

\section{Effect of Pressure on Synthesized Product Liquid Composition}

Figure 31 depicts the effect of reactor pressure on the concentration of methanol and higher alcohols synthesized from syngas having $\mathrm{H}_{2} / \mathrm{CO}$ and $\mathrm{H}_{2} /\left(\mathrm{CO}+\mathrm{CO}_{2}\right)$ ratios of less than 0.89 and reactor temperature maintained constant at $220^{\circ} \mathrm{C}$. The composition of syngas produced in the downdraft gasifier utilizing air as a gasification medium is used in the synthesis experiment. Typically, nitrogen is not present in the syngas used in the large-scale commercial methanol synthesis process; however, it is present in the syngas produced from air-blown gasifiers. The syngas used in the experiments contained a nitrogen concentration in the range of $30 \%-38 \%$. The effect of nitrogen in the syngas is described in an earlier economic feasibility study (1), but generally its presence decreases conversion efficiency and increases the cost of gas compression. The results, therefore, are expected to be representative of the actual syngas from the gasification process that will be utilized in the mobile or truck-mounted biomass-to-methanol synthesis system being designed for demonstration.

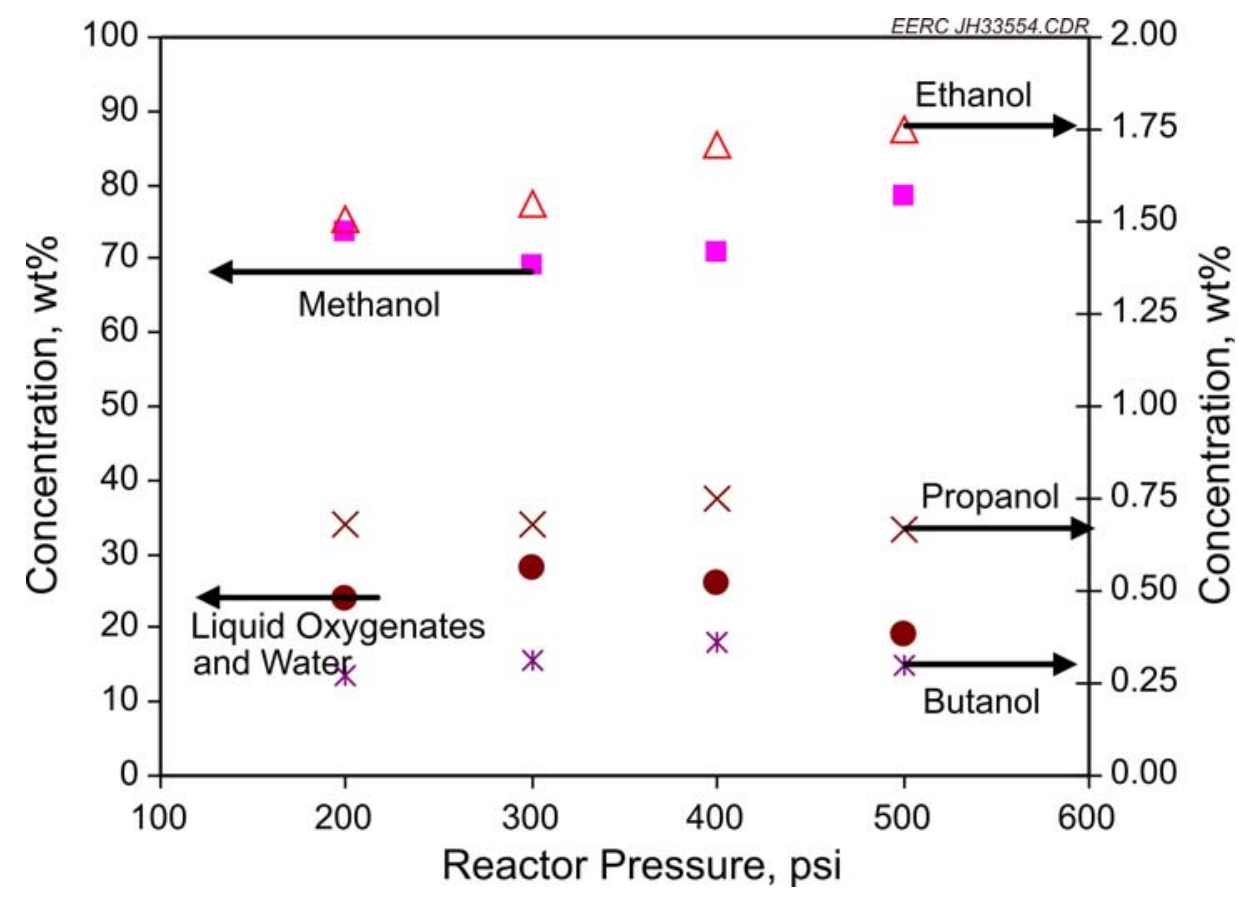

Figure 31. Effect of reactor pressure on the concentrations of various alcohols and liquid oxygenates formed during the synthesis experiments conducted at a constant reactor temperature of $220^{\circ} \mathrm{C}$ and syngas with $\mathrm{H}_{2} / \mathrm{CO}$ and $\mathrm{H}_{2} /\left(\mathrm{CO}+\mathrm{CO}_{2}\right)$ ratios of less than 0.89 and average space velocity of $1580 \mathrm{~h}^{-1}$. 
It can be inferred from Figure 31 that the concentration of methanol either remained constant or slightly increased with an increase in synthesis pressure. The commercial $\mathrm{Zn}-\mathrm{CuO}-$ $\mathrm{Al}_{2} \mathrm{O}_{3}$ catalyst utilized in the experiment is highly selective for methanol synthesis; therefore, the concentration of methanol is expected to be in the range of $70 \%-80 \%$ and is experimentally found to be in this range. The higher alcohols analyzed were ethanol, n-propanol, and n-butanol. The concentration of these alcohols ranged from $0.25 \%$ to $1.75 \%$ and at a given operating pressure, the concentration decreased with the number of carbons in the alcohol. It was observed that the ethanol concentration clearly favored an increase in pressure; however, n-propanol and n-butanol had a weak dependency on the pressure. Higher concentrations of impurities in methanol, particularly those of higher alcohols, are unfavorable in the fuel-reforming stage of the methanol fuel cell. The increase in ethanol concentration with pressure needs to be further examined in light of these observations.

The compounds other than alcohols depicted in Figure 31 are mostly organic oxygenates and water and constitute about $19 \%-28 \%$ of the total yield of liquid. These oxygenates are expected to be methyl formate, ethyl formate, methyl acetate, ethyl acetate, and other branched alcohols including higher alcohols. The combined fraction of these mixtures shows a decreasing trend with an increase in pressure.

\section{Effect of Pressure on $\mathrm{CO}-\mathrm{H}_{2}$ Conversion and Methanol Yield}

Figure 32 depicts the effect of pressure on conversion of $\mathrm{CO}$ and $\mathrm{H}_{2}$ and the yield of methanol expressed as a weight fraction of the syngas in a single pass. The average hourly space velocity maintained during the experiment was $1580 \mathrm{~h}^{-1}$. Degradation in catalyst activity was not observed during the experiment, and this was established by physical observation as well as by determining the gas composition during regeneration experiments. The lack of degradation was also substantiated by observing almost constant $\mathrm{CO}$ and $\mathrm{H}_{2}$ conversion during the span of individual experiments. The experimental data obtained during the steady-state conversion is critical for drawing valid inferences.

One of the primary observations made from the plot shown in Figure 32 is that the $\mathrm{CO}$ and $\mathrm{H}_{2}$ conversions increase with an increase in synthesis pressure. It is also observed that the increase in conversion of $\mathrm{H}_{2}$ is higher than that of $\mathrm{CO}$. This is primarily due to the consumption of $\mathrm{H}_{2}$ in the hydrogenation reaction of $\mathrm{CO}$ and $\mathrm{CO}_{2}$. The observed decrease in $\mathrm{CO}$ partial pressure shown as conversion of $\mathrm{CO}$ is primarily due to the hydrogenation step. This effect is not clearly seen in the case of $\mathrm{CO}_{2}$ since partial pressure increases, indicating a net gain in $\mathrm{CO}_{2}$ due to the internal shift reaction.

The effect of increase in reactor pressure on increase in methanol yield reflects the increase in $\mathrm{CO}$ and $\mathrm{H}_{2}$ conversion with pressure. However, the increase in methanol yield has two distinct slopes. The slope significantly increases beyond 300 psi. This shows that for the given space velocity, $\mathrm{H}_{2} / \mathrm{CO}$, and $\mathrm{H}_{2} /\left(\mathrm{CO}+\mathrm{H}_{2}\right)$ ratios, there exists distinct synthesis pressure regimes. The methanol yield significantly increases beyond an operating pressure of 300 psig. 


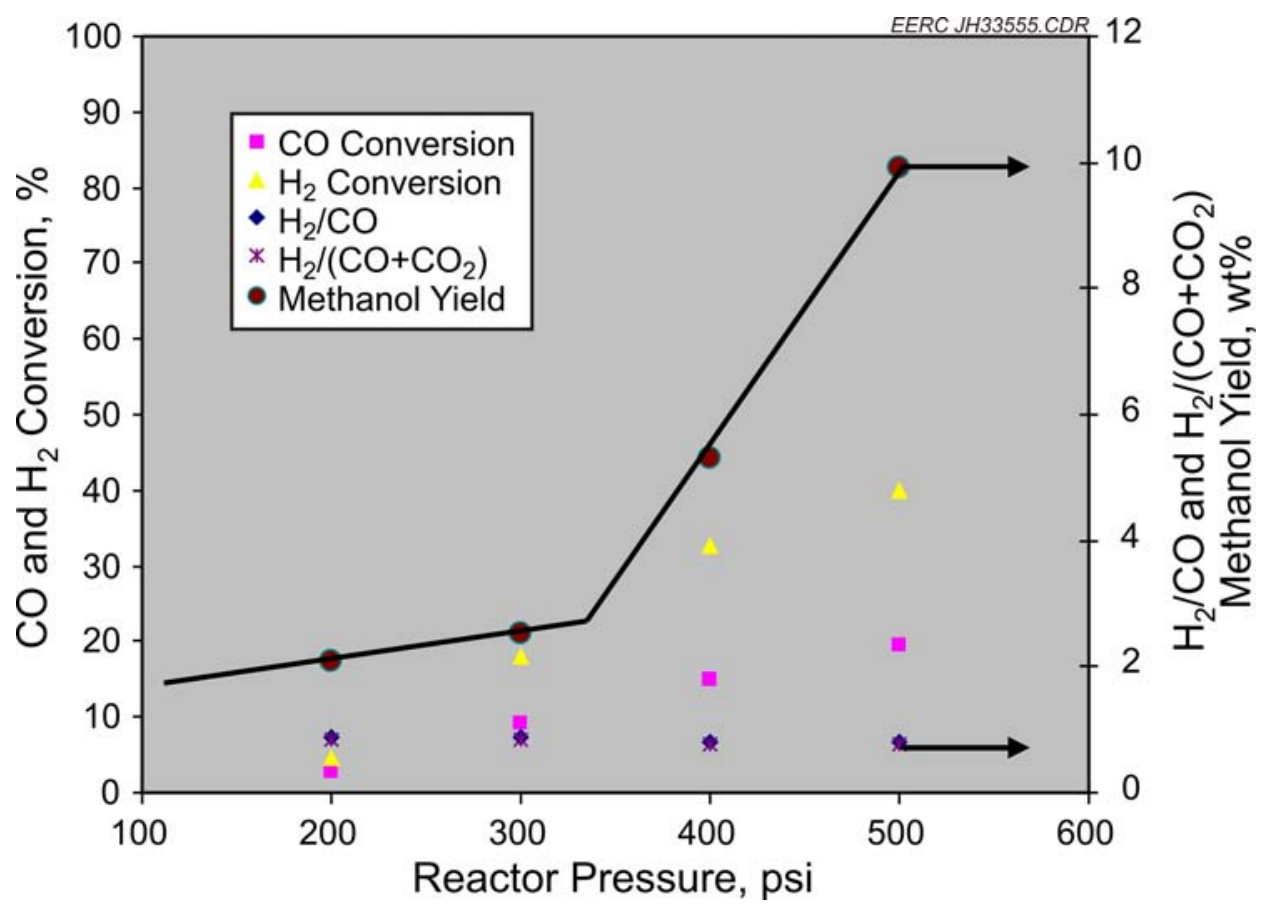

Figure 32. Effect of pressure methanol yield and $\mathrm{CO}$ and $\mathrm{H}_{2}$ conversion.

\section{Effect of $\mathrm{H}_{2} / \mathrm{CO}$ Ratio on Methanol Yield and Their Conversion}

To understand the effect of $\mathrm{H}_{2} / \mathrm{CO}$ ratio on the reactant conversion and yield of methanol, experiments were conducted at constant temperature and pressure of $220^{\circ} \mathrm{C}$ and $500 \mathrm{psig}$, respectively. The selection of the syngas composition for this study is within the production range of the gasifier selected for the mobile biomass-to-methanol system. Table 7 shows the results of the experiments. As can be seen in the table, the increase in $\mathrm{H}_{2} / \mathrm{CO}$ ratio improves methanol yield and $\mathrm{CO}$ conversion. Conversion of hydrogen is not affected significantly, most likely because, at a lower ratio, more of the hydrogen went to the oxygenates and water, and at the higher ratio, more went to the methanol.

Considering the fact that methanol yield obtained at 500 psig is without any recycle, it is very likely that the theoretical yield of $25 \%$, as calculated in the economic feasibility report (1), is achievable by designing the synthesis process with a recycle ratio of 3.5 to 4 . The most important difference is that the economic analysis was performed by considering 1000 psig as the reactor operating pressure. Based on the present experimental findings, it is likely that syngas compression in the vicinity of 500 psig may be adequate. This is expected to reduce the operating cost of the synthesis process and the energy penalty that could be incurred as a result of the compression and expansion process of the inert constituents of the syngas. It is, therefore, likely that the actual methanol production cost may be lower than the predicted cost in the earlier economic feasibility study (1).

Further experiments are required to determine the yield of methanol with a syngas recycle ratio greater than 1 at established operating conditions. The $\mathrm{H}_{2} / \mathrm{CO}$ ratio in the vicinity of 1 appears to be adequate; however, it is likely that the increase in $\mathrm{CO}_{2}$ concentration due to 
Table 7. Effect of $\mathrm{CO}_{2}$ Ratio on Conversion and Methanol Yield at 500-psi Synthesis Reactor Pressure

\begin{tabular}{lccc}
\hline $\mathrm{H}_{2} / \mathrm{CO}$ & \multicolumn{2}{c}{ Conversion, mol\% } & \multicolumn{2}{c}{ Methanol Yield, } \\
$\left(\mathrm{H}_{2} /\left(\mathrm{CO}+\mathrm{CO}_{2}\right)\right.$ & $\mathrm{CO}$ & $\mathrm{H}_{2}$ & $\mathrm{wt} \%$ \\
\hline $0.8(0.76)$ & 19.5 & 40 & 9.9 \\
$1.16(1.09)$ & 26.9 & 38 & 12.9 \\
\hline
\end{tabular}

internal shift may be a limiting factor affecting efforts to improve methanol yield by increasing gas recycle ratio. Operating pressures lower than 300 psi are found to be inadequate for achieving the required methanol yields. However the synthesis process at this low-pressure range needs to be further understood using the same catalyst system, because of the economic advantages, primarily reduced operational and capital costs.

\section{Conclusions}

Biomass is a critical domestic resource in the United States for meeting future electrical demand, reducing dependence on foreign oil, and achieving the numerous greening initiatives launched by federal and state government. An overarching goal of the EERC CBU is to develop technologies that will expand the use of biomass in practical and economical ways within the framework of sustainable development and environmental protection. This study was performed to understand the effect of pressure on the conversion of syngas expected to be produced in an air gasification process specifically designed for utilizing distributed biomass resources for the production of methanol. The following are the general conclusions drawn from the results of the study:

1. It was found that the reactor design and heat management system performed well and within the operating regime and syngas composition; coking was not observed nor did the conversion degrade during individual experiments.

2. The concentration of methanol in the product liquid was in the range of $70 \%-82.5 \%$ and either remained constant or slightly increased with an increase in synthesis pressure range of 100-500 psig while maintaining a $\mathrm{H}_{2} / \mathrm{CO}$ ratio in the vicinity of 1 .

3. The compounds other than alcohols are mostly organic oxygenates and water and constituted about $19 \%-28 \%$ of the total yield of liquid. These mixtures showed a decreasing trend with an increase in pressure.

4. $\mathrm{CO}$ and $\mathrm{H}_{2}$ conversions increase with an increase in synthesis pressure, and the increase in $\mathrm{H}_{2}$ conversion is higher than that of $\mathrm{CO}$.

5. The increase in methanol yield with pressure has two distinct slopes, indicating that for a given space velocity, $\mathrm{H}_{2} / \mathrm{CO}$ and $\mathrm{H}_{2} /\left(\mathrm{CO}+\mathrm{H}_{2}\right)$ ratios, there exists distinct synthesis pressure regimes. The methanol yield significantly increases beyond an operating pressure of $300 \mathrm{psig}$. 
6. The increase in $\mathrm{H}_{2} / \mathrm{CO}$ ratio to greater than 1 significantly improves $\mathrm{CO}$ conversion and methanol yield. Conversion of hydrogen is not significantly affected, most likely because, at a lower ratio, more of the hydrogen went to the oxygenates and water, and at the higher ratio, more went to the methanol.

7. Based on the experimental determination of methanol yield at half the pressure of a typical fixed-bed synthesis reactor (which is 1000 psig), it is likely that the actual methanol production cost is expected to be lower than the earlier-predicted cost (1).

\section{References}

1. Patel, N.; Schmidt, D.D.; Botnen, L.S.; Hurley, J.P. Engineering Analysis of Indirect Biomass Liquefaction: Year 1 -Activity 2.2 Under the Development of a National Hydrogen Technology Center Program; Topical Report for U.S. Department of Energy Cooperative Agreement DE-FC26-05NT42465; Energy \& Environmental Research Center: Grand Forks, ND, May 2007.

\section{Activity 1.3 -Thermochemical Conversion of Biomass to Dimethyl Ether}

\section{Introduction}

\section{Gasification Fundamentals}

Gasification is incomplete combustion where a fuel gas is produced of varying Btu content depending on the oxidation medium utilized. Higher Btu values will be obtained when utilizing oxygen rather than air as the large volume of nitrogen in the air dilutes the fuel value. The main reactions that occur in gasification are listed below. The primary products are carbon monoxide (CO), carbon dioxide $\left(\mathrm{CO}_{2}\right)$, hydrogen $\left(\mathrm{H}_{2}\right)$, and methane $\left(\mathrm{CH}_{4}\right)$. The gasification process takes place at varying temperatures and pressures for different systems:

$\mathrm{C}+\mathrm{O}_{2} \rightleftarrows \mathrm{CO}_{2} \quad$ (combustion reaction; highly exothermic at 14,167 Btu/lb C)

$\mathrm{C}+\mathrm{CO}_{2} \rightleftarrows 2 \mathrm{CO} \quad$ (Boudouard reaction; endothermic at $6016 \mathrm{Btu} / \mathrm{lb} \mathrm{C}$ )

$\mathrm{C}+\mathrm{H}_{2} \mathrm{O} \rightleftharpoons \mathrm{CO}+\mathrm{H}_{2} \quad$ (carbon-steam reaction; endothermic at $4863 \mathrm{Btu} / \mathrm{lb} \mathrm{C}$ )

$\mathrm{CO}+\mathrm{H}_{2} \mathrm{O} \rightleftharpoons \mathrm{CO}_{2}+\mathrm{H}_{2} \quad$ (water-gas shift reaction; mildly exothermic at $1152 \mathrm{Btu} / \mathrm{lb} \mathrm{C}$ )

Another reaction that can take place at temperatures less than $2000^{\circ} \mathrm{F}$ and at very high operating pressures is:

$\mathrm{C}+2 \mathrm{H}_{2} \rightleftharpoons \mathrm{CH}_{4}$ (carbon hydrogenation reaction; exothermic at $3282 \mathrm{Btu} / \mathrm{lb} \mathrm{C}$ )

A further reaction of interest is thermal cracking of volatile matter produced under some conditions to produce methane as shown below. Since biomass can produce significant volumes of volatile matter, this reaction could produce more methane for a given process when compared to coal: 
In the gasification process feedstocks are rapidly dried and devolatilized leaving a char behind. This char is then consumed in both combustion and gasification reactions. Fluidized-bed gasifiers take advantage of this by feeding fuel into the process at the top of the bed which has little oxygen. This creates a scenario that produces a higher-heating-value gas by way of Reaction 6 above. Bed material such as limestone, dolomite, or zeolite minerals in the fluidizedbed gasifier can catalyze this reaction (1).

The production of gas from the char is generally performed with nominally $25 \%$ of stoichiometric oxygen content. This oxidation of the char will provide the heat required for the endothermic reactions listed above as well as part of the $\mathrm{CO}$ in the gas stream. $\mathrm{CO}$ will increase with increasing temperature and dominate at temperatures above $1500^{\circ} \mathrm{F}(1)$. In general, the ratios of $\mathrm{H}_{2} / \mathrm{CO} / \mathrm{CO}_{2}$ in the produced gases will be controlled by the water-gas shift reaction (Reaction 4), and this reaction can be used in part to produce the desired gas product ratios.

The net effect of the gasification process is that a fuel gas is created from steam, oxygen, and a carbon-containing fuel. The fuel gas can be a low-Btu gas (90 to $260 \mathrm{Btu} / \mathrm{scf}$ ) or a medium-Btu gas (270 to $600 \mathrm{Btu} / \mathrm{scf}$ ) depending on the amount of nitrogen dilution introduced through the use of air as the oxidant. The primary products of gasification are $\mathrm{CO}, \mathrm{H}_{2}, \mathrm{CO}_{2}$, and $\mathrm{CH}_{4}$. Secondary products can include tars, oils, phenolic groups, and char. Generally, unwanted products may include hydrogen sulfide, carbonyl sulfide, ammonia, and hydrogen cyanide.

The ratios of products formed in a gasification process are dependent upon a number of factors. One important factor is the temperature at which the gasification process is conducted. The figures below were obtained from gasification of coal; however, the same general trends will apply to biomass. The effects of temperature on gas composition at equilibrium are presented in Figure 33 for a pressure of 20 atm (294 psia) and in Figure 34 comparing 1 versus 70 atm (14.7 versus 1029 psia) (2).

For Figures 33 and 34, the calculations were based on 95\% carbon conversion and little or no excess steam. In reality, there will always be excess steam to ensure high conversion.

What is evident from Figure 33 is that greater amounts of $\mathrm{CO}$ and $\mathrm{H}_{2}$ are obtained at higher gasification temperatures. This is because the higher temperatures favor an equilibrium minimizing methane.

Figure 34 shows convergence of composition at all pressures as temperature is increased. Higher gasification pressure has the advantage that most FT processes are operated at elevated pressure. This can have the advantage of avoiding compression of the synthesis gas produced (or at least avoiding multiple stages of compression) prior to a FT step. However, at low gasification temperatures, lower pressures may favor higher $\mathrm{H}_{2}$ : $\mathrm{CO}$ production ratios, which are more favorable in FT processes. Such factors must be carefully weighed during selection of a gasifier.

Table 8 summarizes the general characteristics of the current large-scale gasification systems. Temperature position profiles are shown in Figure 35 (adapted from Electric Power Research Institute [EPRI] Coal Gasification Guidebook [3]). The selection of an appropriate 


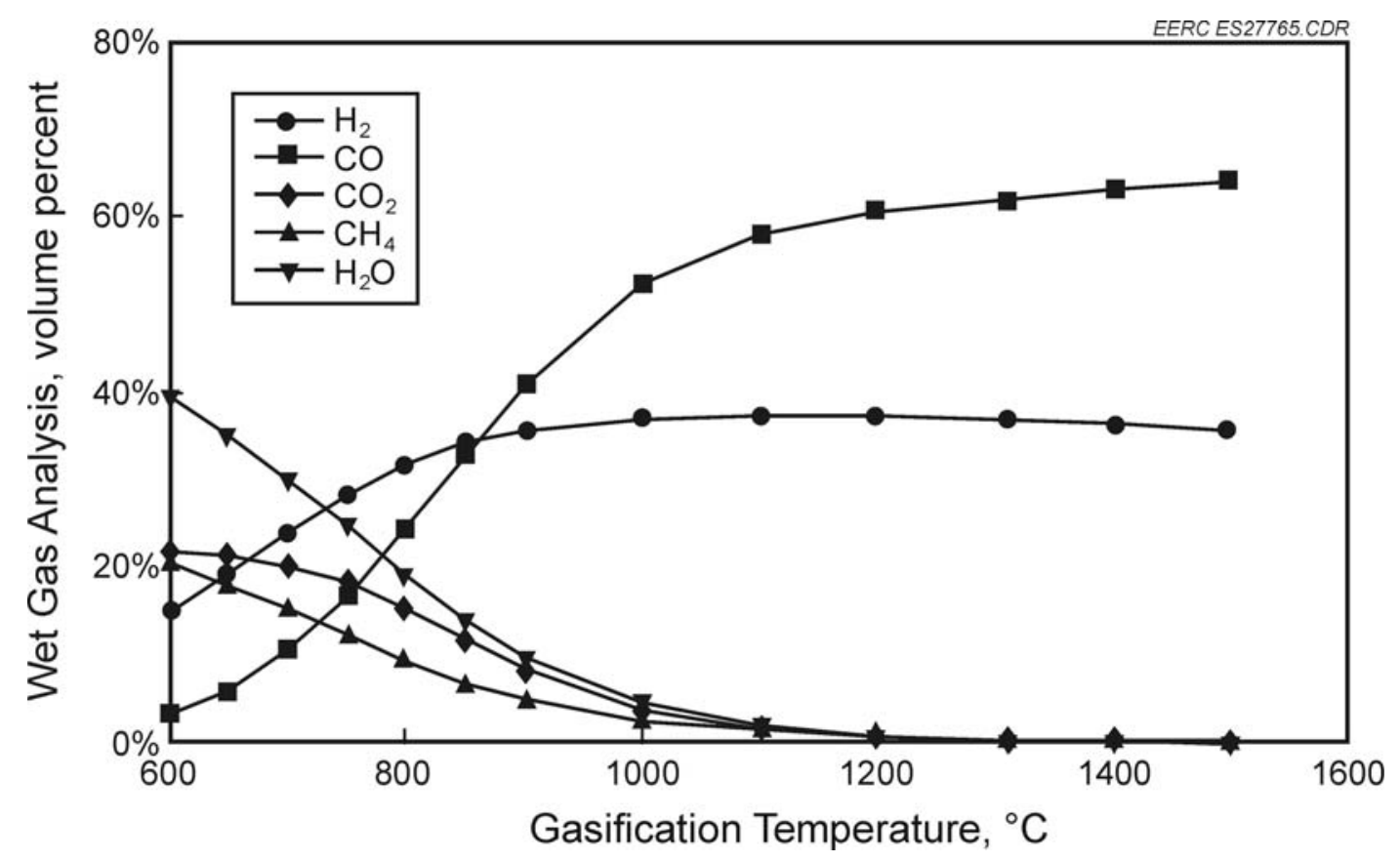

Figure 33. Effect of temperature on gas composition.

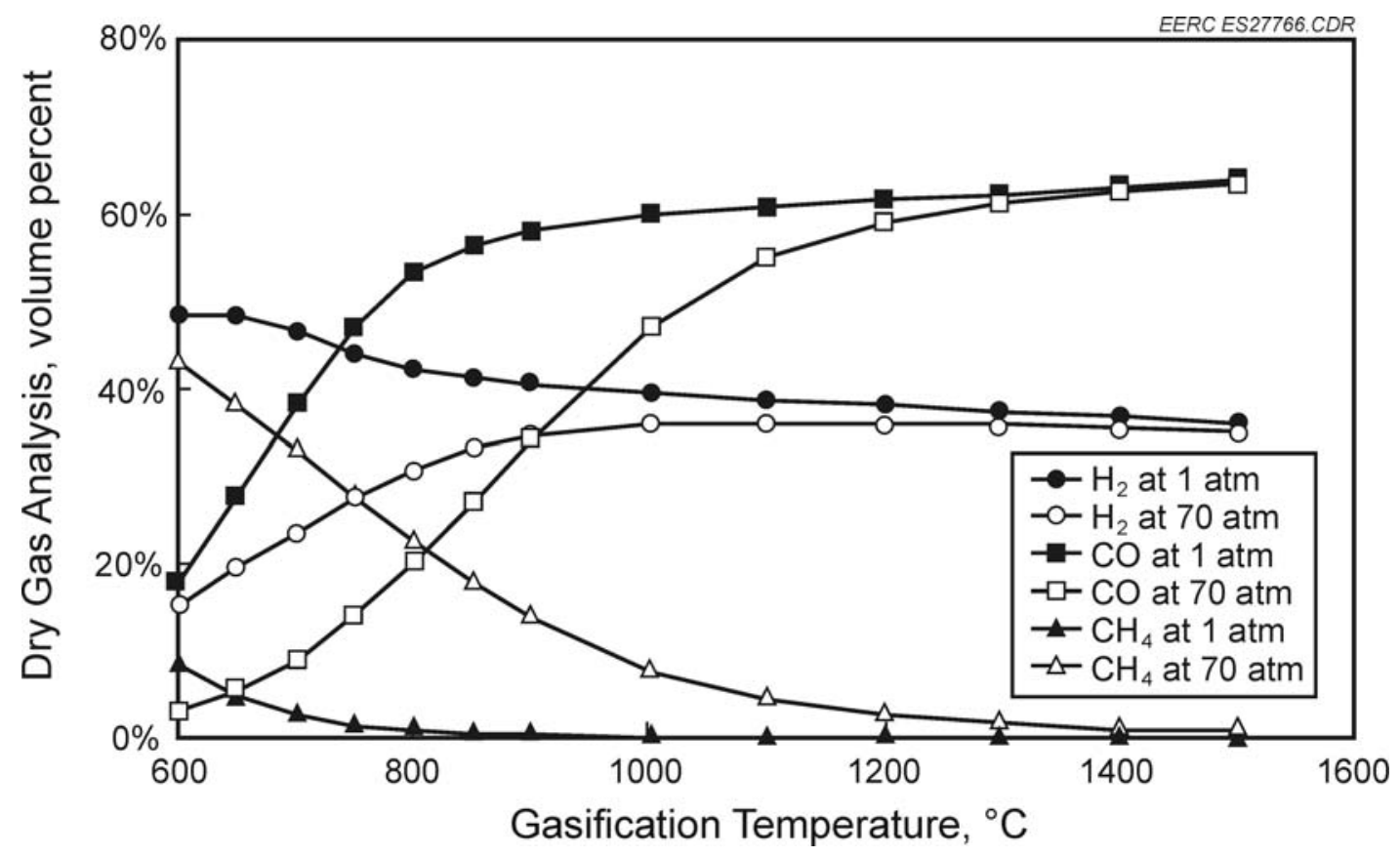

Figure 34. Effect of temperature and pressure on gas composition. 
Table 8. Comparison of Moist Lignin and Low-Rank Lignite Based on Ultimate Analysis

\begin{tabular}{lcc}
\hline Dry-Ash-Free (DAF) Basis & Moist Lignin & Lignite (North Dakota) \\
\hline Carbon, wt $\%$ & 24.23 & 33.41 \\
Hydrogen, wt $\%$ & 7.99 & 7.12 \\
Nitrogen, wt $\%$ & 0.99 & 0.56 \\
Oxygen, wt $\%$ & 58.06 & 48.24 \\
Sulfur, wt $\%$ & 0.20 & 0.95 \\
Ash, wt $\%$ & 8.54 & 9.74 \\
Btu/lb & 4485 & 6008 \\
\hline
\end{tabular}

gasification system needs to consider the downstream gas-cleaning technologies required for the eventual end use of the produced syngas.

\section{Goals and Objectives}

The goal of this activity was to review the gasification and BTL process in general. Specific objectives were to review the available commercial gasification and catalytic conversion of syngas to liquid fuel systems and their applicability to gasifying lignin from a lignocellulosic ethanol production facility.

\section{Commercial Gasifier Review}

Coal gasification technology has been in development since the mid-1930s, making this technology substantially more mature than biomass gasification technology. The bulk of the gasifier technology review will focus on commercially proven coal gasifiers, under the assumption that moist lignin will behave similarly to low-rank lignite coals. However, benchand or pilot-scale demonstrations will need to be performed to adequately assess a produced lignin's physical characteristics, feeding properties, and gasification performance for a given system. Table 8 shows the ultimate analysis of a moist lignin and low-rank lignite coal. The elemental composition of hydrogen, nitrogen, sulfur, and ash are very similar. Lignite has a higher carbon content and energy value. The oxygen content of lignin is higher, and the organic matrix has a more open structure, allowing easier access for oxygen, making it potentially more reactive than lignite.

Essentially every gasification process is based on one of three generic types of reactors: moving bed, fluidized bed, and entrained flow. Figure 35 (adapted from EPRI Coal Gasification Guidebook [3]) illustrates the three types of gasification reactors along with typical temperature profiles and locations of inputs and outputs. Detailed features of different commercial gasifiers of a particular type will be presented in later discussion of individual processes. Table 9 summarizes characteristics of the three gasifier types in reference to feed, operating conditions (temperature, oxidant, and steam), and key technical issues (tar production, char recycle, sensible heat in raw gas, and carbon conversion). Fluidized-bed gasifiers considered will include the High-Temperature Winkler (HTW), Kellogg-Rust-Westinghouse (KRW), Gas Technology Institute (GTI) U-Gas ${ }^{\mathrm{TM}}$, and the advanced transport reactor (ATR). Entrained-flow gasifiers will 

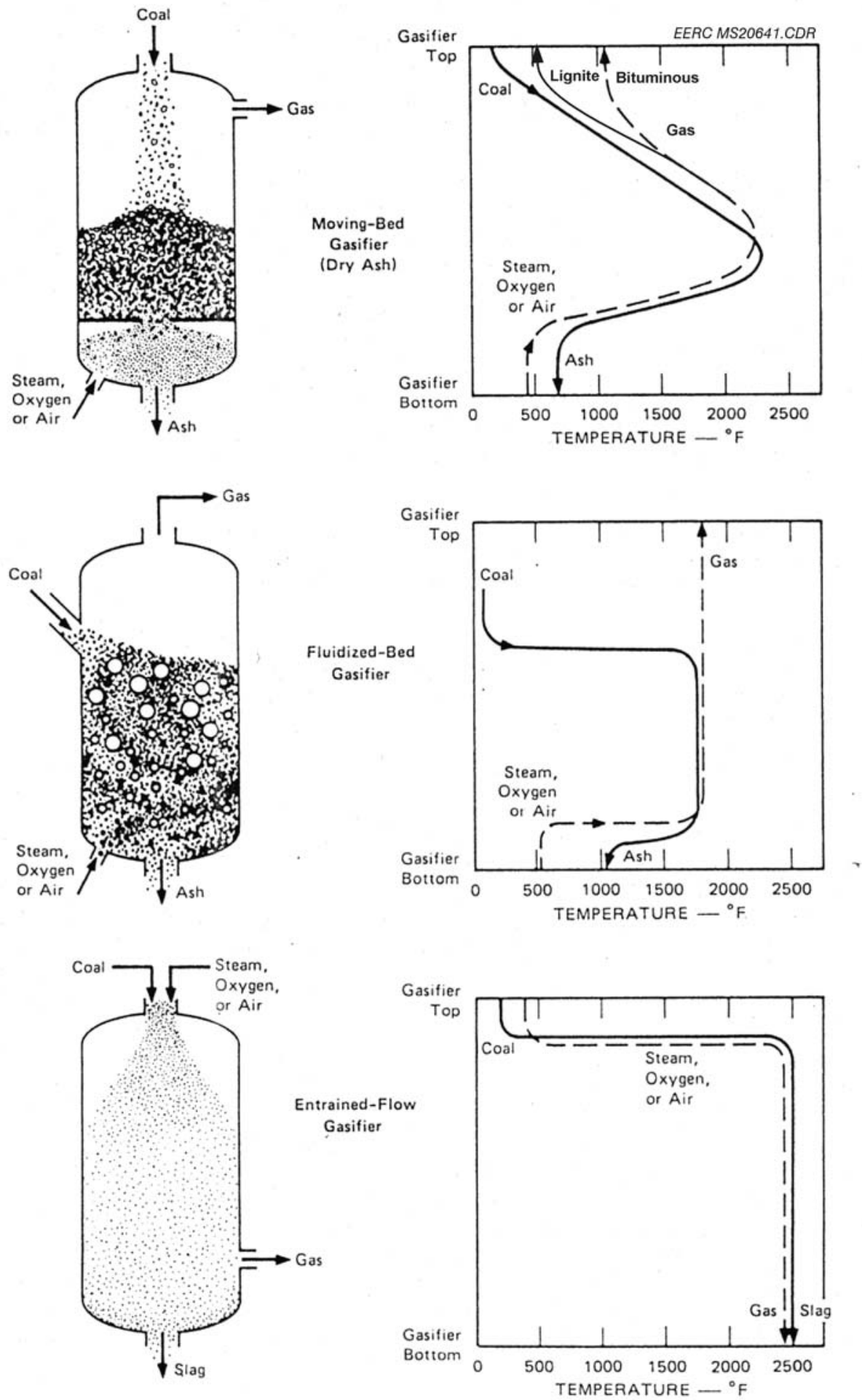

Figure 35. Generic gasification reactors (4). 
Table 9. Important Characteristics of Generic Gasifiers (1)

\begin{tabular}{|c|c|c|c|c|c|}
\hline \multirow[b]{2}{*}{ Ash Conditions } & \multicolumn{2}{|c|}{ Moving Bed } & \multicolumn{2}{|c|}{ Fluidized Bed } & \multirow{2}{*}{$\begin{array}{l}\text { Entrained } \\
\text { Flow } \\
\text { Slagging }\end{array}$} \\
\hline & Dry Ash & Slagging & Dry Ash & Agglomerating & \\
\hline \multicolumn{6}{|c|}{ Feed Coal Characteristics } \\
\hline Size & $\begin{array}{l}\text { Coarse } \\
(-2 \text { inch })\end{array}$ & $\begin{array}{l}\text { Coarse } \\
\text { (-2 inch) }\end{array}$ & $\begin{array}{l}\text { Crushed } \\
(-1 / 4 \text { inch })\end{array}$ & $\begin{array}{l}\text { Crushed } \\
(-1 / 4 \text { inch })\end{array}$ & $\begin{array}{l}\text { Pulverized } \\
(-100 \text { mesh })\end{array}$ \\
\hline $\begin{array}{l}\text { Acceptability of } \\
\text { Fines }\end{array}$ & Limited & $\begin{array}{l}\text { Better than } \\
\text { dry ash }\end{array}$ & Good & Better & Unlimited \\
\hline $\begin{array}{l}\text { Preferred Coal } \\
\text { Rank }\end{array}$ & Low & High or low & Low & Any & Any \\
\hline \multicolumn{6}{|c|}{ Operating Characteristics } \\
\hline $\begin{array}{l}\text { Exit Gas } \\
\text { Temperature }\end{array}$ & $\begin{array}{l}\text { Low } \\
\left(500^{\circ}-\right. \\
\left.1200^{\circ} \mathrm{F}\right)\end{array}$ & $\begin{array}{l}\text { Low } \\
\left(300^{\circ}-\right. \\
\left.1200^{\circ} \mathrm{F}\right)\end{array}$ & $\begin{array}{c}\text { Moderate } \\
\left(1500^{\circ}-\right. \\
\left.1900^{\circ} \mathrm{F}\right)\end{array}$ & $\begin{array}{l}\text { Moderate } \\
\left(1500^{\circ}-\right. \\
\left.1900^{\circ} \mathrm{F}\right)\end{array}$ & $\begin{array}{c}\text { High } \\
\left(>1900^{\circ} \mathrm{F}\right)\end{array}$ \\
\hline $\begin{array}{l}\text { Oxidant } \\
\text { Requirement }\end{array}$ & Low & Low & Moderate & Moderate & High \\
\hline $\begin{array}{l}\text { Steam } \\
\text { Requirement }\end{array}$ & High & Low & Moderate & Moderate & Low \\
\hline $\begin{array}{l}\text { Key } \\
\text { Distinguishing } \\
\text { Characteristics }\end{array}$ & \multicolumn{2}{|c|}{$\begin{array}{l}\text { Hydrocarbon liquids in the } \\
\text { raw gas }\end{array}$} & \multicolumn{2}{|c|}{ Large char recycle } & $\begin{array}{l}\text { High sensible } \\
\text { heat load in } \\
\text { syngas }\end{array}$ \\
\hline $\begin{array}{l}\text { Key Technical } \\
\text { Issue }\end{array}$ & \multicolumn{2}{|c|}{$\begin{array}{l}\text { Utilization of fines and } \\
\text { hydrocarbon liquids }\end{array}$} & \multicolumn{2}{|c|}{ Carbon conversion } & $\begin{array}{l}\text { Raw gas } \\
\text { cooling }\end{array}$ \\
\hline
\end{tabular}

include Shell, Texaco, E-Gas (Destec), and Prenflo. Moving-bed gasifiers will include the Lurgi and the British Gas Lurgi gasifiers.

Fluidized-bed reactors will exhibit slightly lower carbon conversion than entrained-flow gasifiers. Reported carbon conversion values for fixed beds are approximately $96 \%$ and greater than $99 \%$ for entrained flow for select coals (1). Entrained-flow gasifiers produce a very hot gas that must be cooled prior to downstream gas cleaning. This can provide steam output from the gasifier but adds to the complexity of design and operation. Ash in the fuel will also be a factor in gasification performance. Fuels with high alkali and alkaline-earth elements, such as sodium, potassium and calcium, can have a detrimental agglomerating effect on bed material in fluidizedbed gasifiers and can coat the heat-transfer surfaces utilized in entrained-flow gasifiers, reducing their efficiency and increasing pressure drop across them depending on design of the system.

The key issues for moving-bed gasifiers are feed flow and high tar output. Because of the tendency of moving packed beds to bridge, fuels are limited to noncaking biomass and coals. Fuel feed size and friability are important considerations in maintaining gas flow and limiting dust carryover in the product gas. The potentially high tars and oils exiting some moving bed gasifiers, especially in countercurrent gasifiers, require additional processing steps, which add to the complexity and expense of moving-bed systems. However, the separated tars and oils may also provide potentially valuable by-products (1). 


\section{Auxiliary Processes}

An oxidant is needed for the gasification process, and this can be either air or oxygen or an oxygen-enriched air. Oxygen-fired gasification has several advantages over air-fired gasification. Smaller volumes of gas mean smaller capital costs for gasification systems and the gas produced has higher heating value because of less diluent nitrogen. The main drawback to oxygen-fired gasification is the cost of the oxygen plant which can be substantial. However, if considering catalytic conversion of the gas to liquids, the lower cost of synthesis reactor size and productivity due to less diluent nitrogen may outweigh the cost of the oxygen plant.

No matter what the final use of the syngas is, some cleaning of particulate and gas-phase contaminants will be needed. In the conversion to liquids, this will be more rigorous than for the utilization of the gas for heat and power. To control particulate and catalyst poisons such as sulfur and chlorine (which can be detrimental for many catalysts), the gas will first need to be cooled. Hot-gas cleaning methods are expected to be the choice of the future but currently are not widely commercially available. In entrained-flow gasifiers, gas cleaning and cooling will require more cooling than other types of gasifiers because of the high exit gas temperature. Combinations of water quench and heat exchangers have been successfully implemented for this process. Venturi scrubbers can be utilized that can accomplish particulate removal, and gas cooling in one step. High-efficiency cyclones can be utilized for bulk ash removal, and candle filters can be utilized for fine ash removal. Sulfur and ammonia removal will require conventional scrubbing techniques and absorbents such as $\mathrm{ZnO}$ for removal of trace sulfur.

Tars will also need to be dealt with for applications of syngas catalytic conversion to liquids. Tars can be thermally or catalytically cracked to yield lower-molecular-weight products that will not condense onto catalyst surfaces, or they can be scrubbed from the syngas by water quench systems. Water quench systems can perform adequately for this process but will reduce the heating value of the gas, and the wastewater from this quench system will need to be treated. Thermal cracking is the least expensive but is less effectively controlled. Catalytic cracking will consume catalyst, but some catalysts used are relatively inexpensive, such as dolomite.

\section{Gasifier Size}

The commercial availability of a gasifier size that meets the relatively low heat duty for this application (approximately 17-MMBtu/hr heat input based on 25 tons per day lignin) will be an issue for each of the various commercial technologies. A fluidized-bed gasifier operating on oxygen and steam at a typical superficial gas velocity of $12 \mathrm{ft} / \mathrm{sec}$ at $1700^{\circ} \mathrm{F}$ would be on the order of $16 \mathrm{in}$. inside diameter. The gas produced would be approximately $17 \mathrm{scf} / \mathrm{sec}$ at a heating value of ca. $280 \mathrm{Btu} / \mathrm{scf}$. Smaller diameters would be required in gasifiers designed for higher gas velocities, such as the fluidized-bed ATR (40 ft/sec) and the entrained-flow gasifiers. Gasification reactors of this size can be shop-fabricated and delivered as modules that require very little field fabrication.

\section{Entrained-Flow Gasifiers}

Entrained-flow gasifiers rapidly convert pulverized feed to synthesis gas in a short residence time by partial oxidation using air or oxygen at high temperatures of $1370^{\circ}$ to $1925^{\circ} \mathrm{C}$ 
$\left(2500^{\circ}\right.$ to $\left.3500^{\circ} \mathrm{F}\right)$. Molten ash produced at these elevated operating temperatures is continuously water-quenched and removed as a fritty slag. Fuel feed to pressurized units is accomplished either by pumping of a lignin-water slurry or by injecting dry fuel in a dense phase of transporting nitrogen. The principal advantages of entrained-flow gasifiers are their conceptually simple design, good tolerance of caking fuels, high throughput, high carbon conversion efficiency, and thermal flexibility for increasing operating temperatures well beyond the melting point of ash. Disadvantages are the large amount of gas cooling and heat recovery necessitated by the high exit gas temperature, slag attack of refractories and metallic surfaces, the limited opportunities for in-gasifier sulfur capture, the complex feeding systems required for pressure operation, and the necessity for close control of oxygen feed rate for safe operation.

\section{The GE Gasifier System}

The GE (formerly Texaco) design is an oxygen-blown, single-stage, entrained-flow gasifier that uses a pulverized coal slurry feed containing approximately $25 \%$ pasting water in current commercial systems. Raw product gas leaving the gasifier at $1371^{\circ} \mathrm{C}\left(2500^{\circ} \mathrm{F}\right)$ is cooled using either a fuel heat recovery system or is water-quenched followed by partial heat recovery. Capital costs for a 250-MWe GE integrated gasification combined-cycle (IGCC) plant operating on U.S. bituminous coal and using a cold-acid gas removal process are estimated to be US $\$ 1446 / \mathrm{kW}$ with fuel heat recovery and US\$1300/kW with a water quench (1994 \$) (2). More recent figures are at least double this amount for IGCC applications (4, 5). Plant efficiency is reduced when the water quench option is used. GE gasifiers have been demonstrated to operate successfully on a wide range of carbonaceous fuels, including bituminous and subbituminous coal, heavy oil and refinery residues, petroleum coke, mixed-plastic wastes, and sewage sludge.

In the GE oxygen-blown pressurized entrained-flow gasifier shown in Figure 36, coal slurry feed and oxygen are combined in burners that are oriented downward from the top of the gasifier. Operating conditions are typically at or above $400 \mathrm{psig}$ and $1370^{\circ} \mathrm{C}\left(2500^{\circ} \mathrm{F}\right)$, with a 2 -second residence time. The GE design is based on an earlier commercial process for gasifying petroleum residue, and it is the most mature and commercially accepted design of this type. The GE design will gasify any carbonaceous material that can be fed into the gasifier, but economical operations on high-moisture lignin may require hydrothermal pretreatment to provide the high dry solids content in the slurry and low oxygen feed rates required for efficient operation. The oxygen requirement increases substantially as the moisture of the feed slurry increases. Predrying the lignin feed would be far more economical than increasing oxygen to the gasifier if moisture were not reabsorbed when the lignite feedstock is slurried. For this reason, conventional gas-drying methods are not of practical use in this application. GE recently bought the Stamet Posimetric feeder in order to offer a dry feed option; however, this technology is not commercially available.

Commercial applications of the Texaco design for coal gasification have been demonstrated in the Tampa Electric IGCC project which gasifies 2200 tons/day of bituminous coal to generate $250 \mathrm{MW}$ with a $36.5 \%$ efficiency higher heating value (HHV) (6). Carbon conversion has been a little lower than desired at this particular plant. Gasifier availability at the Tampa Electric site has ranged from upper $70 \%$ to lower $80 \%$ in spite of this plant not having a second backup gasifier and much equipment sparing. This plant does not have a dry particulate removal system and uses wet scrubbers to remove particulate to less than its permitted $17 \mathrm{lb} / \mathrm{hr}$. 


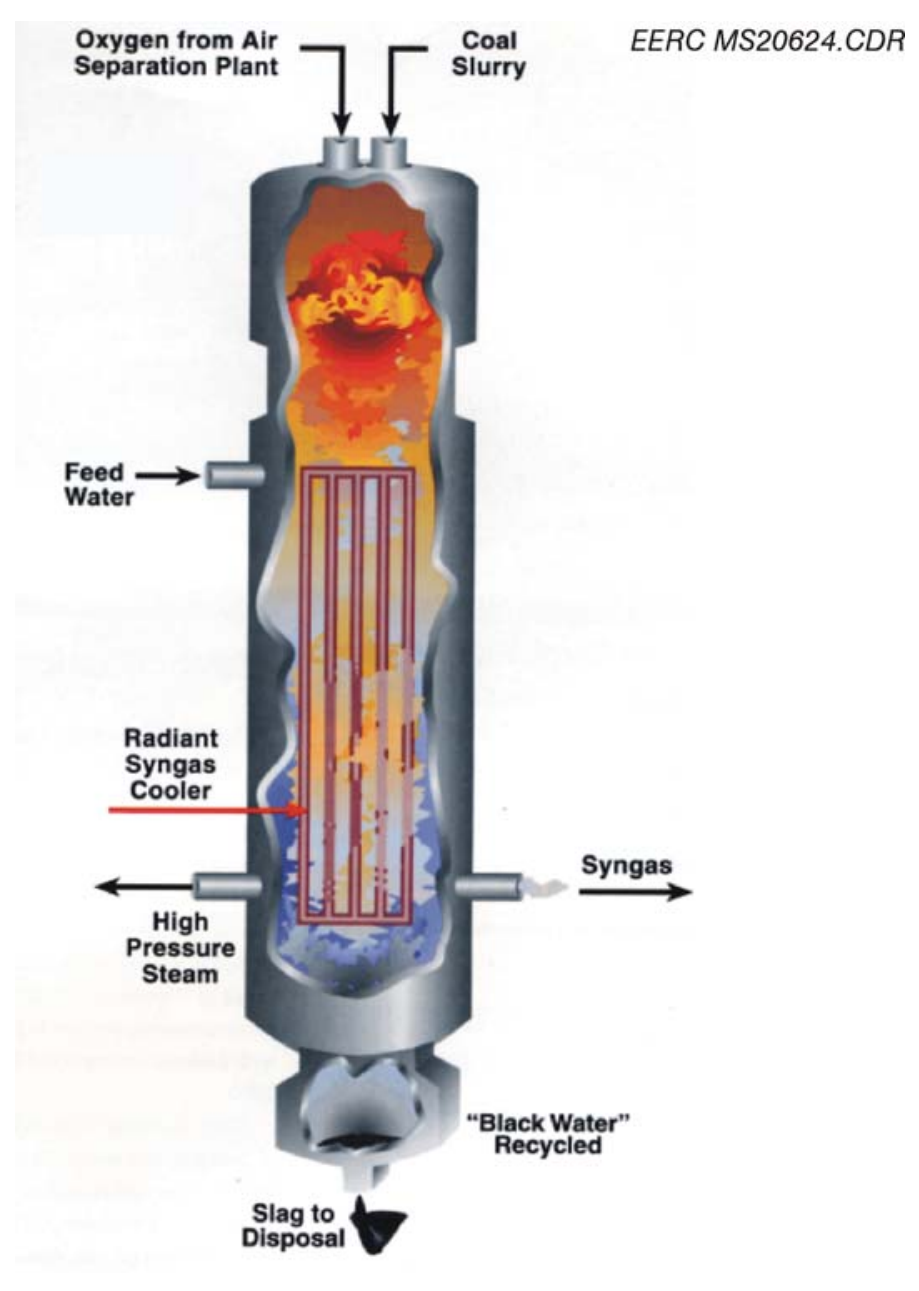

Figure 36. Texaco gasifier at Tampa Electric Integrated Gasification Combined Cycle Project (7).

A typical fuel gas composition of the cleaned fuel gas is shown in Table 10. The Tampa Electric plant injects nitrogen from the air separation unit (ASU) to lower the heating value of the syngas to approximately $120 \mathrm{Btu} / \mathrm{scf}$ in order to reduce the amount of thermal $\mathrm{NO}_{\mathrm{x}}$ formed in the gas turbine combustor. Several other Texaco units are used in chemical manufacturing and petrochemical-refining processes throughout the world. With significant equipment sparing and a second Texaco quench gasifier at the Tennessee Eastman site, gasifier on-stream availability has approached 99\%.

\section{ConocoPhillips E-Gas Gasifier System}

The ConocoPhillips E-Gas gasifier system is described in the EPRI Coal Gasification Guidebook (3). The design is a two-stage, pulverized coal slurry feed, entrained-flow gasifier. The slurry is prepared with a minimum of pasting water and heated to provide some dewatering of coal particles and reduction in slurry viscosity. About three-fourths of the slurry feed is fed to the first stage, operating at $1316^{\circ}$ to $1427^{\circ} \mathrm{C}\left(2400^{\circ}\right.$ to $\left.2600^{\circ} \mathrm{F}\right)$. The remaining slurry is injected 
Table 10. Typical Fuel Gas Composition of Selected Gasifier Technologies

\begin{tabular}{lccccrrr}
\hline & $\begin{array}{c}\text { Texaco } \\
\text { Tampa } \\
\text { Electric }\end{array}$ & $\begin{array}{c}\text { E-Gas } \\
\text { Wabash }\end{array}$ & $\begin{array}{c}\text { Shell } \\
\text { Demkolec }\end{array}$ & $\begin{array}{c}\text { Prenflo } \\
\text { Puertollano }\end{array}$ & $\begin{array}{c}\text { KRW } \\
\text { Piñon } \\
\text { Pine }\end{array}$ & $\begin{array}{c}\text { GTI } \\
\text { U-Gas } \\
\text { Calla }\end{array}$ & $\begin{array}{c}\text { FERCO } \\
\text { SilvaGas } \\
\text { Vermont }\end{array}$ \\
\hline $\mathrm{CO}, \mathrm{mol} \%$ & 42.7 & 45.3 & 63.4 & 60.5 & 23.9 & 15.3 & \\
$\mathrm{H}_{2}, \mathrm{~mol} \%$ & 38.3 & 34.4 & 28.4 & 22.1 & 14.5 & 14.8 & 40.4 \\
$\mathrm{CO}_{2}, \mathrm{~mol} \%$ & 14.4 & 15.8 & 1.5 & 3.9 & 5.5 & 12.3 & 5.1 \\
$\mathrm{CH}_{4}, \mathrm{~mol} \%$ & 0.1 & 1.9 & 0.4 & 0.0 & 1.4 & 2.6 & \\
$\mathrm{H}_{2} \mathrm{O}, \mathrm{mol} \%$ & 0.3 & & & & 5.5 & 13.9 & 11.8 \\
$\mathrm{~N}_{2}, \mathrm{~mol} \%$ & 3.3 & 1.9 & 6.2 & 12.5 & 48.6 & 40.5 & 42.6 \\
$\mathrm{Ar}, \mathrm{mol} \%$ & 0.9 & 0.6 & & 1.0 & 0.6 & & \\
$\mathrm{H}_{2} \mathrm{~S}, \mathrm{ppm}$ & 200 & 68 & 20 & 6 & 20 & 190 & \\
$\mathrm{COS}, \mathrm{ppm}$ & 10 & & & 6 & 0 & & \\
$\mathrm{NH}_{3}, \mathrm{ppm}$ & 0.0 & 0.0 & 0.0 & 0.0 & 200 & 2000 & \\
\hline
\end{tabular}

into the second stage, from which the raw product gas exits at $1038^{\circ} \mathrm{C}\left(1900^{\circ} \mathrm{F}\right)$. The E-Gas IGCC system used for the Wabash River Clean Coal Demonstration Project (8) matches the gasifier with a heat recovery gas cooler, particulate removal, cold-gas sulfur removal, and fuel gas reheat. This project has successfully operated since 1996 on 2450 tons/day of an Indiana bituminous coal in Terre Haute, Indiana, and is currently gasifying 2000 tons/day of petroleum coke to generate $262 \mathrm{MW}$ net to the grid at an overall thermal efficiency of $39.7 \%$. Figure 37 shows the gasifier configuration for the Wabash River Repowering Project. Table 3 also shows the fuel gas composition obtained from the Wabash facility. The Wabash River plant remoisturizes and injects steam to lower the heating value of the syngas entering the gas turbine to approximately $120 \mathrm{Btu} / \mathrm{scf}$. Gasifier availability has been greater than $85 \%$ over the last few years. The Wabash facility does have a spare gasifier, since replacing refractory takes a significant amount of time and the plant wanted to reduce downtime.

The two-stage design of the E-Gas gasifier reduces heat recovery requirements and increases flexibility for using higher-moisture fuels as evidenced by operation of the Plaquemine, Louisiana, gasification facility on U.S. Wyoming subbituminous coal. However, ConocoPhillips has also projected (3) a large increase in oxygen demand for a high-moisture Texas lignite containing 35\% moisture as compared to a low moisture Appalachian bituminous coal. A dryfeed system for this gasifier has not been pursued. The hot product gas is passed through a hotgas filter to separate unreacted char particles for recycling. The benefit of this design is that it increases the overall conversion efficiency of coal to gas while reducing the need for heat recovery from the product hot gas. Carbon conversion efficiency has been greater than 99\%. The E-Gas gasifier, because of its two-stage design, provides increased flexibility in the use of highmoisture fuels without hydrothermal treatment. However, communications with ConocoPhillips personnel suggest that operation of the E-Gas entrained-flow gasifier on high-moisture fuels is probably not economically viable compared with other gasification systems (9).

\section{Shell Gasifier System}

The Shell gasification and cold-gas-cleaning system consists of a dry-feed, oxygen-blown, entrained-flow gasifier followed by a syngas cooler, a wet scrubber, and a cold-acid gas absorption unit (the Sulfinol process was used at Shell's Deer Park, Texas, demonstration plant). 


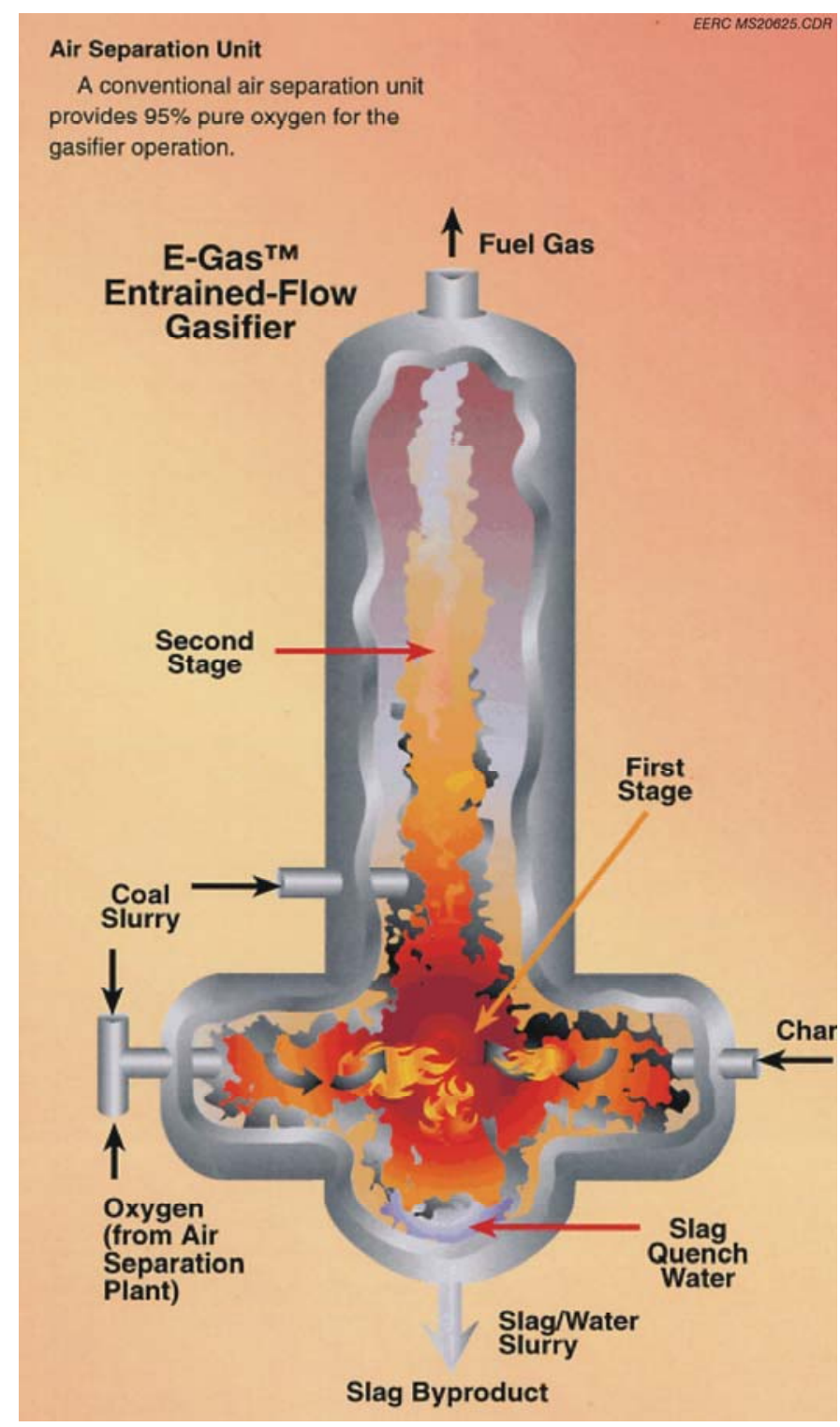

Figure 37. ConocoPhillips E-Gas entrained-flow gasifier (10).

This configuration was demonstrated on a Texas lignite dried to $4.5 \%$ moisture at a capacity of 400 short tons/day where it achieved a carbon conversion of $99.77 \%$, a cold-gas efficiency of $80.3 \%$ (HHV), and a total energy recovery (gas plus steam) of $95.7 \%$ (3). Sulfur control levels of $99 \%$ can be achieved with cold-gas absorption, with conversion to salable sulfur in a Claus-type unit. Shell's estimate of capital cost for a $2 \times 400$-MWe IGCC plant is US $\$ 1500$ to US $\$ 1600 / \mathrm{kW}$ (1993 \$); projected efficiencies are $42 \%$ to $46 \%$ (lower heating value [LHV]) depending on coal quality and turbine efficiency. Hot-gas cleanup is estimated to improve efficiency by 1.3 percentage points, with no estimate given for the expected reduction in capital cost. Here again, more recent projections show a cost double what was predicted in $1993(4,5)$.

The Shell pressurized, oxygen-blown, entrained-flow gasifier (Figure 38) is unique in that dry pulverized coal is pneumatically fed to gasifier burners in a dense fluidized phase transported 


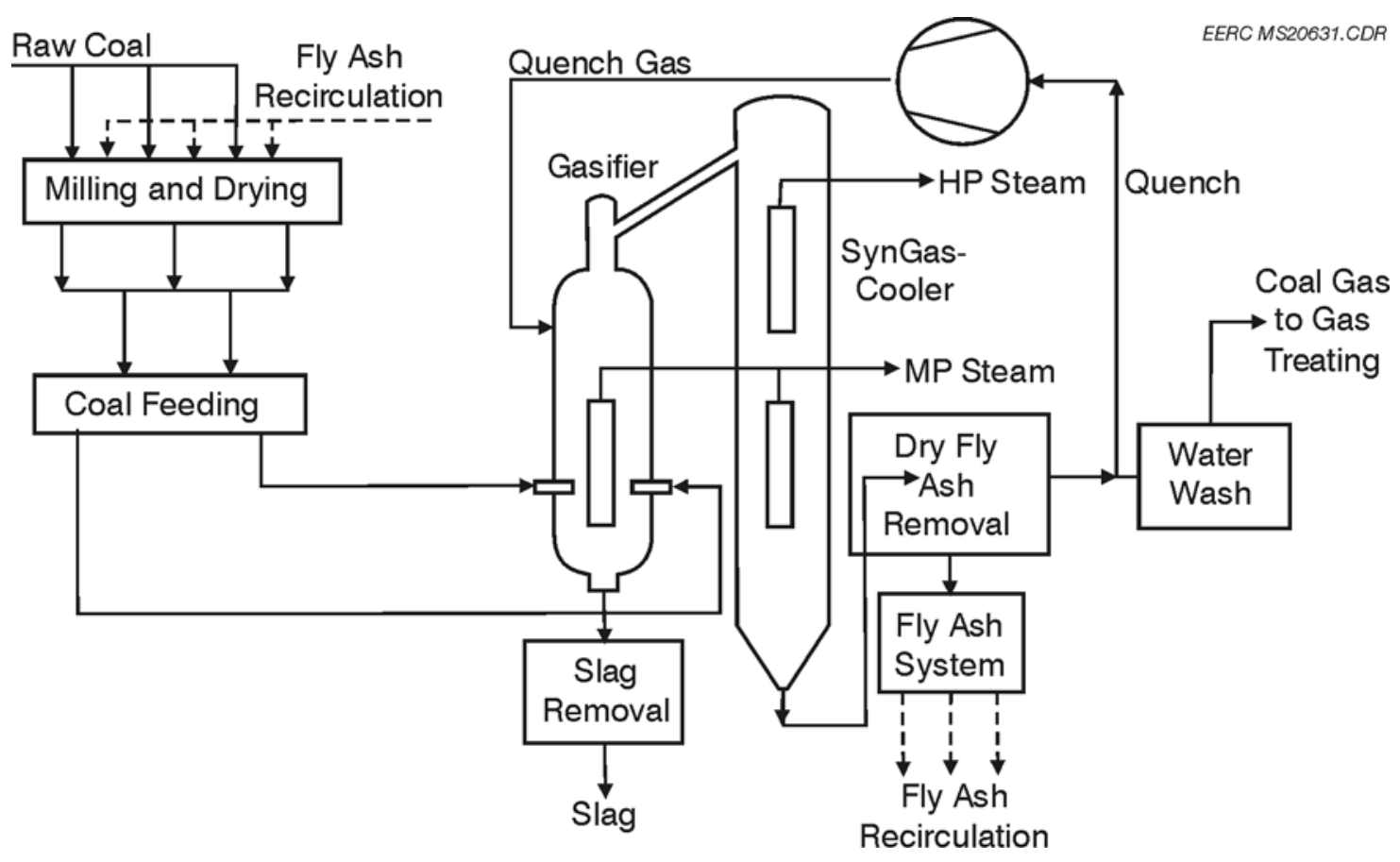

Figure 38. Shell gasification process (11).

in nitrogen. Oxygen is added at the burners, along with steam, as required, to control the gasifier operating temperature. The gasifier is designed to operate at up to $1650^{\circ} \mathrm{C}\left(3000^{\circ} \mathrm{F}\right)$ and 600 psig. Carbon conversions of over $99 \%$ are achieved in a single pass. Over $90 \%$ of the ash is removed as a slag while less than $10 \%$ of the ash leaves the gas as fly slag, where it is first cooled with recycled syngas before entering a syngas cooler to produce high-pressure superheated steam. The fly slag is then removed in a dry-ash removal system before being recycled to the gasifier or removed from the process. Solid residual material has been shown to be environmentally clean and meets all the Resource Conservation and Recovery Act (RCRA) standards to qualify as a nonhazardous waste stream (12). Development of the Shell process started in 1972 and has included work on a 400-ton/day dried lignite feed demonstration plant near Houston, Texas, called the Shell Coal Gasification Process 1 (SCGP-1). The process is reported to be insensitive to fuel properties and to be capable of more efficiently gasifying higher-moisture, higher-volatility fuels. A 250-MWe IGCC plant based on Shell technology has been built and operated successfully by Demkolec near Buggenum, Netherlands (13). In this plant, product gas is first cleaned of particulates and ammonia and is then sent to the Sulfinol-D acid gas recovery system operating at an inlet gas temperature of $32^{\circ} \mathrm{C}\left(90^{\circ} \mathrm{F}\right)$. The Shell gasifier system provides a higher overall efficiency of $43 \%$ in IGCC applications as compared to the slurry-fed entrained-flow gasifiers. This IGCC utilizes remoisturization and nitrogen injection to reduce the fuel gas heating value to approximately $112 \mathrm{Btu} / \mathrm{scf}$ for $\mathrm{NO}_{\mathrm{x}}$ control using a diffusion flame combustion concept (11). Gasifier availability increased to $85 \%$ in 2001 from gasifier availability around $50 \%$ for the previous two years $(14,15)$. Analyses of Shell wastewater has shown that the high operating temperatures have ensured the complete destruction of tars, phenols, and other hydrocarbons heavier than methane (16). This results in wastewater with less than $2 \mathrm{ppm}$ biological oxygen demand (BOD) and less than $15 \mathrm{ppm}$ chemical oxygen demand (COD). Virtually $100 \%$ removal of ammonia and $97 \%$ removal of cyanide were demonstrated in 
the cold-gas cleanup system, with less than 0.5 ppmw ammonia and approximately 50 ppmw of cyanide after steam stripping and biological oxidation in a treatment plant. The water was shown to have no toxicity toward fathead minnows since the cyanide is tightly bound with iron. A subsequent enhanced biological treatment was able to reduce the cyanide concentration to less than 0.1 ppmw.

\section{Prenflo Gasifier}

The Prenflo gasifier at the Puertollano plant is similar to the Shell gasifier in that a dryfeed system is utilized to cofeed a high-ash Spanish coal along with petroleum coke to the gasifier to make $335 \mathrm{MW}$ of electricity at approximately $45 \%$ thermal efficiency (17). The significance of this system is the heat recovery syngas cooler design, with the Prenflo using a radiant waterwall boiler design that offers thermal efficiency advantages but might also present more risk of ash deposition problems for high-alkali fuels. This system started up fairly recently and does not have the long operating history that the other entrained-flow gasifiers currently have. The projected Prenflo gas composition is shown in Table 9. This IGCC also uses nitrogen injection to lower the syngas heating value to approximately $115 \mathrm{Btu} / \mathrm{scf}$ for $\mathrm{NO}_{\mathrm{x}}$ control purposes (14).

The principal advantage of the Shell and Prenflo gasifiers for high-moisture fuels is the dry-feed system, which allows either as-received or thermally dried fuels to be fed to the gasifier without the issues associated with reabsorbing water in a slurry preparation step. The high gasifier exit temperature of $1371^{\circ} \mathrm{C}\left(2500^{\circ} \mathrm{F}\right)$ makes the technology less attractive for simplified designs based on hot-gas cleanup because of the substantial gas cooling required to match a hot metal oxide-sulfur removal system. Prenflo gasifier availability was approximately $43 \%$ in 2000 and increased to $62 \%$ in 2001. While further improvements in on-stream availability are expected, availability remains somewhat of a concern for this plant.

Commercial entrained-flow gasifiers are offered by GE, ConocoPhillips, Shell, and Prenflo for oxygen-blown operation. Demonstrations of advanced IGCC systems based on an entrainedflow gasifier utilizing cold-gas cleanup include Tampa Electric (Texaco), Wabash River (E-Gas), Demkolec in Buggenum of the Netherlands (Shell), and Puertollano in Spain (Prenflo). However, these plants all use cold-gas cleanup technology which tends to lower their thermal efficiency by approximately $2 \%$. Wabash River, Buggenum, and Puertollano all use hot- or warm-gas filter systems to recover dry ash for recycling to the gasifier. However, these plants use water scrubbers and amine-based scrubbers for $\mathrm{H}_{2} \mathrm{~S}$ removal. The use of hot-gas cleanup technologies with these technologies is possible and has been demonstrated in part by operations of pilot-scale and slipstream systems. The high capital and operating costs associated with the need for an air separation unit for the oxygen feed to these gasifiers are also a concern given the smaller scale at which an ICM lignin gasification system would be operating. Internal diameter information on these types of gasifiers is proprietary and not readily available. Lower-pressure operation will result in larger-diameter gasifiers unless higher-pressure operation with pressure letdown across a gas expander for power production could be considered. 


\section{Fluidized-Bed Gasifiers}

Fluidized-bed gasification operates on the principle of suspending coal, along with other solids present in the reactor, in turbulent motion in a high-velocity upward flow of reactant gas. The turbulent environment provides excellent gas-solid contact, which rapidly heats entering reactants to the bed temperature and facilitates their intimate mixing and reaction.

The advantages of fluidized-bed gasifiers are in their ability to incorporate in-bed sulfur capture using limestone and their reduced gas-cooling requirement. Up to $90 \%$ sulfur removal can be accomplished in the bed at temperatures around $900^{\circ} \mathrm{C}$, where the limestone is substantially calcined. At best, in-bed sulfur control does not match the $99 \%$ removal capability of mixed metal oxide sorbents such as zinc ferrite or zinc titanate. Also, in-bed sulfur removal potentially adds complexity by requiring another combustion unit to convert unstable calcium sulfide waste produced in the gasifier into calcium sulfate that is suitable for disposal, as well as to make use of unburned carbon in gasifier char. Operation of the gasifier above $900^{\circ} \mathrm{C}$ with high-alkali fuels also raises concern over bed agglomeration. High carbon conversions at lowchar recycle rates can be achieved at temperatures below $900^{\circ} \mathrm{C}$ when reactive fuels such as lignite are used, provided that a lower level of in-bed sulfur capture is acceptable.

Fluidized-bed gasification systems have been designed for a wide range of operating conditions involving different temperatures, gas velocities, gaseous reactants, and bed materials. Systems can be configured to include two or more beds in series to facilitate sequential reaction steps under optimum conditions. The inherent advantages of fluidized-bed gasification include 1) design flexibility for a wide range of fuels, including caking fuels; 2) high specific gasification rates resulting from high rates of heat and mass transfer; 3) possible in-bed sulfur removal using a limestone bed; 4) good control of gasification temperature and other reaction conditions in one bed or a series of beds to accomplish particular stages of reaction (e.g., preoxidation of the fuel to destroy caking tendency, release of volatile matter, in-bed sulfur capture, char gasification, calcination of recycled bed materials, and high-temperature agglomeration of ash); and 5) highproduct gas uniformity resulting from the highly turbulent mixing. Disadvantages are in the carryover of fuel fines and some limitations in turndown capability due to the need to maintain fluidizing velocities.

Fluidized-bed designs with application for high-reactivity fuels include the transport reactor, KRW gasifiers, HTW, the GTI U-Gas, and the FERCO SilvaGas. Demonstration of IGCC based on fluidized-bed gasifiers includes an ATR at the EERC and the Southern Company Services (SCS) Power Systems Development Facility (PSDF), Piñon Pine IGCC project (KRW), GTI U-Gas in China and RenuGas ${ }^{\text {TM }}$ in the United States, and the HTW in Germany.

\section{HTW Process}

Uhde $\mathrm{GmbH}$, together with Rheinbraun AG and Lurgi GmbH, has developed the fluidizedbed HTW process in Germany for both 1) a 10-bar oxygen-blown bubbling-bed design generating synthesis gas for methanol production from 720 tons/day of dried brown coal and 2) a 25-bar design using either air or steam/oxygen as the gasification agent for IGCC applications (18). 
Dried fuel was fed through a lock hopper system to the lower fluidized zone of the gasifier operation at $850^{\circ} \mathrm{C}$. Figure 39 shows how the gasification agents (air or steam/oxygen) are admitted both to the lower zone and to the above-bed freeboard to gasify entrained carbon at approximately $940^{\circ} \mathrm{C}$. Entrained solids leaving in the raw product gas are separated in a cyclone and fed by gravity back into the gasifier. Ash is withdrawn from the bottom of the gasifier and fed to a moving-bed cooler.

Fuel is reduced to a grain size of $4 \mathrm{~mm}$ maximum, with fines retained in the feed. Design measures are described for preventing ash and slag deposits in the gasifier system. High ash content is indicated to result in a lower cold-gas efficiency, estimated to be $68 \%$ to $70 \%$ for highash lignites versus $76 \%$ for German Rhenish brown coal. Carbon conversions have ranged from $91 \%$ to $96 \%$ for the lignite feedstocks. Rheinbraun has operated a HTW demonstration plant at Berrenrath since 1986, processing 600 tons/day of dried lignite to make $28 \mathrm{Mscf} /$ day of synthesis gas for the production of 330 tons of methanol/day. This plant has a thermal input of approximately $140 \mathrm{MW}$ thermal and has an internal diameter of $9 \mathrm{ft}$ (18). This demonstration plant has generated over 67,000 hours of operation until it shut down in 1997 while averaging approximately $85 \%$ availability over the last 9 years of operation.

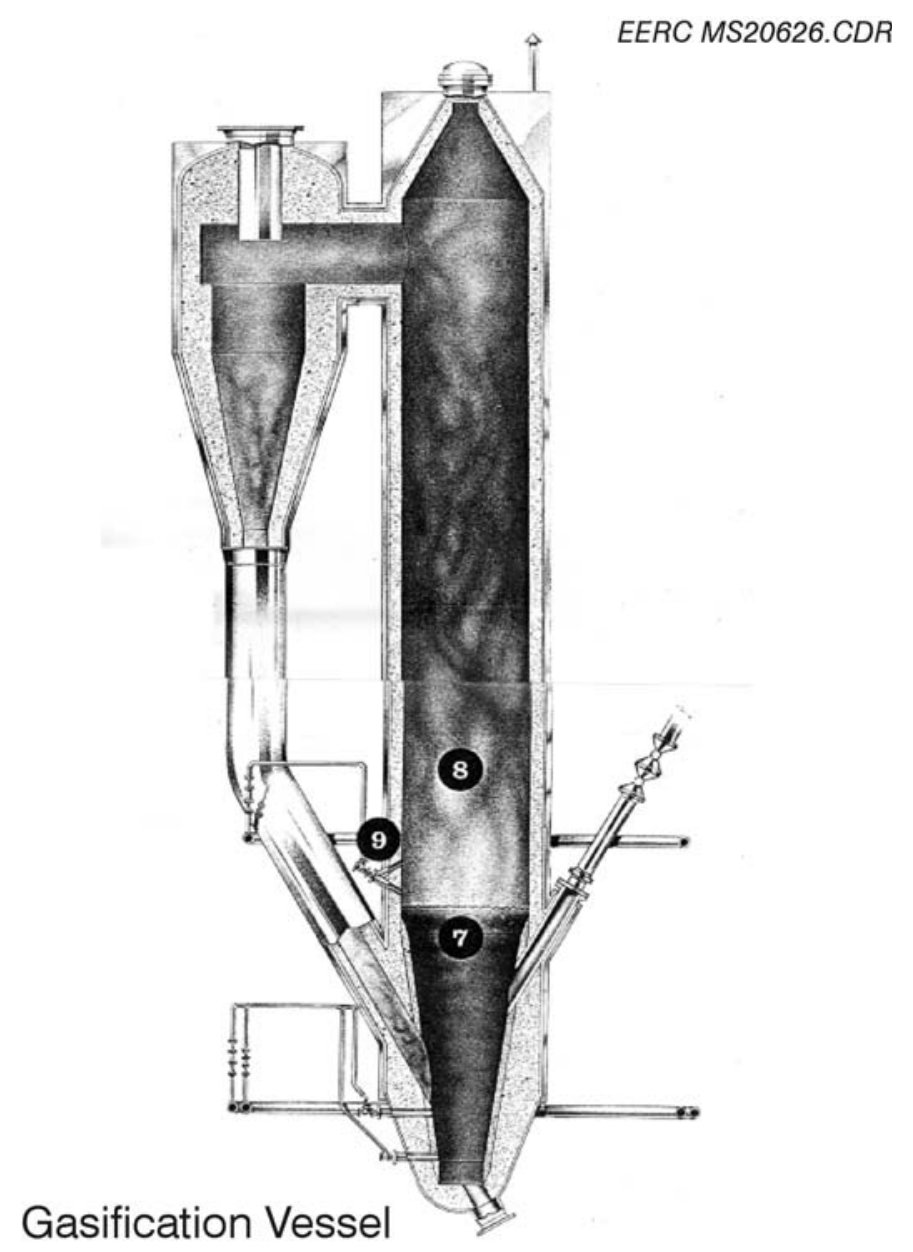

Figure 39. HTW gasifier proposed for the KOBRA plant. 
A dry-gas heating value of $129 \mathrm{Btu} / \mathrm{scf}$ is indicated for air-blown gasification of Rhenish brown coal, compared to $271 \mathrm{Btu} / \mathrm{scf}$ for oxygen gasification.

Both cold-gas and hot-gas-cleaning systems are described for the HTW gasifier. The coldgas case includes 1) gas cooling to $260^{\circ} \mathrm{C}$ in a high-pressure steam generator; 2) particulate filtration using ceramic candle filters; 3) wet scrubbing for removal of alkalies, chlorides, and other trace contaminants; 4) hydrolysis of $\mathrm{COS}$ and $\mathrm{H}_{2} \mathrm{~S}$; 5) desulfurization using a selective process leaving $\mathrm{CO}_{2}$ in the gas stream; and 6) final humidification and pretreating.

Hot-gas cleaning has not been commercially proven as described but is listed as consisting of 1) cooling to $650^{\circ} \mathrm{C}, 2$ ) particulate filtration, 3) treatment in a limestone/dolomite fixed bed for removal of alkalies and heavy metals, 4) metal oxide desulfurization, and 5) final particulate filtration. The retention of $\mathrm{NH}_{3}$ in the treated gas (absent a water scrubber) is identified as an important problem affecting $\mathrm{NO}_{\mathrm{x}}$ emissions.

Use of hot-gas cleaning is estimated to increase efficiency by about 2 percentage points.

\section{Kellogg Gasification Processes}

Kellogg Brown and Root offers two gasification technologies: the KRW process and an advanced transport reactor process that is currently under testing at the EERC and at the SCS PSDF site in Wilsonville, Alabama.

\section{Advanced Transport Reactor}

The transport reactor design feeds a $(\sim 1 / 16$ in. $\times 0$ in.) fuel into a high-velocity fluidized bed operating at a velocity of 20 to $40 \mathrm{ft} / \mathrm{sec}(6.1$ to $12.2 \mathrm{~m} / \mathrm{sec})$. High carbon conversion is achieved by recycling a large flow of solids back into the reactor. The reactor operates at $815^{\circ}$ to $1038^{\circ} \mathrm{C}\left(1700^{\circ}\right.$ to $\left.1900^{\circ} \mathrm{F}\right)$ in gasification mode and at pressures up to $400 \mathrm{psig}$. The transport reactor concept was adapted from the proven design used for fluidized-bed catalytic cracking units used in the petroleum industry. Development for coal conversion has been confirmed at a scale of 2.4 tons/day on a pilot-scale unit at the EERC (18) and on a 38-ton/day proof-of-concept unit at the SCS's PSDF (7). A commercial-sized plant has not been constructed, although the construction of a large commercial plant is being pursued for Mississippi lignite. The transport reactor design, owing to its use of finely crushed fuel (fines are not a problem) and its simple design, may offer future advantages in designing gasification systems at minimum cost. The separation of the fuel feed from the air or oxidant injection ports is an important part of this concept in that it allows the volatile matter in the fuel to be thermally cracked and steamreformed in the absence of oxygen which would otherwise combust with the volatile matter. The oxygen entering at the bottom of the mixing zone partially oxidizes the returning char from the standpipe to form $\mathrm{CO} / \mathrm{CO}_{2}$. Thus the oxygen only consumes returning char material which comprises the hardest material to steam gasify.

The transport reactor is reported to be the highest-throughput gasifier because of its high operating velocities. This high throughput allows a very-small-diameter gasifier to be utilized, which reduces the capital cost of the gasification system as compared to other gasifier systems. Carbon conversions from $85 \%$ to $98 \%$ have been demonstrated on lignite fuel at the EERC and 
the PSDF. The transport reactor is still considered developmental, and a commercial unit would be a first-of-a-kind scaled-up demonstration plant.

\section{KRW Gasifier}

The KRW gasifier illustrated in Figure 40 pneumatically feeds $1 / 4$-in. $\times 0$-in. fuel through a central jet axially located in the bottom of the gasifier along with the combustion air or oxygen. Since this gasifier injects the oxidant with the fuel, significant quantities of the fuel's volatile matter are consumed to generate the process heat. The process has been operated in air- and oxygen-blown modes on U.S. lignites from Texas and North Dakota at a 35-ton/day pilot plant near Pittsburgh, Pennsylvania (8).

The KRW fluidized-bed gasification system, which was successfully tested at a scale of 35 tons/day at Waltz Mill, Pennsylvania, offers high thermal efficiency based on its low steam and oxygen consumption. The KRW system has been developed in both single-stage and twostage configurations to match the processing characteristics of coals of all ranks, from lignite to bituminous. The single-stage design is applicable to higher-reactivity fuels while less reactive fuels use a spouting-type bed wherein coal and recycled fines are pneumatically injected in a high-velocity flow of recycled gas through an axial feeding tube, where they are mixed with preheated steam and oxygen. The fuel experiences rapid devolatilization and partial volatile combustion in the inlet jet zone. The gasifier shell is constructed in sections of successively larger diameter to accommodate combustion, gasification, and disengagement of char solids. The larger unreacted char particles fall back into an internal solids recirculating pattern within the gasifier to undergo further gasification. Fines entrained out of the gasifier are separated in a cyclone and injected back into the gasifier with the coal feed. The gasifier is operated at temperatures of $815^{\circ}$ to $1010^{\circ} \mathrm{C}\left(1500^{\circ}\right.$ to $\left.1850^{\circ} \mathrm{F}\right)$ in an ash-agglomerating mode that causes dense ash to fall to the bottom of the gasifier to be removed through a rotary valve. Over $325 \mathrm{hr}$ of oxygen-blown operation on lignite fuels was completed in the Waltz Mill Facility, including $68 \mathrm{hr}$ on North Dakota lignite from the Indian Head Mine. The lignite fuel feed was sized to $-6.4 \mathrm{~mm}(1 / 4 \mathrm{in}$.), with in-mill drying to reduce moisture to approximately $15 \%$ to $20 \%$ to accommodate pneumatic feeding. Gasification temperatures ranged from $1500^{\circ}$ to $1635^{\circ} \mathrm{F}$ withthe North Dakota lignite run at $1528^{\circ} \mathrm{F}$. Product gas composition was $25.5 \%$ to $26.7 \% \mathrm{H}_{2}$, $39.0 \%$ to $40.8 \% \mathrm{CO}, 4.0 \%$ to $4.1 \% \mathrm{CH}_{4}, 27.6 \%$ to $30.8 \% \mathrm{CO}_{2}$, with the balance being nitrogen and other trace contaminants. Trace contaminants consisted of $1600 \mathrm{ppmv} \mathrm{H}_{2} \mathrm{~S}, 110 \mathrm{ppmv} \mathrm{COS}$, and 3000 ppmv $\mathrm{NH}_{3}$, with a particulate loading of 10 grains/scf in the hot raw gas. Cold-gas cleanup with water scrubbers reduced the ammonia and particulate loading substantially to $51 \mathrm{ppmv}$ and 0.002 grains/scf, respectively, without significantly changing the rest of the fuel gas composition. Wastewater contained up to $100 \mathrm{ppm}$ COS and up to $200 \mathrm{ppm}$ total organic carbon (TOC), indicating that a small amount of condensable organic material was leaving the gasifier. Fuel fines are not a problem, since they can be recycled until completely gasified. Carbon utilization in excess of $95 \%$ has been demonstrated for high-reactivity fuels.

The commercial-sized Piñon Pine project was to utilize 880 tons/day of Utah bituminous coal to produce $100 \mathrm{MW}$ net of power with a thermal efficiency of $40.7 \%$ (19). The internal diameter for this gasifier is 12 feet and operates with a velocity of $1.5 \mathrm{ft} / \mathrm{sec}$ in the freeboard. While the KRW gasification process has been well-demonstrated in the 35-ton/day pilot plant, numerous start-up and operating issues have plagued the Piñon Pine clean coal technology 


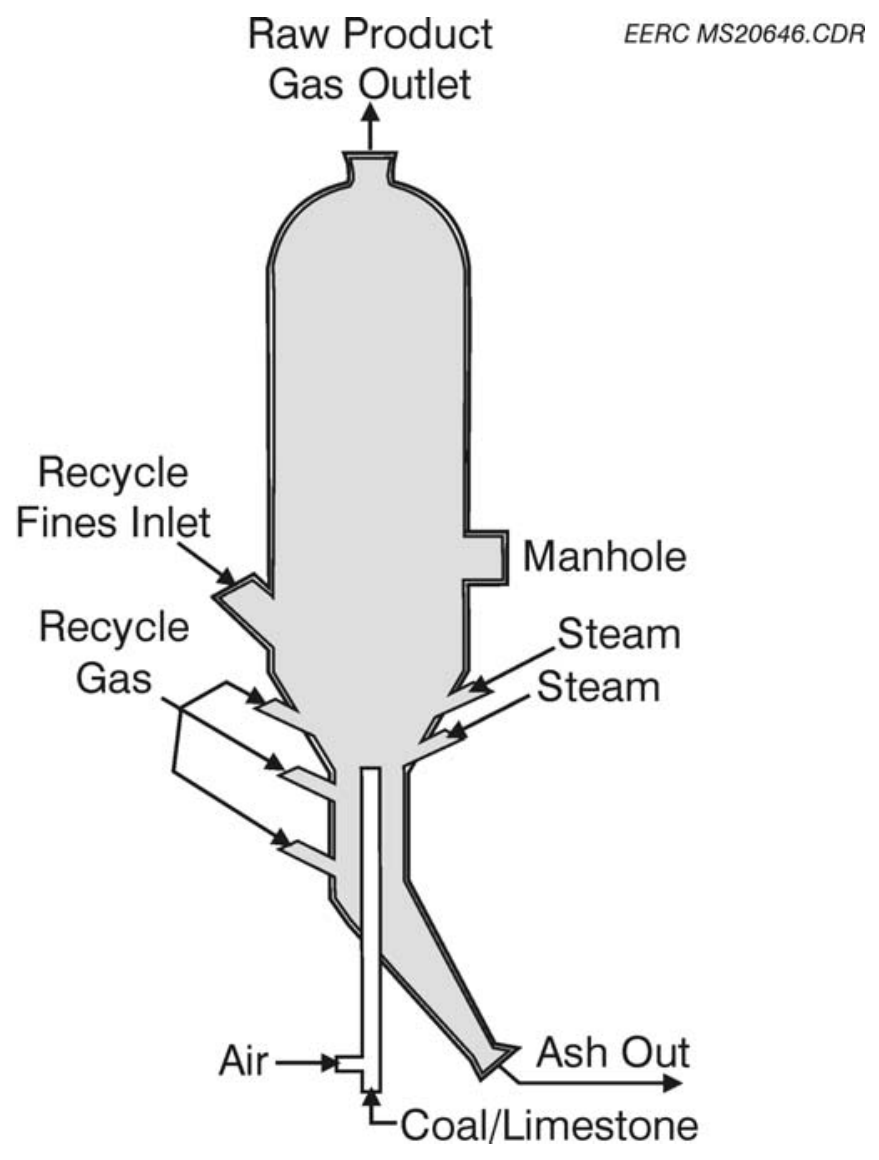

Figure 40. KRW gasifier (19).

commercial demonstration plant. Because of operational problems with solids removal from the system and a desire by the owner, Sierra Pacific Power Company, to divest itself of its powergenerating facilities, the KRW gasifier at Piñon Pine has not operated for any extended period of time and has not supplied any syngas to the gas turbine. Successful demonstration of this technology at this larger scale should be accomplished before serious consideration of this gasification technology.

\section{GTI U-Gas Gasification Process}

The U-Gas and RenuGas gasification process was developed by GTI, formerly the Institute of Gas Technology (IGT), in the United States and licensed to Enviropower in Finland for commercialization in the European markets. Commercially, eight U-Gas gasifiers have been installed in China to supply fuel gas for coke ovens. Figure 41 shows the internal layout of this gasifier. The U-Gas process feeds dried and crushed coal $(25 \%$ moisture, sized to $1 / 4$-in. $\times 0)$ through a lock hopper to a pressurized fluidized-bed (PFB) gasifier that incorporates a hot ashagglomerating zone. Normal operating conditions are $760^{\circ}$ to $980^{\circ} \mathrm{C}\left(1400^{\circ}\right.$ to $\left.1800^{\circ} \mathrm{F}\right)$ and up to $30 \mathrm{~atm}$ (20). Operation has been demonstrated with both oxygen and air. No steam is required for high-moisture fuels under air-blown operation. Ash agglomerates are discharged in an essentially nonleachable vitrified form through a countercurrent heat exchanger where they are cooled to 


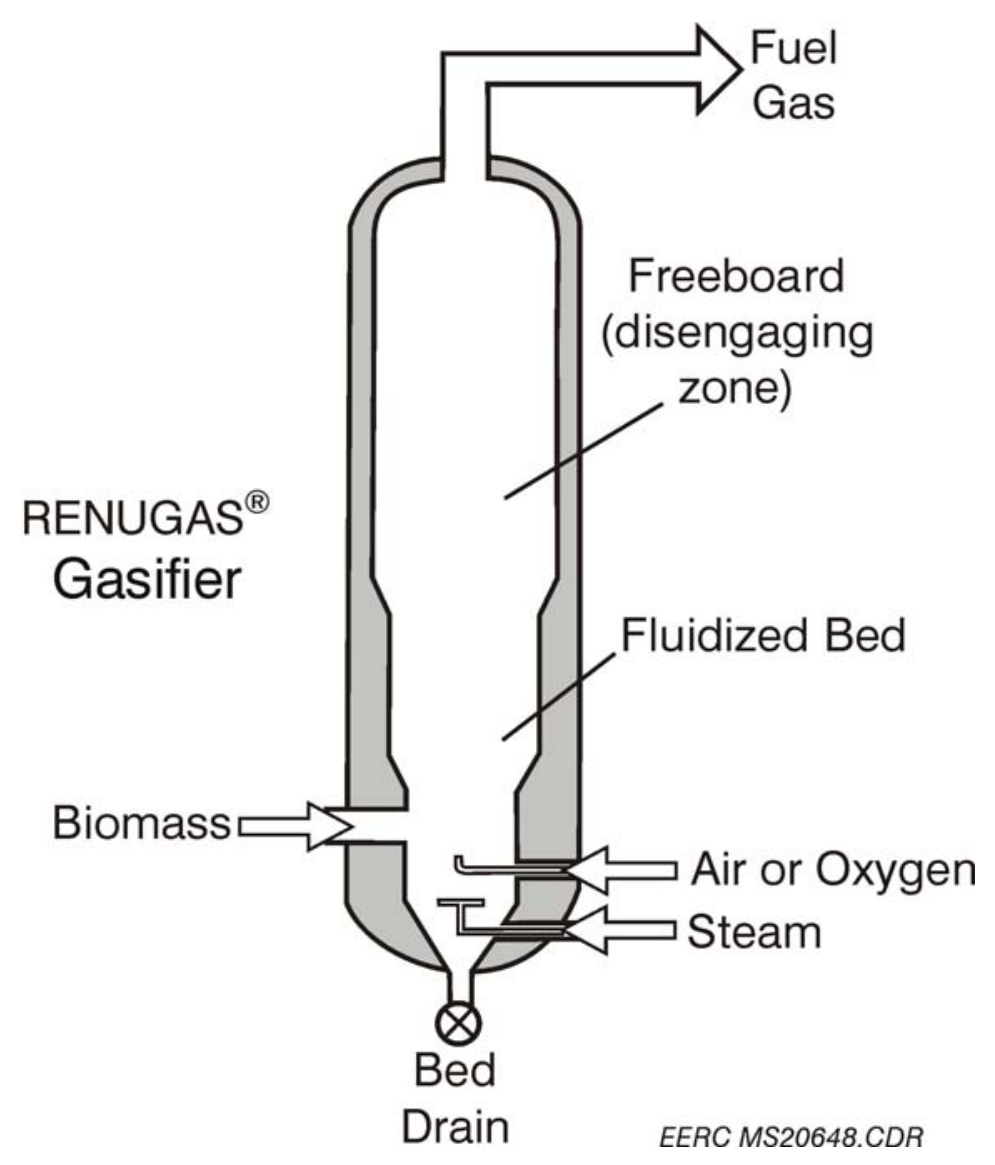

Figure 41. GTI RenuGas gasifier, as proposed (20).

$470^{\circ} \mathrm{C}\left(1200^{\circ} \mathrm{F}\right)$. The high-temperature agglomerating zone reportedly provides a higher carbon conversion (e.g., 95\%) with lower external char recycle than conventional fluidized-bed gasification.

Provisions for dry-fuel feed, char recycle, and ash discharge were deemed satisfactory. Hot-gas cleanup for particulates and sulfur have been investigated by GTI, including limestone addition for in-bed sulfur removal (21).

\section{FERCO SilvaGas Process}

Battelle has developed an indirect gasification process that utilizes two different circulating fluid-bed loops to pyrolyze and steam-gasify the injected biomass, as illustrated in Figure 42. The remaining char is captured in the cyclone and sent to the second circulating fluid bed where it is combusted with air to increase the bed material temperature and burn out the residual char before it is captured in the cyclone of the second circulating bed and returned to the first cyclone. The heating of the bed material in the second bed allows the endothermic pyrolysis and steam gasification reactions to continue in the first bed without having to add oxygen from an ASU or to dilute the syngas with nitrogen by adding air to the gasifier. This allows a medium-Btu (300 to $400 \mathrm{Btu} / \mathrm{scf}$ including the heating value from tars and light organics) fuel gas to be generated. 


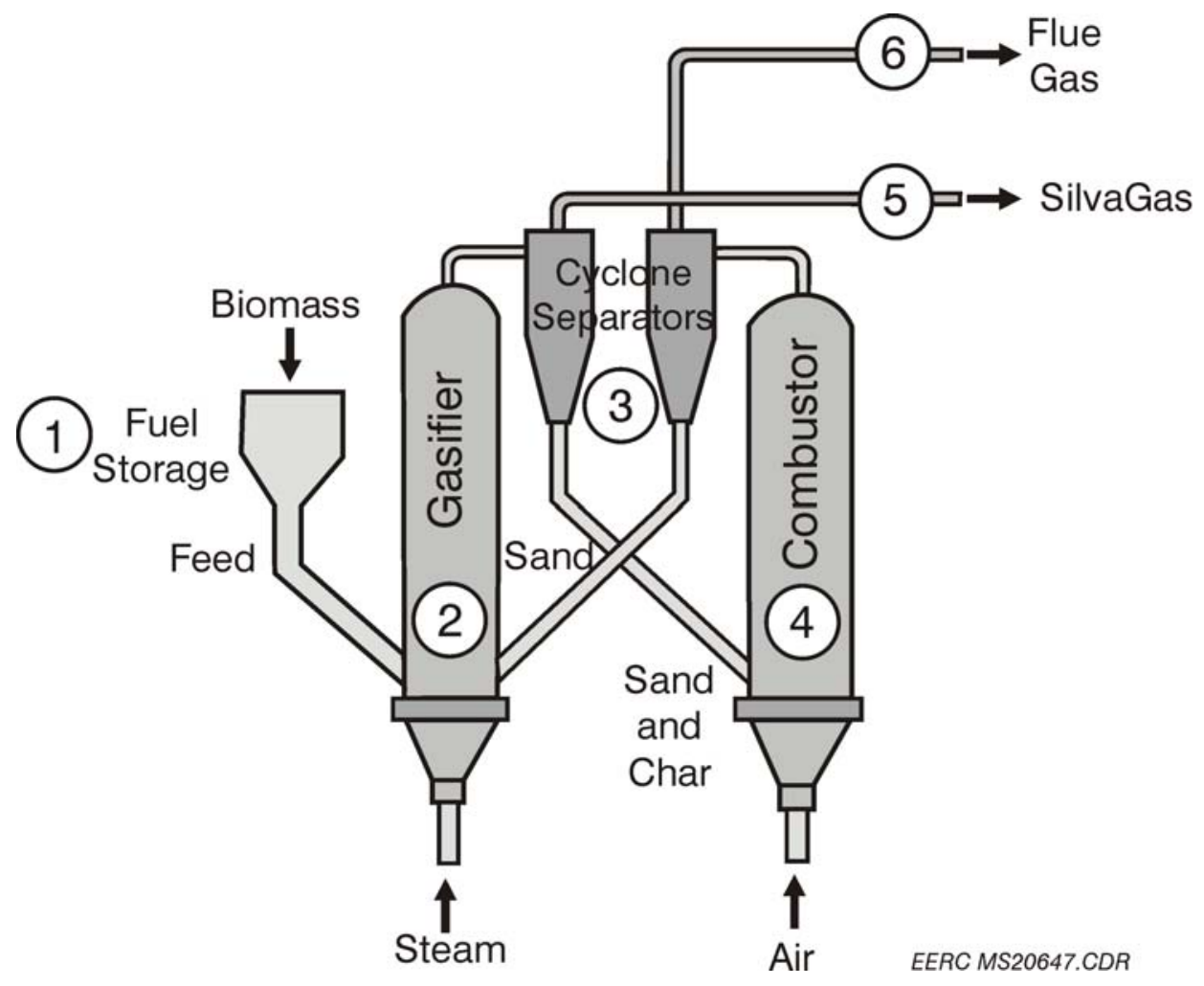

Figure 42. FERCO SilvaGas process (22).

FERCO has bought the rights to the process and has renamed it the SilvaGas process. A 400-ton/day demonstration plant has been built at the McNeil Station in Vermont to utilize wood waste and chips to generate a fuel gas for combustion in an adjacent boiler (22). While some very early work was done under pressure, this process has been developed and demonstrated as an atmospheric pressure gasification system with an emphasis on biomass feedstocks. Some coals were also tested in this system with some success. However, this process generates a lot of higher-heating-value tars that add to the heating value of the fuel gas but can also result in operational problems such as plugging of control valves. If cold-gas cleanup were required, this would present a significant wastewater cleanup problem. The combustion portion of this system might be another emission source that would require a separate air permit.

Table 11 presents fuel gas compositions from gasification tests conducted on lignite fuels in some of these gasifiers. These fuel gases were all from oxygen-blown tests except for the data presented for the U-Gas gasifier, which was an air-blown test. Except for the E-Gas test, these tests were all conducted on dried lignite fuels. The KRW data were only presented on a dry basis, and the total moisture content of the wet gas is not known; however, it would be expected to be similar to that of the HTW gasifier. The Shell data were for lignite dried to $4.5 \%$, while the remaining gasifiers dried the lignite to $12 \%$ for the HTW and $20 \%$ for the KRW and the U-Gas. The E-Gas utilized a slurry feed at $50 \mathrm{wt} \%$ solids in the feed which resulted in the high moisture content of that fuel gas. 
Table 11. Published Fuel Gas Compositions for Selected Gasifier Technology on Lignites

\begin{tabular}{lccccc}
\hline $\mathrm{mol} \%$ & E-Gas & Shell & HTW & KRW & U-Gas \\
\hline $\mathrm{CO}$ & 21.8 & 60.6 & & 39 & 17 \\
$\mathrm{H}_{2}$ & 24.6 & 27.6 & 33.1 & 25.5 & 12 \\
$\mathrm{CO}_{2}$ & 17.2 & 2.8 & 28.3 & 30.8 & 9 \\
$\mathrm{CH}_{4}$ & 0.1 & 0.03 & 15.5 & 4.0 & 3 \\
$\mathrm{H}_{2} \mathrm{O}$ & 34.6 & 3.2 & 4.6 & & 10 \\
$\mathrm{~N}_{2}$ & 0.5 & 4.3 & 16.8 & 0.6 & 49 \\
$\mathrm{Ar}$ & 0.8 & 1.0 & 0.6 & 0.1 & \\
$\mathrm{H}_{2} \mathrm{~S}, \mathrm{ppm}$ & 3000 & 3250 & 0.7 & 1600 & \\
$\mathrm{COS}, \mathrm{ppm}$ & 128 & 310 & 2120 & 110 & \\
$\mathrm{NH}_{3}, \mathrm{ppm}$ & 1670 & 210 & 1100 & 3120 & \\
\hline
\end{tabular}

\section{Moving Packed-Bed Gasifiers}

The dry-ash fixed-bed Lurgi gasifier shown in Figure 43 was first commercially demonstrated in Germany in 1936 and has since been used worldwide on noncaking fuels, including major installations at SASOL in South Africa and the Dakota Gasification Great Plains Synfuels Plant in North Dakota. Other fixed-bed designs include the Wellman-Galusha, the Riley-Morgan, the two-stage Woodall-Duckham, and a number of lesser used designs. All of these gasifiers use the temperature-moderating effect of a high ratio of steam to oxygen to maintain the gasification temperature at the bottom of the bed below the fusion temperature of the ash. Clinker formation can be a problem for high-sodium fuels if the temperature in the combustion zone approaches the initial deformation temperature of the ash. Low-rank fuels such as lignite and biomass are an ideal feedstock in that they are more reactive than coals at relatively low operating temperatures and are also noncaking. Lurgi gasifiers can be operated on either air or oxygen at pressures up to $450 \mathrm{psig}$. Because of their widespread application, including the lessons learned at the Dakota Gasification plant, gasifiers of this design represent a standard against which other designs can be compared (23). This plant was designed for zero liquid discharge by using treated gas liquor as the makeup to cooling towers, which has required ongoing attention to resolve problems of tower plugging and heat exchanger fouling.

Fixed-bed Lurgi gasifiers have the inherent advantages of essentially complete carbon conversion, high thermal efficiency, and relatively low offgas temperature because of the countercurrent flow of fuel and gaseous reactants. A constant bed depth is maintained in the gasifier by adding fuel at the top through a lock hopper and discharging ash through a grate at the bottom. Fuel fed at the top is progressively heated and reacted as it moves down through drying, devolatilization, gasification, and oxidation zones. The air or oxygen and steam used as the gasification medium converts fuel to synthesis gas $\left(\mathrm{CO}\right.$ and $\left.\mathrm{H}_{2}\right)$ by partial oxidation, steam gasification, and water-gas shift reactions. Fuel feed size and friability are important considerations in maintaining gas flow and limiting dust carryover in the product gas, and the fuel feed must be double-screened to remove fines and provide a minimum particle size of about $1 / 4$ inch. Highly friable coals that would crumble within the gasifier are not suitable feedstocks for fixed-bed gasifiers. The Lurgi dry-ash gasifier produces raw product gas with an analysis of $39 \%$ 


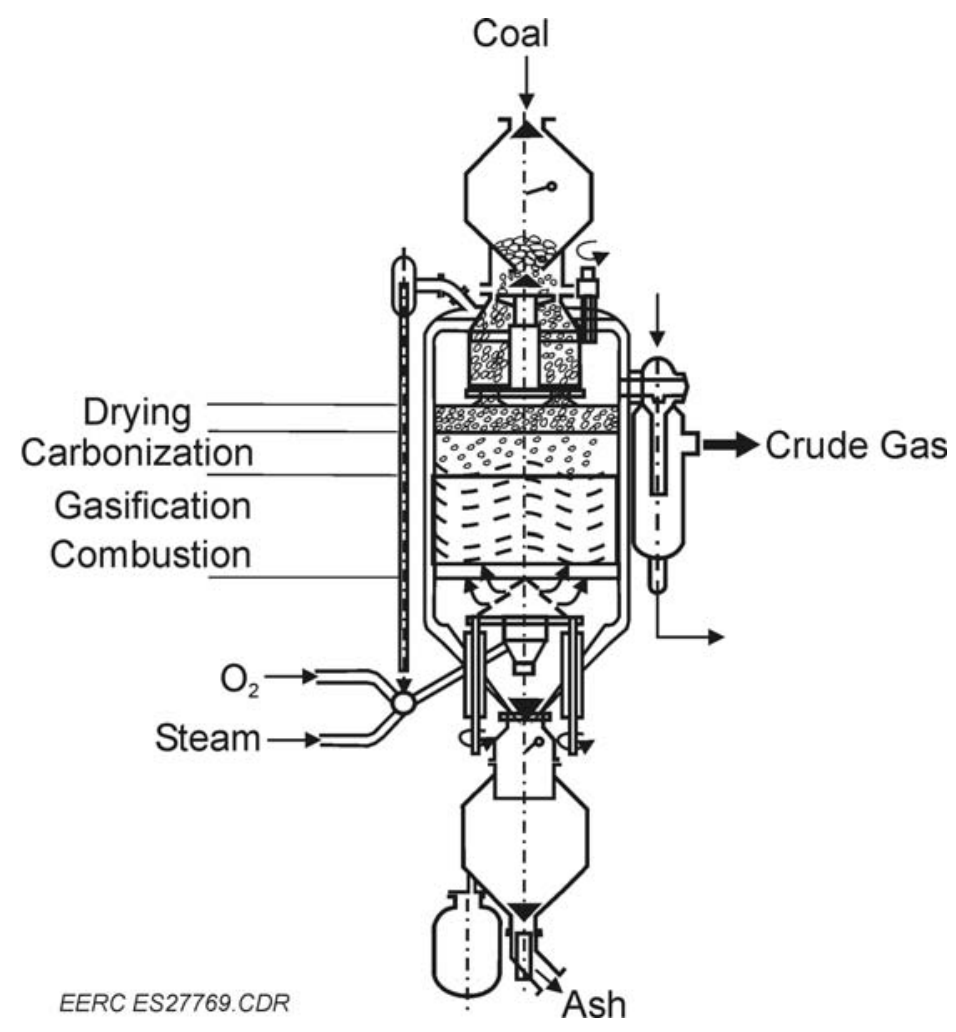

Figure 43. Lurgi fixed-bed gasifier.

$\mathrm{H}_{2}, 16 \% \mathrm{CO}, 31 \% \mathrm{CO}_{2}$, and $11 \% \mathrm{CH}_{4}$ (dry basis) and has an exit gas temperature of $600^{\circ} \mathrm{F}$ $\left(316^{\circ} \mathrm{C}\right)$ operating on lignite containing $33 \%$ moisture $(3)$.

The disadvantage of countercurrent fixed-bed gasifiers is that the raw product gas contains all of the devolatilization products, including methane, water, hydrocarbons, and heavy tars. The processing steps required to condense and separate this tar, oil, and gas liquor add to the complexity and cost of a fixed-bed gasification system, compared to other gasification systems which break down volatile organics within the gasifier; however, the separated tar and oil also provide a source of potentially valuable by-products and fuels.

The creative use of a fixed-bed gasifier was indicated to be a potential least cost IGCC option in a 1990 DOE study report on a broad range of systems (24). The favored system used predried coal as feed to a Lurgi gasifier to provide an exit gas temperature above $1000^{\circ} \mathrm{F}\left(538^{\circ} \mathrm{C}\right)$ that could be matched with a hot-gas cleaning system that incorporated a second fixed bed for tar cracking and desulfurization. This would, in principle, resolve the major disadvantage of a fixedbed gasifier, i.e., tar. The resulting product gas would be a good starting point for producing hydrogen if there were an on-site use for the relatively high yield of methane. The methane separated in the gas separation process could be subsequently reformed. A plant design based on the envisioned system would require process development. 


\section{British Gas Lurgi Fix-Bed Gasifier}

Initial development of the British Gas Lurgi (BGL) slagging fixed-bed gasifier was started by Lurgi and Ruhrgas in Germany in the early 1950s and continued at British Gas between 1955 and 1964 (3). British Gas operated two larger pilot plants of 300- and 500-t/d capacity between 1974 and 1990, supported in part by a consortium of U.S. companies led by Continental Oil. A parallel development was conducted in a smaller 20-t/d pilot plant by the U.S. Bureau of Mines and DOE at the Grand Forks Energy Technology Center (GFETC, later EERC) between 1958 and 1983, focusing on hearth plate design and treatment of liquid effluents (25-27). The research and development sponsored by DOE provides a support database on process effluents, byproducts, and waste treatment methods. Allied Syngas Corporation is commercializing this technology in North America.

The principal differences between the slagging design and a dry-ash Lurgi gasifier are in the substitution of a slagging hearth and taphole for the ash grate and the fourfold reduction in steam flow per ton of coal, which allows the oxidation zone of the gasifier to reach temperatures above the $2500^{\circ} \mathrm{F}\left(1371^{\circ} \mathrm{C}\right)$ required for slag tapping. The configuration of the BGL gasifier is similar to that of the Lurgi dry-ash gasifier shown in Figure 43, except for the slagging bottom. The slagging gasifier requires considerably more oxygen per pound of moisture and ash-free coal than the dry-ash Lurgi gasifier $(0.72$ vs. $0.35 \mathrm{lb}$ [0.33 vs. $0.16 \mathrm{~kg}] \mathrm{O}_{2}$ for lignite $\left.[23,24]\right)$. The typical raw product gas analysis is similar for lignite and bituminous coal (ca. $32 \% \mathrm{H}_{2}, 55 \% \mathrm{CO}$, $3 \%-9 \% \mathrm{CO}_{2}$, and $5 \% \mathrm{CH}_{4}$, dry basis), and the gas exit temperature ranges from about $500^{\circ} \mathrm{F}$ $\left(260^{\circ} \mathrm{C}\right)$ for lignite to over $1000^{\circ} \mathrm{F}\left(538^{\circ} \mathrm{C}\right)$ for bituminous coal $(3,27)$. Because of the lower steam partial pressure, the slagging gasifier produces considerably less $\mathrm{H}_{2}$ and more $\mathrm{CO}$ compared to the dry-ash Lurgi, but less $\mathrm{CO}_{2}$.

The advantages of the slagging gasifier are a higher thermal efficiency and a greatly reduced volume of gas liquor. Also, British Gas has demonstrated that tars and oils can be reinjected into the gasifier and recycled to extinction (28). The high-temperature slagging design is specifically recommended for fuels that would not be suitable for the low temperature, dry-ash Lurgi process because of their lower reactivity. However, the technology is applicable to all ranks of coal and other carbon fuels including petroleum coke and biomass.

British Gas successfully pilot-tested all ranks of coal, including U.S. PRB subbituminous coal (28), and the GFETC (EERC) pilot plant was operated successfully on both lignite and subbituminous coal $(26,27)$. A 12 -ft-diameter, $35-\mathrm{t} / \mathrm{h}$ BGL gasifier has operated commercially since 2000 at Scharze Pumpe in Germany on coal and waste materials to produce syngas for methanol synthesis (28-30). The BGL technology was scheduled to be demonstrated in a 580-MWe IGCC plant by Kentucky Pioneer Energy under the DOE Clean Coal program, but the project is on hold.

Potential problems in operating a slagging fixed-bed gasifier on low-rank coals would concern slag flow and corrosion of refractory materials, similar to the problems discussed previously for slagging entrained-flow gasifiers. In tests performed in the $20-\mathrm{t} / \mathrm{d}$ pilot plant at the EERC, operation on North Dakota lignite resulted in occurrences of interrupted slag flow and severe slag attack on refractory in the hearth zone when high-sodium and high-calcium lowerrank coals were fired (26). Various hearth plate materials in combination with different types of 
cooling coils and taphole inserts were tested. Erosion occurred on all of the refractory hearth plates that were not sufficiently cooled. Slag flow problems were resolved by designing a watercooled metal hearth plate.

\section{Nexterra Gasifier}

The Nexterra gasifier is similar to the Lurgi, with the exception that the biomass is bottomfed into the gasifier, as shown in Figure 44. The biomass is pushed up through the center and falls outward toward the periphery of the reactor. Combustion air, steam, or oxygen is also fed through the bottom. The biomass moves through progressive stages of drying, devolatilization, gasification, and combustion. Combustion temperature is maintained below the fusion temperature of ash to minimize agglomeration.

Nexterra has two working plants installed, operating on wood residue with $25 \%-55 \%$ moisture content, with three more plants planned. The typical heating duty of the plant is reported at $38 \mathrm{MMBtu} / \mathrm{hr}$, equivalent to approximately 100 tons per day of lignin.

\section{Downdraft Gasifiers}

The high tar and oil products in the syngas for countercurrent moving-bed gasifiers, such as the Lurgi gasifiers, can be mitigated by employing a cocurrent moving-bed system, also known as a downdraft gasifier. Fuel flow is identical to the Lurgi system, in which biomass or coal is fed at the top of the gasifier and ash is removed at the bottom. However, in the case of cocurrent moving-bed systems, the gas flow is reversed. Steam, air, or oxygen is injected at the

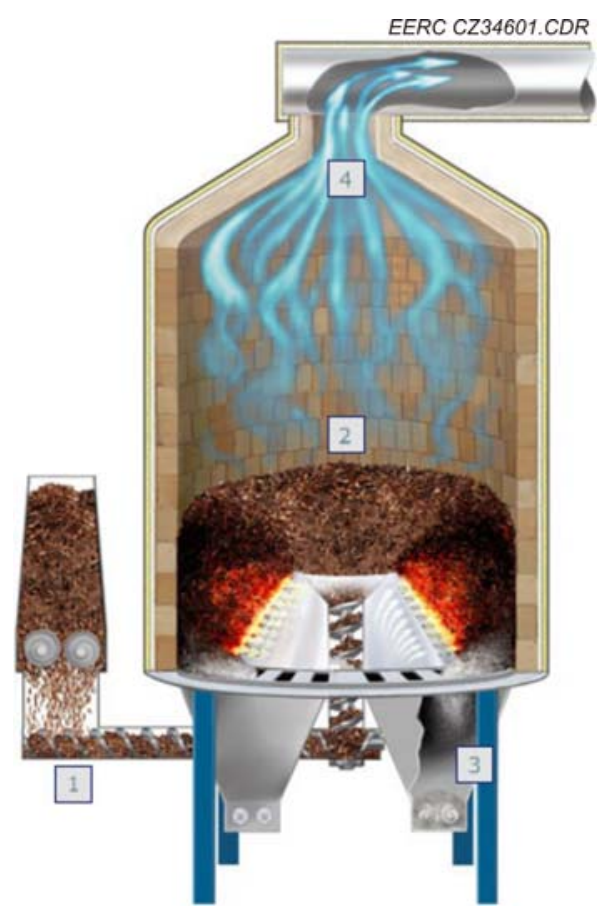

Figure 44. Image of Nexterra gasifier (31). 
top of the gasifier, coflows with the feed, and exits the gasifier through the bottom. Similar to the Lurgi-type gasifiers, fuel fed at the top is progressively heated and reacted as it moves down through drying, devolatilization, oxidation, and gasification zones. Since the gas exits at the bottom of the gasifier, the devolatilization products, which occur at the top of the gasifier, flow down through the reaction zones and react with the chars. This decreases tars and oils in the syngas by several orders of magnitude when compared to Lurgi gasifiers.

Downdraft or cocurrent flow gasification technology is at a much lower development stage than the Lurgi gasifiers. All downdraft gasifiers currently in development or commercialization are air-blown, operate at atmospheric pressure, and are targeted specifically toward distributed biomass resources. Since current operation is at atmospheric pressure, staged compression will be required to convert the syngas to liquids. The advantage of compressing syngas after gasification, as opposed to compressing air or oxygen before gasification, is that the biomass feed system and ash extraction system are significantly simplified, and gas cleaning can be performed at either low pressure or high pressure. The primary disadvantage is that the greater volume of syngas, compared with the input air or oxygen, requires more energy to compress. Of course, most commercial gasifiers described previously can also be operated at atmospheric pressure, if desired.

\section{Ankur Scientific Gasifier}

The most widely employed cocurrent gasifier is developed by Ankur Scientific Technologies. This system is shown in Figure 45. Biomass is input at the top of the gasifier and flows downward through a choke point. Air is sucked in at the choke point, forming a very narrow high-temperature zone. The choke point ensures all char and devolatilization products are concentrated in a high-temperature zone and react. This reduces tar output and ensures up to $98 \%$ carbon conversion. The disadvantage of this type of reactor is that the concentrated high temperature zone may be above the fusion temperature of the biomass ash constituents, causing ash agglomeration and clogging the ash removal system. This limits the type of biomass that can be gasified.

Ankur reports more than 50 gasifiers currently in use, operating on a variety of biomass fuels ranging from fine rice hulls to wood blocks. Two of these are currently in operation at the EERC. Figure 46 shows the Ankur gasifier in an EERC-developed mobile gasification system. This gasifier has operated on a variety of biomass from oak wood pellets to sunflower hulls to wood chunks. Optimal operation requires moisture levels around $15 \%$ and consistent sizing of the fuel. Sizing of the fuel is important to prevent bridging of the fuel bed before the choke point. The typical dry product gas output is $14 \% \mathrm{CO}, 17 \% \mathrm{CO}_{2}, 1.4 \% \mathrm{CH}_{4}, 16 \% \mathrm{H}_{2}$, and $51 \% \mathrm{~N}_{2}$. The thermal efficiency is around $66 \%$.

\section{EERC Indirectly Heated Gasifier}

The EERC is developing an indirectly heated cocurrent gasifier for use on high-moisture biomass. The gasifier was designed to use the available waste energy from high-temperature fuel cell systems or gas-to-liquid systems to aid in the gasification and tar cracking of high-moisture biomass and solid waste. Recycling waste fuel to heat the gasifier results in almost complete carbon conversion and tar cracking in the gasifier on biomass, with moisture levels as high as 


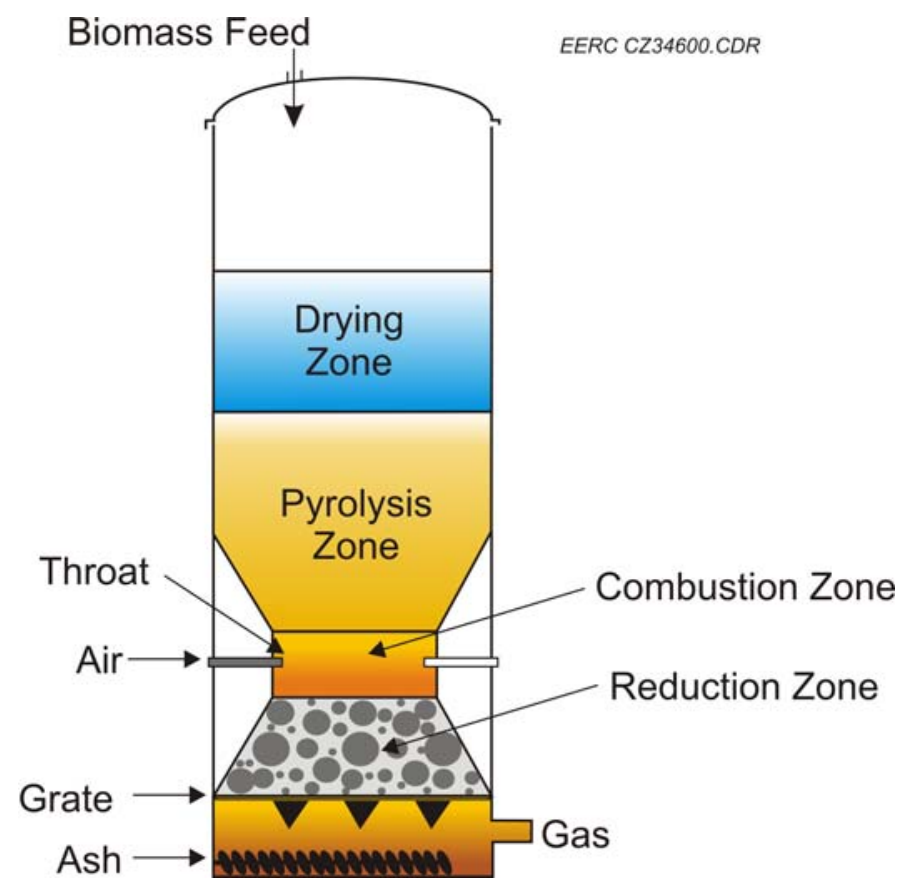

Figure 45. Image of Ankur gasifier (32).

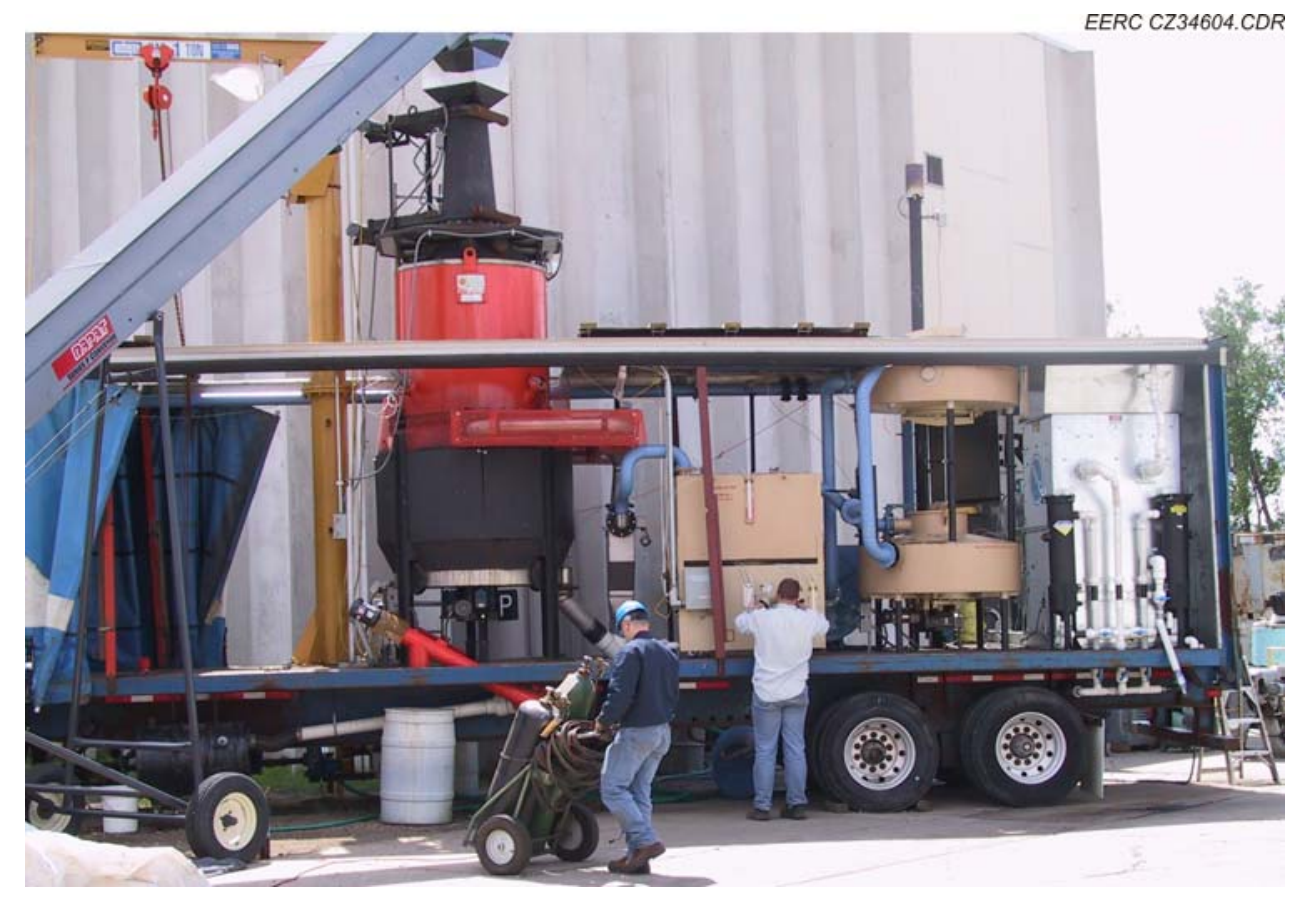

Figure 46. EERC mobile gasification unit utilizing the Ankur gasifier. 
$40 \%$. The ability to use high-moisture feed eliminates drying equipment and the additional labor typically needed for conventional gasifiers. The low tar levels and high carbon conversion reduces the gas cleanup and waste-handling systems. The net result is that the overall power system is simplified and the operating labor minimized.

As part of the development program, a bench-scale gasifier, shown in Figure 47, was constructed and tested on a variety of fuels ranging from nearly green wood to solid waste composed of paper, plastic, and small amounts of inorganic materials such as aluminum foil. The gas composition was consistent with the moisture content in the feed. The runs with highermoisture-content wood chips tended to have higher hydrogen levels and lower nitrogen dilution in the producer gas. Hydrogen and carbon monoxide are approximately $27 \%$. Carbon dioxide levels are relatively low at about $9 \%$. Methane levels were very low at about $2 \%-3 \%$. Nitrogen dilution is significant at $34 \%$, owing to the use of air as the oxidant. This can be reduced to near zero with oxygen. The $\mathrm{HCl}$ levels are shown to be less than $20 \mathrm{ppm}$. The particulate measurements were typically $40 \mathrm{mg} / \mathrm{m}^{3}$. All of the $\mathrm{H}_{2} \mathrm{~S}$ measurements were very consistent and lower than $50 \mathrm{ppm}$.

Table 12 presents fuel gas compositions from gasification tests conducted on some of these gasifiers. Composition data for the Lurgi gasifiers were for oxygen-blown coal fuel. Composition data for the EERC and Ankur gasifiers were for air-blown biomass fuel. All data are presented on a dry gas basis.

\section{Gas-to-Liquids Catalyst Review}

Conversion of syngas to hydrocarbons can be accomplished through the FT process, methanol synthesis, or mixed-alcohol synthesis. In reality, all of these processes produce a mixture of olefins, alcohols, and aldehydes, the primary differences being the selectivity of various groups and mean molecular weight. The selectivity is dependent upon the catalyst used and the operating conditions, most notably temperature, pressure, and residence time. All of these processes are similar in that they convert a mixture of hydrogen and carbon monoxide to hydrocarbons over catalyst. Table 13 provides the general reaction paths for these processes. Ideally, for all reactions the hydrogen and carbon monoxide is fed to a catalytic reactor at a mole ratio of approximately $2: 1$. These processes operate at a temperature between $200^{\circ}$ and $350^{\circ} \mathrm{C}$ and at pressures between 5 and 100 bar. In general, steam, $\mathrm{N}_{2}$, and $\mathrm{CO}_{2}$ act as diluents to the process, although $\mathrm{H}_{2}$ can also be obtained through the oxidation of $\mathrm{CO}$ by steam via the watergas shift reaction, $\mathrm{CO}+\mathrm{H}_{2} \mathrm{O} \rightarrow \mathrm{CO}_{2}+\mathrm{H}_{2}$. If the catalyst has a high shift activity then an input mole ratio closer to $1: 1$ may be desirable to shift the product water to $\mathrm{H}_{2}$. In this case, the primary reaction product becomes $\mathrm{CO}_{2}$, as opposed to $\mathrm{H}_{2} \mathrm{O}$, which may simplify purification somewhat. Additional acid gases such as $\mathrm{H}_{2} \mathrm{~S}$ may act as poisons to the catalyst and should bescrubbed, although the levels are catalyst-specific. As an example, copper-based catalysts require $\mathrm{H}_{2} \mathrm{~S}$ levels below $0.1 \mathrm{ppm}$, while molybdenum-based catalysts require up to $100 \mathrm{ppm}$ of $\mathrm{H}_{2} \mathrm{~S}$ to maintain catalyst activity.

For the FT reaction, the catalysts are typically iron- or cobalt-based. For an ideal $\mathrm{H}_{2}: \mathrm{CO}$ mole ratio of 2:1, cobalt has higher conversion yields and longer life than iron. Typically 100\% of the $\mathrm{CO}$ can be converted to hydrocarbons on a single pass with cobalt catalyst, compared to $50 \%$ for iron. The lower conversion efficiency of iron is due primarily to the water-gas 


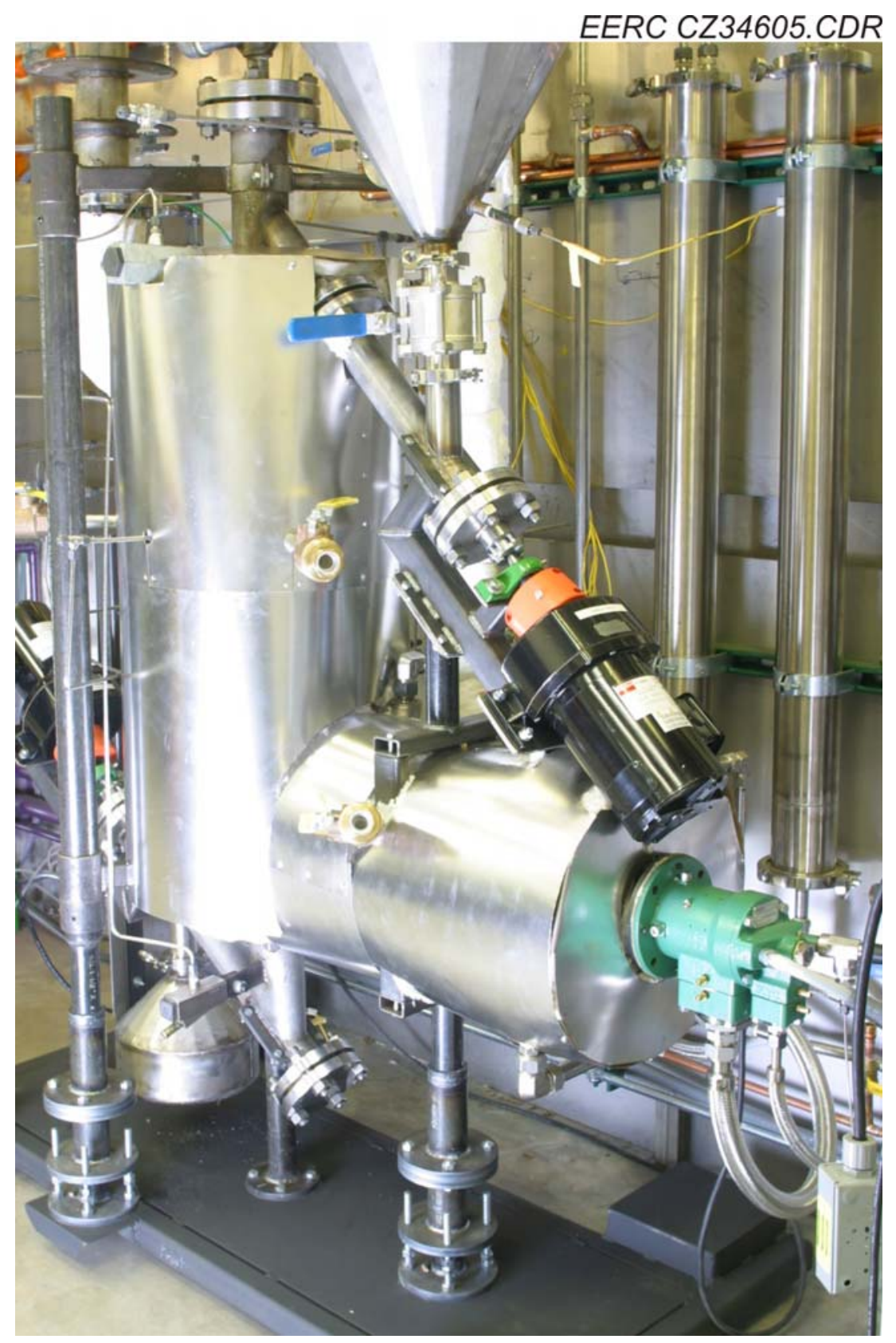

Figure 47. EERC indirectly heated bench-scale gasifier.

Table 12. Typical Cold-Gas Composition of Selected Gasifier Technologies

\begin{tabular}{lcccc}
\hline & & \multicolumn{3}{c}{ EERC Indirectly Heated } \\
& Lurgi & BGL & Gasifier & Ankur Scientific \\
\hline $\mathrm{CO}$ & 16 & 55 & 28 & 14 \\
$\mathrm{H}_{2}$ & 39 & 32 & 27 & 16 \\
$\mathrm{CO}_{2}$ & 31 & 6 & 9 & 17 \\
$\mathrm{CH}_{4}$ & 11 & 5 & 2 & 1 \\
$\mathrm{~N}_{2}$ & 3 & 2 & 34 & 51 \\
\hline
\end{tabular}


Table 13. Gas-to-Liquids Technologies

\begin{tabular}{lcc}
\hline Process & Primary Reaction & Typical Catalyst \\
\hline FT & $\mathrm{nCO}+(2 \mathrm{n}+1) \mathrm{H}_{2} \rightarrow \mathrm{C}_{\mathrm{n}} \mathrm{H}_{2 \mathrm{n}+2}+\mathrm{nH}_{2} \mathrm{O}$ & Iron or cobalt \\
Methanol & $\mathrm{CO}+2 \mathrm{H}_{2} \rightarrow \mathrm{CH}_{3} \mathrm{OH}$ & Copper and zinc oxide \\
Mixed Alcohols & $\mathrm{nCO}+2 \mathrm{nH}_{2} \rightarrow \mathrm{C}_{\mathrm{n}} \mathrm{H}_{2 \mathrm{n}+1} \mathrm{OH}+(\mathrm{n}-$ & $\mathrm{MoS}_{2}$, and modified FT and \\
& $1) \mathrm{H}_{2} \mathrm{O}$ & methanol \\
\hline
\end{tabular}

shift activity of the iron. Cobalt catalysts typically last over 5 years, compared to about 8 weeks for iron. The primary disadvantage of cobalt catalyst is the much higher cost. This is likely to increase if demand for cobalt increases as a result of widespread development of the FT process. For iron catalyst, tail gas recycle can be used to increase total conversion efficiency to approximately $90 \%$, although this complicates system design slightly. In addition, for mole ratios lower than 2:1, the water-gas shift activity of the iron catalyst can be exploited to increase single pass conversions of $\mathrm{CO}$ up to $70 \%$. Selectivity for the FT process can range from a mean carbon number of 3-4, representing light hydrocarbons and gasoline, to a mean carbon number greater than 33, representing waxes. The FT process is the most mature of the gas-to-liquids technologies, with many of the hydrocarbon mixtures, such as FT diesel blends, proven to offer improved performance and reduced emissions versus their petroleum-based counterparts. As an example, synthetic diesel has been shown to reduce nitrogen oxides by $15 \%$ and particulate matter by $25 \%$, when compared with California diesel fuel (33). The improved performance and purity of synthetic fuels may fetch a premium over their petroleum-based counterparts.

The methanol synthesis process is also a mature gas-to-liquids technology. Methanol is currently produced from methane-derived syngas as a raw material for a wide range of chemicals. The market for methanol includes the production of formaldehydes, dimethyl ether, plastics, plywood, paints, explosives, textiles, methyl tert-butyl ether, ethanol, and other products. Methanol catalyst is composed primarily of copper and/or zinc oxide. Because of its widespread synthesis, methanol catalysts have been developed with high selectivity and stability. Experimental catalysts have been reported with over $98 \%$ selectivity and single-pass conversion efficiencies near $50 \%$ (30). The typical operating conditions for methanol synthesis is $250^{\circ} \mathrm{C}$ and $50-100 \mathrm{bar}$, although various catalysts can be employed in a temperature range of $150^{\circ}-300^{\circ} \mathrm{C}$.

Direct synthesis of mixed alcohols from syngas is still in the research stage. Mixed alcohols can be produced by using modified methanol catalyst with less selectivity toward methanol, thus producing a wider range of alcohols and ethanol. Typical modified methanol catalysts have high shift activity and thus require an input mole ratio of $\mathrm{H}_{2}$ : $\mathrm{CO}$ between 1 and 1.2. Standard Alcohol Company of America, Inc., claims to produce a modified methanol catalyst with an ethanol product yield of approximately $50 \%$.

Mixed alcohols can also be produced with modified FT catalyst. In this case, the addition of an alkali promoter to the catalyst decreases selectivity toward hydrocarbons and increases selectivity toward alcohols. Akali- and/or cobalt-promoted $\mathrm{MoS}_{2}$-based catalysts have been tested up to a year with little or no loss in performance (34). Like the modified methanol catalyst, water-gas shift activity is high, allowing the use of a 1-1.2-mole ratio of hydrogen to carbon monoxide. Another advantage of the $\mathrm{MoS}_{2}$-based catalyst is that $\mathrm{H}_{2} \mathrm{~S}$, up to $100 \mathrm{ppm}$, acts as a promoter. Gasification experiments at the EERC on woody biomass using the indirectly heated 
gasifier have measured $\mathrm{H}_{2} \mathrm{~S}$ in the syngas in the range of $20-50 \mathrm{ppm}$. Depending on the lignin ash composition, this catalyst may simplify the syngas-scrubbing system by eliminating the need to scrub $\mathrm{H}_{2} \mathrm{~S}$. Catalyst developers active with this technology are Pearson Technologies; Power Energy Fuels, Inc.; and Western Research Institute (WRI). Of these organizations, Pearson Technologies is the only company with pilot-scale plant experience. Pearson has a 30-ton-perday plant in Aberdeen, Mississippi, and is developing a demonstration sugarcane bagasse plant with the state of Hawaii on the island of Kauai. The other organizations are not yet demonstrated at large scale. In general, single-pass conversion efficiencies range from $10 \%-40 \%$. The selectivity for mixed alcohols ranges from $70 \%$ to $80 \%$. The bulk of the mixed alcohols are methanol and ethanol, with higher alcohols accounting for about $15 \%-20 \%$ of the mix. Ethanol accounts for $30 \%-46 \%$. Methanol makes up the difference.

All of these reactions are exothermic and, thus, thermodynamically favorable. To maintain constant reactor temperature, four types of reactors have been employed commercially. These are presented in Figure 48. Multitubular fixed-bed reactors consist of small tubes with the catalyst as surface-active agents in the tubes. Water surrounds the tubes and maintains temperature through evaporation. Slurry bed reactors are the most common and typically employ embedded heat exchangers in fluid-catalyst slurry. Syngas flows through the slurry, and water/steam flows through the embedded heat exchanger to maintain reactor temperature. This type of reactor can produce high-pressure steam for additional downstream applications, such as biomass pretreatment or ethanol distillation. A fluidized-bed reactor uses syngas flowing through a fluidized bed of catalyst. Both fixed- and fluidized-bed reactors employ embedded heat exchangers to remove heat.

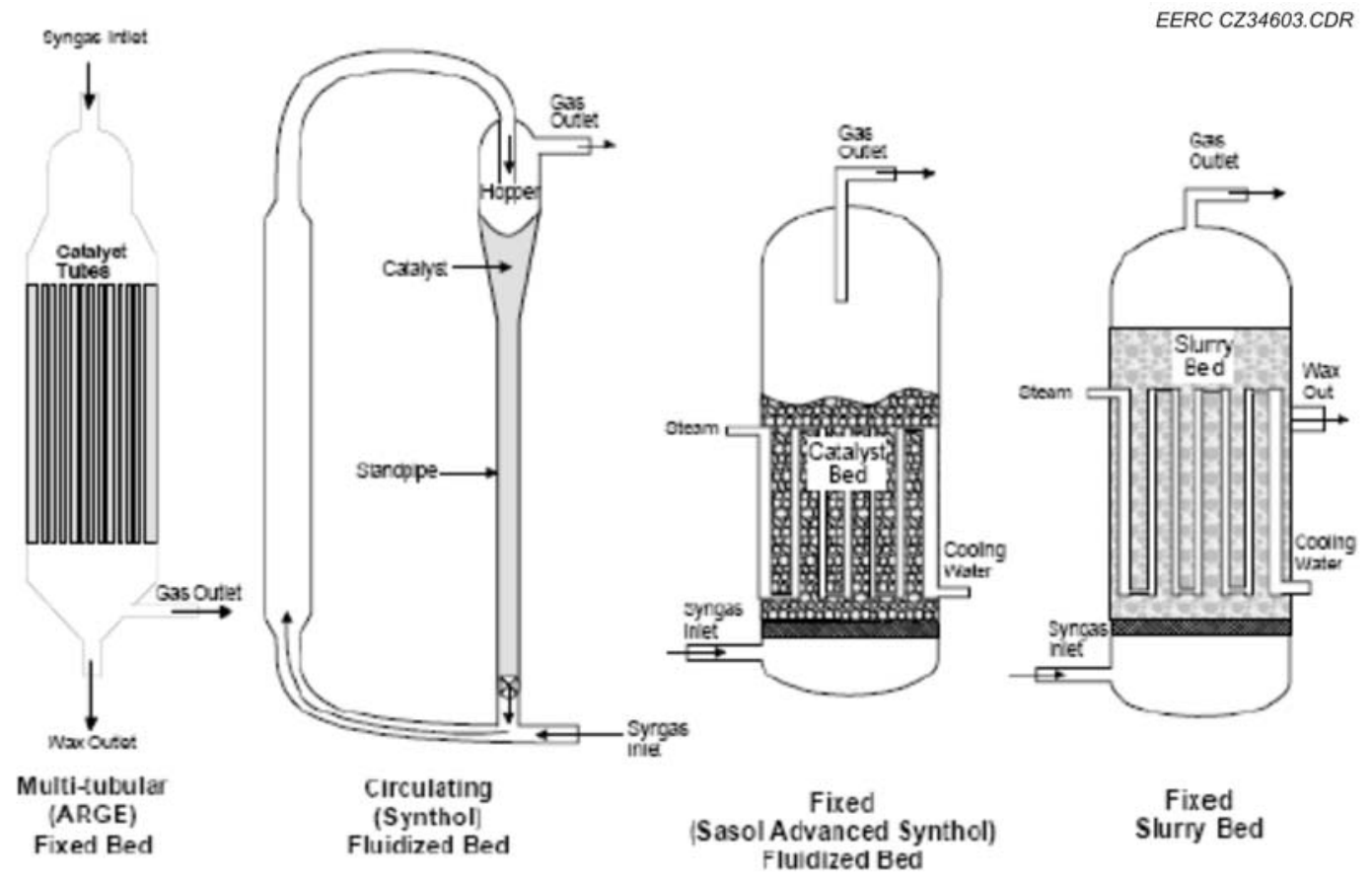

Figure 48. Various commercial GTL reactors (35). 


\section{Review of Ethanol Demonstration Projects}

\section{Gasification Projects}

\section{City of Gridley, California}

The city of Gridley, California, has planned to construct a plant to convert rice straw to ethanol. Originally, the proposed plant was to utilize gasification and an ethanol catalyst to produce the ethanol. The technology was to be provided by Pearson Technologies. However, Pearson Technologies was purchased by Ethxx International before the project could begin. A year later, Silver Spruce Resources offered to purchase Ethxx. This led to a situation where the project as conceived was unable to move forward. As an alternative, BC International proposed building a cellulosic plant near Gridley. Problems developed with the plan when BC International proposed to increase the processing capacity by a factor of 4 and decrease raw material payments to farmers to a level below $\$ 45$ per acre. Both the city of Gridley and area farmers rejected the BC International plan (36).

As originally proposed, this demonstration-scale plant was designed to convert rice straw to ethanol. The key technology includes a steam-blown gasifier and proprietary ethanol synthesis catalyst. The project is funded by the National Renewable Energy Laboratory (NREL) in the form of a \$2.8 million grant. The plant would have consumed 113,000 bone-dry-tons (BDT) of rice straw collected near the city of Gridley. Annual production capacity is listed at 20 million gallons. Experimentally, production has been determined to be 63.3 gallons of ethanol per ton of rice straw. By adding shift technology prior to ethanol synthesis, production could be boosted to 137.4 gallons per ton of rice straw. At a conversion rate of 63.3 gallons per ton, $7,152,900$ gallons of ethanol can be produced annually. Similarly, at a conversion rate of 137.4 gallons per ton, 15,526,200 gallons of ethanol can be produced.

After a period of inactivity, it appears that the rice straw-to-ethanol project is again moving forward. Green Energy Corporation (Denver, Colorado) has stated that its BCT gasifier has been selected as the heart of the technology to convert rice straw to ethanol.

\section{Range Fuels}

Range Fuels is planning to construct a wood-to-ethanol plant near Soperton, Georgia. The facility would produce ethanol and 9 million gallons of methanol per year via conversion of syngas on a proprietary catalyst developed by Range Fuels. A range of mixed alcohols will be produced, including methanol. The alcohols are isolated/purified by standard distillation techniques. The total cost is listed at $\$ 225$ million (37). DOE has provided $\$ 76$ million. The plant utilizes the BCT gasifier, which is a two-stage gasification process, as shown in Figure 49. The biomass feedstock is first devolatilized at relatively low temperature and pressure. The second stage utilizes high pressure and temperature, resulting in complete gasification of the biomass. Ash is removed in a cyclone. Tars and oils are minimized by this two-stage process. The gasifier is steam-blown.

The facility will be constructed in stages. The first stage will produce 10 million gallons of ethanol per year. Ultimately, production capacity will reach 40 million gallons per year by the 


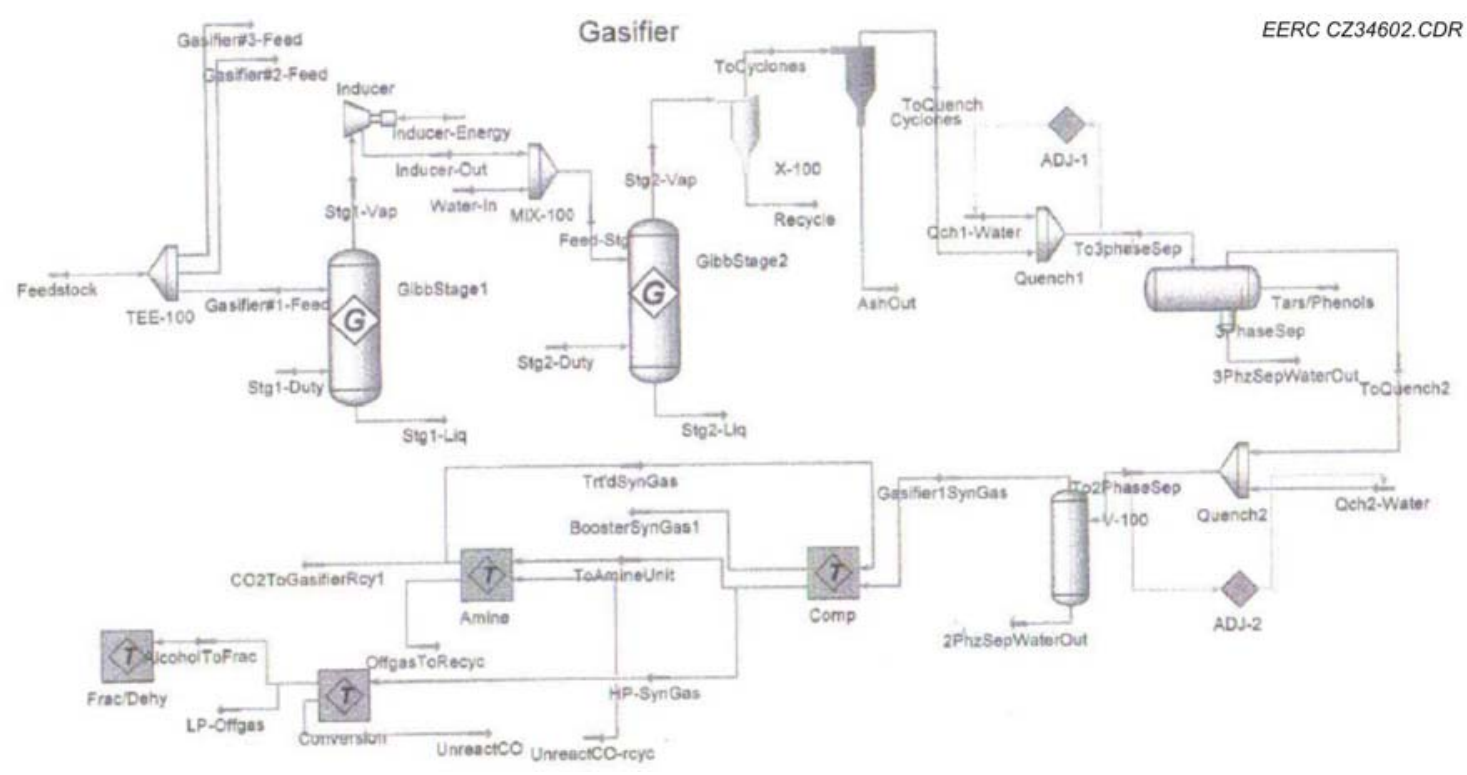

Figure 49. BCT Gasification process flow diagram (37).

addition of duplicate processing units. Feedstock will be unmerchantable timber and forest residue. Consumption will be 1200 tons per day. Construction is scheduled to begin in 2007, with completion of all stages in 2011. Range Fuels is funded in part by Khosla Ventures.

ALICO, Inc.

ALICO, Inc., a land management company based in Florida, was recently awarded (up to) \$33 million by DOE for a plant to be constructed in LaBelle, Florida. Other participants are Bioengineering Resources, Inc. (BRI); Washington Group International; GeoSyntec Consultants; BG Katz Companies; JAKS, LLC; and Emmaus Foundation.

The facility is to comprise two units. The first has an annual production capacity of 7.7 million gallons of ethanol. The second has a capacity of 13.9 million gallons. Other products will include electric power $(6255 \mathrm{~kW})$, ammonia $(50 \mathrm{tpd})$, and hydrogen $(8.8 \mathrm{tpd})$. Construction costs are estimated to be in excess of $\$ 100,000,000$. Based on company information, BRI is using a modified Consutech medical waste incinerator as a gasifier on its pilot unit in Fayetteville, Arkansas. The modifications allow BRI to use a two-stage gasification process, which reduces tars present in the synthesis gas. It should be noted that the first stage of gasification can operate on air, $\mathrm{O}_{2}$-enriched air, or pure oxygen. The capacity of the pilot unit is about 1.5 tons per day.

The first stage operates at about $950^{\circ} \mathrm{F}$, with oxygen-enriched air (or alternatively pure oxygen) injected at a controlled rate below the grate. Pure oxygen is then injected in the throat between the first and second stage to raise temperature to $2250^{\circ} \mathrm{F}$ for tar cracking. The goal is to maximize $\mathrm{CO}$ and $\mathrm{H}_{2}$ production while minimizing other constituents. A schematic of the gasifier is shown in Figure 50. 


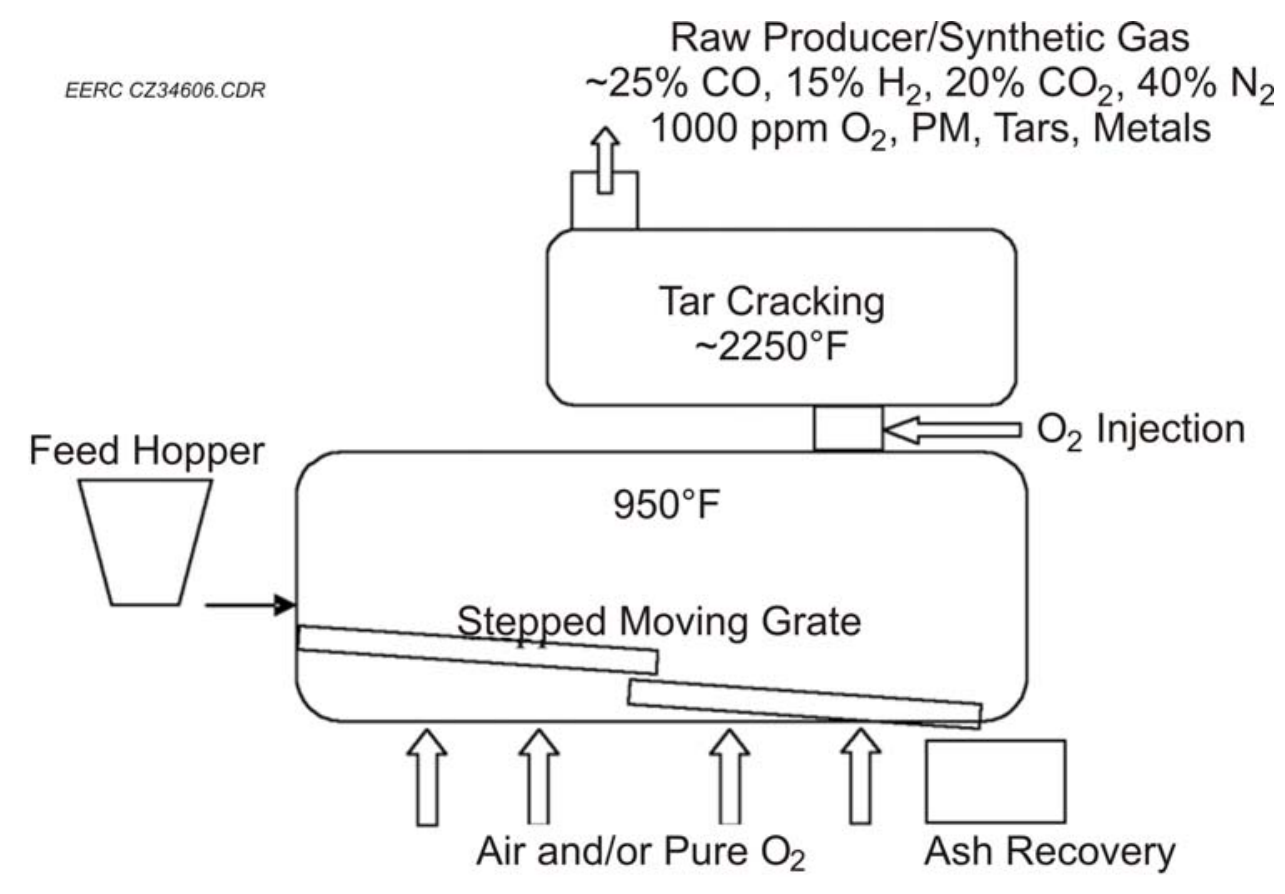

Figure 50. Consutech gasifier diagram.

Following gasification, the syngas is scrubbed by a water spray column directly after the gasifier. The scrubber water requires treatment prior to discharge. Simple mechanical filtering of the water is performed to remove solids and particulate matter. Following gas cleanup, the syngas enters the fermenter at about $100^{\circ} \mathrm{F}\left(38^{\circ} \mathrm{C}\right)$. The fermentative technology is provided by Bioengineering Resources Inc. of Fayetteville, Arkansas. This technology utilizes anaerobic bacteria to convert syngas to ethanol. The process produces mixed alcohols, with ethanol being the most abundant. Purification of ethanol by distillation of a dilute product stream is required. The bioreactor is operated at a pressure of approximately 3 atmospheres.

The fermenter is anticipated to use about $75 \%$ of the gas, so the tail gas (containing mainly $\mathrm{CO}$ and $\mathrm{H}_{2}$ ) will be combusted as a flare or for steam at a commercial facility. At the pilot plant, the tail gas is vented. Flow rate of tail gas was estimated by the source test engineer to be about $0.2 \mathrm{cfm}$. Ethanol produced in the bioreactor is purified via a distillation column and molecular sieve, resulting in anhydrous (fuel-grade) ethanol. Construction will begin in 2008, with completion scheduled for 2010. Feedstocks will be consumed at a rate of 770 tons per day. Sources include yard, wood, and vegetable wastes, including citrus peels. Energycane is to be added as a feedstock as supplies develop. Ethanol will be produced at a rate of 20.9 million gallons per year with both units in operation.

\section{Choren}

The Carbo- $\mathrm{V}^{\circledR}$ process is a three-stage gasification process involving the following subprocesses: 
- Low-temperature gasification

- High-temperature gasification

- Endothermic entrained-bed gasification

During the first stage of the process, the biomass (with a water content of $15 \%-20 \%$ ) is broken down into a gas-containing tar (volatile parts) and solid carbon (char) through partial oxidation with air or oxygen at temperatures between $400^{\circ}$ and $500^{\circ} \mathrm{C}$. During the second stage of the process, the gas containing tar is postoxidized hypostoichiometrically using air and/or oxygen in a combustion chamber operating above the melting point of the fuel's ash. During the third stage of the process, the char is ground down into pulverized fuel and blown into the hot gas produced in the second stage. The pulverized fuel and the second-stage gasification products react in the gasification reactor and are converted into a raw synthesis gas. Once this gas has been treated in the appropriate manner, it can be used as a combustible gas for generating electricity, steam, and heat or as a synthesis gas for producing products.

The technology platform comprises Choren gasification technology on the front end and Shell FT technology on the back end. Choren has entered into an agreement with Shell, and the Choren gasifier can only be used to make FT diesel using Shell FT platform.

\section{Frontline Bioenergy}

Frontline Bioenergy is installing gasification technology at the Chippewa Valley Ethanol Company facility in Benson, Minnesota. The goal of the project is to replace all natural gas consumed by the plant for process heat and steam with biogas. The project will be performed in stages. The first stage will utilize 75 tons per day of biomass. The second stage will add Frontline CLEANGAS ${ }^{\mathrm{TM}}$ technology to eliminate boiler and tube fouling. The third phase will increase biomass utilization to 300 tons per day.

The technology will employ a bubbling-fluidized-bed gasifier. The initial stages of the project will be directed at replacing natural gas for heating. The third stage will bring in BRI syngas fermentation technology (see ALICO section above) for additional production of ethanol.

\section{Cellulosic Sugar Fermentation Projects}

\section{Abengoa Bioenergy Biomass of Kansas (a LLC of Chesterfield, Missouri)}

Abengoa has been awarded (up to) $\$ 76$ million for a plant to be located in Kansas. Other participants include Antares Corporation and Taylor Engineering. The goal of the project is to demonstrate a commercial-scale plant integrating both biochemical and thermochemical processing to produce ethanol. The long-term strategy is to utilize syngas for ethanol and chemical production. The estimated construction cost of the project is $\$ 300,000,000$ (38). Abengoa has been operating a demonstration-scale hybrid facility in Spain for over 1 year.

Abengoa has a number of long-standing partners with which it has developed technology in the past, including Aicia, a university research organization based in Spain. It is believed that Abengoa will utilize an Aicia-designed circulating-fluidized-bed gasifier technology at the Colwich site. Further, Abengoa has developed a proprietary ethanol catalyst in partnership with 
ICP, another R\&D organization based in Spain. It is believed that Abengoa will utilize this catalyst for the conversion of syngas to ethanol at the Colwich site. Other technology which Abengoa has access to is SunOpta steam explosion technology. This technology may be used on the bio side of the hybrid plane in order to make more sugars available for fermentation. The lignin-based residue would be subjected to gasification.

Feedstock will be consumed at a rate of 700 tons per day, with an anticipated output of 11.4 million gallons per year. Excess energy will be provided to a collocated dry-grind ethanol plant. Feedstock will include corn stover, wheat straw, milo stubble, switchgrass, and other opportunity fuels. Construction is to begin in 2008, with completion in 2011.

\section{BlueFire Ethanol, Inc.}

BlueFire has been awarded (up to) $\$ 40$ million for a plant to be located in Southern California. The plant will be located at an existing landfill site. Other participants include Waste Management, Inc.; JGC Corporation; MECS Inc.; NAES; and PetroDiamond. BlueFire currently has a demonstration-scale plant in Izumi, Japan, producing ethanol at a rate of 300 liters per day ( $\sim 80$ gallons per day). This facility also utilizes membrane distillation technology, which results in claimed economy of operation. Construction of the new U.S.-based plant is to begin in 2008, with completion in 2009. The estimated cost of construction is $\$ 110,000,000$ (39).

The technology is based upon Arkenol strong acid hydrolysis of lignocellulosic feedstocks. The acid used is sulfuric acid. Economy of operation is founded in the acid being inexpensive and recyclable through reconcentration technology. Simulated-moving-bed chromatography units are employed to separate the sugar and the acid. The sugar is sent to fermentation, while the acid is sent to a reconcentration unit. Feedstock will be consumed at a rate of 700 tons per day, with an anticipated output of 19 million gallons per year. Feedstock will include sorted green waste and wood waste from landfills.

\section{POET (formerly Broin Companies)}

POET has been awarded (up to) $\$ 80$ million for a plant to be located near Emmetsburg, Iowa. Other participants include E.I. du Pont de Nemours and Company, Novozymes North America, and NREL. The goal of the project is to demonstrate integration of a cellulosic ethanol plant with an existing dry-grind corn-to-ethanol plant. It should be noted that this a biological approach to creating a hybrid plant, complementing (and competing with) the Abengoa thermochemical approach. To achieve this goal, POET will need to integrate technologies provided by du Pont and Novozyme. The construction costs for this project are estimated to be $\$ 200,000,000$ (40). Construction is scheduled to begin in 2007 and require 30 months for completion.

The technology is founded in enzymes to hydrolyze lignocellulose. POET has two technology platforms. The first, BPX, is a starch-to-sugar hydrolysis technology. The second, BFRAC, is a separation technology that partitions corn into fiber, germ, and endosperm components. The endosperm is processed to ethanol, while the fiber and germ are processed to distillers grain and other by-products. The Emmetsburg facility will demonstrate the integration of the BPX and BFRAC technologies. Output is anticipated to be 125 million gallons per year, 
with $\sim 25 \%$ of the output being from lignocellulosic feedstock. Feedstock will be consumed at a rate of 842 tons per day. Feedstock will be corn fiber and stover.

\section{Iogen Biofinery Partners, LLC}

Iogen Biorefinery Partners has been awarded (up to) $\$ 80$ million for a plant to be located near Idaho Falls. Other participants include Iogen Corporation, Goldman Sachs, Royal Dutch Shell Oil Company, and others. The goal of the project is to demonstrate feedstock flexibility in a scaled-up biochemical process. The technology is based on enzymatic hydrolysis and fermentation utilizing engineered microorganisms. The microorganisms are producers of enzymes which are separated from the microorganism, then sent to the hydrolysis or fermentation processes as biochemical catalysts. This is complementary to the POET approach, which is to add the microorganisms to the feedstock, not just the enzymes.

Feedstock will be consumed at a rate of 700 tons per day, with an anticipated output of 18 million gallons per year. Feedstock will be wheat straw, barley straw, corn stover, switchgrass, rice straw and, potentially, other agricultural crop residues. Construction of the new facility is scheduled to begin in 2008 with completion near the end of 2010.

Iogen built and operated a demonstration-scale cellulose-to-ethanol plant located near Ottawa, Canada. Output at this plant is about 1 million gallons per year.

\section{Other Industrial Ethanol Technology}

\section{Masada}

Masada's business and technology interests revolve around converting municipal waste and sludge into ethanol and industrial by-products. They have patented a process which they call "OxyNol." The process is claimed to release cellulose from lignocellulosic waste. Subsequent saccharification and fermentation provide ethanol. The OxyNol process utilizes sulfuric acid to facilitate the decomposition of lignin, similar to the Arkenol and BlueFire technologies. Pencor Masada OxyNol, LLC, is a Birmingham, Alabama-based corporation jointly formed between Pencor and Masada. This company has recently announced its plan to develop a $\$ 287$ million facility near Middletown, New York (41). It has a preapplication to DOE for up to \$229 million in federal construction guarantees to assist in the project.

\section{Coskata}

Coskata is a venture capital firm supported in part by Khosla Ventures. There is not much information available on this company. It is based in the Chicago area and is focusing on cellulosic ethanol. The company claims to be "leveraging innovative intellectual property, a strong engineering foundation, and emerging process development to bring proprietary technology to the market." 


\section{Lanza Tech}

Lanza Tech is another venture capital firm supported in part by Khosla Ventures. This company is based in Auckland, New Zealand. Its technology centers on conversion of municipal solid waste (MSW) to ethanol. The company claims to possess a "purpose-built laboratory" in which it has invented its technology. The company is in the process of refinement and scale-up.

\section{SunOpta}

SunOpta is an engineering firm based in Brampton, Ontario, Canada. It seems to be based in steam explosion of biomass for the purpose of lignin destruction and saccharide release from the feedstock. It has supported the design, construction, and operation of plants worldwide, including Italy, France, Finland, and the United States.

\section{ZeaChem}

Based in Menlo Park, California, ZeaChem is focused on integration of thermochemical and biochemical utilization of biomass feedstocks. It does not disclose ownership of laboratory or pilot facilities.

\section{Primenergy}

Primenergy has constructed a number of biomass gasifiers around the United States. Two separate systems have been installed in Arkansas for the gasification of rice hulls (total capacity is 550 tpd), a wood gasifier in Little Falls, Minnesota (240 tpd), a biosolids/sludge facility in Philadelphia (67 tpd), and an olive waste gasifier in Italy (144 tpd).

Since the gasifier is air-blown, most projects produce steam and heat or electrical energy. No project has produced a transportation fuel. Table 14 provides a summary of selected ethanol demonstration projects.

\section{Experimental}

\section{See Appendix A.}

\section{Results and Discussion}

Selection of gasifier type should be coordinated with the gas-to-liquids (GTL) catalyst and the lignin gasification characteristics. The high moisture content of the lignin after fermentation will require a significant heat load if it must be dried prior to gasification. If the lignin can be slurry-fed to the gasifier, then both the feed system and lignin preparation steps for gasification may be significantly simplified.

The choice of high-pressure gasification or atmospheric gasification requires an economic analysis of the tradeoffs associated with each type of plant. The primary advantage of highpressure gasification is that postgasification compression is minimized and compression is completed on clean air while postgasification compression is completed on a contaminant 
Table 14. Summary of Selected Ethanol Projects

\begin{tabular}{|c|c|c|c|c|c|c|c|c|c|c|}
\hline & $\begin{array}{l}\text { Range } \\
\text { Fuels }\end{array}$ & ALICO & Abengoa & BlueFire & POET & Iogen & Choren & Frontline & SunOpta & Masada \\
\hline $\begin{array}{l}\text { Project } \\
\text { Cost } \\
\text { (millions) }\end{array}$ & $\$ 225$ & $\$ 250$ & $\$ 300$ & $\$ 110$ & $\$ 200$ & $\$ 320$ & $\begin{array}{c}\$ 50 \\
(\operatorname{Ref} 49)\end{array}$ & $\$ 60$ & $\$ 16$ & $\$ 287$ \\
\hline $\begin{array}{l}\text { DOE } \\
\text { Award } \\
\text { (millions) }\end{array}$ & $\$ 76$ & $\$ 33$ & $\$ 76$ & $\$ 40$ & $\$ 80$ & $\$ 80$ & $\$ 0$ & $\$ 0$ & $\$ 4$ & \\
\hline $\begin{array}{l}\text { Project } \\
\text { Location }\end{array}$ & $\begin{array}{l}\text { Soperton, } \\
\text { GA }\end{array}$ & $\begin{array}{l}\text { LaBelle, } \\
\text { FL }\end{array}$ & $\begin{array}{l}\text { Colwich, } \\
\text { KS }\end{array}$ & $\begin{array}{l}\text { Southern } \\
\text { CA }\end{array}$ & $\begin{array}{l}\text { Emmetsburg, } \\
\text { IA }\end{array}$ & $\begin{array}{l}\text { Shelley, } \\
\text { ID }\end{array}$ & $\begin{array}{l}\text { Alberta, } \\
\text { Canada }\end{array}$ & $\begin{array}{l}\text { Benson, } \\
\mathrm{MN}\end{array}$ & $\begin{array}{l}\text { Jennings, } \\
\text { LA }\end{array}$ & $\begin{array}{c}\text { Orange } \\
\text { County, } \\
\text { NY }\end{array}$ \\
\hline $\begin{array}{l}\text { Annual } \\
\text { Production } \\
\text { (MM Gal) }\end{array}$ & 40 & 20.9 & 11.4 & 19 & 31.25 & 18 & $\begin{array}{c}\text { Hydrogen } \\
10,000 \\
\mathrm{Nm}^{3} / \mathrm{hr}\end{array}$ & $\begin{array}{l}\text { Natural gas } \\
\text { replacement, } \\
\text { ethanol }\end{array}$ & 1.4 & 7.1 \\
\hline Feedstock & Forest & $\begin{array}{l}\mathrm{Ag} \& \\
\text { Forest }\end{array}$ & $\mathrm{Ag}$ & MSW & $\mathrm{Ag}$ & $\mathrm{Ag}$ & $\mathrm{Ag}$ & $\mathrm{Ag}$ & Forest & MSW \\
\hline $\begin{array}{l}\text { Feedstock, } \\
\text { tons/day }\end{array}$ & 1200 & 770 & 700 & 700 & 842 & 700 & 240 & 300 & & 800 \\
\hline Gallons/ton & 95.2 & 77.6 & 46.5 & 77.6 & 106 & 73.5 & $\mathrm{~N} / \mathrm{A}$ & $\mathrm{N} / \mathrm{A}$ & & 25.4 \\
\hline $\begin{array}{l}\text { Installed } \\
\text { Cost, \$/gal }\end{array}$ & $\$ 5.63$ & $\$ 11.96$ & $\$ 26.32$ & $\$ 5.79$ & $\$ 6.40$ & $\$ 17.78$ & $\mathrm{~N} / \mathrm{A}$ & N/A & $\$ 11.43$ & $\$ 40.42$ \\
\hline $\begin{array}{l}\text { Core } \\
\text { Technology }\end{array}$ & Gasify & Gasify & Gasify & $\begin{array}{l}\text { Acid \& } \\
\text { Steam }\end{array}$ & $\begin{array}{l}\text { Microbial } \\
\text { Digestion }\end{array}$ & $\begin{array}{l}\text { Enzymatic } \\
\text { Digestion }\end{array}$ & Gasify & Gasify & $\begin{array}{l}\text { Steam } \\
\text { Explosion }\end{array}$ & $\begin{array}{c}\text { Acid } \\
\text { Digestion }\end{array}$ \\
\hline $\begin{array}{l}\text { Supporting } \\
\text { Technology }\end{array}$ & Catalyst & $\begin{array}{l}\text { Syngas } \\
\text { Ferment. }\end{array}$ & Catalyst & Ferment & $\begin{array}{c}\text { GMO } \\
\text { Ferment }\end{array}$ & $\begin{array}{l}\text { Adapted } \\
\text { Ferment. }\end{array}$ & $(\mathrm{F}-\mathrm{T})$ & $\begin{array}{c}\text { Syngas } \\
\text { Ferment. }\end{array}$ & Ferment & $\begin{array}{l}\text { Syngas } \\
\text { Ferment. }\end{array}$ \\
\hline $\begin{array}{l}\text { Other } \\
\text { Technology }\end{array}$ & $\begin{array}{l}\text { Steam } \\
\text { Reforming } \\
\text { gasifier }\end{array}$ & $\begin{array}{c}\text { 2-stage } \\
\text { Gasifier, } \\
\text { BRI }\end{array}$ & $\begin{array}{l}\text { Integrate } \\
\text { Starch }\end{array}$ & SMB & $\begin{array}{l}\text { Separation of } \\
\text { feedstock } \\
\text { components }\end{array}$ & $\begin{array}{c}\text { Steam } \\
\text { explosion }\end{array}$ & $\begin{array}{l}\text { 3-stage } \\
\text { gasifier }\end{array}$ & $\begin{array}{c}\text { CLEANGAS } \\
\text { BRI }\end{array}$ & $\begin{array}{c}\text { Steam } \\
\text { explosion }\end{array}$ & BRI \\
\hline
\end{tabular}


containing hydrogen-rich syngas. Depending on the initial and final syngas pressures, this may require several staged compression steps. For an atmospheric pressure gasifier, as much as five staged compression steps may be required to bring the syngas to the pressure needed for the GTL plant. The syngas-scrubbing and conditioning system is also more complex at higher pressures. Both the air separation unit and the staged compression units are capital-intensive and require high electrical loads to operate.

Gasification conditions (oxygen-to-steam ratio, feed moisture level, temperature, and pressure) can be optimized to provide syngas compositions that best match the requirements of the GTL catalyst. This would minimize the syngas-scrubbing and conditioning system needed to condition the syngas for the GTL plant. In general, mixed-alcohol catalysts require hydrogen-tocarbon monoxide ratios slightly greater than one. Nitrogen dilution should be kept to a minimum. This would require oxygen or steam gasification. Carbon dioxide and methane should also be kept to a minimum, thereby excluding the fixed-bed gasification systems. High $\mathrm{CO}_{2}$ will inhibit shifting of steam to hydrogen, increasing the optimal $\mathrm{H}_{2}: \mathrm{CO}$ ratio of the syngas closer to 2 . Methane will act as a inert diluent during liquid fuel production. Depending on catalyst, $\mathrm{H}_{2} \mathrm{~S}$ will probably have to be scrubbed to extremely low concentrations.

In general high-temperature entrained-flow gasification systems with gas temperatures of $1040^{\circ}$ to $1430^{\circ} \mathrm{C}\left(1904^{\circ}\right.$ to $\left.2606^{\circ} \mathrm{F}\right)$ will produce ratios of $\mathrm{H}_{2}$ to $\mathrm{CO}$ of 0.5 to 1 with little methane. $\mathrm{CO}_{2}$ will be proportional to the amount of oxidant and varies between $0 \%-16 \%$. Slurry-fed gasifiers will require more oxidant than dry fed gasifiers and, therefore, will produce more $\mathrm{CO}_{2}$ at high temperatures. Fixed-bed gasifiers with exit gas temperatures of $260^{\circ}$ to $540^{\circ} \mathrm{C}$ $\left(500^{\circ}\right.$ and $\left.1004^{\circ} \mathrm{F}\right)$ will produce methane of $8 \%$ to $10 \%$ in the syngas. Fluid-bed gasifiers will produce a syngas with somewhat lower methane concentrations at exit temperatures of $820^{\circ}$ to $1000^{\circ} \mathrm{C}\left(1508^{\circ}\right.$ and $\left.1832^{\circ} \mathrm{F}\right)(42)$. Appendix B contains additional comments on a National Renewable Energy Laboratory (NREL) report regarding gasification that may be of interest.

\section{Conceptual Plant Approach}

The following is an evaluation of the economics and performance of a viable biomass-toliquids technology.

\section{Process Flow, Mass, and Energy Balance}

The process flow diagram (PFD) for the lignin gasification diesel facility is provided in Appendix C. The composition of the wet lignin that will be used in the system is currently unknown. Therefore, the wet lignin was modeled after wet distillers' grains with $64 \%$ moisture, and the dry lignin is modeled after dry distillers' grains with solubles at $10 \%$ moisture (43). A generic drying and feed system was used for the PFD design. Lignin composition and physical characteristics will dictate the specific drying and feed equipment necessary to condition the lignin for gasification. Heated air can be used to predry the lignin, and a gas dyer would remove the remaining water. Depending on the characteristics, the lignin can be pneumatically fed to the gasifier or augured through a series of pressurized lock hoppers. 
The gasifier was modeled after a dry-feed, entrained-flow, pressurized gasifier, as described by Sondreal et al. (44). The gasifier was operated using oxygen at an $\mathrm{O} / \mathrm{C}$ mole ratio of 0.93 suggested by EPRI for the gasification of Texas lignite. This provides an equivalence ratio of 0.40 and gasifier energy efficiency of 77\% (HHV basis), which are typical of most gasifier technologies. Syngas composition was modeled using FactSage 5.5 and gas-phase equilibrium at an operating temperature of $2800^{\circ} \mathrm{F}$ and pressure of 350 psia. The high operating temperatures of entrained-flow gasifiers minimize tars in the syngas and melt the inorganic ash in the lignin to slag for easy discharge under pressure. Heat recovery can thus be obtained by heating the air for lignin drying and cooling the syngas to about $600^{\circ} \mathrm{F}$ via a heat exchanger without tar deposition.

The syngas is then quenched to $98^{\circ} \mathrm{F}$ through a wet venturi scrubber for desulfurization, condensing moisture and any residue tars in the syngas. The tars are hydrophilic in nature and can be separated from water in a flotation unit with a skimmer. Depending on the composition and amount, the tars may be combined with the product diesel/gasoline or combusted. In the PFD design, the tars are pumped to the diesel separation unit and fractionated with the diesel/gasoline product from the FT reactor. The water from the flotation unit is sent to a cooling tower for heat removal and recycled back to the scrubber. Depending on the amount and nature of any residue tars left in the water after skimming, the water removed may require filtering through a carbon bed to prevent fouling the cooling tower.

The cool, dry syngas is desulfurized and preheated for conversion to diesel/gasoline. For small systems nonregenerable, fixed-bed sponge iron reactors provide a relatively simple and economical means to remove $\mathrm{H}_{2} \mathrm{~S}$ to the single-digit ppm level or below. Work at the EERC has demonstrated the removal of $\mathrm{H}_{2} \mathrm{~S}$ from biomass-derived syngas to below 1 ppm (45). Estimates by manufacturers put the lower limit at $0.1 \mathrm{ppm}$ (3). Additional polishing units may be required, depending on the amount of sulfur that must be removed and the requirements of the FT catalyst.

A condensing heat exchanger is used to preheat the syngas to $495^{\circ} \mathrm{F}$ prior to entering the FT reactor. The FT reaction is highly exothermic, and product distribution is dependent upon reactor temperature. Higher temperatures $\left(\sim 600^{\circ} \mathrm{F}\right)$ produce olefins and hydrocarbon distributions similar to gasoline. Lower temperatures $\left(\sim 360^{\circ} \mathrm{F}\right)$ produce waxes. Midrange temperatures $\left(\sim 500^{\circ} \mathrm{F}\right)$ produce hydrocarbon distributions similar to diesel (46). High-pressure cooling water is used to maintain isothermal reactor temperature at $510^{\circ}-620^{\circ} \mathrm{F}$, depending on the desired product distribution. Cooling water is maintained at about 850 psia to produce a boiling point of $525^{\circ} \mathrm{F}$, using the heat of vaporization from boiling water for maximum heat removal with minimum flow. This high-temperature steam is subsequently used to preheat the syngas through the condensing heat exchanger. Approximately $30 \%$ of the steam is condensed to preheat the syngas to temperature. The steam-water mixture is passed through a second condensing heat exchanger using the return water from the flotation unit as cooling water to condense the stream entirely, allowing it to be recycled back to the FT reactor's cooling loop. The return water from the flotation unit is then sent to the cooling tower for heat removal and recycling. The heat removal rate of $3 \mathrm{MMBtu} / \mathrm{hr}$ to completely condense the hot water/steam stream increases the inlet water temperature to the cooling tower to approximately $110^{\circ} \mathrm{F}$.

An iron catalyst is the FT catalyst of choice because of its relatively low cost, ability to process a wider range of $\mathrm{H}_{2}$ : $\mathrm{CO}$ ratios, higher sulfur tolerance, and ability to promote the water- 
gas shift reaction along with hydrocarbon chain growth. Chain growth occurs through the FT reaction, $\mathrm{nCO}+2 \mathrm{nH}_{2} \rightarrow\left(\mathrm{CH}_{2}\right)_{\mathrm{n}}+\mathrm{nH}_{2} \mathrm{O}$. The water-gas shift reaction regenerates additional hydrogen through the reaction of $\mathrm{CO}$ with water, $\mathrm{nCO}+\mathrm{nH}_{2} \mathrm{O} \rightarrow \mathrm{nCO}_{2}+\mathrm{nH}_{2}$. The net reaction for chain growth with the iron catalyst is thus $2 \mathrm{nCO}+\mathrm{nH}_{2} \rightarrow\left(\mathrm{CH}_{2}\right)_{\mathrm{n}}+\mathrm{nCO}_{2}$, producing $\mathrm{CO}_{2}$ as the main by-product of the reaction. The minimum $\mathrm{H}_{2}: \mathrm{CO}$ ratio is 0.5 . The typical $\mathrm{H}_{2}: \mathrm{CO}$ ratio in the raw syngas from a dry feed, entrained-flow gasifier is approximately $0.5-1.0$. Single-pass CO conversion for iron catalysts has been reported as high as $90 \%$, although $50 \%-60 \%$ tends to be more typical, as reported in literature (47). A single-pass conversion of $60 \%$ was assumed. The resulting stream is then sent through a staged separation process to remove any unconverted gases from the diesel/gasoline product. The unconverted gas has an energy value of approximately $190 \mathrm{Btu} / \mathrm{scf}$, suitable to offset the natural gas load in the plant.

\section{Economics}

Process economics are measured by analyzing and providing the following: a pro forma analysis over a 20-year term, internal rate of return, and a sensitivity analysis to determine the economic factors that have the most impact on the plant's financial performance. In general biomass costs vary from a negative value, representing opportunity fuels and waste residue, to a high value due to the high cost of growing, harvesting, and transportation. The base case pro forma assumes a net zero cost for the lignin. If a market currently exists for the lignin, then the cost would increase to the market value of the lignin. Likewise, if the lignin currently incurs a disposal cost, then the lignin costs would represent a net revenue source. The pro forma is based on a feed rate of 50 tons/day on a dry, ash-free-lignin basis. This is equivalent to approximately 150 tons/day on a wet-lignin basis, assuming $64 \%$ moisture for wet lignin and $10 \%$ moisture for dry lignin. Product generation was estimated to be 0.68 million gallons diesel annually. The pro forma includes escalation rates on all economic factors based on historical data.

\section{Capital Costs}

Table 15 provides a summary of the capital equipment costs. Capital equipment costs for the heat exchangers, pressure swing adsorption (PSA), SulfaTreat system, and cooling tower were obtained from estimates by manufacturers (48-52). The gasification, dryer and feed system estimates were obtained from prior experience at the EERC in costing gasification and feed systems for a $250-\mathrm{MW}$ th biomass IGCC system. The six-tenths-factor rule, as provided by Peters and Timmerhaus (53), was used to scale costs to a gasifier and feed system of 50 tons/day. Subsequent research and testing is required to design the drying and high-pressure feed system specific to the feed characteristics of the wet and dry lignin. The FT reactor costs were estimated by costing the price of the catalyst and an internal estimate of the material and fabrication costs for the reactor vessel. Dissolved air flotation (DAF) is common practice in municipal (waste) water treatment. The cost of a DAF system was estimated by scaling from an equipment price list of the new water treatment facility being installed in Winnipeg, Manitoba (54). The cost of staged separation was derived from typical ethanol distillation equipment (55). The contingency is an estimate for piping, valves, associated hardware, and contingencies associated with first-ofa-kind plant construction. Industry rules of thumb (56) indicate that these costs typically account for $10 \%-20 \%$ of the total cost of the plant. For the base case, this amount was set to approximately $10 \%$. 
Table 15. Summary of Capital Equipment Costs

\begin{tabular}{lr}
\hline Dryer and Feed System & $\$ 1,500,000$ \\
Air PSA & $\$ 850,000$ \\
Gasification System & $\$ 10,000,000$ \\
Water Scrubber & $\$ 10,000$ \\
SulfaTreat (two vessels) & $\$ 900,000$ \\
Heat Exchangers (three) & $\$ 54,000$ \\
FT Catalyst Reactors (two) & $\$ 660,000$ \\
Flotation Unit & $\$ 50,000$ \\
Separation Unit & $\$ 500,000$ \\
Cooling Tower & $\$ 10,000$ \\
Contingency, $10 \%$ & $\$ 1,600,000$ \\
Total & $\$ 16,134,000$ \\
\hline
\end{tabular}

\section{Operating Costs}

Table 16 provides a summary of the annual operating costs for the base case. The annual operating costs assume the major thermal load associated with drying the wet lignin and heating the syngas for conversion is recovered from the system. This eliminates additional natural gas costs associated with adding the facility to the ethanol plant. The pro forma estimates three additional operators per shift, based on experience with the EERC pilot-scale gasification system. Ash disposal price is based on personal communication with the Bismarck Public Works (57). Labor rates were based on typical rates obtained from past projects (58).

The maintenance cost estimate is detailed in Table 17. The general maintenance cost is associated with maintaining equipment and is assumed to be $5 \%$ of the capital cost. The SulfaTreat maintenance cost is for replacing the sulfur absorbent every 15 weeks, based on a maximum sulfur level of $500 \mathrm{ppm}$ in the raw syngas. Higher sulfur levels in the syngas will decrease replacement intervals. Lower sulfur levels in the syngas will increase replacement intervals. The maintenance cost for heat exchangers are for replacing the heater cores on a yearly basis as recommended by the manufacturer (50). The FT reactor costs are an estimate of the catalyst fabrication costs prorated by the estimated replacement intervals of 8 weeks. A contingency of $10 \%$ is added to the total maintenance costs.

\section{Revenue}

Facility income was estimated to be about $\$ 4.3$ million, as shown in Table 18. Product revenue was determined using the current diesel wholesale price of $\$ 3.50$ per gallon (59), providing an income of $\$ 2.4$ million the first year of operation. Unconverted gas not used for feedstock drying could be utilized to offset natural gas prices elsewhere in the facility for processing or space heating needs. This would provide a savings from current natural gas expenses at a rate of $\$ 7.3 / \mathrm{MMBtu}$ (56). It was estimated that the excess syngas could replace approximately $81,000 \mathrm{MMBtu} / \mathrm{yr}$ of natural gas, resulting in a savings of about $\$ 590,000$ annually. 
Table 16. Summary of Operating Costs for Base Case Pro Forma

\begin{tabular}{lcrr}
\hline Operating Variable & Value & Year 1 & \multicolumn{1}{c}{ Year 20 } \\
\hline Wet Lignin Price & $\$ 0 /$ ton & & \\
Annual Use & 49,200 tons/yr & $\$ 0$ & $\$ 0$ \\
Ash Disposal Price & $\$ 10 /$ ton & & \\
Annual Production & 1720 tons/yr & $\$ 17,200$ & $\$ 33,400$ \\
Electricity Price & $\$ 0.062 / \mathrm{kWh}$ & & \\
Annual Use & $776 \mathrm{MWh} / \mathrm{yr}$ & $\$ 47,800$ & $\$ 79,800$ \\
Labor Price & $\$ 45 / \mathrm{hr}$ & & \\
Three persons, three shifts & $35,000 \mathrm{hrs} / \mathrm{yr}$ & $\$ 1,580,000$ & $\$ 3,090,000$ \\
Maintenance, regular & See Table 3 & $\$ 2,010,000$ & $\$ 3,940,000$ \\
Total & & $\$ 3,652,000$ & $\$ 7,137,000$ \\
\hline
\end{tabular}

Table 17. Detailed Maintenance Cost Estimate

\begin{tabular}{lr} 
Maintenance, annual & $\$ 2,010,000$ \\
General, annual & $\$ 807,000$ \\
SulfaTreat, annual & $\$ 325,000$ \\
Replacement, yr & 0.3 \\
Replacement Cost & $\$ 93,000$ \\
HXs, annual & $\$ 13,000$ \\
FT Reactor, annual & $\$ 664,000$ \\
Replacement, per yr & 6.0 \\
Catalyst, tons & 1.5 \\
Cost per Ton & $\$ 73,000$ \\
Contingency, $10 \%$ & $\$ 201,000$ \\
\hline
\end{tabular}

Table 18. Summary of Revenue for Base Case Pro Forma

\begin{tabular}{lccr}
\hline Income Variable & \multicolumn{1}{c}{ Value } & Year 1 & \multicolumn{1}{c}{ Year 20 } \\
\hline Natural Gas Price & \multicolumn{1}{c}{$\$ 7.33 / \mathrm{MMBtu}$} & & \\
Annual Offset & 80,600 MMBtu/yr & $\$ 591,000$ & $\$ 2,430,000$ \\
Diesel Price & $\$ 3.50$ per gallon & & \\
Annual Production & 681,000 gallons/yr & $\$ 2,380,000$ & $\$ 27,700,000$ \\
Tax Credits & $\$ 2.10$ per gallon & $\$ 1,430,000$ & $\$ 0$ \\
Renewable Diesel & $\$ 1.00$ per gallon & & \\
Mixture Credit & $\$ 1.00$ per gallon & & \\
Small Agri-Biodiesel & $\$ 0.10$ per gallon & & \\
$\quad$ Producers & & $\$ 4,406,000$ & $\$ 30,140,000$ \\
Total & & & \\
\hline
\end{tabular}


Biodiesel tax credits for renewable diesel income, mixture, and small producer credits will be available for the next decade for a total credit of $\$ 2.10$ per gallon produced, generating additional income of about $\$ 1.4$ million annually for the first 10 years of operation. Renewable diesel refers to diesel fuel derived from biomass using a thermal process. Mixture credits are available for those mixing biodiesel or renewable diesel with petroleum diesel up to $99.9 \%$ purity for resale or distribution. Each credit is worth $\$ 1.00$ per gallon produced or mixed, respectively $(60,61)$. An additional credit for small agri-biodiesel producers provides $\$ 0.10$ per gallon for the first 15 million gallons produced at facilities with capacities less than 60 million gallons annually (60). Other credits available are for methyl esters meeting ASTM International (D 6751-03a) standards made from virgin oils derived from agricultural commodities and animal fats or from waste agricultural products or by-products and animal fats. These credits are $\$ 1.00$ and $\$ 0.50$ per gallon, respectively (60).

\section{Escalation}

The economic analysis includes escalation rates for electricity, natural gas, labor, and diesel contract prices based on historical data. The escalation rates for diesel fluctuate significantly, depending on the time interval taken. Table 19 shows the contract prices for diesel

Table 19. Average Annual Escalation Rates for Diesel Wholesale Price (59)

\begin{tabular}{lc}
\hline Year & Price, $\phi /$ gal \\
\hline 1987 & 53.4 \\
1988 & 47.3 \\
1989 & 56.7 \\
1990 & 69.4 \\
1991 & 61.5 \\
1992 & 59.1 \\
1993 & 57.0 \\
1994 & 52.9 \\
1995 & 53.8 \\
1996 & 65.9 \\
1997 & 60.6 \\
1998 & 44.4 \\
1999 & 54.6 \\
2000 & 89.8 \\
2001 & 78.4 \\
2002 & 72.4 \\
2003 & 88.3 \\
2004 & 118.7 \\
2005 & 173.7 \\
2006 & 201.2 \\
2007 & 220.4 \\
Escalation Rates & \\
$20 \mathrm{yr}$ & $7.3 \%$ \\
$10 \mathrm{yr}$ & $13.8 \%$ \\
5 yr & $24.9 \%$ \\
\hline
\end{tabular}


over the last 20 years and the calculated escalation rates over 20 years, 10 years, and 5 years. The escalation rate used in the pro forma was based on the past 10 -year escalation rate of diesel. The escalation rate for labor is assumed $3.6 \%$, which is the annual escalation in the consumer price index (CPI) from 1980 to present as provided by the U.S. Department of Labor (57). A "general" escalation also uses the CPI rate to account for potential annual increases in maintenance and ash disposal costs. The historical price data for natural gas and electricity were obtained from the EIA $(56,57)$ and are provided in Table 20.

\section{Sensitivity Analysis}

Process economics are sensitive to a number of economic factors and assumptions. Sensitivity analyses were performed for $\mathrm{CO}$ conversion (yield), diesel contract price, diesel escalation rate, and facility size. The internal rate of return (IRR) is used as the sensitivity metric. Typically, an IRR of $12 \%$ provides a rate of return comparable to the stock market. For comparison, the base case IRR is $19 \%$.

The single-pass conversions of $\mathrm{CO}$ to hydrocarbons for iron catalyst have been reported as high as $90 \%$. However, because reaction rates decline rapidly above $60 \%$ conversion (47), the base case economics use $60 \%$ conversion per pass. Unconverted syngas is used to dry the wet lignin for gasification and offset additional natural gas consumption in the ethanol plant. Both streams provide revenue for the plant; however, the higher value of diesel relative to natural gas favors maximizing the yield to diesel. Figure 51 shows the sensitivity of IRR to the single-pass $\mathrm{CO}$ conversion of the FT reactor. At $80 \%$ conversion, the IRR increases to $25 \%$. At $40 \%$ conversion, the IRR decreases to $12 \%$, similar to typical yields from the stock market. Below $20 \%$ conversion, the operating cost of the facility is higher than the revenue.

Table 20. U.S. Historical Industrial Prices for Electricity and Natural Gas

\begin{tabular}{lcc}
\hline Year & $\begin{array}{c}\text { Electricity, } \\
\varnothing / \mathrm{kWh}\end{array}$ & $\begin{array}{c}\text { Natural Gas, } \\
\$ / \text { MMBtu }\end{array}$ \\
\hline 1995 & 4.66 & \\
1996 & 4.60 & \\
1997 & 4.53 & 3.49 \\
1998 & 4.48 & 3.05 \\
1999 & 4.43 & 3.03 \\
2000 & 4.64 & 4.32 \\
2001 & 5.05 & 5.09 \\
2002 & 4.88 & 3.90 \\
2003 & 5.11 & 5.72 \\
2004 & 5.25 & 6.34 \\
2005 & 5.73 & 8.31 \\
2006 & 6.16 & 7.63 \\
2007 & 6.44 & 7.33 \\
Ave Esc. Rate & $2.7 \%$ & $7.7 \%$ \\
\hline
\end{tabular}




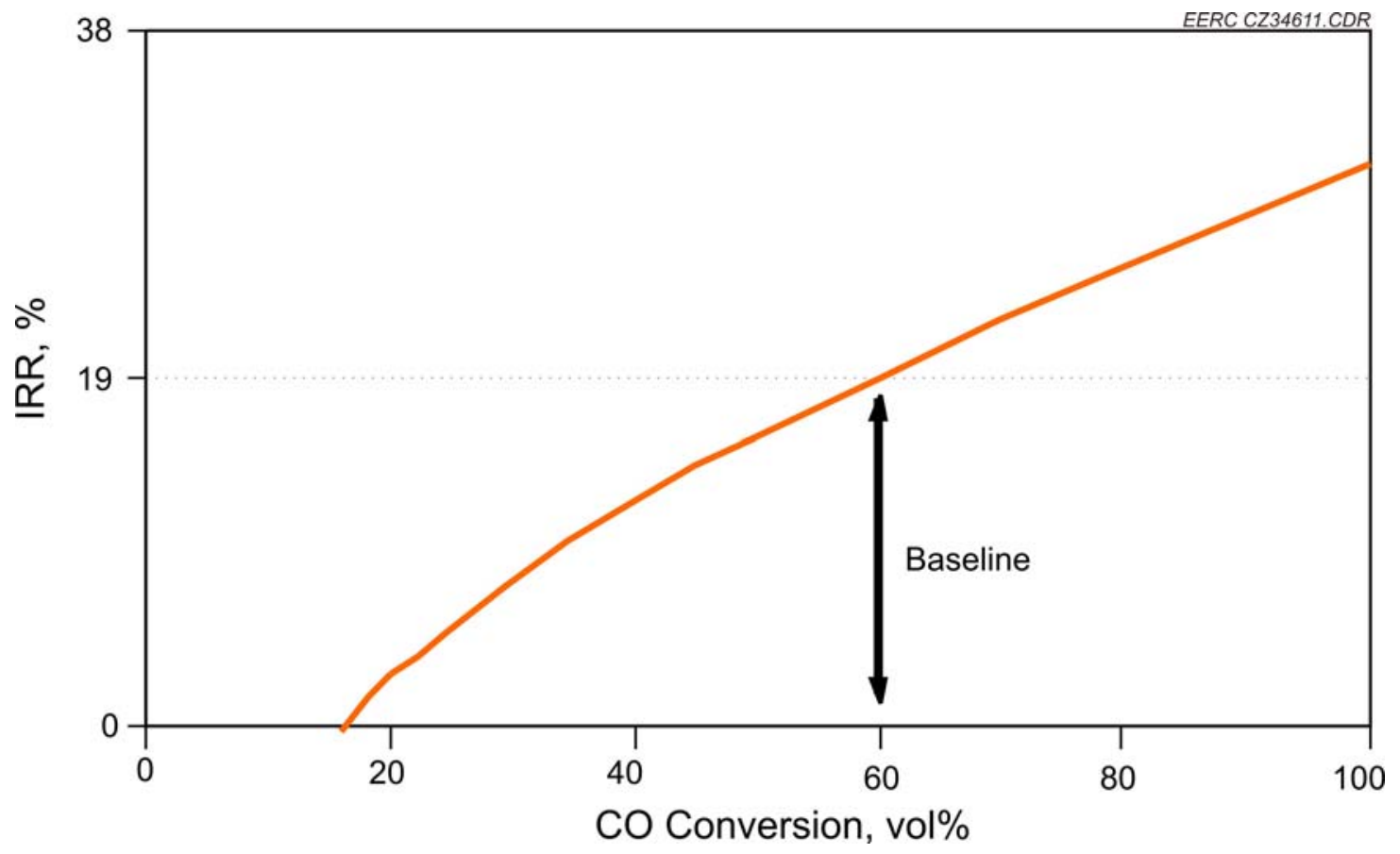

Figure 51. Dependence of IRR in base case economics to CO conversion.

The variation in IRR with the contract price of diesel is shown in Figure 52, assuming all other economic factors of the base case remain the same. The base case contract price is $\$ 3.50$ per gallon, with an escalation rate of $13.8 \%$ per year. At $\$ 2.50$ per gallon, the IRR is $12 \%$, approximately the same as the stock market. As the contract price increases to $\$ 5.00$ per gallon, the IRR increases to $26 \%$.

The escalation rate estimates future revenue assuming an increase in the diesel contract price over the life span of the plant. Over the past 8 years, the cost of crude oil has risen from $\$ 20$ per barrel to over $\$ 120$ per barrel (59). Prior to 2000 , the cost of crude oil was relatively stable at $\$ 15-\$ 20$ per barrel back to 1975 . This changes the escalation rate significantly, depending on the time period the escalation is calculated. Figure 53 shows the variation in IRR for different escalation rates. The escalation rate of $13.8 \%$ for the base case economics was calculated from the past 10 years. An escalation rate of $7.3 \%$, corresponding to the diesel prices for the past 20 years, provides an IRR of approximately $8 \%$. An escalation rate of $25 \%$ corresponding to diesel prices over the past 5 years provides an IRR of approximately $32 \%$. However, as petroleum companies increase production to accommodate increasing demand, it is also possible that diesel prices will eventually level off, generating a lower escalation rate.

Increasing the facility size would benefit from economies of scale. Figure 54 shows the variation in IRR with the facility size. A 25 -ton/day, dry-lignin-basis plant decreases the IRR to approximately $13 \%$. The IRR increases to $25 \%$ when the facility size is doubled to 100 tons/day. At 200 tons/day, the IRR increases to $31 \%$. 


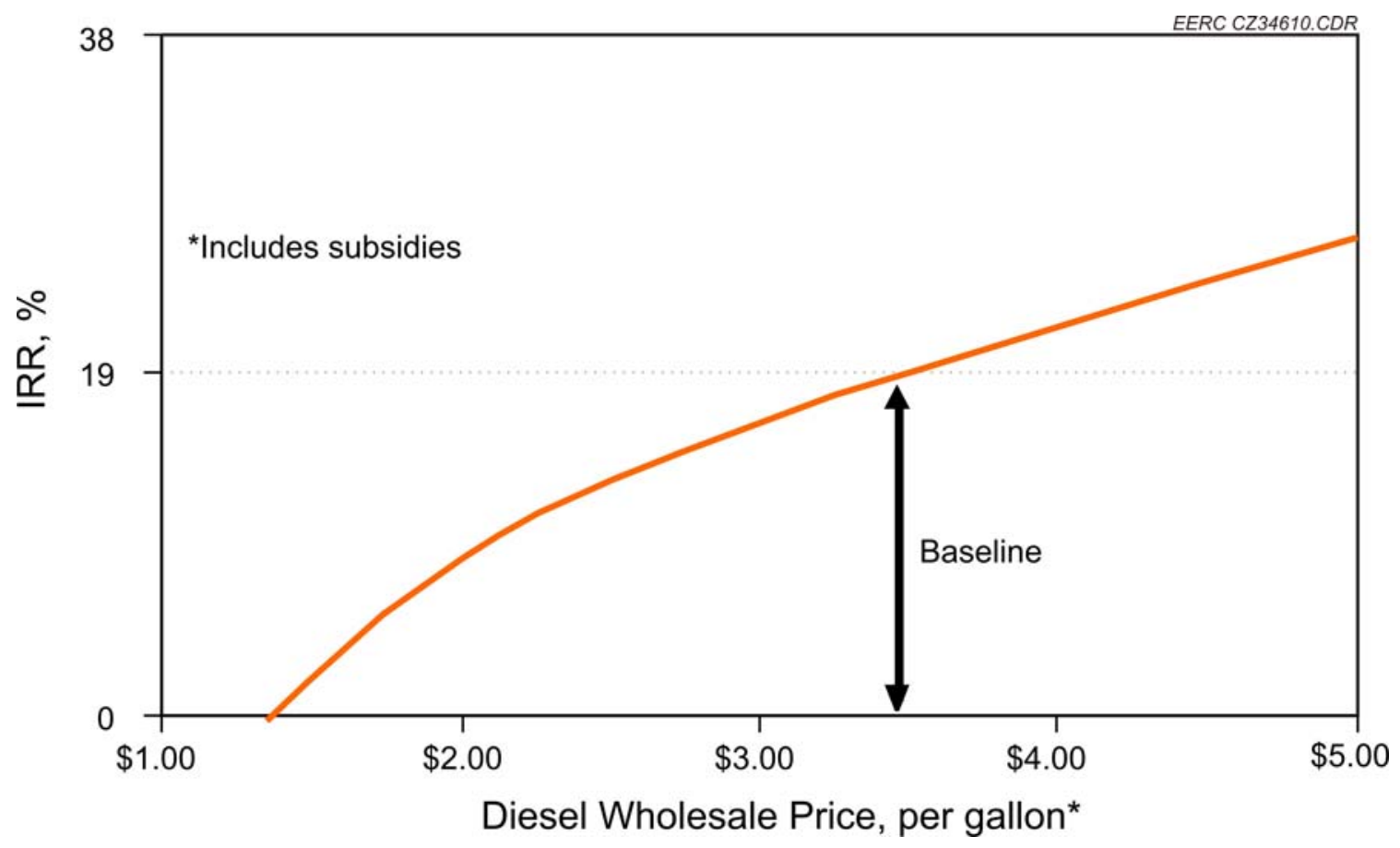

Figure 52. Dependence of IRR in base case economics to diesel contract price.

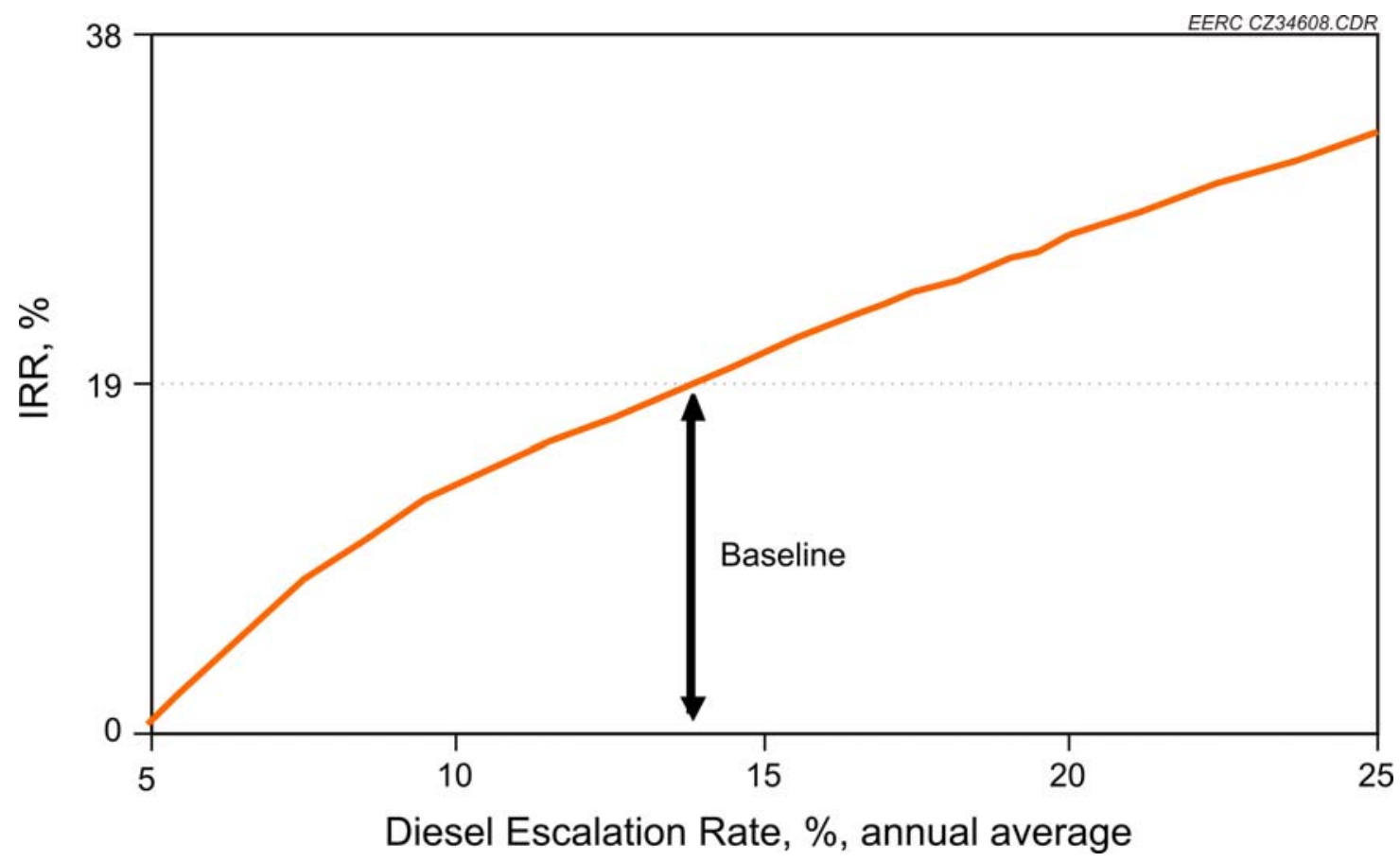

Figure 53. Dependence of IRR in base case economics to diesel escalation rate. 


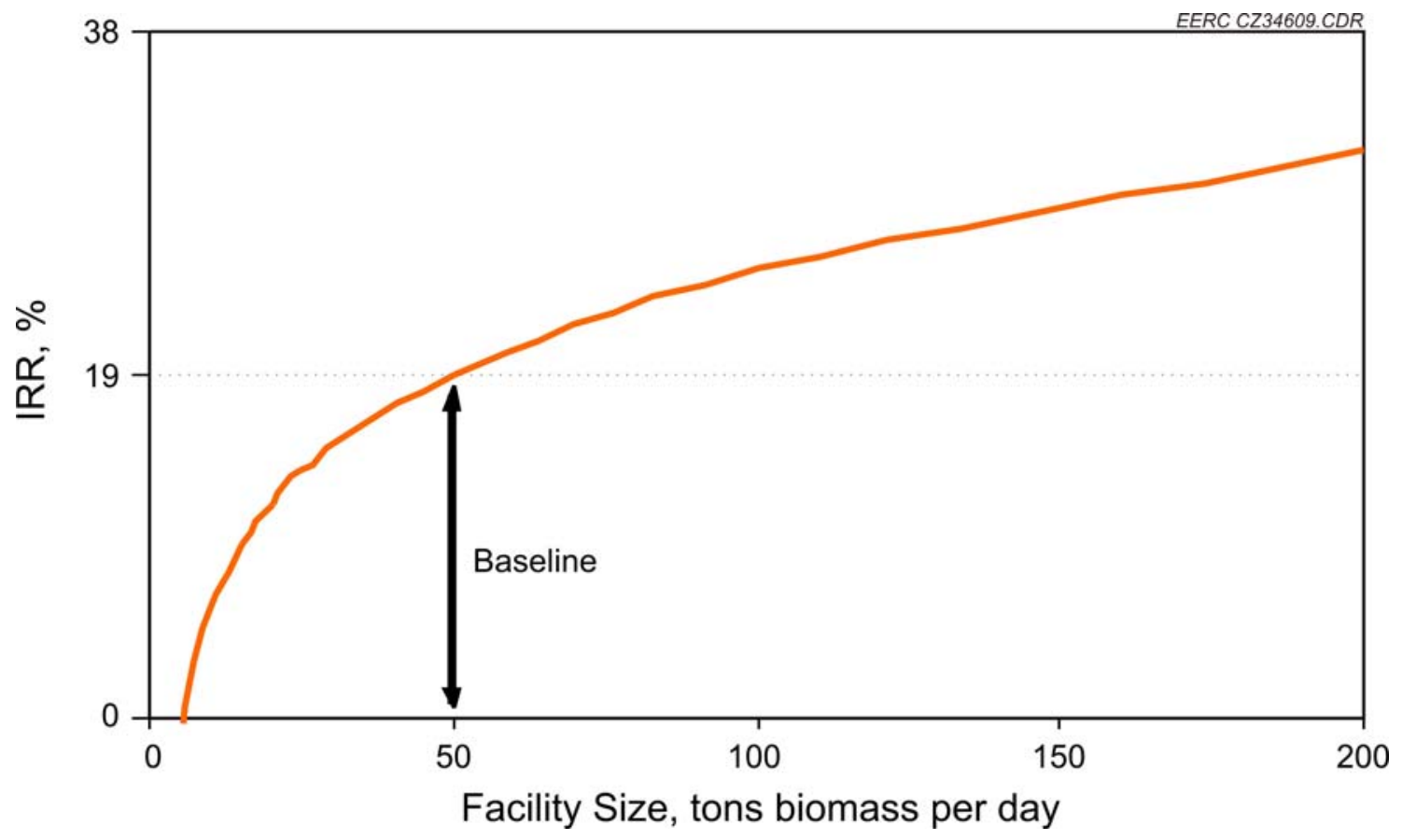

Figure 54. Dependence of IRR in base case economics to plant size.

\section{Conclusions}

This report has presented information on the available types of gasifiers. Emphasis within the report has been on commercially available gasification systems for coal since these are the systems with the greatest amount of operational and cost data for comparison. Several gasification systems specific to biomass have been listed, but little or no data are available for assessment of the systems. Conversely, the coal-fired gasification systems have a multitude of data but the scale of the commercial systems is far larger than is required for application to biomass and integration with cellulosic ethanol production facilities either at the demonstration scale or full scale. There is a commercial dearth of gasification systems at the scale required. The KBR Transport Reactor gasification system is viewed by the EERC as one of the better selections for gasification of lignin and biomass in general for several reasons. However, in conversations with several members of management at KBR to assess their willingness to scale a version of the transport reactor gasification system to either demonstration scale for ICM of approximately 25 tpd or to the scale required for full-scale deployment in the next generation of cellulosic ethanol plants, we have received a mixed response at best. While the company is currently focused on the deployment of larger coal-based electrical generation and has few personnel to devote to biomass applications that are smaller, they have not ruled out this application for the future. How far into the future one would have to wait is unclear. An initial guess would be 4 to 5 years until they have deployed their commercial version of the power generation IGCC plant. In recent reports from DOE on gasification installations planned for the near future, Shell is positioned to go from a current market syngas capacity share of $28 \%$ to $45 \%$. This means Shell will probably not be focused on smaller biomass systems for the near future either. Lurgi gasifiers, which currently provide the syngas for SASOL gas-to-liquid plants in 
South Africa and the Great Plains Synfuels Plant, are not suitable for friable or fine fuels. In the experience of the EERC, lignin from acid hydrolysis enzymatic ethanol processes will be a rather friable product with many fines. For other gasification systems specific to biomass, most would be the first commercial deployment of the technology, and if ICM is going to be part of the learning cycle for a manufacturer, it should also then gain some of the revenue from the market penetration from subsequent improved and proven installations. Additionally, there are no gasification systems tailored for BTL, and this is a developing field that will only grow in the future. For this reason, it is recommended that the EERC and ICM team together to design and develop a gasification system for the purpose of integration into cellulosic ethanol plants for increased efficiency and throughput in the plant overall. Many of the unit operations are readily available commercially but many would need to be developed for this scale. There is a significant market for the scale of this system greater than the cellulosic ethanol market and this could very well prove to be a large revenue stream for ICM in the future.

\section{References}

1. Sondreal, E.A.; Swanson, M.L. EERC Internal Report; 2002.

2. Sondreal, E.A.; Swanson, M.L.; Benson, S.A.; Holmes, M.J.; Jensen, M.D. A Review of Gasification Technology for Coproduction of Power, Synfuels and Hydrogen from LowRank Coals; Western Fuels Symposium, Denver CO, Oct 2006.

3. Electric Power Research Institute. Coal Gasification Guidebook: Status Applications, and Technologies; Prepared by SFA Pacific, Inc., EPRI TR-102034, 1993.

4. Holt, N. Preliminary Economics of SCPC and IGCC with $\mathrm{CO}_{2}$ Capture and Storage. 2nd IGCC and XtL Conference, Freiberg, Saxony, Germany, May 9-10, 2007.

5. Platts. IGCC: ... The Struggles with New Technology Adoption. www.platts.com/ Magazines/Insight/2007/oct/ (accessed March 2008).

6. Tampa Electric Integrated Gasification Combined-Cycle Project, An Update; Clean Coal Technology Topical Report No. 19; July 2000; 24 p.

7. Leonard, R.; Rogers, L.; Vimalchand, P.; Liu, G.; Smith, P.; Longanbach, J. Development Status of the Transport Gasifier at the PSDF. Presented at the Gasification Technologies Conference, San Francisco, CA, Oct 7-10, 2001, 15 p.

8. Ostheim, S.T.; Lewandowski, D.A. Applicability of the Westinghouse Process for Gasifying Lignite Coals. In Proceedings of the 12th Biennial Lignite Symposium: Technology and Utilization of Low-Rank Coals; DOE/METC/84-13, Feb 1984; Vol. 1, pp 129-148.

9. Tsang, A. Manager of Research and Development at Global Energy. Personal Communication, 2002. 
10. The Wabash River Coal Gasification Repowering Project Status, An Update; Clean Coal Technology, Topical Report No. 20, Sept 2000; 24 p.

11. Huth, M.; Gaio, G.; Heilos, A.; Vortmeyer, N.; Schetter, B.; Karg, J. Experiences in Development and Operation of Siemens IGCC Gas Turbines Using Gasification Products from Coal and Refinery Residues. Presented at the Gasification Technologies Conference, San Francisco, CA, Oct 4-7, 1998, 11 p.

12. Perry, R.J.; Salter, J.A.; Baker, D.C.; Potter, M.W. Environmental Characterization of the Shell Coal Gasification Process. III. Solid By-Products. In Proceedings of the 7th Annual Pittsburgh Coal Conference; Pittsburgh, PA, Sept 10-14, 1990; pp 269-278.

13. Eurlings, G.M.; Th, J.; Ploeg, J.E.G. Process Performance of the SCGP at Buggenum IGCC. Presented at the Gasification Technologies Conference, San Francisco, CA, Oct 18-20, 1999; $20 \mathrm{p}$.

14. deWinter, H.M.J.; Eurlings, G.M.; Th, J. IGCC Buggenum Commercial Operation. Presented at the Gasification Technologies Conference, San Francisco, CA, Oct 4-7, 1998, 20 p.

15. Ploeg, J.E.G. Shell Gasification Process: Status of Shell Gasification Projects. Presented at the Gasification Technologies Conference, San Francisco, CA, Oct 7-10, 2001, 19 p.

16. Baker, D.C.; Bush, W.V.; Loos, K.R.; Potter, M.W.; Swatloski, R.A. Environmental Characterization of the Shell Coal Gasification Process. II. Aqueous Effluents; In Proceedings of the 6th Annual Pittsburgh Coal Conference; Pittsburgh, PA, Sept 25-29, 1989; pp 801-810.

17. Méndez-Vigo, I. Puertollano IGCC, ELCOGAS. Presented at the Gasification Technologies Conference, San Francisco, CA, Oct 8-11, 2000, 21 p.

18. Renzenbrink, W.; Wischnewski, R.; Engelhard, E.; Mittelstädt, A. High-Temperature Winkler (HTW) Coal Gasification: A Fully Developed Process for Methanol and Electricity Production. Presented at the Gasification Technologies Conference, San Francisco, CA, Oct 4-7, 1998, $16 \mathrm{p}$.

19. The Piñon Pine Power Project; Clean Coal Technology, Topical Report No. 8, Dec 1996; $23 \mathrm{p}$.

20. Lau, F.; Rabovitser, J.; Byran, B.; Stopek, D. Biomass Gasification Co-Firing Project in Kentucky. Presented at the 18th Pittsburgh International Coal Conference, Sydney, Austrailia, Dec 3-7, 2001, 12 p.

21. Wiant, B.; Byran, B.; Miles, T. Hawaiian Biomass Gasification Facility: Testing Results and Current Status. In Proceedings of BioEnergy >98: Expanding BioEnergy Partnerships; 1998; pp 414-423. 
22. Paisley, M.A.; Farris, M.C.; Black, J.; Irving, J.M.; Overend, R.P. Commercial Demonstration of the Battelle/FERCO Biomass Gasification Process: Start-Up and Initial Operating Experience; In Proceedings of the 4th Biomass Conference of the Americas; Vol. 2, Overend R.P. and Chornet, E., Eds.; Oakland, CA, Sept 1999; pp 1061-1066.

23. Miller, W.R.; Lang, R.A. Great Plains Coal Gasification Plant Public Design Report; DOE/CH/10088-1874, 1985.

24. Notestein, J.E. Commercial Gasifier for IGCC Applications; DOE Study Report; DOE/METC No. 91/6118, June 1990.

25. Willson, W.G.; Hendrikson, J.G.; Mann, M.D.; Galegher, S.J.; Gallagher, J.R.; Mayer, G.G.; Thomas, W.C.; Winton, S.L.; Nelson, D.F. Use of Treated Gasification Wastewater in a Pilot Cooling Tower, Phase I; Final Report for the Period Ending Jan 31, 1984; DOE/FE/601811602, 1984.

26. Hauserman, W.B.; Willson, W.G. Mechanical Problems in the Design of a Fixed-Bed Slagging Gasifier. In Proceedings of the Technical Economics Synfuels and Coal Energy Symposium; ASME 7th Annual Energy-Sources Technology Conference; Houston, TX, 1984.

27. Gronhovd, G.H.; Harak, A.E.; Fegley, M.M.; Severson, D.E. Slagging Fixed-Bed Gasification of North Dakota Lignite at Pressures to 400 psig; Bureau of Mines RI 7408, 1970.

28. Shellhorse, V. The BGL Slagging Gasifier - Fuel Flexibility. Presented at the Gasification Technology Conference, San Francisco, CA, Oct 2005.

29. Sander, H.J.; Daradimos, G.; Hirschfelder, H. Operating Results of the BGL Gasifier at Schwarze Pumpe. Presented at the Gasification Technology Conference, San Francisco, CA, Oct 2003.

30. Picard, L. Development Status of BGL Gasification. Presented at the International Freiberg Conference on IGCC Technologies, June 2005.

31. Nexterra. www.nexterra.ca (accessed March 2008).

32. Ankur Scientific. www.ankurscientific.com (accessed March 2008).

33. Clark, N.; Gautam, M.; Lyons, D.; Atkinson, C.; Xie, W.; Norton, P.; Vertin, K.; Goguen, S.; Eberhardt, J., On-Road Use of Fischer-Tropsch Diesel Blends, SAE Technical Paper 199901-2251, April 1999.

34. Phillips, S.; Aden, A.; Jechura, J.; Dayton, D.; Eggman, T. Thermochemical Ethanol via Indirect Gasification and Mixed Alcohol Synthesis of Lignocellulosic Biomass; NREL/TP510-41168; April 2007. 
35. Zero Emission Resource Organization. www.zero.no/transport/bio/fischer-tropsch-reactorfed-by-syngas (accessed March 2008).

36. Western Farm Press. Rice Straw Producers Back to Square One on Ethanol Plant, http://westernfarmpress.com/news/farming_rice_straw_producers/(accessed May 2007).

37. Florida Times-Union. http://cgi.jacksonville.com/cgi-bin/printit.cgi?story=ZZNOSTORYZZ, June 6, 2007 (accessed March 2008).

38. Wichita Business Journal. Abengoa Bioenergy to build plant in Kansas, March 7, 2007. www.bizjournals.com/wichita/stories/2007/03/05/daily18.html?t=printable (accessed June 2007).

39. Los Angeles Times. Plant to convert trash to ethanol, March 1, 2007. http://latimes.com/business/la-fi-ethanol1mar01,1,3185071,print.story?ctrack=1\&cset... (accessed June 2007).

40. Iowa Senate Democrats. In the News, State Senator Jack Kibbie, Feb 28, 2007. www.iowasenatedemocrats.org/kibbie/news.htm (accessed June 2007).

41. Masada Resources Group. Press release, May, 21, 2007. www.masadaonline.com (accessed March 2008).

42. Leininger, T.F. Manager of Technology Development at Texaco. Personal Communication, 2002.

43. Morey, R.V.; Hatfield, D.L.; Sears, R.; Tiffany, D.G. Characterization of Feed Streams and Emissions from Biomass Gasification/Combustion at Fuel Ethanol Plants. 2006 ASABE Annual International Meeting, Paper Number 064180, July 2006.

44. Sondreal, E.A; Swanson, M.L.; Benson, S.A.; Holmes, M.J.; Jenson, M.J. A Review of Gasification Technology for Coproduction of Power, Synfuels, and Hydrogen from LowRank Coals; EERC Internal Report, 2007.

45. Hutton, P.N.; Patel, N.; Martin, K.E.; Songh, D. Development and Testing of a Thermally Integrated SOFC-Gasification System for Biomass Power Generation; Final Report, Cooperative Agreement No. DE-FC26-98FT40321; Nov 2007.

46. Chemlink. Gas to Liquids. www.chemlink.com.au/gtl.htm (accessed March 2008).

47. Raje, A.P.; Inga, J.; Davis, B.H. Fischer-Tropsch Synthesis: Process Considerations Based on Performance of Iron-Based Catalyst. Fuel 1997, 76, 273.

48. Cooling Tower Systems, Inc. Cooling Tower List Price. www.coolingtowersystems.com/listpriceguide/coolingtowerlistprice.html (accessed March 2008). 
49. Smith, K., Product Development Engineer, Dresser-Rand Company. Personal Communication, Jan 30, 2008.

50. Groh, A. Xchanger, Inc. Personal Communication, Nov 19 - Dec 31, 2007.

51. Chan, N., Manager, Proposals \& Process Engineering, QuestAir Inc. Personal Communication, Oct 12 - Nov 14, 2007.

52. Patel, N.; Schmidt, D.D.; Botnen, L.S.; Hurley, J.P. Engineering Analysis of Indirect Biomass Liquefaction; Year 1 - Activity 2.2 Topical Report, National Center for Hydrogen Technology Program, DOE NETL Cooperative Agreement DE-FC26-05NT42465; May 2007.

53. Peters, M.S.; Timmerhaus, K.D. Plant Design and Economics for Chemical Engineers, 3rd Edition; McGraw-Hill Book Company: New York, 1980.

54. Earth Tech. Red River - Biota WTP: 100MLD Water Treatment Plant, Job No. 89638, 17Feb-08, www.usbr.gov/gp/dkao/naws/DEIS/comments_deis/app_b2.pdf (accessed May 2008).

55. Leroux, K.M.B.; Wocken, C.A. CBU 2004, Process Integration for Economic Hydrogen Production from Ethanol; Energy \& Environmental Research Center: Grand Forks, ND, 2005.

56. Energy Information Administration. Natural Gas http://tonto.eia.doe.gov/dnav/ng/ng_pri_sum_dcu_nus_m.htm (accessed Feb 2008).

57. Energy Information Administration. Average Retail Price of Electricity to Ultimate Customers by End-Use Sector. www.eia.doe.gov/cneaf/electricity/epa/epat $7 \mathrm{p} 4 . \mathrm{html}$ (accessed Feb 2008).

58. Hunke, K., Director, Bismarck Public Works. Personal Communication, Feb 22, 2006.

59. Energy Information Administration. Refiner Petroleum Product Prices by Sales Type, http://tonto.eia.doe.gov/dnav/pet/hist/a223700002A.htm (accessed April 2008).

60. Renewable Fuels Association. Federal Regulations: Biodiesel Tax Credits, www.ethanolrfa.org/policy/regulations/federal/biodiesel (accessed May 2008).

61. Tanner, D. Tax break for biodiesel could be extended until 2017, Land Line Magazine, March 15, 2007. www.landlinemag.com/todays_news/Daily/2007/Mar07/031207/03150706.htm (accessed May 2008). 


\title{
TASK 2 - CROP OIL BIOREFINERY PROCESS DEVELOPMENT
}

\author{
Activity 2.1 - Candidate Fuel Generation and Fuels Testing
}

\section{Introduction}

With the exception of hydroelectricity and nuclear energy, the majority of the world's energy resources are based on fossil fuels such as petroleum, coal, and natural gas. All of these natural reserves are finite and, at current usage rates, may be consumed by the end of the next century (1). The depletion of world fossil fuel reserves and increasing environmental concerns have stimulated recent interest in alternative sources for petroleum-based fuels. Biodiesel, made by transesterification of crop oil, has been successfully introduced into the motor transportation fuel pool as an alternative diesel fuel. Just as biodiesel has critical properties similar to diesel fuel, it is postulated that a biojet fuel, an aviation fuel made from crop oil and/or its derivatives (biodiesel), could be developed as a substitute for petroleum-based jet fuel.

The University of North Dakota (UND) has conducted an extensive project to generate a biojet fuel from soybean/canola oil and/or its derivatives (soy/canola methyl ester), which most fully complies with aviation fuel (JP-8) specifications. Preliminary emissions and performance testing on a commercial aviation turbine indicated that development of an aviation fuel from biodiesel was feasible (2). However, the cold-flow properties of biodiesel limit utilization at high altitude and cold-temperature climate conditions $(2,3)$.

A literature review has shown that there are four main solutions to overcome these coldflow limitations: winterization, additives, branched-chain esters, and chemical manipulation. The latter solution was believed to hold the greatest long-term promise for development of an acceptable crop oil-derived aviation fuel product: biojet fuel. Thermal separation coupled with mild thermal/catalytic cracking has become the focus of this project in order to modify the chemical structure of crop oil and its derivatives with subsequent purification. By this modification, organic compounds present in the fuel feedstock are transformed into lighter organic compounds, and thus a fuel is produced that is amenable to cold conditions. Preliminary experimental results demonstrated that the thermal approach can be used to overcome the coldflow limitations of crop oil and its derivatives (4).

This study investigated the major operating variables affecting conversion and product composition. Using a design of experiment methodology, we identified the significant reaction conditions as well as potential interaction factors that have the greatest impact on the cracking product (crackate). An analytical procedure that quantified the product and extent of conversion represents the single most important requirement of this study. Nevertheless, developing an analytical procedure that routinely provided trustworthy and reproducible results presented a significant hurdle which consumed the major part of this research.

Bench experiments typically took 4 hours to conduct; analytical preparations took approximately 12 hours. This limited the total number of experiments and samples that could feasibly be conducted and analyzed in the period available. 


\section{Environmental Issues}

Besides being independent from the imported commodity petroleum and not depleting natural resources, health and environmental concerns are the driving forces for alternative fuel demands. These concerns are manifested in various regulatory mandates of pollutants, particularly the Clean Air Act Amendments (CAAA) of 1990 and the energy security provisions of the Energy Policy Act of 1992 (EPAct). Currently, one of the most important concerns is global warming.

Legislation, such as the CAAA and EPAct, has created markets for alternative fuels that can be produced from renewable resources and are more environmentally benign than petroleumbased fuels. The CAAA requires the U.S. Environmental Protection Agency (EPA) to identify and regulate air emissions from all major sources. In October 1996, EPA certified B20 (a biodiesel blend with $20 \%$ biodiesel and $80 \%$ petroleum-based diesel), used in combination with a catalytic converter, as a particulate matter (PM) control device (5). Fuel emission control programs for motor vehicles have increased the need for alternative fuels. Provisions of EPAct mandate federal, state, and alternative fuel providers to increase their purchases of alternativefueled equipment. The regulation is to encourage the use of alternative fuels that could help reduce dependence on foreign oil in transportation applications.

Global warming refers to the increases in the average temperature of the Earth's atmosphere and oceans in recent decades. According to the National Academy of Sciences, the Earth's surface temperature has risen by about $0.6 \pm 0.2^{\circ} \mathrm{C}\left(1.1 \pm 0.4^{\circ} \mathrm{F}\right)$ in the past century, with accelerated warming during the past 25 years. There is strong evidence that most of the warming over the last 50 years is likely attributable to human activities. The increased volumes of carbon dioxide and other greenhouse gases released by the burning of fossil fuels, land clearing, and agriculture are the primary sources of the human-induced component of warming. The combustion of fuels is responsible for about $98 \%$ of U.S. carbon dioxide emissions (6). Therefore, shifting from fossil fuels to alternative fuels may be a significant mitigation of global warming.

\section{Crop Oil}

The use of crop oil as an alternative fuel has been around since 1900 when the inventor of the diesel engine, Rudolph Diesel, first tested it in his compression engine. The first international conference on plant and vegetable oils as fuels was held in Fargo, North Dakota, in August 1982 (7).

Most crop oils are primarily water-insoluble, hydrophobic substances commonly referred to as triglycerides (7). Figure 55 shows a typical triglyceride molecule. Triglyceride has a glycerol "backbone" to which is attached three fatty acids (FAs). These FAs differ by the length of the carbon chains as well as the number, orientation, and position of double bonds in these chains. There is a substantial amount of oxygen in the structure.

The FAs which are most commonly found in crop oils are palmitic, stearic, oleic, linoleic, and linolenic (8). The chemical structures of these FAs are given in Table 21. Table 22 


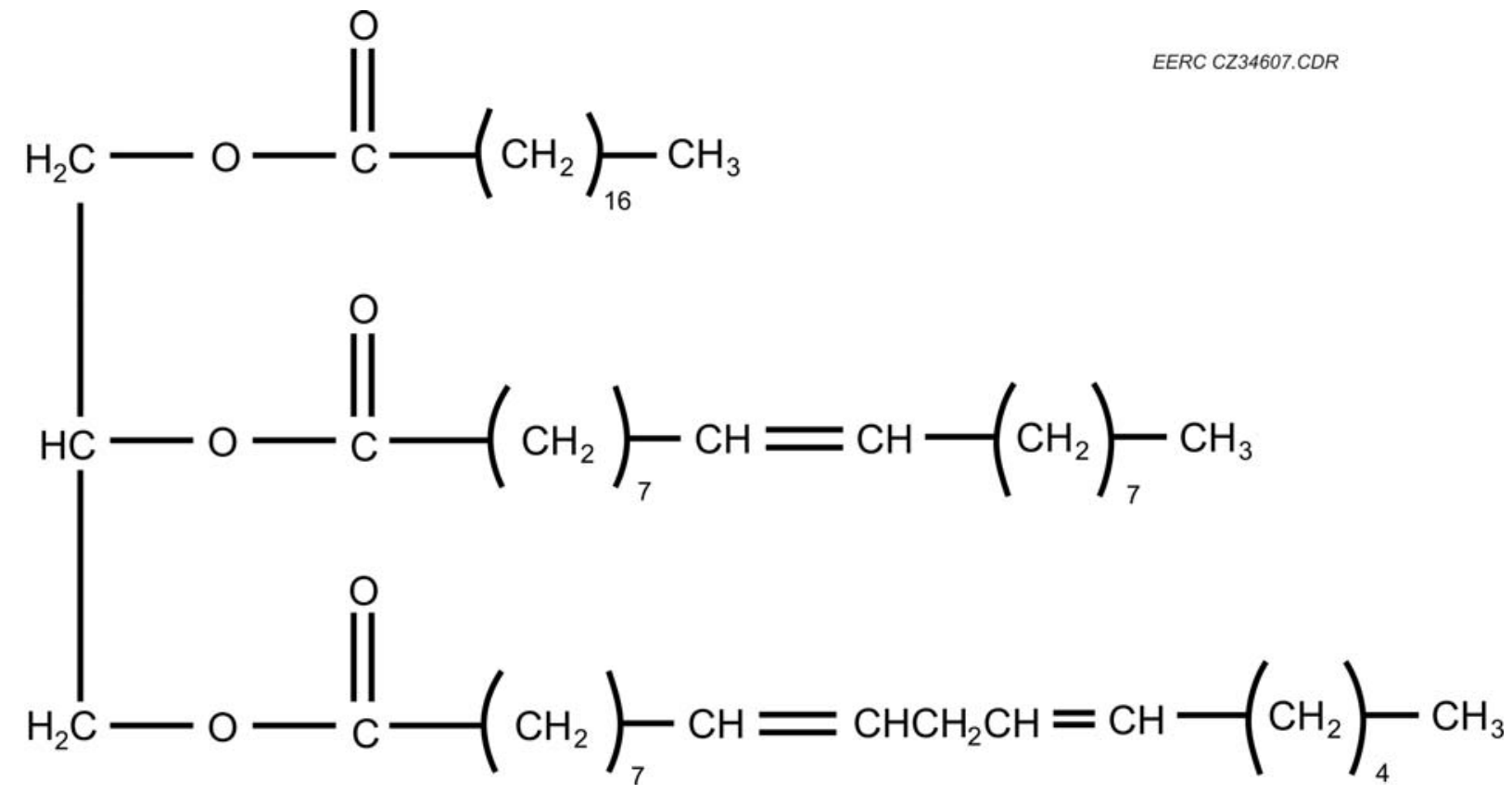

Figure 55. Structure of a typical triglyceride molecule (9).

Table 21. Chemical Structure of Common Fatty Acids (8)

\begin{tabular}{lcc}
\hline Fatty Acid & Formula & Structure \\
\hline Palmitic & $\mathrm{CH}_{3}\left(\mathrm{CH}_{2}\right)_{14} \mathrm{COOH}$ & $16: 00$ \\
Stearic & $\mathrm{CH}_{3}\left(\mathrm{CH}_{2}\right)_{16} \mathrm{COOH}$ & $18: 00$ \\
Oleic & $\mathrm{CH}_{3}\left(\mathrm{CH}_{2}\right)_{7} \mathrm{CH}=\mathrm{CH}\left(\mathrm{CH}_{2}\right)_{7} \mathrm{COOH}$ & $18: 1$ \\
Linoleic & $\mathrm{CH}_{3}\left(\mathrm{CH}_{2}\right)_{4} \mathrm{CH}=\mathrm{CHCH}_{2} \mathrm{CH}=\mathrm{CH}\left(\mathrm{CH}_{2}\right)_{7} \mathrm{COOH}$ & \\
\hline
\end{tabular}

Table 22. Fatty Acid Composition of Soybean Oil (10)

\begin{tabular}{lcc}
\hline Fatty Acid & Canola Oil, wt $\%$ & Soybean Oil, wt $\%$ \\
\hline Palmitic C16:0 & $4.0-5.0$ & $2.3-11.0$ \\
Stearic C18:0 & $1.0-2.0$ & $2.4-6.0$ \\
Oleic C18:1 & $55.0-63.0$ & $22.0-30.8$ \\
Linoleic C18:2 & $20.0-31.0$ & $49.0-53.0$ \\
Linolenic C18:3 & $9.0-10.0$ & $2.0-10.5$ \\
\hline
\end{tabular}

summarizes the common FA composition of canola and soybean oils. The degree of unsaturation is dictated by the number of double bonds in the FAs. Thus C18:1 (oleic acid), for example, denotes a carbon length of 18 with one double bond.

To date, there have been many problems found with using crop oil directly in diesel engines (especially in direct injection engines) for longer periods of time. These problems include (7): 
1. Injector coking and trumpet formation to such an extent that fuel atomization does not occur properly or is even prevented as a result of plugged orifices.

2. Oil ring sticking.

3. Carbon deposits.

4. The lubricating oil thickening and gelling as a result of contamination by crop oils.

The major causes are the high viscosity and oxidative instability of crop oils. The high viscosity of these oils is due to large molecular mass and chemical structure. Crop oils have high molecular weights in the range of 600 to 900 , which is three or more times higher (8) and viscosities 10 to 20 times greater than petroleum diesel fuel (11). This results in the formation of deposits in engines because of incomplete combustion and incorrect vaporization characteristics. Unsaturated fatty acids are very susceptible to polymerization and gum formation caused by oxidation during storage or by complex oxidation and thermal polymerization at the higher temperatures and pressures experienced during combustion (7).

\section{JP-8 and Its Specifications}

The single-fuel concept was conceived after World War II in order to simplify the logistic supply chain for petroleum products. In 1988, the North Atlantic Treaty Organization (NATO) nations decided to move toward the use of a single fuel, jet propellant 8 (JP-8), for both aircraft and ground equipment (12). The logic behind such a decision comes not only from the gain of big logistical advantages in wartime, but also from the more pragmatic fact of being able both to simplify and to make better use of NATO's extensive and expensive pipeline systems in times of peace. The current estimates of the worldwide use of JP-8 are approximately 60 billion gallons per year (43\% in the United States) (13).

JP-8 is a kerosene-based aviation fuel with a minimum gross heat of combustion of $42.6 \mathrm{MJ} / \mathrm{kg}$ (14) and has additives to improve performance. The detailed specifications of JP-8 are listed in Table 23. It has a complex hydrocarbon mixture containing over 400 hydrocarbons. The actual composition varies from batch to batch.

JP-8 mainly comprises four classes of compounds: n-alkanes and isoalkanes, olefins, naphthenes, and aromatics. About $18 \%$ of this fuel (Table 24) is aromatic hydrocarbons, while the remaining components are aliphatic alkanes and their isomers $(9 \% \mathrm{C} 8-\mathrm{C} 9,65 \% \mathrm{C} 10-\mathrm{C} 14$, and 7\% C15-C17) (14).

\section{Cold-Flow Impacts/Cold-Flow Properties}

Cold-flow properties measure the ability of a fuel to function in cold temperature. One of the major issues associated with the use of crop oil and biodiesel is poor cold-flow properties, indicated by relatively high freezing points (FPs), cloud points (CPs), and pour points (PPs) compared to petroleum fuels. FP is the temperature or temperature range in which a pure compound or mixture freezes. Pure compounds freeze at a specific temperature, while mixtures 
Table 23. Typical Properties of JP-8 Aviation Fuel (6)

\begin{tabular}{lcc}
\hline Fuel Type & JP-8 & Method \\
\hline Molecular Weight & 180 (average) & *E/M 1999 \\
Density, g/mL, $15^{\circ} \mathrm{C}$ & 0.795 & ASTM D1298 \\
Viscosity, cSt, $-20^{\circ} \mathrm{C}$ & 3.87 & ASTM D455 \\
Freezing Point, ${ }^{\circ} \mathrm{C}$ & -47 & ASTM D2386 \\
Flash Point, ${ }^{\circ} \mathrm{C}$ & 41 & ASTM D93 \\
Conductivity, pS/m & 375 & ASTM D2624 \\
Sulfur, wt $\%$ & 0.23 & ASTM D4294 \\
Nitrogen, ppm & 14 & \\
Aromatics, vol\% & 15.3 & ASTM D1319 \\
Olefins, vol\% & 0.3 & ASTM D1319 \\
Water, ppm & 23 & ASTM D1744-83 \\
Copper Strip Cor. & $1 ?$ & ASTM D130 \\
Lubricity & & CEC F-06-A-90 \\
Initial Measurement, $\mu \mathrm{m}$ & 754 & \\
Repeated Measurement, $\mu \mathrm{m}$ & 758 & \\
Distillation, ${ }^{\circ} \mathrm{C}$ & 145 & \\
Initial Boiling Point & 174 & \\
$10 \%$ & 181 & \\
$20 \%$ & 200 & \\
$50 \%$ & 233 & \\
$90 \%$ & 250 & \\
Final Boiling Point & 251 & \\
\hline
\end{tabular}

$* \mathrm{EM}=$ Exxon/Mobile.

Table 24. Typical JP-8 Composition

\begin{tabular}{lc}
\hline Component & Concentration, $\mathrm{mg} / \mathrm{mL}$ \\
\hline Aliphatic & \\
Undecane & 48.4 \\
Dodecane & 36.1 \\
Decane & 30.2 \\
Tridecane & 21.9 \\
Tetradecane & 14.6 \\
Nonane & 9.2 \\
Pentadecane & 8.4 \\
Atomatic & \\
Trimethylbenzene & 9.7 \\
Methylnaphthalenes & 9.9 \\
Dimethylnaphthalenes & 6.3 \\
Dimethylbenzene (xylene) & 4.8 \\
Naphthalene & 2.1 \\
Ethyl Benzene & 1.2 \\
Methylbenzene (toluene) & 0.5 \\
\hline
\end{tabular}


freeze over a range (5). For complex mixtures, such as petroleum fuels, crop oils, and biodiesel blends, FP may be characterized by a range of temperatures reflecting the freezing point of the individual components. In order to better describe flow characteristics of these complex mixtures, the CP and PP are routinely used (15), which are the key cold-flow properties for winter fuel specification.

Crop oil is used here as an example to describe the freezing process. Almost all crop oils are made primarily from a mixture of different triglycerides. These triglycerides are made up of a molecule of glycerin linked to three FAs, which solidify at different temperatures. As the oil is cooled toward its FP (or PP), the different triglycerides solidify, in turn, causing the oil to become cloudy and increasingly thick before it finally solidifies completely. The temperature at which an oil begins to solidify is known as the CP. When the temperature drops to the oil PP, the oil will become solid and no longer flow. Eventually, it will block any fuel system components in which it lies (16).

CP (ASTM D2500) is the temperature at which the first formation of wax crystals appear as the fuel is cooled. As the temperature decreases below the CP, wax crystals rapidly grow and agglomerate until they are large enough to clog fuel filters and supply lines and, eventually, lead to major operability problems (17). With further decreasing temperature, the fuel can gel up and cease to pour, approaching its PP.

PP (ASTM D97) is the temperature at which the fuel is no longer pumpable (5). Thus PP is very useful for characterizing the suitability of a fuel for large storage and pipeline distribution (9). The CP is always equal to or higher than the PP. It is recommended by engine manufacturers that the $\mathrm{CP}$ be below the temperature of use and not more than $6^{\circ} \mathrm{C}$ above the $\mathrm{PP}(10)$.

Cold-flow properties are critical for aviation fuels because aircraft often operate at high altitudes where temperature is extremely low. If fuel tanks are not heated or insulated, only the thin tank metal wall separates the fuel from air temperatures that decrease as altitude increases. Military specifications require JP-8 fuel to resist the formation of solid crystals (CP) at temperatures as low as $-47^{\circ} \mathrm{C}$, which corresponds to an altitude of 9500 meters $(31,000$ feet $)$ (3).

Most biodiesel fuels have CPs and PPs near $0^{\circ} \mathrm{C}$ and $-5^{\circ} \mathrm{C}$, respectively (17). When blended with JP-8, the fuel's CP and PP exceed the specification value. FP increases with increasing volume fraction of biodiesel in the fuel blends, as shown in Table 25. This less desirable cold-flow property limits aircraft operation to lower altitudes and land-based equipment operation to warmer conditions, which is unacceptable for both commercial and military applications.

\section{Goals and Objectives}

The overall objective of this work was to develop and optimize a thermocatalytic process for production of a viable jet fuel blendstock from crop oils. In Year 1, which was funded by DOE, the North Dakota State Board of Agricultural Research and Education (SBARE), and the North Dakota Soybean Council (NDSC), concept feasibility was studied by 1) operating a commercial-scale aviation turbine with $2 \%, 10 \%$, and 20\% SME (soy methyl 


\begin{tabular}{|c|c|}
\hline Fuel Blend, \% biodiesel & Freezing Point, ${ }^{\circ} \mathrm{C}$ \\
\hline 2 & -50 \\
\hline 10 & -27 \\
\hline 20 & -19 \\
\hline
\end{tabular}

ester) in JP-8 fuel blends and 2) determining how closely these fuel blends met JP-8 specifications.

In Year 2, which was funded by DOE, SBARE, NDSC, and the North Dakota Agricultural Products Utilization Committee (APUC), a 1-L lab-scale cracking reactor apparatus was built and used to evaluate the technical feasibility of a cracking-based process for biojet fuel production.

Year 3 activities were funded by DOE, SBARE, NDSC, APUC, and the National Science Foundation (NSF) and included 1) building infrastructure for product development, 2) fuel prototype turbine testing, 3) process optimization, 4) fuel characterization, 5) commercial feasibility, and 6) business model development.

Preliminary research at UND has shown that esterified crop seed oils (specifically, SME, one of a class of fuels labeled as "biodiesel") can be utilized as an aviation fuel at low-altitude conditions. The primary impediment for high-altitude utilization is the cold-flow properties of these oils and esters. Biodiesel complies with many, but not all, of the specifications required for a JP-8 fuel. Noncompliance generally falls into two categories: those due to the presence of glycerol (a by-product of the esterification process) in the biodiesel and those related to coldflow properties of the heavier esters present in the biodiesel.

UND developed a process to produce a fuel from crop oil or animal fat oils that operates at very cold temperatures and is suitable as an aviation turbine fuel, a diesel fuel, a fuel blendstock, or any fuel having lower CPs, PPs, or FPs. The process is based on the cracking of crop oil FAs or their associated esters, known as biodiesel, to generate lighter chemical compounds that have lower freeze, cloud, and/or PPs than the original oil or biodiesel. Cracked oil is processed using separation steps together with analysis to select fractions with low-temperature stability by removing undesirable compounds that raise temperature properties.

The process utilizes thermal or catalytic cracking methods coupled with separation technologies selected by chemical analysis to produce crop oil-based fuels that can be utilized at high-altitude conditions and/or very cold temperatures. A simplified block diagram of the biofuel process is shown in Figure 56. The crop oil or animal fat feedstock, 10 (see figure for bolded numbers), is fed to the cracking reactor, 12. When the time, temperature, and pressure under which a particular feedstock remains under cracking conditions are varied, the desired degree of cracking (conversion) can be controlled. Temperature and time (residence time) are the more important process variables, with pressure playing a secondary role. The products of the cracking process are dependent upon the conditions of cracking and the original composition of the 


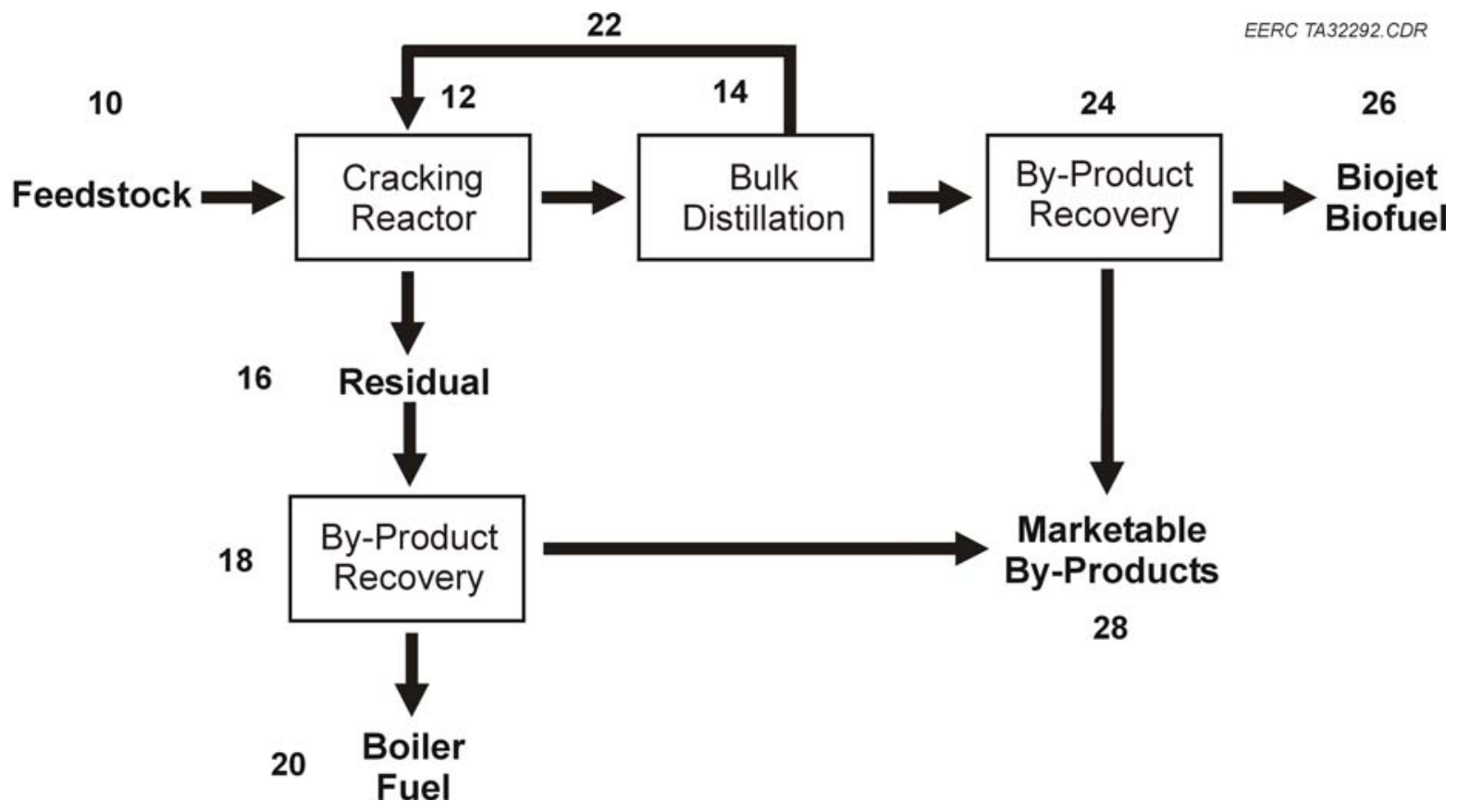

Figure 56. Biojet fuel process (simplified block flow diagram).

feedstock oil (2). The cracking conditions are varied based on detailed chemical analysis and evaluation of their low-temperature stability of the feedstock and cracking products in order to produce an acceptable biojet fuel. The presence of a catalyst can be used to improve the yield of desirable products, decrease the formation of unwanted products, or increase the efficiency of the cracking reaction because of lower pressure, temperature, or residence time requirements.

The cracking output is subjected to a variety of processing steps, 14, dependent upon the material generated. Material generated in the cracking reactor consists of four general classes: 1) light ends; 2) biojet fuel chemical components, 26; 3) unreacted raw materials; and 4) residual materials or residue, $\mathbf{1 6 .}$

The light ends consist of the unreacted vapor-phase material that was added to the reactor to manipulate the cracking reaction, such as hydrogen plus small-molecular-weight organic chemicals and hydrocarbons generated in the cracking reactor. The small-molecular-weight organic chemicals and hydrocarbons have chemical and physical properties that are undesirable in an aviation turbine or cold-flow diesel fuel such as being too volatile. Light ends are separated from the other material that exits the reactor, 24.

The biojet fuel chemical components, 26, are those portions of the material generated in the cracking reactor that contribute to desirable chemical and physical properties of the biojet fuel. For example, jet and diesel fossil fuels such as those that meet the fuel specifications for JP8 are primarily made up of $\mathrm{C} 6-\mathrm{C} 12$ straight-chain alkane hydrocarbons, where " $\mathrm{C}$ " refers to carbon and the number (6 or 12) refers to the number of carbon atoms in the molecule. Typical 
desirable compounds generated in the cracking reactor include $\mathrm{C} 4$ to $\mathrm{C} 12 \mathrm{FA}$ methyl esters, $\mathrm{C} 4$ to $\mathrm{C} 12$ FAs, and C6-C16 alkanes.

Unreacted raw materials are chemicals that entered the cracking reactor but, for some reason, did not experience cracking reactions. These materials have some chemical and physical properties that are undesirable in an aviation turbine or cold-flow diesel fuel. Unreacted raw materials are separated from the biojet fuel chemical components, 14. These unreacted or uncracked raw materials, 22, can then be returned to the cracking reactor.

Residual, 16, consists of chemicals produced during cracking reactions that have a higher molecular weight and/or lower volatility and/or lower heating value than is desirable for the biojet fuel product. Some of the residual components can be separated, 16, from the biojet fuel chemical components along with the unreacted raw materials and processed with these unreacted raw materials. Other residue components, typically those of higher molecular weight, will be in the form of solid material after the cracking reaction. These compounds are typically known as "coke." The coke may contain valuable chemical compounds, such as boiler fuel, 20, or other by-products, 28, that can be extracted from the residue, 18.

\section{Experimental}

\section{Materials}

In this study, coconut methyl ester (CME), SME, canola oil, and soybean oil were used as thermal cracking feedstocks. CME was obtained from the North Dakota State University (NDSU) North Central Research Station in Minot, North Dakota. Canola oil was a superdegummed variety purchased from Archer Daniel Midlands (ADM) in Velva, North Dakota. Refined soybean oil and SME were purchased from Ag Processing Inc, a cooperative located in the state of Minnesota. Compositional analysis of the CME-SME and canola-soybean oil are given in Table 26.

Several standard mixtures were used for GC identification and quantification of all samples used in this study. The alkane standard was formulated using Protocol Analytical, LLC - TX-HC-18, which contained 18 alkane compounds as listed in Table 27. The FA methyl esters (FAMEs) standard was obtained from RESTEK - Food Industry Fame Mix, which consisted of 37 FAME compounds as listed in Table 28.

The alkene, FA, and BTEX (benzene, toluene, ethylbenzene, $o$-xylene, and $p$-xylene) standard mixtures were internally prepared. These mixtures were formulated by mixing individual compounds with a specific carbon number at the same concentration together. The

alkene individual compounds included C9, C11, C13, C14, C16, C17, C18, C19, and C23. The FA individual compounds were saturated C4, C5, C6, C7, C8, C9, C10, and C12.

\section{Equipment}

All experimental runs were carried out in a 1-L bench-scale thermal cracking reactor (4). Three critical factors were taken into consideration while selecting and designing this reactor: homogeneous heat distribution, minimization of coke formation, and temperature/pressure rating. 
Table 26. Key Components of CME/SME and Canola/Soybean Oil

\begin{tabular}{lcccc}
\hline Component & CME, wt $\%$ & SME, wt $\%$ & Canola Oil & Soybean Oil \\
\hline Palmitic C16:0 & 4.3 & 8 & 4 & 12 \\
Stearic C18:0 & 2.1 & 4 & 2 & 3 \\
Oleic C18:1 & 62.3 & 21 & 60 & 23 \\
Linoleic C18:2 & 19.1 & 60 & 20 & 56 \\
Linolenic C18:3 & 9.2 & 7 & 10 & 6 \\
Eicosenoic C20:1 & 11.2 & 0 & 1.6 & 0 \\
Erucic C22:1 & 1.8 & 0 & 2.4 & 0 \\
\hline
\end{tabular}

Table 27. Composition of Alkane Standard

\begin{tabular}{lcc}
\hline Compound & Carbon Number & Final Concentration, $\mu \mathrm{g} / \mathrm{mL}$ \\
\hline Hexane & C6 & 1000.0 \\
Heptane & C7 & 1000.0 \\
Octane & C8 & 1000.0 \\
$n$-Nonane & C 9 & 1000.0 \\
Decane & C10 & 1000.0 \\
Undecane & C11 & 1000.0 \\
Dodecane & C12 & 1000.0 \\
$n$-Tridecane & C13 & 1000.0 \\
$n$-Tetradecane & C14 & 1000.0 \\
$n$-Pentadecane & C15 & 1000.0 \\
Hexadecane & C16 & 1000.0 \\
Heptadecane & C17 & 1000.0 \\
Octadecane & C18 & 1000.0 \\
Nonadecane & C19 & 1000.0 \\
Eicosane & C20 & 1000.0 \\
Pentacosane & C25 & 1000.0 \\
Octacosane & C28 & 1000.0 \\
$n$-Pentatriacontane & C35 & 1000.0 \\
\hline
\end{tabular}

Figures 57 and 58 are a schematic and a picture of the thermal cracking apparatus used for the thermal cracking of CME, SME, canola oil, and soybean oil. The system consists of an autoclave reactor, condenser, flash traps, residual drum, vacuum pump, pressure transducer, Fluke Hydra Logger, and computer.

The thermal cracking reactor was made of stainless steel with a $14.0-\mathrm{cm}$ (5.5-inch) diameter and $26.7-\mathrm{cm}(10.5$-inch) height. This 1-L autoclave reactor was rated for a pressure of up to $37,200 \mathrm{kPa}(5400 \mathrm{psi})$ and was compatible with hot-charge reactant injection and the removal of reaction-temperature volatile materials at reaction pressure. The reactor was externally heated by an electrical ceramic heater and was fitted with a magnetic stirrer to provide uniform heat distribution inside during experiments in order to avoid coke formation on the reactor walls. 
Table 28. Composition of FAME Standard

\begin{tabular}{lcc}
\hline Compound & Carbon Number & Composition, wt $\%$ \\
\hline Methyl Butyrate & C4:0 & 4.0 \\
Methyl Hexanoate & C6:0 & 4.0 \\
Methyl Octanoate & C8:0 & 4.0 \\
Methyl Decanoate & C10:0 & 4.0 \\
Methyl Undecanoate & C11:0 & 2.0 \\
Methyl Laurate & C12:0 & 4.0 \\
Methyl Tridecanoate & C13:0 & 2.0 \\
Methyl Myristate & C14:0 & 4.0 \\
Methyl Myristoleate (cis-9) & C14:1 & 2.0 \\
Methyl Pentadecanoate & C15:0 & 2.0 \\
Methyl Pentadecenoate (cis-10) & C15:1 & 2.0 \\
Methyl Palmitate & C16:0 & 6.0 \\
Methyl Palmitoleate (cis-9) & C16:1 & 2.0 \\
Methyl Heptadecanoate & C17:0 & 2.0 \\
Methyl Heptadecanoate (cis-10) & C17:1 & 2.0 \\
Methyl Stearate & C18:0 & 4.0 \\
Methyl Elaidate (trans-9) & C18:1 & 2.0 \\
Methyl Oleate (cis-9) & C18:1 & 4.0 \\
Methyl Linoelaidate (trans-9, 12) & C18:2 & 2.0 \\
Methyl Linoleate (cis-9, 12) & C18:2 & 2.0 \\
Methyl Linolenate (cis-9, 12, 15) & C18:3 & 2.0 \\
Methyl Gamma-Linolenate (cis-6, 9, 12) & C18:3 & 2.0 \\
Methyl Arachidate & C20:0 & 4.0 \\
Methyl Eicosenoate (cis-11) & C20:1 & 2.0 \\
Methyl Eicosadieonoate (cis-11, 14) & C20:2 & 2.0 \\
Methyl Eicosatrienoate (cis-8, 11, 14) & C20:3 & 4.0 \\
Methyl Eicosatrienoate (cis-11, 14, 17) & C20:3 & 2.0 \\
Methyl Arachidonate (cis-5, 8, 11, 14) & C20:4 & 2.0 \\
Methyl Eicosapentaenoate (cis-5, 8, 11, 14, 17) & C20:5 & 2.0 \\
Methyl Heneicosanoate & C21:0 & 2.0 \\
Methyl Behenate & C22:0 & 2.0 \\
Methyl Erucate (cis-13) & C22:1 & 2.0 \\
Methyl Docosadienoate (cis-13, 16) & C22:2 & 2.0 \\
Methyl Docosahexaenoate (cis-4, 7, 10, 13, 16, 19 & C22:6 & 2.0 \\
Methyl Tricosanoate & C23:0 & 2.0 \\
Methyl Lignocerate & C24:0 & 4.0 \\
Methyl Nervonate (cis-15) & C24:1 & 2.0 \\
\hline
\end{tabular}




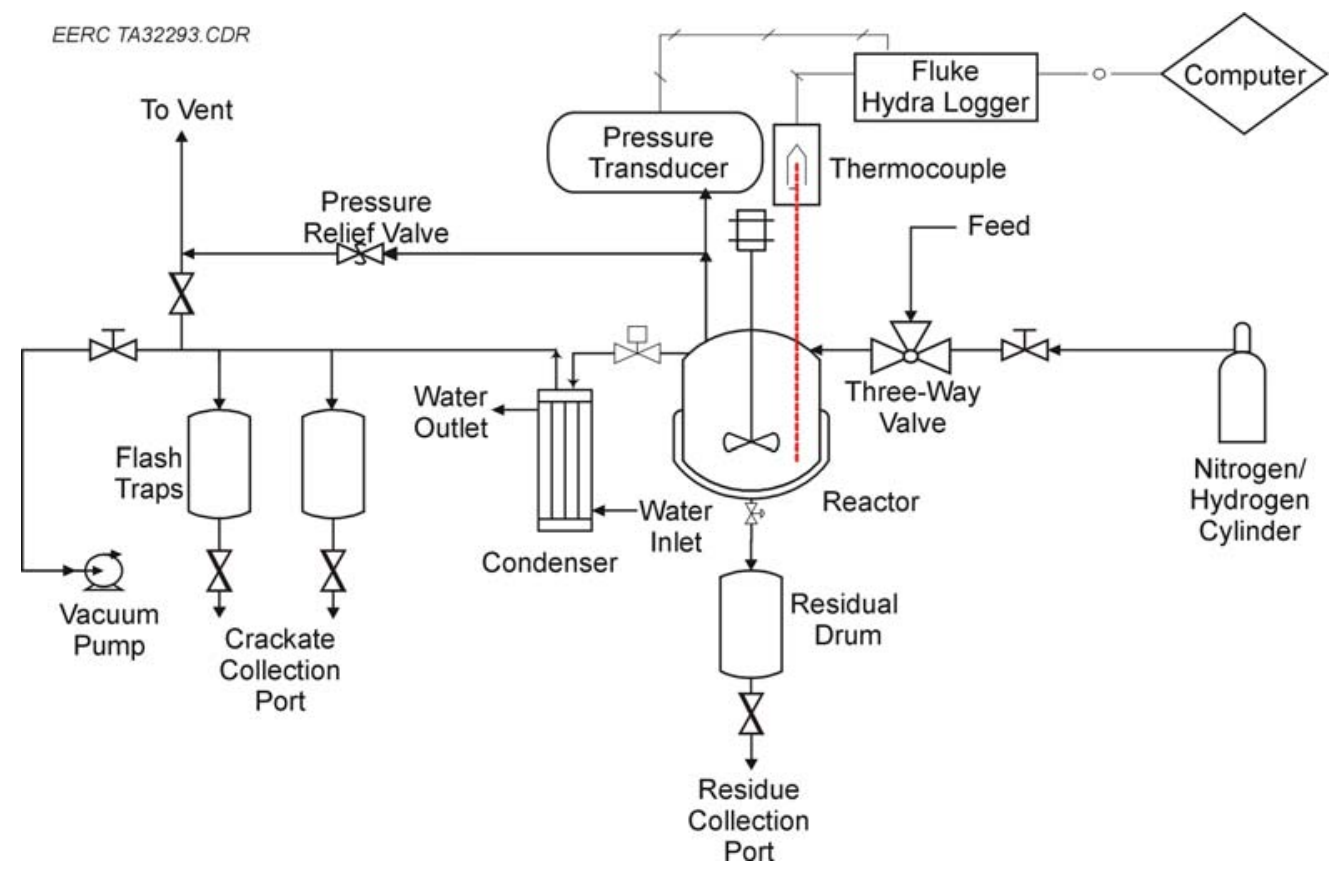

Figure 57. Schematic of thermal cracking apparatus.

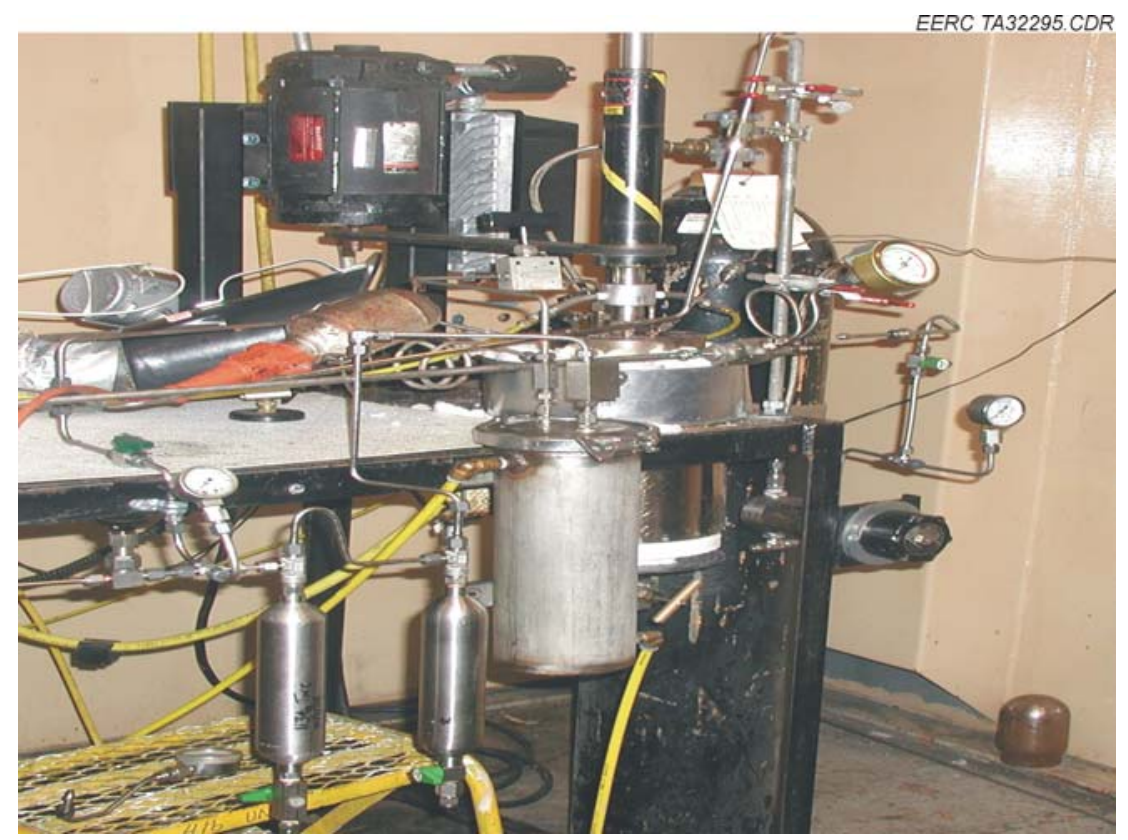

Figure 58. Photo of thermal cracking apparatus. 
The reactor contains four ports. One is the sample port at the bottom of the reactor through which heavy cracked oil (residual) was collected after thermal cracking was completed. The other three ports were used for thermocouples (both liquid and vapor), collection of overhead products, and introduction of feedstock/hydrogen. Additionally, careful control of the heating protocol allowed the exploration of various thermal cracking scenarios. A condenser was used tocool down the overhead vapor product (crackate). Also included are two flash traps $(300 \mathrm{~mL}$ each) in which overheads are collected. All connections were made with $0.32-\mathrm{cm}(1 / 8$-inch) or 0.64-cm (1/4-inch) stainless steel tubing (Swagelok).

The thermal cracking system was tested for leaks before use. The parts for testing include the reactor, two flash traps, the condenser, and the residue drum. The first step in the test was isolating the thermal cracking reactor from the flash traps, condenser, and residue drum. Then the autoclave was initially pressurized with nitrogen to approximately $4100 \mathrm{kPa}$ (600 psig) and left for 30 minutes. After 30 minutes, the pressure was measured in the autoclave and compared with the initial pressure. If the pressure difference was greater than 10 psig, a leak was assumed to exist.

All of the gas lines and reactor fittings were tested for leaks by allowing nitrogen to flow through the system at high pressures $1400 \mathrm{kPa}$ (approximately $200 \mathrm{psig}$ ) and holding it for 510 minutes in the system. Soapy water was sprayed on all the joints and fittings to test for leaks.

\section{Sample Characterization Procedure}

A biojet fuel was generated by removing the heavy components via separation from the crackates of CME, SME, canola oil, and soybean oil. The separation process was carried out using an Orbis PAM distillation unit (ASTM D86). In order to more fully comply with JP-8 specification, the distillation cut was set at $300^{\circ} \mathrm{C}$. The samples (crackates and distillates) obtained from thermal cracking/distillation units were characterized by their properties and chemical compositions. Three properties measured by analyzer systems were CP, PP, and FP. The compositions of samples were obtained by $\mathrm{GC}-\mathrm{MS}$ and $\mathrm{GC}-$ flame ionization detector (GCFID).

An ISL CPP 5Gs analyzer (PAC, Houston, Texas) was used to measure CP (ASTM D2500) and PP (ASTM D97). Flash point (ASTM D93) tests were conducted by a Setaflash Series 3 FP tester. Samples were analyzed with an Agilent 6890 N GC equipped with a FID and an Agilent 7683 series autosampler. A Hewlett-Packard 5890 GC equipped with an MS detector was also used for identification purposes. Data collection and basic analysis were performed by GC Chemsation software.

Two different GC columns and conditions were employed in this study. Column 1 was $30 \mathrm{~m}$ long, with $0.25-\mathrm{mm}$ i.d., film thickness of $0.25 \mu \mathrm{m}$, and coated with a $5 \%$ phenylmethylpolysiloxane stationary phase film (DB-5, J\&W Scientific). Column 1 operating conditions were injector temperature at $300^{\circ} \mathrm{C}, 1.0-\mu \mathrm{L}$ injection volume in splitless mode with splitless time of $0.3 \mathrm{~min}$, detector temperature $320^{\circ} \mathrm{C}$, hydrogen as carrier gas, and total flow rate of $68.7 \mathrm{~mL} / \mathrm{min}$. The temperature program for Column 1 started at $30^{\circ} \mathrm{C}$ for $1 \mathrm{~min}$, then ramped at $30^{\circ} \mathrm{C} / \mathrm{min}$ to $80^{\circ} \mathrm{C}$, followed by the gradient of $3^{\circ} \mathrm{C} / \mathrm{min}$ to $300^{\circ} \mathrm{C}$, and maintained for $5 \mathrm{~min}$. 
Column 2 was $100 \mathrm{~m}$ long, with $0.25-\mathrm{mm}$ i.d., film thickness of $0.5 \mu \mathrm{m}$, and coated with a $100 \%$ dimethylpolysiloxane stationary phase film (DB-PETRO, 122-10A6, Agilent Technologies). Column 2 operating conditions were injector temperature at $300^{\circ} \mathrm{C}, 1.0-\mu \mathrm{L}$ injection volume in splitless mode with splitless time of $0.3 \mathrm{~min}$, detector temperature $325^{\circ} \mathrm{C}$, hydrogen as carrier gas, and linear flow rate of $2.3 \mathrm{~mL} / \mathrm{min}$. The temperature program for Column 2 started at $35^{\circ} \mathrm{C}$ for $1 \mathrm{~min}$, then ramped at $30^{\circ} \mathrm{C} / \mathrm{min}$ to $90^{\circ} \mathrm{C}$ with $5 \mathrm{~min}$ hold, followed by the gradient of $4^{\circ} \mathrm{C} / \mathrm{min}$ to $320^{\circ} \mathrm{C}$, and maintained for $10 \mathrm{~min}$.

O-terphenyl (C18H14) was used as an internal standard. An internal standard stock solution of methylene chloride $\left(\mathrm{CH}_{2} \mathrm{C}_{12}\right)$ with a known amount of o-terphenyl was prepared prior to sample preparation and used for analysis in this study. Samples were prepared for the analysis by adding approximately $100 \mathrm{mg}$ of crackates to $10 \mathrm{~mL}$ of methylene chloride and then by mixing $0.8 \mathrm{~mL}$ of this mixture with $0.8 \mathrm{~mL}$ of the internal standard stock solution. The mixture was then injected into the GC injection port. One $\mu \mathrm{L}$ of the sample was injected into the column. The alkane (C6-C35), alkene (C9-C23), BTEX, FAs (C4-C12), and FAME (C4-C24) standards were used as standard samples to determine the retention times of alkanes, alkenes, BTEX, FAs, and FAMEs. The method of preparation of the samples and standard samples were the same for all samples of cracked soybean/canola oil and SME/CME.

\section{Results and Discussion}

A series of experimental runs and tests were conducted to optimize the operating conditions to produce biojet fuel from canola oil or CME. In this study, multiple predicted variables including yield, CP, PP, FP, and chemical compositions were used to determine these optimal operating conditions. In order to use biojet fuel as a substitution for JP-8, the properties of biojet fuel must mostly meet JP-8 specifications. Performance specifications of JP-8 used in this study were boiling point $\left(500^{\circ} \mathrm{F}, 260^{\circ} \mathrm{C}\right), \mathrm{FP}\left(41^{\circ} \mathrm{C}\right), \mathrm{CP}\left(-47^{\circ} \mathrm{C}\right)$, and $\mathrm{PP}\left(-50^{\circ} \mathrm{C}\right)$.

\section{Experimental Design}

In the bench-scale thermal cracking unit, six major variables (i.e., reaction conditions, also called factors) were considered which could affect the yield, CP, PP, and chemical compositions (i.e., predicted variables, also called responses) of the product. Thus it was decided to determine which of these factors were significant in the formation of the product. As the six factors would require 64 runs for a full-factorial design, or 32 for a half-factorial design, a 12-run PlackettBurman design was employed, as shown in Table 29.

The "+" stands for one setting of a factor (the high-level setting if the factor is quantitative) and the "-" stands for another setting of the factor (the low-level setting if the factor is quantitative). Each of the rows corresponds to a set of experimental conditions that were run. Any number of responses can be measured in each experiment. At the end of the experimental program, each response was analyzed separately. The 12 experimental runs were also done in random order so that no "order" bias would be introduced. 
Table 29. Design of Experimental Matrix for Thermal Cracking Optimization

\begin{tabular}{lcccccccccccc}
\hline Random & Run & $\mathrm{A}$ & $\mathrm{B}$ & $\mathrm{C}$ & $\mathrm{D}$ & $\mathrm{E}$ & $\mathrm{F}$ & \multicolumn{7}{c}{ Unassigned } \\
No. & No. & $\mathrm{X}_{1}$ & $\mathrm{X}_{2}$ & $\mathrm{X}_{3}$ & $\mathrm{X}_{4}$ & $\mathrm{X}_{5}$ & $\mathrm{X}_{6}$ & $\mathrm{X}_{7}$ & $\mathrm{X}_{8}$ & $\mathrm{X}_{9}$ & $\mathrm{X}_{10}$ & $\mathrm{X}_{11}$ \\
\hline 9 & 1 & + & + & - & + & + & + & - & - & - & + & - \\
11 & 2 & + & - & + & + & + & - & - & - & + & - & + \\
4 & 3 & - & + & + & + & - & - & - & + & - & + & + \\
2 & 4 & + & + & + & - & - & - & + & - & + & + & - \\
6 & 5 & + & + & - & - & - & + & - & + & + & - & + \\
12 & 6 & + & - & - & - & + & - & + & + & & + & + \\
3 & 7 & - & - & - & + & - & + & + & - & + & + & + \\
8 & 8 & - & - & + & - & + & + & - & + & + & + & - \\
10 & 9 & - & + & - & + & + & - & + & + & + & - & - \\
5 & 10 & + & - & + & + & - & + & + & + & - & - & - \\
7 & 11 & - & + & + & - & + & + & + & - & - & - & + \\
1 & 12 & - & - & - & - & - & - & - & - & - & - & - \\
\hline
\end{tabular}

A Plackett-Burman design is an economical design with the run numbers (n) a multiple of 4 rather than a power of 2 . When only the main effects are of interest, as in this study, it is an extremely efficient design. However, in a Plackett-Burman design, main effects are, in general, heavily confounded with 2-factor interactions. In order to use the Plackett-Burman design, all interactions must be assumed to be negligible (18).

The six factors considered in thermal cracking were reaction temperature, initial pressure, heating rate, residence time, amount of feedstock, and stirring rate. Tables 30 and 31 show the factors and the levels studied. For canola oil, when cracking at a reaction temperature of $440^{\circ} \mathrm{C}$ and/or residence time of $30 \mathrm{~min}$, the thermal cracking unit was frequently blocked because of canola's higher viscosity than CME. Therefore, the range of these 2 factors was selected differently for canola oil than for CME.

Optimization results are presented in Tables 32 and 33. Because the probe of the ISL CPP 5 Gs analyzer (testing for $\mathrm{CP}$ and $\mathrm{PP}$ ) was broken during the study, tests for $\mathrm{CP}$ and $\mathrm{PP}$ of canola oil could not be done after each experimental run until 1 month later. Three tested CME crackates were analyzed again for calibration purposes for the analyzer, and the results were almost the same as before. However, for most canola oil crackates, CP and PP could not be

Table 30. Parameters in Experimental Matrix for the Cracking of CME

\begin{tabular}{lcccc}
\hline & & \multicolumn{2}{c}{ Range of Factors } \\
Factor & Definition & Label & Low Level $(-)$ & High Level $(+)$ \\
\hline A & Reaction Temperature, ${ }^{\circ} \mathrm{C}$ & $\mathrm{X} 1$ & 430 & 440 \\
$\mathrm{~B}$ & Heating Rate, ${ }^{\circ} \mathrm{C} / \mathrm{min}$ & $\mathrm{X} 2$ & 1 & 2 \\
$\mathrm{C}$ & Stirring Rate, $\mathrm{rpm}$ & $\mathrm{X} 3$ & 192 & 395 \\
$\mathrm{D}$ & Amount of Feedstock, $\mathrm{g}$ & $\mathrm{X} 4$ & 180 & 260 \\
$\mathrm{E}$ & Initial Pressure, $\mathrm{kPa}$ & $\mathrm{X} 5$ & -420 & 2200 \\
$\mathrm{~F}$ & Residence Time, $\mathrm{min}$ & $\mathrm{X} 6$ & 20 & 30 \\
\hline
\end{tabular}


Table 31. Parameters in Experimental Matrix for the Cracking of Canola Oil

\begin{tabular}{lcccc}
\hline & & & \multicolumn{2}{c}{ Range of Factors } \\
Factor & Definition & Label & Low Level $(-)$ & High Level $(+)$ \\
\hline $\mathrm{A}$ & Reaction temperature, ${ }^{\circ} \mathrm{C}$ & $\mathrm{X} 1$ & 420 & 430 \\
$\mathrm{~B}$ & Heating rate, ${ }^{\circ} \mathrm{C} / \mathrm{min}$ & $\mathrm{X} 2$ & 1 & 2 \\
$\mathrm{C}$ & Stirring rate, rpm & $\mathrm{X} 3$ & 192 & 395 \\
$\mathrm{D}$ & Amount of feedstock, $\mathrm{g}$ & $\mathrm{X} 4$ & 180 & 260 \\
$\mathrm{E}$ & Initial pressure, $\mathrm{kPa}$ & $\mathrm{X} 5$ & -420 & 2200 \\
$\mathrm{~F}$ & Residence time, min & $\mathrm{X} 6$ & 20 & 20 \\
\hline
\end{tabular}

Table 32. Results from Experimental Matrix Tests for the Cracking of CME

\begin{tabular}{lcccccc}
\hline Run No. & Random Order & Label No. & Project No. & Yield, $\%$ & $\mathrm{CP},{ }^{\circ} \mathrm{C}$ & $\mathrm{PP},{ }^{\circ} \mathrm{C}$ \\
\hline 1 & 9 & Y35-1 & Bio No. 54 & 80.23 & -21 & -23 \\
2 & 11 & Y37-1 & Bio No. 56 & 85.61 & -18 & -20 \\
3 & 4 & Y30-1 & Bio No. 49 & 83.85 & -14 & -17 \\
4 & 2 & Y67-1 & Bio No. 84 & 82.06 & -19 & -23 \\
5 & 6 & Y32-1 & Bio No. 51 & 79.89 & -23 & -29 \\
6 & 12 & Y38-1 & Bio No. 57 & 73.74 & -19 & -20 \\
7 & 3 & Y29-1 & Bio No. 48 & 75.10 & -17 & -20 \\
8 & 8 & Y34-1 & Bio No. 53 & 79.89 & -13 & -14 \\
9 & 10 & Y68-1 & Bio No. 85 & 72.24 & -8 & -14 \\
10 & 5 & Y27-1 & Bio No. 46 & 83.80 & -21 & -26 \\
11 & 7 & Y33-1 & Bio No. 52 & 82.97 & -13 & -14 \\
12 & 1 & Y66-1 & Bio No. 83 & 71.30 & -15 & -16 \\
\hline
\end{tabular}

Table 33. Results from Experimental Matrix Tests for the Cracking of Canola Oil

\begin{tabular}{lcccccc}
\hline Run No. & Random Order & Label No. & Project No. & Yield, $\%$ & $\mathrm{CP},{ }^{\circ} \mathrm{C}$ & $\mathrm{PP},{ }^{\circ} \mathrm{C}$ \\
\hline 1 & 9 & Y52-1 & Bio No. 70 & 63.12 & - & - \\
2 & 11 & Y53-1 & Bio No. 71 & 69.92 & - & - \\
3 & 4 & Y48-1 & Bio No. 66 & 59.70 & -1 & - \\
4 & 2 & Y47-1 & Bio No. 65 & 67.60 & -17 & - \\
5 & 6 & Y49-1 & Bio No. 67 & 62.78 & -17 & - \\
6 & 12 & Y75-1 & Bio No. 88 & 67.20 & -26 & -34 \\
7 & 3 & Y44-1 & Bio No. 62 & 61.36 & -4 & - \\
8 & 8 & Y57-1 & Bio No. 75 & 55.56 & - & - \\
9 & 10 & Y58-1 & Bio No. 76 & 47.71 & - & - \\
10 & 5 & Y73-1 & Bio No. 86 & 70.70 & -15 & -31 \\
11 & 7 & Y55-1 & Bio No.73 & 59.78 & - & - \\
12 & 1 & Y74-1 & Bio No. 87 & 54.90 & -18 & -28 \\
\hline
\end{tabular}


found by the analyzer. Although $\mathrm{CP}$ of two canola oil crackates was found, which were $-1^{\circ}$ and $-4^{\circ} \mathrm{C}$, the results were suspicious. Repeating the whole 12 runs of canola oil cracking was not possible. Thus only three runs were replicated. The cause of this phenomenon might be the formation changes in the canola oil crackates due to the existence of gum, glycerol, or polymer. Stability issues for products generated from canola oil might be an area for future study.

\section{Statistical Analysis}

Data analysis was performed to determine which factors had the greatest impact on yield, $\mathrm{CP}$, and PP, respectively, when factors were changed. To calculate the effect of any factor, the average of the results at the low level of that factor was subtracted from the average of the results at the high level of the same factor. In this work, effects were calculated according to the following equation:

$$
E_{x_{i}}=\frac{1}{6} \times\left[\sum(+)-\sum(-)\right]
$$

The calculated effects of the unassigned factors were used to estimate the standard deviation of the effects:

$$
s_{E}=\sqrt{\frac{1}{M}\left(E_{X_{7}}^{2}+E_{X_{8}}^{2}+E_{X_{9}}^{2}+E_{X_{10}}^{2}+E_{X_{11}}^{2}\right)}
$$

where $\mathrm{E}_{\mathrm{X} 7}$ is the average effect for column $\mathrm{X}_{7}$, etc., and $\mathrm{M}$ is the number of unassigned factors used to assess experimental error.

The statistical significance of each effect and interaction is judged by comparing its $t$ value (without negative sign) to the tabulated critical t value (also called Student's $t$ ). If the $t$ value of an effect exceeds the critical t value, the effect is statistically significant, and the factor is important. The critical $t$ value is based on the appropriate confidence level and the $\mathrm{M}$ degrees of freedom. In this case, degrees of freedom used was 5, and the critical t value was 2.571 at the $95 \%$ confidence level.

For thermal cracking of $\mathrm{CME}$, the results indicate that reaction temperature had the greatest impact on all responses (yield, CP, and PP). The higher reaction temperature resulted in higher yield and better cold-flow properties of crackates. Hydrogen, feedstock quantity, and heating rate did not play an important role in these responses. Better cold-flow properties were obtained under vacuum conditions and/or a longer residence time. The stirring rate had a positive impact on yield and PP.

For thermal cracking of canola oil, the results show that reaction temperature was the only factor having a significant effect on the yield of crackates. Because of the lack of CP and PP data, calculation of effects for CP and PP could not be performed. 


\section{Separation to Biojet Fuel}

A distillation column was used to separate light components (biojet fuel) from heavier ones in the crackates in order to achieve JP-8 cold-flow specifications. The distillation cut was $300^{\circ} \mathrm{C}$. Tables 34 and 35 present results of the biojet fuels.

The findings indicate that the optimal results determined in the cracking study are the overall optimal results after separation is considered. The higher reaction temperature of cracking gave a higher yield and better cold-flow properties of biojet fuel. In general, nearly 57\% of biojet fuel could be obtained by the CME process (cracking and distillation), while $47 \%$ of biojet fuel was generated from canola oil. If the differences of variable levels for CME and canola oil are taken into account, the yield of biojet fuel can be conservatively estimated as 50\% of feedstocks for a single reactor, single separation process.

The CP and PP were greatly improved after the separation process. $\mathrm{CP}, \mathrm{PP}$, and FP of the biojet fuel were comparable to those in JP-8 specifications. The biojet fuel from the CME process gave better results than that from the canola oil process. It is believed that if we manipulate the temperature of the distillation cut, further-improved $\mathrm{CP}, \mathrm{PP}$, and FP can be obtained for biojet fuels.

\section{Soybean Oil/SME}

A study was performed to determine the optimal conditions for thermal cracking of soybean oil or SME in a 1-liter batch reactor. Figure 59 shows the results of cracking and distillation for SME and soybean oil.

Table 34. Cold-Flow Properties of Biojet Fuel Produced from CME

\begin{tabular}{lccccc}
\hline $\begin{array}{l}\text { GC Label No.: } \\
\text { Project No.: }\end{array}$ & $\begin{array}{c}\text { Y20-1 } \\
\text { Bio No. 84 }\end{array}$ & $\begin{array}{c}\text { Y35-1 } \\
\text { Bio No. 54 }\end{array}$ & $\begin{array}{c}\text { Y27-1 } \\
\text { Bio No. 46 }\end{array}$ & $\begin{array}{c}\text { Y39-1 } \\
\text { Bio No. 56 }\end{array}$ & $\begin{array}{c}\text { Y29-1 } \\
\text { Bio No. 48 }\end{array}$ \\
\hline Temperature, ${ }^{\circ} \mathrm{C}$ & 440 & 440 & 440 & 440 & 430 \\
Heating Rate, ${ }^{\circ} \mathrm{C} / \mathrm{min}$ & 2 & 2 & 1 & 1 & 1 \\
Residence Time, min & 20 & 30 & 30 & 20 & 30 \\
Stirring Rate, rpm & 395 & 192 & 395 & 395 & 192 \\
Amount of Feedstock, g & 180 & 260 & 260 & 260 & 260 \\
Initial Pressure, kPa & -420 & 2200 & -420 & 2200 & -420 \\
Yield of Overhead, \% & 82.1 & 80.2 & 83.8 & 85.6 & 75.1 \\
CP, ${ }^{\circ} \mathrm{C}$ & -21 & -21 & -21 & -17 & -17 \\
PP, ${ }^{\circ} \mathrm{C}$ & -23 & -26 & -26 & -17 & -20 \\
Yield of Distillate, $\%$ & 71.2 & 67.5 & 67.5 & 64.2 & 62.8 \\
Yield of Biojet Fuel, \% & $\mathbf{5 8 . 5}$ & $\mathbf{5 6 . 6}$ & $\mathbf{5 6 . 6}$ & $\mathbf{5 5 . 0}$ & $\mathbf{4 7 . 2}$ \\
$\mathrm{CP},{ }^{\circ} \mathrm{C}$ & $-\mathbf{3 8}$ & $-\mathbf{3 8}$ & $-\mathbf{3 9}$ & $-\mathbf{3 7}$ & $-\mathbf{3 6}$ \\
PP, ${ }^{\circ} \mathrm{C}$ & $-\mathbf{6 2}$ & $\mathbf{- 6 2}$ & $-\mathbf{6 0}$ & $\mathbf{- 6 2}$ & $-\mathbf{5 6}$ \\
FP, ${ }^{\circ} \mathrm{C}$ & $\mathbf{6 8}$ & $\mathbf{6 8}$ & $\mathbf{5 3}$ & $>\mathbf{8 0}$ & $\mathbf{5 8}$ \\
\hline
\end{tabular}


Table 35. Cold-Flow Properties of Biojet Fuel Produced from CME

\begin{tabular}{lccccc}
\hline $\begin{array}{l}\text { GC Label No.: } \\
\text { Project No.: }\end{array}$ & $\begin{array}{c}\text { Y50-1 } \\
\text { Bio No. 86 }\end{array}$ & $\begin{array}{c}\text { Y53-1 } \\
\text { Bio No. 71 }\end{array}$ & $\begin{array}{c}\text { Y52-1 } \\
\text { Bio No. 70 }\end{array}$ & $\begin{array}{c}\text { Y44-1 } \\
\text { Bio No. 62 }\end{array}$ & $\begin{array}{c}\text { Y58-1 } \\
\text { Bio No. 76 }\end{array}$ \\
\hline Temperature, ${ }^{\circ} \mathrm{C}$ & 430 & 430 & 430 & 420 & 420 \\
Heating Rate, ${ }^{\circ} \mathrm{C} / \mathrm{min}$ & 1 & 1 & 2 & 1 & 2 \\
Residence Time, min & 20 & 10 & 20 & 20 & 10 \\
Stirring Rate, rpm & 395 & 395 & 192 & 192 & 192 \\
Amount of Feedstock, g & 260 & 260 & 260 & 260 & 260 \\
Initial Pressure, kPa & -420 & 2200 & 2200 & -420 & 2200 \\
Yield of Overhead, \% & 70.7 & 69.9 & 63.1 & 61.4 & 47.7 \\
CP, ${ }^{\circ} \mathrm{C}$ & -15 & -25 & -18 & -17 & - \\
PP, ${ }^{\circ} \mathrm{C}$ & -31 & -33 & 30 & -28 & - \\
Yield of Distillate, \% & 67.4 & 66.2 & 72.3 & 69 & 70.5 \\
Yield of Biojet Fuel, \% & $\mathbf{4 7 . 7}$ & $\mathbf{4 6 . 3}$ & $\mathbf{4 5 . 6}$ & $\mathbf{4 2 . 4}$ & $\mathbf{3 3 . 6}$ \\
$\mathrm{CP},{ }^{\circ} \mathrm{C}$ & $-\mathbf{3 6}$ & $-\mathbf{3 6}$ & $-\mathbf{3 6}$ & $-\mathbf{3 3}$ & $-\mathbf{2 1}$ \\
PP, ${ }^{\circ} \mathrm{C}$ & $-\mathbf{4 3}$ & $-\mathbf{4 1}$ & $-\mathbf{4 3}$ & $-\mathbf{4 0}$ & $-\mathbf{3 2}$ \\
FP, ${ }^{\circ} \mathrm{C}$ & $\mathbf{3 4}$ & $\mathbf{4 4}$ & $\mathbf{4 0}$ & $\mathbf{4 2}$ & $\mathbf{3 6}$ \\
\hline
\end{tabular}

EERC TA32298.CDR

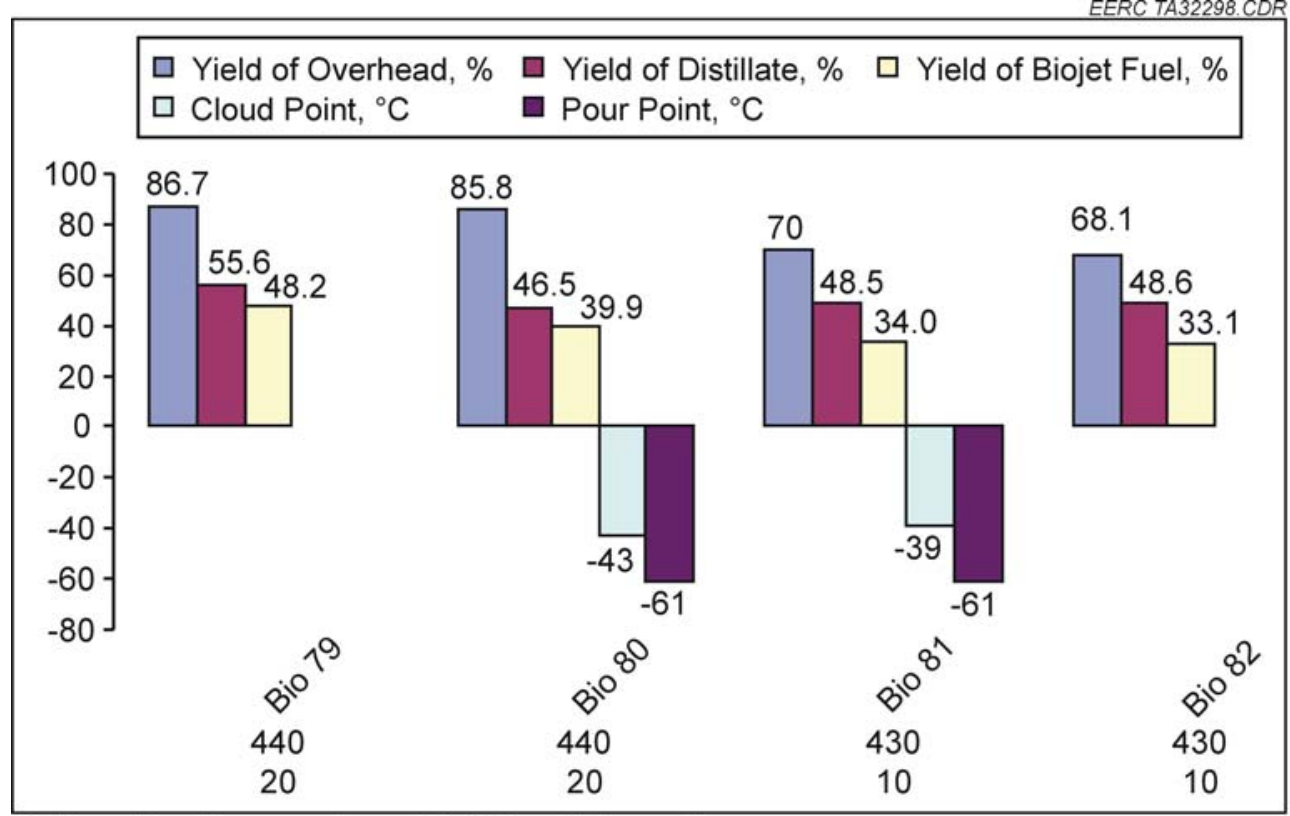

T: Reaction Temperature, ${ }^{\circ} \mathrm{C}$; SR: stirring rate, rpm.

Figure 59. The generation of biojet fuel from soybean oil and SME. Bio Nos. 79 and 80 are from SME feedstock, while Bio Nos. 81 and 82 are from soybean oil feedstock. 


\section{GC Characterization Results}

MS identification and GC-FID quantification were used to define the chemical compositions of the samples (crackates or biojet fuels). Each sample included identified and unidentified components. The unidentified components are composed of small amounts of hundreds of hydrocarbons that cannot be analytically separated well enough to be identified by GC.

For thermal cracking and distillation from SME, the results from GC analysis are presented in Table 36. Identified compounds account for approximately $67 \%$ of the mass of both crackates and biojet fuels. The other $33 \%$ is unidentified components. Of the total mass of identified compounds of crackates, about 18\% were alkanes (17\% C7-C15), 2.5\% BTEX, 1.2\% dimer fatty methyl esters (DFMEs), 75\% saturated FAMEs (53\% C4-C15), and 3.3\% unsaturated C18 FAMEs. Of the total mass of the identified compounds in the final biojet fuel sample, around 24\% were alkanes (almost all C7-C15), 5\% BTEX, 70\% saturated FAs (67\% C4-C15), and 1\% alkenes.

For thermal cracking and distillation from soybean oil, the results are listed in Table 37. Identified compounds account for approximately $55 \%$ of the mass of crackates and $65 \%$ of the mass of biojet fuels. The other $45 \%$ of crackates and $35 \%$ of biojet fuel are unidentified components. Of the total mass of identified compounds of crackates, around $45 \%$ were alkanes (38\% C7-C15 for crackates and 47\% C4-C15 for biojet fuel), 3\% BTEX, and 48\% saturated FAs (47\% C4-C15 for crackates and 49\% C4-C15 for biojet fuel).

For the analysis of crackates and biojet fuel from canola oil and CME, two separate GC columns were used. GC analysis using Column 1 was only performed on samples of crackates produced from CME under vacuum conditions. These are shown in Table 38. Identified compounds account for approximately $55 \%$ of the mass of the crackates. The other $45 \%$ is unidentified components. Of the total identified compounds, there were about $22.5 \%$ alkanes

Table 36. The Composition of Crackates and Final Biojet Fuel Samples Generated from SME

\begin{tabular}{lcccc}
\hline $\begin{array}{l}\text { GC Label No.: } \\
\text { Project No.: }\end{array}$ & $\begin{array}{c}\text { Y61-1 } \\
\text { Bio No. 79 }\end{array}$ & $\begin{array}{c}\text { Y62-1 } \\
\text { Bio No. 80 }\end{array}$ & DY61-1 & DY62-1 \\
\hline Alkanes C7-C15 & 11.2 & 11.5 & 15.9 & 15.4 \\
Total Alkanes & 12.2 & 12.3 & 16.1 & 15.5 \\
Saturated FAMEs C4-C15 & 34.9 & 36.2 & 43.8 & 44.3 \\
Saturated FAMEs C16-C24 & 14.6 & 13.5 & 2.7 & 1.6 \\
Unsaturated FAMEs C18:x (x=1,2,3) & 49.5 & 49.7 & 46.5 & 45.9 \\
Total Saturated FAMEs & 3.4 & 2.8 & - & - \\
Total Alkenes & 0.0 & 0.0 & 0.3 & 0.5 \\
Total BTEX & 1.7 & 1.9 & 2.9 & 3.0 \\
Total DFMEs & 0.7 & 0.8 & - & - \\
Unidentified & 32.5 & 32.5 & 34.1 & 35.1 \\
\hline
\end{tabular}


Table 37. The Composition of Crackates and Final Biojet Fuel Samples Generated from SME

\begin{tabular}{lccrc}
\hline $\begin{array}{l}\text { GC Label No.: } \\
\text { Project No: }\end{array}$ & $\begin{array}{c}\text { Y64-1 } \\
\text { Bio No. 81 }\end{array}$ & $\begin{array}{c}\text { Y65-1 } \\
\text { Bio No. 82 }\end{array}$ & DY64-1 & DY65-1 \\
\hline Alkanes C7-C15 & 18.9 & 22.0 & 25.7 & 29.1 \\
Total Alkanes & 23.2 & 25.8 & 27.8 & 30.6 \\
Saturated FAs C4-C15 & 25.6 & 25.1 & 33.9 & 32.3 \\
Saturated FAs C16-C24 & 3.2 & 2.1 & 0.3 & 0.3 \\
Total Saturated FAs & 28.8 & 27.2 & 34.2 & 32.7 \\
Unsaturated FAMEs C18:x (x=1,2,3) & 0.1 & 0.0 & 0.0 & 0.0 \\
Total Alkenes & 0.0 & 0.0 & 1.1 & 0.8 \\
Total BTEX & 1.5 & 1.9 & 1.1 & 2.0 \\
Unidentified & 46.5 & 45.1 & 35.8 & 33.9 \\
\hline
\end{tabular}

Table 38. Results and GC Analysis of CME Crackates Using Column 1

\begin{tabular}{|c|c|c|c|c|c|c|c|}
\hline $\begin{array}{l}\text { GC Label No.: } \\
\text { Project No.: }\end{array}$ & $\begin{array}{l}\text { Y16-1 } \\
\text { Bio } \\
\text { No. } 40\end{array}$ & $\begin{array}{l}\text { Y17-1 } \\
\text { Bio } \\
\text { No. } 41\end{array}$ & $\begin{array}{l}\text { Y18-1 } \\
\text { Bio } \\
\text { No. } 42\end{array}$ & $\begin{array}{l}\text { Y19-1 } \\
\text { Bio } \\
\text { No. } 43\end{array}$ & $\begin{array}{c}\text { Y20-1 } \\
\text { Bio } \\
\text { No. } 44\end{array}$ & $\begin{array}{l}\text { Y22-1 } \\
\text { Bio } \\
\text { No. } 45\end{array}$ & Y15-1 \\
\hline Temperature, ${ }^{\circ} \mathrm{C}$ & 440 & 440 & 430 & 440 & 440 & 430 & \\
\hline Heating Rate, ${ }^{\circ} \mathrm{C} / \mathrm{min}$ & 2 & 1 & 4 & 2 & 1 & 1 & \\
\hline Residence Time, min & 30 & 30 & 20 & 20 & 20 & 20 & \\
\hline Stirring Rate, rpm & 192 & 395 & 192 & 192 & 395 & 395 & \\
\hline Amount of Feedstock, $g$ & 260 & 180 & 180 & 260 & 180 & 260 & \\
\hline Initial Pressure, $\mathrm{kPa}$ & w/o $\mathrm{H}_{2}$ & w/o $\mathrm{H}_{2}$ & w/o $\mathrm{H}_{2}$ & w/o $\mathrm{H}_{2}$ & w/o $\mathrm{H}_{2}$ & w/o $\mathrm{H}_{2}$ & \\
\hline Yield of Overhead, \% & 79.5 & 84.4 & 59.8 & 72.4 & 82.3 & 80.1 & \\
\hline $\mathrm{CP},{ }^{\circ} \mathrm{C}$ & -23 & -21 & -15 & -21 & -19 & -13 & -2 \\
\hline $\mathrm{PP},{ }^{\circ} \mathrm{C}$ & -25 & -30 & -16 & -23 & -23 & -15 & -10 \\
\hline Alkanes C7-C15 & 11.9 & 11.8 & 5.6 & 9.6 & 11.5 & 6.7 & 0.0 \\
\hline Total Alkanes & 12.8 & 12.8 & 6.2 & 10.4 & 12.4 & 7.3 & 0.0 \\
\hline Saturated FAMEs C4-C15 & 30.4 & 29.0 & 22.4 & 28.8 & 30.6 & 24.0 & 0.1 \\
\hline Saturated FAMEs C16-C24 & 3.2 & 6.0 & 4.7 & 3.8 & 4.3 & 6.1 & 7.5 \\
\hline Total Saturated FAMEs & 33.6 & 35.0 & 27.1 & 32.6 & 34.9 & 30.1 & 7.7 \\
\hline Unsaturated FAMEs C4-C15 & 2.0 & 2.3 & 5.6 & 2.8 & 2.4 & 3.5 & 0.0 \\
\hline Unsaturated FAMEs C16-C22 & 3.5 & 3.5 & 14.1 & 5.8 & 4.8 & 11.6 & 89.6 \\
\hline $\begin{array}{l}\text { Unsaturated FAMEs C18:x }(\mathrm{x}=1,2 \text {, } \\
\text { 3) }\end{array}$ & 3.5 & 3.5 & 14.1 & 5.8 & 4.8 & 11.6 & 89.6 \\
\hline Total Unsaturated FAMEs & 5.6 & 5.8 & 19.7 & 8.7 & 7.2 & 15.0 & 89.6 \\
\hline Total FAMEs & 39.2 & 40.9 & 46.8 & 41.3 & 42.1 & 45.1 & 97.3 \\
\hline Total Alkenes & 0.8 & 1.1 & 2.7 & 1.1 & 0.4 & 0.7 & 0.0 \\
\hline Total BTEX & 2.1 & 2.1 & 0.6 & 1.5 & 2.0 & 0.8 & 0.0 \\
\hline Unidentified & 45.1 & 43.1 & 43.8 & 45.7 & 43.2 & 46.1 & 2.7 \\
\hline
\end{tabular}


(20\% C7-C15), 1.5\% alkenes, 3.6\% BTEX, 61.4\% saturated FAMEs (56\% C4-C15), and 11\% unsaturated FAMEs $(6.8 \% \mathrm{C} 16-\mathrm{C} 22)$.

The chemical compositions of crackates generated from CME and analyzed using Column 2 are listed in Table 39. Identified compounds account for approximately $60 \%$ of the mass of the crackates. The other $40 \%$ is unidentified components. Of the total identified compounds of crackates, there were about $22 \%$ alkanes $(20.5 \% \mathrm{C} 7-\mathrm{C} 15), 2 \%$ alkenes, $3 \%$ BTEX, 3\% DFMEs, 60\% saturated FAMEs (48\% C4-C15), and 10\% unsaturated FAMEs C16C22. Comparing these GC analysis results to prior data, the chemical compositions are equivalent for each component, except DFME composition and saturated C4-C15 FAMEs. The anticipated advantage of using Column 2, better resolution of unidentified compounds, did not appear as expected in this study. On the contrary, the retention time for alkanes and FAMEs were too close to each other; thus the chromatograms were not shown well, and the identification became more difficult.

Table 40 shows the composition of biojet fuels generated from CME. Identified compounds account for approximately $60 \%$ of the mass of the biojet fuel. The other $40 \%$ is unidentified components. Of the total identified compounds of biojet fuels, there were about 26.5\% alkanes (25.4\% C7-C15), 2.8\% alkenes, 3.7\% BTEX, 3.5\% DFMEs, $61.5 \%$ saturated FAMEs (58\% C4-C15), and 2\% unsaturated FAMEs (C16-C22). The heavy components were removed by the separation process, especially saturated and unsaturated C16-C22 FAMEs, which might be CME uncracked during the cracking process.

Table 39. Results and GC Analysis of CME Crackates Using Column 2

\begin{tabular}{lccccc}
\hline $\begin{array}{l}\text { GC Label No.: } \\
\text { Project No.: }\end{array}$ & $\begin{array}{c}\text { Y20-1 } \\
\text { Bio No. } 84\end{array}$ & $\begin{array}{c}\text { Y35-1 } \\
\text { Bio No. 54 }\end{array}$ & $\begin{array}{c}\text { Y27-1 } \\
\text { Bio No. 46 }\end{array}$ & $\begin{array}{c}\text { Y39-1 } \\
\text { Bio No. 56 }\end{array}$ & $\begin{array}{c}\text { Y29-1 } \\
\text { Bio No. 48 }\end{array}$ \\
\hline Temperature, ${ }^{\circ} \mathrm{C}$ & 440 & 440 & 440 & 440 & 430 \\
Heating Rate, ${ }^{\circ}$ C/min & 2 & 2 & 1 & 1 & 1 \\
Residence Time, min & 20 & 30 & 30 & 20 & 30 \\
Stirring Rate, rpm & 395 & 192 & 395 & 395 & 192 \\
Amount of Feedstock, g & 180 & 260 & 260 & 260 & 260 \\
Initial Pressure, kPa & -420 & 2200 & -420 & 2200 & -420 \\
Alkanes C7-C15 & 12.3 & 12.8 & 13.0 & 12.4 & 10.1 \\
Total Alkanes & 13.1 & 13.5 & 13.4 & 13.1 & 10.8 \\
Saturated FAMEs C4-C15 & 29.9 & 29.6 & 30.1 & 28.8 & 28.5 \\
Saturated FAMEs C16-C24 & 8.1 & 6.9 & 6.8 & 7.6 & 9.8 \\
Total Saturated FAMEs & 38.0 & 36.4 & 36.9 & 36.4 & 38.3 \\
Unsaturated FAMEs C16- & 6.4 & 4.5 & 4.9 & 5.7 & 9.1 \\
$\quad$ C22 & & & & & \\
Unsaturated FAMEs C18:x & 6.1 & 4.2 & 4.7 & 5.4 & 8.6 \\
$\quad$ (x = 1, 2, 3) & & & & & \\
Total Alkenes & 1.4 & 1.3 & 1.5 & 1.2 & 1.6 \\
Total BTEX & 1.7 & 1.9 & 1.9 & 1.7 & 1.3 \\
Total DFMEs & 2.9 & 2.3 & 3.0 & 2.2 & 4.0 \\
Unidentified & 36.4 & 40.1 & 38.4 & 39.7 & 35.0 \\
\hline
\end{tabular}


Table 40. Results and GC Analysis of CME Biojet Fuel Using Column 2

\begin{tabular}{lcrrrr}
\hline GC Label No.: & DY20-1 & DY35-1 & \multicolumn{1}{c}{ DY27-1 } & DY39-1 & DY29-1 \\
\hline Alkanes C7-C15 & 15.0 & 15.4 & 15.1 & 15.2 & 13.5 \\
Total Alkanes & 15.5 & 15.8 & 15.5 & 15.6 & 14.1 \\
Saturated FAMEs C4-C15 & 34.5 & 34.7 & 33.9 & 34.3 & 36.3 \\
Saturated FAMEs C16-C24 & 2.1 & 1.8 & 1.8 & 2.1 & 2.7 \\
Total Saturated FAMEs & 36.6 & 36.5 & 35.6 & 36.4 & 39.0 \\
Unsaturated FAMEs C16-C22 & 1.6 & 1.1 & 1.1 & 0.8 & 2.0 \\
Unsaturated FAMEs C18:x (x=1,2,3) & 1.5 & 1.1 & 1.1 & 0.8 & 2.0 \\
Total Alkenes & 1.7 & 1.6 & 1.7 & 1.5 & 2.1 \\
Total BTEX & 2.2 & 2.3 & 2.3 & 2.1 & 1.7 \\
Total DFMEs & 2.1 & 1.6 & 2.1 & 1.6 & 3.0 \\
Unidentified & 40.4 & 41.1 & 41.7 & 42.1 & 38.1 \\
\hline
\end{tabular}

The chemical compositions of crackates generated from canola oil are presented in Table 41. Identified compounds account for approximately 55\% of the mass of the biojet fuel. The other $45 \%$ is unidentified components. Of the total identified compounds of crackates, there were about $32 \%$ alkanes $(27 \% \mathrm{C} 7-\mathrm{C} 15), 2.3 \%$ alkenes, $2.7 \%$ BTEX, and $63 \%$ saturated FAs. Apparently, crackates generated from canola oil yield more desired alkanes than from CME. This is because components removed by the transesterification process can also be cracked into small molecular compounds like alkanes by thermal cracking. Therefore, using canola oil to generate biojet fuel might be more economical than using CME because the transesterification process can be eliminated.

Table 42 shows the chemical compositions of biojet fuels generated from canola oil. Identified compounds account for approximately $64 \%$ of the mass of the biojet fuel. The other $36 \%$ is unidentified components. Of the total identified components of biojet fuels, there were about $33 \%$ alkanes $(30 \% \mathrm{C} 7-\mathrm{C} 15), 2.4 \%$ alkenes, $3.6 \% \mathrm{BTEX}$, and $61 \%$ saturated FAs.

The results from the GC analysis confirmed that reaction temperature was the most important variable in biojet fuel generation. The alkanes and desired $\mathrm{C} 7-\mathrm{C} 15$ yield increased as the cracking temperature was raised from $430^{\circ}$ to $440^{\circ} \mathrm{C}$. Hydrogen did not impact the yield of alkanes and the desired C7-C15. Canola oil and CME crackates have a higher concentration of alkane compounds present in them compared to soybean oil and SME at the same cracking conditions. This is because of their difference in FA/ester profile. It is believed since the canola oil and CME consist of 60\%-63\% oleic acid-ester (one double bond), it facilitates the production of alkanes in thermal cracking.

CME and SME produce higher yields compared to canola oil and soybean oil. However, the yield of alkane and C7-C15 are higher from canola oil and soybean oil than CME and SME. It is believed that components, which were not removed by the transesterification process, facilitated the formation of alkane and $\mathrm{C} 7-\mathrm{C} 15$ in thermal cracking. Distillation was used to remove heavy compounds from the crackates so that biojet fuel more comparable to JP-8 specifications was produced. 


\begin{tabular}{lccccc} 
Table 41. Results and GC Analysis of Canola Oil Using Crackates Using Column 2 \\
\hline GC Label No.: & Y50-1 & Y53-1 & Y52-1 & Y44-1 & Y58-1 \\
Project No.: & Bio No. 86 & Bio No. 71 & Bio No. 70 & Bio No. 62 & Bio No. 76 \\
\hline Temperature, ${ }^{\circ} \mathrm{C}$ & 430 & 430 & 430 & 420 & 420 \\
Heating Rate, ${ }^{\circ}$ C/min & 1 & 1 & 2 & 1 & 2 \\
Residence Time, min & 20 & 10 & 20 & 20 & 10 \\
Stirring Rate, rpm & 395 & 395 & 192 & 192 & 192 \\
Amount of Feedstock, g & 260 & 260 & 260 & 260 & 260 \\
Initial Pressure, kPa & -420 & 2200 & 2200 & -420 & 2200 \\
Alkanes C7-C15 & 21.6 & 16.0 & 14.1 & 17.1 & 11.4 \\
Total Alkanes & 25.3 & 18.8 & 16.3 & 20.5 & 13.3 \\
Saturated FAs C4-C15 & 28.7 & 37.1 & 35.5 & 33.2 & 42.5 \\
Total Alkenes & 1.2 & 1.3 & 1.4 & 1.2 & 1.4 \\
Total BTEX & 1.7 & 1.5 & 1.5 & 1.4 & 1.2 \\
Unidentified & 43.1 & 41.3 & 45.2 & 43.8 & 41.4 \\
\hline
\end{tabular}

Table 42. Results and GC Analysis of Canola Oil Biojet Fuel Using Column 2

\begin{tabular}{lccrrr}
\hline GC Label No.: & DY50-1 & DY53-1 & DY52-1 & DY44-1 & DY58-1 \\
\hline Alkanes C7-C15 & 23.4 & 18.6 & 19.4 & 19.2 & 36.0 \\
Total Alkanes & 25.7 & 20.7 & 21.5 & 21.9 & 36.0 \\
Saturated FAs C4-C15 & 31.3 & 40.5 & 38.8 & 36.2 & 11.3 \\
Total Alkenes & 1.3 & 1.5 & 1.9 & 1.4 & 6.6 \\
Total BTEX & 1.9 & 1.8 & 2.1 & 1.5 & 4.5 \\
Unidentified & 39.8 & 35.6 & 35.9 & 38.9 & 41.5 \\
\hline
\end{tabular}

\section{Conclusions}

1. A high yield $(50 \%$ for a single-pass reaction/single-pass separation and around $86 \%$ with recycle) of biojet fuel can be obtained that meets the required $\mathrm{CP}, \mathrm{PP}$, and FPs analogous to those in JP-8 specifications. The biojet fuel consists of approximately 15\% alkanes, $2 \%$ alkenes, 2\% BTEX, and 34\% C4-C15 saturated fatty compounds.

2. The optimal operating conditions for cracking in a 1-L bench-scale cracking reactor are stirring rate at $395 \mathrm{rpm}$, heating rate at $1^{\circ}-2^{\circ} \mathrm{C} / \mathrm{min}$, initial pressure under vacuum, reaction temperature at $440^{\circ} \mathrm{C}$ for $\mathrm{SME}$ and $430^{\circ} \mathrm{C}$ for soybean oil, and residence time at 2030 minutes for SME and 10-20 minutes for soybean oil. The distillation cut point of $300^{\circ} \mathrm{C}$ is optimal.

3. Hydrogen does not play an important role in the cracking process and formation of products but helps minimize polymerization, especially for oil as a feedstock.

4. A higher yield of crackates can be obtained from biodiesel than its feedstock oil, but the quality (defined as percentage of $\mathrm{C} 4-\mathrm{C} 15$ content) is less from biodiesel than its feedstock oil. 
5. Canola oil and CME crackates have a higher concentration of alkane compounds present in them compared to soybean oil and SME produced at the same cracking conditions.

6. Reaction temperature is the most important variable for the yield and quality of biojet fuel generation. A higher reaction temperature of cracking near the feedstock's boiling point results in a higher yield and better cold-flow properties of crackates.

\section{References}

1. Aksoy, H.A.; Becerik, I.; Karaosmanoglu, F.; Yatmaz, H.C.; Civelekoglu, H. Utilization Prospects of Turkish Raisin Seed Oil as an Alternative Engine Fuel. Fuel 1990, 69, 600-603.

2. Larson, V. Emission Analysis of Biodiesel in a Commercial Aircraft Engine. Master's Thesis, University of North Dakota, 2004.

3. Dunn, R.O. Alternative Jet Fuels from Vegetable Oils. Am. Soc. Agricul. Eng. (ISSN 00012351) 2001, 44 (6), 1751-1757.

4. Ahmed, I. Cold-Flow Biojet Fuel from Soybean Oil. Master's Thesis, University of North Dakota, 2005.

5. Duffield, J.; Shapouri, H.; Graboski, M.; McCormick, R.; Wilson R. U.S. Biodiesel Development: New Markets for Conventional and Genetically Modified Agricultural Fats and Oils, 1998. http://usda.mannlib.cornell.edu/usda/reports/general/aer/aer770.pdf (accessed May 2006).

6. EPA. http://yosemite.epa.gov/oar/globalwarming.nsf/content/climate.html (accessed June 2006).

7. Ma, F.; Hanna, M.A. Biodiesel Production: A Review. Biores. Technol. 1999, 70, 1-15.

8. Srivastava, A.; Prasad, R. Triglycerides-Based Diesel Fuels. Renew. Sustain. Energy Rev. 1999, 4, 111-133.

9. Chiu, C.W.; Schumacher, L.G.; Suppes, G.J. Impact of Cold-Flow Improvers on Soybean Biodiesel Blend. Biomass Bioenergy 2004, 27, 485-491.

10. Knothe, G.; Dunn, R.O.; Bagby, M.O. Biodiesel: The Use of Vegetable Oils and Their Derivatives as Alternative Diesel Fuels. http://journeytoforever.org/biofuellibrary/ VegetableOilsKnothe.pdf (accessed June 2006).

11. Lang, X.; Dalai, A.K.; Bakhshi, N.N.; Reaney, M.J.; Hertz, P.B. Preparation and Characterization of Bio-Diesels from Various Bio-Oils. Biores. Technol. 2001, 80, 53-62. 
12. Arkoudeas, P.; Kalligeros, S.; Zannikos, F.; Anastopoulos, G.; Karonis, D.; Korres, D.; Lois, E. Study of Using JP-8 Aviation Fuel and Biodiesel in CI Engines. Energy Convers. Manage. 2003, 44, 1013-1025.

13. Ritchie, G.D.; Bekkedal, M.Y.V.; Bobb, A.J.; Still, K.R. Biological and Health Effects of JP-8 Exposure. U.S. Army Petroleum Center, http://usapc.army.mil/miscellaneous/JP8HazardsStudy.doc (accessed June 2006).

14. Dietzel, K.D.; Campbell, J.L.; Bartlett, M.G.; Witten, M.L.; Fisher, J.W. Validation of a Gas Chromatography/Mass Spectrometry Method for the Quantification of Aerosolized Jet Propellant 8. J. Chromatogr. A 2005, 1093, 11-20.

15. Petroleum HPV Testing Group. www.petroleumhpv.org/Product_Categories/Kerosene\&JetFuel/jetfuel_robsumm_final_123103.pdf (accessed July 2006).

16. Veg Burner. http://vegburner.co.uk (accessed July 2006).

17. Knothe, G. Dependence of Biodiesel Fuel Properties on the Structure of Fatty Acid Alkyl Esters. Fuel Process. Technol. 2005, 86, 1059-1070.

18. Lawson, J.; Erjavec J. Modern Statistics for Engineering and Quality Improvement. Wadsworth Group, 2001; pp 421-431.

\section{Activity 2.2 - Commercial Feasibility Study}

\section{Introduction}

A scoping study was completed to evaluate the technical and commercial feasibility for building and operating a biojet fuel production facility in North Dakota. The study included a preliminary process design, capital cost estimate, operating cost estimate, and economic assessment for a 3-million-gallon-per-year demonstration-scale facility. The same information was generated for a biodiesel plant of the same size for feasibility comparison. While the specific data for an actual facility will vary somewhat from those generated, these data and the comparison to a biodiesel plant of the same capacity provide a useful assessment of the attractiveness of this new technology.

In the research reported in the above sections, parallel development paths were pursued for biojet fuel production from two different feedstocks: soybean-canola oil and soy-canola methyl ester. One of the preliminary conclusions from this work is that an acceptable biojet fuel can be produced from either and that the yields and fuel quality are fairly comparable. One caveat concerning this conclusion is that, to date, we have not performed long-term turbine testing or material corrosion tests to ascertain that the FA-containing biojet fuel made directly from soybean/canola oil is an acceptable product. We are more confident that the FAME-containing biojet fuel made from SME-CME is acceptable based on the acceptance of SME-CME as biodiesel fuels. 


\section{Goals and Objectives}

\section{Biodiesel and Its Basic Economics}

Biodiesel, such as SME, refers to mono alkyl esters of long-chain FAs derived from renewable sources such as animal fats and crop oils (canola oil or soybean oil), most commonly by a transesterification process, as shown in Figure 60. This process reduces the molecular weight to one-third that of oil, lessens viscosity by a factor of eight, and increases volatility (1).

The gross heat of combustion of FA and esters is in the range of 39 to $40 \mathrm{MJ} / \mathrm{kg}$ for C16C18 FAs and esters, while this value for petroleum diesel fuel is about $45 \mathrm{MJ} / \mathrm{kg}(2-4)$. The heat of combustion increases with increasing chain length. In general, biodiesel and its feedstock contain nearly $10 \%$ less heat energy on a mass basis compared with petroleum diesel fuel because of the presence of chemically bound oxygen in the biodiesel chemical structures. Biojet heating values are similar to those of biodiesel.

At present production levels (75 million gallons per year) (5), biodiesel requires a subsidy to compete directly with petroleum diesel. As of now, the government is offering incentives that encourage the rapid growth of the biodiesel industry. The combined vegetable oil and animal fat production in the United States totals about 35.3 billion pounds per year (4.2 billion gallons per year) (6). This production could provide 4.6 billion gallons of biodiesel. However, the annual consumption of on-highway diesel fuel in the United States. is almost 33 billion gallons. If all of the vegetable oil and animal fat produced in the United States were available to produce biodiesel, it would only replace approximately $14 \%$ of the current demand for on-highway diesel fuel (7). If biodiesel were blended with petroleum-based diesel fuel, e.g., B20, the total supply of this blended fuel would be about 23 billion gallons, or $70 \%$ of U.S. annual diesel consumption.

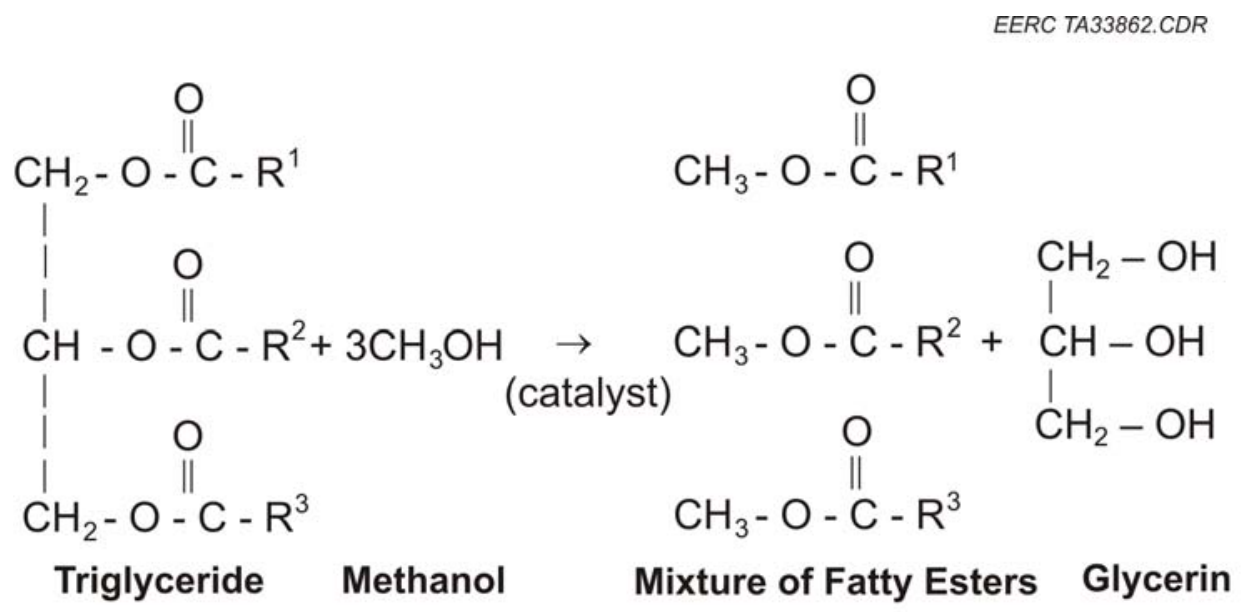

Figure 60. Transesterification reaction $\left(\mathrm{R}^{1}, \mathrm{R}^{2}\right.$, and $\mathrm{R}^{3}$ are $\mathrm{FA}$ chains) (7). 
Although biodiesel cannot entirely replace petroleum diesel fuel, there are many reasons that justify its development:

1. It provides a market for excess production of vegetable oil and animal fat.

2. It can be used in any conventional, unmodified diesel engine.

3. It decreases, but will not eliminate, the nation's dependence on imported petroleum.

4. It is renewable and does not contribute to global warming because of its closed carbon cycle. A life-cycle analysis of biodiesel showed that overall $\mathrm{CO}_{2}$ emissions were reduced by $80 \%$ compared with petroleum diesel fuel.

5. Biodiesel is an oxygenated fuel. The exhaust emissions of $\mathrm{CO}$, unburned hydrocarbons, and particulate emissions from biodiesel are lower than those of petroleum diesel, although a slight increase in oxides of nitrogen $\left(\mathrm{NO}_{\mathrm{x}}\right)$ has been shown in most emission tests.

6. When added to petroleum diesel fuel in an amount equal to $1 \%-2 \%$, biodiesel can convert fuel with poor lubricating properties, such as modern ultralow-sulfur diesel fuel, into an acceptable fuel (7).

7. Biodiesel is nontoxic and biodegradable, with a high flash point. Therefore, handling and storage are safer than petroleum diesel.

\section{Experimental}

\section{Study Methodology}

Based on the data obtained in the process optimization and fuels characterization studies described previously, a computer process simulation model was developed to estimate conditions in a demonstration-scale production system using equivalent unit operations. The computer simulation model mimics the laboratory setup used in bench-scale experiments and has the ability to separate the profitability problem into unit operation capital cost components and operational cost components. The computer model enabled the use of rigorous mathematical and thermodynamic calculations to simulate actual production stages of a 3-million-gallon biojet facility.

This study is based on scale-up from our bench scale to production scale. Further, there is a limited pool of both process and economic data available. Therefore, a number of assumptions were made during the study. The most notable assumptions are as follows:

- Facility yield at $86 \%$.

- Facility operating at capacity at $90 \%$.

- Process will be continuous flow.

- Facility has a life span of 20 years with no salvage value of capital equipment. 
- Capital costs, utility costs, and operating expenses were determined using standardized industry forecasting methods (8).

Economic assessment was based on the net present value (NPV) method. NPV is a formula calculating a future stream of benefits and costs converted into equivalent values today. This is done by assigning monetary values to benefits and costs, discounting future benefits and costs using an appropriate discount rate, and subtracting the sum total of discounted costs from the sum total of discounted benefits. The goal of the NPV calculation is to return a number that is greater than zero when future cash flows are discounted by a "hurdle rate" or "minimum acceptable rate of return" (MARR). The MARR is typically $5 \%-10 \%$ above the prime lending rate. A zero NPV represents the point of economic breakeven, thus a desirable economic model would be one that generates a positive NPV. A model that returns a negative NPV indicates that the facility will operate at a loss over the estimated time frame.

The biodiesel facility is based on processing 3 million gallons of refined soybean oil. This facility design was adapted from a UND Chemical Engineering senior plant design project design of a 50-million-gallon-per-year facility (9). The process design was scaled down to the target production rate, and the costs and economics were adjusted accordingly. Proprietary process flow diagrams for a 3-million-gallon-per-year biojet fuel production facility were developed and used as the basis for estimating capital and operating costs.

\section{Results and Discussion}

\section{Cost Estimates and Economic Assessment Results}

The capital cost estimate for the biojet fuel facility is shown in Table 43. This facility, based on the direct processing of soybean oil, is roughly one-third less costly than the comparable biodiesel facility, which has an estimated capital cost of $\$ 3,000,000$.

The basis for the yearly operating (manufacturing) costs for the biojet fuel facility are shown in Table 43. A similar basis was used for the biodiesel facility operating cost estimates. These values were used to generate the operating cost estimate shown in Table 44. The biojet fuel facility has slightly lower operating costs compared to a biodiesel facility. Raw material costs are higher in the biodiesel plant because of the extra methanol and catalyst that have to be provided for the process. The biojet fuel plant requires 10 operators and a supervisor. This is two operators fewer than the biodiesel plant, which decreases the labor cost by about $\$ 100,000$ a year. Maintenance, operating supplies, overhead, licensing fees, laboratory charges, and insurance costs were obtained using standardized factors (Figure 61). Since these cost parameters are based on the total capital cost investment, all of them are lower for the biojet fuel plant. Administration costs were obtained by adding the cost for two office administrative assistants and administrative supplies. Distribution and selling costs were obtained by assuming that the sales team would consist of two sales people. A standard rate for fuel of approximately $\$ 0.02$ per gallon was applied. 


\section{Table 43. Annual Operating (manufacturing) Expenses for a Biojet Fuel}

Facility and a 3-million-gallon-per-year Biodiesel Facility

\begin{tabular}{lcc}
\hline Cost Element, $\$ / y r$ & Biojet Fuel Facility & Biodiesel Facility \\
\hline Raw Material $^{\mathrm{a}}$ & $6,400,000$ & $7,000,000$ \\
Labor Expenses & 510,000 & 610,000 \\
Maintenance & 120,000 & 163,000 \\
Utilities $^{\text {General Expenses }}{ }^{\mathrm{b}}$ & 590,000 & 91,000 \\
Indirect Expenses $^{\mathrm{c}}$ & 430,000 & 430,000 \\
Miscellaneous Expenses $^{\mathrm{d}}$ & 330,000 & 410,000 \\
Yearly Total $^{\mathrm{a}}$ Includes operating, supervisory, and clerical labor. & 530,000 \\
${ }^{\mathrm{b}}$ Includes administrative, distribution and selling, and research and design costs. \\
${ }^{\mathrm{c}}$ Includes overhead and insurance. \\
${ }^{\mathrm{d}}{ }^{2}$ Laboratory charges, operating supplies, and licensing fee.
\end{tabular}

Revenue in a biodiesel plant is slightly higher than the biojet fuel plant for two reasons:

1. A biodiesel plant that consumes $3,000,000$ gallons of soybean oil per year produces approximately $3,100,000$ gallons of biodiesel per year. On the other hand, a biojet fuel plant is currently forecasted to produce approximately 2,600,000 gallons of biojet fuel per year.

2. In addition to increased production, there is a $\$ 1$ per gallon subsidy. Since a biodiesel plant produces over 500,000 gallons more product per year than a biojet fuel plant, this has a big impact on the revenue.

Annual gross revenues from the sales of products for the two facilities are summarized in Table 45 . The biodiesel facility has a gross revenue of approximately $\$ 1,000,000$ per year more than the biojet fuel facility based on current product prices. This is due to the higher yield of biodiesel produced per gallon of feed soybean oil to the facility. In this evaluation, a yield of $86 \%$ was assumed for the biojet fuel product. The remaining $14 \%$ of the feedstock material was assumed to be consumed internally in the process as a source of boiler fuel to generate steam and heat the soybean oil.

Yearly revenue of $\$ 8,100,000$ is obtained by selling the biojet fuel product at a projected price of $\$ 3.12$ per gallon. This is an extremely conservative price, as jet fuel is currently retailing locally at $\$ 3.90$ per gallon while diesel at present sells at $\$ 3.00$ per gallon. There is also a possibility of additional revenues generated by the value-added chemicals that have been identified in the by-products for the biojet fuel process. There is a considerable amount of work left to be done on quantifying and qualifying these compounds. For this reason, they were not included in this cost analysis. 
Table 44. Capital Cost Summary for a 3-million-gallon-per-year Biojet Fuel Facility

\begin{tabular}{|c|c|c|c|c|c|c|c|c|c|}
\hline $\begin{array}{l}\text { Equipment } \\
\text { I.D. No. }\end{array}$ & Description & Specifications & $\begin{array}{c}\text { Purchased } \\
\text { Equipment } \\
\text { Cost, } \mathrm{C}_{\mathrm{P}} \\
(\mathrm{CEPCI}=382)\end{array}$ & $\begin{array}{c}\text { Material } \\
\text { Factor, } \\
\text { FM }\end{array}$ & $\begin{array}{c}\text { Pressure } \\
\text { or Other } \\
\text { Factors, } \\
F_{\mathrm{P}}\end{array}$ & $\begin{array}{l}\text { Actual } \\
\text { Bare } \\
\text { Mod. } \\
\text { Factor, } \\
\text { F }^{\mathrm{A}} \text { BM }\end{array}$ & $\begin{array}{c}\text { Quantity } \\
\text { Factor }\end{array}$ & $\begin{array}{c}\text { Actual Bare } \\
\text { Module Cost, } \\
\mathrm{C}^{\mathrm{A}} \text { BM }(\$ \text { mid- } \\
1996)\end{array}$ & $\begin{array}{c}\text { Actual Bare } \\
\text { Module } \\
\text { Cost, } \$ 2006\end{array}$ \\
\hline $\mathrm{D}-1 \mathrm{~A}$ & Tar removal flash drum & $\mathrm{L}=6.5 \mathrm{ft}, \mathrm{D}=1.5 \mathrm{ft}$ & 2,000 & 1 & 1.0 & 3.0 & 1 & 6,000 & 7,500 \\
\hline D-2 & Light ends distillation column & $\mathrm{H}=17 \mathrm{ft}, \mathrm{D}=2.5 \mathrm{ft}$ & 12,000 & 1 & 1.0 & 4.2 & 1 & 50,000 & 63,000 \\
\hline D-2 & Light ends distillation column & 34 trays & 10,200 & 1 & 1.0 & 2.2 & 1.2 & 27,000 & 34,000 \\
\hline D-3 & D-2 holdup drum & $\mathrm{L}=6 \mathrm{ft}, \mathrm{D}=2 \mathrm{ft}$ & 2,000 & 1 & 1.0 & 3.0 & 1 & 6,000 & 7,500 \\
\hline D-5 & Product distillation column & 34 trays & 10,200 & 1 & 1.0 & 2.2 & 1.2 & 27,000 & 34,000 \\
\hline D-5 & D-4 holdup drum & $\mathrm{L}=6 \mathrm{ft}, \mathrm{D}=2 \mathrm{ft}$ & 2,000 & 1 & 1.0 & 3.0 & 1 & 6,000 & 7,500 \\
\hline E-1 A/B & Heat exchanger $1 \mathrm{~A} / \mathrm{B}$ & $91 \mathrm{~kW}, \mathrm{~A}=63 \mathrm{ft}^{2}$ & 8,000 & 1 & 1.3 & 3.0 & 2 & 48,000 & 60,000 \\
\hline E-2 A/B & Heat exchanger $2 \mathrm{~A} / \mathrm{B}$ & $101 \mathrm{~kW}, \mathrm{~A}=43 \mathrm{ft}^{2}$ & 7,500 & 1 & 1.3 & 3.0 & 2 & 45,000 & 56,000 \\
\hline E-3 A/B & Heat exchanger $3 \mathrm{~A} / \mathrm{B}$ & $231 \mathrm{~kW}, \mathrm{~A}=39 \mathrm{ft}^{2}$ & 1,200 & 1 & 1.0 & 3.0 & 2 & 7,200 & 9,000 \\
\hline E-4 A/B & Heat exchanger $4 \mathrm{~A} / \mathrm{B}$ & $195 \mathrm{~kW}, \mathrm{~A}=53 \mathrm{ft}^{2}$ & 1,300 & 1 & 1.0 & 3.0 & 2 & 7,800 & 9,800 \\
\hline E-5 A/B & D-2 condenser $\mathrm{A} / \mathrm{B}$ & $121 \mathrm{~kW}, \mathrm{~A}=33 \mathrm{ft}^{2}$ & 1,200 & 1 & 1.0 & 3.0 & 2 & 7,200 & 9,000 \\
\hline E-6 A/B & D-2 reboiler A/B & $17 \mathrm{~kW}$ & 1,000 & 1 & 1.0 & 2.0 & 2 & 4,000 & 5,000 \\
\hline E-8 A/B & D-4 reboiler A/B & $218 \mathrm{~kW}$ & 9,000 & 1 & 1.0 & 2.0 & 2 & 36,000 & 45,000 \\
\hline L-1 A/B & Oil feed pump A/B & $1 \mathrm{hp}, \mathrm{P}=120 \mathrm{psia}$ & 3,800 & 1 & 1.0 & 3.2 & 2 & 24,000 & 30,000 \\
\hline L-2 A/B & Recycle stream pump A/B & $1 \mathrm{hp}, \mathrm{P}=120 \mathrm{psia}$ & 3,800 & 1 & 1.0 & 3.2 & 2 & 24,000 & 30,000 \\
\hline L-3 A/B & D-2 reflux pump A/B & $1 \mathrm{hp}, \mathrm{P}=50 \mathrm{psia}$ & 3,800 & 1 & 1.0 & 3.2 & 2 & 24,000 & 30,000 \\
\hline $\mathrm{L}-4 \mathrm{~A} / \mathrm{B}$ & D-4 reflux pump A/B & $1 \mathrm{hp}, \mathrm{P}=25$ psia & 3,800 & 1 & 1.0 & 3.2 & 2 & 24,000 & 30,000 \\
\hline $\mathrm{R}-1$ & Tubular reactor & $\mathrm{L}=420 \mathrm{ft}, \mathrm{D}=5 \mathrm{in}$. & 13,000 & 1 & 1.3 & 2.2 & 1 & 29,000 & 36,000 \\
\hline $\mathrm{R}-1$ & Fired heaters & $3.9 \mathrm{MW}$ & 260,000 & 1 & 1.1 & 2.2 & 1 & 570,000 & 720,000 \\
\hline \multicolumn{8}{|c|}{ Total Bare Module Cost } & $1,000,000$ & $1,300,000$ \\
\hline \multicolumn{8}{|c|}{ Contingency and Fee } & 190,000 & 230,000 \\
\hline \multicolumn{8}{|c|}{ Total Module Cost } & 120,000 & $1,500,000$ \\
\hline \multicolumn{8}{|c|}{ Auxiliary Facilities } & 370,000 & 460,000 \\
\hline \multicolumn{8}{|c|}{ Grassroots Capital (FCI*) } & $1,600,000$ & $2,000,000$ \\
\hline \multicolumn{8}{|c|}{ Total Capital Investment in 2005 dollars (including $12 \%$ working capital) } & & $2,200,000$ \\
\hline
\end{tabular}




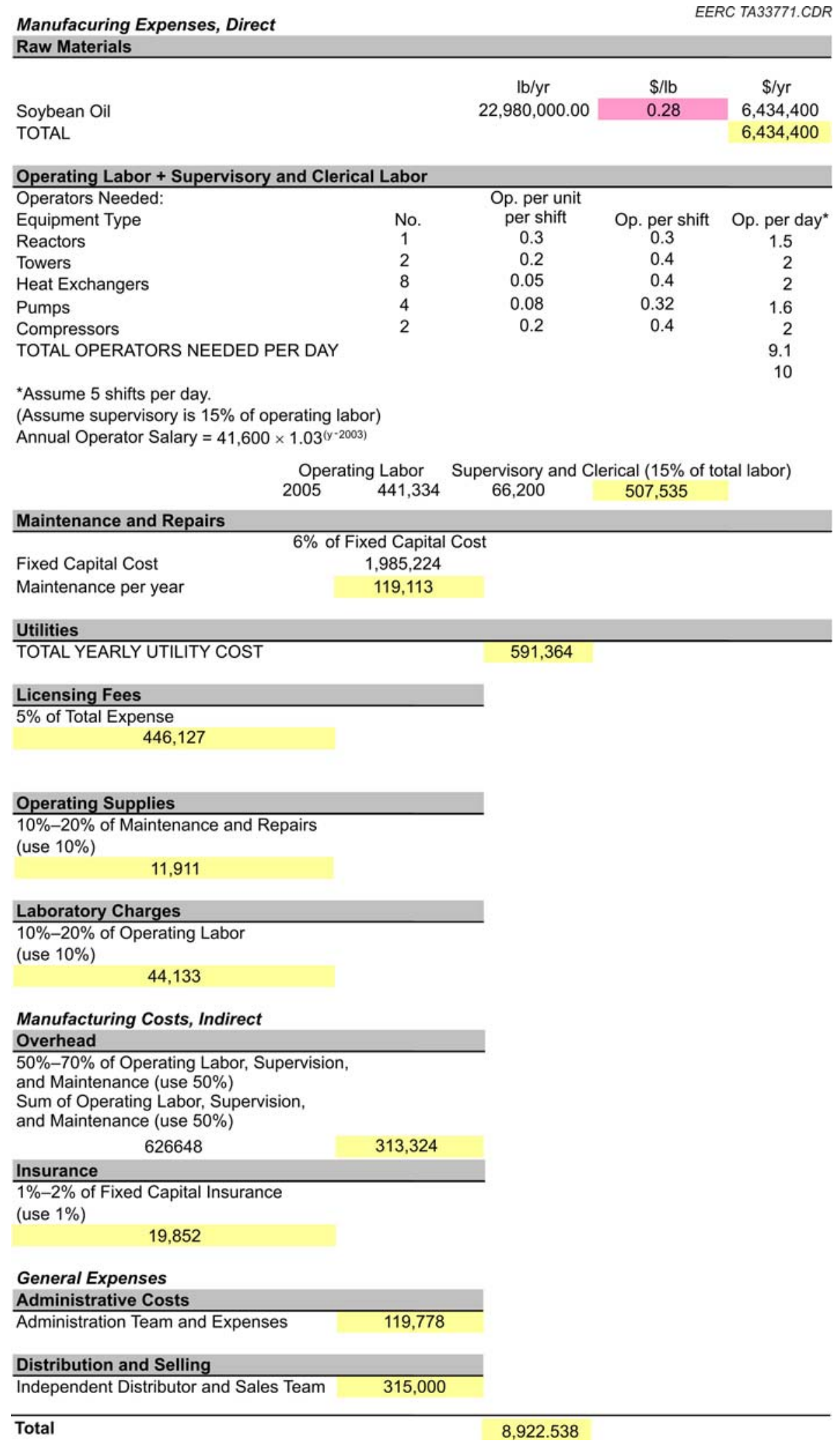

Figure 61. Operating cost basis for a 3-million-gallon-per-year biojet fuel facility. 
Table 45. Annual Revenues for a Biojet Fuel Facility and a 3-milliongallon-per-year Biodiesel Facility (June 2006 basis)

\begin{tabular}{lccr}
\hline Revenue Source & $\mathrm{gal} / \mathrm{yr}$ & $\$ / \mathrm{gal}$ & \multicolumn{1}{c}{$\$ / \mathrm{yr}$} \\
\hline Biojet Fuel & $2,600,000$ & 3.12 & $8,100,000$ \\
Biodiesel & $3,100,000$ & 2.92 & $9,000,000$ \\
Glycerol & 250,000 & 0.25 & 63,000 \\
Total Biodiesel Revenues & & & $9,000,000$ \\
\hline
\end{tabular}

Combining all of the economic data, a cash flow sheet was constructed summarizing the economics for each facility. Two scenarios were considered: 1) with the current $\$ 1 /$ gallon subsidy and 2) without the current $\$ 1 /$ gallon subsidy. These are shown for the biojet fuel facility in Tables 46 and 47, respectively. As shown, the facility is profitable with the subsidy, but at current biojet fuel prices is not profitable without a subsidy.

Comparing the economics of a biojet fuel facility to a biodiesel facility based on current price levels and yields (Table 48), the biojet facility profitability is slightly lower. This is primarily due to decreased revenues from the $86 \%$ yield of biojet fuel compared to the near$100 \%$ yield of biodiesel.

A first-year balance sheet for each facility is shown in Table 49, while Table 50 shows the costs of production per gallon of product. The values for the two facilities are statistically identical within the accuracy of these estimates.

\section{Economic Sensitivity Analysis}

There are three important factors that have the greatest influence on the economics of the biojet fuel process:

- The net margin between product and raw material prices

- The ability to convert by-product fuel-grade material into by-products

- The continuation of the federal subsidy

These factors can greatly affect the NPV of the biojet commercial venture with small changes in price.

\section{Jet Fuel Demand}

Current U.S. jet fuel demand has been fluctuating in the range of 24-26 billion gallons per year (10). All of this jet fuel is currently being produced from petroleum oil. This demand has been steady for the last 5-6 years. There are two reasons for the stabilized jet fuel demand in the midst of increased gasoline and diesel demand. One is the fact that following September 11, 
Table 46. Cash Flow Sheet for a 3-million-gallon-per-year Biojet Fuel Facility with a \$1/gallon Subsidy

\begin{tabular}{|c|c|c|c|c|c|c|c|c|c|c|}
\hline Year & Revenues & $\begin{array}{l}\text { Total Capital } \\
\text { Investment }\end{array}$ & $\begin{array}{l}\text { Operating } \\
\text { Expenses }\end{array}$ & $\begin{array}{l}\text { Gross } \\
\text { Profit }\end{array}$ & $\begin{array}{l}\text { Tax-Basis } \\
\text { Depreciation }\end{array}$ & $\begin{array}{l}\text { Income } \\
\text { Taxes }\end{array}$ & Net Profit & $\begin{array}{l}\$ 1 / \text { gal } \\
\text { Subsidy }\end{array}$ & $\begin{array}{l}\text { After-Tax } \\
\text { Profit }\end{array}$ & PV at MARR \\
\hline 0 & & $2,200,000$ & & & & & $-2,200,000$ & & & $-2,200,000$ \\
\hline 1 & $8,000,000$ & & $9,000,000$ & $-810,000$ & 220,000 & $-410,000$ & $-400,000$ & $2,600,000$ & $2,600,000$ & $2,300,000$ \\
\hline 2 & $8,000,000$ & & & & 200,000 & $-400,000$ & $-400,000$ & $2,600,000$ & $2,500,000$ & $2,000,000$ \\
\hline 3 & $8,000,000$ & & & & 180,000 & $-400,000$ & $-410,000$ & $2,600,000$ & $2,500,000$ & $1,800,000$ \\
\hline 4 & $8,000,000$ & & & & 160,000 & $-390,000$ & $-420,000$ & $2,600,000$ & $2,500,000$ & $1,600,000$ \\
\hline 5 & $8,000,000$ & & & & 150,000 & $-380,000$ & $-430,000$ & $2,600,000$ & $2,500,000$ & $1,400,000$ \\
\hline 6 & $8,000,000$ & & & & 130000 & $-380,000$ & $-430,000$ & $2,600,000$ & $2,500,000$ & $1,300,000$ \\
\hline 7 & $8,000,000$ & & & & 120,000 & $-380,000$ & $-440,000$ & $2,600,000$ & $2,500,000$ & $1,100,000$ \\
\hline 8 & $8,000,000$ & & & & 110,000 & $-380,000$ & $-440,000$ & $2,600,000$ & $2,500,000$ & $1,000,000$ \\
\hline 9 & $8,000,000$ & & & & 96,000 & $-370,000$ & 450,000 & $2,600,000$ & $2,500,000$ & 890,000 \\
\hline 10 & $8,000,000$ & & & & 86,000 & $-360,000$ & 450,000 & $2,600,000$ & $2,500,000$ & 800,000 \\
\hline 11 & $8,000,000$ & & & & 78,000 & $-360,000$ & 460,000 & $2,600,000$ & $2,500,000$ & 700,000 \\
\hline 12 & $8,000,000$ & & & & 78,000 & $-360,000$ & 460,000 & $2,600,000$ & $2,500,000$ & 630,000 \\
\hline 13 & $8,000,000$ & & & & 78,000 & $-360,000$ & 460,000 & $2,600,000$ & $2,500,000$ & 560,000 \\
\hline 14 & $8,000,000$ & & & & 78000 & $-360,000$ & 460,000 & $2,600,000$ & $2,500,000$ & 500,000 \\
\hline 15 & $8,000,000$ & & & & 78,000 & $-360,000$ & 460,000 & $2,600,000$ & $2,500,000$ & 450,000 \\
\hline 16 & $8,000,000$ & & & & 78000 & $-360,000$ & 460,000 & $2,600,000$ & $2,500,000$ & 400,000 \\
\hline 17 & $8,000,000$ & & & & 78,000 & $-360,000$ & 460,000 & $2,600,000$ & $2,500,000$ & 360,000 \\
\hline 18 & $8,000,000$ & & & & 78,000 & $-360,000$ & 460,000 & $2,600,000$ & $2,500,000$ & 320,000 \\
\hline 19 & $8,000,000$ & & & & 78,000 & $-360,000$ & 460,000 & $2,600,000$ & $2,500,000$ & 290,000 \\
\hline 20 & $8,000,000$ & $-240,000$ & & & 78,000 & $-360,000$ & $-220,000$ & $2,600,000$ & $2,700,000$ & 280,000 \\
\hline \multirow{2}{*}{\multicolumn{10}{|c|}{$\begin{array}{l}\text { NPV at } 12 \% \text { MARR } \\
\text { Federal Tax }(33 \%) \text { and Local (North Dakota corporation income) Tax Rates }(7 \%)\end{array}$}} & $16,800,000$ \\
\hline & & & & & \multicolumn{6}{|c|}{ Federal Tax (33\%) and Local (North Dakota corporation income) Tax Rates $(7 \%)$} \\
\hline \multicolumn{3}{|c|}{ Fixed Capital Investment } & \multicolumn{3}{|c|}{200,000} & \multicolumn{2}{|c|}{ MARR: $12 \%$} & & & \\
\hline \multicolumn{3}{|c|}{ Total Capital Investment } & \multicolumn{2}{|c|}{$2,200,000$} & & \multicolumn{2}{|c|}{ Taxes: $40 \%$} & & & \\
\hline \multicolumn{3}{|c|}{ Working Capital } & \multicolumn{2}{|c|}{240,000} & & & & & & \\
\hline \multicolumn{3}{|c|}{ Salvage } & \multicolumn{2}{|c|}{0} & & & & & & \\
\hline \multicolumn{2}{|c|}{ Life } & & \multicolumn{2}{|c|}{20 years } & & & & & & \\
\hline
\end{tabular}


Table 47. Cash Flow Sheet for a 3-million-gallon-per-year Biojet Fuel Facility with No Subsidy

\begin{tabular}{|c|c|c|c|c|c|c|c|c|}
\hline Year & Revenues & $\begin{array}{c}\text { Total Capital } \\
\text { Investment }\end{array}$ & $\begin{array}{c}\text { Operating } \\
\text { Expenses }\end{array}$ & Gross Profit & $\begin{array}{c}\text { Tax-Basis } \\
\text { Depreciation }\end{array}$ & $\begin{array}{c}\text { Income } \\
\text { Taxes }\end{array}$ & Net Profit & $\begin{array}{c}\text { PV at } \\
\text { MARR }\end{array}$ \\
\hline 0 & & $2,200,000$ & & & & & $-2,200,000$ & $-2,200,000$ \\
\hline 1 & $8,000,000$ & & $8,900,000$ & $-800,000$ & 220,000 & $-410,000$ & $-400,000$ & $-350,000$ \\
\hline 2 & $8,000,000$ & & $8,900,000$ & $-800,000$ & 200,000 & $-400,000$ & $-400,000$ & $-320,000$ \\
\hline 3 & $8,000,000$ & & $8,900,000$ & $-800,000$ & 180,000 & $-400,000$ & $-410,000$ & $-300,000$ \\
\hline 4 & $8,000,000$ & & $8,900,000$ & $-800,000$ & 160,000 & $-390,000$ & $-430,000$ & $-270,000$ \\
\hline 5 & $8,000,000$ & & $8,900,000$ & $-800,000$ & 150,000 & $-380,000$ & $-430,000$ & $-270,000$ \\
\hline 6 & $8,000,000$ & & $8,900,000$ & $-800,000$ & 130,000 & $-380,000$ & $-440,000$ & $-220,000$ \\
\hline 7 & $8,000,000$ & & $8,900,000$ & $-800,000$ & 120,000 & $-370,000$ & $-440,000$ & $-200,000$ \\
\hline 8 & $8,000,000$ & & $8,900,000$ & $-800,000$ & 110,000 & $-360,000$ & $-450,000$ & $-180,000$ \\
\hline 9 & $8,000,000$ & & $8,900,000$ & $-800,000$ & 96,000 & $-360,000$ & $-450,000$ & $-170,000$ \\
\hline 10 & $8,000,000$ & & $8,900,000$ & $-800,000$ & 86,000 & $-355,000$ & $-450,000$ & $-145,000$ \\
\hline 11 & $8,000,000$ & & $8,900,000$ & $-800,000$ & 78,000 & $-355,000$ & $-460,000$ & $-130,000$ \\
\hline 12 & $8,000,000$ & & $8,900,000$ & $-800,000$ & 78,000 & $-355,000$ & $-460,000$ & $-120,000$ \\
\hline 13 & $8,000,000$ & & $8,900,000$ & $-800,000$ & 78,000 & $-355,000$ & $-460,000$ & $-100,000$ \\
\hline 14 & $8,000,000$ & & $8,900,000$ & $-800,000$ & 78,000 & $-355,000$ & $-460,000$ & $-93,000$ \\
\hline 15 & $8,000,000$ & & $8,900,000$ & $-800,000$ & 78,000 & $-355,000$ & $-460,000$ & $-83,000$ \\
\hline 16 & $8,000,000$ & & $8,900,000$ & $-800,000$ & 78,000 & $-355,000$ & $-460,000$ & $-74,000$ \\
\hline 17 & $8,000,000$ & & $8,900,000$ & $-800,000$ & 78,000 & $-355,000$ & $-460,000$ & $-66,000$ \\
\hline 18 & $8,000,000$ & & $8,900,000$ & $-800,000$ & 78,000 & $-355,000$ & $-460,000$ & $-60,000$ \\
\hline 19 & $8,000,000$ & & $8,900,000$ & $-800,000$ & 78,000 & $-355,000$ & $-460,000$ & $-53,000$ \\
\hline 20 & $8,000,000$ & $-240,000$ & $8,900,000$ & $-800,000$ & 78,000 & $-355,000$ & $-220,000$ & $-22,000$ \\
\hline \multicolumn{5}{|c|}{ NPV at $12 \%$ MARR } & \multirow{2}{*}{\multicolumn{2}{|c|}{ MARR: $12 \%$}} & & $-5,400,000$ \\
\hline \multicolumn{2}{|c|}{ Fixed Capital Investment } & & \multicolumn{2}{|l|}{200,000} & & & & \\
\hline \multicolumn{2}{|c|}{ Total Capital Investment } & & \multicolumn{2}{|l|}{$2,200,000$} & \multicolumn{2}{|c|}{ Taxes: $40 \%$} & & \\
\hline \multicolumn{2}{|c|}{ Working Capital } & & \multicolumn{2}{|l|}{240,000} & & & & \\
\hline \multicolumn{2}{|c|}{ Salvage } & & \multicolumn{2}{|l|}{0} & & & & \\
\hline \multicolumn{2}{|c|}{ Life } & & 20 years & & & & & \\
\hline
\end{tabular}


Table 48. Comparison of Economic Worth for 3-million-gallon-per-year Facilities

\begin{tabular}{lcc}
\hline & $\begin{array}{c}\text { Subsidized Fuel Price } \\
\text { (\$ millions) }\end{array}$ & $\begin{array}{c}\text { Unsubsidized Fuel Price } \\
\text { (\$ millions) }\end{array}$ \\
\hline Biojet Fuel NPV at 12\% & 16.8 & -5.4 \\
Biodiesel NPV at $12 \%$ & 20.0 & -2.9 \\
\hline
\end{tabular}

Table 49. Comparison of First-Year Balance Sheets for a 3-million-gallon-per-year Facility with Subsidy

\begin{tabular}{lcc}
\hline Balance Sheet Costs & Biojet Fuel \$ year & Biodiesel \$/year \\
\hline Revenues & $8,100,000$ & $9,200,000$ \\
Operating Costs & $8,900,000$ & $9,300,000$ \\
Depreciation (20-yr straight line) & 100,000 & 150,000 \\
Gross Profit & $(900,000)$ & $(100,000)$ \\
Taxes & $(400,000)$ & $(100,000)$ \\
Subsidy & $2,600,000$ & $3,100,000$ \\
Net Profit (unsubsidized) & $(500,000)$ & $(150,000)$ \\
Net Profit (subsidized) & $2,100,000$ & $3,000,000$ \\
\hline
\end{tabular}

Table 50. Comparison of Production Costs per Gallon of Product

\begin{tabular}{lcc} 
& Biojet Fuel, \$/gal & Biodiesel, \$/gal \\
\hline Raw Material Cost & 2.15 & 2.15 \\
Operating Costs & 0.95 & 0.72 \\
Capital Costs (10-year payback) & 0.08 & 0.10 \\
Total Production Costs & 3.18 & 2.97 \\
\hline
\end{tabular}

2001, jet fuel prices have increased drastically along with the price of other petroleum derivatives such as gasoline and diesel. This has forced commercial airlines to decrease consumption of the jet fuel used through optimization and a decrease in the number of flights. The second reason for the stability of the demand is an increased military jet fuel consumption following September 11, 2001, and the subsequent international activities.

Figure 62 shows a historic trend of the price of petroleum jet fuel and soybean oil. The price of jet fuel is rising 2.5 times faster than the price of soybean oil. This is a win-win situation for soybean farmers since the raw product (soybean oil) and the value-added product (biojet fuel) prices are increasing. Once the biojet fuel is certified for use in jet turbines, the revenue of a biojet fuel plant will increase dramatically. As an illustration, in our projections, we estimated that 1 gallon of biodiesel fuel is $\$ 2.92$. Currently, jet fuel sells for $\$ 3.90$ per gallon at the Grand Forks Airport. This would amount to almost \$1 per gallon premium over the selling price of diesel.

In the baseline economic data shown above, the price of jet fuel was held constant at $\$ 3.12$ per gallon over the 20-year lifetime of the facility. If the wholesale price of the product biojet 


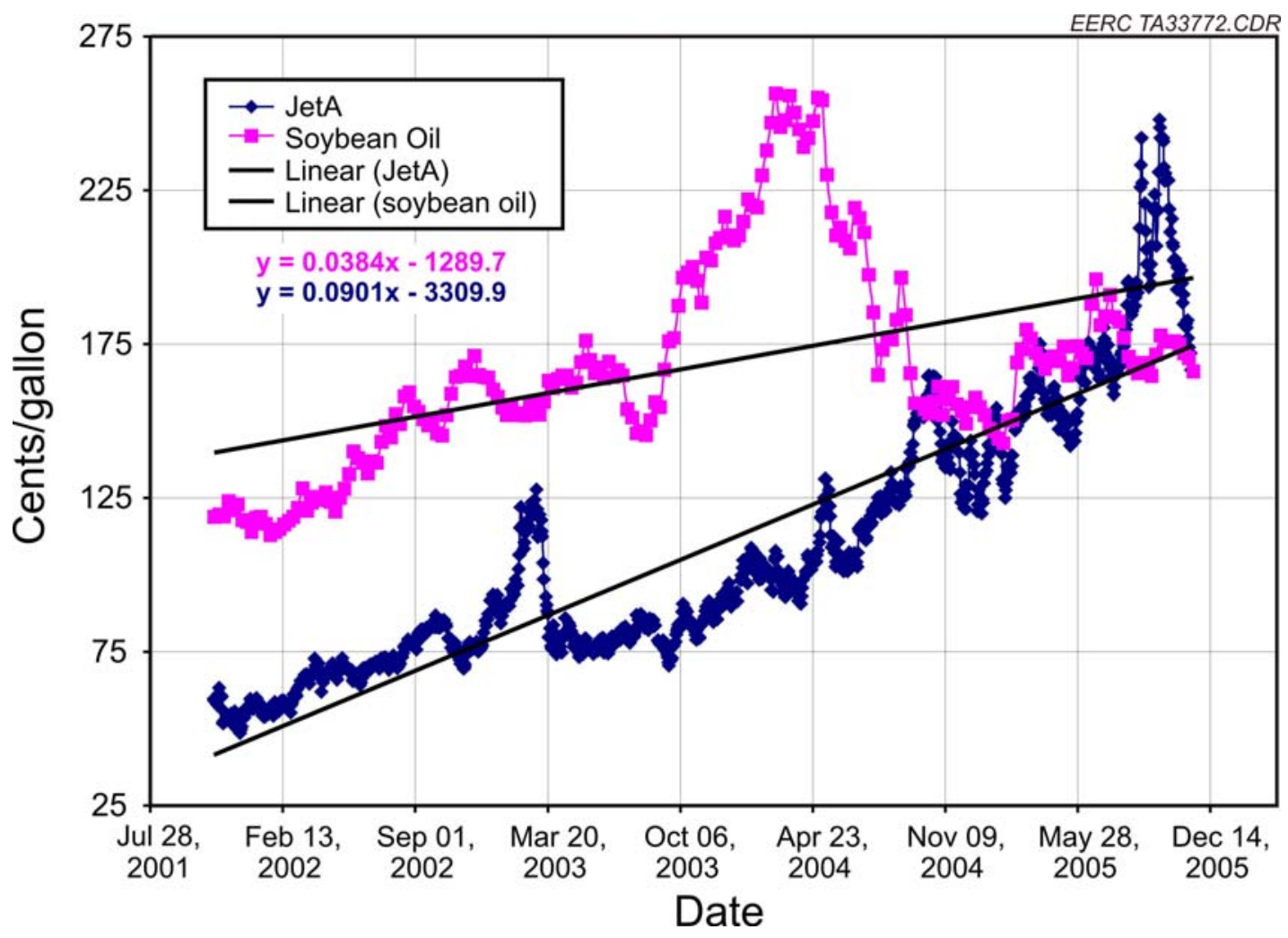

Figure 62. Historical prices of jet fuel and soybean oil $(11,12)$. Jet A is a commercial jet fuel.

fuel were increased from $\$ 3.12$ to $\$ 3.85$, the NPV at $12 \%$ MARR rapidly climbs to a favorable $\$ 5.3$ million even without a subsidy.

Conversely, if the raw material price can be dropped, the NPV will also increase. The key is to drop the raw material price without reducing the price of the agricultural product to the farmer. This can be accomplished by reducing the costs required to extract the soybean oil from the soybeans. The current soybean oil price is based on the production of food-grade soybean oil. It may be possible to reduce the costs to generate this oil when it is a feedstock for the biojet fuel process. This highlights the need for additional research and development in this area. On the other hand, a lowering of operating costs also has a favorable impact on NPV. The best way to get the equivalent of an operating cost reduction is to generate valuable by-products from the facility.

\section{Business Model Development}

The scientific work summarized thus far in this report strongly supports the existence of a technical opportunity for a functionally superior biobased fuel for use in jet turbines. The pertinent business development questions then loom, just what biojet product(s) does a biofuel facility manufacture and offer to an awaiting market, and is there evidence that this so-identified technical opportunity will translate into value (for whom and to what amount)? 
The work conducted to date shows that for the UND biojet fuel process, a favorably comparable projected cost estimate for a manufacturing facility can be made to that of traditional transesterified biodiesel produced for over-the-road and ground-based applications. This early look at comparable production economics encourages continued interest in biojet as a platform technology. But what additional support can be brought to bear to develop a best strategic, sustainable advantage business model to leverage this unique technology? This section takes a first look at the business model question and points to further research needs in this area.

The capacity of traditional transesterified biodiesel in the North Dakota and Minnesota region is rapidly increasing. North Dakota will bring online 85 million gallons of biodiesel production in the next year, and Minnesota already leads the nation in biodiesel capacity development. However, this traditional transesterified biodiesel cannot access or compete with the 26 billion gallons of petroleum-based jet fuel used in the United States each year. Hence, the UND biojet technology has an inherent strategic advantage with its use in jet turbines. North Dakota uses approximately 22 million gallons of petroleum-based jet fuel in its eight regional airports of significant size (see Figure 63). Thus even an initial 3-million-gallon demonstration facility could easily supply the region's 1.1 -million-gallon demand if a $5 \%$ biojet blend were used.

Besides the obvious regional commercial and private airport businesses in the neighboring states, a new significant volume business development interest is in military flight fuel

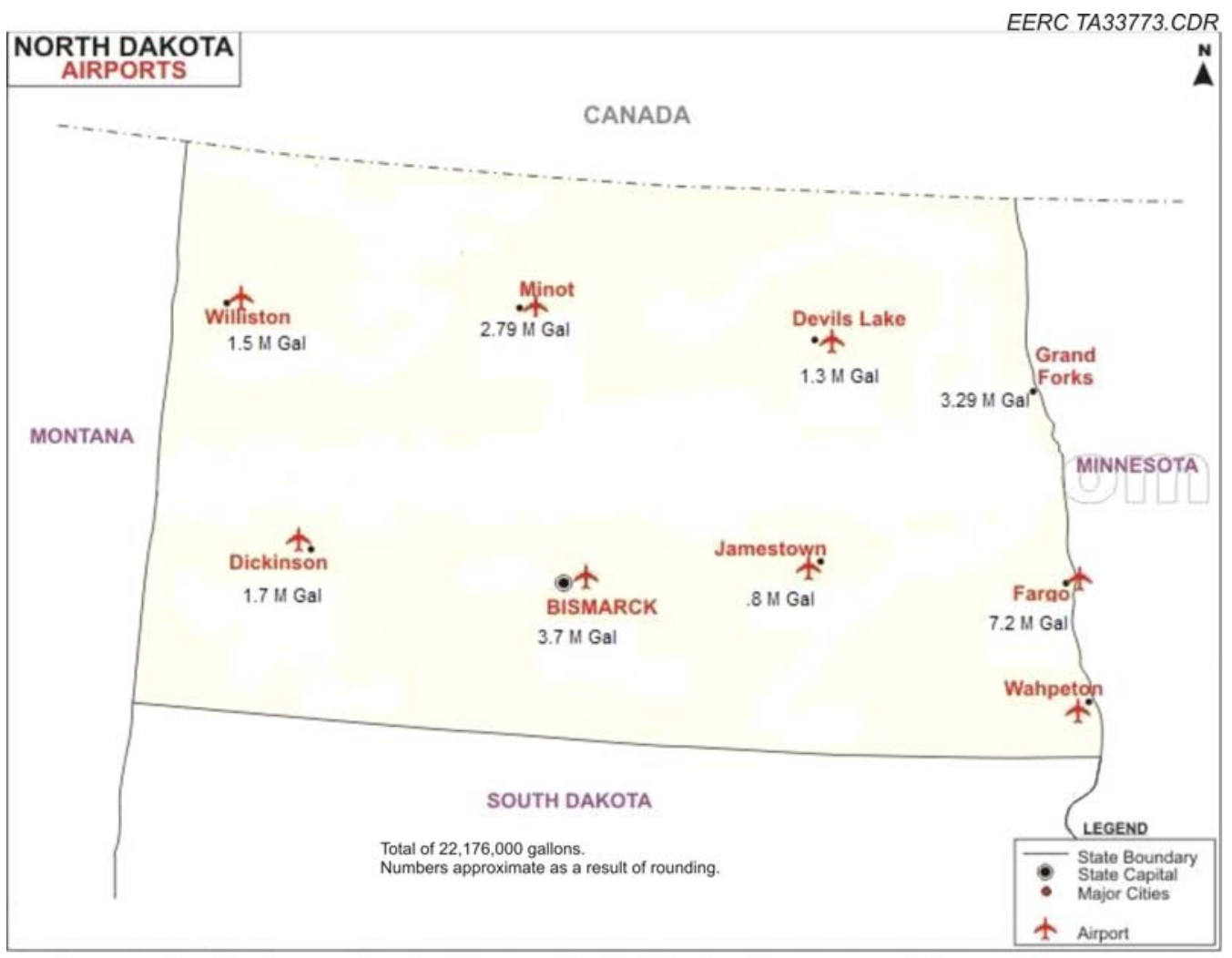

Figure 63. North Dakota jet fuel (JP-8) usage by regional airports (2004). 
applications. The U.S. military has already begun to use a $20 \%$ biodiesel standard in its groundbased applications. The military is also searching for more domestic sources of fuel and consumed 5.5 billion gallons of jet fuel in 2004 .

North Dakota is host to two major consumers (Grand Forks and Minot Air Force Bases [AFBs]) and one major distributor of military aviation fuel (Grand Forks AFB). The Grand Forks AFB is a major component in the fuel distribution grid for the U.S. military. It houses the 319th tactical air refueling wing, which is responsible for flight fueling to military aircraft throughout the entire northern sector of the U.S. air space. The Grand Forks AFB hosts some 48 large KC135 refueling aircraft. In addition, in 2006, the U.S. Air Force announced a major program at the Grand Forks AFB to develop unmanned drone reconnaissance jet aircraft for the military. Thus there is ample test market capability if the military segment can be penetrated.

These identified markets for the finished biojet fuel make it obvious that the placement of a biojet fuel-manufacturing facility would bring positive economic impact to the region. However, for equal comparison reasons, our economic feasibility assessment started from the intermediate soybean oil and not from the farm production side. The sourcing and cost of transporting soybean oil is one of the major costs in the production of biofuels. In addition, even within the region, a significant logistical effort must be undertaken in order to satisfy the local demand for biodiesel. In interviews with local diesel fuel retailers, it was discovered that the typical journey of biodiesel in order to end up at an eastern North Dakota independent fuel wholesaler comprises soybeans grown in North Dakota that are trucked to Manitoba for processing, then routed to a biofuel manufacturer in northeast South Dakota, and finally trucked back to the eastern North Dakota fuel wholesaler to be blended for retail sale.

This circuitous process adds a total shipping cost of 40 cents a gallon to the $100 \%$ biodiesel stock. While this ingredient transportation cost gets diluted when blended with the petroleum-based diesel product cost, the total impact at the pump is a nonarbitrary 2 cents $(5 \%$ blend, B5). The question then becomes is there an economic advantage to processing the agricultural biomass feedstock at the same location where the biofuel is produced? The objective benefit here is to bring better overall economics to the biofuel process and bring value closer to the farm producer.

Minnesota biodiesel proponents have also considered the question of making a greater instate value contribution to the soybean production industry. Among the five leading soybean states in the United States, Minnesota has the lowest soybean prices, while Illinois has the highest, with an average price difference of $\$ 0.24$ per bushel. This price difference may reflect the level of soybean processing conducted in each state. In Illinois, an average of $76 \%$ of the soybean crop is processed in-state over the past 5 years compared to 35\% in Minnesota during the same time period (13). Most economic impact studies show that only marginal increases of 1 to 7 cents on a per bushel basis (averaged across all production across the United States) is realized by the farmer for the increased demand for biodiesel. However, this does not match with some regional pricing increases being seen. A soybean processor in Manitoba reported in an interview that, as a result of the year-round demand for soybeans for its crushing facility, the local market price reached as high as CAN\$0.60 per bushel within a 30-mile radius of the plant. This local market effect needs to be better quantified as it pertains to a North Dakota scenario. 
Thus the case can be made for business model development suggesting a single regionalsized facility that functions as a total soybean-manufacturing center. With biofuels as simply one of the component pieces in the overall business strategy, better profitability can be derived from a diversified market mix of products that include oil, meal, biofuels, and other high-value products. The inclusion of a multiproduct business model makes a significant impact on the local economy. A soybean-processing facility on-site with a biofuel-manufacturing facility would improve the local economy an additional $\$ 7$ of impact for every dollar of revenue generated. And for every direct job created at the facility, an additional three indirect jobs are created in the community. In addition, the availability of a cost-effective source of soybean meal gives a boost to allied industries such as cattle and swine production.

A business plan was developed for a branded concept called "GreenFlight, LLC." GreenFlight was designed as a scenario that involved partnering with a regional soybeanprocessing mill being built in Northwood, North Dakota, and collocating the 3-million-gallon biojet demonstration facility described above on the same site. The business plan was developed by two students (one from UND Chemical Engineering and one from Entrepreneurship) and entered into a national sustainable energy business plan competition held at the University of Colorado at Boulder to evaluate its viability by the outside investment community. The assumptions set forth in the plan were to raise $\$ 3$ million in a combination of private equity investments or loan guarantees to build and operate this facility with a liquidity exit for the investors in 5 years.

The proceeds of the investment would be used to build the biojet-manufacturing portion that would partner with the soybean processor to purchase degummed oil for conversion into biojet product. The plan showed a similar set of base-cost-of-production economics to those developed for our commercial feasibility assessment and additionally increased facility output to a total of 6 million gallons annually by the end of Year 5 of the plan. Interestingly, the plan won the national business plan competition based on overall merit and investability. The student team was invited to present its plan at the Fall 2006 NREL Investor Conference in Philadelphia. In addition, this plan has generated interest from private equity investors in Michigan and New Mexico as well as North Dakota. In this scenario, a return of 35\% to the investors gives this plan the ability to place the $\$ 3$ million in required capital to build such a facility and retain majority ownership with a North Dakota entity. As shown in Table 51, the founding investors (management team) also realized a significant sixfold return (on share price) on their initial investment. Such business plan scenarios, when placed in an externally judged business plan competition (by judges from the private equity investment community), give real-world plausibility to a developing early-stage business model. In addition, these business model development scenarios give support to the grower investment models being touted in the ethanol industry where, in Minnesota, 14 ethanol production facilities have over 8000 farmer investors.

\section{Conclusions}

From this preliminary business model development based solely on the UND biojet technology, further model development needs to include a more robust view of the regional impact on farmer-level pricing, and improvements in feedstock oil economics by developing a more detailed analysis of the contribution to additional on-site unit operations to that developed 
Table 51. Implicit Valuation Analysis* for a 3-million-gallon Biojet Fuel Start-Up Venture Based in North Dakota

\begin{tabular}{lr}
\hline Founders Initial Investment & $\$ 100,000$ \\
Initial Share Issue & $1,000,000$ \\
Initial Profit per Share & $\$ 0.10$ \\
Options Pool & $10 \%$ \\
Total Capital Required & $\$ 2,000,000$ \\
Investor Tranches & 1 \\
Investor-Required Internal Rate of Return & $\mathbf{3 5 \%}$ \\
Exit Time (yr) & 5 \\
Required Future Value (RFV) (Investment) & $\mathbf{\$ 8 , 9 6 8 , 0 6 7}$ \\
Profit per Exit & 10 \\
Exit Net Profits & $\$ 2,100,000$ \\
Exit Value & $\$ 21,000,000$ \\
Initial Investor Ownership & $\mathbf{4 2 . 7 1 \%}$ \\
Min. Exit Margin & $10.00 \%$ \\
New Shares Issued & 745,355 \\
Premoney Evaluation & $\$ 2,683,284$ \\
Founder's Carried Interest & $\$ 2,583,284$ \\
Postmoney Evaluation & $\$ 4,683,284$ \\
Premoney Stock & $\$ 2.68$ \\
Postmoney Stock & $\$ 2.68$ \\
Share Price at Exit & $\$ \mathbf{1 2 . 0 3}$ \\
\hline *aluation assumes a $\$ 2$ million investment by private equity investors for a 42.71\% stake in the venture with an \\
additional \$1 million secured by the Bank of North Dakota. The RFV of the investment at a liquidation event in \\
Year 5 achieves the 35\% return expected by the investors.
\end{tabular}

in an advanced biorefinery concept. In addition, retail markets for winterization and other valueadded retail product developments of the UND biojet fuel in ground-based applications is warranted. As other FAME-derived chemical-manufacturing intermediates are found to be abundant, isolatable, and purifiable, these can be added to the business model to increase profitability. A closer look at market mix and profitability will help to generate a winning regional business model.

\section{References}

1. Prakash, C.B. A Critical Review of Biodiesel as a Transportation Fuel in Canada, 1998, Transportation System Branch. www.ec.gc.ca/cleanair-airpur/CAOL/transport/ publications/ biodiesel/biodiesel.pdf (accessed June 2006).

2. U.S. Environmental Protection Agency. http://yosemite.epa.gov/oar/globalwarming.nsf/ content/climate.html (accessed June 2006).

3. Srivastava, A.; Prasad, R. Triglycerides-Based Diesel Fuels. Renew. Sustain. Energy Rev. 1999, 4, 111-133. 
4. Idem, R.O.; Katikaneni, S.P.R.; Bakhshi, N.N. Thermal Cracking of Canola Oil: Reaction Products in the Presence and Absence of Steam. Energy Fuels 1996, 10, 1150-1162.

5. National Biodiesel Board. www.nbb.org/resources/pressreleases/gen/20051108 Productionvolumes05NR.pdf (accessed July 2006).

6. Ahmed, I. Cold-Flow Biojet Fuel from Soybean Oil. Masters Thesis, University of North Dakota, 2005.

7. Gerpen, J.V. Biodiesel Processing and Production. Fuel Process. Technol. 2005, 86, $1097-$ 1107.

8. Turton, R.; Bailie, R.C.; Whiting, W.B.; Shaeiwitz, J.A. Analysis, Synthesis, and Design of Chemical Processes, 2nd ed.; Prentice Hall International: 2002.

9. Slee, B.; Nyberg, C.; Visina, T. Scoping Study and Partial Conceptual Design: $\mathrm{ZnO} / \mathrm{Al}_{2} \mathrm{O}_{3}$ Catalyzed Reaction of Refined Soybean Oil and Methanol in a 50-million-gallon Biodiesel Production Facility. ChE 412-Plant Design II from the Chemical Engineering Department at the University of North Dakota, 2006.

10. Air Transport Association. www.airlines.org/econ/d.aspx?nid=10027 (accessed July 2006).

11. Energy Information Administration. www.eia.doe.gov/oil_gas/petroleum/info_glance/ jetfuel.html (accessed July 2006).

12. Track' $n$ Trade Pro version 4.0; Gecko Software, Inc. www.trackntrade.com (accessed July 2006).

13. Ye, S. Economic Impact of Soy Diesel in Minnesota, 2004, Agricultural Marketing Services Division, Minnesota Department of Agriculture. www.mda.state.mn.us (accessed July 2004).

\section{Activity 2.4 - Low-Temperature Diesel Additives from Extracted Oil}

\section{Introduction}

Technical work on this project was completed on June 30, 2007, and a large amount of the data were collected in 2006. Prior to discussing the results of this work, it must be noted that the price of glycerol has risen significantly since the project was completed (1). Much of the work described in this report was based on the concept that glycerol was a cheap feedstock that would be available in large quantities at biodiesel facilities. It is now clear that this will not be true anytime in the near future, so the limited technical success of this project has become largely irrelevant against new economic constraints.

As the biodiesel industry expanded in scope during the early part of this decade, the market for the glycerol by-product of traditional FAME was rapidly becoming saturated. To allow for further increases in the scale of the biodiesel industry, it was apparent that either new markets 
would need to be found for glycerol or a new process would need to be found to eliminate the glycerol by-product.

One option for eliminating the glycerol by-product of the FAME process is conversion of glycerol into chemical feedstocks. This can be achieved by a number of routes. The Belgian company Solvay began producing epichlorohydrin, an epoxy precursor, from glycerol around 2006 (2). Cargill and other companies pursued conversion of glycerol to propylene glycol, a nontoxic antifreeze agent (3). Melero and other researchers studied esterification with acetic acid to produce glyceryl acetate, which shows promise as a fuel additive for both gasoline and biodiesel (4).

Glycerol can also be converted into chemical feedstocks by oxidation to aldehydes and carboxylic acids. One such method is to cleave the glycerol oxidatively and selectively using periodic acid (5). Although this method is efficient, the high cost of periodic acid makes this process economically unfavorable on a commercial scale. Another possible option for glycerol oxidation is reaction with ozone. Reaction of glycerol with ozone is thermodynamically favorable; however, the kinetic rate of reaction is effectively zero for direct ozonolysis by traditional methods. As such, a catalytic method is required to make the rate of glycerol ozonolysis favorable.

It was recognized early in the project that, to be successful in the near term, any approach to glycerol transformation would need to utilize the existing biodiesel infrastructure. The simplest solution to dealing with glycerol is not replacement of FAME facilities with new biodiesel plants, but add-on modification of existing facilities. Ideally, such a process would utilize only those resources already available to a biodiesel plant, eliminating the need to coordinate new chemical transportation or to expand an existing tank farm.

While the EERC project funded by DOE and the Waste Management and Research Center (WMRC) during the 2006 fiscal year was initially envisioned as a process to produce lowtemperature biodiesel additive, the project instead found a process for converting glycerol into high-value chemical feedstocks. The process could function as a slipstream parallel reaction in a traditional FAME facility and could be installed without modification of the existing facility. Moreover, a potential by-product of the process is a biodiesel additive that could improve lowtemperature properties of purified traditional FAME biodiesel, thus fulfilling the original intent of the DOE- and WMRC-funded project.

The process tested by the EERC under the 2006 funding involves simultaneous glycerol dehydration and ozonolysis in a single reactor. During acid-catalyzed dehydration, glycerol briefly transforms into one of two unstable intermediate enol tautomers, as shown in Equations 1 and 2 (6):

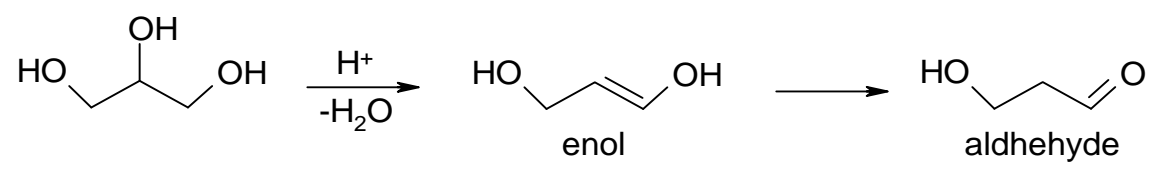




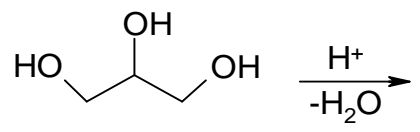<smiles>C=C(O)CO</smiles>

[Eq. 2]

The enol tautomers are susceptible to ozonolysis (Equation 3). Ozonides are unstable and tend to undergo rearrangement to malozonides, as seen in Equation 4. Laboratory and commercial ozonolysis processes allow for this rearrangement and are designed to transform the malozonide product into two carboxylic acids or two aldehydes, as shown in Equations 5 and 6, respectively.<smiles>O/C=C/CO</smiles>

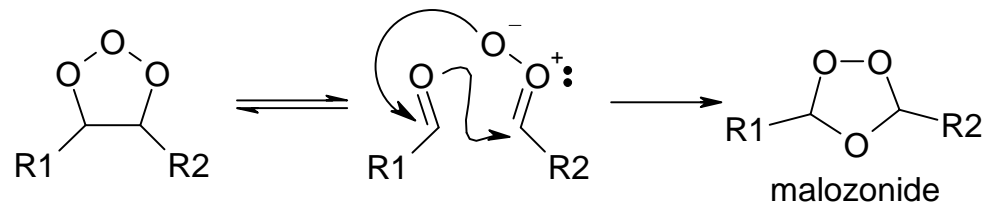

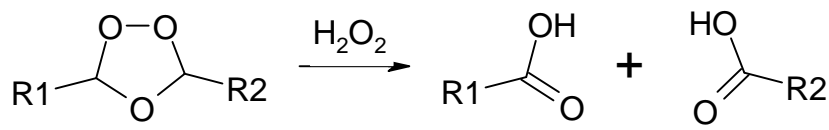

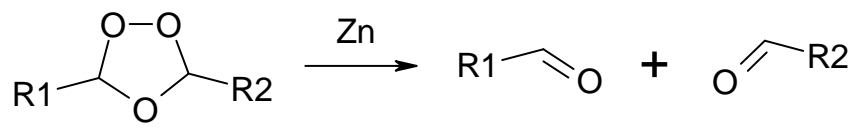

However, in the presence of an alcohol, malozonide formation can be disrupted and, instead, an aldehyde and a hydroperoxyhemiacetal are formed. At elevated temperatures, the hydroperoxyhemiacetal is not stable and may undergo a number of decomposition reactions, several of which result in formation of a water molecule and an ester. Glycerol, containing three hydroxyl $(\mathrm{OH})$ groups, may function as the alcohol in this reaction, giving a glyceryl ester:<smiles>[R1]C=C[O+]=[O+][O-]</smiles>

The glyceryl ester may then be transesterified with methanol to give methyl ester and glycerol or it may be hydrolyzed with water to give carboxylic acid and glycerol. The exact carboxylic acid(s) produced by this process depends on the process conditions but may include glycolic acid, glyoxylic acid, or formic acid. The aldehydes may include formaldehyde, 
glycolaldehyde (also known as hydroxyacetaldehyde), or glyoxal. The structures of these compounds are presented in Figure 64, and Table 52 lists their common uses.

The acid catalyst used to affect glycerol dehydration may be sulfuric acid, which is typically used in FAME facilities to neutralize basic product after transesterification. Methanol, which can be used to recover carboxylic acid products, is one of the primary reagents of FAME biodiesel and is in abundant supply at any biodiesel facility. Thus all of the chemicals required to produce the products listed in Table 52 should be readily available at any commercial FAME biodiesel facility.

Because the enol tautomers in Equations 1 and 2 are not stable, excess ozone must be used to ensure that the ozonolysis reaction takes place with high selectivity. The excess ozone from this process can be bubbled through biodiesel to recover short-chain FAs and/or aldehydes using several well-established processes (7-13). The products from these processes have a wide variety of uses, including pharmaceutical and cosmetic application (14, 15), resin production (11), production of nylon and other polymers $(16,17)$, and biodiesel improvement $(18-21)$.

The method used to react glycerol with ozone could also be used on olefins, the typical feedstocks for ozonolysis. In this case, alcohol would be mixed with the olefin to provide a replacement for the glycerol in Equation 7. Each double bond would be cleaved, with one carbon forming an aldehyde and the other forming an ester. Vegetable oil and biodiesel both contain olefins and could be used as a feedstock. To maximize product slate from a FAME facility, ozonolysis could be performed in a heated solution of methanol and triglyceride, yielding the variety of compounds listed in Table 53. However, separation may be an issue for recovering each of the individual components, and the technical barriers to commercializing ozonolysis in a heated methanol solution were not examined in great detail during this study.

A simple process flow diagram of the glycerol ozonolysis process is illustrated in Figure 65. As shown in the drawing, the reactor system can be installed on the back end of an existing biodiesel facility to increase product slate and to improve the cold-weather properties of the FAME biodiesel product. This avoids the locating, permitting, and shakedown issues associated with greenfield construction of new chemical plants.

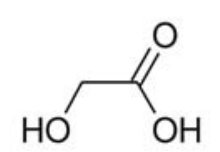

Glycolic Acid

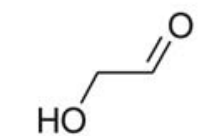

Glycolaldehyde

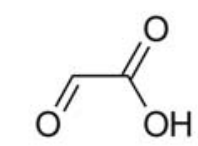

Glyoxylic Acid

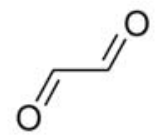

Glyoxal
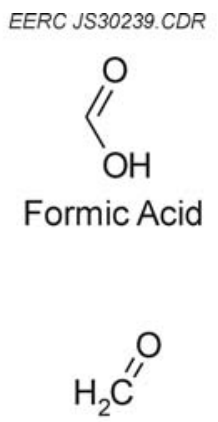

Formaldehyde

Figure 64. Compounds produced by glycerol ozonolysis. 
Table 52. Marketability Data for Various Glycerol Ozonolysis Products

\begin{tabular}{|c|c|}
\hline Compound & Market Application \\
\hline Formic Acid & $\begin{array}{l}\text { Solvent, disinfectant, textile processing (dyeing } \\
\text { fabrics and tanning leather), electroplating, latex } \\
\text { rubber preparation, grain preservation, and } \\
\text { intermediate for numerous chemicals and } \\
\text { pharmaceuticals. }\end{array}$ \\
\hline Formaldehyde & $\begin{array}{l}\text { Wood products (including pressed wood, paper, and } \\
\text { wood adhesives), cosmetics, disinfectants, textiles, } \\
\text { and paints. }\end{array}$ \\
\hline Glycolic Acid & $\begin{array}{l}\text { Cosmetics, biodegradable polymers, cleaning agent, } \\
\text { textile processing, flavoring agent and preservative, } \\
\text { and paints. }\end{array}$ \\
\hline Glyoxylic Acid & $\begin{array}{l}\text { Chemical platform for materials used in various } \\
\text { industries, including agrochemicals, } \\
\text { pharmaceuticals, polymers, and aroma compounds. }\end{array}$ \\
\hline Glyoxal & Browning agents (food industry). \\
\hline Glycolaldehyde & Browning agents, and cosmetics. \\
\hline
\end{tabular}

Table 53. Theoretical List of Compounds Produced by Ozonolysis of Soybean Oil in Methanol (saturated FAs are assumed to transesterify with methanol to form methyl esters)

\begin{tabular}{lccc}
\hline & & Boiling & Hypothetical \\
Name & Formula & Point, ${ }^{\circ} \mathrm{C}$ & Yield, wt $\%{ }^{1}$ \\
\hline 1-Propanal & $\mathrm{OCHCH}_{2} \mathrm{CH}_{3}$ & $49^{2}$ & 0.5 \\
Methyl Propionate & $\mathrm{CH}_{3}-\mathrm{O}-\mathrm{COCH}_{2} \mathrm{CH}_{3}$ & $80^{2}$ & 0.8 \\
Malondialdehyde & $\mathrm{OCHCH}{ }_{2} \mathrm{CHO}$ & $\mathrm{N} / \mathrm{A}^{3}$ & 3.2 \\
Methyl 3-Oxopropanoate & $\mathrm{CH}_{3}-\mathrm{O}-\mathrm{COCH}_{2} \mathrm{CHO}$ & $\mathrm{N} / \mathrm{A}$ & 9.0 \\
Dimethyl Malonate & $\mathrm{CH}_{3}-\mathrm{O}-\mathrm{COCH} \mathrm{CO}_{2}-\mathrm{O}-\mathrm{CH}_{3}$ & 183 & 5.8 \\
1-Hexanal & $\mathrm{OCH}\left[\mathrm{CH}_{2}\right]_{4} \mathrm{CH}_{3}$ & 129 & 7.0 \\
Methyl Caproate & $\mathrm{CH}_{3}-\mathrm{O}-\mathrm{CO}\left[\mathrm{CH}_{2}\right]_{4} \mathrm{CH}_{3}$ & 150 & 9.1 \\
1-Nonanal & $\mathrm{OCH}\left[\mathrm{CH}_{2}\right]_{7} \mathrm{CH}_{3}$ & 191 & 4.4 \\
Methyl 1-Nonanoate & $\mathrm{CH}_{3}-\mathrm{O}-\mathrm{CO}\left[\mathrm{CH}_{2}\right]_{7} \mathrm{CH}_{3}$ & 214 & 5.3 \\
Methyl 9-Oxononanoate & $\mathrm{CH}_{3}-\mathrm{O}-\mathrm{CO}\left[\mathrm{CH}_{2}\right]_{7} \mathrm{CHO}$ & $\mathrm{N} / \mathrm{A}$ & 20.4 \\
Dimethyl Azelate & $\mathrm{CH}_{3}-\mathrm{O}-\mathrm{CO}\left[\mathrm{CH}_{2}\right]_{7} \mathrm{CO}_{-} \mathrm{O}-\mathrm{CH}_{3}$ & 156 & 23.7 \\
Methyl Palmitate & $\mathrm{CH}_{3}-\mathrm{O}-\mathrm{CO}\left[\mathrm{CH}_{2}\right]_{14} \mathrm{CH}_{3}$ & $>185$ & 7.7 \\
Methyl Stearate & $\mathrm{CH}_{3}-\mathrm{O}-\mathrm{CO}\left[\mathrm{CH}_{2}\right]_{16} \mathrm{CH}_{3}$ & $>215$ & 3.1 \\
\hline
\end{tabular}

${ }^{1}$ Hypothetical yield on a dry, glycerol-free basis. The yield calculations were based on the following assumptions: 1) atoms connected by an unsaturated bond have equal probabilities of becoming methyl esters or aldehydes.

2) all unsaturated bonds are broken, 3) ozonolysis products do not undergo further reactions, and 4) all triglycerides are transesterified to give methyl esters.

${ }^{2}$ Pure compound requires cool or cold storage, indicating high volatility or reactivity.

${ }^{3}$ Not available because product is either rare or unstable. 


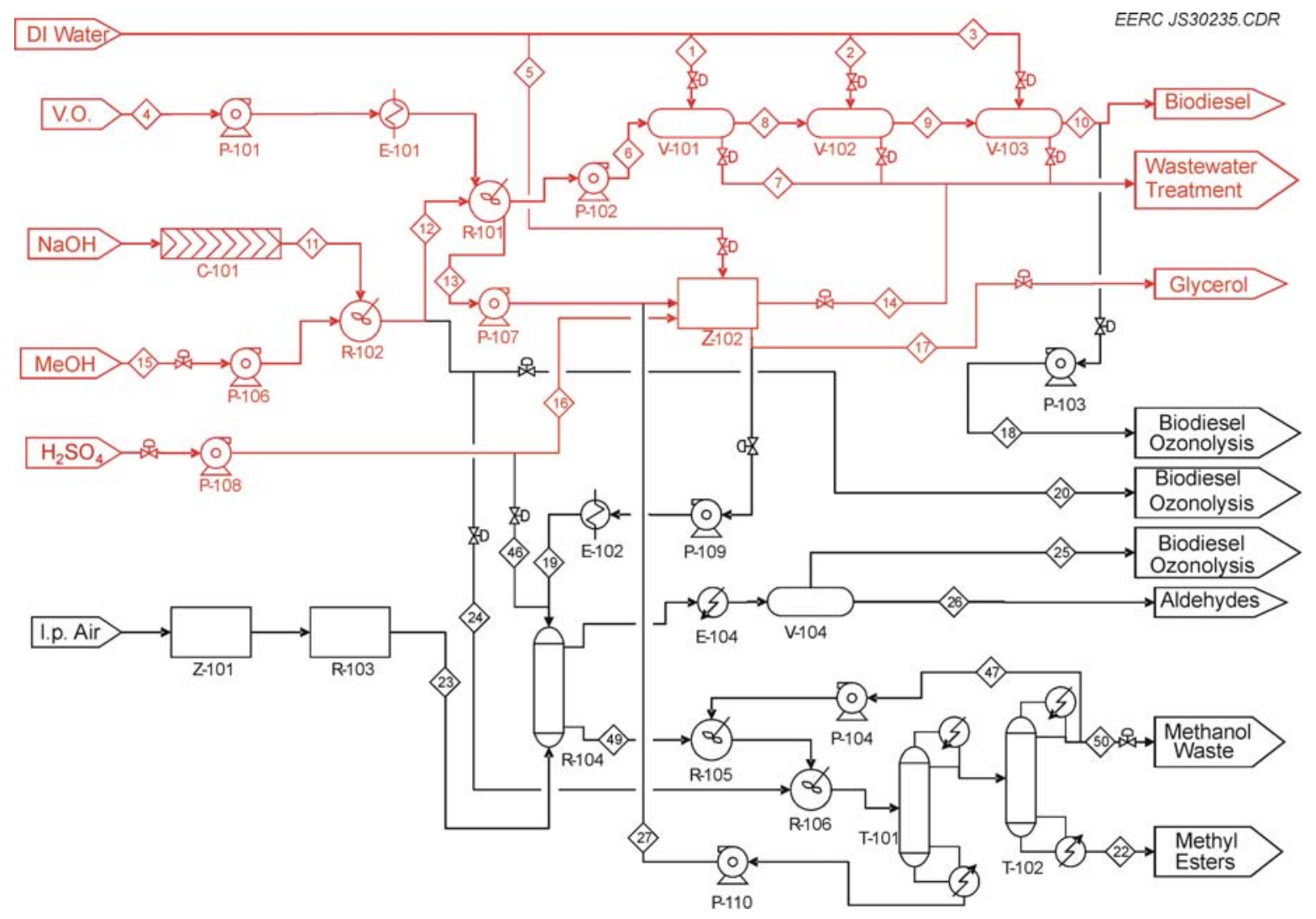

Figure 65. Process flow diagram of a slipstream glycerol ozonolysis reactor system installed at a preexisting biodiesel facility. The biodiesel facility is drawn in red, while the new construction is in black.

\section{Goals and Objectives}

The original goals of the proposal were to develop an ozonolysis-derived additive for biodiesel and to test the PP and CP suppression of the product. Production of chemicals from glycerol was to be a minor component of the project. However, early in the literature review, it became apparent that low blend levels of ozonolysis products into biodiesel would not achieve significant suppression of PP and CP $(18,22,23)$. Research has since shown that many coldweather issues can be resolved by removing select components from biodiesel $(24,25)$. Although additives used in conjunction with biodiesel purification might have an appreciable effect on the cold-weather properties of biodiesel, the high capital and operating costs of large-scale ozonolysis suggest that purification alone is the most economical route to improving biodiesel cold-weather properties.

Because ozonolysis for biodiesel additives did not appear promising, the primary goal of the project shifted to chemical production from glycerol. The original goal was maintained by considering potential by-products of the glycerol ozonolysis process as biodiesel additives. 
Two of the objectives in producing chemicals from glycerol via ozonolysis were to identify a pathway with low capital and operating cost relative to traditional ozonolysis and to identify the likely products of this pathway. A third objective was to test and then optimize the proposed pathway on the bench scale. A further objective was to estimate the economic favorability of the proposed pathway. The final objective was to determine whether a similar process could yield products with some ability as PP or CP suppressants, and if not, whether a traditional ozonolysis route would be economically favorable as a back-end process to the proposed glycerol ozonolysis process.

\section{Experimental}

\section{Glycerol Ozonolysis}

Prior to testing, an extensive review of literature on known ozonolysis mechanisms was conducted to predict the likely products of glycerol ozonolysis. Reaction pathways were ranked in terms of favorability at various conditions. Once a preliminary reactor scheme was envisioned, the most likely products at reaction conditions were identified.

The glycerol ozonolysis portion of the process depicted in Figure 65 was optimized in the laboratory by conducting a matrix of tests. The experimental design of this test matrix was a Box-Behnken design, as shown in Table 54. As can be seen from Table 54, the parameters tested included temperature, time, and amount of catalyst (in this case, 5-molar $\mathrm{H}_{2} \mathrm{SO}_{4}$ ). The parameter ranges were selected after extensive initial testing using a variety of reactor setups. This initial testing revealed that temperatures higher than $180^{\circ} \mathrm{C}$ tended toward runaway dehydration with minimal ozonolysis, while temperatures lower than $150^{\circ} \mathrm{C}$ generally gave unacceptably slow reaction rates. Similar effects were observed and used to define the upper and lower limits for time and amount of sulfuric acid used.

The test order in Table 54 was randomized and run in the order shown in the second column. After several tests using the Box-Behnken design, it became clear that the combination of test conditions was too extreme. For instance, screening tests showed that using $3 \mathrm{~mL}$ of sulfuric acid would allow for successful ozonolysis, as would temperatures of $180^{\circ} \mathrm{C}$ or reaction times of up to 3 hours. When two or more of the conditions were combined (as in Test Number 8 in Table 54), the glycerol underwent rapid exothermic dehydration, forming a blackened char that became hot enough to autoignite. Because of the potential for damage to labware and injury to workers, the test matrix was revised from a standard Box-Behnken design to the test matrix shown in Table 55. The changes were made in such a way as to minimize the number of tests that would need to be repeated while keeping the run order shown in Table 54.

The reactor setup used to perform the test matrix is shown in Figure 66. Ozone is generated from bottled oxygen in the Orec Model 03B1-0 Ozonator reactor shown in Figure 67. This generator is a water-cooled unit capable of delivering up to 12 liters per minute of gas at pressures of up to $30 \mathrm{psig}$. Output voltage is AC and can be varied between zero and 100 volts, giving rms amperages of up to $5 \mathrm{amps}$. Flow can be delivered to a reaction vessel or to a smallsample port that can be used for online calibration. In the event of a fuse failure or a loss in power, gas flow is automatically stopped at the inlet to prevent ozone leakage. Removable access panels are located on the front and both sides of the reactor for maintenance and internal 
Table 54. Planned Box-Behnken Test Design

\begin{tabular}{lcccc}
\hline Test Number & Run Order & $\begin{array}{c}\text { Temperature, } \\
{ }^{\circ} \mathrm{C}\end{array}$ & $\begin{array}{c}\text { Test Time, } \\
\text { hours }\end{array}$ & $\begin{array}{c}\text { Sulfuric Acid, } \\
\text { mL }\end{array}$ \\
\hline 1 & 12 & 150 & 1 & 2 \\
2 & 7 & 180 & 1 & 2 \\
3 & 6 & 150 & 3 & 2 \\
4 & 15 & 180 & 3 & 2 \\
5 & 13 & 150 & 2 & 1 \\
6 & 11 & 180 & 2 & 1 \\
7 & 3 & 150 & 2 & 3 \\
8 & 4 & 180 & 2 & 3 \\
9 & 9 & 165 & 1 & 1 \\
10 & 10 & 165 & 3 & 1 \\
11 & 2 & 165 & 1 & 3 \\
12 & 5 & 165 & 3 & 2 \\
13 & 8 & 165 & 2 & 2 \\
14 & 1 & 165 & 2 & 2 \\
15 & 14 & 165 & 2 & \\
\hline
\end{tabular}

Table 55. Modified Test Design

\begin{tabular}{lccc}
\hline Test Number & $\begin{array}{c}\text { Temperature, } \\
{ }^{\circ} \mathrm{C}\end{array}$ & $\begin{array}{c}\text { Test Time, } \\
\text { hours }\end{array}$ & $\begin{array}{c}\text { Sulfuric Acid, } \\
\mathrm{mL}\end{array}$ \\
\hline 1 & 150 & 1 & 2 \\
2 & 135 & 1 & 2 \\
3 & 150 & 1.5 & 2 \\
4 & 135 & 1.5 & 2 \\
5 & 150 & 2 & 1 \\
6 & 135 & 2 & 1 \\
7 & 150 & 2 & 3 \\
8 & 135 & 2 & 3 \\
9 & 165 & 1 & 1 \\
10 & 165 & 1.5 & 1 \\
11 & 165 & 1 & 3 \\
12 & 165 & 1.5 & 3 \\
13 & 165 & 2 & 2 \\
14 & 165 & 2 & 2 \\
15 & 165 & 2 & 2 \\
\hline
\end{tabular}




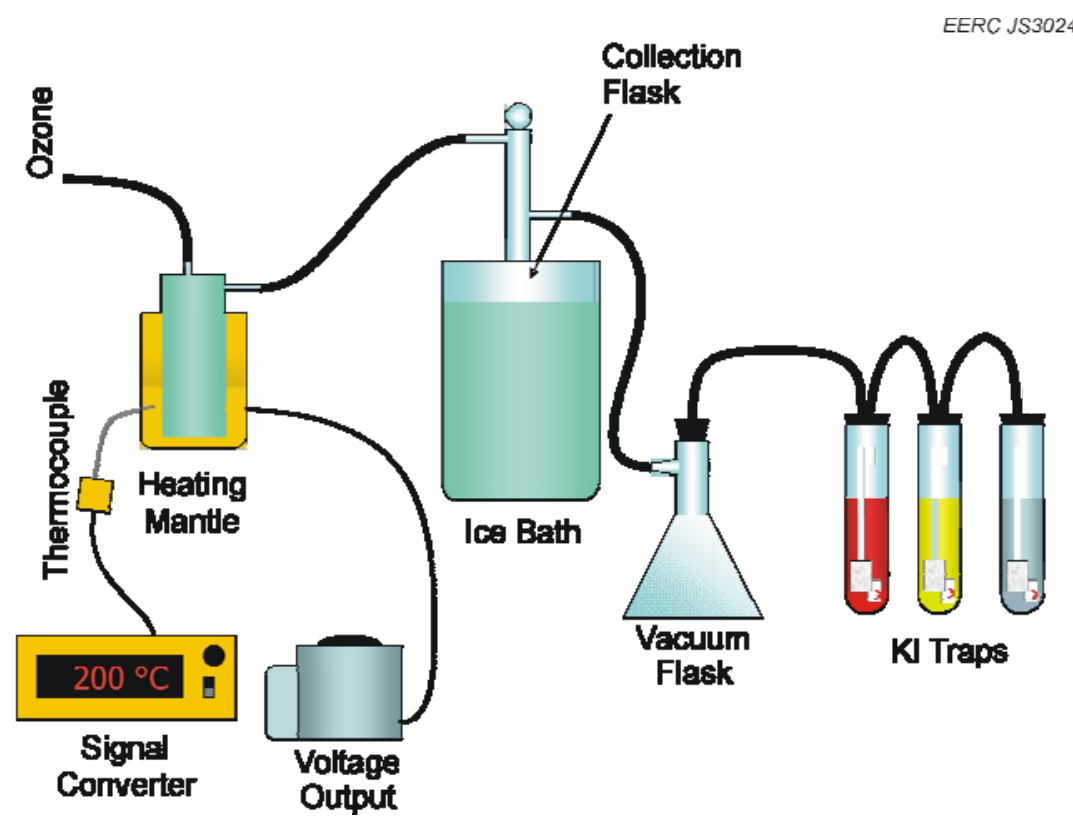

Figure 66. Laboratory reactor system used to optimize ozonolysis process.

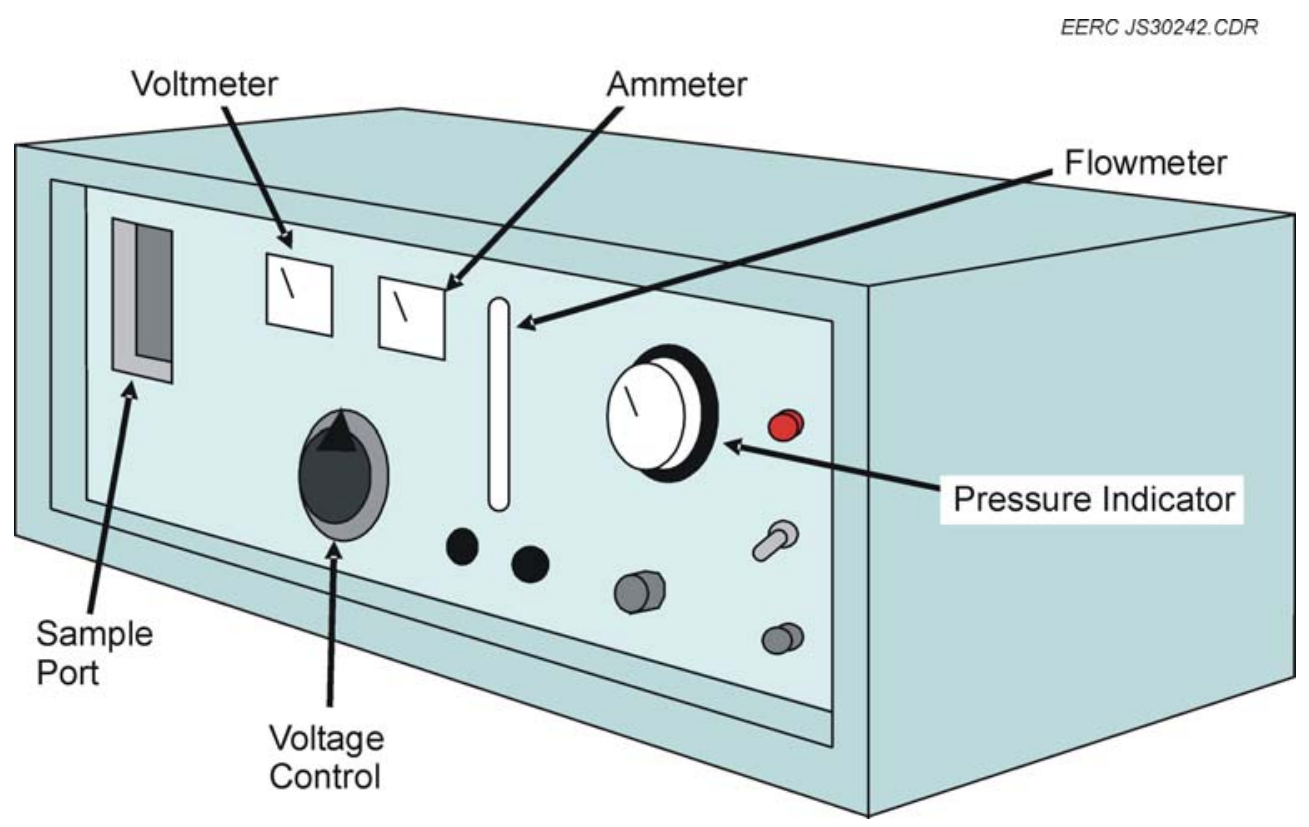

Figure 67. Ozone generator. 
leak checking, and a spring-loaded safety kill switch is opened when the access panel nearest the power source is removed. At full power and flow, the generator is capable of delivering well over $200 \mathrm{mg}$ of ozone per minute. Under the conditions used during the Box-Behnken testing, ozone delivery was approximately $70 \mathrm{mg} / \mathrm{min}$.

The reactor in Figure 66 consists of a $50-\mathrm{mL}$ glass vial that is externally heated by a heating mantle. The heating mantle contains a thermocouple near the hot surface that is used for temperature control. Ozone is preheated through a Teflon line wrapped in heating tape and is introduced to the reactor through a fitting that is submerged beneath the liquid reagent (a solution of glycerol and acid catalyst).

Gas exits the reactor through a short horizontal crossover (approximately $1 \frac{1}{2} \mathrm{in}$. long) and enters a condenser cooled by ice water. Volatile material condenses and runs down into a $25-\mathrm{mL}$ round-bottom flask, where it is collected after the test. Uncondensed gas exits the round-bottom flask and passes through a water trap before being bubbled through a series of potassium iodide (KI) traps. The water trap is an empty glass container intended to prevent KI solution from being pulled back into the condenser in the event of a pressure drop. The KI traps convert ozone to harmless oxygen, which is then vented into a fume hood. As the traps become saturated, iodide ions are oxidized to iodine, and the solutions change color from clear to deep red. The color change is used as an indicator that solutions need to be replaced to prevent ozone leakage.

During each of the tests, the ozone inlet line was heated to $65^{\circ} \mathrm{C} .15 \mathrm{~g}$ of glycerol was used in each test. The ozone generator was consistently set to $1.0 \mathrm{lpm}$ of flow, with an output current of $4.0 \mathrm{amps}$ (AC, rms). These conditions were kept to ensure that the only changes between tests were those listed in Table 55.

After each test, the distillate (the product in the collection flask) was recovered and diluted to $1 \%$ on a weight basis in distilled, deionized (DI) water. The undistilled reflux product (the material remaining in the reactor) was also diluted to a $1 \%$ solution in DI water. The diluted distillate and reflux product of each test were analyzed by high-performance liquid chromatography (HPLC) to determine product yield and composition.

The HPLC used for analysis uses a dual analyzer to detect products. An ultraviolet (UV) detector operating with sensitivity to $210 \mathrm{~nm}$ light is used to detect carbonyl compounds including carboxylic acids, aldehydes, and ketones. In addition, a refractive index (RI) detector is used to detect all product components with a RI different than water. While the RI detector will detect virtually any species present in solution, its sensitivity is low, and it is susceptible to baseline drift when solutions are analyzed with $\mathrm{pH}$ different than the $\mathrm{pH}$ of the carrier/purge solution. As such, UV results are preferred. Using the results of the HPLC analyses, theoretical optimum process conditions were calculated using regression analysis.

After the optimum process conditions for product yield were calculated, a test was performed at these conditions to ensure that the regression model was accurate. A sample of the best-available product was then submitted to WMRC for HPLC-MS analysis. A proposed separation technique was attempted on this product to determine technical feasibility. The separation process involves methyl esterification by refluxing the product from the reactor in 
methanol for 1 hour. As short-chain methyl esters are formed, they are volatilized and may be condensed downstream. This permits the separation of compounds that would otherwise polymerize in their pure states. Moreover, the separation process uses only methanol and heat, both of which are readily available at any commercial FAME biodiesel facility.

\section{Vegetable Oil Ozonolysis}

Prior to conducting ozonolysis of vegetable oil or biodiesel, a literature review was conducted of known ozonolysis pathways and of the PP and CP suppression effects of ozonolysis products. A possible pathway toward novel cold-weather additives was proposed and tested in the laboratory.

Vegetable oil ozonolysis was carried out by pouring $12.4 \mathrm{~mL}$ soybean oil and $19.0 \mathrm{~mL}$ methanol into an electrically heated glass reactor connected by a short crossover to an ice-cooled condenser. This is the same reactor system used for glycerol ozonolysis (Figure 66). Mixing of the liquid layers was achieved by the action of bubbling gas. The immiscible liquids were heated mildly to $40^{\circ} \mathrm{C}$ while oxygen bubbled through the reactor. Once the reactor reached temperature, the ozone generator was turned on to convert some of the bubbling oxygen into ozone.

Preheating served three purposes. First, higher temperatures encouraged methyl esterification of free FAs produced by ozonolysis. Second, higher temperatures encouraged destruction of unstable hydroperoxyhemiacetals into methyl esters or other products. Third, higher temperatures prevented buildup of ozonides or malozonides, both of which are stable at lower temperatures but can explode if allowed to build up to high concentrations.

Following ozonolysis, the product was rinsed with DI water and allowed to separate into two layers. The aqueous layer was removed, and the product was rinsed again in DI water. After the final rinse, the product was dried over mild heat until clear and colorless. The dried product was then mixed with biodiesel at blends of $1 \%, 5 \%$, and $10 \%$ at volumes of $10 \mathrm{~mL}$ apiece. Because only $5.8 \mathrm{~mL}$ of additive was available, preparation of separate blends higher than $10 \%$ was not feasible. Instead, $1.25 \mathrm{~mL}$ of the ozonolysis product was added to the $10 \%$ blend to give $11.25 \mathrm{~mL}$ of a $20 \%$ blend, after which an additional $2.95 \mathrm{~mL}$ of product was added to give $14.2 \mathrm{~mL}$ of a $37 \%$ blend. The CP of each blend was tested using a Phase Technology CPA-T30 analyzer. The $\mathrm{CP}$ of a $10-\mathrm{mL}$ sample of unblended biodiesel was also measured to use as a baseline.

To test PP, a sample size of approximately $50 \mathrm{~mL}$ was required. All of the solutions from the $\mathrm{CP}$ testing $(0 \%, 1 \%, 5 \%$, and $37 \%)$ were combined to give $44.2 \mathrm{~mL}$ of a blend of $13 \%$ ozonolysis product in biodiesel. The PP of this blend was determined using a CPP-5Gs analyzer. The PP of pure biodiesel was also measured for comparison. 


\section{Results and Discussion}

\section{Glycerol Ozonolysis}

HPLC UV analysis of the distillate products revealed a single strong aldehyde peak for almost all tests. In most cases, RI analysis of the distillate samples also revealed no other peaks. HPLC UV analysis of the reflux products revealed smaller aldehyde peaks. RI analysis revealed peaks corresponding to unreacted glycerol as well as to what appeared to be glyceryl esters. Ion spectrometry further suggested that the secondary peaks were glyceryl esters. Ion spectrometry results are shown in Figure 68 for a preliminary reflux sample that was produced prior to the test matrix in Table 55 and, as such, had lower concentrations of products and higher concentrations of unreacted glycerol than most samples.

Attempts to correlate UV peak area and height to concentration of aldehydes in distillate products yielded physically impossible results. For example, some product solutions showed concentrations twice as high as concentrations found in pure crystalline structures. RI peak areas could not be used to estimate concentration because of low sensitivity and baseline drift.

The reason for nonsensically high concentrations predicted from the UV-based calibration equation is uncertain. The error may have been due to contamination in or damage to the HPLC. It is also possible that unexpected carbonyl compounds may have formed during ozonolysis and been confused with known standards. However, HPLC-MS results (discussed later) suggest that the products were those expected and not unknown compounds.

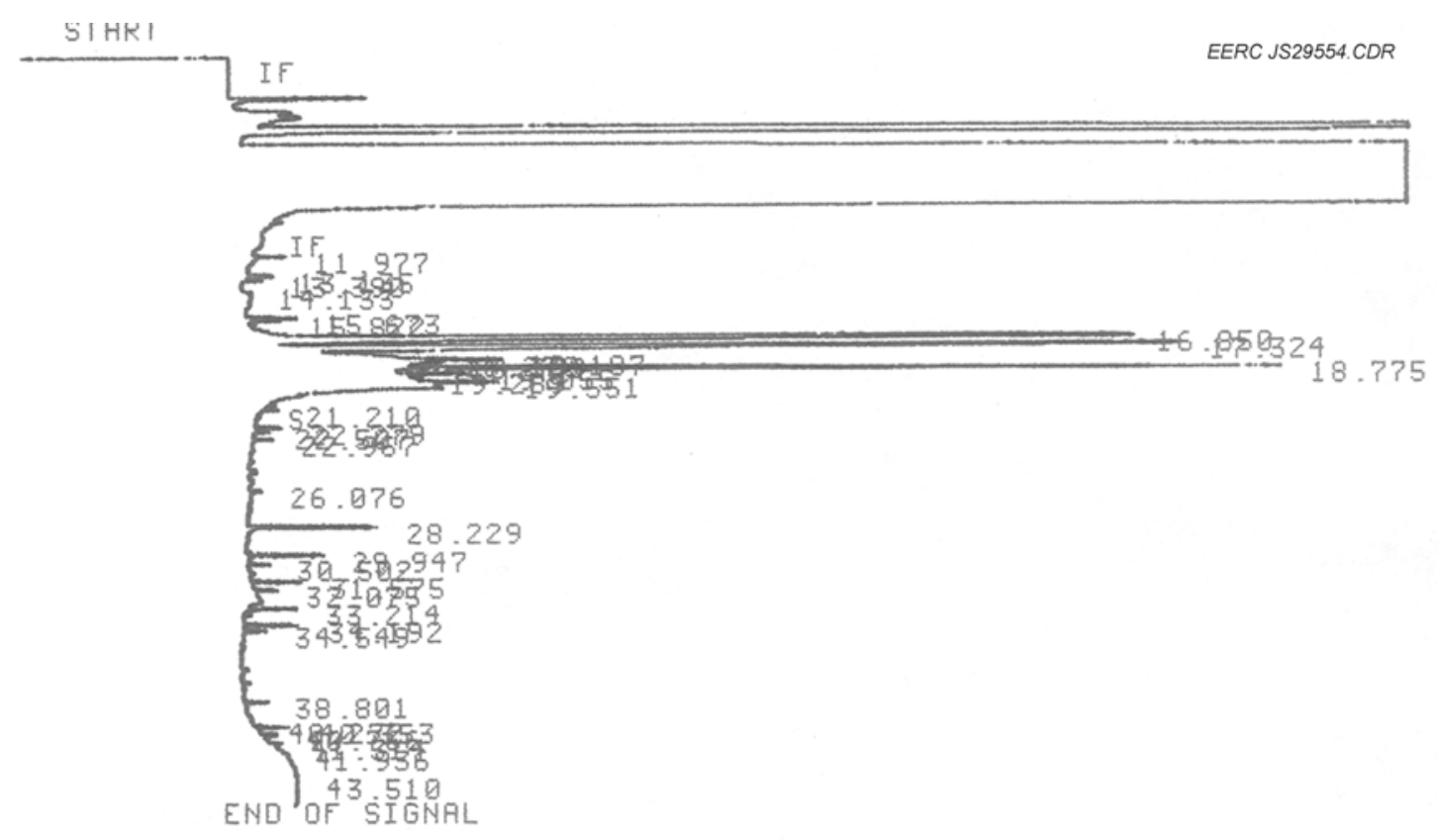

Figure 68. Ion chromatograph of an early glycerol ozonolysis product. The large peak at top is glycerol; the peaks between 14 and 22 minutes are monoesters; the peaks between 28 and 34 minutes are diesters; and the peaks at 38 minutes and above are triesters. 
Table 56 lists the results of testing according to the modified test matrix. It should be noted that the table reports free glycerol remaining in the reflux product rather than glycerol conversion. This is because the acidic ozonolysis products were esterified with some of the glycerol that had not undergone ozonolysis, so the amount of free glycerol remaining in solution does not directly translate to glycerol conversion efficiency. It should also be noted that HPLC UV peak area rather than product concentration is reported for the distillate product. This is because the UV-based calibration equation gave nonsensical product concentrations, as discussed above.

From Table 56, it is apparent that both yield and conversion were low for every test in the matrix. $15 \mathrm{~g}$ of glycerol was used as the starting material in each test. Test 10 , which had the lowest amount of free glycerol remaining, yielded only $11.3 \mathrm{~g}$ of total product, giving $74 \%$ yield by mass. The reason for the low yields is likely that an undesirably large amount of glycerol was oxidized to uncondensed products such formaldehyde, $\mathrm{CO}$, or $\mathrm{CO}_{2}$. The situation is worse when one considers that the desired product is the distillate. The maximum yield of distillate was observed in Test 7 , and the yield was only $15 \%$ by mass.

The test with the lowest free glycerol remaining (Test 10) had at least $21 \%$ of the initial glycerol remaining unconverted, meaning that the maximum conversion was $79 \%$. Given that some glycerol was tied up as glycerol esters formed from reaction with acidic products, the actual conversion was probably even poorer.

Table 56. Glycerol Ozonolysis Test Results

\begin{tabular}{lcccc}
\hline $\begin{array}{l}\text { Test } \\
\text { Number }\end{array}$ & $\begin{array}{c}\text { Distillate } \\
\text { Yield, g }\end{array}$ & $\begin{array}{c}\text { Aldehyde Peak Area (AU·s) } \\
\text { in Distillate Product }^{1}\end{array}$ & $\begin{array}{c}\text { Refluxed } \\
\text { Product, g }\end{array}$ & $\begin{array}{c}\text { Free Glycerol } \\
\text { Remaining }^{2}\end{array}$ \\
\hline 1 & 0.3542 & 36,008 & 13.5623 & $86 \%$ \\
2 & 0.5248 & 54,657 & 12.0162 & $73 \%$ \\
3 & 0.9471 & 74,270 & 13.3675 & $81 \%$ \\
4 & 0.7423 & 78,734 & 11.3200 & $62 \%$ \\
5 & 0.7617 & 358,322 & 10.1471 & $36 \%$ \\
6 & 0.4514 & 90,543 & 11.7019 & $77 \%$ \\
7 & 2.2154 & 61,747 & 10.6463 & $40 \%$ \\
8 & 1.0677 & 22,660 & 10.8131 & $57 \%$ \\
9 & 0.1280 & 14,522 & 9.6765 & $65 \%$ \\
10 & 1.7079 & 216,209 & 9.6032 & $21 \%$ \\
11 & 1.1854 & 51,872 & 13.8756 & $87 \%$ \\
12 & 0.3327 & 17,483 & 13.5178 & $54 \%$ \\
13 & 1.6399 & 97,263 & 8.9436 & $29 \%$ \\
14 & 2.1821 & 113,247 & 9.5832 & $24 \%$ \\
15 & 1.1969 & 88,227 & 10.0868 & $37 \%$ \\
\hline 1 & Results from HPLC using UV detector. & & \\
2 & Based on total mass of glycerol detected in products divided by $15 \mathrm{~g}$ (starting glycerol). Glycerol \\
\multicolumn{2}{c}{ detection is by RI only, as glycerol does not have a UV peak at $210 \mathrm{~nm}}$. &
\end{tabular}


The distillate sample from Test 10 was shipped to WMRC for HPLC-MS analysis. Recall that all distillate samples showed the same single peak. Assuming that the HPLC-MS results from WMRC on the distillate sample from Test 10 apply to all distillate samples, the distillate samples are a solution of glyoxal and formic acid.

The reason that two compounds were found by MS while only a single peak was seen in the UV results is not clear. It is possible that the HPLC UV equipment was malfunctioning, which would explain why the known calibration curve did not produce meaningful data when applied to distillate samples. It is also possible that glyoxal and formic acid undergo polymerization or some other reaction in strong solution, causing the product UV peaks to either overlap or become nondetectable by UV at $210 \mathrm{~nm}$.

Although at least one sample of the distillate product was identified by HPLC-MS, the reflux products were not successfully separated or purified for further identification. Because of budget constraints, only the best reflux product was to be separated and analyzed. Carboxylic acid separation from this reflux product was attempted but abandoned after the reflux product was inadvertently destroyed. Part of the separation test involved taking a small portion of the best-available sample and refluxing in a dilute methanol solution. Poor communication between project management and a laboratory assistant resulted in the entire best-available sample being heated to boiling without methanol present. This caused volatile product to boil off while free glycerol in the sample underwent dehydration and polymerization, giving a thick brown liquid rich in acrolein. The time and cost required to attempt a second separation test was beyond the project budget.

Because the reflux product was a complex solution that would require significant separation to recover salable products, the distillate product was considered the most promising reaction product. The results from the modified test matrix in Tables 55 and 56 were used to generate a regression equation predicting optimum operating conditions for generating large yields of high-purity distillate. As stated previously, calibration equations could not be used to determine distillate product concentration based on UV detection. HPLC peak areas rather than concentrations were used to construct the equation for predicting optimum yield.

The resulting equation proved inaccurate when tests were performed at the predicted optimum conditions. The equation predicted a maximum distillate product yield of $51 \%$ by weight at $165^{\circ} \mathrm{C}$ over 1 hour with $1 \mathrm{~mL} \mathrm{5-molar} \mathrm{H}_{2} \mathrm{SO}_{4}$, while the actual distillate product yield was $2.7 \%$ at these conditions. Similarly, the equation predicted that the reflux product obtained at these conditions would contain essentially no free glycerol, while the actual product (which was not analyzed) was similar in color, clarity, and viscosity to pure glycerol. It is because optimum conditions could not be predicted that the best-available sample (Test 10) was sent to WMRC for HPLC-MS analysis instead of the optimized product.

The inability of the regression equation to accurately predict optimum test conditions was due to the change in experimental design. One of the key features of a Box-Behnken design is its mathematical symmetry. When the Box-Behnken design was altered in this work, its design symmetry was lost. This caused an unequal weighting toward higher temperatures and longer residence times. More importantly, fewer tests were performed at average temperatures or 
residence times, meaning that an abundance of data were available for extreme conditions but very little data were available at average conditions. Not surprisingly, the resulting equation shows high curvature at extreme conditions but relatively flat behavior at average conditions.

Although the equation was not useful in predicting optimum test conditions, limited conclusions were drawn from the best-case tests. One advantage of the process developed in the project is that cost and safety may not be as severe as they are for traditional ozonolysis. One of the reasons for the historically high cost of ozonolysis has been the safety concerns associated with ozonolysis. These safety concerns arise because ozonides and malozonides can accumulate during reaction and build up to explosive concentrations. The glycerol ozonolysis process destroys ozonides and malozonides as they are formed and is, therefore, much less prone to explosion.

An analogy may be taken from the flare at a chemical plant producing flammable gases. Although flammable gases would form a dangerous and explosive cloud if simply vented, they are quickly combusted at high flare temperatures and can be vented safely. Similarly, traditional ozonolysis occurs at subzero temperatures and allows high concentrations of explosive compounds to form, while glycerol ozonolysis occurs at high temperatures. Ozonides are unstable at these conditions and rapidly decompose into more stable products (Equation 7).

A clear demonstration that explosive solutions do not form in glycerol ozonolysis was observed in one of the early tests, when a temperature excursion led to rapid exothermic dehydration. Although ozonolysis had been ongoing for approximately 1 hour with no ozone detected in the gas outlet stream (demonstrating that all available ozone was reacting with the liquid), the product autoignited without exploding. Had ozonides been forming over the hour of ozonolysis, they would have been present at a high enough concentration to cause a major explosion. The fact that the reaction solution instead caught fire and was safely extinguished strongly suggests that ozonides were not present at appreciable concentrations.

\section{Vegetable Oil Ozonolysis}

Figure 69 provides results on the $\mathrm{CP}$ testing of the ozonolysis product of vegetable oil in methanol. Only at the highest blend ratio (37\%) was an appreciable drop in CP observed. The PP test showed a net increase in PP from $-8.0^{\circ} \mathrm{C}$ to $-6.0^{\circ} \mathrm{C}$ when the ozonolysis product was added to biodiesel.

The CP of neat biodiesel decreased as ozonolysis product was added to biodiesel, while the PP increased slightly. This is in contrast with the results of Soriano et al., who reported that blending ozonolysis product into biodiesel caused a decrease in PP but not in CP relative to pure biodiesel (18). This difference may be due to differences in the degree of unsaturation of oil feedstocks, in the amount of steryl glucoside present in the blend, or in the ozonolysis method used to produce the fuel additive.

Given the high blend ratio required to cause a measurable effect on cold-temperature properties and the small effect observed even at this high blend ratio, direct use of the ozonolysis product generated in this work does not appear to be an economically viable solution to 


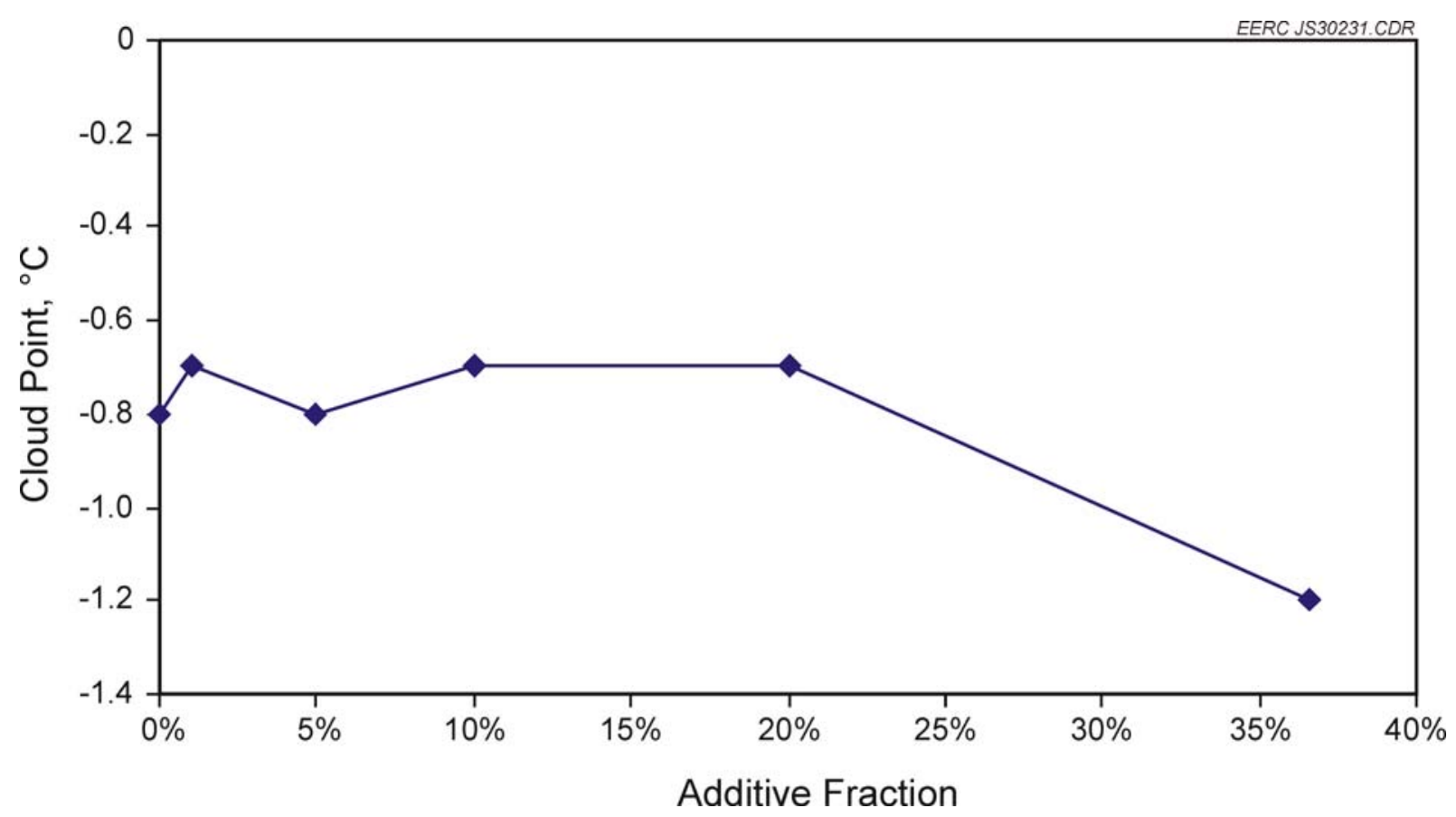

Figure 69. Effect of additive blending on biodiesel CP.

improving the cold-weather properties of biodiesel. Distillation or other separation techniques may yield a product that is better able to suppress cold-weather properties, but this will add further processing costs to the ozonolysis product. Alternatively, low-temperature oxidative ozonolysis could be performed on biodiesel to preferentially yield methyl esters that could have a greater impact on the cold-weather properties of biodiesel (19).

After this project was proposed, various studies began to show that the poor cold-weather properties of soy-based biodiesel are due in large part to steryl glucosides present in the fuel (2225). This being the case, no additive will fully correct the cold-weather properties of soy biodiesel, because steryl glucosides can condense at relatively high temperatures regardless of the bulk composition or average FP of the methyl ester portion of the fuel. The best solution to preventing clouding and freezing of biodiesel at cold temperatures is not through use of additives but rather by removal of steryl glucosides from the biodiesel product (23). With the removal of steryl glucosides, existing additives may have more success at suppressing PP and CP. At this point, it does not appear favorable to pursue further research into novel biodiesel PP suppressants.

\section{Economic Analysis}

Prior to discussing process economics, it should be stressed again that the economic climate for glycerol ozonolysis has seen substantial changes since this work was completed. The assessment provided here is no longer accurate.

Limited chemical commodity cost data are available for the chemicals used and produced by the process described in this report. For many chemicals, no data are readily available. 
Traditionally, the trade journal Chemical Market Reporter $(C M R)$ has provided commodity data. However, this practice was ended after March 21, 2005.

Figure 70 provides cost data for glycerol, formaldehyde, methanol, oleic acid, and propionic acid for the period September 25, 2004, to March 24, 2005, as taken from CMR. Although data for other products were not listed, analogous products are used where applicable. For glycolic acid, lactic acid is used to estimate cost, as both products have similar application, have similar (traditional) production methods, and are used together to manufacture biodegradable PLGA polymer. For glycolaldehyde, acetaldehyde is substituted. Not shown in Figure 70 but taken from $C M R$ are the costs for sodium hydroxide, sodium sulfate, sulfuric acid, and dichloromethane (methylene chloride in $C M R$ ). Also taken from $C M R$ were the costs for maleic anhydride and low-grade oleic acid, which were used to estimate the costs of malonic acid and capric acid, respectively.

Part of the separation in the envisioned process required the use of petroleum ether. The cost of petroleum ether is unknown from $C M R$, and so the cost of snow white petrolatum was used as an estimate. This value was not used because snow white petrolatum is chemically similar to ether; in fact, petrolatum, more commonly known as petroleum jelly, is a solid at room temperature and is used primarily in the cosmetics industry. Rather, the cost for snow white petrolatum was used because it was the highest-priced petroleum product reported in the final issue of $C M R$ to include chemical commodity prices and so was considered a worst-case estimate.

As can be seen, the cost of glycerol (glycerine in CMR) dropped by nearly half over the period of reporting. Looking further back, glycerol costs had risen between 1998 and 2003 from $\$ 0.53$ per pound to $\$ 0.66$ per pound as glycerol found increased application in cosmetics. The expansion of the biodiesel industry then produced a large excess of glycerol that temporarily drove the price down. Thus the cost of $\$ 0.36 / 1 \mathrm{~b}$ in March 2005 represented its lowest value in at least 7 years. There were reports that crude glycerin was selling for less than $\$ 0.05 / 1 \mathrm{~b}$ for a short time (26). However, glycerol has since found increased use in food and personal care products. As of March 2, 2008, spot prices are reported above \$1.00/lb (1). This has negatively impacted the economics of chemical production using glycerol as starting material. At the time that this study was conducted, the economics looked favorable, and many of the original conclusions have since been falsified.

Over the period of reporting shown in Figure 70, the cost of lactic acid remained steady at $\$ 0.70 / \mathrm{lb}$ without fluctuation. Assuming that the cost of lactic acid is similar to the cost of glycolic acid and that the market behavior is similar, this suggested that glycolic acid would continue to be both a more valuable product than glycerol and also a more stable investment. As stated above, this assumption has since proved false as glycerol prices have risen dramatically.

As mentioned in the Introduction, heated vegetable oil ozonolysis in methanol solution may yield a maximum number of total products, but the economics of this process were not considered. The number of separations required to recover each product to appreciable purity would likely increase the capital and operating costs too greatly to justify such a process. Instead, a more conventional process involving low-temperature oxidative ozonolysis was assumed for 


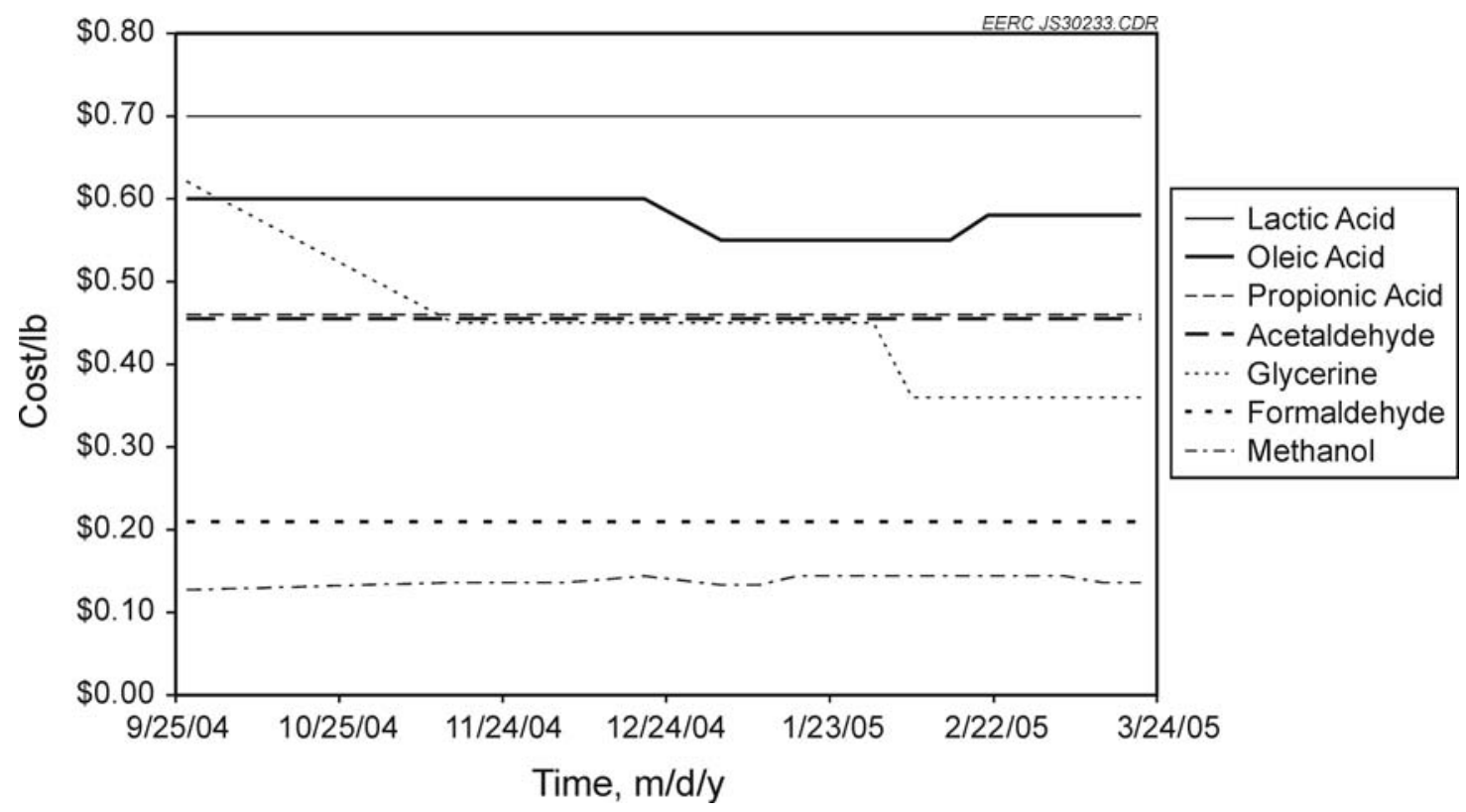

Figure 70. Bulk chemical costs as reported by CMR during the period September 25, 2004, to March 24, 2005.

converting biodiesel. The products of biodiesel ozonolysis are a mix of carboxylic acids and dicarboxylic acids, including propionic acid. Figure 70 shows both propionic and oleic acid prices as being fairly stable over a 6-month period. Other sources (27) have shown average propionic prices as increasing from $\$ 0.46$ in 2000 to $\$ 0.62 / \mathrm{lb}$ in 2005 , without downward fluctuations. Recovery of propionic acid represents a significant value increase as compared to simple vegetable oil esterification, as biodiesel typically sold in bulk for around $\$ 0.30 / \mathrm{lb}$ during the same period. In addition, the total volume and mass of salable fuel would increase, as ozonolysis of $100 \mathrm{~g}$ of soybean-derived vegetable oil is capable of producing up to $148 \mathrm{~g}$ of methyl ester product.

For conducting a preliminary economic analysis, the results of the optimization study can be used to estimate product yields. Using Test 10 from Table 56 as a model, $37 \%$ of the glycerol can be expected to undergo ozonolysis in a single pass. For every pound of glycerol fed both as fresh feed and as recycle, $0.13 \mathrm{lb}$ of the reaction product will be distilled by heat of reaction and condensed downstream as an aqueous solution of formic acid and glycolaldehyde, which is the preferred aldehyde product owing to its price and range of applications (28); $0.51 \mathrm{lb}$ of the product will be glycolic acids present as glyceryl glycolate esters that can be transesterified to $0.30 \mathrm{lb}$ methyl esters, distilled, and recovered in high purity; $0.02 \mathrm{lb}$ of the undistilled reaction product will be aldehydes that are unrecovered; and $90 \%$ of the unreacted glycerol (including that recovered from transesterification of the glyceryl glycolate) can be recovered and recycled back into the ozonolysis reactor, which will be fed a gas stream containing $20 \%$ excess ozone.

The excess ozone could be passed to a FA reactor to produce short-chain methyl esters from biodiesel. $100 \%$ of the ozone can be expected to react. This will convert $6.1 \%$ of the total biodiesel produced by the FAME plant into products. $0.2 \%$ of the biodiesel will be converted to 
methyl propionate; $1.7 \%$ of the biodiesel will be converted to dimethyl malonate that can be distilled to high purity for recovery; $1.4 \%$ of the biodiesel will be converted to methyl caproate that can be distilled and recovered; and the remaining biodiesel will either remain unreacted or will be present as nine-carbon methyl esters. These longer-chain products can be left in the biodiesel to act as a cold-flow additive and to dilute unsaturated methyl esters. This will give a premium biodiesel product that can be sold for an estimated $\$ 0.10$ per gallon more than standard biodiesel. The prices per pound for the methyl esters are taken to be the same as the costs per pound for the respective carboxylic acids. This is approximately correct if the cost of the methanol portion of the methyl esters is added to the cost of the acid portion of the esters.

The plant capacity is assumed to be 5 MMGY biodiesel, which was the approximate median plant size as of 2007 (29). The assumptions given above are listed in Table 57, along with the results of a brief economic analysis based on the PFD from Figure 70 and a PFD for a low-temperature biodiesel ozonolysis process as shown in Figure 71. As can be seen from Table 57, the proposed ozonolysis process has a negative NPV when collocated with a 5-MMGY biodiesel plant.

The reason for the negative NPV is that the costs of the raw materials are greater than the selling prices of the products, even using 2005 values. Analysis of the overall process reveals that the losses are almost entirely due to the biodiesel ozonolysis process. Olefin ozonolysis has been practiced commercially since at least the 1950s for production of cosmetics (15). However, in traditional olefin ozonolysis, the products are high-purity specialty carboxylic acids or

Table 57. Results of Economic Analysis and Assumptions Used to Construct Economic Analysis

Assumptions, glycerol reactor (single-pass values)

$\begin{array}{ll}\text { Glycerol Conversion, single-pass } & 37 \%\end{array}$

Aqueous Aldehyde Yield, per pound glycerol basis $\quad 13 \%$

Methyl Ester Yield, per pound glycerol basis $\quad 30 \%$

Glycerol Recycle Efficiency $\quad 90 \%$

$\begin{array}{ll}\text { Excess Ozone } & 20 \%\end{array}$

Assumptions, biodiesel ozonolysis reactor

$\begin{array}{ll}\text { Biodiesel Conversion (mole percent) } & 6.10 \%\end{array}$

Methyl Propionate Yield, per mole biodiesel basis $\quad 0.18 \%$

Dimethyl Malonate Yield $\quad 1.74 \%$

Methyl Caproate Yield $\quad 1.38 \%$

C9 Concentration in Premium Biodiesel Product $\quad 2.72 \%$

Results $^{1}$

Capital Cost (5 MMGY biodiesel capacity) $\$ 12,900,000$

20 -year Net Present Value vs. FAME Process $\quad-\$ 38,000,000$

Discounted Rate of Return N/A

Discounted Payback Period N/A

${ }^{1}$ All results are calculated assuming a 10-year modified accelerated cost reduction system (MACRS) depreciation and a 20-year plant life. 


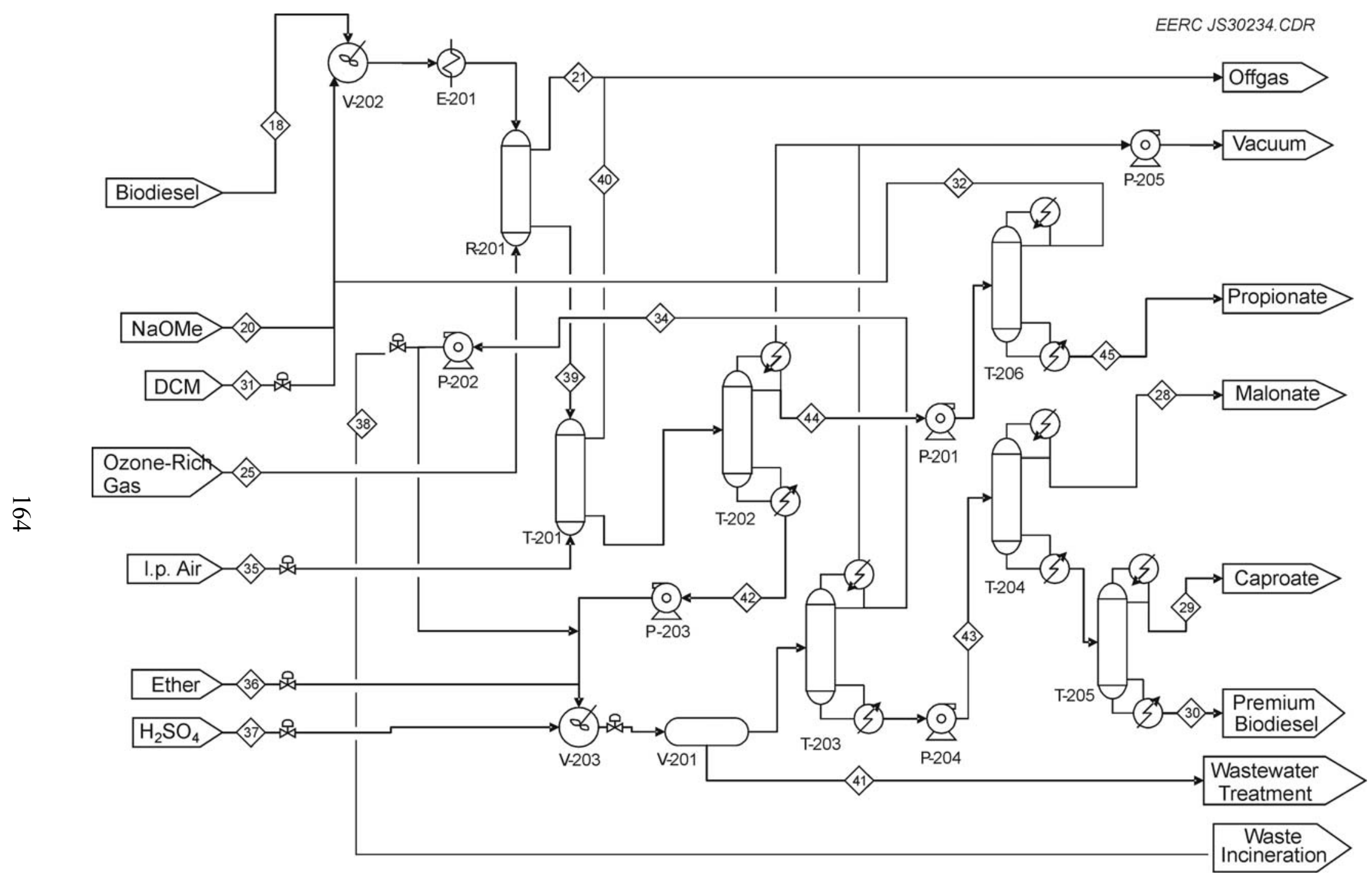

Figure 71. Biodiesel ozonolysis plant with fractionation to recover separate products. 
aldehydes that can be sold for a high price. While such products are likewise produced in this scenario, a significant fraction of the ozonolysis products are left undistilled in the biodiesel to act as a fuel additive. The estimated selling price for the resulting premium biodiesel blend is only $\$ 0.10 /$ gallon higher than is the selling price for base biodiesel, which presents a negative gross profit in terms of revenue minus cost of raw materials.

In addition to producing chemical streams with a combined revenue lower than the cost of raw materials, the biodiesel ozonolysis process requires equipment that must be explosion-rated and must operate at extremely low temperatures. As such, the gross profit must be high to achieve a relatively short payback period. Thus, in general, biodiesel ozonolysis to produce fuel is unlikely to be economically viable on the commercial scale even with a positive gross profit.

The process economics can be improved if the biodiesel ozonolysis section of the plant is removed and the excess ozone from glycerol ozonolysis is instead sent to a collocated water treatment facility. Under this scenario, there is no revenue gained from the excess ozone, but there is also no cost of raw materials beyond what is required for glycerol ozonolysis. This would result in a positive gross profit on a basis of revenue minus cost of raw materials using the costs from 2005 presented in Figure 70. However, the process remains uneconomical in this simulation because of the costs of utilities, operating labor, taxes, and depreciation. Moreover, the price of glycerol has since risen substantially, making the process even less economically favorable.

A sensitivity analysis was performed on the example of a glycerol ozonolysis facility without a biodiesel ozonolysis facility, as this was the example with a positive gross profit. Economic sensitivity was determined by varying equipment costs, chemical market prices, utility costs, and number of new operators. Each of these variables is listed with the sensitivity range in Table 58. Fixed capital investment is varied between $-50 \%$ and $+100 \%$ because of the uncertainty in actual costs of equipment. Utility costs are varied more drastically, between $-80 \%$ and $+100 \%$, because much of the equipment was probably oversized and because of uncertainty in the actual electrical, steam, and water demands for each unit operation.

The baseline case assumes four new operators for 25 new unit operations added onto an existing 5-MMGY biodiesel facility, with auxiliary units such as pumps and heat exchangers for distillation counted as individual unit operations. This number was calculated by taking the number of operators needed for the plant shown in Figure 65 and subtracting the number of operators needed for the biodiesel portion of the plant $(30,31)$. This method may not be appropriate because the FAME biodiesel process is sufficiently simple that it likely requires fewer operators than expected, while a $220-1 \mathrm{~b} / \mathrm{h}$ ozone generator is so complicated that it likely requires more operators than expected. As such, it is unlikely that fewer than four new operators will be needed, but it is probable that more than four operators will be required. The sensitivity analysis was performed by allowing up to 14 new operators without allowing for fewer than four operators. The value of 14 was chosen as an upper limit because this is the number of operators required for the 25 stand-alone unit operations of the ozonolysis facility.

The uncertainty in each area-capital costs, utility costs, chemical market prices, and number of operators - was used to conduct a Monte Carlo simulation of process economics. The 
Table 58. Sensitivity Analysis Parameters

\begin{tabular}{lccc}
\hline & & \multicolumn{2}{c}{ Range } \\
\cline { 3 - 4 } Variable & Baseline & Min. & Max. \\
\hline Fixed Capital Investment & $\$ 6.6 \mathrm{MM}^{1}$ & $\$ 3.3 \mathrm{MM}$ & $\$ 13.2 \mathrm{MM}$ \\
Chemical Market Prices (cost/year) & & & \\
$\quad$ Raw Materials & $\$ 1.4 \mathrm{MM}$ & $\$ 720 \mathrm{M}^{2}$ & $\$ 2.9 \mathrm{MM}$ \\
$\quad$ Products & $\$ 2.0 \mathrm{MM}$ & $\$ 1.0 \mathrm{MM}$ & $\$ 4.0 \mathrm{MM}$ \\
Utility Costs & $\$ 664 \mathrm{M}$ & $\$ 130 \mathrm{M}$ & $\$ 1.3 \mathrm{MM}$ \\
Number of New Operators & 4 & 4 & 14 \\
\hline${ }^{1} \mathrm{MM}=$ million. & & & \\
${ }^{2} \mathrm{M}=$ thousand. & & &
\end{tabular}

results of the sensitivity analysis are displayed in Figure 72 . As can be seen, there were no scenarios encountered under which the glycerol ozonolysis process would have a positive NPV.

\section{Conclusions}

Vegetable oil ozonolysis in methanol to produce biodiesel cold-weather additives does not appear to be a technically feasible goal. Literature data show that removal of biodiesel contaminants such as steryl glucosides has a significant effect on filter plugging from soy biodiesel. The combined effect of cold-weather additives and biodiesel purification on $\mathrm{CP}$ and PP could be more pronounced than the effect of either variable alone, but this concept was not investigated in this study. Moreover, it is possible that existing cold-weather additives will be sufficiently effective when combined with purification that expensive and hazardous ozonolysis processes will not be justifiable for producing novel fuel additives.

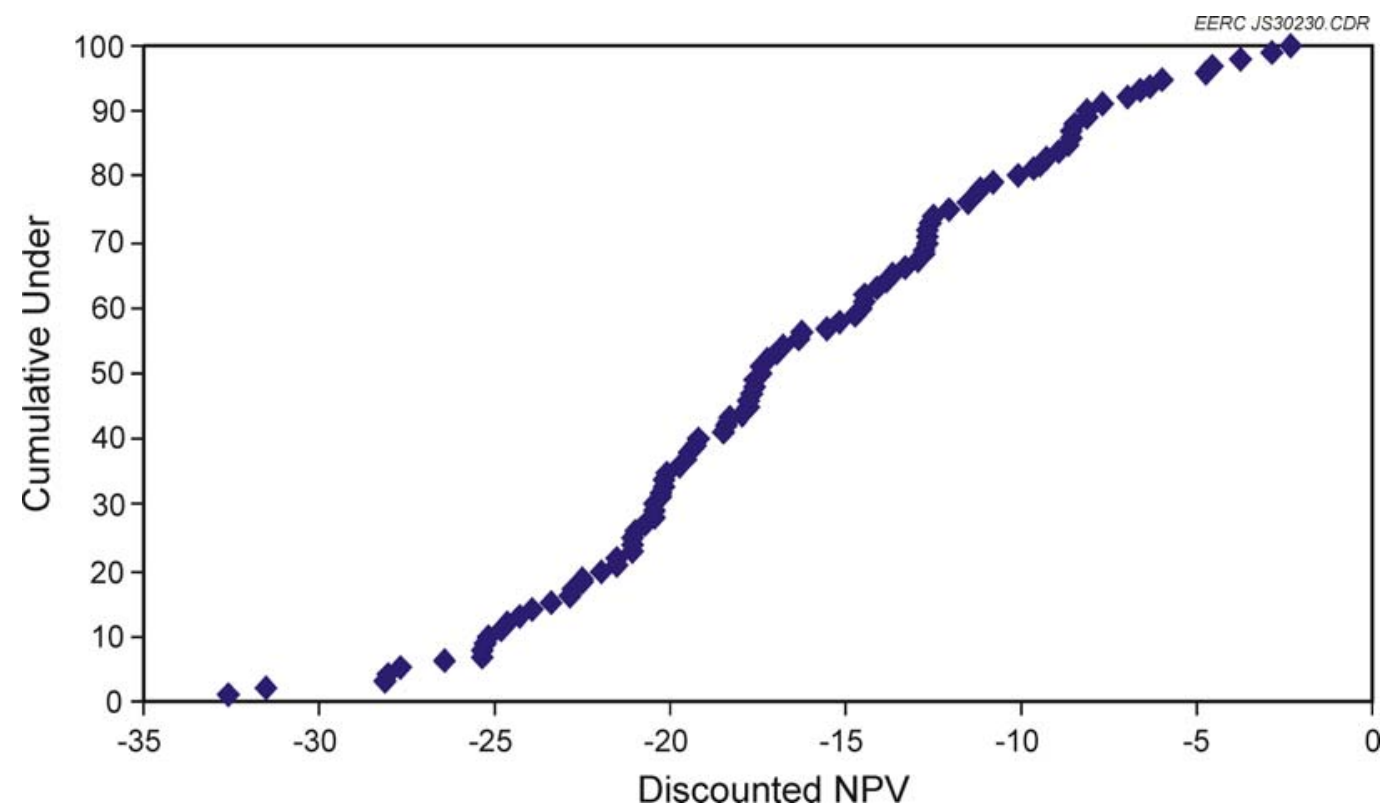

Figure 72. Results of 100-case Monte Carlo sensitivity analysis using parameters in Table 58. 
Glycerol ozonolysis is technically feasible and appears to be safer than traditional ozonolysis. However, the conversion efficiency and yield observed in this testing were low. Both properties could be potentially improved through process optimization. If optimization is attempted in future work, continuous reaction in a countercurrent columnar reactor with glycerol entering from the top and ozone entering from the bottom would be preferable to further study in a batch reactor, as reaction temperature and glycerol-to-ozone stoichiometry would both be more easily controlled. Moreover, a continuous countercurrent reactor would better represent the type of ozonolysis reactor likely to be used on a larger scale.

The feasibility of product separation remains uncertain. Glyoxal and formic acid are easily recovered during reaction, as they are significantly more volatile than glycerol or glyceryl esters and thus can be distilled during reaction and condensed downstream. However, heavier acid products form esters with available glycerol during ozonolysis and remain in the liquid state. If these esters can be easily transesterified with methanol to more volatile methyl esters, they can be distilled off of unreacted glycerol, which could then be recycled. Barring this, some more expensive method of separation may be necessary, or glycerol recycle may be limited.

The process economics for collocation of a glycerol ozonolysis plant with a 5-MMGY biodiesel plant are unfavorable. Given the high price of glycerol today, the process is unlikely to be economically favorable at any time in the foreseeable future.

If glycerol prices do drop at some point in time, or the cost of short-chain aldehydes and acids rises above the cost of glycerol, the proposed process could be improved through more efficient plant design. For instance, in the design used to conduct the economic assessment, all pumps and mixing drives are assumed to be electrically driven and to have one identical backup. If the motors could instead be powered by auxiliary streams, utility costs could be decreased. Mixers or pumps that are sized identically could have shared backup units, decreasing the plant's capital cost. This would indirectly improve yearly economics by reducing the depreciation costs. Similarly, there is no effort made to recover process heat, although in some cases one stream entering a reactor is preheated with steam while a second stream exiting the same reactor is cooled with water. If the two utility-driven heat exchangers were replaced by a single countercurrent heat exchanger, the utility, operator, and capital costs could be further decreased. Such changes could be sufficient to make the process economically favorable if glycerol prices drop to very low values or short-chain aldehydes and acids see dramatically increase cost and demand. However, at this point in time, the technical and economic obstacles to commercialization are too large to recommend any further work in the area of glycerol ozonolysis.

\section{References}

1. Chemical Profile: Glycerin. ICIS Chemical Business 2008, 273 (8), 38-39.

2. McCoy, M. Glycerin Surplus: Plants are Closing, and New Uses for the Chemical Are Being Found. Chem. Eng. News 2006, 8 (6) 7.

3. Millis, J. Glycerin - New Applications and Markets. Presented at 4th Annual World Congress on Industrial Biotechnology \& Bioprocessing, Orlando, FL, March 21-24, 2007. 
4. Melero, J.A.; van Grieken, R.; Morales, G.; Paniagua, M. Acidic Mesoporous Silica for the Acetylation of Glycerol: Synthesis of Bioadditives to Petrol Fuel. Energy Fuels 2007, 21, $1782-1791$.

5. Vanlerberghe, G.; Zysman, A.; Sebag, H. New Hemiacetal Compounds and the Applications Thereof. U.S. Patent No. 5,164,488, 1992.

6. Nimlos, M.R.; Blanksby, S.J.; Qian, X.; Himmel, M.E.; Johnson, D.K. Mechanisms of Glycerol Dehydration. J. Physic. Chem. A 2006, 110, 6145-6156.

7. Twombly, A.H. Composition Yielding Ozone. U.S. Patent No. 984,722, 1911.

8. Beal, R.E. Ozonization of Vegetable Oils in an Improved Aqueous Medium. U.S. Patent No. 3,504,038, 1970.

9. Marshall, J.A.; Garofalo, A.W. Oxidative Cleavage of Mono-, Di-, and Trisubstituted Olefins to Methyl Esters Through Ozonolysis in Methanolic NaOH. J. Org. Chem. 1993, $58,3675-3680$.

10. Ramachandran, S.; Rao, P.V.; Cornwell, D.G. New Method for the Reductive Ozonolysis of Double Bonds in Monoenoic Fatty Acid Methyl Esters. J. Lipid Res. 1968, 9, 137-139.

11. Khan, M.L.; Tomkinson, J.; Fitchett, C.S.; Black, M.J. Oxidative Cleavage of Unsaturated Oils and Products Obtained Therefrom. U.S. Patent No. 6,768,029 B1, 2004.

12. Hapeman, C.J.; Anderson, B.G.; Torrents, A.; Acher, A.J. Mechanistic Investigations Concerning the Aqueous Ozonolysis of Bromacil. J. Agric. Food Chem. 1997, 45, 10061011.

13. Pryde, E.H.; Anders, D.E.; Teeter, H.M.; Cowan, J.C. The Ozonization of Methyl Oleate. J. Org. Chem. 1960, 25 (4), 618-621.

14. Narazzo-Porro, M. Process for the Treatment of Hyperpigmentary Dermatoses. U.S. Patent No. 4,292,326, 1981.

15. Mirabal, J.M.; Menendez-Cepero, S.A.; Diaz-Rubi, V.F.; Ledea-Lozano, O.E.; DiazGomez, M.F.; Lezcano-Lastre, I. Method for Obtaining Ozonized Oils and Vegetable Fats and Use of Said Products for Pharmaceutical and Cosmetic Purposes. U.S. Patent Application No. 2006/0074129 A1, 2006.

16. Erickson, D.B.; Bassin, P. Rapeseed \& Crambe: Alternative Crops with Potential Industrial Uses. Bulletin 656, Agricultural Experiment Station, Kansas State University, Manhattan, KS, 1990.

17. Narayan, R.; Graiver, D.; Farminer, K.W.; Tran, P.T. Novel Triglycerides and Method of Preparation Thereof. U.S. Patent Application No. US 2006/0194974 A1, 2006. 
18. Soriano, N.U.; Migo, V.P.; Matsumura, M. Ozonized Vegetable Oil as Pour Point Depressant for Neat Biodiesel. Fuel 2006, 85, 25-31.

19. Baber, T.M.; Graiver, D.; Lira, C.T.; Narayan, R. Application of Catalytic Ozone Chemistry for Improving Biodiesel Product Performance. Biomacromolecules 2005, 6, 1334-1344.

20. Murakami, S.; Fujita, H. Process for Producing Fuel for Diesel Engine. International Patent No. WO 02/38708 A1, 2002.

21. Matsumura; Masatoshi; Murakami; Seishiro. Method and Equipment of Refining Plant Oil and Waste Vegetable Oil into Diesel Engine Fuel. U.S. Patent No. 6,364,917. 2002.

22. Lee, I.; Pfalzgraf, L.; Poppe, G.; Powers, E.; Haines, T. The Role of Sterol Glucosides on Filter Plugging. Biodiesel Magazine 2007, April.

23. Archer-Daniels Midland Company. Processes of Producing Biodiesel and Biodiesel Produced Therefrom. International Patent WO 2007/076163 A2. July 5, 2007.

24. Moreau, R.A. Scott, K.A. Haas, M.J. The Identification and Quantification of Steryl Glucosides in Precipitates from Commercial Biodiesel. JAOCS 2008, 85, 761-770.

25. Tang, H. Salley, S.O. Ng, K.Y.S. Fuel properties and precipitate formation at low temperature in soy-, cottonseed-, and poultry fat-based biodiesel blends. Fuel 2008, 87, 3006-3017.

26. Lemke, D. Syrupy Sweet Fuel: Biodiesel Processing Is Yielding Surpluses of Glycerin That May Be Burned for Energy. Ag Innovation News 2007, 16, 1.

27. Kirschner, M. Chemical Profile: Propionic Acid. Chemical Market Reporter 2006, 20-26, 30 .

28. Majerski, P.A.; Piskorz, J.K.; Radlein, D. Production of Glycolaldehyde Hydrous Thermolysis of Sugars. U.S. Patent Application No. US 2004/002912 A1, 2004.

29. Pearson, A. State of Biodiesel in the United States. Presented at Biomass '07: Power, Fuels, and Chemicals Workshop, Grand Forks, ND, May 15-16, 2007.

30. Alkhayat, W.A.; Gerrard, A.M. Estimating Manning Levels for Process Plants; AACE Transactions, I.2.1-I.2.4, 1984.

31. Turton, R.; Bailie, R.C.; Whiting, W.B.; Shaeiwitz, J.A. Analysis, Synthesis, and Design of Chemical Processes, 2nd Ed. Prentice Hall: Upper Saddle River, NJ, 2003. 


\section{Activity 2.5 - Guerbet Alcohol Condensation Process Development}

\section{Introduction}

The condensation of inexpensive methanol and ethanol offers a relatively simple way to produce higher alcohols, which can be used as fuel or fuel additives, and solvents. The reaction known as the Guerbet reaction produces higher-value 1-butanol from self-condensation of ethanol or a mixture containing 2-methyl-1-propanol and 1-propanol from a methanol-methanol mixture. In this direction, several catalysts were prepared and tested for the conversion of ethanol or an ethanol-methanol mixture to higher alcohols.

Butanol has not been commercialized as a fuel oxygenate primarily because of its cost of production. Made from petroleum, butanol sells wholesale for about \$2.75-\$3.00 a gallon. Butanol is used as a chemical intermediary in the production of latex paints, solvents, synthetic resins, plasticizers, and brake fluids, and the current U.S. butanol market is about 300 million gallons a year and predicted to grow at about $2.5 \%$ per year (1). Although butanol made from renewable resources should qualify for the same tax treatment as ethanol and butanol production from corn and other renewable feedstock, the economics of traditional butanol-from-starch technologies are not favorable. However, butanol can be produced from ethanol, and the economics may be viable. Conversion of ethanol to butanol and higher alcohols is achievable via a catalytic process (Guerbet reaction) that converts a lower-molecular-weight alcohol to a branched or linear higher-molecular-weight alcohol in the presence of an alkali metal alkoxide dissolved in the alcohol to be converted. However, the Guerbet reaction suffers an economic disadvantage because part of the starting alcohol is consumed by oxidation to the corresponding carboxylic acid.

An improvement in the Guerbet reaction uses a magnesium oxide, potassium carbonate, and copper chromite catalyst for converting, for example, ethanol to higher alcohols including 1-butanol, and 1-butanol to higher alcohols including 2-ethyl-1-hexanol (2), but the catalyst has a limited lifetime. Another improvement (3) uses a catalyst comprising sodium alkoxide mixed with $5 \%$ rhodium on alumina. Some other batch Guerbet reaction variations include water removal to improve yield and the use of an alkali metal hydroxide "catalyst" (4), the use of an alkali metal alcoholate/boric acid ester "catalyst" (5), the use of magnesium oxide (6), and the addition of a nickel "catalyst" to the metal alkoxide (7). A catalyst system suitable for continuous reactors was patented in 1994 (8). The primary catalyst for the process is inexpensive magnesium oxide. The process has not been commercialized because of past low oil prices, and commercialization would require optimization of the catalyst system and the overall process configuration.

Olson and coworkers designed and tested a series of novel carbon-based fixed-bed catalysts in a bench-scale, tubular-flow reactor (9). The evaluation showed that the new catalysts gave high yields of butanol from ethanol or other higher alcohols for mixed alcohol feeds. However, like all of the previous catalyst systems, it did not have a long lifetime. Conversion of the Guerbet products from ethanol and ethanol-methanol mixtures to esters was carried out, and evaluation of the esters as gasoline fuel additives was performed (10). The Guerbet products from ethanol can also be converted to ethers and certain types of esters that have very high- 
blending cetane numbers for diesel fuels (11-13). The processes described in these papers are compatible with the concept of an efficient parallel processing biorefinery (14). Recently, Sangi Corporation (Japan) obtained a U.S. patent (15) for the use of a hydroxyapatite (calcium phosphate) catalyst. The patent claims high yields of higher alcohols with little decrease in catalyst activity over time, but these claims have not been verified elsewhere.

The most successful catalysts so far have been multifunctional catalytic carbons with impregnated base; however, catalyst activity deteriorated somewhat over time. Therefore, regeneration of these catalysts as well as development of other less expensive catalysts with longer life is desired for the success of this process. The hydroxyapatite (calcium phosphate) catalyst used in Sangi's process has been reported to be effective in the conversion of ethanol to higher alcohols (16); however, research at the EERC has shown that synthesis of hydroxyapatite catalysts is time-consuming and yields are very low. Furthermore, these catalysts have higher selectivity for the formation of undesirable gaseous product (17).

Therefore, modifications to the Sangi catalyst were performed to improve the catalyst yield, acidity/basicity, and/or higher hydrogen transfer activity. Carbon or surface-modified carbon-based catalysts were impregnated with active metals such as nickel or copper to improve the activity and selectivity of the catalysts. Modified catalysts were evaluated based on 1) conversion and selectivity of ethanol or methanol-ethanol mixture to higher alcohols, 2) catalyst life, 3) reaction rate, 4 ) space velocity, and 4) reaction temperature. The ease of catalyst regeneration was also investigated. The catalyst(s) that performed best based on these criteria will be tested in the future at pilot-scale facilities for large-scale production of higher alcohols.

\section{Goals and Objectives}

The EERC has recently conducted research on modified carbon-based catalysts to determine the commercial potential of producing higher alcohols from ethanol or a mixture of ethanol and methanol. The developed catalysts are intended to facilitate dehydrogenation of the feed alcohols, followed by condensation and hydrogenation of the aldehyde intermediates to form the desired higher alcohols.

\section{Experimental}

\section{Preparation of Catalysts}

Preparation of Carbon-Based Catalysts

A commercial carbon was chemically treated and activated to generate surface-modified carbon (SOF). These carbons were chemically impregnated with additives to generate catalysts (FM or SOFM). Hydrogenation potential of these catalysts was further improved by the addition of $3-5 \mathrm{wt} \%$ nickel or copper. 


\section{Preparation of Hydroxyapatite Catalysts}

Several methods were used to prepare hydroxyapatite catalysts as described below:

Procedure A: Initially, hydroxyapatite catalysts were prepared according to the procedure reported by Tsuchida et al. (15) and for alcohol(s) condensation reactions. Active metals such as copper, nickel, and platinum were incorporated into these catalysts to facilitate hydrogen transfer during the condensation reaction.

Procedure B: Calcium phosphate hydroxyapatite (HAP) catalysts were prepared using a variation of the Hall's method $(18,19)$ developed at the EERC. In this method, phosphoric acid was slowly added to calcium acetate solution, followed by precipitation of the catalyst by adding ammonium hydroxide until the $\mathrm{pH}$ of the slurry reached 10 to 11 . The amounts of calcium acetate and phosphoric acid were adjusted in order to obtain a $\mathrm{Ca} / \mathrm{P}$ ratio of 1.62 to 1.67. These HAP catalysts containing $\mathrm{Ni}$ or $\mathrm{Cu}(\mathrm{Cu}$ or $\mathrm{Ni} / \mathrm{Ca}$ ratio of 0.005 to 0.05$)$ incorporated into hydroxyapatite to improve the hydrogenation of intermediates were also prepared. The $\mathrm{Ni}$ - or $\mathrm{Cu}$-containing $\mathrm{HAP}$ catalysts were reduced in hydrogen flow at $500^{\circ} \mathrm{C}$. These catalysts were characterized by x-ray diffraction (XRD) analyses (Table 59).

Procedure C: The previously reported method for the preparation of HAP catalysts (15) showed poor selectivity for the production of desired higher alcohols. However, these catalysts showed a preferred selectivity for the formation of less desirable gaseous products. Also the methods were very tedious, requiring large amounts of water to produce small amounts of catalysts. In order to overcome these problems, a modified method based on the digestion of the concentrated slurry in a closed vessel was employed. This method required far less water, and the yield of the product catalyst was much higher. The methods described previously required large volumes of water, which made it difficult to produce larger quantities of HAP catalysts. Furthermore, the process was time consuming. A new method based on the digestion of the concentrated slurry in a closed system was employed. The catalyst was analyzed by XRD.

\section{Preparation of Alumina-Based Catalysts}

Several alumina supports (acidic, basic, and neutral) with a wide range of surface areas were used for preparing catalysts based on the work described by Yang et al. (20). In thismethod, nickel was supported on alumina support by impregnating an aqueous nickel(II) nitrate solution. The catalyst was heated in nitrogen flow to decompose the nitrate.

\section{Flow-Through Reactions at Ambient Pressure}

Initially, the experiments were performed using a $40-\mathrm{cm}$-long $(\mathrm{i} . \mathrm{d} .=1 \mathrm{~cm})$ stainless steel reactor. Figure 73 illustrates the design of the flow-through reaction experimental components. The reactor was packed with the desired catalyst and placed in a tubular furnace heated to $300^{\circ}-$ $400^{\circ} \mathrm{C}$. The inlet of the reactor was attached to a syringe pump and a source of nitrogen gas, and the outlet of the reactor was attached to two stainless steel traps. Once the reactor had attained the desired temperature, the syringe pump was used to deliver the alcohol solution (a mixture of 
Table 59. Effect of Preparative Technique on the Structure of the HAP Catalyst

\begin{tabular}{llc}
\hline Method & $\begin{array}{c}\text { Structure } \\
\text { Reactants were dissolved in } 4000 \mathrm{~cm}^{3} \text { water. Product was } \\
\text { evaporated to dryness at low temperature and heated in air } \\
\text { at } 500^{\circ} \mathrm{C} \text {. }\end{array}$ & $\begin{array}{c}\text { High crystalline } \\
\text { crystalline }\end{array}$ \\
\hline $\begin{array}{l}\text { Reactants were dissolved in } 4000 \mathrm{~cm}^{3} \text { water. Product was } \\
\text { filtered, dried, and heated in air at } 500^{\circ} \mathrm{C} .\end{array}$ & $\begin{array}{l}\text { Low-crystalline } \\
\text { hydroxyapatite }\end{array}$ & 1.65 \\
\hline $\begin{array}{l}\text { Reactants were dissolved in } 100 \mathrm{~cm}^{3} \text { water. Product was } \\
\text { evaporated to dryness at low temperature and heated in air } \\
\text { at } 500^{\circ} \mathrm{C} .\end{array}$ & $\begin{array}{l}\text { Low-crystalline } \\
\text { hydroxyapatite }\end{array}$ & 1.64 \\
\hline
\end{tabular}

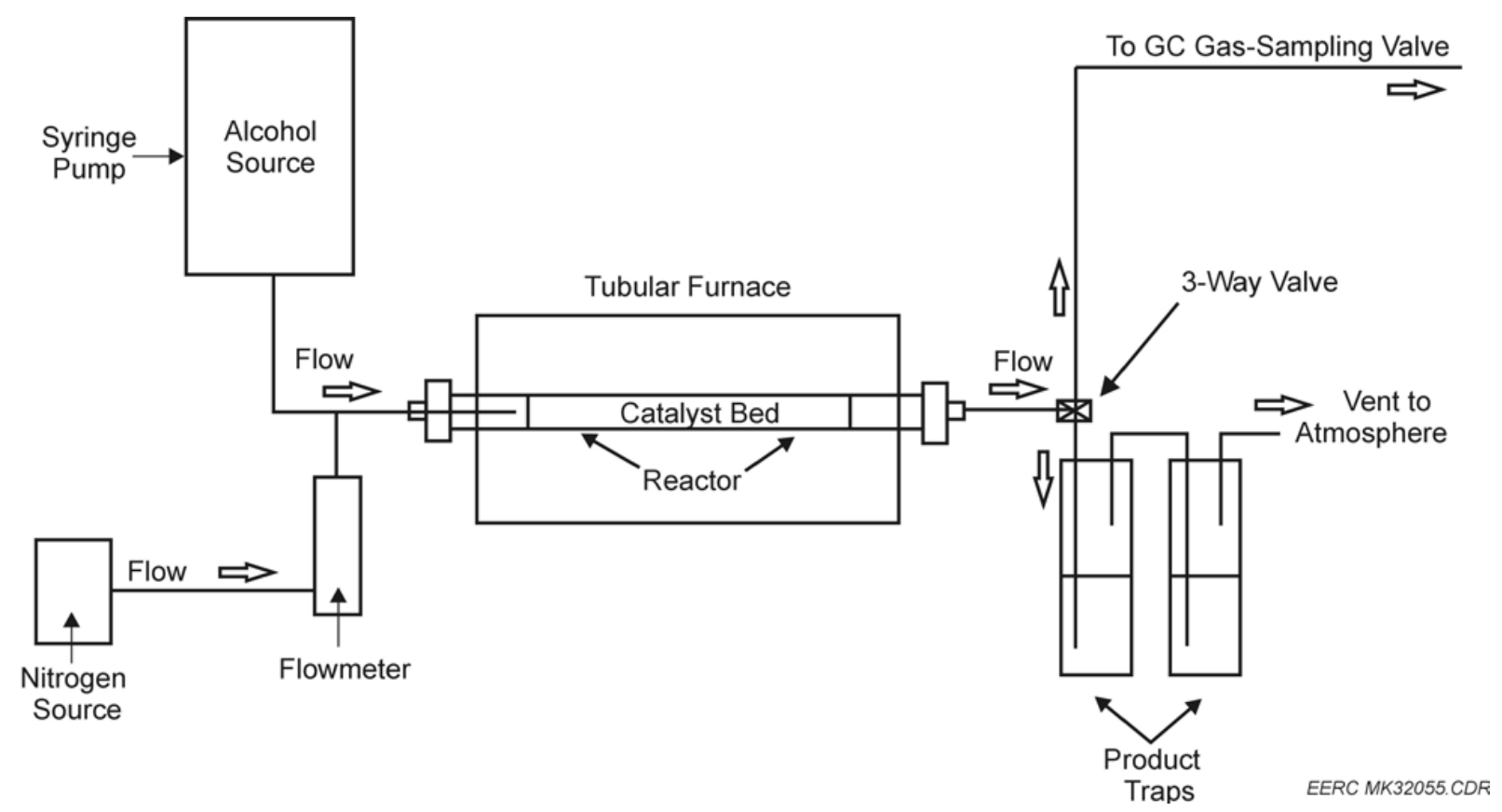

Figure 73. Schematic diagram of reactor system.

ethanol and methanol) to the catalyst bed at the desired rate of $0.1 \mathrm{~mL} / \mathrm{min}$. In order to facilitate the flow of the alcohol vapors through the catalyst bed, a gentle flow of nitrogen $\left(80 \mathrm{~cm}^{3} / \mathrm{min}\right)$ was passed through the reactor. The reaction products were then condensed in the two ice-cooled traps at the outlet of the reactor. The alcohol flow was stopped after the desired run time of $60 \mathrm{~min}$; however, the nitrogen flow was continued for an additional $15 \mathrm{~min}$ to flush out any remaining reaction products. The solvent in each of the two ice-cooled traps was then collected for analysis by GC-FID. At the completion of each test, the reactor was cooled to room temperature and the spent catalyst was removed and stored in a $20-\mathrm{mL}$ scintillation vial. Specific conditions of each test are shown in Table 60. 
Table 60. Yield of Ethanol Condensation Reactions with FM Catalyst

\begin{tabular}{lccccccc}
\hline $\begin{array}{l}\text { Temp., } \\
{ }^{\circ} \mathrm{C}\end{array}$ & $\begin{array}{c}\text { Conv., } \\
\text { \% }\end{array}$ & $\begin{array}{c}\text { 1-PrOH } \\
\text { Ether }\end{array}$ & $\begin{array}{c}\text { Mei-Bu } \\
\text { ErOH }\end{array}$ & $\begin{array}{c}\text { 2-Me-1- } \\
\text { 1-Butanal }\end{array}$ & i-Buhemiformal & Remainder \\
\hline 300 & 48.7 & 25.2 & 2.8 & 32.4 & 2.1 & 4.0 & 33.5 \\
325 & 56.7 & 20.3 & 4.2 & 41.1 & 2.8 & 4.3 & 27.3 \\
360 & 76.7 & 23.3 & 2.8 & 50.5 & 2.9 & 3.2 & 17.3 \\
380 & 90.9 & 15.5 & 2.3 & 55 & 2.7 & 10.0 & 14.5 \\
380 & 90.4 & 18.5 & 3.4 & 58 & 2.7 & 7.9 & 14.5 \\
400 & 94.2 & 21 & 3.2 & 62 & 2.7 & 7.7 & 3.4 \\
\hline
\end{tabular}

- Light fraction consisted of methanal, ethanal, and propanal; hydrogen; nitrogen; and light alkanes and alkenes. Because of the volatility of these components, analytical techniques in use did not permit quantification. A new GC has been installed. This GC will be used to analyze products directly, without using any solvent, to provide more complete and accurate quantification. These products along with unreacted alcohol(s) can be easily recycled.

- Percent conversion was calculated on the basis of ethanol remaining after reaction.

- Percent selectivity was calculated on the basis of ethanol used in the reaction.

- Percent rest was calculated by subtraction of known products from 100.

- 2-Me-1-propanal could not be resolved as it coeluted with 1-PrOH.

\section{Results and Discussion}

\section{Evaluation of Carbon Catalysts}

- A 36-inch-long (0.5-inch and 1-inch-o.d.) reactor equipped with stainless steel traps was fabricated (Figures 74-76). These reactors were used to carry out reactions as well as product collection under pressure if needed.

- Carbon catalysts were tested using a new temperature-programmable furnace and reactor (0.5-inch-o.d.) using various feed compositions, space velocities, and temperatures in order to improve the conversion and selectivity of condensation reactions. The products were collected in two ice-cooled traps. The second trap contained $10 \mathrm{~cm}^{3}$ of water. After the second trap, a gas bag was attached to collect the product gas.

- Liquid and gaseous products were weighed in order to determine percentage yields.

- The products from reactions of a methanol-ethanol mixture were identified completely by calibrated-GC-MS data. The percent yields and composition data are given in Tables 61-67. 


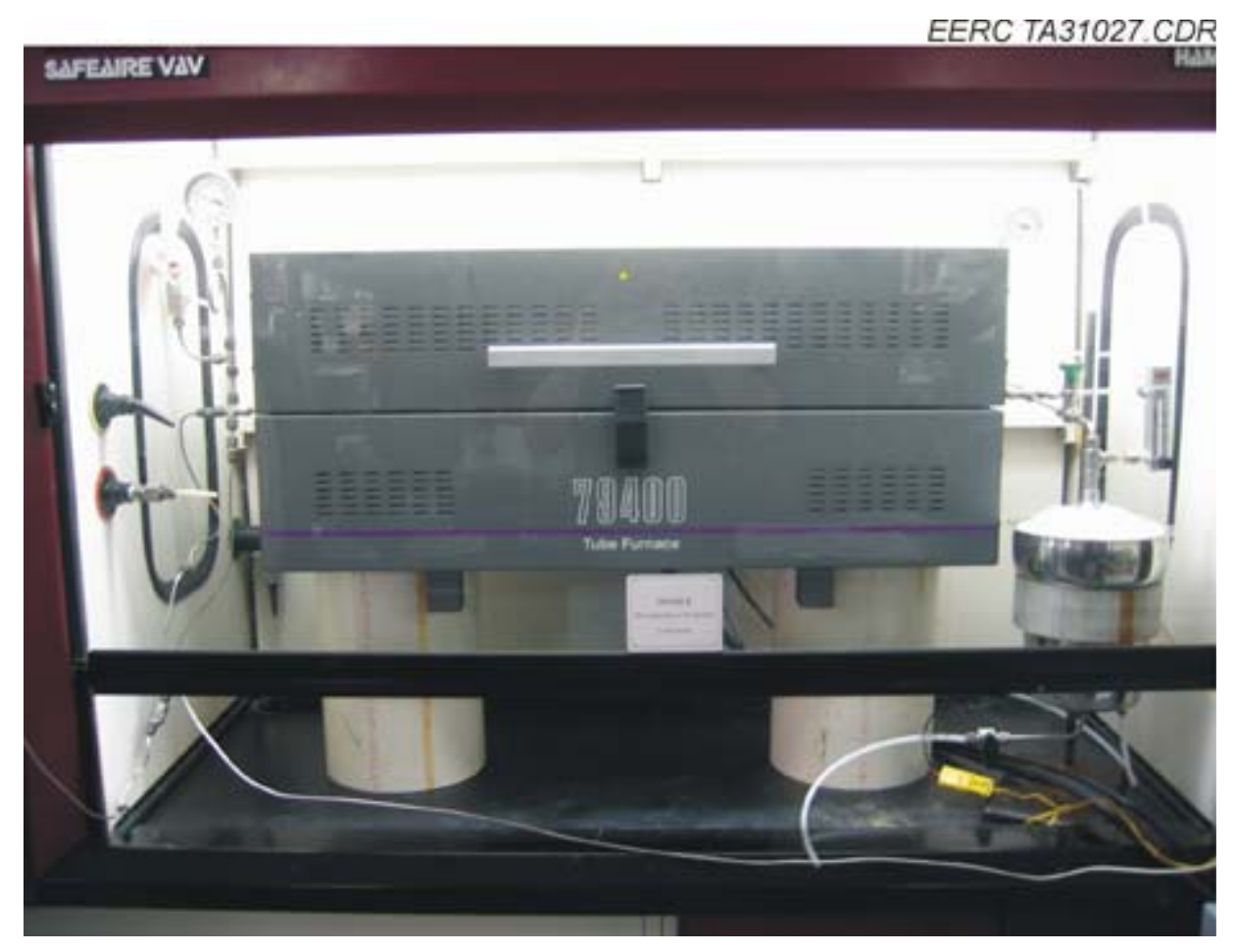

Figure 74. Reactor system.

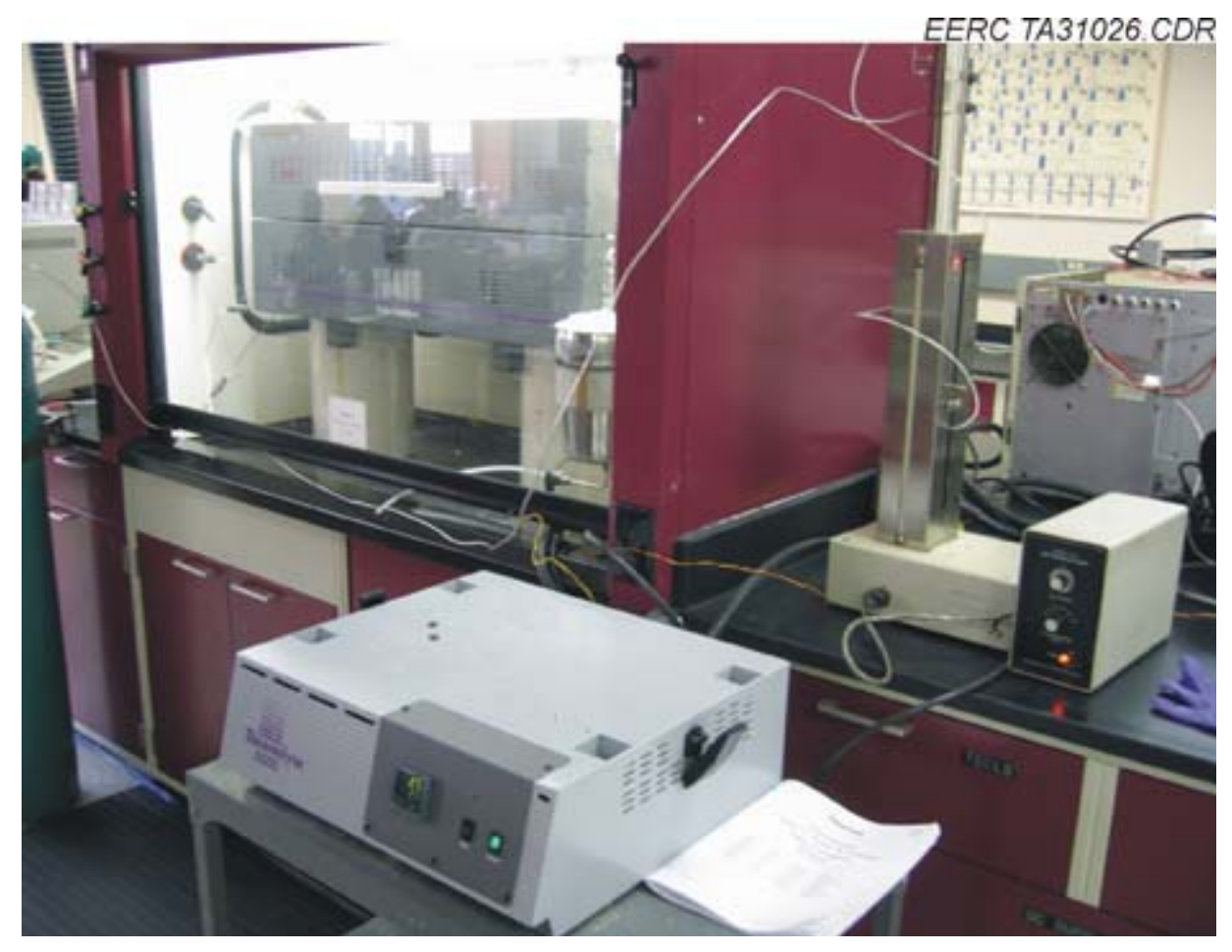

Figure 75. Feedstock pump system. 


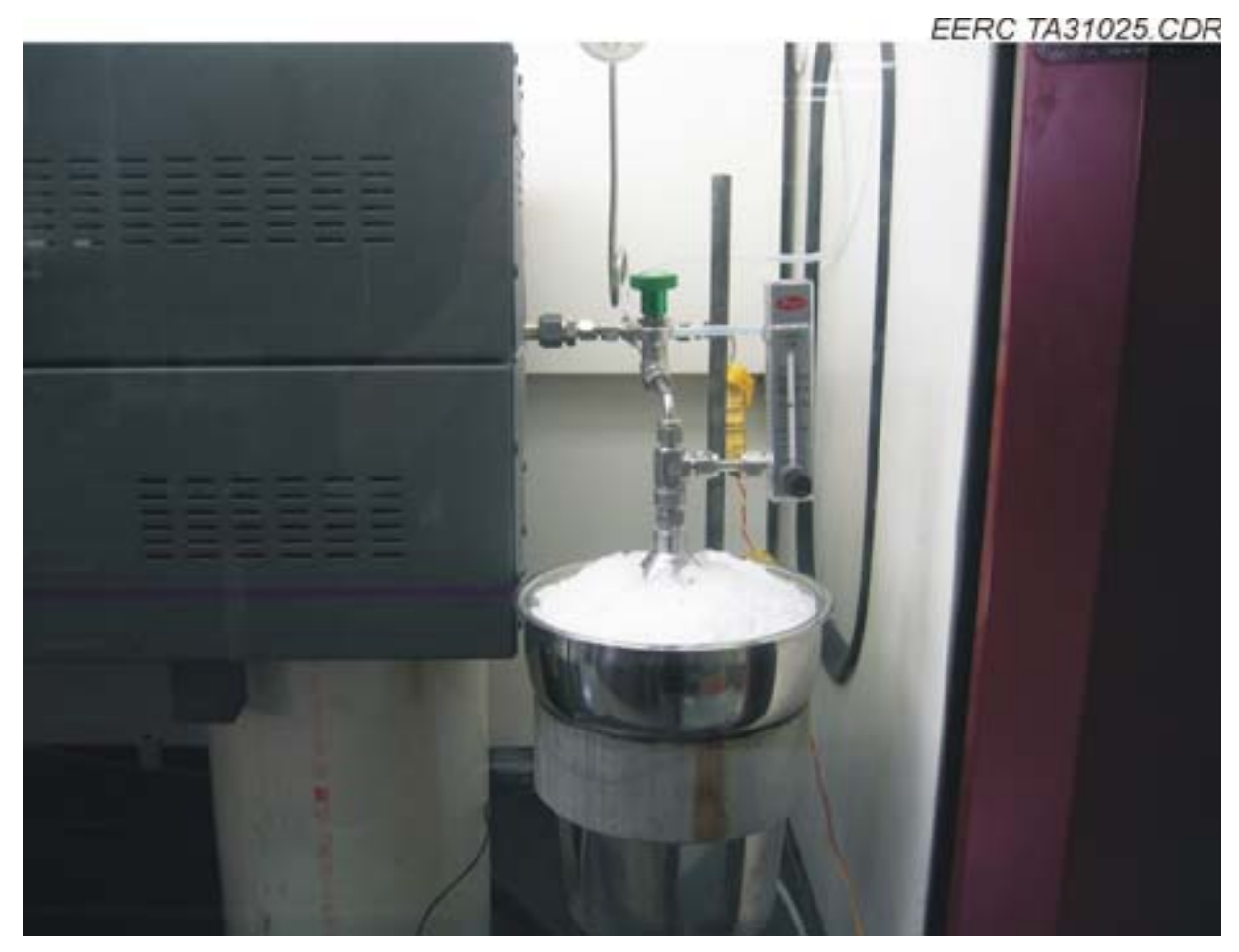

Figure 76. Product condensation.

Table 61. Percent Selectivity of Ethanol Condensation Reactions With FM Catalyst

\begin{tabular}{lcc}
\hline Temp., ${ }^{\circ} \mathrm{C}$ & Ethanol Conv., $\%$ & Selectivity, $\%$ \\
\hline 300 & 16 & 58 \\
325 & 20 & 51 \\
360 & 47 & 38 \\
380 & 59 & 20 \\
400 & 65 & 14 \\
\hline
\end{tabular}

Table 62. Product Distribution of Ethanol Condensation with FM Catalyst

\begin{tabular}{lcccc}
\hline Temp., ${ }^{\circ} \mathrm{C}$ & Ethanol Conv., $\%$ & \multicolumn{3}{c}{ Product Distribution, \% } \\
\hline 300 & & Light & 1-Butanol & Remainder \\
325 & 16 & 16 & 58 & 26 \\
360 & 20 & 12 & 51 & 37 \\
380 & 47 & 10 & 38 & 52 \\
400 & 59 & 8 & 20 & 72 \\
\hline
\end{tabular}


Table 63. Product Distribution of Methanol/Ethanol Condensation

\begin{tabular}{lccccc}
\hline Temp., & $\begin{array}{c}\text { Ethanol Conv., } \\
{ }^{\circ} \mathrm{C}\end{array}$ & \multicolumn{4}{c}{ Product Distribution, \% } \\
\cline { 3 - 6 } & 48.7 & 0 & 25.2 & 32.4 & 42.4 \\
\hline 300 & 56.7 & 0 & 20.3 & 41.1 & 38.6 \\
325 & 76.7 & 0 & 23.3 & 50.5 & 26.2 \\
360 & 90.9 & 0 & 15.5 & 55 & 29.5 \\
380 & 90.4 & 0 & 18.5 & 58 & 23.5 \\
380 & 94.2 & 0 & 21 & 62 & 17 \\
400 & & & & &
\end{tabular}

Table 64. Product Distribution of Methanol/Ethanol Condensation Reactions

Catalyst $=$ SOFM

Bed Length $=30 \mathrm{~cm}^{3}$, volume $=20.8 \mathrm{~cm}^{3}$

\begin{tabular}{lcccccc}
\hline Temp., ${ }^{\circ} \mathrm{C}$ & \multicolumn{2}{c}{ Feed, $\mathrm{g}$} & Conv., $\%$ & \multicolumn{3}{c}{ Product Distribution, g \% } \\
\hline \multirow{3}{*}{350} & Methanol & Ethanol & & Liquid & Gas & \% Recovery \\
\cline { 2 - 7 } & 10.52 & 2.12 & 52 & 12.8 & 0 & 100 \\
400 & & & & $(100)$ & $(0)$ & \\
& 10.52 & 2.12 & \multirow{2}{*}{80} & 9.43 & 0.93 & 82 \\
& & & & $(74.6)$ & $(7.4)$ & \\
\hline
\end{tabular}

Table 65. Percent Selectivity of Condensation of Methanol-Ethanol Mixture

Catalyst $=$ SOFM

Ethanol

Temp., Conv., Reacted, ${ }^{\circ} \mathrm{C} \quad \% \quad \mathrm{mmol}$

$\begin{array}{lll}350 & 52 & 23.9\end{array}$

400

80

36.3

$\mathrm{A}=1$-propanol.

$\mathrm{B}=1$-propanal.

$\mathrm{C}=$ 2-methyl-1-propanol.

$\mathrm{D}=2$-methyl-1-propanal.

$\mathrm{E}=$ isobutyl hemiacetal.

* = 1-butanol.
Liquid Products, \% yield

(\% selectivity)

\begin{tabular}{ccccccc} 
A & B & C & D & E & Remainder & Water \\
\hline 43.1 & 6.7 & 17.1 & 6.7 & $7.58^{*}$ & 18.8 & 30.4 \\
$(43.1)$ & $(6.7)$ & $(17.1)$ & $(6.7)$ & $(7.5)$ & $(18.8)$ & \\
19.0 & 6.1 & 43.3 & 1.9 & 2.2 & 2.2 & 41.9 \\
$(25.5)$ & $(8.1)$ & $(57.9)$ & $(2.6)$ & $(3.0)$ & $(3.0)$ & \\
\hline
\end{tabular}


Table 66. Product Distribution of Methanol-Ethanol Condensation Reactions

\begin{tabular}{|c|c|c|c|c|c|c|c|c|}
\hline \multicolumn{9}{|c|}{ Catalyst $=\mathrm{FM}$} \\
\hline $\begin{array}{l}\text { Run } \\
\text { No. }\end{array}$ & $\begin{array}{l}\text { Temp., } \\
{ }^{\circ} \mathrm{C}\end{array}$ & $\begin{array}{l}\text { Nitrogen } \\
\text { Flow, }\end{array}$ & \multicolumn{2}{|c|}{ Feed, g } & $\begin{array}{c}\text { Conv., } \\
\%\end{array}$ & \multicolumn{3}{|c|}{$\begin{array}{l}\text { Product Distribution } \\
\mathrm{g}(\%)\end{array}$} \\
\hline & & & Methanol & Ethanol & & Liquid & Gas & $\begin{array}{c}\% \\
\text { Recovery }\end{array}$ \\
\hline $1 *$ & 400 & 80 & 6.16 & 0 & - & $\begin{array}{r}4.32 \\
(70.2)\end{array}$ & $\begin{array}{r}0.91 \\
(14.9)\end{array}$ & 85.1 \\
\hline $2 * *$ & 400 & 80 & 5.26 & 1.06 & 62 & $\begin{array}{r}4.62 \\
(72.34)\end{array}$ & $\mathrm{ND}^{1}$ & - \\
\hline $3 * * *$ & 400 & 80 & 11.52 & 2.12 & 69 & $\begin{array}{c}11.4 \\
(90.4)\end{array}$ & ND & - \\
\hline $4 * * * *$ & 400 & 160 & 5.26 & 1.06 & 73 & $\begin{array}{r}4.40 \\
(69.6)\end{array}$ & ND & - \\
\hline & 400 & 80 & 5.59 & 1.12 & 86 & $\begin{array}{c}5.17 \\
(77.05) \\
\end{array}$ & ND & - \\
\hline
\end{tabular}

\footnotetext{
${ }^{1}$ Not determined.

* = Methanol alone was used as feed. Only formaldehyde was identified as major product.

$* *=$ Hydrogen was used as carrier gas.

$* * *=$ Feed flow was doubled.

$* * * *=$ Nitrogen flow was doubled.
}

Table 67. Effect of Reaction Conditions on the Condensation of Alcohols

\begin{tabular}{|c|c|c|c|c|c|c|c|c|c|}
\hline \multicolumn{10}{|c|}{ Catalyst $=\mathrm{FM}$} \\
\hline \multirow[t]{2}{*}{$\begin{array}{l}\text { Temp. } \\
{ }^{\circ} \mathrm{C}\end{array}$} & \multirow[t]{2}{*}{$\begin{array}{c}\text { Conv., } \\
\%\end{array}$} & \multirow[t]{2}{*}{$\begin{array}{c}\text { Ethanol } \\
\text { Reacted, } \\
\text { mmol }\end{array}$} & \multicolumn{7}{|c|}{$\begin{array}{l}\text { Liquid Products, \% yield } \\
\text { (\% selectivity) }\end{array}$} \\
\hline & & & $\begin{array}{c}1- \\
\mathrm{PrOH}\end{array}$ & $\begin{array}{c}1- \\
\text { Propanal }\end{array}$ & $\begin{array}{c}2-\mathrm{Me}- \\
1- \\
\mathrm{PrOH}\end{array}$ & $\begin{array}{l}\text { 2-Me-1- } \\
\text { Propanal }\end{array}$ & Isobutylhemiacetal & Water & Remainder \\
\hline $400^{*}$ & - & 0 & - & - & - & - & - & - & - \\
\hline $400^{* *}$ & 62 & 14.3 & $\begin{array}{c}14.7 \\
(20.2)\end{array}$ & $\begin{array}{c}7.7 \\
(10.6)\end{array}$ & $\begin{array}{c}37.8 \\
(51.9)\end{array}$ & $\begin{array}{c}6.3 \\
(8.7)\end{array}$ & $\begin{array}{c}2.1 \\
(2.9)\end{array}$ & $\begin{array}{c}4.2 \\
(5.8)\end{array}$ & 17.0 \\
\hline $400^{* * *}$ & 69 & 31.7 & $\begin{array}{l}23.0 \\
(28.7)\end{array}$ & $\begin{array}{c}6.3 \\
(7.9)\end{array}$ & $\begin{array}{c}38.5 \\
(48.0)\end{array}$ & $\begin{array}{c}6.9 \\
(8.7)\end{array}$ & $\begin{array}{c}0.6 \\
(0.8)\end{array}$ & $\begin{array}{c}4.7 \\
(5.9)\end{array}$ & 40.0 \\
\hline $400^{* * * *}$ & 73 & 16.7 & $\begin{array}{l}16.8 \\
(24.1)\end{array}$ & $\begin{array}{c}7.8 \\
(11.2)\end{array}$ & $\begin{array}{c}32.3 \\
(46.7)\end{array}$ & $\begin{array}{c}7.8 \\
(11.2)\end{array}$ & $\begin{array}{c}2.4 \\
(3.4)\end{array}$ & $\begin{array}{c}2.5 \\
(3.4)\end{array}$ & 18.3 \\
\hline 400 & 86 & 20.9 & $\begin{array}{c}14.8 \\
(19.1)\end{array}$ & $\begin{array}{c}5.3 \\
(6.8)\end{array}$ & $\begin{array}{c}43.1 \\
(55.6)\end{array}$ & $\begin{array}{c}3.8 \\
(4.9)\end{array}$ & $\begin{array}{c}2.9 \\
(3.7)\end{array}$ & $\begin{array}{c}7.7 \\
(9.9)\end{array}$ & 26.0 \\
\hline
\end{tabular}

$*=$ Methanol alone was used as feed. Only formaldehyde was identified as major product.

$* *=$ Hydrogen was used as carrier gas.

$* * *=$ Feed flow was doubled.

$* * * *=$ Nitrogen flow was doubled. 
- The products in the gas bag consisted of hydrogen, nitrogen, carbon monoxide, carbon dioxide, and light alkanes and alkenes. These products along with unreacted alcohol(s) can be easily recycled.

- The product in the first trap consisted of water, formaldehyde, 1-propanal, 2-methyl1-propanal, 1-propanol, 2-methyl-1-propanol, and hemiacetal. There were some unidentified products.

- The products in the second trap were methanol, ethanol, 1-propanol, 2-methyl-1-propanol, and small amounts of 1-propanal and 2-methylpropanal and hemiacetal.

- Alcohol fraction components are desired alcohols (1-propanol and isobutanol from methanol/ethanol or 1-butanol from ethanol reaction).

- The remainder consisted of alkenes, alkanes, ethers, hemiacetals, alcohols, and aldehydes $\left(\mathrm{C}_{4}-\mathrm{C}_{10}\right)$. These products can be mildly hydrogenated and used for blending with fuels.

- Formaldehyde, methanol, and ethanol can be separated from the product and recycled.

- Percent conversion was calculated on the basis of ethanol reacted (Table 65).

- Percent yield was calculated on the basis of ethanol reacted.

- Percent selectivity was calculated on the basis of liquid products recovered and ethanol reacted.

- Percent remainder was calculated from the peak areas of the unknown components in GC.

- Theoretical millimoles of water were calculated from the millimoles of products formed.

- Percent conversion was calculated on the basis of ethanol reacted.

- Percent yield was calculated on the basis of ethanol reacted.

- Percent selectivity was calculated on the basis of liquid products recovered and ethanol reacted.

- Percent remainder was calculated from the peak areas of the unknown components in GC.

- Theoretical mmoles of water were calculated from the mmoles of products formed.

- The major problem associated with the above procedure is that only $75 \%$ of the products could be condensed in the traps. The rest of the product escapes with the exit gas. Therefore, only a part of the product could be collected and analyzed. In order to overcome this problem and achieve a complete mass balance, a new GC with a gas valve was installed. The outlet of 
the reactor was directly attached to the $\mathrm{GC}$ via a heated line. This eliminated the need for solvent to trap the products. This GC was used to analyze products directly from the reactor without using any solvent to provide more complete and accurate quantification.

The experiments were conducted utilizing a high-temperature furnace, stainless steel reactor, GC, and various other plumbing components, as shown in Figure 73, to determine the potential applicability of the developed catalyst.

The stainless steel reactor was 2 feet long with an internal diameter of 0.5 inches and was used for conducting the catalytic experiments at atmospheric pressure. The reactor was packed with 20 grams of the carbon-based granular catalyst, resulting in a 12-inch catalyst bed length. The inlet of the reactor was attached to a pump to provide the ethanol-methanol feed mixture that was transported through the reactor via a nitrogen carrier gas. The outlet of the reactor was plumbed simultaneously to a liquid product-trapping mechanism consisting of two separate icecooled traps in series and also directly to a GC sampling valve inlet. A three-way valve was used to divert the product stream to either the condensation traps or GC valve. All lines exiting the reactor were heated with heat tape to inhibit condensation prior to entering the traps or the GC valve. The reactor was placed in a tubular furnace maintained at $400^{\circ} \mathrm{C}$. After the desired temperature was achieved, the methanol/ethanol $(5: 1 \mathrm{v} / \mathrm{v})$ mixture was pumped into the reactor at the desired flow rate of $8 \mathrm{~cm}^{3}$ per hour. The nitrogen carrier gas was passed through the reactor, carrying the alcohol vapors through the catalyst bed, at a flow rate of $70 \mathrm{~cm}^{3}$ per min. The products were then collected in the ice-cooled traps. A GC analysis was performed periodically by directing the gas products into the gas-sampling valve by manipulating the in-line three-way valve. The gas-sampling valve was capable of injecting a precisely graduated amount of sample $\left(1 \mathrm{~cm}^{3}\right)$ into the GC column. Calibrations of the expected products were conducted to accurately determine the composition of the resulting gas stream via the GC analysis.

The analysis of the feed mixture and the resulting products was carried out utilizing a GCFID and a GC-MS. The GC was instrumented with a 30-m-long narrow-bore DB-1 glass column with $0.320 \mathrm{~mm}$ i.d. and $0.25-\mu \mathrm{m}$ phase thickness. The GC-MS analysis was carried out using a 30 -m-long narrow-bore DB-5 glass column with $0.320 \mathrm{~mm}$ i.d. and $0.25-\mu \mathrm{m}$ phase thickness, supplied by J\&W Scientific. A solution comprising equal volumes of methanol, ethanol, propanol, isobutanol, and butanol was analyzed by utilizing the furnace and reactor setup design, under the same experimental conditions as used for the condensation reaction experiments, with no catalyst charged in the reactor. Four different flow rates of nitrogen, 50, 75, 100, and $150 \mathrm{~cm}^{3}$ per min, were used to create a calibration table. This calibration table was used for quantitative analysis of the condensation products obtained during the catalytic reactions.

The initial testing of the catalyst was performed over a period of approximately 31 hours, with the product stream being analyzed periodically. A breakdown of the product components is illustrated in Table 68. The desired alcohol, isobutanol, is low in concentration at the onset of the testing. However, as the reaction progresses, more and more isobutanol is formed and the undesirable products such as aldehydes get lower in concentration. After 24 hours of operation, the catalyst shows some loss of activity, as indicated by a slight decrease in isobutanol formation for the last 8 hours of testing. At the end of the 31-hour test, the catalyst was regenerated by heating the reactor to $400^{\circ} \mathrm{C}$ for 3 hours under a gentle flow of nitrogen. The thermally 
Table 68. Condensation Reaction Product Composition Utilizing Fresh FM Catalyst

\begin{tabular}{lccccccccc}
\hline & \multicolumn{2}{c}{ Feed Components } & \multicolumn{2}{c}{ Alcohol Components } & \multicolumn{2}{c}{ Aldehyde Components } & \multicolumn{3}{c}{ Other By-Products } \\
\hline $\begin{array}{l}\text { Time, } \\
\text { hr }\end{array}$ & $\begin{array}{c}\text { Methanol, } \\
\%\end{array}$ & $\begin{array}{c}\text { Ethanol, } \\
\%\end{array}$ & $\begin{array}{c}\text { Propanol, } \\
\%\end{array}$ & $\begin{array}{c}\text { Isobutanol, } \\
\%\end{array}$ & $\begin{array}{c}\text { Ethanal, } \\
\%\end{array}$ & $\begin{array}{c}\text { Propanal, } \\
\%\end{array}$ & $\begin{array}{c}\text { Isobutanal, } \\
\%\end{array}$ & $\begin{array}{c}\text { Unknown, } \\
\%\end{array}$ & $\begin{array}{c}\text { Water, } \\
\%\end{array}$ \\
\hline 0.2 & 3.39 & 0.40 & 0.20 & 0.42 & 6.97 & 1.44 & 1.14 & 84.76 & 1.28 \\
2.2 & 43.69 & 0.10 & 0.18 & 5.07 & 4.90 & 1.36 & 1.44 & 39.60 & 3.66 \\
4.0 & 59.29 & 0.24 & 0.39 & 7.83 & 3.80 & 1.32 & 1.34 & 20.78 & 5.01 \\
6.9 & 57.07 & 0.45 & 0.64 & 7.47 & 2.86 & 1.24 & 1.15 & 24.34 & 4.78 \\
8.0 & 66.13 & 0.78 & 0.97 & 8.63 & 2.62 & 1.30 & 1.24 & 12.81 & 5.52 \\
23.1 & 67.88 & 1.37 & 1.68 & 9.66 & 1.76 & 1.16 & 0.88 & 9.61 & 6.00 \\
28.8 & 77.29 & 1.86 & 1.92 & 8.75 & 1.77 & 1.23 & 0.84 & 0.71 & 5.63 \\
30.6 & 72.98 & 1.69 & 1.63 & 7.32 & 1.83 & 1.27 & 0.87 & 7.53 & 4.88 \\
\hline
\end{tabular}

* Water content is determined on a theoretical molar ratio basis of the condensation reaction components. 
regenerated catalyst was then tested for 22 hours under the same conditions as the first 31-hour test. The results of the regenerated catalyst are shown in Table 69. These results indicate that the regenerated catalyst does not have the initial lag in isobutanol formation as was seen in the testing of the fresh catalyst. In addition to the products listed in Tables 68 and 69, small concentrations of other alcohols, aldehydes, and oxygenates were also produced.

The amounts of ethanol conversion and product selectivity for both the fresh and regenerated catalysts are listed in Tables 70 and 71 . The results for the fresh catalyst illustrate a preferential selectivity for aldehydes, primarily ethanal, and lower selectivity for isobutanol in the first few hours of the test, as well as increasing isobutanol selectivity as the test progresses. However, the thermally regenerated catalyst has high selectivity for isobutanol from the onset of the testing, with lower selectivity for the less desirable aldehydes. In both the fresh and regenerated catalyst tests, the amount of ethanol conversion ranged from approximately $90 \%$ to just over $99 \%$, and in both cases, the conversion of ethanol gradually decreases throughout the duration of the test. This is likely the result of moderation of the active sites of the catalyst making it less active over time. The activity of the catalyst appears to be restored through the thermal regeneration process, as is illustrated with the higher conversion of ethanol in the first several hours of testing using the regenerated catalyst. It is also worth noting that the lowest ethanol conversion coincides with the highest selectivity for isobutanol and the lowest selectivity for aldehydes. This phenomenon is only observed with the fresh catalyst, as the selectivity of aldehyde and isobutanol appear to not be related to the percentage of ethanol conversion.

Figures 77 and 78 illustrate the selectivity for each major product component over the duration of the test for both the fresh and regenerated catalyst. Again, the decreasing selectivity for ethanal and the increasing selectivity for isobutanol over the first several hours of the test can be observed. The regenerated catalyst does not illustrate this change in selectivity and is relatively constant for the entire period of the test.

The two main product components of interest are isobutanol and ethanal. Tables 72 and 73 show the data for selectivity of these two components on the basis of ethanol conversion. Again, the selectivity for isobutanol gradually increases over time with the fresh catalyst to an approximate average of $60 \%$. The selectivity for ethanal illustrates an opposite trend, decreasing from $43 \%$ to just over $10 \%$. In the case of the regenerated catalyst, the selectivity for both isobutanol and ethanal remains relatively constant at approximate averages of $60 \%$ and $11 \%$, respectively.

Figures 79 and 80 illustrate the selectivity of isobutanol and ethanal for both the fresh and regenerated catalysts. The times of analysis were averaged and are plotted up to 22 hours for comparison. Again, the increasing selectivity for isobutanol is observed with the fresh catalyst and is relatively constant for the test utilizing the regenerated catalyst.

\section{Evaluation of Alumina Catalysts}

Using the tubular reactor system and alumina catalysts, attempts were made to replicate higher-alcohol production results reported by Yang et al. (20), with the objective of establishing a baseline for comparison with results from the EERC-developed catalysts. These catalysts were 
Table 69. Condensation Reaction Product Composition Utilizing Regenerated FM Catalyst

\begin{tabular}{|c|c|c|c|c|c|c|c|c|c|}
\hline & \multicolumn{2}{|c|}{ Feed Components } & \multicolumn{2}{|c|}{ Alcohol Components } & \multicolumn{3}{|c|}{ Aldehyde Components } & \multicolumn{2}{|c|}{ Other By-Products } \\
\hline $\begin{array}{l}\text { Time, } \\
\mathrm{hr}\end{array}$ & $\begin{array}{c}\text { Methanol, } \\
\%\end{array}$ & $\begin{array}{c}\text { Ethanol, } \\
\%\end{array}$ & $\begin{array}{c}\text { Propanol, } \\
\%\end{array}$ & $\begin{array}{c}\text { Isobutanol, } \\
\%\end{array}$ & $\begin{array}{c}\text { Ethanal, } \\
\%\end{array}$ & $\begin{array}{c}\text { Propanal, } \\
\%\end{array}$ & $\begin{array}{c}\text { Isobutanal, } \\
\%\end{array}$ & $\begin{array}{c}\text { Unknown, } \\
\%\end{array}$ & $\begin{array}{c}\text { Water,* } \\
\%\end{array}$ \\
\hline 0.3 & 61.49 & 0.19 & 1.79 & 8.95 & 2.08 & 1.03 & 0.87 & 18.00 & 5.60 \\
\hline 1.0 & 70.38 & 0.64 & 1.74 & 9.32 & 2.15 & 1.04 & 0.87 & 8.05 & 5.81 \\
\hline 2.0 & 73.50 & 1.22 & 1.40 & 8.630 & 1.82 & 1.02 & 0.82 & 6.29 & 5.33 \\
\hline 4.5 & 71.17 & 1.04 & 1.36 & 8.58 & 2.01 & 1.05 & 0.88 & 8.55 & 5.36 \\
\hline 7.0 & 74.96 & 1.39 & 1.72 & 9.74 & 1.87 & 1.01 & 0.81 & 2.53 & 5.97 \\
\hline 21.5 & 71.75 & 1.45 & 1.91 & 9.39 & 1.65 & 0.90 & 0.69 & 6.49 & 5.77 \\
\hline
\end{tabular}

* Water content is determined on a theoretical molar ratio basis of the condensation reaction components. 
Table 70. Ethanol Conversion Product Selectivity Utilizing Fresh FM Catalyst*

\begin{tabular}{lcccccc}
\hline $\begin{array}{l}\text { Time, } \\
\mathrm{hr}\end{array}$ & $\begin{array}{c}\text { Ethanol } \\
\text { Conversion, } \%\end{array}$ & $\begin{array}{c}\text { Ethanal, } \\
\%\end{array}$ & $\begin{array}{c}\text { Propanal, } \\
\%\end{array}$ & $\begin{array}{c}\text { Propanol, } \\
\%\end{array}$ & $\begin{array}{c}\text { Isobutanal, } \\
\%\end{array}$ & $\begin{array}{c}\text { Isobutanol, } \\
\%\end{array}$ \\
\hline 0.2 & 97.2 & 43.0 & 8.9 & 1.2 & 7.0 & 2.6 \\
2.2 & 99.1 & 29.7 & 8.4 & 1.1 & 8.7 & 30.7 \\
4.0 & 98.2 & 23.2 & 8.1 & 2.4 & 8.2 & 47.8 \\
6.9 & 96.9 & 17.6 & 7.6 & 4.0 & 7.1 & 46.2 \\
8.0 & 95.0 & 16.5 & 8.0 & 6.1 & 7.8 & 54.5 \\
23.1 & 91.4 & 11.5 & 7.1 & 11.0 & 5.7 & 63.4 \\
28.8 & 88.5 & 11.9 & 7.6 & 13.0 & 5.7 & 59.4 \\
30.6 & 89.5 & 12.2 & 7.8 & 11.0 & 5.7 & 49.1 \\
\hline
\end{tabular}

* Selectivity was calculated on the basis of reacted ethanol and does not include water.

\begin{tabular}{|c|c|c|c|c|c|c|}
\hline $\begin{array}{l}\text { Time, } \\
\mathrm{hr}\end{array}$ & $\begin{array}{c}\text { Ethanol } \\
\text { Conversion, } \\
\%\end{array}$ & $\begin{array}{c}\text { Ethanal, } \\
\%\end{array}$ & $\begin{array}{c}\text { Propanal, } \\
\%\end{array}$ & $\begin{array}{c}\text { Propanol, } \\
\%\end{array}$ & $\begin{array}{c}\text { Isobutanal, } \\
\%\end{array}$ & $\begin{array}{c}\text { Isobutanol, } \\
\%\end{array}$ \\
\hline 0.3 & 98.9 & 12.8 & 6.2 & 10.8 & 5.3 & 55.0 \\
\hline 1.0 & 96.2 & 13.4 & 6.5 & 10.9 & 5.4 & 58.9 \\
\hline 2.0 & 92.7 & 11.8 & 6.6 & 9.1 & 5.3 & 56.4 \\
\hline 4.5 & 93.7 & 12.9 & 6.8 & 8.8 & 5.7 & 55.7 \\
\hline 7.0 & 91.7 & 12.2 & 6.6 & 11.3 & 5.3 & 64.5 \\
\hline 21.5 & 91.3 & 10.9 & 5.9 & 12.6 & 4.5 & 62.5 \\
\hline
\end{tabular}

*Selectivity was calculated on the basis of reacted ethanol and does not include water.

evaluated in tests with ethanol and ethanol-methanol feedstock. Contrary to the results of Yang et al., ethanol conversion to products was very low $(5 \%-12 \%)$ at $200^{\circ} \mathrm{C}$. However, the selectivity to 1 -butanol was $60 \%$. At higher temperatures $\left(300^{\circ}-350^{\circ} \mathrm{C}\right)$, the conversion was up to $100 \%$, but the selectivity to 1 -butanol was $<10 \%$. Most of the ethanol was converted into light hydrocarbons. A possible explanation for these results could derive from dehydration caused by the high acidity of gamma alumina at elevated temperatures.

\section{Evaluation of HAP Catalysts}

The screening of these catalysts for the condensation of the ethanol and methanol mixture to higher alcohols was carried out at $200^{\circ}-350^{\circ} \mathrm{C}$.

Condensation of ethanol containing pentane as an internal standard was carried out. On the basis of initial screening tests conducted so far, Ni-containing HAP catalyst gave the best conversion of $60 \%$ of ethanol into products. The products were acetaldehyde $(35 \%)$, 1-butanol $(11 \%)$, and other products $(15 \%)$. The extensive testing of HAP catalysts prepared by a variety of techniques indicated a high conversion of the alcohol(s) used, but the selectivity to produce desired alcohol was poor. These catalysts produced a large amount of gaseous product. Further testing of the HAP catalysts was abandoned. 


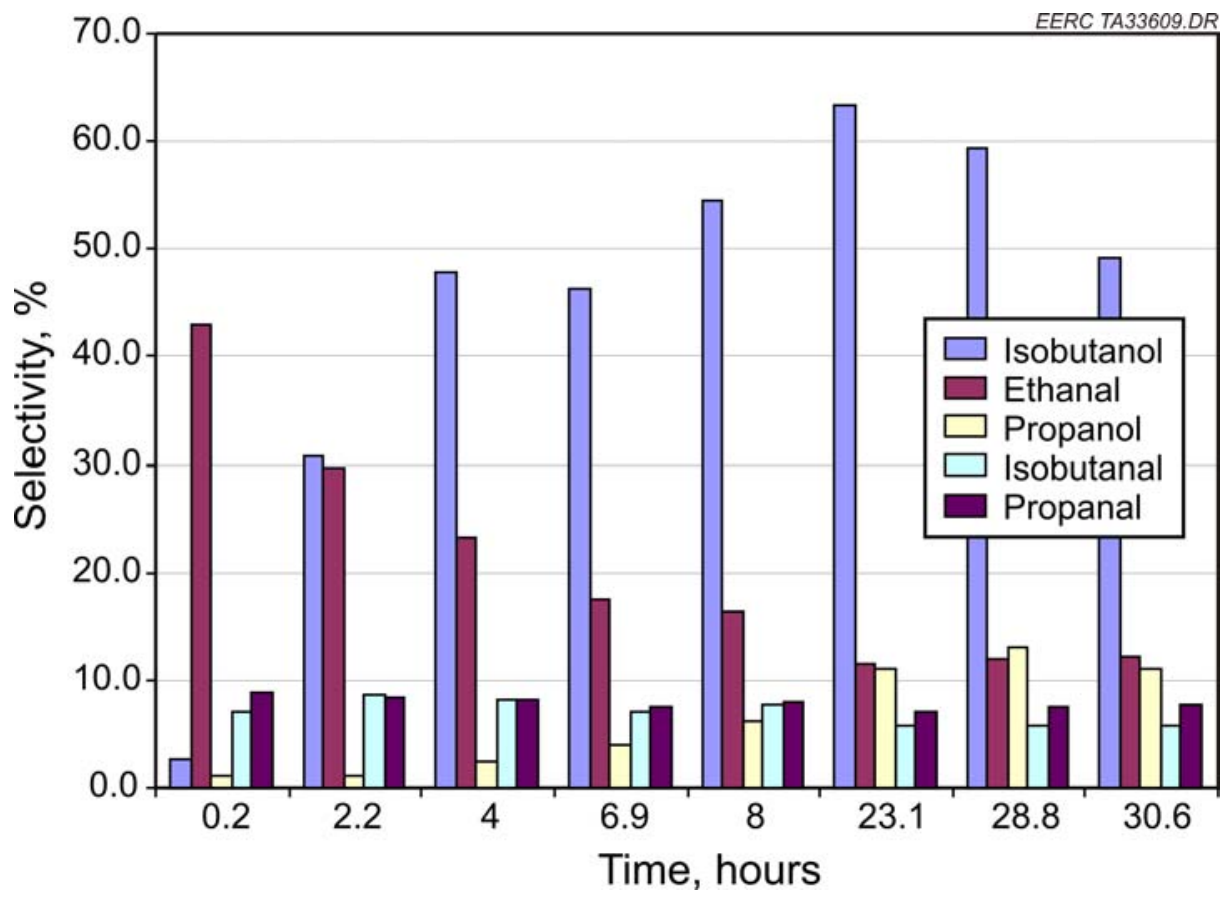

Figure 77. Percent selectivity of condensation reactions FM catalyst.

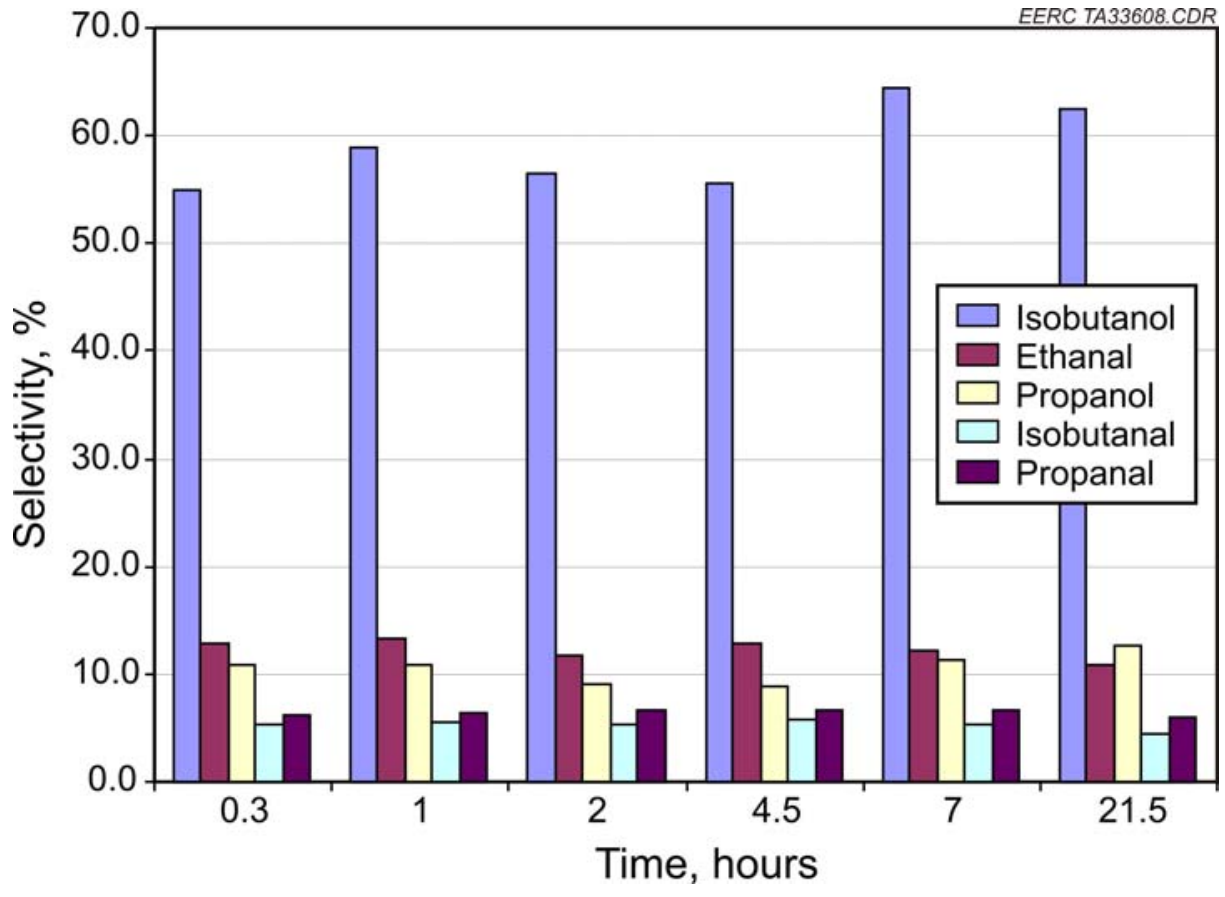

Figure 78. Ethanol conversion product selectivity with regenerated FM catalyst. 
Table 72. Selectivity for Isobutanol and Ethanal Using Fresh FM Catalyst*

\begin{tabular}{lccc}
\hline $\begin{array}{l}\text { Time, } \\
\mathrm{hr}\end{array}$ & $\begin{array}{c}\text { Ethanol } \\
\text { Conversion, \% }\end{array}$ & $\begin{array}{c}\text { Isobutanol } \\
\text { Selectivity, \% }\end{array}$ & $\begin{array}{c}\text { Ethanal } \\
\text { Selectivity, \% }\end{array}$ \\
\hline 0.2 & 97.2 & 2.6 & 43.0 \\
2.2 & 99.1 & 30.7 & 29.7 \\
4.0 & 98.2 & 47.8 & 23.2 \\
6.9 & 96.9 & 46.2 & 17.6 \\
8.0 & 95.0 & 54.5 & 16.5 \\
23.1 & 91.4 & 63.4 & 11.5 \\
28.8 & 88.5 & 59.4 & 11.9 \\
30.6 & 89.5 & 49.1 & 11.9 \\
\hline
\end{tabular}

* Selectivity was calculated on the basis of reacted ethanol and does not include water.

Table 73. Selectivity of Isobutanol and Ethanal Utilizing Thermally Regenerated FM Catalyst*

\begin{tabular}{lccc}
\hline $\begin{array}{l}\text { Time, } \\
\mathrm{hr}\end{array}$ & $\begin{array}{c}\text { Ethanol } \\
\text { Conversion, } \%\end{array}$ & $\begin{array}{c}\text { Isobutanol } \\
\text { Selectivity, } \%\end{array}$ & $\begin{array}{c}\text { Ethanal } \\
\text { Selectivity, \% }\end{array}$ \\
\hline 0.3 & 98.9 & 55.0 & 12.8 \\
1.0 & 96.2 & 58.9 & 13.4 \\
2.0 & 92.7 & 56.4 & 11.8 \\
4.5 & 93.7 & 55.7 & 12.9 \\
7.0 & 91.7 & 64.5 & 12.2 \\
21.5 & 91.3 & 62.5 & 10.9 \\
\hline
\end{tabular}

*Percent selectivity was calculated on the basis of reacted ethanol and does not include water.

\section{Conclusions}

- The EERC-developed FM catalyst has demonstrated the ability to selectively produce isobutanol from a methanol-ethanol feedstock. Additionally, other by-products of the reaction could be utilized by either recycling them and/or hydrogenating them for conversion into fuel additives.

- HAP catalysts showed high conversion of the alcohol(s) used, but the selectivity for the desired higher alcohol was poor.

- Alumina-based catalysts gave low conversion and low selectivity.

\section{References}

1. Industrial Bioprocessing 1999.

2. Dvornikoff, M.N.; Farrar, M.W. J. Org. Chem. 1957, 22, 540-2. 


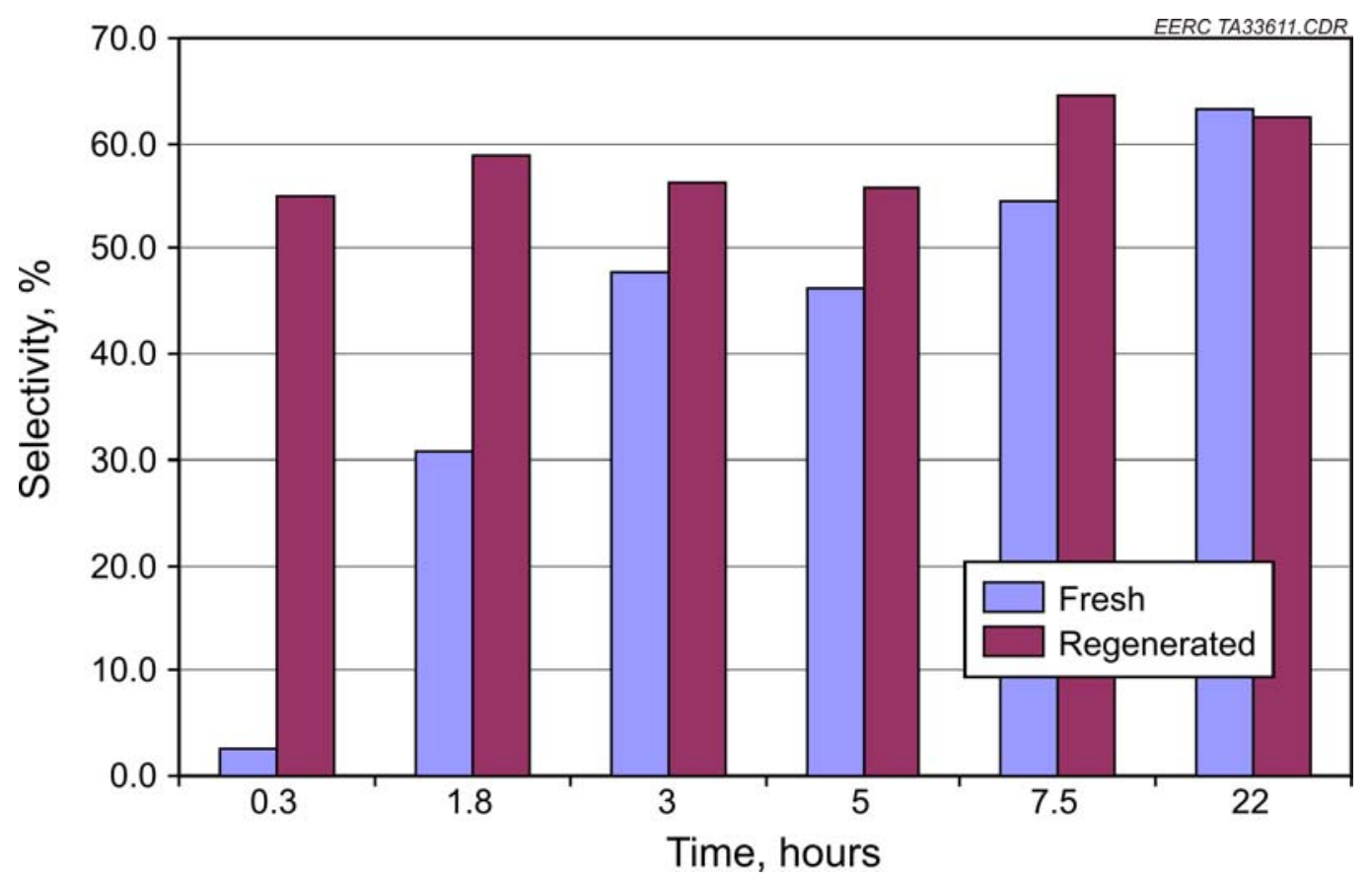

Figure 79. Isobutanol selectivity with both fresh and regenerated FM catalyst.

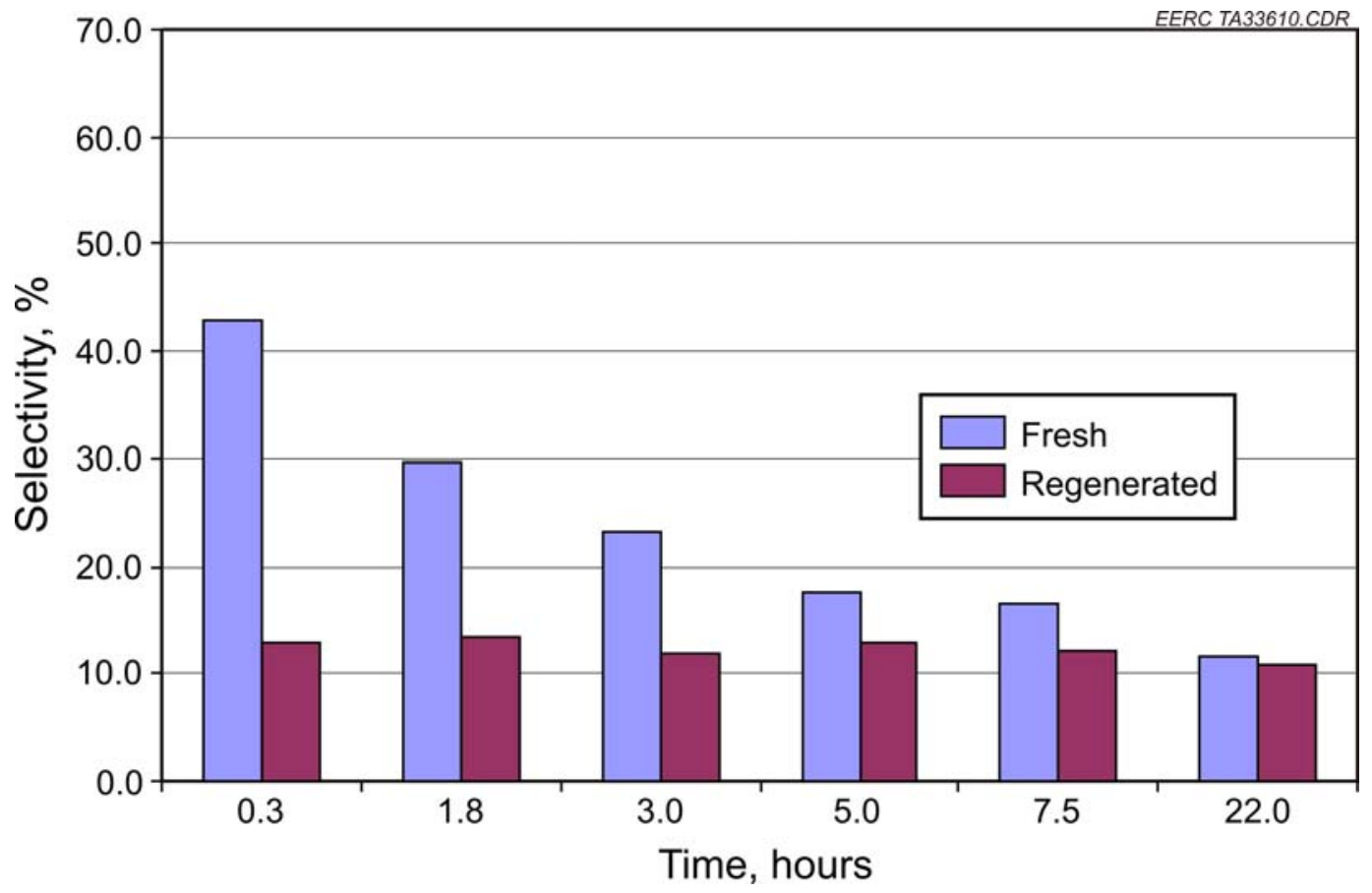

Figure 80. Ethanal selectivity with both fresh and regenerated FM catalyst. 
3. Burk, P.L.; Pruett, R.L.; Campo, K.S. J. Mol. Catalysis 1985, 33, 1-14.

4. Poe, R.L. U.S. Patent 3,328,470, 1967.

5. Herzenberg, J.; Cevidalli, G.; Nenz, A. U.S. Patent 2,861,110, 1958.

6. Ueda, W.; Kuwabara, T.; Oshida, T.; Morikawa, Y. J. Chem. Soc. Chem. Commun. 1990, 1558.

7. Pratt, E.F.; Kubler, D.G. J. Am. Chem. Soc. 1953, 76, 52.

8. Radlowski; C.; Hagen; G.P.; Grimes; L.E.; Tatterson; D.F. U.S. Patent 5,364,979, 1994.

9. Olson, E.S.; Sharma, R.K.; Aulich, T.R. The Higher-Alcohols Biorefinery: Improvement of the Catalyst for Ethanol Conversion. Appl. Biochem. Biotechnol. 2004, 113-116, 913-932.

10. Olson, E.S.; Sharma, R.K.; Aulich, T.R. Ester Fuels and Chemicals from Biomass. Appl. Biochem. Biotechnol. 2003, 105-108, 843-851.

11. Olson, E.S.; Sharma, R.K.; Aulich, T.R. The Higher Alcohols Biorefinery II: Conversion of Ethanol to High-Cetane Diesel Additives. Presented at the 26th Symposium on Biotechnology for Fuels and Chemicals, Chattanooga, TN, May 9-12, 2004.

12. Olson, E.S.; Sharma, R.K.; Timpe, R.C.; Aulich, T.R. High-Cetane Diesel Fuels from Biomass. In Proceedings of the 27th Symposium on Biotechnology for Fuels and Chemicals; Denver, CO, May 1-4, 2005.

13. Olson, E.S.; Sharma, R.K.; Timpe, R.C.; Aulich, T.R. High-Cetane Diesel Fuels from Biomass. Appl. Biochem. Biotechnol. 2006, in review.

14. Olson, E.S. Parallel Processing Biorefineries. Prepr. Pap.-Am. Chem. Soc., Div. Fuel Chem. 2005, 50 (2).

15. Tsuchida, T.; Atsumi, K.; Sakuma, S.; Inui, T. U.S. Patent 6,323,383, 2001.

16. Tsuchida, T.; Sakuma, S.; Takeguchi, T., and Ueda, W., Direct Synthesis of n-Butanol from Ethanol over Nonstoichiometric Hydroxyapatite. Ind. Eng. Chem. Res. 2006, 45, 8634-8642.

17. Aulich, T.; Sharma, R.K.; Olson, E.S. 2007-2008 Quarterly Reports to Archer Daniels Midland Company; Energy \& Environmental Research Center: Grand Forks, ND, 20072008.

18. Kibby, C.L.; Hall, W.K. Biosurfaces; Marcel Dekker: New York, 1972; Vol. 2.

19. Bett, J.A.S.; Christner, L.G.; Hall, W. Keith, Studies of the Hydrogen Held by Solids, XII, Hydroxyapatite Catalysts. J. Am. Chem. Soc. 1967, 89 (22), 5535. 
20. Yang, K.W.; Jiang, Z.Z.; Zhang, W.C. Chin. Chem. Lett. 2004, 15 (12), 1497-1500.

\section{TASK 3 - MANAGEMENT, EDUCATION, AND OUTREACH}

\section{Introduction}

Traditionally, renewable energy and products are derived from hydroelectric, solar, biomass, wind, wave, and geothermal energy forms. These energy forms are renewable in the sense that they are sustained in the earth's environment year after year without depletion, unlike fossil fuels which were formed only once, thousands of years ago, and are being depleted each year. The EERC deems biomass resources as a viable and necessary component of renewable energy to become a significant component of the total energy mix in the United States in the future. Presently, the U.S. Energy Information Agency estimates that biomass is only about $2.5 \%$ of the total U.S. energy generation (1). This percentage is bound to grow for a variety of reasons. One reason for the necessity of growth in biomass utilization is that domestic fossil fuels are bound to dwindle in the next several decades, especially petroleum and natural gas, and steps need to be taken now to find alternative energy forms. U.S. coal reserves have the potential to sustain the U.S. electrical generation need for many, many decades, but petroleum for transportation fuels and chemicals has a more near-term timetable for depletion. It also makes sense, for national security and domestic economic reasons, to promote the development of bioenergy and biofuels now. A final reason that necessitates the growth of biomass utilization is the positive impact on the environment.

Environmental impacts that are related to energy production take two major pathways: terrestrial and atmospheric. The consumption of fossil fuels results in a variety of terrestrial or land-based environmental challenges, some of which include coal mine reclamation, preventing contamination of hydrologic aquifers from oil rig activity or coal mine drainage water, land surface disruption from oil and gas rigs, oil spills on land and sea, and negative impacts on pristine plant and wildlife. Atmospheric emission challenges are actually more direct and include controlling the atmospheric release of acids (nitrogen or sulfur-based), particulate, mercury and other metals, and greenhouse gases. Shifting to biomass resources can, in some cases, eliminate and, in most cases, at least slow down detrimental impacts on the earth's terrestrial and atmospheric environments. Biomass can be grown in fields and does not have to be excavated out of the ground; biomass contains no sulfur and very little, if any, mercury; biomass is $\mathrm{CO}_{2}$ neutral, and spills of ethanol and biodiesel, at least in pure form, are harmless to the environment. With respect to greenhouse gas emissions, biomass utilization in the replacement of fossil fuels can help slow down this deleterious effect. Fossil fuels release $\mathrm{CO}_{2}$ that has been locked in the earth for millions of years. Biomass conversion also releases $\mathrm{CO}_{2}$, but that $\mathrm{CO}_{2}$ comes directly from the current atmosphere with a fairly balanced ecosystem. Biomass cycles $\mathrm{CO}_{2}$ and does not add additional fossil $\mathrm{CO}_{2}$ to the atmosphere. Another type of by-product environmental impact of biomass utilization is that biomass normally taken to a landfill to decay into methane or burned in the field can be reduced using conversion systems to capture energy and reduce the production of methane, which is much more of a greenhouse gas agent than $\mathrm{CO}_{2}$. 
In summary, biomass utilization is one solution to our nation's addiction to oil and fossil fuels. What is needed now is applied fundamental research that will cause economic technology development for the utilization of the diverse biomass resources in the United States. This final report describes an applied fundamental research project that contributed to the development of economical biomass utilization for energy, transportation fuels, and marketable chemicals using biorefinery methods that include thermochemical and fermentation processes. The work supported the broad scientific objectives of the Biological and Environmental Research Program of the DOE Office of Science, especially in the area of life sciences, climate change, and environmental remediation. Deliverables included 1) identifying and understanding environmental consequences of energy production from biomass, including the impacts on greenhouse gas production, carbon emission abatement, and utilization of waste biomass residues, and 2) developing biology-based solutions that address DOE and national needs related to waste cleanup, hydrogen production from renewable biomass, biological and chemical processes for energy and fuel production, and environmental stewardship. The project served the public purpose of encouraging good environmental stewardship by developing biomass-refining technologies that can dramatically increase domestic energy production to counter current trends of rising dependence on petroleum imports. Decreasing the nation's reliance on foreign oil and energy will enhance national security, the economy of rural communities, and future competitiveness. Although renewable energy has many forms, such as wind and solar, biomass is the only renewable energy source that can be governed through agricultural methods and that has an energy density that can realistically compete with, and even replace, petroleum and other fossil fuels in the near future. It is a primary domestic, sustainable, renewable energy resource that can supply liquid transportation fuels, chemicals, and energy that are currently produced from fossil sources, and it is a sustainable resource for a hydrogen-based economy in the future.

\section{Goals and Objectives}

The goal of the proposed EERC CBU Program 2006 was to develop economically and environmentally sound technologies to promote efficient biopower or bioenergy, transportation biofuels, and bioproducts such as marketable chemicals and hydrogen. Biomass is a critical domestic resource in the United States for meeting future electrical demand, reducing dependence on foreign oil, and achieving the numerous "greening" initiatives launched by federal and state government. An overarching goal of the EERC CBU was to develop technologies that would expand the use of biomass in practical and economical ways within the framework of sustainable development and environmental protection.

Specific objectives for Task 3 - Management, Education, and Strategic Studies included:

- Providing management for the EERC CBU 2005 project.

- Implementing a quality assurance and quality review process for all research activities and spending, including periodic internal project review meetings.

- Spearheading all necessary DOE reports, including NEPA, quarterly, final, and other report types. 
- Promoting attendance and dissemination of information generated through the project at a two-day regional technical workshop on biomass in Grand Forks and also at international biomass-related conferences and meetings abroad.

- Networking with commercial industry clients and peers to provide sound, applied fundamental research.

- Performing outreach to disseminate technologies being developed in biomass at several conference, workshop and other public events.

\section{Experimental}

This task did not have an experimental component.

\section{Results and Discussion}

Project management and quality control were provided for all of the project's technical activities. This included administering all obligations to the Biological and Environmental Research (BER) Program of the DOE Office of Science. All project postaward contract negotiations related to reporting, project extensions, and billing were handled under this task as well as the preparation of all reports and project review presentations; the management of quality assurance/quality control activities; the facilitation of kickoff, midproject review, and bimonthly renewables/biomass informational meetings with individual Task leaders; and a host of miscellaneous project management activities.

An internal project kickoff meeting was held in October 2006. At this meeting, activity managers described the scope of work for their projects to an audience that included other researchers and project managers at the EERC working within and outside of CBU projects. The meeting also served to explain reporting requirements, deadlines, milestones, environmental issues, and quality assurance/quality control project reviews. Quarterly meetings were held thereafter where the status of project results, milestones, timetables, and budgets were reviewed. In addition, the quarterly internal meetings served as a venue for listening to presentations on cutting-edge research from other researchers. A 30-40-minute presentation was occasionally given by either a researcher from an academic department of UND, from the EERC, or from a visiting agency. The presentations centered on utilizing biomass for energy and fuels. Presenters included the following: Dr. Michael Mann, professor and Chemical Engineering Department Chair at UND discussed a research effort centered on cracking vegetable oils to make smallerchain renewable additive transportation fuels; Ted Aulich of the EERC spoke on renewable jet fuel production; and Philip Hutton of the EERC spoke on an integrated biomass gasifier-solid oxide fuel cell system.

With respect to reporting, all quarterly reports and milestone activity logs were written and submitted to DOE. All projects within EERC CBU 2006 were reviewed, and project managers queried on deliverables, milestones, and remaining objectives and budgets. 
Part of the education and outreach objectives of Task 3 was to support, host, and conduct a biomass workshop. A workshop was assembled and facilitated called Biomass '07: Power, Fuels, and Chemicals Workshop, held at the Alerus Center in Grand Forks on May 15-16, 2007. The workshop exceeded expectations, with 400 participants and 40 exhibitors from over 230 different organizations, three foreign countries, and 28 states. It was an excellent team effort, with substantial collaboration from the North Dakota Department of Commerce Division of Community Services, DOE, BBI International, MDU Resources Group Inc., Xcel Energy, Great River Energy, Minnkota Power Cooperative Inc., the City of Grand Forks, and the North Dakota Department of Agriculture.

The workshop opened on the afternoon of the 15th with Dr. Gerry Groenewold, Director of the EERC, providing an overview of the EERC and a thank you to Senator Byron Dorgan for his support. Dr. Groenewold introduced Senator Dorgan who addressed the crowd by video from Washington, D.C., emphasizing the importance of utilizing biomass in the energy portfolio of the U.S., both in the transportation and electricity sectors. In 1999, Senator Dorgan was instrumental in helping to establish initial seed funding that was leveraged through joint ventures with industry within what is now the CBU at the EERC. It is the CBU that now spearheads the Biomass Workshop every year.

Chris Zygarlicke from the EERC started off the technical portion of the workshop by giving a general overview of the state of biomass in the northern Great Plains. His main point was that the potential for utilizing biomass as a feedstock to supplant a portion of current U.S. energy needs is at an all-time high, especially in the plains states. Farmlands in the Dakotas can grow soybeans in the south and canola in the north and switchgrass or varieties of prairie grasses throughout. Large biodiesel and ethanol plants are being erected, rural economies are close to booming in some areas, and entire communities are wanting to learn how to better utilize this renewable domestic biomass feedstocks. Betsy Engleking, Manager, Resource Planning at Xcel gave an excellent industry perspective on the electricity side of biomass utilization. Xcel Energy has a goal of $25 \%$ renewable energy generation within 20 years or so and currently has $25 \mathrm{MW}$ of wood residue biomass heat and power at the District Energy St. Paul plant, plus another 55 MW of poultry litter biomass electricity from the Fibrominn plant near Benson, Minnesota. Kevin Kephart, Vice President for Research and Dean of the Graduate School at South Dakota State University, gave the first real technical presentation of the workshop, focusing primarily on energy crops such as switchgrass. He has roots in the agricultural side of growing prairie grasses and gave a thorough explanation of how native prairie grasses such as big blue stem, are actually heartier in a broader array of climatic conditions such as drought and are less prone to disease than monocultures such as switchgrass. Rounding out the first session of talks was a presentation by Gerson Santos-Leon, Director of R\&D at Abengoa Bioenergy. He described Abengoa's successful \$80 million award from DOE, matched with about \$200 million in private investment, to build and demonstrate a small commercial-scale cellulosic ethanol plant in Kansas. Abengoa's concept will use its patented fractionation process on corn ethanol combined with enzymatic hydrolysis of wheat straw to produce ethanol. In addition, there were 21 other speakers. Highlights include Bill Lee, General Manager of Chippewa Valley Ethanol Company of Benson, Minnesota, who gave an excellent, down-to-earth talk on his grower-owned corn ethanol plant taking a very progressive approach to supplanting natural gas with biomass gasifier syngas; the only ethanol plant to use biomass gasification in the United States. Ted Aulich, Senior Research 
Manager and Process Chemist at the EERC, discussed lignocellulose-based transportation fuels. The most technical of all talks was given by semiretired former DuPont engineer Leo Manzer from Catalytic Insights, LLC, in Wilmington, Delaware, who intrigued the crowd with the prospect of not only renewable fuels but also biobased chemicals that are coming of age with cutting-edge catalysis and process research. In summary, Biomass '07 provided an excellent snapshot of biomass technologies that are no longer a dream but a reality. The business side of making biomass projects profitable was a part of many conversations overheard during the breaks, luncheons, and networking receptions. Key to many of these discussions throughout these outreach events is collaboration and dialogue between DOE, academicians, and industry.

In addition to the workshop and conference-type educational outreach venues, materials were developed to provide an overview of the opportunities and activities related to biomass as an alternative fuel in the United States, with special emphasis on the northern Great Plains region. These materials were incorporated into a booth display that was used for public outreach at the North Dakota State Fair in Minot, North Dakota, in the summer of 2006. The display introduced the public to the utilization of biomass as an energy resource for electricity, heat, and transportation fuels. It included a series of video segments that streamed on a plasma television screen that described the production and utilization of biofuels such as ethanol, biodiesel, and biohydrogen for transportation vehicles. This outreach event was done in collaboration with several utilities and automobile dealerships and displayed other demonstrations of hydrogen and alternative-fueled vehicles. The state fair is an annual event that features carnival rides, agricultural expositions, trade shows, government and commercial exhibitions, and a variety of musical and performance entertainment. It is the largest event in the state, drawing around 250,000 people during the 2006 venue with the biomass utilization display.

Through the strategic studies portion of this activity, several meetings and conferences were attended or arranged related to forward planning of future biomass research, pathways forward to biomass-driven energy and fuels, and dissemination of applied biomass research results. Such events attended included presentations and meetings related to the biomass activities and biomass sessions chaired at the 31st International Technical Conference on Fuel Technology in Clearwater, Florida, May 21-26, 2006; discussions held with interested industry representatives for technologies being developed in the project at the PowerGen Renewable Conference on April 10-12, 2006, in Las Vegas, Nevada; a meeting attended and the state of biomass gasification and fermentation to ethanol and chemicals discussed at the North Dakota Biomass Taskforce final meeting in Jamestown, North Dakota, in December 2006; a working group discussion on biomass utilization related to agricultural economies attended and participation in the midwest Ag-Energy Network meeting in St. Paul, Minnesota, in December 2006; a meeting with a several engineering groups building biomass gasification systems and the thermochemical conversion of biomass to ethanol at the Western Fuels Symposium in Denver, Colorado, in October 2006; discussions with staff from the Office of Science BER program office in Germantown, Maryland, related to biomass utilization for fuels, chemicals, and energy in conjunction with attendance and discussions with other DOE officials on the state of biofuels research at the Cellulosic Ethanol Summit in Washington, D.C., in October 2007; meetings held with Dupont at the EERC to discuss potential use of CBU research results on converting biomass residues to biobased chemical feedstocks; meetings attended at a workshop sponsored by the University of Minnesota in St. Paul, Minnesota, in July 2007 where discussions were centered on 
biomass energy crop development and impacts on land use, water, and wildlife; and finally several meetings with several individuals from Barkley Ag Enterprises, WestBred LLC, the Montana State University Institute for Bio-Based Products, whereby the discussion was related to biojet fuel and green diesel production with a particular focus on camelina as a feedstock.

As a result of interaction and discussion in formal peer review meetings and other more informal meetings with DOE personnel and biomass industry experts, specific areas related to biofuels and bioenergy were identified and targeted as great needs to the United States and as relevant areas needing federal assistance to perform higher-risk applied research or demonstration. Some of these areas include indirect liquefaction of wood wastes integrated with small-scale syngas reactors for methanol/ethanol or distributed hydrogen production; lowtemperature catalytic reforming of glycerol to hydrogen using improved catalysts; high-pressure electrolysis of biobased glycerol and biobased alcohols for on-demand hydrogen production; well-integrated gas turbine biomass gasifier power plants for distributed power production; gasification of wet biomass utilizing supercritical hydroconversion; mitigation of hydrogen sulfide concomitant enhancement of methane production; thermal conversion of torrefied biomass pellets; integrating fermentation ethanol and crop oil in processing that creates ethyl biodiesel and glycerol-based products; production of formic acid-based chemicals and hydrogen via gasification of cellulosic biomass; and developing robust microgasification technology for MSW.

Also, through the strategic studies portion of Task 3 the debate was carried forth at several meetings and educational venues on the topic of starch-based ethanol versus lignocellulosic ethanol and biodiesel-based fuels. Opinions from politicians, scientists, investors, and developers range from the ability of the United States. to replace nearly all its transportation fuel use with biofuels to less than a fourth. Currently, the United States consumes about 4\% ethanol in the transportation sector, most of that number relating to corn- or starch-based ethanol. With over 200 ethanol plants slated to be operating in 3 years or so, it can be seen that ethanol will soon easily comprise $8 \%$ or more of our gasoline consumption. After that, the picture dims a bit; especially when diesel fuel consumption is added to the mix. To achieve significant levels of total biofuel consumption, meaning both ethanol and biodiesel production, more attention is going to need to be paid to biomass, a lot more attention. The EERC sees a great need for investment in fundamental research and development to improve all aspects of field-to-wheels efficiency in biofuels. Replacing a significant portion of petroleum-derived transportation fuels with domestic renewable alternatives from biomass will require new, innovative pathways that 1) compete economically with petroleum and 2) maximize the fuel production capacity of U.S. agricultural lands, which means achieving a maximum "vehicle miles traveled" per acre. This involves a paradigm shift in thinking and conducting research on both the development of biofuels and how the fuels are consumed. In other words, we tie together how we convert biomass, such as by fermentation or thermochemical means, with how we convert the products into propulsion, such as spark ignition engines, compression-ignition engines, turbines, and fuel cells. This project was able to introduce concepts on how to bring about this paradigm shift in biofuel production and use by discussing in several venues, papers, and articles six primary options for biomass or lignocellulose-based biofuels production. These options include 1) enzyme hydrolysis of biomass followed by conventional fermentation of the sugars made available from the cellulose to ethanol process, 2) thermal gasification of biomass to convert it to 
mostly volatile carbon monoxide, hydrogen, carbon dioxide, and methane, followed by fermentation of this mixture to ethanol; 3) thermal gasification of biomass followed by nonfermentative alcohol synthesis and mixed alcohol production; 4) thermal gasification of biomass followed by FT conversion to distillates or green diesel; 5) thermal gasification of biomass followed by methanol synthesis, dehydration, and catalytic conversion to dimethyl ether, a higher-reaction-temperature, higher-cetane compound that is an excellent diesel fuel substitute; and 6) pyrolysis conversion of biomass to bio-oil followed by hydrogenation and conversion to distillates or green diesel.

The first pathway is enzyme hydrolysis of cellulose in biomass to sugars followed by fermentation of the sugars to ethanol. This is the process used today in pilot plants being built by Iogen, Abengoa, BlueFire, and Broin under the recent multimillion-dollar DOE program for cellulosic ethanol plants that will each produce around 20 million gallons of ethanol per year. The primary advantage that this pathway has over others is that the fermentation step is unchanged from conventional ethanol production. This would allow enzyme hydrolysis plants to be readily collocated with existing ethanol production facilities. However, the connection to conventional ethanol production also presents a number of disadvantages. In conventional fermentation, approximately one-third of the carbon available in the sugar is lost as $\mathrm{CO} \neg 2$, and the water demand for hydrolysis and fermentation is high. Both of these negative traits carry over to the enzyme hydrolysis pathway.

The second pathway is thermal gasification of biomass to produce syngas, consisting primarily of carbon monoxide, hydrogen, carbon dioxide, and methane, followed by fermentation of the syngas to ethanol. To date, this process has only been examined in the laboratory, but it could prove to be a low-cost option in the future. This process could be problematic in that the bacteria currently used for fermentation will occasionally produce products other than ethanol, leading to inconsistent product quality and yield. The bacteria may also require long gas residence times to achieve good conversion of syngas to ethanol at acceptable yields. The unused syngas can be recycled to increase its total residence time, but this, in turn, requires an expensive compressor to recycle large quantities of gas. In addition, keeping a bacterial strain alive and functioning in the presence of syngas could prove to be a difficult challenge for large-scale production.

The third pathway is thermal gasification of biomass followed by alcohol synthesis over a catalyst. This is the process being pursued by Range Fuels, Inc., under the DOE award mentioned above. This process has an advantage over the first two pathways in that there is no biological component, allowing for higher temperatures and lower water demand. Similarly, the catalyst cannot mutate or alter its biology, so the alcohol product is of consistent quality over the catalyst lifetime. The main disadvantage of this process is that the product is not pure ethanol, but is, instead, a blend of alcohols containing a significant fraction of methanol. The high methanol content could negatively impact vapor pressure.

All of the processes listed so far involve production of alcohols for blending with gasoline. Alcohol cannot be used as a replacement fuel in most existing gasoline or diesel engines. Instead, the mixed alcohols must be blended with gasoline for use as an octane booster, limiting the amount of petroleum fuel that can be offset by biofuel. Use of biomass to produce fuel for spark 
ignition engines further limits the amount of petroleum fuel that can be replaced with biomassderived fuel. This is because spark ignition, which is used to convert gasoline to energy, is inherently less efficient than is compression ignition, which is used to convert diesel to energy. For biomass to achieve the greatest impact on fossil fuel usage, it must be used to produce synthetic diesel fuel. One opinion is that the greatest impact on the transportation industry that biomass can achieve on a field-to-wheels basis (that is, on a basis of miles driven per acre harvested) is when used to produce synthetic diesel, or green diesel. The greatest disadvantage of green diesel versus ethanol is the public perception of diesel engines as noisy and polluting. As improved technology leads to greater acceptance of diesel engines, this disadvantage will disappear, putting green diesel in a position to surpass ethanol in scale and economics.

The fourth pathway from biomass to diesel fuel is thermal gasification to syngas followed by FT conversion to green diesel. This pathway has the significant advantage of being a wellestablished process for natural gas feedstock, used by Germany during World War II and then by Sasol, Ltd., of South Africa to produce a fuel that is almost completely compatible with petroleum-derived diesel. However, the product of FT synthesis contains no aromatics or cyclic compounds, which can negatively impact the fuel density. These problems are often overcome by blending the FT product with petroleum products that contain aromatics.

The fifth pathway is thermal gasification followed by methanol synthesis over a catalyst bed, followed, in turn, by conversion of the methanol to dimethyl ether (DME). DME is used today as an aerosol propellant and is manufactured by several companies using nonrenewable methanol as a feedstock. Like diesel, DME can be used in compression ignition engines and presents a higher fuel economy than do spark-ignition fuels. Unlike diesel, DME is molecularly homogeneous, which allows engines to be precisely tuned to optimize combustion. However, DME is also a gas at room temperature and pressure, requiring it to be compressed to a liquid for transportation. There is no existing infrastructure designed to deliver pressurized liquid DME to vehicle fuel tanks. This is a significant disadvantage for DME as compared to drop-in compatible alcohols and green diesel fuels. Outside of the transportation fuels market, DME may be useful as a replacement for liquid petroleum gas (LPG), which has an existing infrastructure better suited to transporting and utilizing DME.

The final and sixth pathway is pyrolysis followed by hydrogenation of the bio-oil product to green diesel. Pyrolysis is already practiced on the commercial scale for production of food additives. Bio-oil often contains aromatic and cyclic compounds, so hydrogenated bio-oil is likely to meet all of the existing specifications for diesel fuel without requiring any additives. The primary disadvantage to using hydrogenated bio-oil is the risk that the green diesel product may contain unacceptable amounts of aromatics or other unsaturated compounds. These compounds can lead to smog formation and can limit the shelf life of the fuel. Such compounds could be eliminated by adding more hydrogen to the fuel during hydrogenation, but unless this hydrogen is available in the process gas produced by pyrolysis, hydrogen would have to be supplemented using bottled gas or a separate thermal gasifier. Either option would negatively impact the process cost and complexity.

The six pathways described are by no means the only pathways from biomass to transportation fuel that are being considered today, but the EERC considers these pathways the 
most likely to find success on the large scale. Some of the processes have already found commercial success in other markets (for example, as food additives) or using raw materials other than biomass (for example, using natural gas instead of syngas). Other processes show promise because they represent simple, efficient, or low-cost options. Whichever process or combination of processes ultimately finds the greatest success at producing transportation fuels, it is clear that the future of biofuels will have a larger and more varied market than the corn ethanol and biodiesel markets of today.

\section{References}

1. Energy Information Administration. Annual Energy Review 2005; Report No. DOE/EIA0384(2005); July 27, 2006. 
APPENDIX A

\section{GASIFICATION OF CORN STOVERS: COMPARISON OF ETHANOL VERSUS FISCHER- TROPSCH (FT) DIESEL}




\section{GASIFICATION OF CORN STOVER: COMPARISON OF ETHANOL VERSUS FISCHER-TROPSCH DIESEL}

A comparison of ethanol versus Fischer-Tropsch (FT) diesel was performed. The basis of comparison was $\sim 17,700$ tons per year of corn stover feedstock converted to either ethanol or FT diesel with $45 \%$ thermal efficiency, producing $1.25 \times 10^{11}$ Btu of fuel per year. This translates to producing either 1.5 million gallons per year of ethanol, or 932,327 gallons per year FT diesel (Figure A-1). The net inputs and outputs for carbon, hydrogen, and oxygen are shown for each plant (Tables A-1 and A-2) below. It should be noted that both plants will produce $\sim 5.88$ short tons per day of ash.

Tables A-1 and A-2 show only net material balance for the conversion of biomass to a liquid fuel. They do not account for utility water requirements for cooling purposes. Likewise, they do not show that water should be added to gasification or shift conversion units, only that there is a net production of water by the overall chemical process.

Several differences are apparent from Tables A-1 and A-2. First, the production volume and weight of ethanol is significantly more than that for FT diesel (yet the Btus are the same). Second, ethanol produces slightly more $\mathrm{CO}_{2}$ than does FT diesel. And third, FT diesel produces almost twice as much water as ethanol. Oxygen consumption is somewhat less for FT diesel than for ethanol.

The water production may be an issue, depending on the site location chosen for such a facility. If wastewater disposal is an economic issue, then a plant that produces less water is

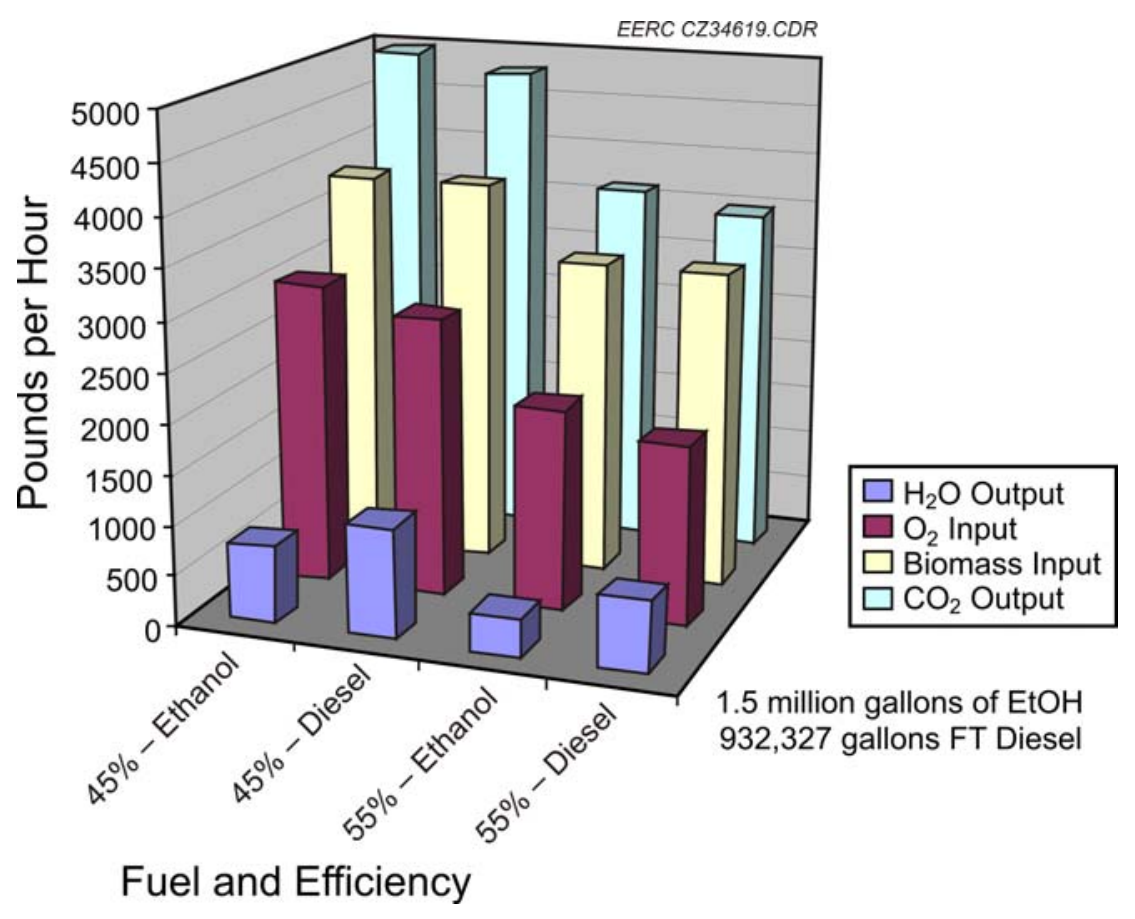

Figure A-1. Gasification of corn stover. 
Table A-1. Net Element and Feedstock Balance for Gasification of Corn Stover with Ethanol Production for a 45\% Thermal Efficiency Process

\begin{tabular}{lccccrr}
\hline & \multicolumn{3}{c}{ Input, lb/hr } & \multicolumn{3}{c}{ Output, lb/hr } \\
& Biomass & $\mathrm{H}_{2} \mathrm{O}$ & $\mathrm{O}_{2}$ & $\mathrm{CO}_{2}$ & $\mathrm{H}_{2} \mathrm{O}$ & EtOH \\
\hline $\mathrm{C}$ & 1966 & & & 1352 & & 614 \\
$\mathrm{H}$ & 239 & & & & 85 & 153 \\
$\mathrm{O}$ & 1669 & & 3028 & 3606 & 682 & 409 \\
Subtotal & 3873 & 0 & 3028 & 4958 & 767 & 1176 \\
Total & & & 6901 & & & 6901 \\
\hline
\end{tabular}

Table A-2. Net Element and Feedstock Balance for Gasification of Corn Stover with Diesel Production for a 45\% Thermal Efficiency Process

\begin{tabular}{lcccccr}
\hline & \multicolumn{3}{c}{ Input, lb/hr } & \multicolumn{3}{c}{ Output, lb/hr } \\
& Biomass & $\mathrm{H}_{2} \mathrm{O}$ & $\mathrm{O}_{2}$ & $\mathrm{CO}_{2}$ & $\mathrm{H}_{2} \mathrm{O}$ & Diesel \\
\hline $\mathrm{C}$ & 1966 & & & 1309 & & 657 \\
$\mathrm{H}$ & 239 & & & & 122 & 116 \\
$\mathrm{O}$ & 1669 & & 2800 & 3490 & 979 & 0 \\
Subtotal & 3873 & 0 & 2800 & 4799 & 1101 & 773 \\
Total & & & 6673 & & & 6673 \\
\hline
\end{tabular}

more desirable. If wastewater can be cleaned up and used in a collocated ethanol fermentation facility, perhaps a plant producing more water would be highly desirable.

For the purposes of comparison, a thermal efficiency of 55\% was calculated for both ethanol and FT diesel (Tables A-3 and A-4). The amount of fuel produced remains the same as in the examples above, but the consumption of biomass has decreased to accommodate the higher thermodynamic efficiency. Ash production at 55\% thermal efficiency decreases to 4.81 short tons per day.

Comparing the results from the $45 \%$ thermal efficiency process versus those from the $55 \%$ thermal efficiency process shows some interesting differences. For the lower thermal efficiency process, significantly more oxygen is required, by about 769 pounds per hour. Also, more water is produced by the process, by about 390 pounds per hour.

Feedstock is another factor. The lower-thermal-efficiency process will consume an extra 8.45 tons per day of corn stover. At a market value of $\$ 45$ per ton, this an extra $\$ 380$ in operating expense per day, or $\$ 133,000$ per year. The added costs for oxygen production and wastewater treatment indicate that the more thermally efficient process will be more economical to operate, as would be expected.

\section{GASIFICATION OF LIGNIN: COMPARISON OF ETHANOL AND DIESEL}

Similarly to the corn stover gasification exercise, lignin was studied as a feed stock for gasification and conversion to either ethanol or FT diesel. In this study, both dry and moist 
Table A-3. Net Element and Feedstock Balance for Gasification of Corn Stover with Ethanol Production for a 55\% Thermal Efficiency Process

\begin{tabular}{|c|c|c|c|c|c|c|}
\hline & \multicolumn{3}{|c|}{ Input, lb/hr } & \multicolumn{3}{|c|}{ Output, lb/hr } \\
\hline & Biomass & $\mathrm{H}_{2} \mathrm{O}$ & $\mathrm{O}_{2}$ & $\mathrm{CO}_{2}$ & $\mathrm{H}_{2} \mathrm{O}$ & $\mathrm{EtOH}$ \\
\hline $\mathrm{C}$ & 1608 & & & 995 & & 614 \\
\hline $\mathrm{H}$ & 195 & & & & 42 & 153 \\
\hline $\mathrm{O}$ & 1365 & & 2031 & 2653 & 335 & 409 \\
\hline Subtotal & 3169 & 0 & 2031 & 3647 & 377 & 1176 \\
\hline Total & & & 5200 & & & 5200 \\
\hline
\end{tabular}

Table A-4. Net Element and Feedstock Balance for Gasification of Corn Stover with Diesel Production for a 55\% Thermal Efficiency Process

\begin{tabular}{|c|c|c|c|c|c|c|}
\hline & \multicolumn{3}{|c|}{ Input, lb/hr } & \multicolumn{3}{|c|}{ Output, lb/hr } \\
\hline & Biomass & $\mathrm{H}_{2} \mathrm{O}$ & $\mathrm{O}_{2}$ & $\mathrm{CO}_{2}$ & $\mathrm{H}_{2} \mathrm{O}$ & Diesel \\
\hline $\mathrm{C}$ & 1608 & & & 951 & & 657 \\
\hline $\mathrm{H}$ & 195 & & & & 79 & 116 \\
\hline $\mathrm{O}$ & 1365 & & 1803 & 2537 & 632 & 0 \\
\hline Subtotal & 3169 & 0 & 1803 & 3488 & 711 & 773 \\
\hline Total & & & 4972 & & & 4972 \\
\hline
\end{tabular}

lignin were examined as feedstocks. The utility of wet lignin would be that in an integrated biorefinery, the lignin recovered from the "sugar" side of the plant would be gasified prior to drying.It is the purpose of this exercise to determine if drying the lignin and paying the associated cost of the drying would reap any obvious benefit in the gasification process.

Tables A-5-A-12 show the gasification of lignin (moist and dry) with conversion to either ethanol or FT diesel at both $45 \%$ and $55 \%$ thermal efficiency. Again, the numbers shown are the net products, and do not show any use of these products, such as water for evaporation in cooling towers. An interesting side note is that based upon available information, the lignin feedstock contains very low ash and high Btu values. The Btu value used was 8970 Btu per pound (oven dry material) and 4555.5 Btu per pound for material that was assumed to be $50 \%$ moisture by mass.

The comparisons again show that less $\mathrm{CO}_{2}$ and more water are produced when FT diesel is the product. Both water and $\mathrm{CO}_{2}$ production decrease as thermal efficiency is increased.

The use of moist lignin results in the same amount of $\mathrm{CO}_{2}$ production as in the case where dry lignin was the feedstock, but water is shown as being produced in greater quantity. This is not actually the case as the water is simply passed through the process and potentially recovered in the end. It should be remembered that using a 50\% moist lignin will require heating of water upon entry to the gasifier. Water separation via cooling to a liquid state will be required at the backend of the gasification process. All this means that there will be a significant amount of Btus expended heating up water that is not really required in the unit operation. Also, extra cooling capacity will be required on the backend. 
Table A-5. Net Element and Feedstock Balance for Gasification of Lignin (oven dry) with Ethanol Production for a 45\% Thermal Efficiency Process

\begin{tabular}{lcccccc}
\hline & \multicolumn{3}{c}{ Input, lb/hr } & \multicolumn{3}{c}{ Output, lb/hr } \\
& Biomass & $\mathrm{H}_{2} \mathrm{O}$ & $\mathrm{O}_{2}$ & $\mathrm{CO}_{2}$ & $\mathrm{H}_{2} \mathrm{O}$ & EtOH \\
\hline $\mathrm{C}$ & 1791 & & & 1178 & & 614 \\
$\mathrm{H}$ & 180 & & & & 26 & 153 \\
$\mathrm{O}$ & 1007 & & 2753 & 3140 & 211 & 409 \\
Subtotal & 2978 & 0 & 2753 & 4318 & 237 & 1176 \\
Total & & & 5731 & & & 5731 \\
\hline
\end{tabular}

Table A-6. Net Element and Feedstock Balance for Gasification of Lignin (oven dry) with Diesel Production for a 45\% Thermal Efficiency Process

\begin{tabular}{lcccccc}
\hline & \multicolumn{3}{c}{ Input, $\mathrm{lb} / \mathrm{hr}$} & \multicolumn{3}{c}{ Output, lb/hr } \\
& Biomass & $\mathrm{H}_{2} \mathrm{O}$ & $\mathrm{O}_{2}$ & $\mathrm{CO}_{2}$ & $\mathrm{H}_{2} \mathrm{O}$ & Diesel \\
\hline $\mathrm{C}$ & 1791 & & & 1134 & & 657 \\
$\mathrm{H}$ & 180 & & & & 63 & 116 \\
O & 1007 & & 2525 & 3025 & 507 & 0 \\
Subtotal & 2978 & 0 & 2525 & 4159 & 571 & 773 \\
Total & & & 5503 & & & 5503 \\
\hline
\end{tabular}

Table A-7. Net Element and Feedstock Balance for Gasification of Lignin (oven dry) with Ethanol Production for a 55\% Thermal Efficiency Process

\begin{tabular}{lcccccc}
\hline \multicolumn{3}{c}{ Input, $\mathrm{lb} / \mathrm{hr}$} & \multicolumn{3}{c}{ Output, lb/hr } \\
& Biomass & $\mathrm{H}_{2} \mathrm{O}$ & $\mathrm{O}_{2}$ & $\mathrm{CO}_{2}$ & $\mathrm{H}_{2} \mathrm{O}$ & EtOH \\
\hline $\mathrm{C}$ & 1466 & & & 852 & & 614 \\
$\mathrm{H}$ & 147 & 6 & & & & 153 \\
$\mathrm{O}$ & 824 & 51 & 1857 & 2272 & & 409 \\
Subtotal & 2437 & 57 & 1857 & 3124 & 0 & 1176 \\
Total & & & 4350 & & & 4300 \\
\hline
\end{tabular}

Table A-8. Net Element and Feedstock Balance for Gasification of Lignin (oven dry) with Diesel Production for a 55\% Thermal Efficiency Process

\begin{tabular}{lcccccc}
\hline & \multicolumn{3}{c}{ Input, $\mathrm{lb} / \mathrm{hr}$} & \multicolumn{3}{c}{ Output, lb/hr } \\
& Biomass & $\mathrm{H}_{2} \mathrm{O}$ & $\mathrm{O}_{2}$ & $\mathrm{CO}_{2}$ & $\mathrm{H}_{2} \mathrm{O}$ & Diesel \\
\hline $\mathrm{C}$ & 1466 & & & 809 & & 657 \\
$\mathrm{H}$ & 147 & & & & 31 & 116 \\
$\mathrm{O}$ & 824 & & 1578 & 2156 & 246 & 0 \\
Subtotal & 2437 & 0 & 1578 & 2965 & 277 & 773 \\
Total & & & 4015 & & & 4015 \\
\hline
\end{tabular}


Table A-9. Net Element and Feedstock Balance for Gasification of Lignin (moist) with Ethanol Production for a 45\% Thermal Efficiency Process

\begin{tabular}{lcccccc}
\hline & \multicolumn{3}{c}{ Input, $\mathrm{lb} / \mathrm{hr}$} & \multicolumn{3}{c}{ Output, lb/hr } \\
& Biomass & $\mathrm{H}_{2} \mathrm{O}$ & $\mathrm{O}_{2}$ & $\mathrm{CO}_{2}$ & $\mathrm{H}_{2} \mathrm{O}$ & EtOH \\
\hline $\mathrm{C}$ & 1791 & & & 1178 & & 614 \\
$\mathrm{H}$ & 591 & & & & 437 & 153 \\
O & 4292 & & 2756 & 3140 & 3499 & 409 \\
Subtotal & 6675 & 0 & 2756 & 4318 & 3937 & 1176 \\
Total & & & 9430 & & & 9430 \\
\hline
\end{tabular}

Table A-10. Net Element and Feedstock Balance for Gasification of Lignin (moist) with Diesel Production for a 45\% Thermal Efficiency Process

\begin{tabular}{lcccrrr}
\hline & \multicolumn{3}{c}{ Input, lb/hr } & \multicolumn{3}{c}{ Output, lb/hr } \\
& Biomass & $\mathrm{H}_{2} \mathrm{O}$ & $\mathrm{O}_{2}$ & $\mathrm{CO}_{2}$ & $\mathrm{H}_{2} \mathrm{O}$ & Diesel \\
\hline $\mathrm{C}$ & 1791 & & & 1134 & & 657 \\
$\mathrm{H}$ & 591 & & & & 474 & 116 \\
$\mathrm{O}$ & 4292 & & 2528 & 3025 & 3796 & 0 \\
Subtotal & 6675 & 0 & 2528 & 4159 & 4270 & 773 \\
Total & & & 9203 & & & 9203 \\
\hline
\end{tabular}

Table A-11. Net Element and Feedstock Balance for Gasification of Lignin (moist) with Ethanol Production for a 55\% Thermal Efficiency Process

\begin{tabular}{lccccrr}
\hline & \multicolumn{3}{c}{ Input, lb/hr } & \multicolumn{3}{c}{ Output, lb/hr } \\
& Biomass & $\mathrm{H}_{2} \mathrm{O}$ & $\mathrm{O}_{2}$ & $\mathrm{CO}_{2}$ & $\mathrm{H}_{2} \mathrm{O}$ & EtOH \\
\hline $\mathrm{C}$ & 1466 & & & 852 & & 614 \\
$\mathrm{H}$ & 483 & & & & 330 & 153 \\
$\mathrm{O}$ & 3512 & & 1809 & 2272 & 2640 & 409 \\
Subtotal & 5461 & 0 & 1809 & 3124 & 2970 & 1176 \\
Total & & & 7270 & & & 7270 \\
\hline
\end{tabular}

Table A-12. Net Element and Feedstock Balance for Gasification of Lignin (moist) with Diesel Production for a 55\% Thermal Efficiency Process

\begin{tabular}{lccccrr}
\hline & \multicolumn{3}{c}{ Input, lb/hr } & \multicolumn{3}{c}{ Output, lb/hr } \\
& Biomass & $\mathrm{H}_{2} \mathrm{O}$ & $\mathrm{O}_{2}$ & $\mathrm{CO}_{2}$ & $\mathrm{H}_{2} \mathrm{O}$ & Diesel \\
\hline $\mathrm{C}$ & 1466 & & & 809 & & 657 \\
$\mathrm{H}$ & 483 & & & & 367 & 116 \\
$\mathrm{O}$ & 3512 & & 1581 & 2156 & 2937 & 0 \\
Subtotal & 5461 & 0 & 1581 & 2965 & 3304 & 773 \\
Total & & & 7042 & & & 7042 \\
\hline
\end{tabular}


It should be noted, as shown in Figures A-2 and A-3, that for production of ethanol via gasification of lignin, a net input of water is required for the gasification of lignin at $55 \%$ thermal efficiency.

\section{GASIFICATION: COMPARISON OF CORN STOVER VERSUS LIGNIN}

A comparison of corn stover versus lignin (Table A-13) was performed so that the two potential feedstocks could be compared side by side to see what potential features each feed stock might display. From the numbers shown in Figures A-4 and A-5, it is obvious that a greater mass of material must be handled in order to gasify moist lignin than for corn stover. It is interesting that less oxygen is required for moist lignin than for corn stover.

If one is considering potential capital and operating costs when deciding what feedstock to utilize, it would appear that lignin possesses an economic advantage over corn stover, when the cost of oxygen is considered.

If one divides the tons per day of fuel produced by the tons per day of oxygen consumed, a number is obtained that is quite instructive. It should be remembered that the number of fuel Btus produced is the same in all instances. The calculated ratio shows that the best utilization of oxygen is obtained from conversion of lignin to ethanol. If the fixed capital investment and operating costs for an oxygen plant are considered important, these data show that the lowest cost of production fuel (as far as oxygen costs are concerned) would be ethanol from lignin.

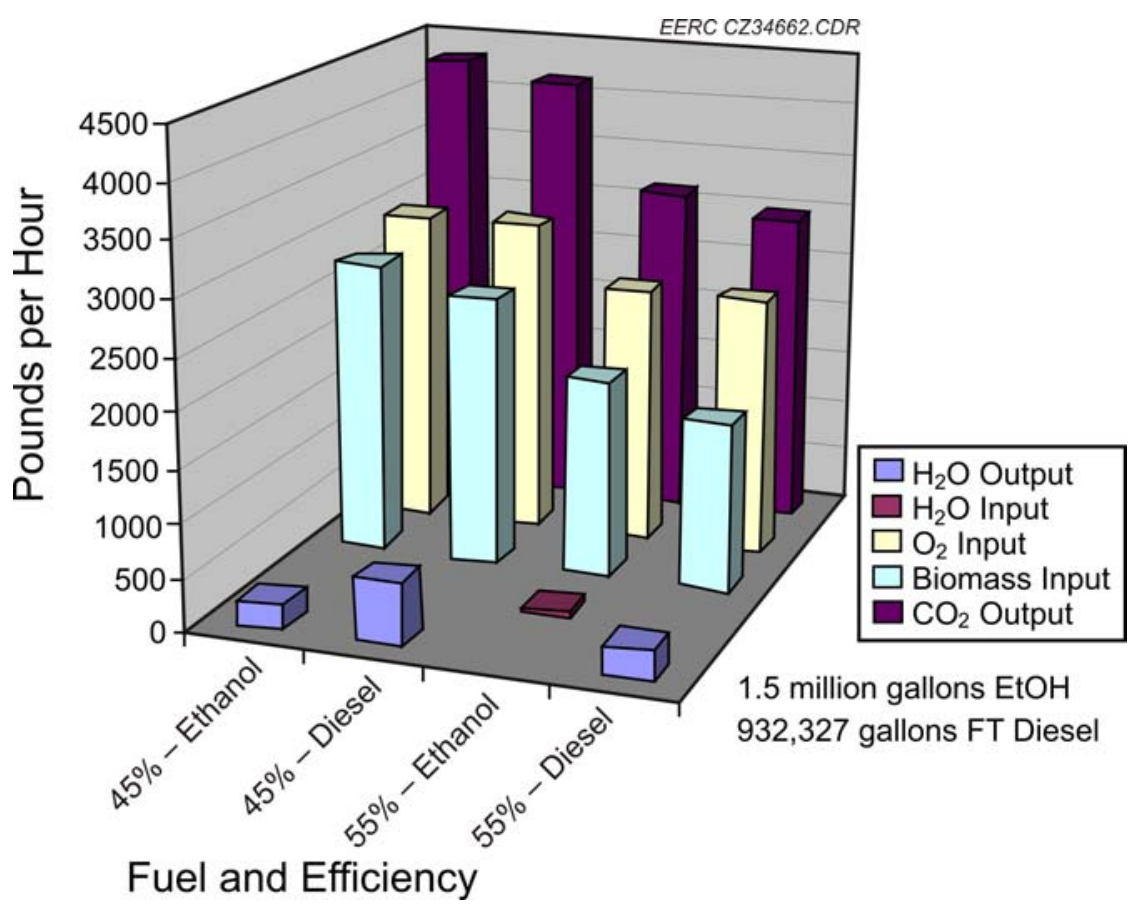

Figure A-2. Gasification of lignin. 


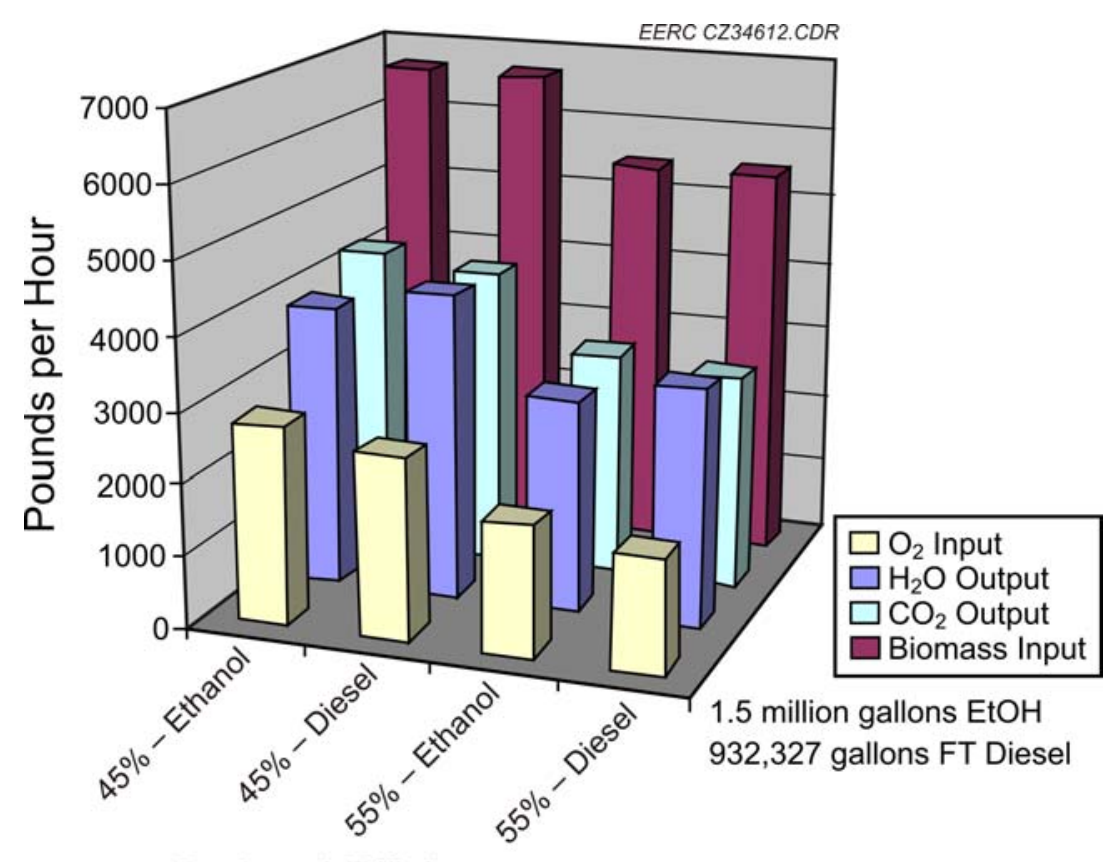

Fuel and Efficiency

Figure A-3. Gasification of moist lignin.

Table A-13. Comparison of Tons-per-Day Inputs and Outputs for Corn Stover and Lignin at $45 \%$ Thermal Efficiency

\begin{tabular}{|c|c|c|c|c|}
\hline \multirow[b]{2}{*}{ Feedstock } & \multicolumn{2}{|c|}{ Ethanol, pph } & \multicolumn{2}{|c|}{ Diesel, pph } \\
\hline & Corn Stover & Lignin, moist & Corn Stover & Lignin, moist \\
\hline $\mathrm{CO}_{2}-$ Out (pph) & 4958 & 4318 & 4799 & 4159 \\
\hline $\mathrm{H}_{2} \mathrm{O}-$ Out (pph) & 767 & 3937 & 1101 & 4270 \\
\hline Biomass - In (pph) & 3873 & 6675 & 3873 & 6675 \\
\hline $\mathrm{O}_{2}-\mathrm{In}(\mathrm{pph})$ & 3028 & 2756 & 2800 & 2528 \\
\hline Total Mass (pph) & 13,802 & 18,860 & 13,346 & 18,406 \\
\hline Fuel Production (gpy) & $1.5 \times 10^{6}$ & $1.5 \times 10^{6}$ & 932,327 & 932,327 \\
\hline $\mathrm{O}_{2}$ :Fuel ratio & 2.57 & 2.34 & 3.62 & 3.27 \\
\hline
\end{tabular}

\section{REFORMING OF CORN STOVER: COMPARISON OF ETHANOL VERSUS FT DIESEL}

The reforming of corn stover (Figure A-6) is not significantly different than that of gasifying the same material. For the same thermal efficiencies, identical amounts of $\mathrm{CO}_{2}$ are formed. The primary difference is that in gasification, $\mathrm{O}_{2}$ is an input, while in reforming, $\mathrm{H}_{2} \mathrm{O}$ is an input. Reforming can provide $\mathrm{H}_{2}$ as a by-product. From a thermal standpoint, additional fuel is required to heat the $\mathrm{H}_{2} \mathrm{O}$ to steam in order to reform the biomass. The amount of fuel required is not considered in the calculations in Tables A-14-A-17. 


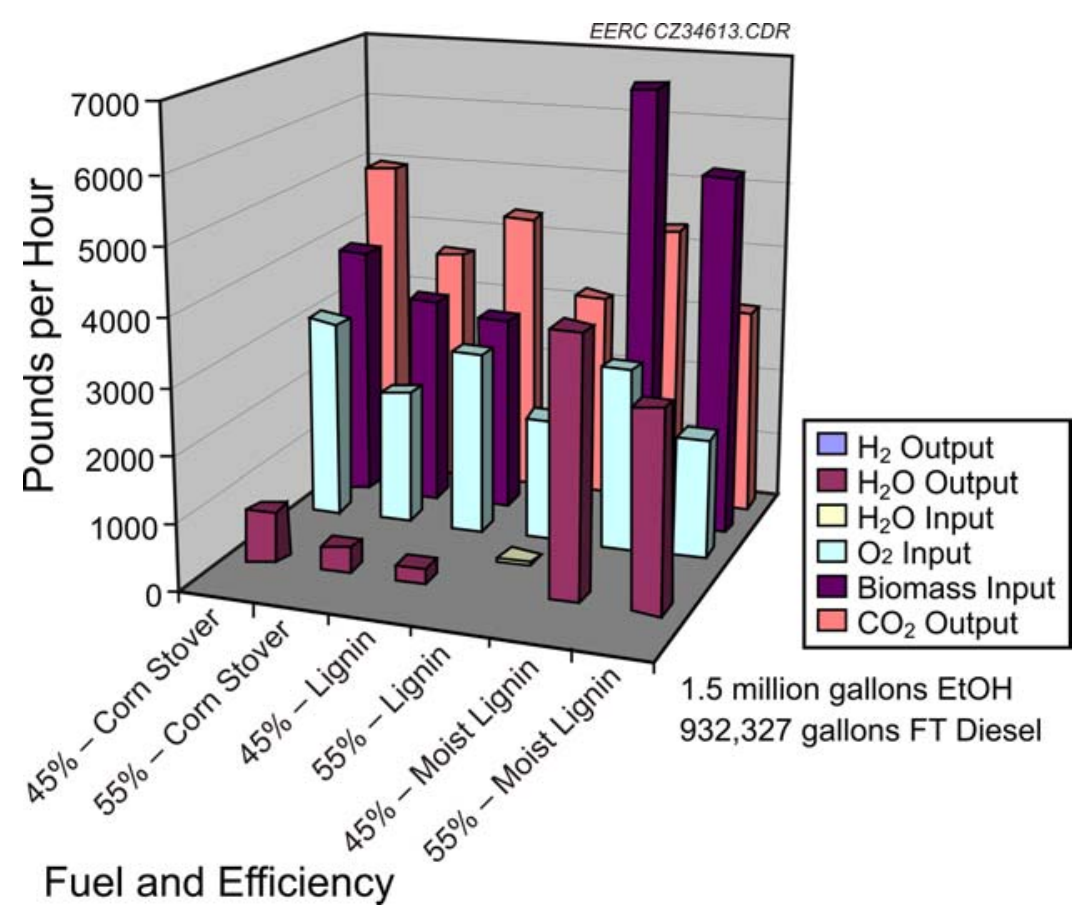

Figure A-4. Gasification to ethanol.

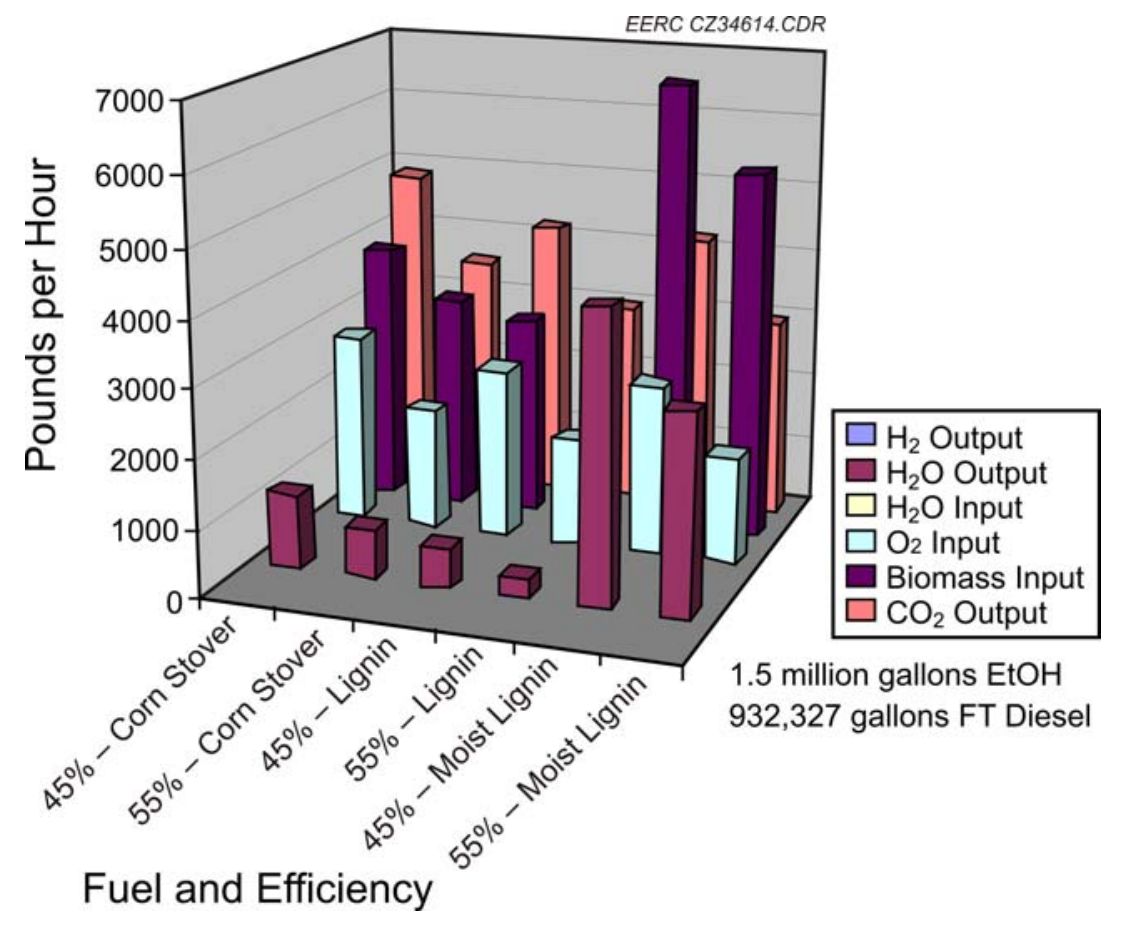

Figure A-5. Gasification to diesel. 


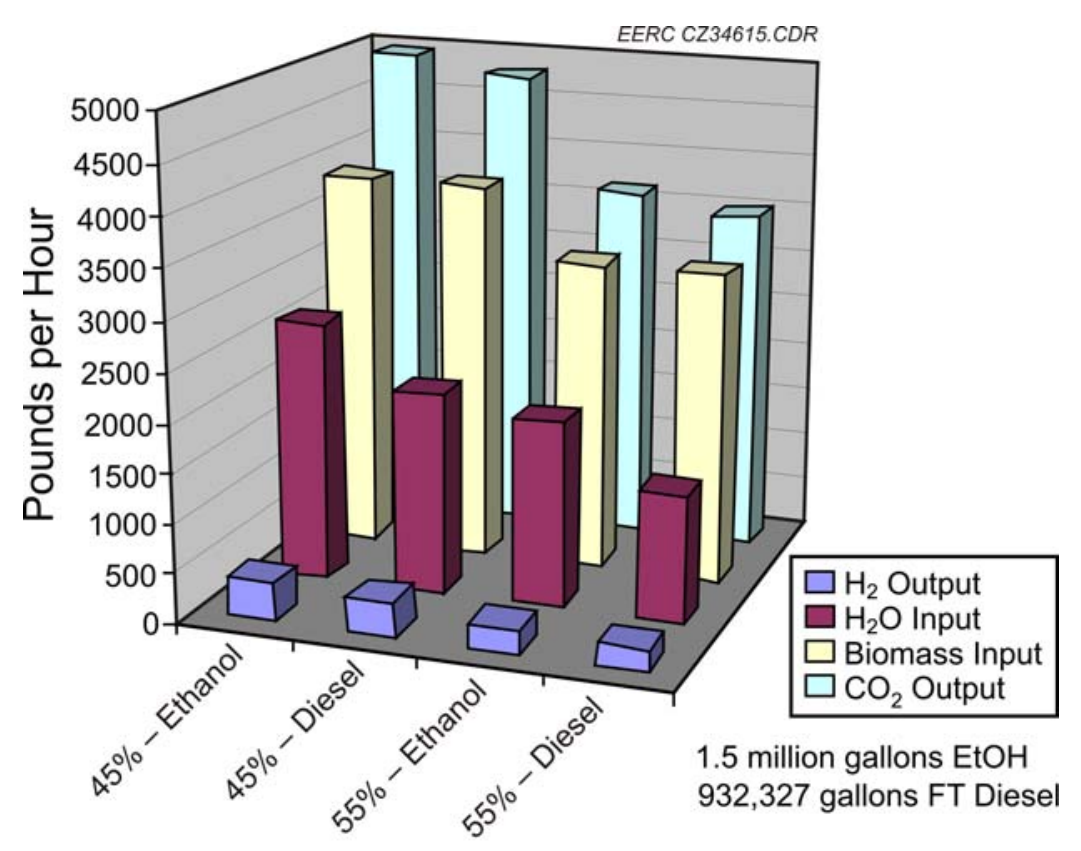

Fuel and Efficiency

Figure A-6. Reforming of corn stover.

Table A-14. Net Element and Feedstock Balance for Gasification of Corn Stover with Ethanol Production for a 45\% Thermal Efficiency Process

\begin{tabular}{lcccccc}
\hline & \multicolumn{3}{c}{ Input, $\mathrm{lb} / \mathrm{hr}$} & & \multicolumn{3}{c}{ Output, lb/hr } \\
& Biomass & $\mathrm{H}_{2} \mathrm{O}$ & \multicolumn{1}{c}{$\mathrm{O}_{2}$} & $\mathrm{CO}_{2}$ & $\mathrm{H}_{2}$ & EtOH \\
\hline $\mathrm{C}$ & 1966 & & & 1352 & & 614 \\
$\mathrm{H}$ & 239 & 293 & & & 378 & 153 \\
$\mathrm{O}$ & 1669 & 2346 & & 3606 & & 409 \\
Subtotal & 3873 & 2639 & 0 & 4958 & 378 & 1176 \\
Total & & & 6512 & & & 6512 \\
\hline
\end{tabular}

Table A-15. Net Element and Feedstock Balance for Gasification of Corn Stover with Diesel Production for a 45\% Thermal Efficiency Process

\begin{tabular}{lcccccc}
\hline & \multicolumn{3}{c}{ Input, $\mathrm{lb} / \mathrm{hr}$} & \multicolumn{3}{c}{ Output, lb/hr } \\
& Biomass & $\mathrm{H}_{2} \mathrm{O}$ & \multicolumn{1}{c}{$\mathrm{O}_{2}$} & $\mathrm{CO}_{2}$ & $\mathrm{H}_{2}$ & Diesel \\
\hline $\mathrm{C}$ & 1966 & & & 1309 & & 657 \\
$\mathrm{H}$ & 239 & 228 & & & 350 & 116 \\
$\mathrm{O}$ & 1669 & 1821 & & 3490 & & 0 \\
Subtotal & 3873 & 2049 & 0 & 4799 & 350 & 773 \\
Total & & & 5922 & & & 5922 \\
\hline
\end{tabular}


Table A-16. Reforming of Corn Stover with Production of Ethanol at 55\% Thermal Efficiency (ethanol only basis)

\begin{tabular}{lcrrrrr}
\hline & \multicolumn{3}{c}{ Input, $\mathrm{lb} / \mathrm{hr}$} & & \multicolumn{3}{c}{ Output, lb/hr } \\
& Biomass & $\mathrm{H}_{2} \mathrm{O}$ & $\mathrm{O}_{2}$ & $\mathrm{CO}_{2}$ & $\mathrm{H}_{2}$ & EtOH \\
\hline $\mathrm{C}$ & 1608 & & & 995 & & 614 \\
$\mathrm{H}$ & 195 & 212 & & & 254 & 153 \\
$\mathrm{O}$ & 1365 & 1696 & & 2653 & & 409 \\
Subtotal & 3169 & 1908 & 0 & 3647 & 254 & 1176 \\
Total & & & 5077 & & & 5077 \\
\hline
\end{tabular}

Table A-17. Net Element and Feedstock Balance for Gasification of Corn Stover with Diesel Production for a 55\% Thermal Efficiency Process

\begin{tabular}{lcccccr}
\hline & \multicolumn{3}{c}{ Input, $\mathrm{lb} / \mathrm{hr}$} & \multicolumn{3}{c}{ Output, lb/hr } \\
& Biomass & $\mathrm{H}_{2} \mathrm{O}$ & $\mathrm{O}_{2}$ & $\mathrm{CO}_{2}$ & $\mathrm{H}_{2}$ & Diesel \\
\hline $\mathrm{C}$ & 1608 & & & 951 & & 657 \\
$\mathrm{H}$ & 195 & 146 & & & 225 & 116 \\
$\mathrm{O}$ & 1365 & 1171 & & 2537 & & 0 \\
Subtotal & 3169 & 1318 & 0 & 3488 & 225 & 773 \\
Total & & & 4487 & & & 4487 \\
\hline
\end{tabular}

\section{REFORMING OF LIGNIN: COMPARISON OF ETHANOL AND DIESEL}

The outcome of reforming of lignin will depend greatly upon the amount of water in the feedstock. The two cases considered here are dry lignin (Tables A-18-A-21) and lignin that is $50 \%$ water by mass (Tables A-22-A-25). In the case of dry lignin, $\mathrm{H}_{2}$ can be a product of the reforming process (Figures A-7 and A-8). In the case of moist lignin, $\mathrm{H}_{2}$ is not a product, water is carried through the process and is shown as a net product, which is not true. All the water in the moist lignin is just not consumed, and the excess will come out the backend of the reforming unit.

What this really means is that the moist lignin is too moist as a feedstock, Btus are being wasted heating unneeded water, and extra cooling capacity is required following the reforming step. Thermally balancing the input and output could be achieved, but overall efficiency would suffer.

Table A-18. Net Element and Feedstock Balance for Reforming of Lignin (oven dry) with Ethanol Production for a 45\% Thermal Efficiency Process

\begin{tabular}{lccrccr}
\hline & \multicolumn{3}{c}{ Input, lb/hr } & \multicolumn{3}{c}{ Output, lb/hr } \\
& Biomass & $\mathrm{H}_{2} \mathrm{O}$ & $\mathrm{O}_{2}$ & $\mathrm{CO}_{2}$ & $\mathrm{H}_{2}$ & EtOH \\
\hline $\mathrm{C}$ & 1791 & & & 1178 & & 614 \\
$\mathrm{H}$ & 180 & 318 & & & 344 & 153 \\
$\mathrm{O}$ & 1007 & 2542 & & 3140 & & 409 \\
Subtotal & 2978 & 2860 & 0 & 4318 & 344 & 1176 \\
Total & & & 5838 & & & 5838 \\
\hline
\end{tabular}


Table A-19. Net Element and Feedstock Balance for Reforming of Lignin (oven dry) with Diesel Production for a 45\% Thermal Efficiency Process

\begin{tabular}{lcccccc}
\hline & \multicolumn{3}{c}{ Input, lb/hr } & \multicolumn{3}{c}{ Output, lb/hr } \\
& Biomass & $\mathrm{H}_{2} \mathrm{O}$ & $\mathrm{O}_{2}$ & $\mathrm{CO}_{2}$ & $\mathrm{H}_{2}$ & Diesel \\
\hline $\mathrm{C}$ & 1791 & & & 1134 & & 657 \\
$\mathrm{H}$ & 180 & 252 & & & 316 & 116 \\
O & 1007 & 2018 & & 3025 & & 0 \\
Subtotal & 2978 & 2270 & 0 & 4159 & 316 & 773 \\
Total & & & 5248 & & & 5248 \\
\hline
\end{tabular}

Table A-20. Net Element and Feedstock Balance for Reforming of Lignin (oven dry) with Ethanol Production for a 55\% Thermal Efficiency Process

\begin{tabular}{lcccccc}
\hline & \multicolumn{3}{c}{ Input, lb/hr } & \multicolumn{3}{c}{ Output, lb/hr } \\
& Biomass & $\mathrm{H}_{2} \mathrm{O}$ & $\mathrm{O}_{2}$ & $\mathrm{CO}_{2}$ & $\mathrm{H}_{2}$ & EtOH \\
\hline $\mathrm{C}$ & 1466 & & & 852 & & 614 \\
$\mathrm{H}$ & 147 & 232 & & & 226 & 153 \\
$\mathrm{O}$ & 824 & 1857 & & 2272 & & 409 \\
Subtotal & 2437 & 2089 & 0 & 3124 & 226 & 1176 \\
Total & & & 4525 & & & 4525 \\
\hline
\end{tabular}

Table A-21. Net Element and Feedstock Balance for Reforming of Lignin (oven dry) with Diesel Production for a 55\% Thermal Efficiency Process

\begin{tabular}{lcccccc}
\hline & \multicolumn{3}{c}{ Input, lb/hr } & \multicolumn{3}{c}{ Output, lb/hr } \\
& Biomass & $\mathrm{H}_{2} \mathrm{O}$ & $\mathrm{O}_{2}$ & $\mathrm{CO}_{2}$ & $\mathrm{H}_{2}$ & Diesel \\
\hline $\mathrm{C}$ & 1466 & & & 809 & & 657 \\
$\mathrm{H}$ & 147 & 167 & & & 197 & 116 \\
$\mathrm{O}$ & 824 & 1332 & & 2156 & & 0 \\
Subtotal & 2437 & 1499 & 0 & 2965 & 197 & 773 \\
Total & & & 3935 & & & 3935 \\
\hline
\end{tabular}

Table A-22. Net Element and Feedstock Balance for Reforming of Lignin (moist) with Ethanol Production for a 45\% Thermal Efficiency Process

\begin{tabular}{lcccccc}
\hline & \multicolumn{3}{c}{ Input, $\mathrm{lb} / \mathrm{hr}$} & & \multicolumn{3}{c}{ Output, lb/hr } \\
& Biomass & $\mathrm{H}_{2} \mathrm{O}$ & $\mathrm{O}_{2}$ & $\mathrm{CO}_{2}$ & $\mathrm{H}_{2} \mathrm{O}$ & EtOH \\
\hline $\mathrm{C}$ & 1791 & & & 1178 & & 614 \\
$\mathrm{H}$ & 591 & & & & 437 & 153 \\
$\mathrm{O}$ & 4292 & & & 3140 & 743 & 409 \\
Subtotal & 6675 & & 0 & 4318 & 1181 & 1176 \\
Total & & & 6675 & & & 6675 \\
\hline
\end{tabular}


Table A-23. Net Element and Feedstock Balance for Reforming of Lignin (moist) with Diesel Production for a 45\% Thermal Efficiency Process

\begin{tabular}{lcccccc}
\hline & \multicolumn{2}{c}{ Input, $\mathrm{lb} / \mathrm{hr}$} & \multicolumn{3}{c}{ Output, lb/hr } \\
& Biomass & $\mathrm{H}_{2} \mathrm{O}$ & $\mathrm{O}_{2}$ & $\mathrm{CO}_{2}$ & \multicolumn{1}{c}{$\mathrm{H}_{2} \mathrm{O}$} & Diesel \\
\hline $\mathrm{C}$ & 1791 & & & 1134 & & 657 \\
$\mathrm{H}$ & 591 & & & & 474 & 116 \\
$\mathrm{O}$ & 4292 & & & 3025 & 1268 & 0 \\
Subtotal & 6675 & & 0 & 4159 & 1742 & 773 \\
Total & & & 6675 & & & 6675 \\
\hline
\end{tabular}

Table A-24. Net Element and Feedstock Balance for Reforming of Lignin (moist) with Ethanol Production for a 55\% Thermal Efficiency Process

\begin{tabular}{lcrrrrr}
\hline & \multicolumn{2}{c}{ Input, $\mathrm{lb} / \mathrm{hr}$} & \multicolumn{3}{c}{ Output, lb/hr } \\
& Biomass & $\mathrm{H}_{2} \mathrm{O}$ & $\mathrm{O}_{2}$ & $\mathrm{CO}_{2}$ & $\mathrm{H}_{2} \mathrm{O}$ & EtOH \\
\hline $\mathrm{C}$ & 1466 & & & 852 & & 614 \\
$\mathrm{H}$ & 483 & & & & 330 & 153 \\
$\mathrm{O}$ & 3512 & & & 2272 & 831 & 409 \\
Subtotal & 5461 & & 0 & 3124 & 1161 & 1176 \\
Total & & 5461 & & & 5461 \\
\hline
\end{tabular}

Table A-25. Net Element and Feedstock Balance for Reforming of Lignin (moist) with Diesel Production for a 55\% Thermal Efficiency Process

\begin{tabular}{lcccccr}
\hline & \multicolumn{3}{c}{ Input, $\mathrm{lb} / \mathrm{hr}$} & \multicolumn{3}{c}{ Output, $\mathrm{lb} / \mathrm{hr}$} \\
& Biomass & $\mathrm{H}_{2} \mathrm{O}$ & $\mathrm{O}_{2}$ & $\mathrm{CO}_{2}$ & $\mathrm{H}_{2} \mathrm{O}$ & Diesel \\
\hline $\mathrm{C}$ & 1466 & & & 809 & & 657 \\
$\mathrm{H}$ & 483 & & & & 367 & 116 \\
$\mathrm{O}$ & 3512 & & & 2156 & 1356 & 0 \\
Subtotal & 5461 & 0 & 2965 & 1723 & 773 \\
Total & & 5461 & & & 5461 \\
\hline
\end{tabular}

\section{REFORMING: COMPARISON OF CORN STOVER VERSUS MOIST LIGNIN}

A comparison can be made between corn stover and moist lignin as feedstocks for a reforming process. Either feedstock can be used to produce either ethanol or diesel fuel. Key differences would be amount of biomass required, but for moist lignin, half the biomass comprises water. Table A-26 shows the tabular results, while Figures A-9 and A-10 show them graphically. 


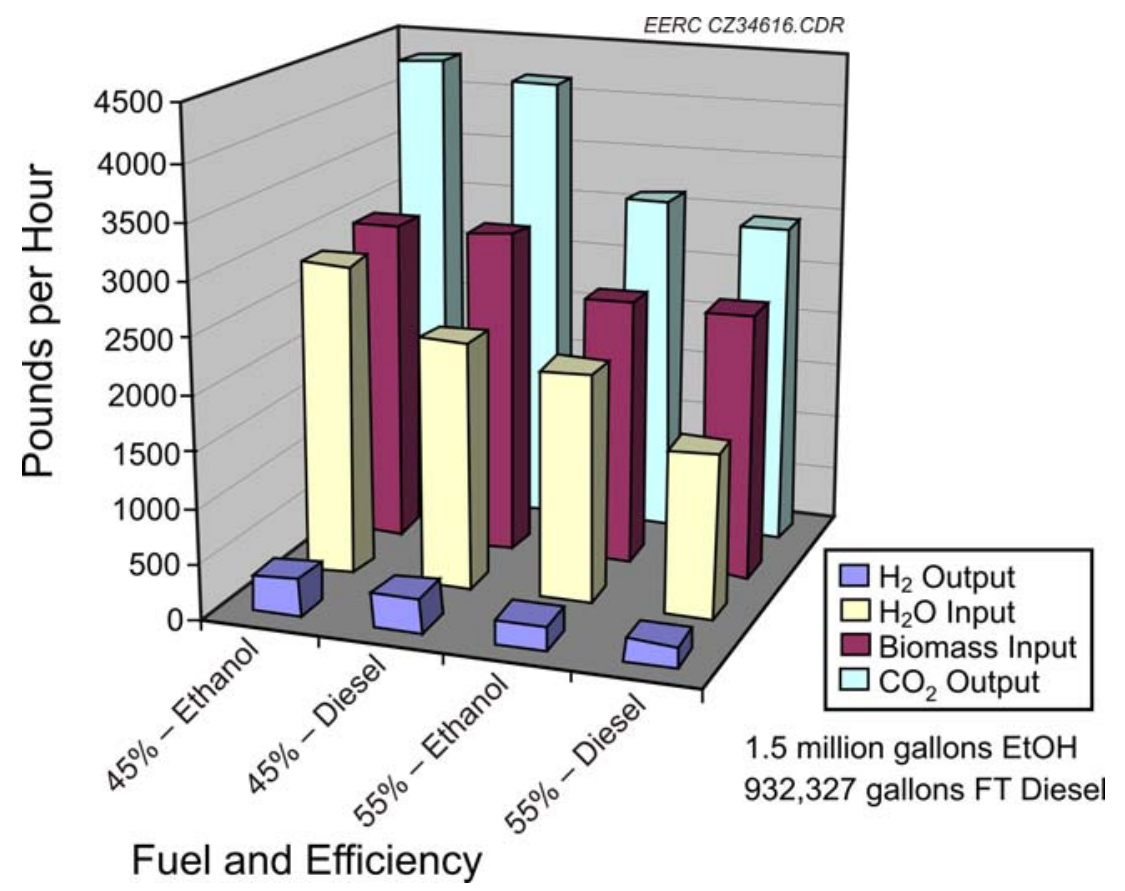

Figure A-7. Reforming of lignin.

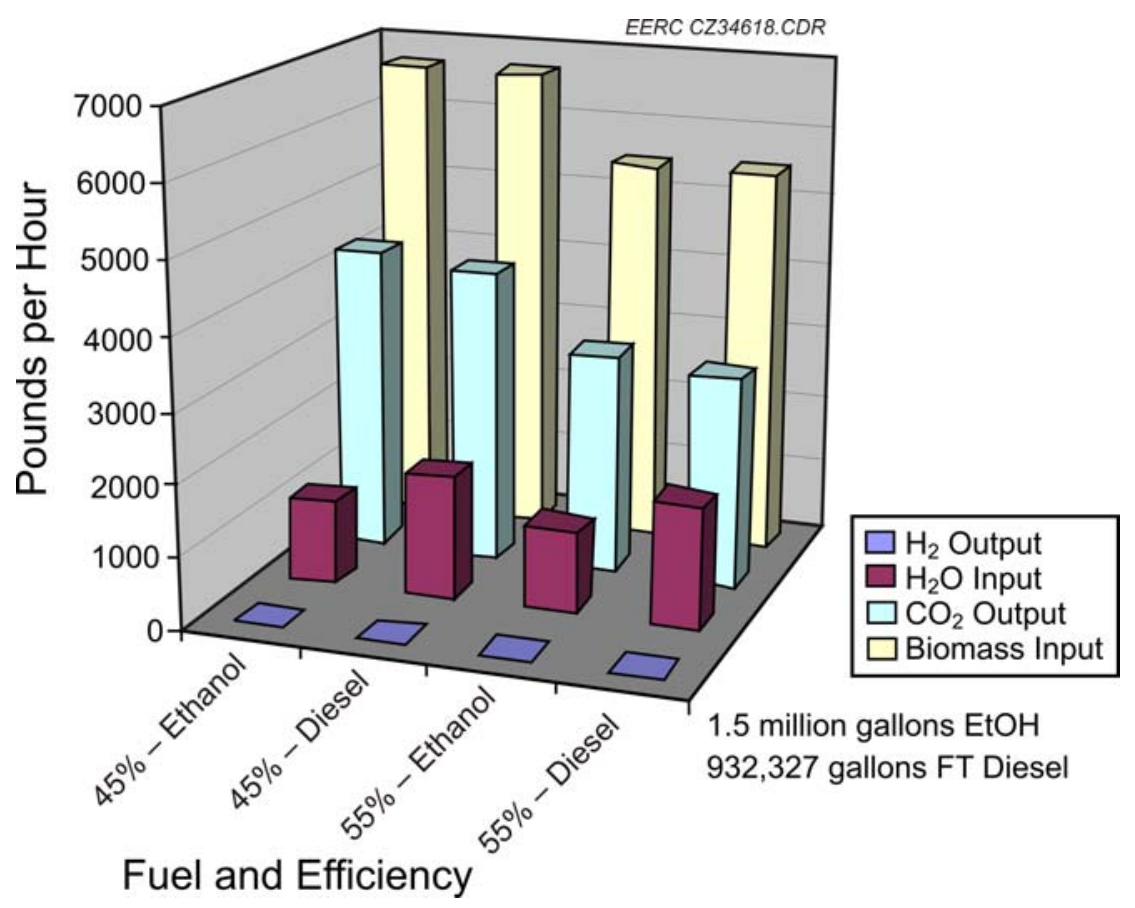

Figure A-8. Reforming of moist lignin. 
Table A-26. Comparison of Tons-per-Day Inputs and Outputs for Reforming of Corn Stover and Lignin at $45 \%$ Thermal Efficiency

\begin{tabular}{lcccc}
\hline & \multicolumn{2}{c}{ Ethanol, pph } & \multicolumn{2}{c}{ Diesel, pph } \\
Feedstock & Corn Stover & Lignin, moist & Corn Stover & Lignin, moist \\
\hline $\mathrm{CO}_{2}-$ Out, pph & 4958 & 4318 & 4799 & 4159 \\
$\mathrm{H}_{2}-$ Out, pph & 378 & & 350 & \\
$\mathrm{H}_{2} \mathrm{O}-$ Out, pph & & 1181 & & 1742 \\
$\mathrm{H}_{2} \mathrm{O}-$ In, pph & & & 2049 & \\
Biomass - In, pph & 2639 & & 3873 & 6675 \\
Total Mass, pph & $\mathbf{1 3 , 0 2 4}$ & $\mathbf{1 3 , 3 5 0}$ & $\mathbf{1 1 , 8 4 4}$ & $\mathbf{1 3 , 3 5 0}$ \\
$\begin{array}{l}\text { Fuel Production, } \\
\quad \text { gpy }\end{array}$ & $\mathbf{1 . 5 \times 1 0 ^ { 6 }}$ & $\mathbf{1 . 5 \times 1 0 ^ { 6 }}$ & $\mathbf{9 3 2 , 3 2 7}$ & $\mathbf{9 3 2 , 3 2 7}$ \\
Steam:Fuel Ratio & $\mathbf{2 . 2 4}$ & & & \\
\end{tabular}

\footnotetext{
${ }^{a}$ Includes moisture in biomass.
}

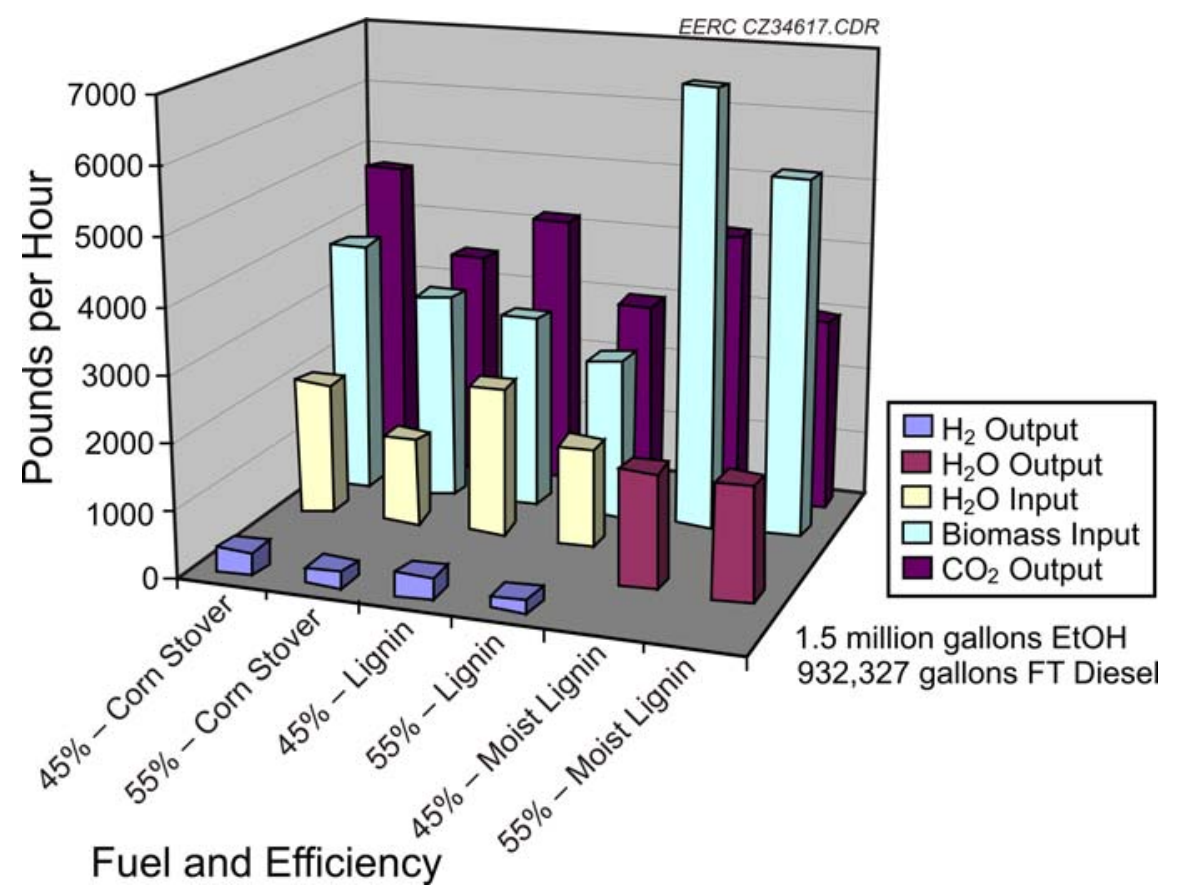

Figure A-9. Reforming to ethanol. 


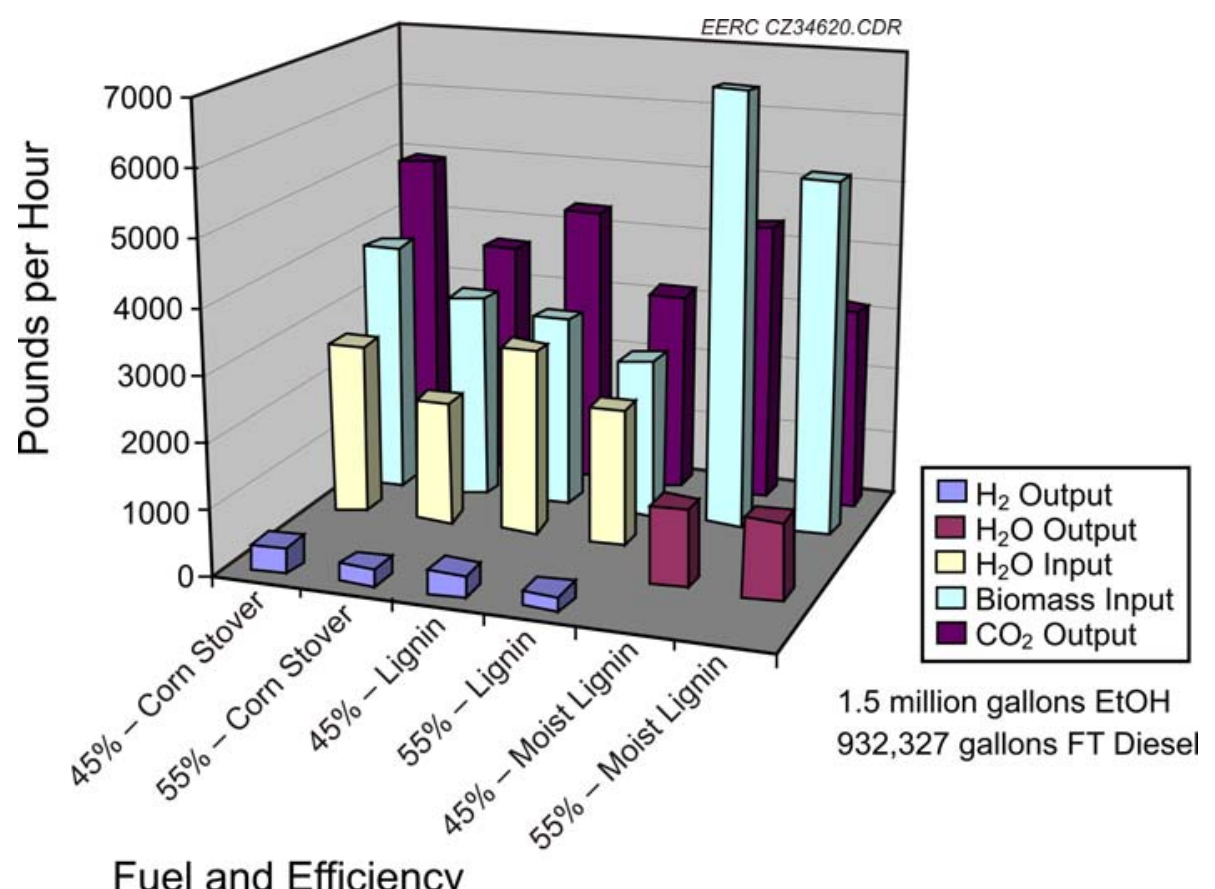

Figure A-10. Reforming to diesel.

\section{SULFUR AND NITROGEN CAPTURE}

Conversion of corn stover will result in formation of hydrogen sulfide $\left(\mathrm{H}_{2} \mathrm{~S}\right)$ and ammonia $\left(\mathrm{NH}_{3}\right)$. These species will need to be removed from the synthesis gas prior to any catalyst bed that would convert the synthesis gas to a liquid fuel product.

National Renewable Energy Laboratory Report NREL/TP-510-41168 proposes converting $\mathrm{H}_{2} \mathrm{~S}$ to elemental sulfur $(\mathrm{S})$ via Lo-Cat ${ }^{\circledR}$ technology. The amounts of sulfur and $\mathrm{NH}_{3}$ formed are shown in Tables A-27 and A-28. The table shows both daily and annual formation rates in long tons.

The final disposition of these products would have to be determined via marketing studies. Traditionally, elemental sulfur is very difficult to market, especially elemental sulfur produced via a tail gas remediation method. For ammonia, the annual quantity produced is less than a dayand-a-half production at a moderate-scale ammonia plant. Any plan to market these by-products may result in a loss enterprise. Disposal or destruction may be a more economically attractive alternative.

Table A-27. Hydrogen Sulfide and Ammonia Formation Rates for Corn Stover

\begin{tabular}{lcc}
\hline & $45 \%$ Thermal Efficiency & $55 \%$ Thermal Efficiency \\
\hline $\mathrm{H}_{2} \mathrm{~S}$ Formation (pph) & 3.58 & 2.93 \\
$\mathrm{NH}_{3}$ Formation (pph) & 34.3 & 28.1 \\
Pounds $\mathrm{S}$ per Pound Fuel & 0.00304 & 0.00234 \\
Pounds $\mathrm{NH}_{3}$ per Pound Fuel & 0.0292 & 0.0239 \\
\hline
\end{tabular}


Table A-28. Hydrogen Sulfide and Ammonia Formation Rates for Moist Lignin

\begin{tabular}{lcc} 
& $45 \%$ Thermal Efficiency & $55 \%$ Thermal Efficiency \\
\hline $\mathrm{H}_{2} \mathrm{~S}$ Formation $(\mathrm{pph})$ & 14.0 & 11.4 \\
$\mathrm{NH}_{3}$ Formation $(\mathrm{pph})$ & 78.6 & 64.3 \\
Pounds $\mathrm{S}$ per Pound Fuel & 0.0119 & 0.0097 \\
Pounds $\mathrm{NH}_{3}$ per Pound Fuel & 0.0547 & 0.0668 \\
\hline
\end{tabular}


APPENDIX B

\section{COMMENTS ON NREL/TP-510-41168}




\section{COMMENTS ON NREL/TP-510-41168}

The report "Thermochemical Ethanol via Indirect Gasification and Mixed Alcohol Synthesis of Lignocellulosic Biomass" is only a guide and not a road map for the gasification of corn stover or any other agriculturally produced biomass. This is primarily because NREL/TP$510-41168$ covers the gasification of forest products.

There are fundamental chemical differences that make the gasification of wood products more facile than agricultural products. First, the nitrogen and sulfur content of forest products is much less than that of agricultural biomass (see Table B-1 for a direct comparison).

The greater nitrogen and sulfur content of the corn stover (no cobs) will lead to greater amounts of hydrogen disulfide $\left(\mathrm{H}_{2} \mathrm{~S}\right)$ and ammonia $\left(\mathrm{NH}_{3}\right)$ in the synthesis gas produced from this source.

The National Renewable Energy Laboratory (NREL) study assumes lower production levels of $\mathrm{H}_{2} \mathrm{~S}$ and $\mathrm{NH}_{3}$ and makes reasonable assumptions on how to deal with these two synthesis gas "contaminants." The $\mathrm{NH}_{3}$ is dealt with by simply sending it to the tar reformer. The claim is made that the $\mathrm{NH}_{3}$ will be converted to nitrogen $\left(\mathrm{N}_{2}\right)$ and hydrogen $\left(\mathrm{H}_{2}\right)$. This is a reasonable claim. However, if this were to be attempted at more than 20 times the $\mathrm{NH}_{3}$ feed rate (such as would occur with the gasification of corn stover), then significant $\mathrm{NH}_{3}$ slip through the tar reformer would most likely be observed.

Similarly, the NREL study claims that the MeriChem Lo-Cat ${ }^{\circledR} \mathrm{H}_{2} \mathrm{~S}$ scrubbing technology would be suitable for the gasification of wood feedstocks. This is a reasonable claim, and the Lo$\mathrm{Cat}^{\circledR}$ technology will probably be suitable for corn stover gasification also. However, at $\sim 6$ times the $\mathrm{H}_{2} \mathrm{~S}$ production rate as wood gasification, operating expenses for the Lo-Cat ${ }^{\circledR}$ process will increase by the same magnitude.

The NREL study assumes that an ethanol synthesis catalyst will tolerate high levels of nitrogen and, therefore, assumes that air-blown gasification for the production of producer gas will be acceptable. This may not be the case. An oxygen $\left(\mathrm{O}_{2}\right)$ plant may be required. This will increase the capital cost for construction of the plant.

Also, the equipment list for the proposed plant is incomplete. Many pieces of equipment show " $\$ 0$ " for a cost. Costs are shown only for major equipment. Additionally, steel and erection costs are not included. Therefore, a total investment cost will far exceed the \$137 million that can be obtained by summing all shown equipment costs.

The bottom line is that the gasification of agriculturally produced biomass is a far different endeavor than gasifying wood. There needs to be a significant effort put forth to determine the technological obstacles and work-arounds. The good news is that all the technology that is required is available. It just needs to be placed into a coherent package that can be evaluated from a science, engineering, and business perspective. 
Table B-1. Comparison of Nitrogen and Sulfur Content

\begin{tabular}{lcc}
\hline & Corn Stover (Zea mays) & Wood (Pinus radiate) \\
\hline Nitrogen, wt $\%$ & 0.65 & 0.03 \\
Sulfur, wt $\%$ & 0.06 & 0.01 \\
\hline
\end{tabular}




\section{APPENDIX C}

\section{PROCESS FLOW DIAGRAM (PFD) OF THE LIGNIN GASIFICATION DIESEL FACILITY}




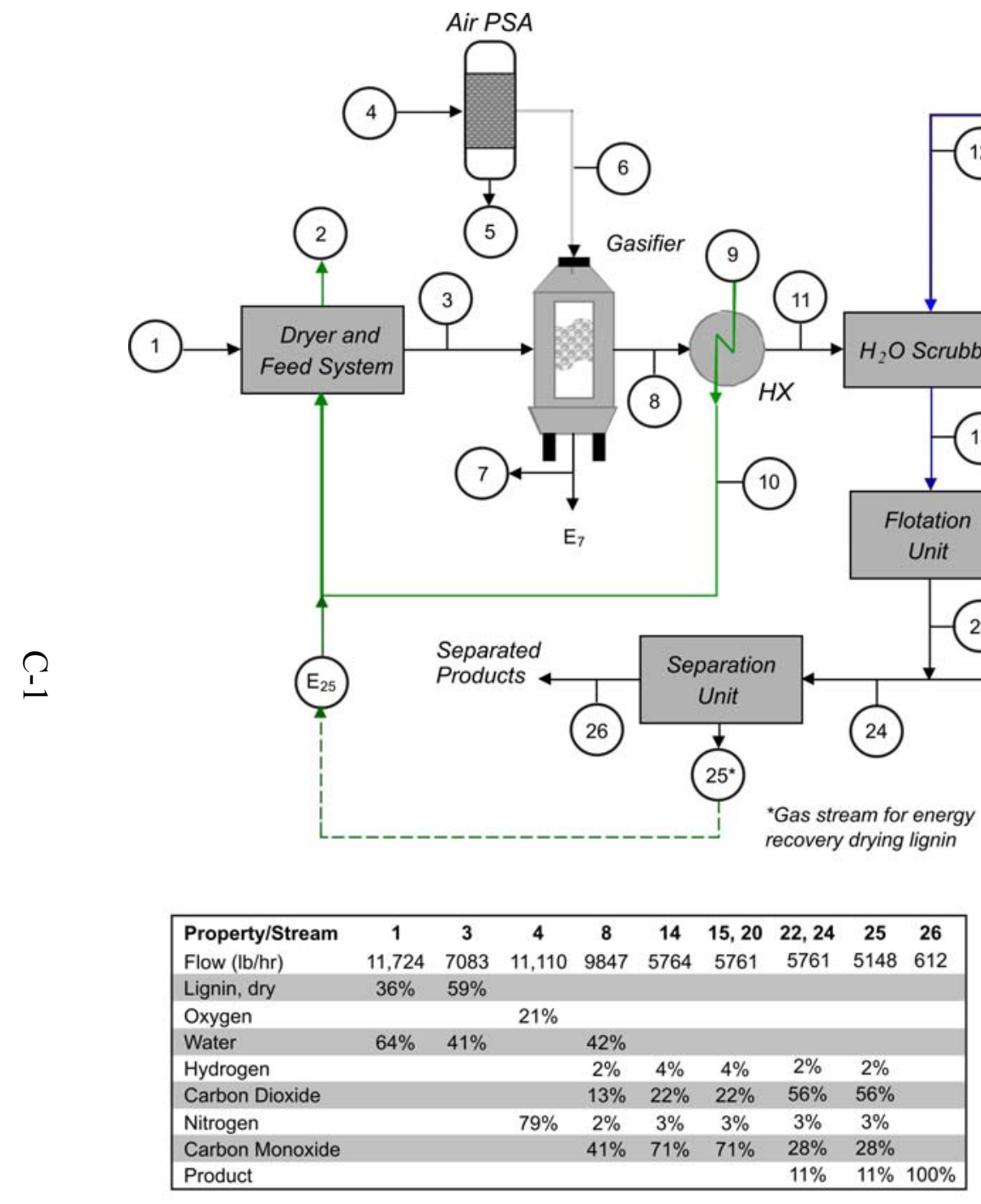

EERC BF34921.CDR

\section{Stream Legend}

1 Lignin, wet

2 Air w/Evaporated Water

3 Lignin, dry

4 Air

5 Nitrogen

6 Oxygen

7 Ash, heat loss

8 Produced Syngas

9 HXAir

10 Heated Air

11 Cooled Syngas

12 Scrubbing Water In

13 Water and Tars

14 Cleaned Syngas

15 Desulfurized Syngas

$16 \mathrm{HX}$ Steam In

17 HX Water/Steam Out

18 Cooling Water In

19 Cooling Water Out

20 Heated Syngas

21 Hot Water

22 FT Products

24 Ctream

25 Waste Gases

26 Separated FT Products

\begin{tabular}{|c|c|c|c|c|c|c|c|c|c|}
\hline Property/Stream & 1 & 2 & 3 & 4 & 5 & 6 & 7 & 8 & 9 \\
\hline Temp., ${ }^{\circ} \mathrm{F}$ & 77 & 227 & 227 & 120 & 112 & 119 & 2795 & 2795 & 77 \\
\hline Pressure, psia & 14.7 & 14.7 & 14.7 & 3 & 17 & 350 & 14.7 & 350 & 14.7 \\
\hline Flow, lb/hr & 11,724 & 77,041 & 7083 & 11,110 & 8777 & 2333 & 146 & 9847 & 72,400 \\
\hline Energy, MMBtu/hr & 38.9 & 8.0 & 42.5 & 0.1 & 0.1 & $<0.1$ & $<0.1$ & 45.1 & \\
\hline$E_{n}, M M B t u / h r$ & & & & & & & 2.6 & & \\
\hline Property/Stream & 10 & 11 & 12 & 13 & 14 & 15 & 16 & 17 & 18 \\
\hline Temp., ${ }^{\circ} \mathrm{F}$ & 570 & 600 & 77 & 98 & 98 & 98 & 590 & 525 & 98 \\
\hline Pressure, psia & 14.7 & 350 & 14.7 & 14.7 & 350 & 350 & 850 & 850 & 14.7 \\
\hline Flow, lb/hr & 72,400 & 9847 & 293,823 & 297,906 & 5764 & 5761 & 2724 & 2724 & 297,906 \\
\hline Energy, MMBtu/hr & 9.1 & 36.1 & & 6.4 & 29.7 & 29.7 & 4.0 & 3.1 & 6.4 \\
\hline \multicolumn{10}{|l|}{$\mathrm{E}_{\mathrm{n}}, \mathrm{MMBtu} / \mathrm{hr}$} \\
\hline Property/Stream & 19 & 20 & 21 & 22 & 23 & 24 & 25 & 26 & \\
\hline Temp., ${ }^{\circ} \mathrm{F}$ & 108 & 495 & 138 & 620 & 98 & 620 & 77 & 77 & \\
\hline Pressure, psia & 14.7 & 350 & 850 & 350 & 350 & 350 & 14.7 & 14.7 & \\
\hline Flow, lb/hr & 297,906 & 5761 & 2724 & 5761 & $<1$ & 5761 & 5148 & 612 & \\
\hline Energy, MMBtu/hr & 9.3 & 30.6 & 0.2 & 26.8 & $<0.1$ & 26.8 & 13.7 & 12.1 & \\
\hline$E_{n}, M M B t u / h r$ & & & & & & & 13.7 & & \\
\hline
\end{tabular}

Figure C-1. Process flow diagram of the lignin gasification diesel facility. 